







\section{Neue und interessante Dipteren}

\section{aus dem kaiserl. Museum in Wien.}

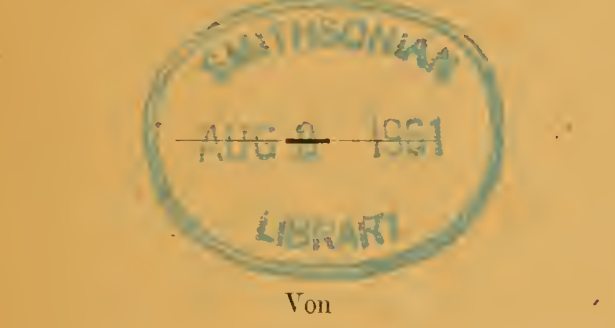

Friedrich IIendel

in Wien.

(Mit Tafel I.)

Sonderabdruck aus der' „Wiener Entomologischen Zeitung““,

XXVI. Jahrgang 1907.

WIEN, 1907. 

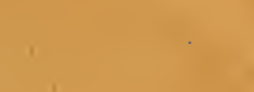

s.

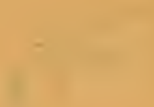

- 1

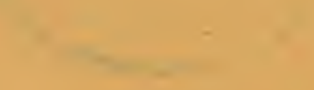

$y$

$-$

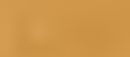

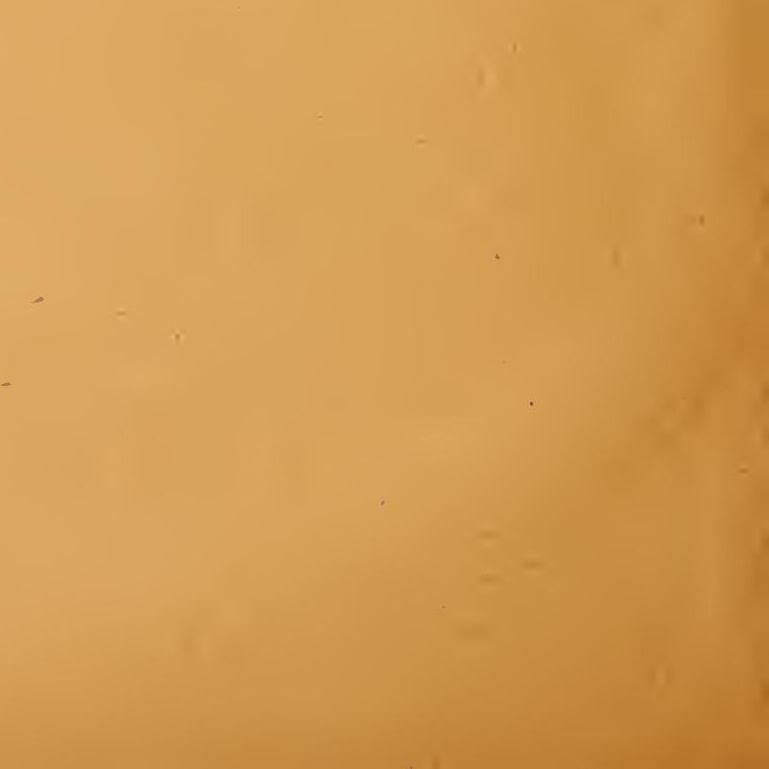




\section{Nene und interessante Dipteren aus dem kaiserl. Museum in Wien.}

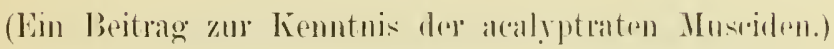

Von Friedrich Hendel in Winn.

(Hiræal Tafel I.)

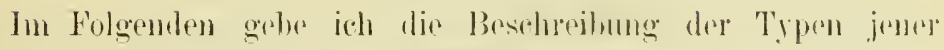

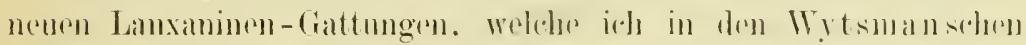

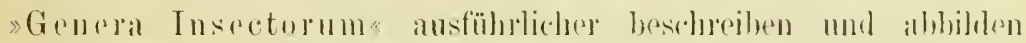
werde, forner schliebe ich daran Mitteilungen ïbre dinige anderes

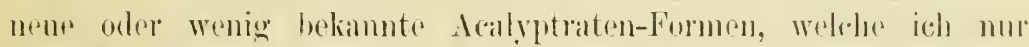

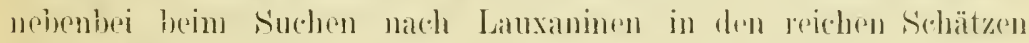

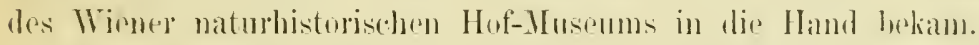

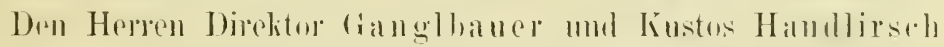
des dusenms spreche ich hier meinen Dank alls, die in wohleer-

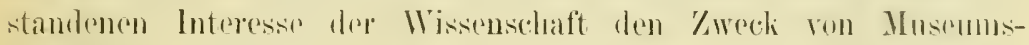

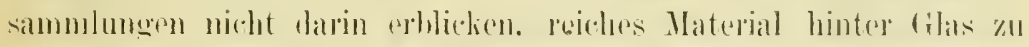

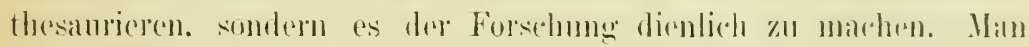

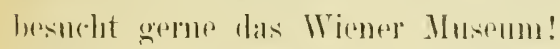

\section{Subfill. Lauxaninae.}

\section{J. Camptoprosopell a nor. grent.}

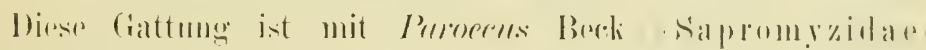

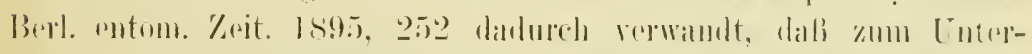

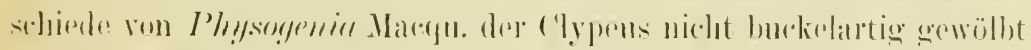

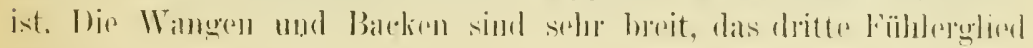

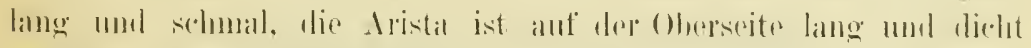

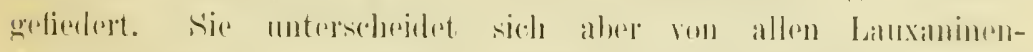

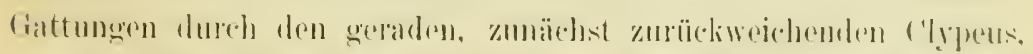

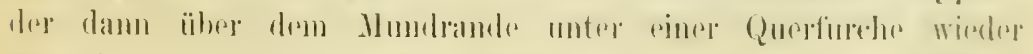

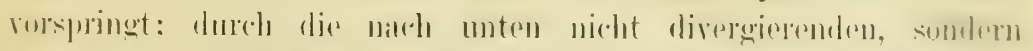

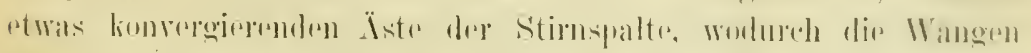

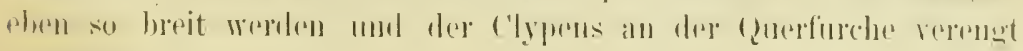
erschent. 


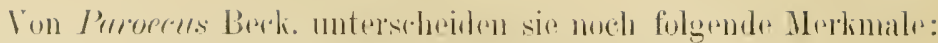

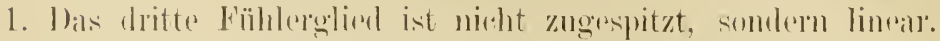

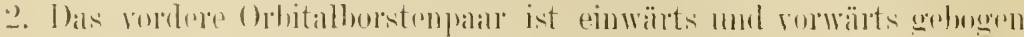
and strht mithe ror dem oheren Palitre.

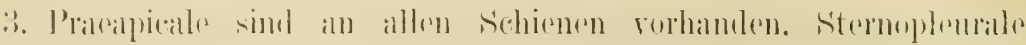
1111\% (2011).

\section{Camptoprosopella melanoptera $11.4 \%$}

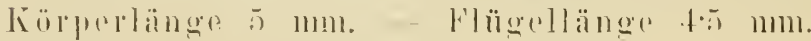
P’ubla, Moxiøu (lex. Bilimok 18T1, Jumi).

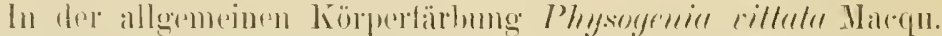

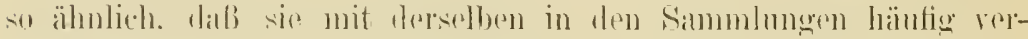

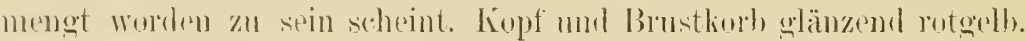

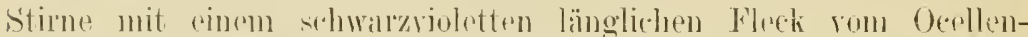

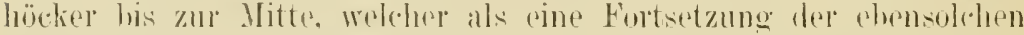

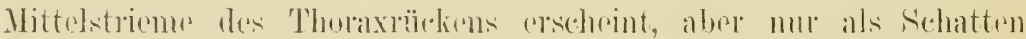

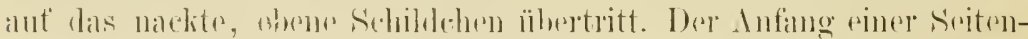

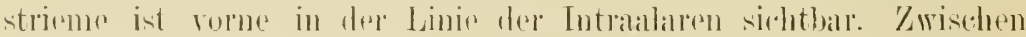

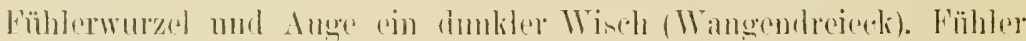

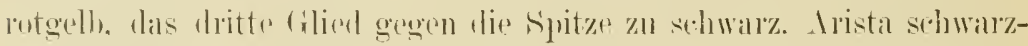

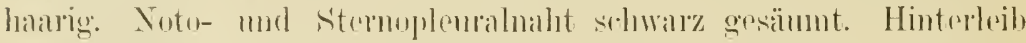

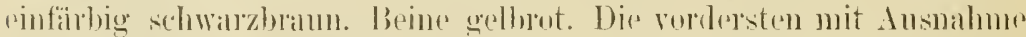

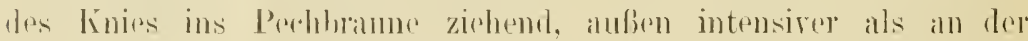

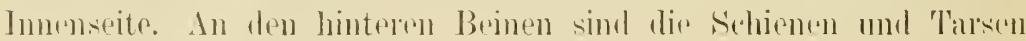

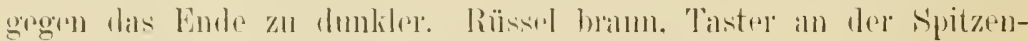

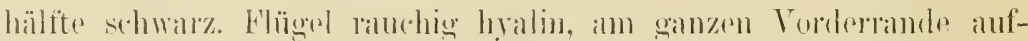

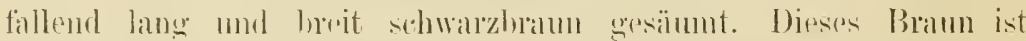

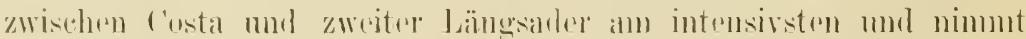

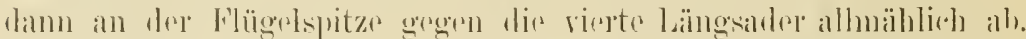

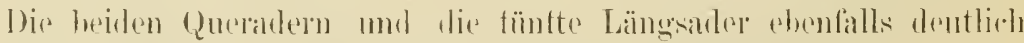

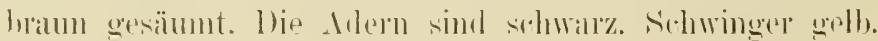

\section{․ Camptoprosopella xanthoptera 11.4 .}

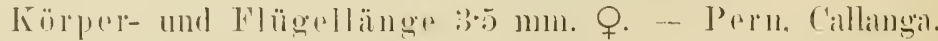
In dre Coll. Wirdemann. Kais. Mns. Wien und im ungar. National-

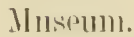

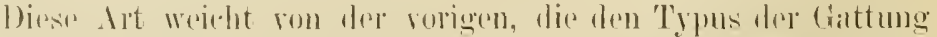

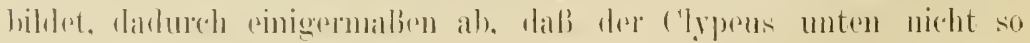

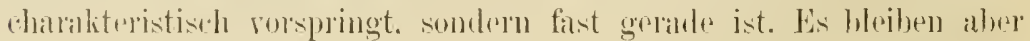


immer noch die ïbrigen Merkmale, die zur Winreihnug in diess Gattmog nötigen.

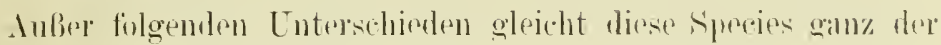
vorriginll :

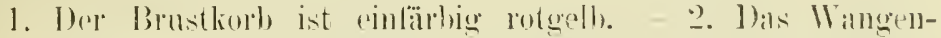

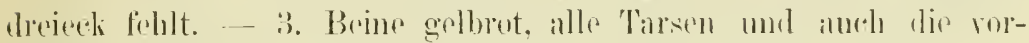

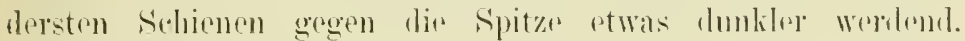

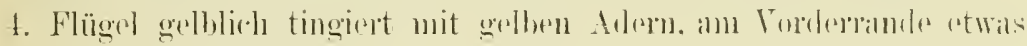
intensiver goll).

\section{:3. Camptoprosopella albiseta $11.8 \mathrm{p}$.}

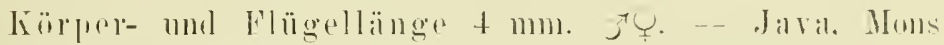

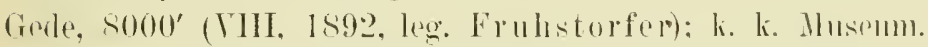

Diese dritte drt der ciattung hat wio die vorhererehende

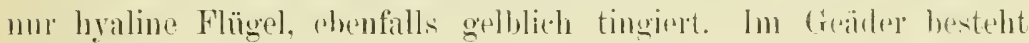
aber der Enterschied, dab der lotate Abschnitt der vierten Längs-

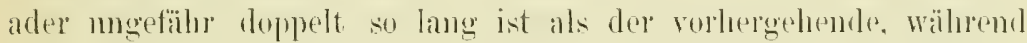
er bej den rorhergehenden Arten hob anderthalbunal so lang ist.

bie nir vorliegenden stürlie sims aber alle melı woniger

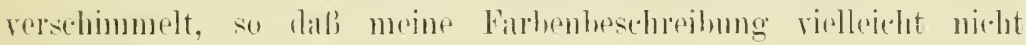
gamz genall sein wirl.

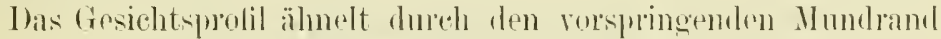

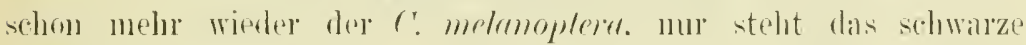

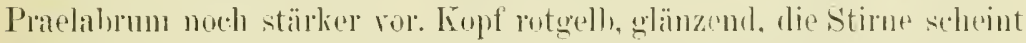

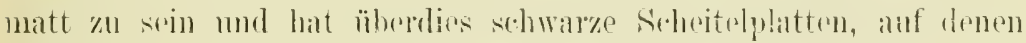
die borsten stehen. Ocellade fuhles oder sind rudimentair. Die beiden esten Fühlerolialed sind pelativ länger als bei den anderen Alten, rotgell,; ehenso die Murzol des sonst schwarzen, linearen

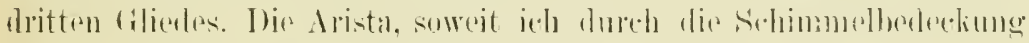

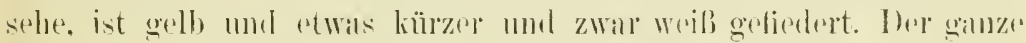

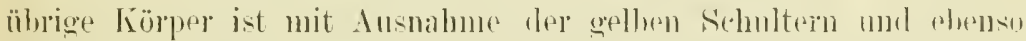

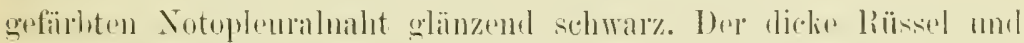

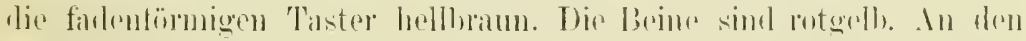

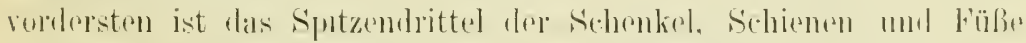

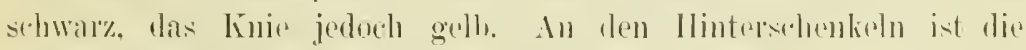
IIIzel mele weniger starli geselowirzt.

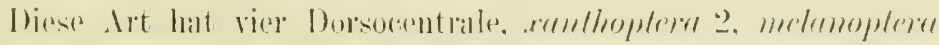

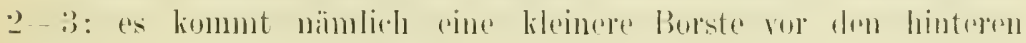
z.wei stïlieren manchmal ror.

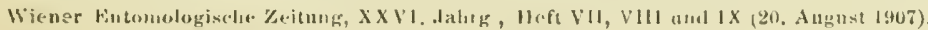




\section{Physoclypeus mor. gen.}

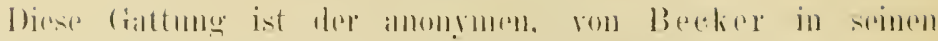

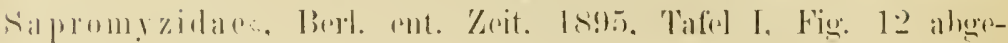

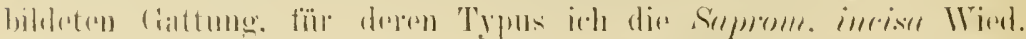

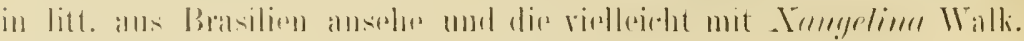

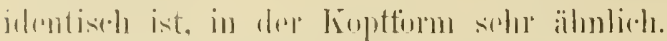

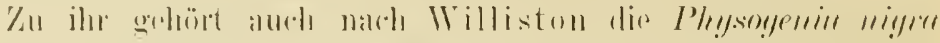

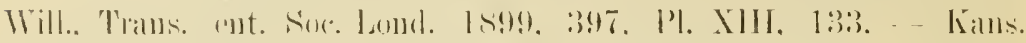

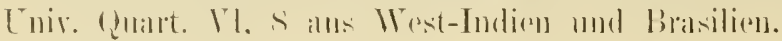

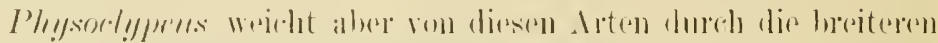

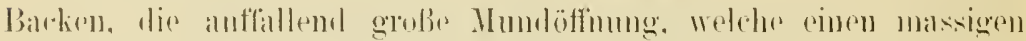

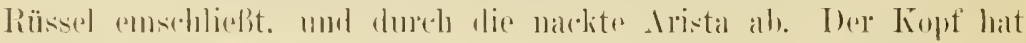

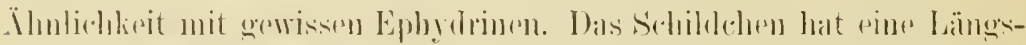

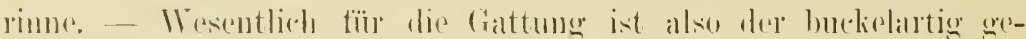

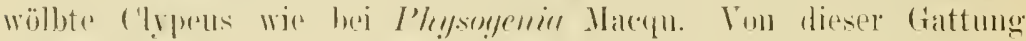

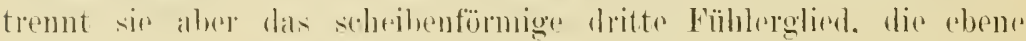

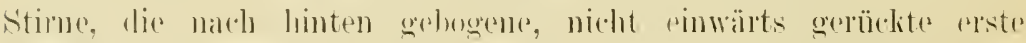

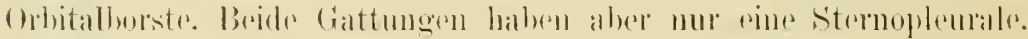

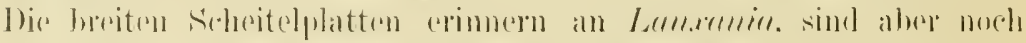

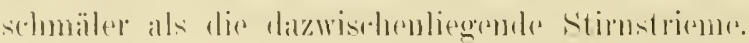

T'111:

\section{Physoclypeus flavus Wimi.}

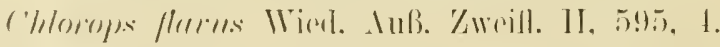

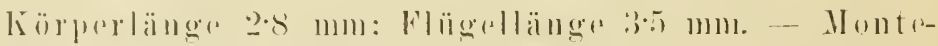

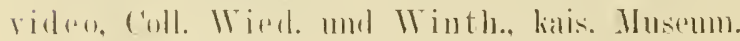

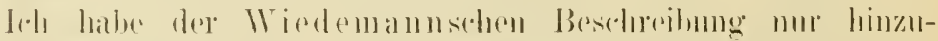

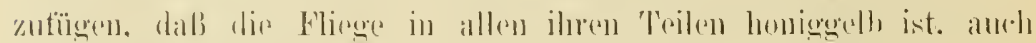

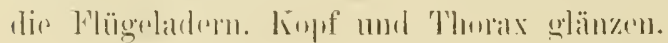

\section{Pseudogriphoneura nor. gurm.}

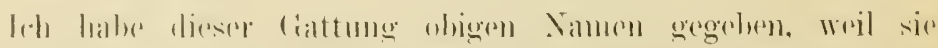

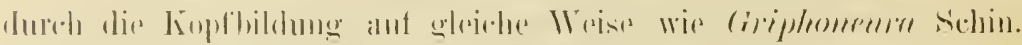

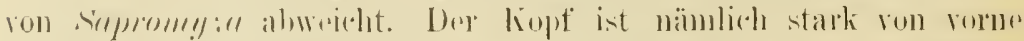

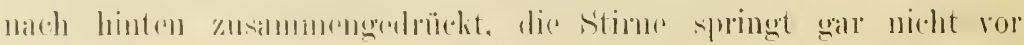

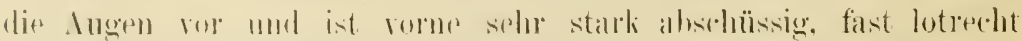

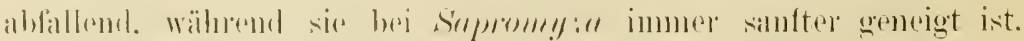

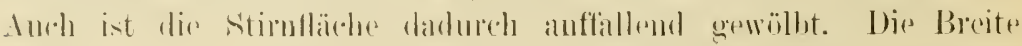

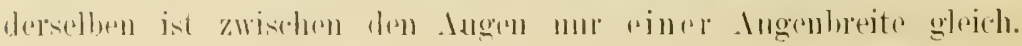




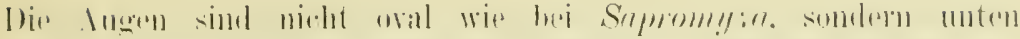

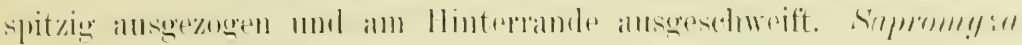

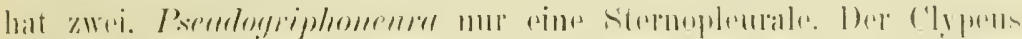

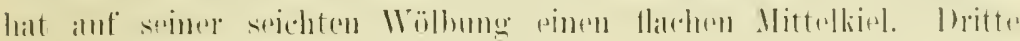

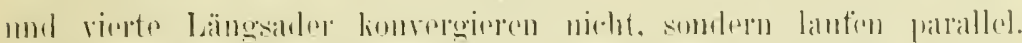

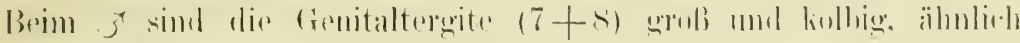

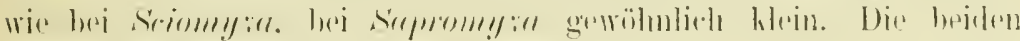
litril sind unotropisich.

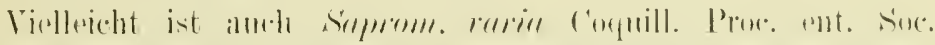

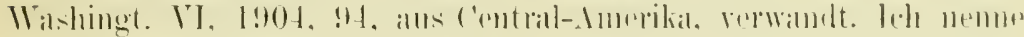

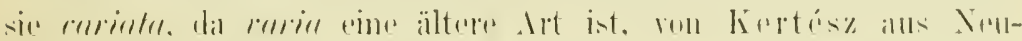

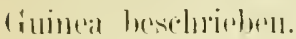

Typus:

5. Pseudogriphonenra cinerella $11.4 \%$

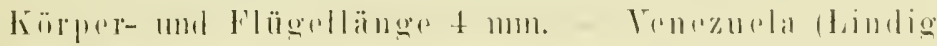
Istil. kils. Musinum).

Stime und Hinterliopt ascligran. "rstere mit rince hammen

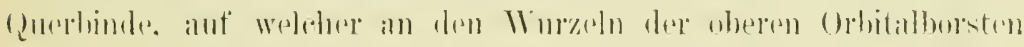

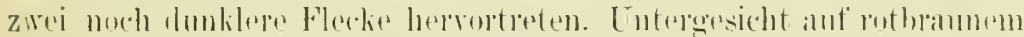

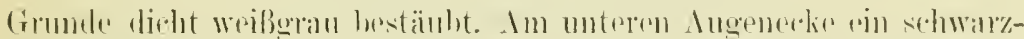

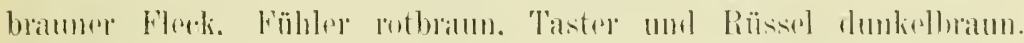

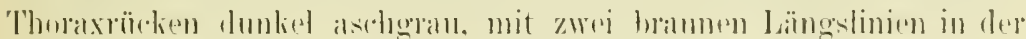

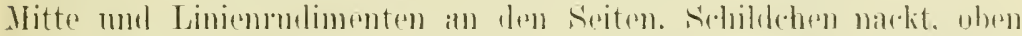

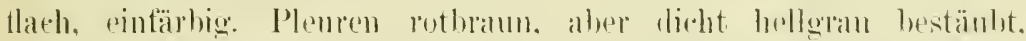

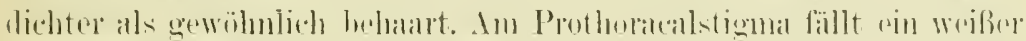

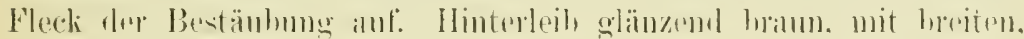

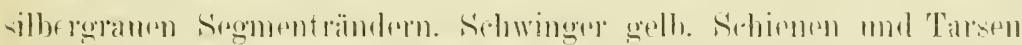

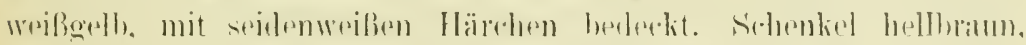

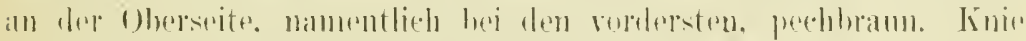

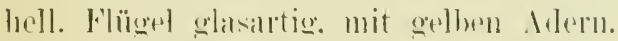

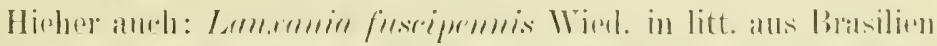

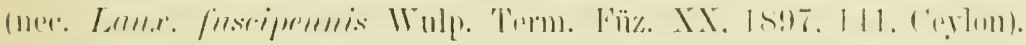

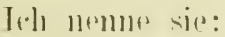

\section{(i. Pseudogriphoneura cormoptera ". . p.}

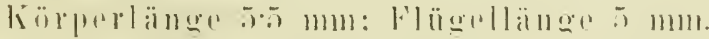

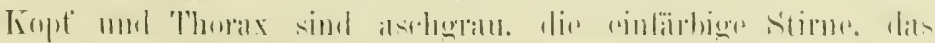

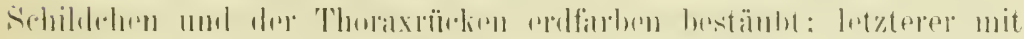

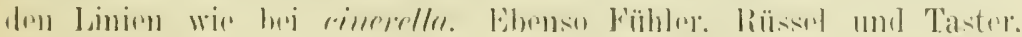




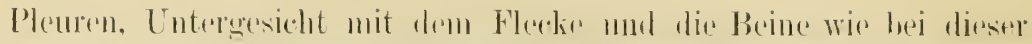

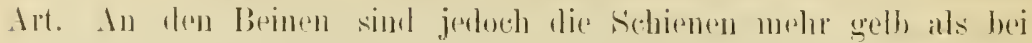

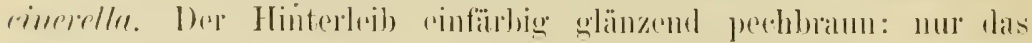

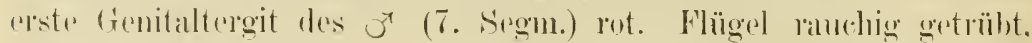
an Vordertande hinter dor Vündung der arsten Jängsadder mol

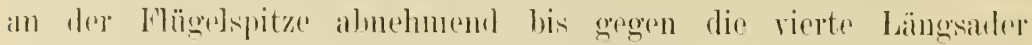
intensiy brann. 1)ie hintere Querader und die fünfte Längsinler

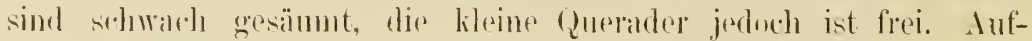

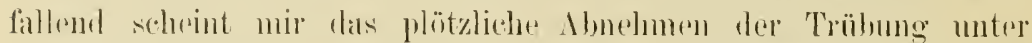

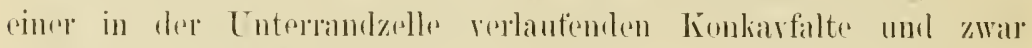

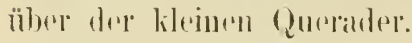

\section{Poecilohetaerus nw. gen.}

Von staprom!g:a ahweichend durch die cinwärts gebogene erste (Oplitale, durch das unten rorgezogene. aber gerade Untergesicht, das spitz vorspringende Prathbrum. Die hasig anfgetriebenen Labellen sind wahrscherinlich nur ein Zufall der Konservation. Auch

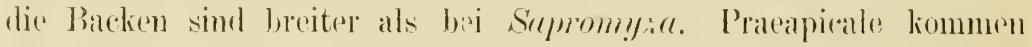
an allen sthienen vor, deren vordere kisulenfürnig sind.

\section{Typus: P.Schineri nom. nor.}

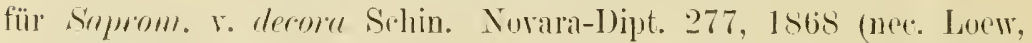
Cent. Y. 96. 1864).

Das Sthinersehe Original-Stück des kaiserl. Mrusemms stammt alus Nen-Seeland. IuBerdem simmelte Birí 1900 ein Stïrk in Sydney (N.-S.-Wales), das sich im Besitze des ungar. NationalMusemus befindet. Letzteres besitzt aber eine dunkel sepiabraune Stirnstrieme, sepiabramen Thorax und dunkelbranen Hinterleil) und Vorderschenkel. Trotzlem lingt aher sicher nur aine Art ror.

\section{r. Chatocoelia (iigl. Tos.}

Die Gattung gleicht habitucll in Gestalt und Fïrbung sehr gewissin Arten der Bombliden-Gattung Anthrex. Alle his jetzt hicher gehörig lowkannten Arten baben vorherrschenel tief schwally-

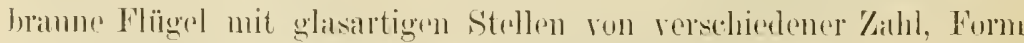
und Gröbe, einen anffillend kileinen kopf und einen hinten dunklen, vorne an der Basis leelgenben Hinterleil. Eigentümlich ist anch die relative Schlankheit des Leibes im Verhälnis zu den groben Flügehn. welehe, wie Sehiner sagt, leulenförmig sind, weil die Spltze stmupt und hreit int. der Wurzelteil aber schmäler wird. Das wesentlichste 


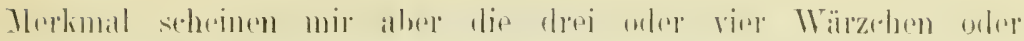

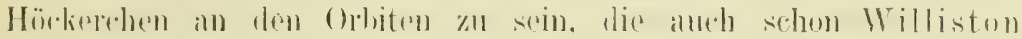

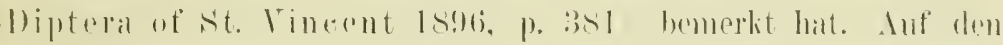

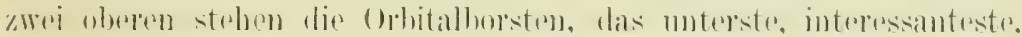

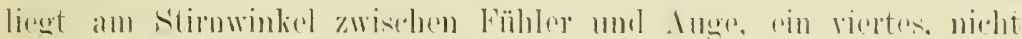

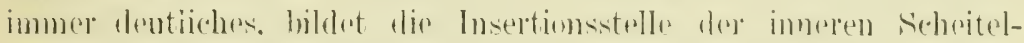

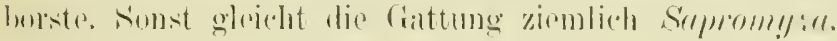

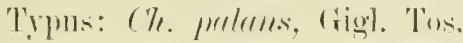

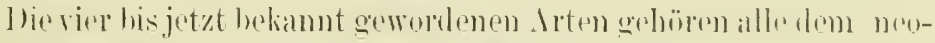

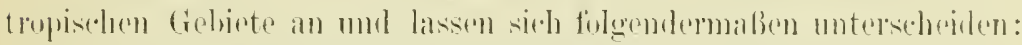

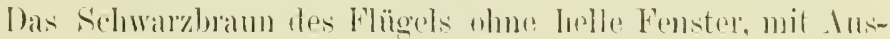

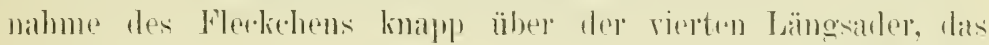

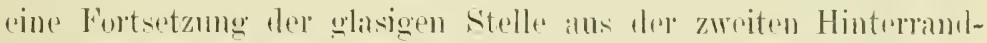

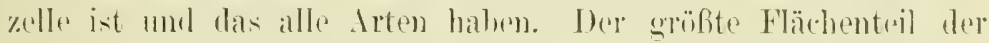
zweiten Hinterramdzolle und as ganzen Flügellappens unter der tïnften längsider hyalin, der liest braun. Die zwoj schwarzen

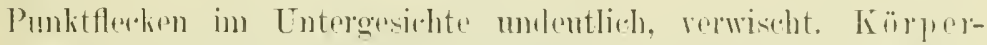

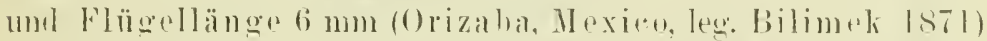
'Titel I. Fig. '…

prolams Gigl. Tus.

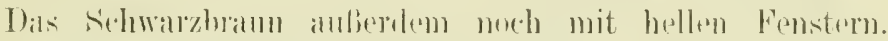

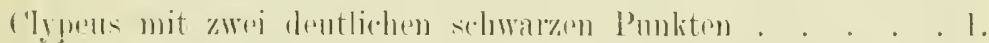

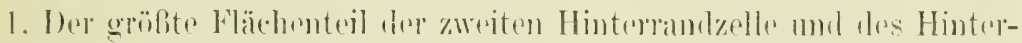

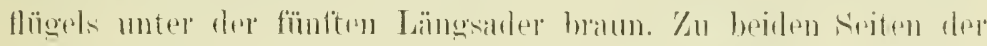

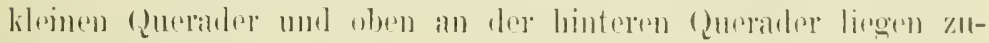

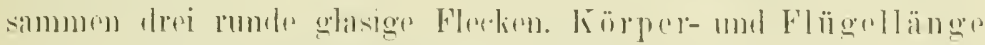

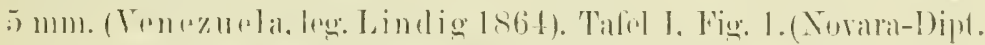

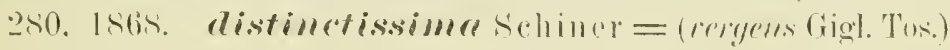

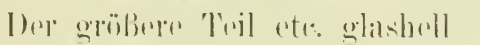

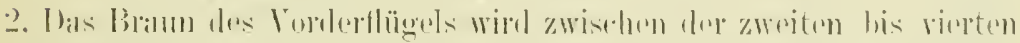

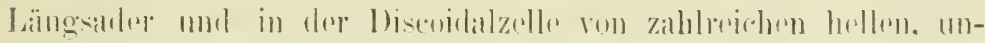

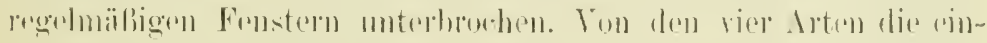

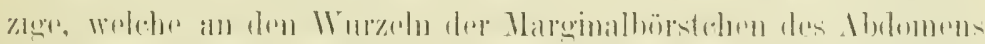

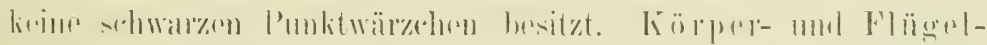

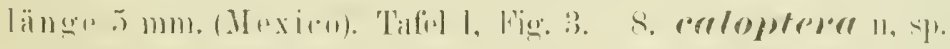

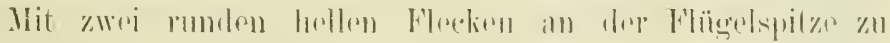

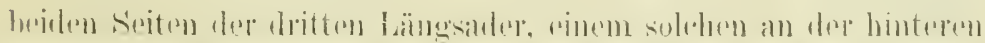

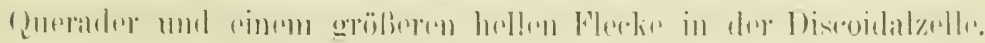

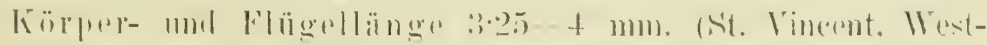

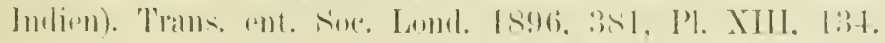




\section{I'. Siplonophysa nor. gen.}

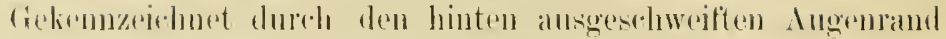

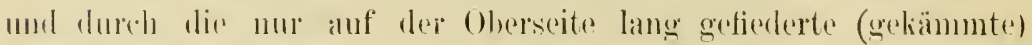
Arista. Der liässed nut namentlich die Labellen sind blasig anfgetrieben. Was vialleicht auch nur ein /anfall ist; das Untergesicht ist

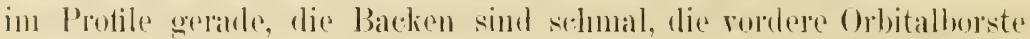
ist weit nach rorne gerürlit. Nur eine Sternoplenrale. I)ir Präipicalen an den sichienen sind sehr sehwath.

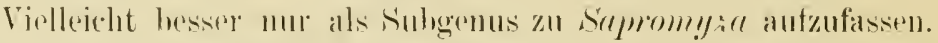

\section{!) Siphonophysa pectinata n. sp.}

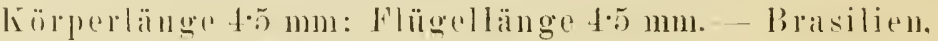
('oll. Nierlum., kais. Musenm.

linpe muel 'l'horax ockergell, durch Bestänbung matt. Die Stimstriems sticht dureh satteres (ielb ron den Siheitelplatten ab. In der Wrumel der vorderen Orbitalborste liegt je ain eiförmiger. samtsehwarex Fleck, mit ler sjoitze nach eimwäts mol rorwäts gerichtet. Untrogexicht und Barken seidenweib. Fülıler golb, an der Unterseite der Spitze und die Arista schwarz. Das dritte (ilied ist länglieh oval und zweimal so lang als die ersten zwej zusanmen. Taster dünn, b]ann; Rüssel weißgelh. Ocellarborsten fehlon. Anf dem Thoraxrärken verlanfen in der Linie der Dorsocentralen zwei loreite aschgraue längsstremen, die zwischen sich nur einen schmalen Raum der fromelfurbe freilassen, sich hinten rereinen mol etwas anf die Mittr des oben vollkommen flachen und matkiten Sehildchens ähertreten. Die Meso- und Stermoplemen zeigen oben und hinten rinen hellbrannen Fluck. Hinterleib etwas dunkler als dit Pleuren, melu hrann, am vorderen AuBenecke des vierten bis sechsten 'Tergits mit einem hellen. matt weißgelben Dreiecke geziert. Beine weißgelb. Mittel- und Hinterschienen ïber den linien mit einem dunkleren Ringe', Tarsen etwas intensiver gelb. Grumdbehaammg les Thorax dichter als gewöhnlich. Torne mit acht Reihen Acrusticalbörstehen, inklusive derjenigen in der Dorsocentrallinic. Flügel weiBlich mit brannen Flecten: an den beiden Queradern, an den zwei anfwärts-

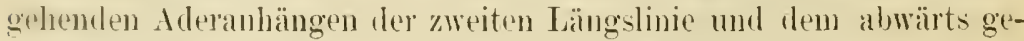
richteten ıler vierton Längsader, lamn ror der Mündnng der ersten Längsader, zwischen der Wrurzel der dritten und vierten Längsader und cutlich ein Spitzensamm zwischen der zweiten und vierten Längsarter.

Hieher gehöt anch wahrscheinlich Samomyia sosdida (Tied.) Willis1. Mipt. St. Vincent, $1896,38: 7$. 


\section{Paranomina nor. gent}

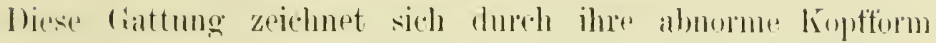
als. Dor horizontale Kopfilurehmesser ist nämlich rtwas graßer als der vertikale. Der Kopt rseheint im allgemeinen liat kugelig. Ferner weicht der vollkommen gerale und ehene c'lypous stark

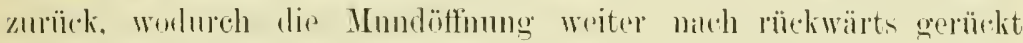
wirel. Kenmzeichnend ist fermer ler fï̈ seine länge ziemlich sehmale Hinterleih, eler vielmeln an die sciomyzinen erinnert, namentlich dureh die Gröbe der heiden Genitaltergite $(7+s)$ des $\sigma^{x}$.

Sonst fallen ant: Der lange, schmale Flügel, der volmminöse Rüssel, die rndimentären ()oellarborsten, die einwäts gobogenen rorkeren Orbitalen. zwej Sternoplemale. Praserpiale an allen Sichienen. Das dritte Fühlerglied ist fast scheibenförmig, die Irista natelit, das Sehildehen oben Hareh.

Ty IIIs:

\section{Paranomina unicolor $11 . ; 1$.}

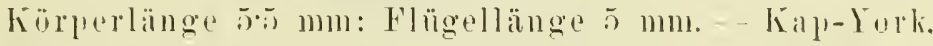
Instralien, leg. Thorey, 1868: kais. Musem.

Dip Fliege ist durchaus rotgell, gefärbt. Wie Stimstrieme mattgelb. Das Untergesicht ist weil bereift, die Plemen schwäther. Die Fïhler simel dunkler. mehr brann zn nemnen. Die drista ist schwarz, ter Flügel gethlirh lyalin, am Vorderrande intensiver, die deren sind gelh.

\section{IIII. Rhagadolyra nor. gen.}

Anch dioses Groms ist an seiner anffallenden Kopfform leicht zu rekenmen. Die Stim springt nämlich so stark über die dugen ror, dak die Breitr des rorragenden Teiles fast glaich ist dem horizontalen Augendurehmesser. Dadurch muf anderserits das Cntergesicht stark zurückweidhend gehildet spin. In Profile ersolemt rabei der clypems sanft S-förmig geschwmingen, am IImolrandr zwar nicht vorspringemel, aber dickwulstig. Betrachtet man den liople ron rorme, so "rscheinen die die Stirne begrenzenden Angenrïnter stark cingebuchtet, lonkas - - bei allen anderen mir bekannten Sapronyzinen-Ciattungen gerade - die Stirnspaltenäste verlanfen mus die: Fïhler herum lejeförmig geschwungen. Die verengte Stolle des eingeschlossunen clypens liegt an der seichten douerfintehe. welele rinen länglichen Hërkes zwisehen und unter den Fühlern 


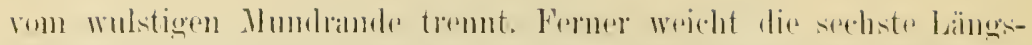

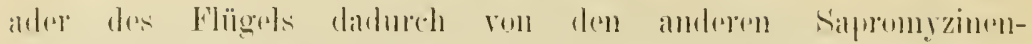

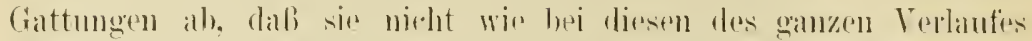

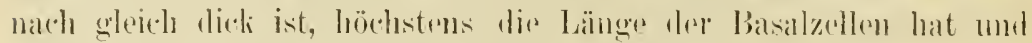
damm stmmpt, wie abgeschnitten randet. somdern dal sich atn dieses

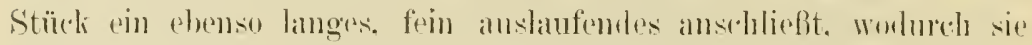

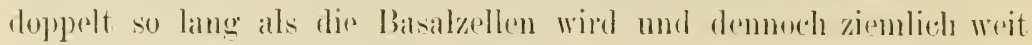
ror dem Flügelramle pudet. Flügrel lang und selmmal, Rüssol dick,

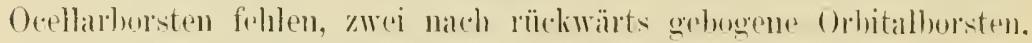

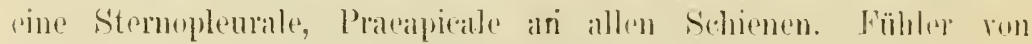

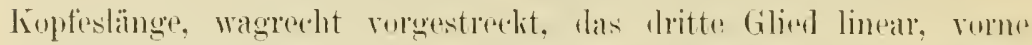
abgerumdet. drobual so lang als die hriden proten zosammen. mit bataler, nacliter Aristat. Schildrhen gewölht, oben nicht alogeflateht. Hinterleih oval, breit. wir hei allen sapponyzinen in Allgeneinen.

Typus:

\section{Rh. Handlirschi nov}

Körlveränge mit den lïhlem 8 mm: Flügellänge - Q. Syenry, Anstralien. leg. Thorey, 1S64. kais. Musemu.

Vorbersobend glanzend rotgolls gefälst. nur der Hinterleih wird rom zweiten Ringe an immer dunkler. dam pechbram, nach hinten zu wiedrer rot. Tielleicht ist as nur oine Nacholumliehng. Die zwej Genitaltregite $(\bar{\tau}+s)$ liboin, rundlich. Thorax mit fünf

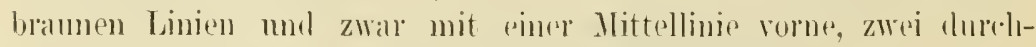
gehenden Striemen in ler Linie der Dorsocentralen und je einer phensolehen, mur hinten siehthar, in der dor Intrabaron. Schildeluen

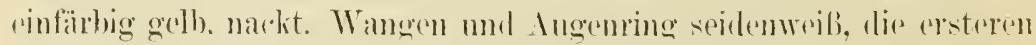

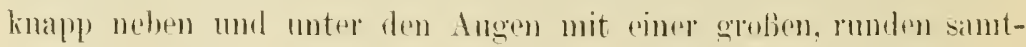

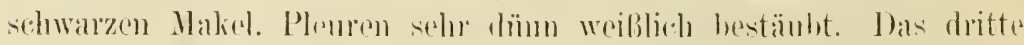

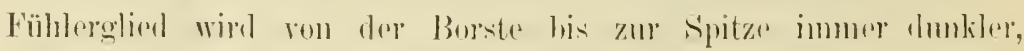

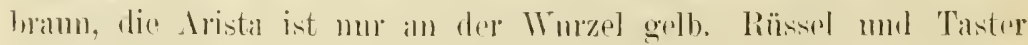

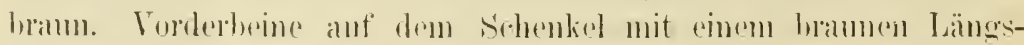

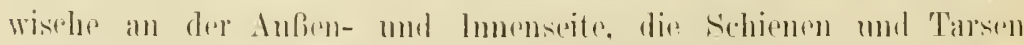

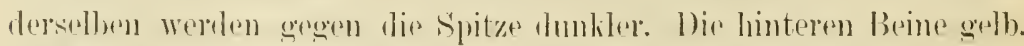

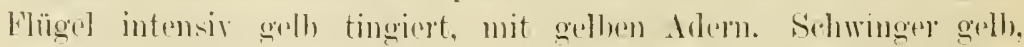
Sichïplechen hell gowimpert.

Ich hemenne diese interessimte Australierin zu Ehren des Heron linstos A. Handliesell. 


\section{Hypagoga nor. gen.}

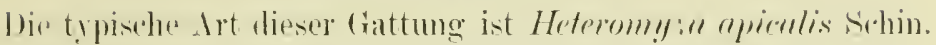

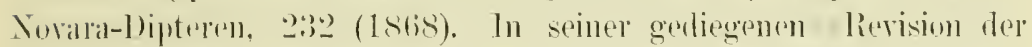

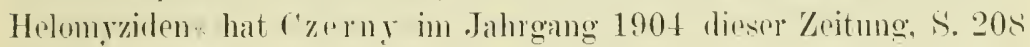
daranf hingewiesen, dab die Schinersche drt keine Helomyzide ist; er hat aber mangels gentuerer Notizen kein weiteres Urteil äber die systematiche Stellung dieser Gattmo abgegehen.

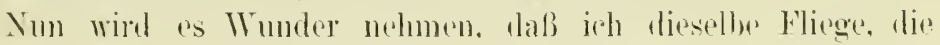
Schiner fïr eine Helonyzide hiolt und die sogenannte shomelbursten besitzt, zu den Lamxaninen bringe. lingohomdere dusminandersetzungen hierüber muk iels mir aber hier rersagen und dieselben anf die Genera Insectormm rerschiehen.

Die Crattung unterscheidet sich leicht ron allen übrigen Latuximinen-(ienera dadurch. dab die Gesiehtsheisten. ohne eine Tihrissenecke wie bei den Helomyzinen zu bithen, unter den Inge eine Rerihe rom 5-7 langen, einwärts und abwärts gebogenen Borsten Insitzen. wie soldhe in der Fin- oder Zwoizahl anch bei anderen Gattungen dieser Ciruppe. wie anch bei Ephydrinen. rorkommen. Die Backen sind breit und hinten herahgesenkt. der Clypens im Profile lotrecht und gerade. rom rome gesehen fast eben. Der Rässel ist voluminös, der Flügel ein typischor Lauxaninenflüged nit divergierender drittu und vierter Längsadru. Das eiförmige Schiddchen hat eine konkare Oberfliche wie ron einem Eindrucke herrührend. Schienen mit Praeapicalem. Beborstung: Dorsocentrale $2+1$, Humerale 1. Notoplemale 2, Snprablare 3, Praescutellare 2, Pracisturale 0, Scutellare 4, divergierend. - 1 Prothoracale, 1 Mesoplenrale, -2 Stemopleuralu. liopfborsten wie bei Supromy:

\section{Sciasmomyia mw. gen.}

Diese ind die folgender Gattung gohören in jentre Verwandtshaftsgruppe, deren Lntergesiedte (rlypens) stallk buckelartig anf-

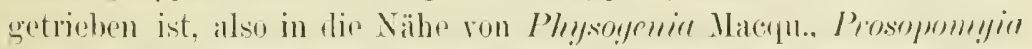

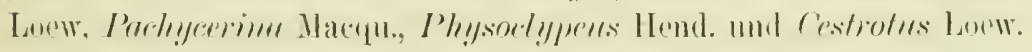

Von restroters unterseheidet sie das Fehlen des tomartigen

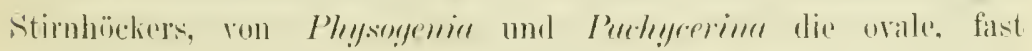

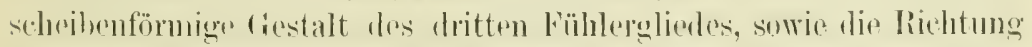
der beiden erbitalhorstem, walche nach hinten gebogen sind, ron

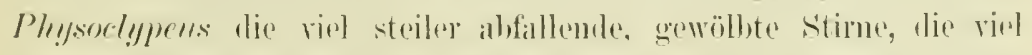

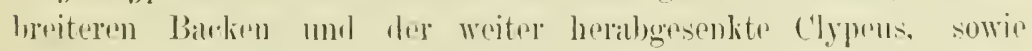

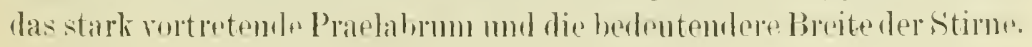




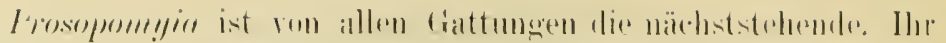

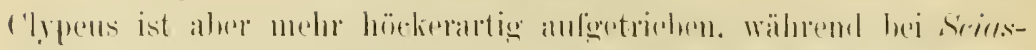

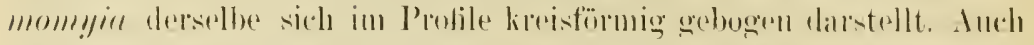

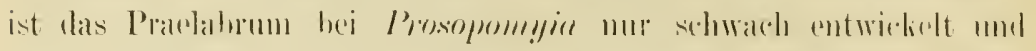

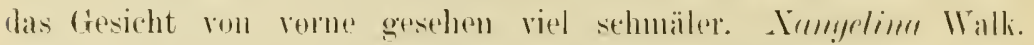

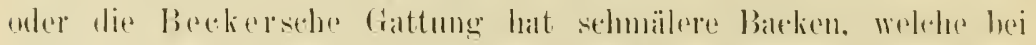

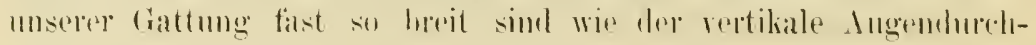
mestere

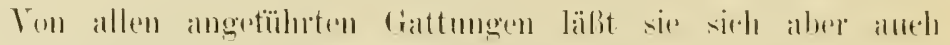

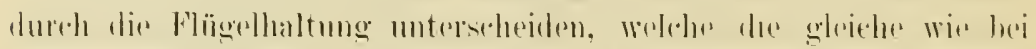

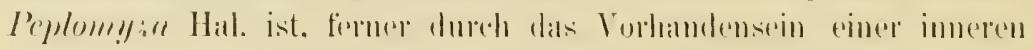

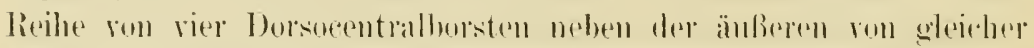

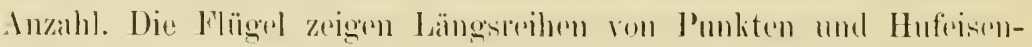

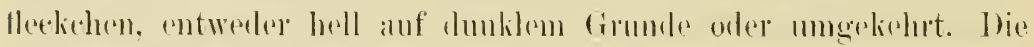

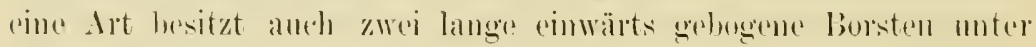

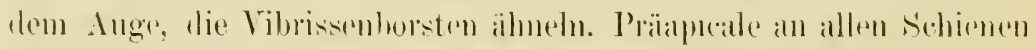
vorhanden. '/wei sternu-, aire Mesiplentale.

\section{Sciasmomyia Meijerei $\left.{ }^{1}\right)$ n. sp.}

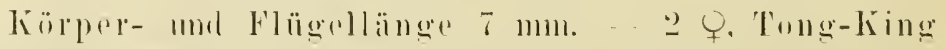

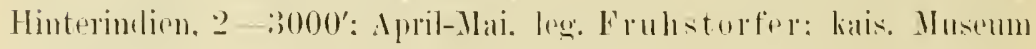
in Wien.

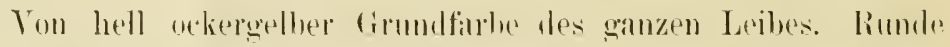

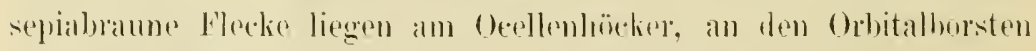

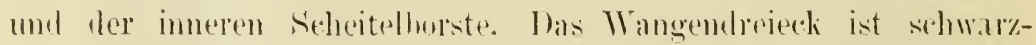

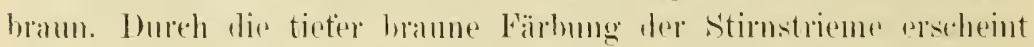

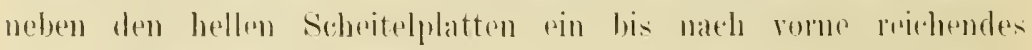

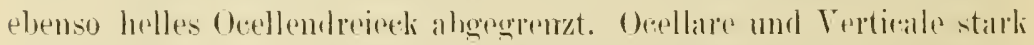

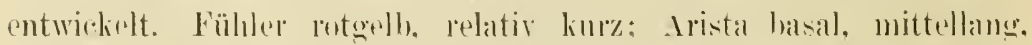
foin, tast woblig gefiedert. Clypens mit ano bramen Mittelstriemu

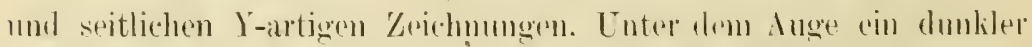

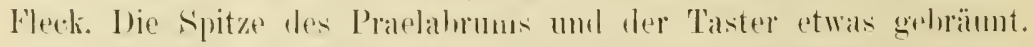

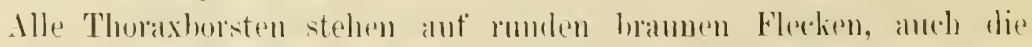

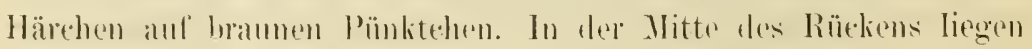

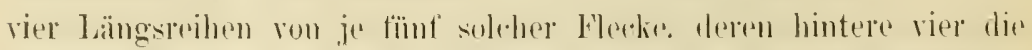

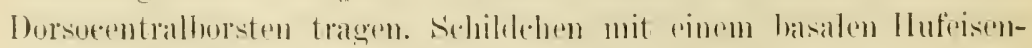

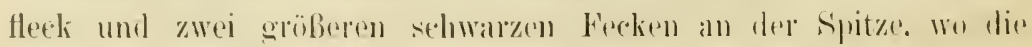

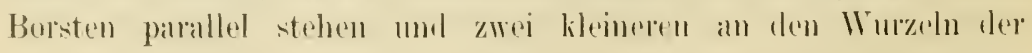

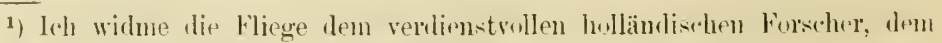

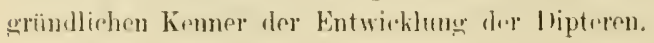




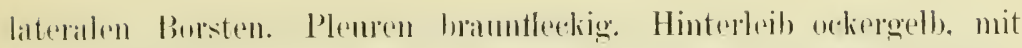

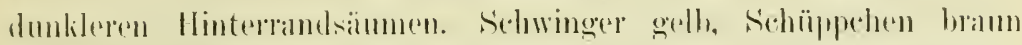

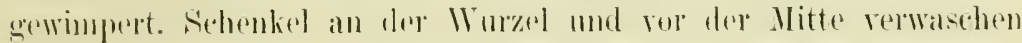

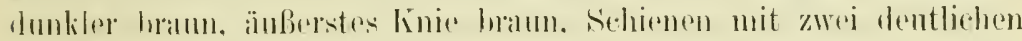

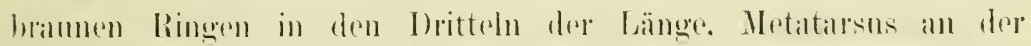

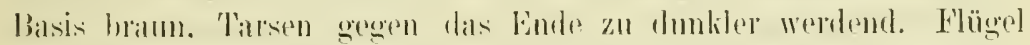

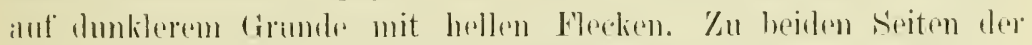

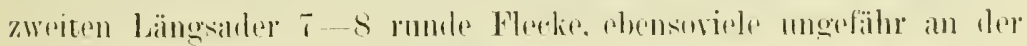

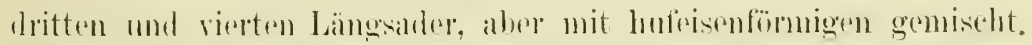

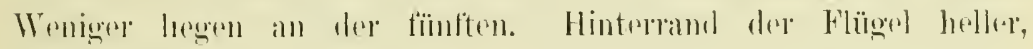
mehr hyilin.

\section{1:3. Sciasmomyia dichaetophora $11 . .4$.}

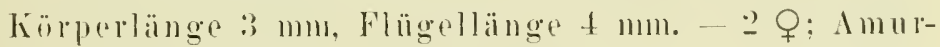
gedrict. leg. Schrenk. kiris. Musenm Wien.

Diese Art unterseheidet sidh von der vorbergebenden dureh

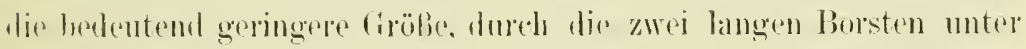

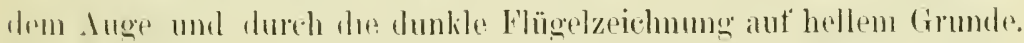

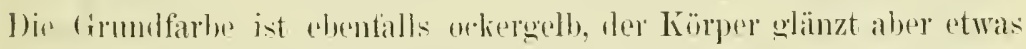

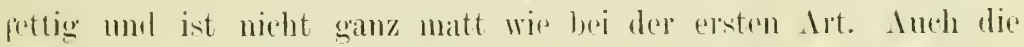

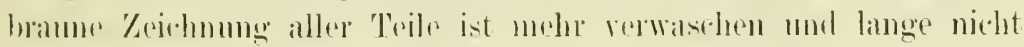

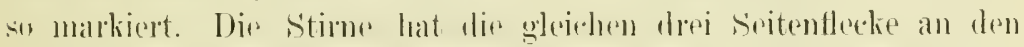

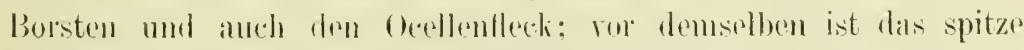
Oecllembreck aber nicht hell, sondern hier dunklep hraun als die scitliche, helle Seitenstrione. Fühler und Intergesiedt wie bei der

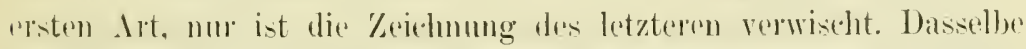

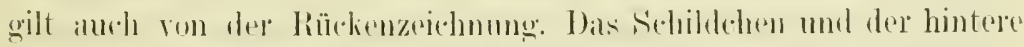

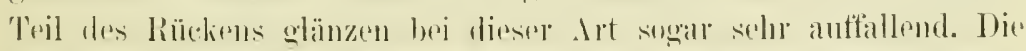

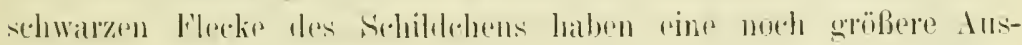

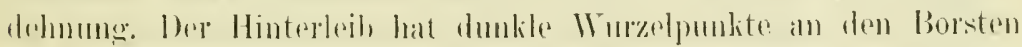

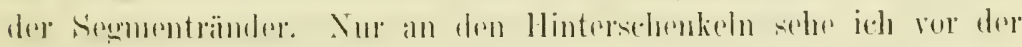

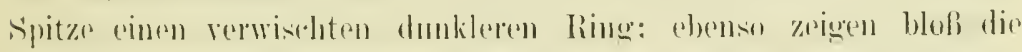

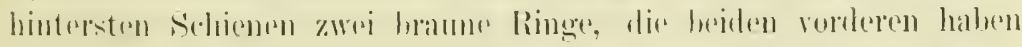

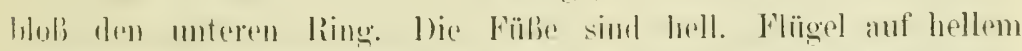

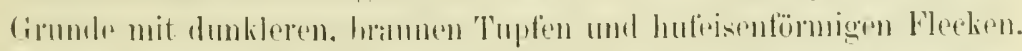

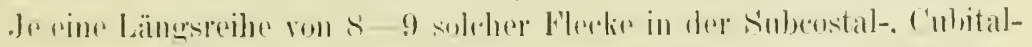
und resten Hinterrandzelle. Die hinteren Zerllen ter Flügel ärmer

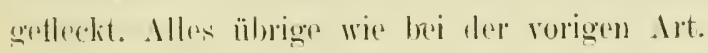




\section{Cerataulina nov. gen.}

Vortrefflich charaliterisient durch die äberkopflangen. vorgestreckten Fühler, deren alufatlembe Lünge alber nicht durch dis dritte Fühlerglied. sondern durth die beiden Basalediender horvorgerufen wirl. Das erste (ilied ist das längste. otwats weniger als dir Hällte der ganzon Fühlerlänge lang. Es ist an der Wrurzel dümner als gegen das zweite Fühlerglied zu, oben mol meten behorstert. Das zwoite cilied ist die Hälte des erstem lang. etwas kin̈reer als dis kegelförmig zugespitzte dritte: gleichfalls oben und unten borsten tragend. Die Arista steht medial und ist beiderseits dicht grefiedert.

Die Gattung gehört anch zu denjenigen, deren C'lypeus lö̈clierartig aufgetriohen ist und zwal hat sie von allen den an stärksten gekrïmmten Clypeus, der ziembich weit äber die Angen rorsteht und steil zum Mnudrande uml zur Stime alffillt. Dis Pratiburum steht etwas ror. Von den zweiten Orbitalborsten sind die unteren rorwärts mul einwälts gebogent. Ocellare fehlen. Rüsscel mod Taster siml normal, ebenso der Flägel we bei der ganzen cimppe gewälnhlich geadert. Behorstung: D.- $\div 2+1$ : Prasecut. I Par; 1 Praesuturale, 1 Hum., 2 Notnpleur., : Supral.; 1 ILesu- und 1 Sternopleur.

1 Prothorateale. -. Prateapicale an allen Schienen. Sehildehen selor lang, die Hältte des gamzen Thorax. eifömig spitz. whon flach und mackit, mit vier Borsten, dira an der Spitze divergieren.

\section{Cerataulina longicornis $11 . \mathrm{sp}$.}

Körperlänge vhne Fühler und Flügellänge : 11 m. Xen-Guinea, Friedrich Wilhelms-Hafen, log. Biró, 1900. E'ngar National-1Iusemm.

Die Gromdfürhung des ganzen Leibes ist ein mscheinhares weiBliches Gells, mit ziemlich starkem Gilanze. Stime in ter oberen Hälfte hellbraun. Gleich unterhalh der vorderen (orbitalborstr liegt rin ovaler samtschwarzer Fleck, der den gamzen Ramm zwisehen Fïhlerwurzel und Auge anslüllt und mit seiner unteren Hälte aul den Wangen liegt. Der (lypens ist dunkelbram, gäunzent. die Trangen und Backen aber weiBgelb. T'aster golb, num an dor Spitze schwärzlich. Die Fühler sind gelblich, gegen die spitze zu hellhraun. Die Arista ist äuBerst dicht und mehr anliegend mittelmäBigg gefiedert, die Fiederhatre sind dunkelbram. Der Thoraxrücken und das Sidhildden sind in Vergleiche zu den lieden Plenren hellhram. In der, linie der Dorsucentralen sind verwatidone, dunklere Längsstriemon orkennbar. Undeutliche längsstriemen sind anch ïber und unter 


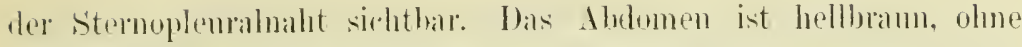

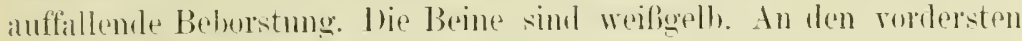

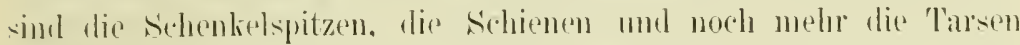

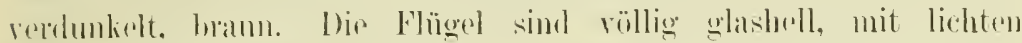

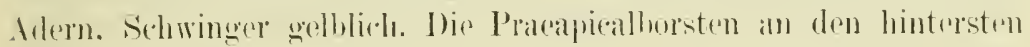
stehienen sind nur selur kilein.

Pachycerina javana Marpliat.

Diprtios exotiques, s./4, 27.4, 20. - reylun (Nattrere), Jara umil Itarjeeling (Fruhstorfor). Kaiserl. Mnsenm.

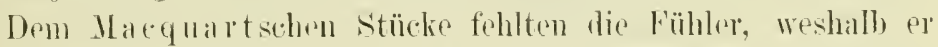
die Gattung nicht erliannte. She Art zeigt folgende Lnterschiede ron seternoris Fallén. wie sie berker in semer Monographe hes.lurielon liat:

Das dritte Fühlorglied ist schmöler, der clypens molo hasig aufgetrieben mol diw Mundöffinmog daher gröber, die Taster sind

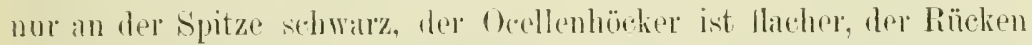

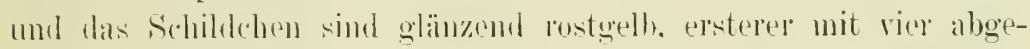

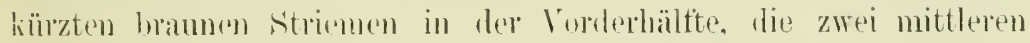

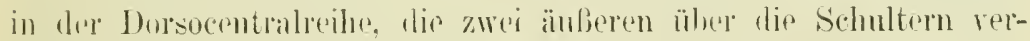
lanfend. und zorei abensolehen in der Hinterhälte, in der Linie der Intrablaren. Hinterleib rostgells, sechstes 'Tergit mit zwei sehwarzen

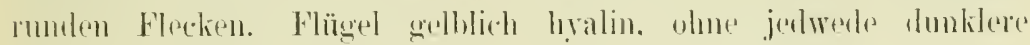
š̈แmmแng mond 'Trülumg.

\section{Sultiun. Milichinae.}

Leptometopa Buelier. (Tiafil J, lig. S.)

Diese Milichinen-tattmon war Becker, als er sir in den

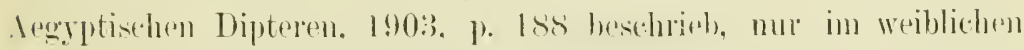

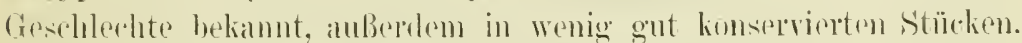

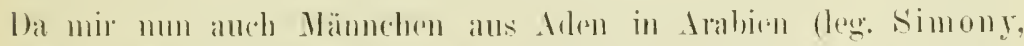

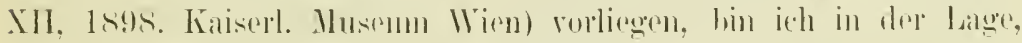

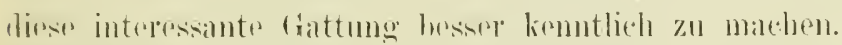

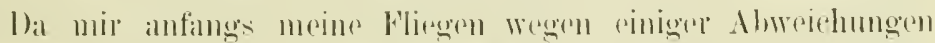

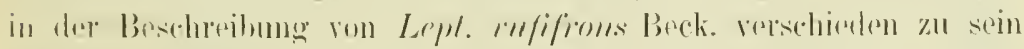

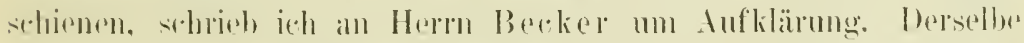

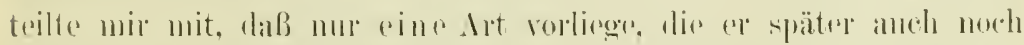

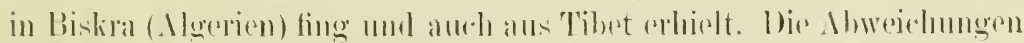

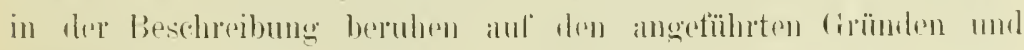
luminhen sich anf folgendes: 
Suprabalare drei: statt Mesoplenralr soll es heiBen Pteropleurale 1-2: Thaster sind rorhanden und zwar sind diesclloen lang, gegen das Ende etwas keulig und gelh. Das Sedildehen ist unhedaart,

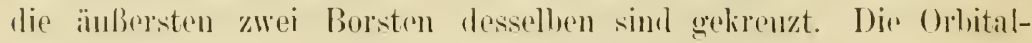
borsten zerfallen in brei einwärts gebogene muteres und zwei answälts gobogene soberes, von denen dip vordere rorwärts, die hintere rückwïrts genogen ist. Dir Verticalloursten sind stark entwiekelt. lionvergierend, fast gelireuzt. Inf der Stirustrieme, whe hesondero

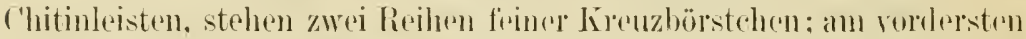
Stimrante äher den Fühlern vier zarte Borsten. Lun anffallendsten sind die beim Männchen stark erweiterten Hintersehienen, wie soldhe

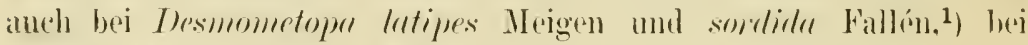
letzterer Art nath einer Mitteihng Beeliers, vorkommen.

Völlig unautgedlärt ist natürlieh dire biologische Bedentung dieser Schienenerweiterung beim or. Am ehesten seheint es mir ein Sammelapparat zu suin. wie ein soleher ja ähnlich bei den Sammelbienem ansgedsilet ist. Die Anbenseite der Erweitermng ist

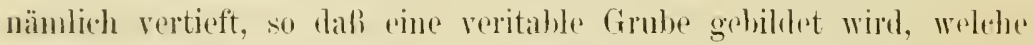
unbehart und unbeborstet ist, aber eine feine, ans Punliten und Rillen gebildete skulptur besitz. Parallel damit sind die Mretatarsen der Torder- und Hinterbene mit strifin Borstenhalaren bürstenartign

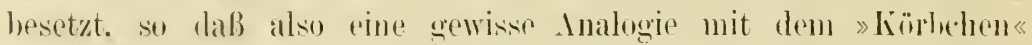
und dem » Bürstchen « der Honigbiene gregehen arscheint. Anch der lange gelniclite Rüssel dentet auf den Besuch ron Blüten hin. Interessant ist ferner alteh die Vorliebe des Tieres für Wüsten:

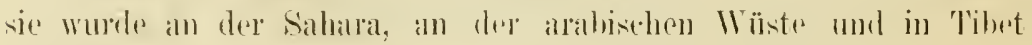
gefangent.

\section{Horaïmoptera nw. gen.}

Am näthaten rerwandt mit Meonemon Roml., rom dop sie sich dureh den mit weitläntigen Borsten besetzten Flägelvorderand und

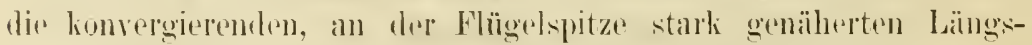

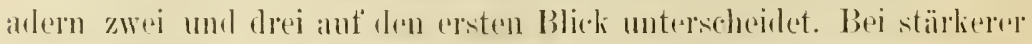

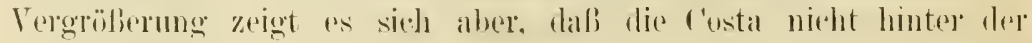
dritten lä̈ngsaler ahhricht, sondern sich. wernn andh viel dümner. bis zur Jlündung der vierten Längsader fortsetzt.

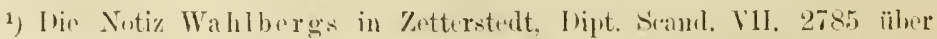

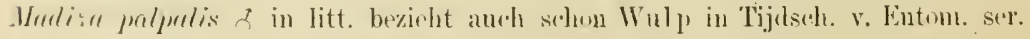
11, 6. P. 197 (1871) auf sombleta Fallén. 


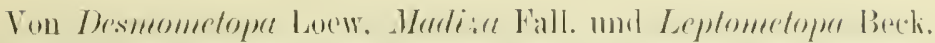
unterscheidet sie sich dadureh, dab der flejschige Rössel nicht hakig mmgeschlagen ist mod daß die Mrsoplemen nicht mackt sind, smmlem

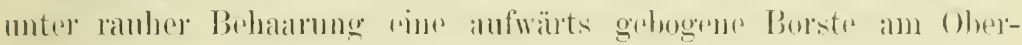

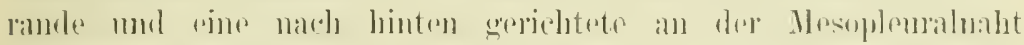
trigin.

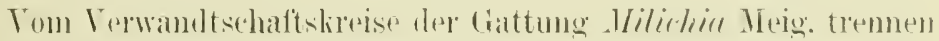

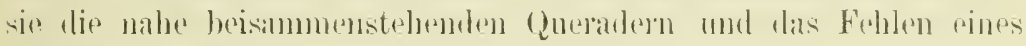

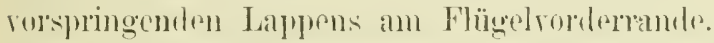

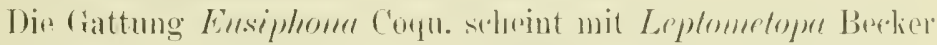

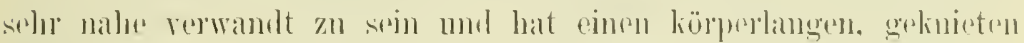
Rïissel.

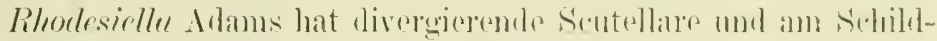

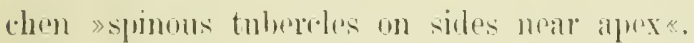

Aphaniosomu Beclier, rom Autor zu den finomyzinen gestult,

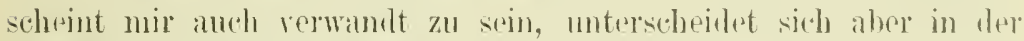

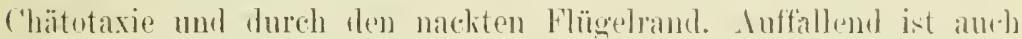

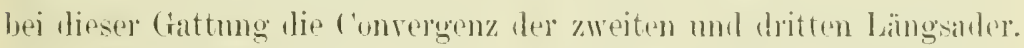

Der Kopef ist so breit als der 'Thorax, seine Form ron rormes umel im Profile sind ans der Kejehmmen arsiohtlich. Die stime ist

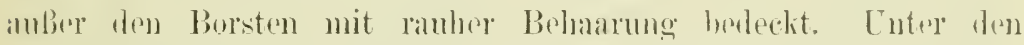
Fïhlern befindet sich aine hablungelige, grmbenartige Tertiofung. Die Belorstung zejgt elenfills die Tafel. Hinterkopt sanft ansge-

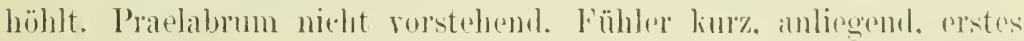

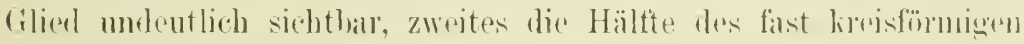
drittru lang, hatrig, an dor Tnnenseite mit zwei nach anben grebogenen domartigen Borsten besetzt. Arista an der Basis dieliel. óegen die Splitze zu äuberst zart pubeszent. Taster keulenfömig. Thorax mäßig gewrillet, im Profile olen ziemlich gerade. Humerale zwei, pine darom

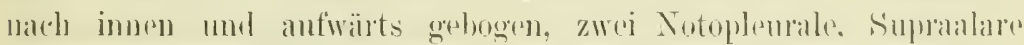

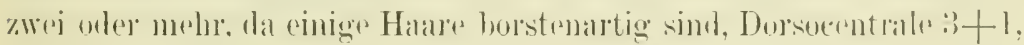

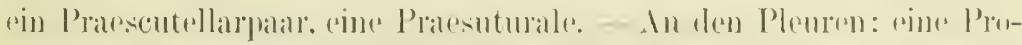
theracales, zorej If

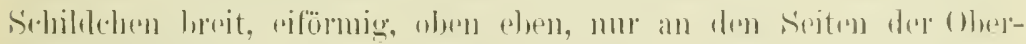

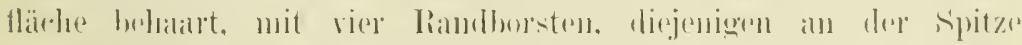

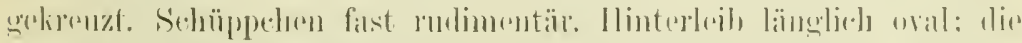

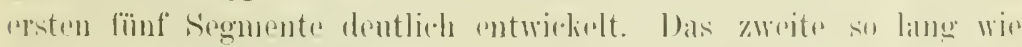

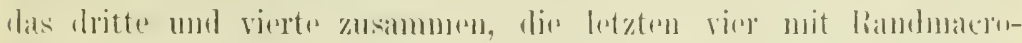

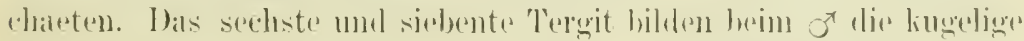

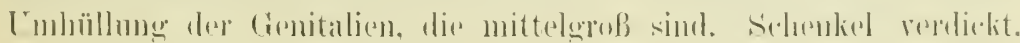




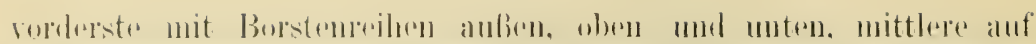

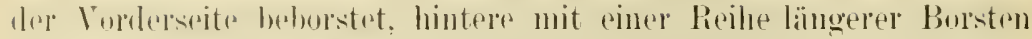

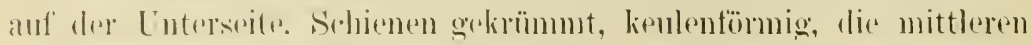

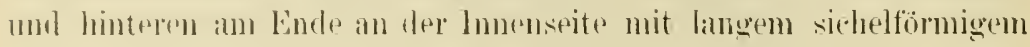
śporns. Hinterschienen an der Aubenseite wimperartig beborstet.

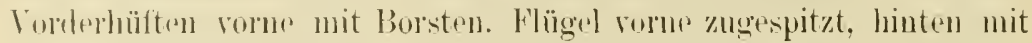
Ineitems Hinterlappen, wie die Abhildung zrigt, geadert. Der letzte

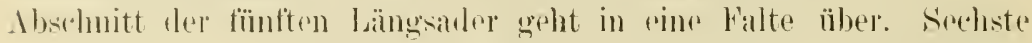

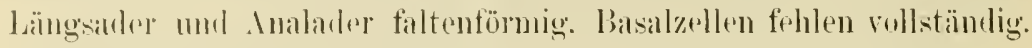

15. Horaïsmoptera vulpina n. sp. $\mathrm{J}^{\top}$ (T'itel I, Fig. (9--11).

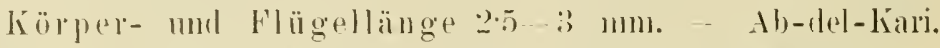
Arahien, low. Prot. (). Śmony. Jännel 1899: kaiser. Museum.

Stimstriems. Fülslor, Wangen lis himmoter zum Enterande des Limptes gellnow, Sehejtelplatten, Hinterkopf, Bareken und C'lypeus zwischen den borstenteilen as.hgran. Dolsselbe (irau zeigt der ganze Brustlorl) und der Hinterleily; letzterer sugar einen Stich ins Violette. Die rauhe Boharlung, womit der ganze Körper berleckt ist, zeigt

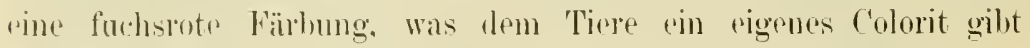

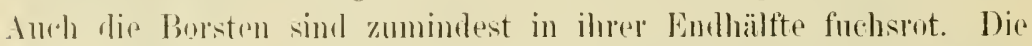
Beine sind kurz mul stark, ron rotbramer Farbe, die Schenkel lunklor mul meln weniger grau hestäuht, mit Ausnahme der Spitze. Die Tarsen sind breitgedrülekt, das letzte Glied dunkel. Die Arlern

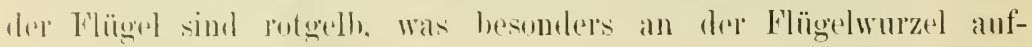
fallemel ist.

\section{X11. Hypaspistomyia n. gren.}

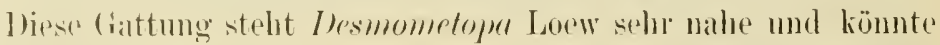
somst mit lieinel muleren Gattmo rerwedsalt werlen. Es gilt für sie alles, was ide in diesel Keitumg, Jalugamg 190:3. Seite 251

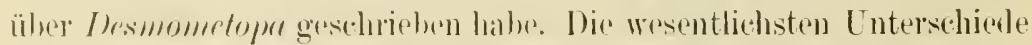

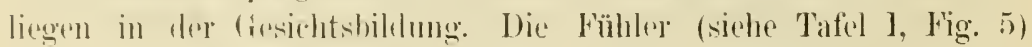

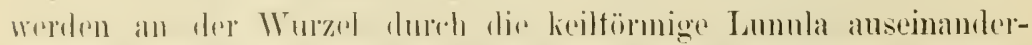

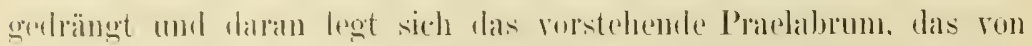

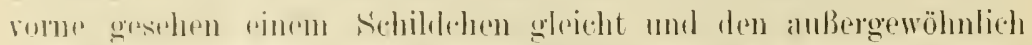

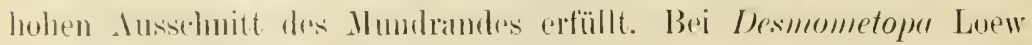

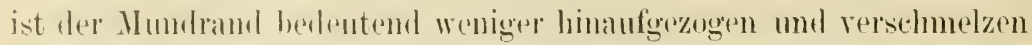
die birs getrementen föhlergruben in cine gemeinseluattiche. AnBer-

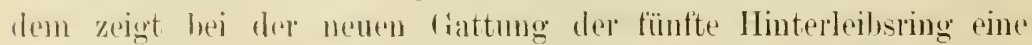
alnormu Lä̈nge, indenn ar beinalse die Hälfte des Ibelomens an Längั rrovicht. 


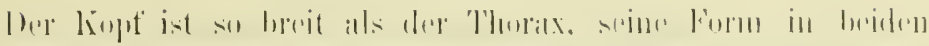

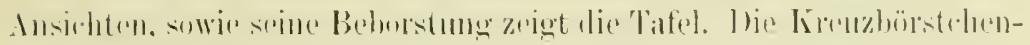

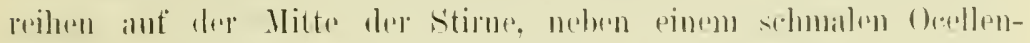

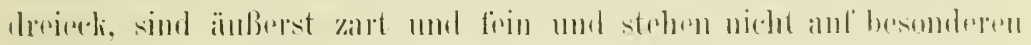

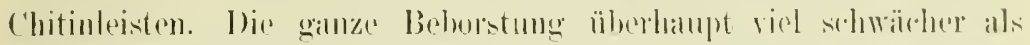

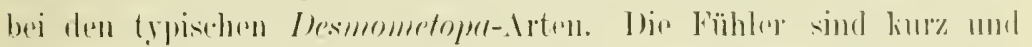

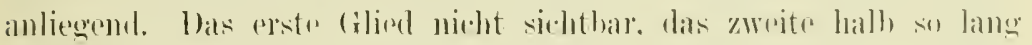

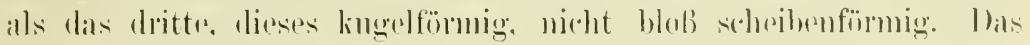

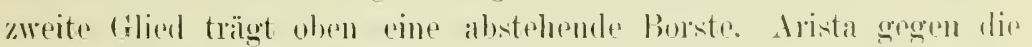

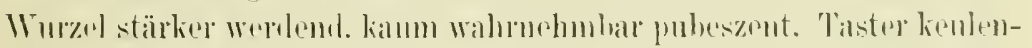

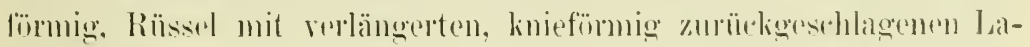

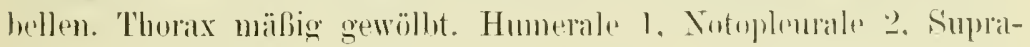
alare::; rorne lieine Dorsocentrale; doreh den hinteren Riöckien geht die Nadol, weshalh ich die Beborstmme nicht walnmelnom

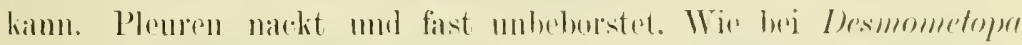

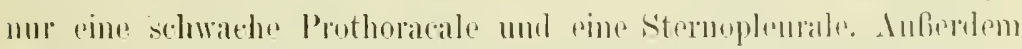

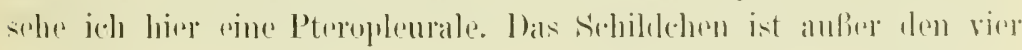
Randhorsten, ron denen die an der Spitze gelipenzt simd, nadit, an

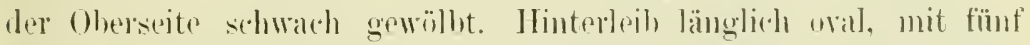
deutlich sichtbaren Segmenten, wovon das zoroite so lange we das

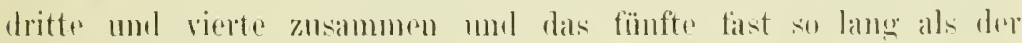
hallhe Hinterleib ist. Beine wie hei Lesmometoper ohme anffallende

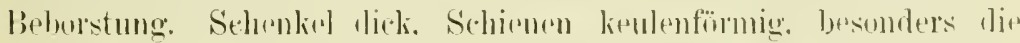
hintersten flacls. Ich rermute, dab das s erweiterte Hintersebiomen,

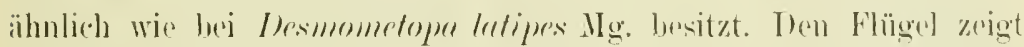

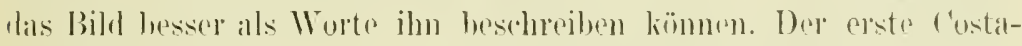

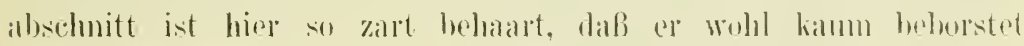

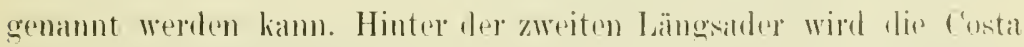

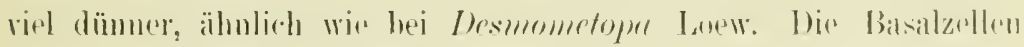
sind 110 sehr weng antwickelt. roudimentär.

\section{Hypaspistomyia Coquilletti ${ }^{1}$ ) $11 .-\mathrm{s}$.}

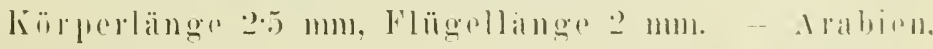

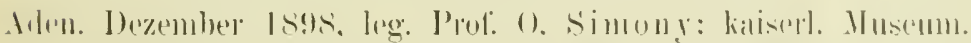

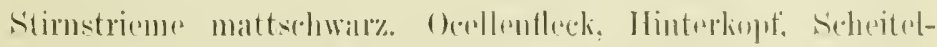

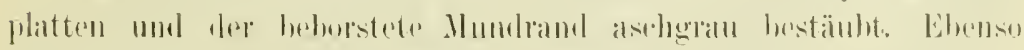

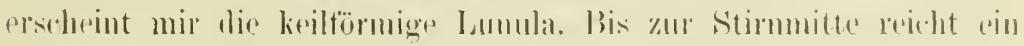

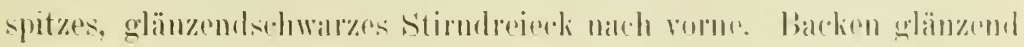

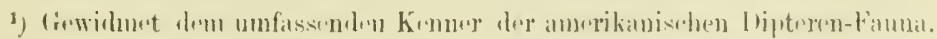




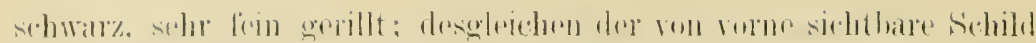

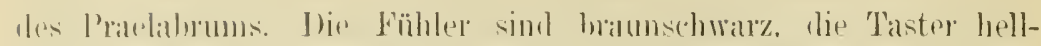

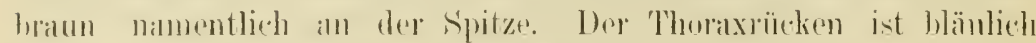

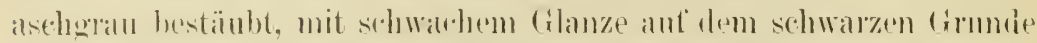

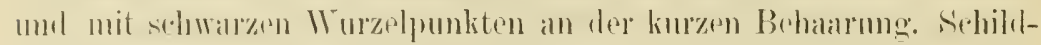
thes glämzend schwarz. Als Fortsutzmng dre glänzend sedorarzen

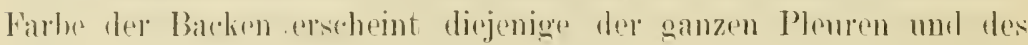
Scitentandes des Alubmons. Din asten vier Hinterleibsringe sind

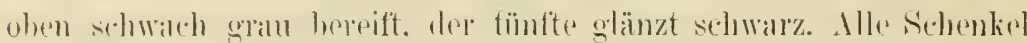

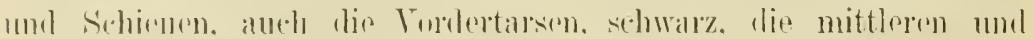

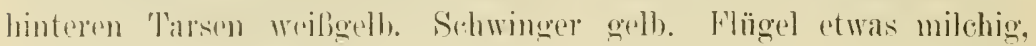
mit ganz liehten delern.

\section{Desmometopa lewew.}

Hrre 'Th. Brolieg hat in dieser Keitung, Seite $1-5$ eint: Amsemamlersetzung der palacarlitischen Lesmometopm-Arten gehracht. Bis jotat sind folgende and Irten lekannt geworlen:

1. I). hullerrlis ('oquillett, Proced. Enit. Stat. Mus. XXII, 2067 (1900). Portarlico.

‥ D. lutipes Meigen (= ammulitursis Kett. ot Roser: = ammulil.111!l! Ros.).

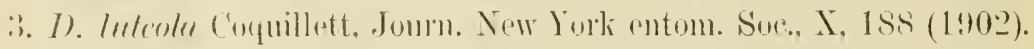
Arizmal.

1. I). minnlissimm Mulp., Telmés\%. Füzetel, XX, (i11, 1s!t7, abs

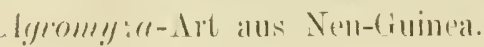

I) dies ain Jumen his lectum ist, nemme ich die rom

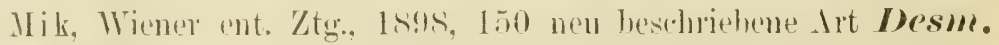
Wilpi.

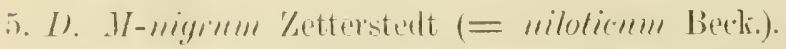

(i. I). sordidu Fallén (= M-alinm IIeigen).

7. D. Inserlix loow, Hipht. Amer. sejt. ind., ('ent. V1. 96 (1565).

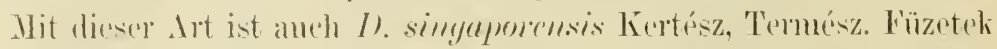
XX11. 19.t (1s!9!), dessen Typen im k. k. Miusem rorhanten sind, jolentiseh. su dab diese dit losmmpolitiseh ist. Man kemnt diesertie aus ("ubat, degypten, drabion (Alen, leg. O. Simony, k. k. Mnsemm), Kimerum (II ijere, Zeitseh. f. Hymenopt. u. Dipt., 1906, 342) und Singapore.

¿. I). simplicipes Becker, 1. (. 


\section{Sulfim. Thyreophorinae.}

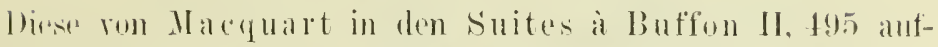
gestelle Gruple der dealyptraten wurde rom sehiner aloutiert mol anteh rom den folgenden Ihiptroulugen angenommen. Im Jahr-

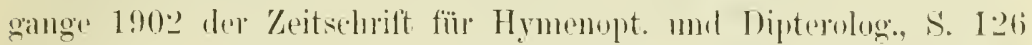
habe ich der einzigen, bis dahin heliamnten Gattung Thypeophome Ueigen mit dem Typus agnophlile Pamzer ane zweite cattung hinzu-

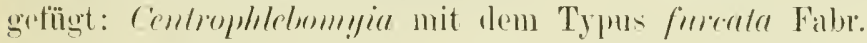

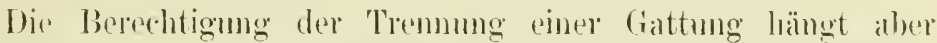
nicht rom der Artenzahl derselben ab, sendern ron dem Werte der ('haralitere. (.). W. Lerbury, Trans. ent. Sore Lomon. 190\%, LX.).

Die bis jetzt belamnten formen lass'n sieh folgendermaßen anseinanderhalten:

1. Costa mur wimperartig beladart, Thorax und schildehen langzottig.

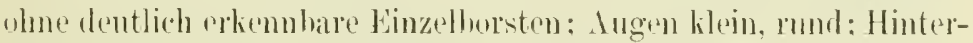
linf amberordentlich aufgeblasen: Thyreophore Meigen.

Th, rymophilu Panzer, Europa.

Th. antleropopherga R.-D. Buropa.

(Essai sur les Myombires 623. 》Long. 1 ligne. Tont-ì-fait pretite: lintaire: d'un rougeâtre mêlé de brun; eensson prolongé et bicipinenx.

II. Costa auber den Haren mit oiner Reiles Starehelbërstehen besetzt; Thurax und schildehen hurzharig. mit dentlichen Maderochaeten: Angen relatir gröfer, wagrecht oval: Hinterkopf schwach gepolstert.

Centroplolebom!gia Hendel.

a) Fühler schwar, Thorax und Kople rostfirben. Abelomen glänzend schwar\%.

(: antipolmm Osten-Sacken. (Ent. Month. Mag. XVIII, 20, I881. Tamanient).

ß) Fühler rostfarben, Thorax dunkelgrau oder schwarz. Eine Orbitale, $:+1$ Dersocentrale, o Humeralu. Leib) aschgrau. C. furreter l'an\%. Enmpla.

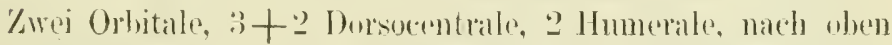
divergierend. Thorix und Hinterleib glänzend schwarz, letzterer violett sehimmernd. Länge $4 \mathrm{~mm}$.

17. C. orientalis 11. sp.

(Indien: Darjeeling, Juni; am Himalaya, leg. Fruhsturfer: k. k. Museum). 


\section{Sullim. Trypetinae.}

'Toxotrypana frerstiekerr. ('Tif. I, Fig. 7.)

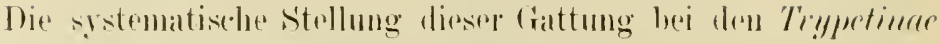

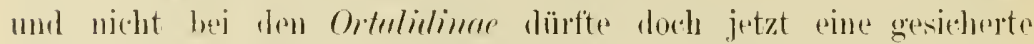
sin. Irh kamn nur die Ansülıungen S'nows (Kans. Unir. Quart. IV, 117, mit Abbild., Is!5) bestatigen und billigen, der anch diro früheren Literaturangaben matht. Niteh ihm (1S98) hat aber Wulp in der Biulogia Centr.-Aner. (II. 379. Thafel X. 2., 2a) die Art wieder zu den Ortulidinae gestellt, was hei dem Vorhandonsein sunterer《 (Orbitalloursten nicht riehtig ist.

Milimenge Bigot, Bull. Sote ent. Flanter. 188t, XXIX, ist, wie Ilik dargetan hat, synonym mit Torotrymene Gerst. (Ob abor die

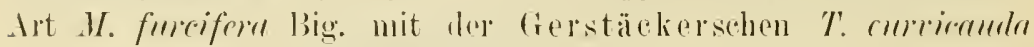
zusimmenfüllt, mördite ieh nicht unbedingt als richtig bezodehnen.

Mir liegt ein Weibehen von Toxotrypano ans Rie Grande do sul (leg. Stiegluayer, kaiserl. Museum) ror, das mit lieiner der üher die lliege gemachten Beschreibungen ïbereinstimmt, am ehesten noch mit den Angahen Rö̊lers in ter Wien. ent. Zeit., X, 320 (IS91) über ein brasilianisedes Webluchen. Seme MaBe sind: Kärper- und Flügcllänge 12 mu, Lageröhre Is $11 m$.

Die Abweichungen hezichen sich auf folgende Unstände:

1. Der Mundrand ist nielst leicht antgebogen, der ('lypens ist vielmehr vollständig chen, ohne ann Mumdrande im Profile otwals rorzustehon.

z. Die zweite Längsider mündlet ungefähn in der Mlitte zwisedon dre ersten und dritten Längsaler, während die Abhildungen

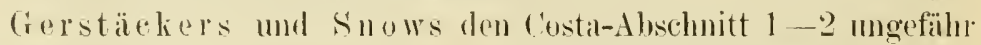
doppelt so lang erseheinen lassen als den zwischen zwei und drei.

3. Die Gabelzinle der zweiten Längsitler geht nicht nach vorne zul Costa, sondern nach hinten zur dritten Längsader und zwall

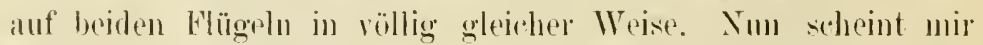
freilich auf diese Zinlinn der zweiten Längsodter kiem hesonderes Gerwicht gelegt werden zu sollen, dal v. d. Wulp in seincer Mbbildung neben apm Crabelast zur Costa auelo ein Rudiment zur dritten Längsider anf dem einen flügel abbildet und anch Snow dergleithen arwänt. Inmerhin scheint mir aber dic RegelnäBigkeit der Querader zwischen der zwoiten und dritten Längsaler hei meiner Fliege hemerkenswert zn sein. 


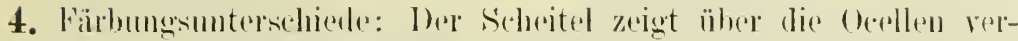

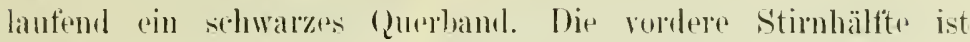
samtartig hraunschwarz, bogenartig nach oben begrenzt. Die zwei Mittelstriemen des Thorax rerlaufen gleich breit bleibend bis zom Sthildchen, ror wetchen sie ein Querhäntchen bihden. Dir zwei Seitenstriemen hinter der Quemaht grade, mach hinten dirergicrend. Intathorax mit rier schwarblomen Striemen, der Raum zwischen den zwei mittleren etwats rorlunkelt. Nir die Hesor- und Pteroplemen mit emer hramen strieme. Der Flügel zerigt wohl die goldgelbe Tingiernng in der Auslehnung wie sie Cierstacker l. e. beschreibt, aber nicht den braunen Wisch an der dritten Längsalder, welcher auch in r. d. Wulps Abbilhumg siehthar ist. Der schwarze Mumband bildet mit der sehwarzen Vittellinie des Clypeus rine Krenzzeichmung.

Von Borsten sind nur entwickelt: zwei sehr kleme parallele Postrerticale, die imnere, convergente Scheitelhorste etwas stärkrer, und rome einge hauförmige »untere Orbitaborsten. Am Thorax dir hintere Notopheurale, fermer am schildchen zwei kleine aufrechte und gelirenzte an der spitze und je eine haarförmige Borste an den Seiten.

Da mir kein weiteres Jateral rorliegt, will irh nur aut dieses Lxemplar aufmerkam gemacht laben.

\section{Erklärung der Tafel I.}

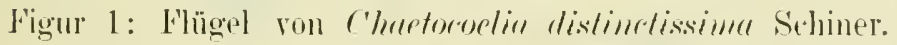

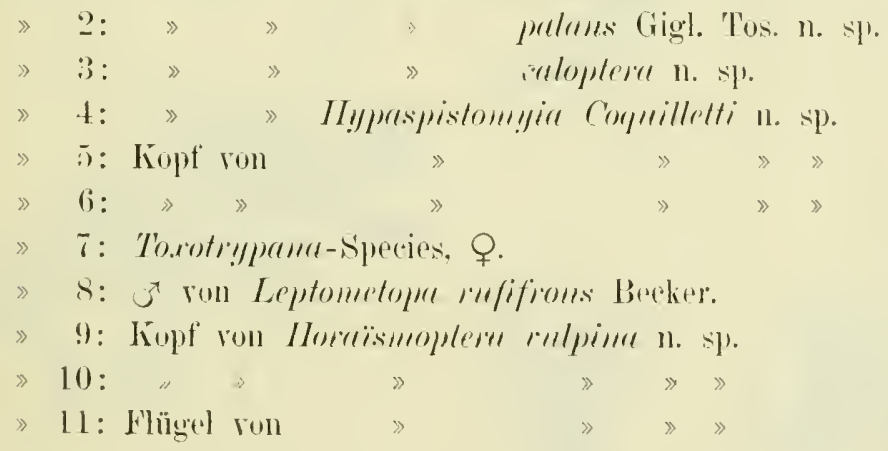



Winen.Entomol.Zcitung

DITt.Jahrqang 1907.

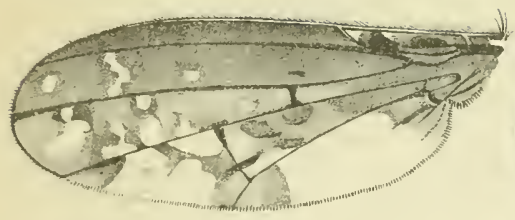

3

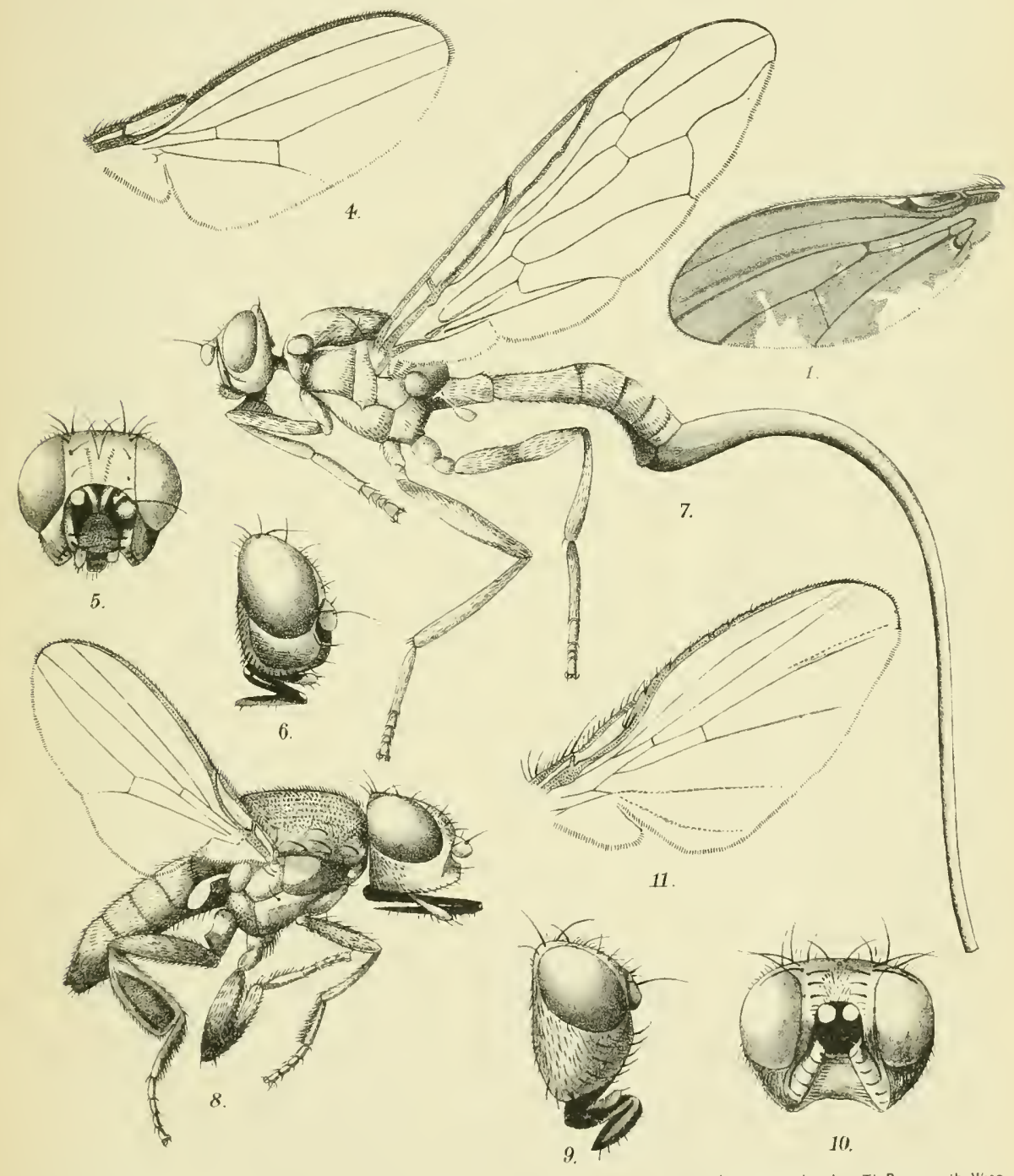

Tafel I

Frictrich Hewdel:

- Neue bipteren aus dem knis inspum.

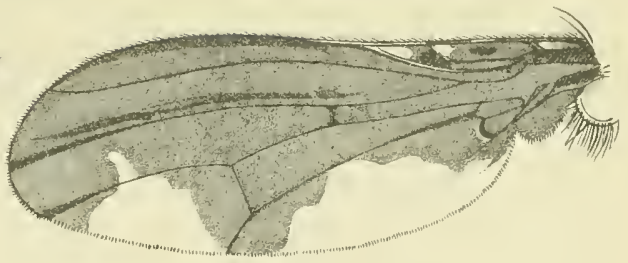

2

F.Hendel fec. 



\section{Anmerkung.}

Figur 1. in ungarischen Texte stellt vor: Onereus ller-Macchia bei der Bocea falsa.

2. Olcu curopaea aus dem Val oscuro bei Lussin-grande.

3. Olea europaea bei der Privlaka nächst Lussin-piccolo.

4. Theil eines Querschnittes durch das Blatt von Olea enropaea. Es fällt anf das dichte Chlorophyllgewebe, die mehrreihige Palissadschicht, das palissadartige Aussehen der untersten Zellreilıe im Schwammgewebe, die vielen Sklereïden, die dickwandige Epidermis und die über den Spaltöffnungen sich ausbreitenden Schuppenhaare. Schwache V'ergrösserung.

《

j. Spaltöfnung nnl Schuplenhaar in der untern Epidermis des Blattes von Oleı europaca. Stärkere Vergrösserung.

" 6. Querschnitt aus dem Blatte von Queveus Llex. Theilweise schematisch. Es fallen anf die Haarbildungen an ler untern Epirlermis, dieselben bedecken die Spaltöffnungen; ferner der dichte Bau des Chlorophyllgewelıes nnd die intensiv entwickelten Stereombündel, die jeden dïnnsten Mestomzweig begleiten und selbe sowohl mit der untern als auch mit der obern Epidermis verbinden.

"7. Querschnitt aus lem Blatte von Cistus villosus. Schematisch. Es wird ersichthich die Welluug der Blattspreite, die dichte Behaarung und die die Mestombündel umfangenden, beiderseits bis zur Epirlermis reiclenden Stereombïndel.

"S. Spaltöfnungen ron wumiperus Oxyeedrus.

" 9. Spaltöffnung von Trichonemer Bulbocodium.

" 10. Quercus llex bei der Bocca falsa, ausserhalb der Macchia gestanden.

" 11. Im Gestrïppe gewachsener Jumiperus Oxyeedrus-Stranch.

" 12. In Laub-Hochwald gewachsener Jumiperus Oxycedrus-Stranch, aus der Gegend ron Orehovicza (Kroatien).

" 13. Fruchttragender Zweig von Myptus communis.

" 14. Fruchttragender Zweig von Vilumum Timus.

"15. Zick-zackförmiger Zweig ron similax aspera. 


\title{
ZUR KENNTNIS DER TETANO(ERINEN (DIPT.).
}

\author{
Von Friedrich Hendel in Wien.
}

Herr Dr. Kéertész war so freundlich, mir das Tetanocerenmaterial des ungarischen National Museums zur Durchsicht zu übersenden. Gemäss der Fanma Regmi Hunguriar: Itiplen von Prof. Thalmammer (Budapest, 1899) sind nach dieser Collection neu für Ungarn: Limmin trivillalı Lw. = Memmii Schis. und Telemocen pmintifrous Rond.

Auch eine neue Art der Gattung Telunorerı aits T'ransbaikalien fand sich darin vor.

\section{Tetanocera Kertészii nov. spec.}

Slime wenig vorstehend, ihr Rand, die Lunula deckend, bis zu den Fühlerwurzeln reichend und dort kaum ausgebuchtet. Stirnstrieme mattgelb. Mittelleiste vorne nicht verkürzt, glänzend; der Ocellenhöcker und vorne zwei längliche Randflecken der Mittelleiste glänzend sch rvarzbraun.

Wrangensirheilclplallen wachsglänzend, von der Farbe des Hinterliopfes; sie reichen weiter nach vorne als bei den übrigen Tetanoceraarten s. str., indem sie $2 / 3$ der weissschimmernden Augenränder einnehmen, während dieselben bei den übrigen Arten blos in der oberen Hälfte liegen. Daher stehen die beiden Orbitalborsten nicht oben eng bei einander, wie bei fermginu FaLL., sondern in den Dritteln des Augenrandes.

Ganz abweicliend von allen anderen verwandten Arten zeigt diese Art, wie die sehr nahe stehende Tel punrlifioms Rond. beim on eime"t summtschurenzen Fleck anf dem sonst silberschimmernden Wungendrei-

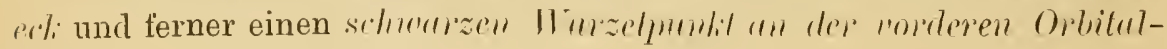
lowste.

Hinkrliop/'matt ockergelb, mit einem schwarzen, von unten hufeisenförmig weissschimmernd umgebenen Flecke auf dem Cerebrale.

Gesicht im Profile etwas zurückweichend, schwach concav, seidenartig gelblichweiss glänzend. Backen ca. $1 / 2$ des Augendurchmessers breit. luyp'll einfärbig und rund, wie bei ferruginea FALL.

Fühler so lang wie die Stirne bis zu den Ocellen, rothgelb; drittes Glied 11/2-mal so lang wie das zweite, von der im ersten Drittel stehenden, ganz tiefschwarzen und ebenso lang und abstehend gefiederten Borste an zu einer abgerundeten Spitze concav abfallend.

Thoruxüclien u. S'childrhen rostgelb; ersterer matt gelblichweiss 
bestäubt, was nach hinten zu und auf dem Schildchen in einen Wachsglanz ïbergeht. Über die Rückenmitte ziehen durchgehend 2 schmale, genäherte rothbraune Längslinien, die nur in schräger Richtung sichtbar werden. Die seitlichen unbehaartan Längsvertiefungen des Thoraxrückens lichtweisslich bestäubt und unten von einer längs der Notopleuralnaht von der Schulter bis zur Flügelwurzel ziehenden braunen Binde begrenzt.

Plewen "1. Miflen rothgelb, erstere mehr gelblich, letztere weiss bereift. Hinterleib einfärbig rostgelb.

$\sigma^{7}$ : 5-ter Tergit unverkürzt, 6-ter liugelig und überragt etwas den unter der wagrechten Trennungsnaht liegenden kleineren 7-ten.

q: unbekannt.

Ramdmacrochuelen hlos am 5-len Ringe iorlumelen, aber auch da blos seitlich und schwach; am 4-ten ganz fehlend.

Beine rostgelb, blos das Tarsenendglied etwas gebräunt. Beborstung normal. Flügcl fast gleichmässig schwach gelblich-hyalin: Queradern kaum dunkler gesäumt; hintere etwas schief und schwach doppelt geschwungen.

Anmerliuny: Diese Art gehört zur Gattung Tclunocera s. str., wie ich sio in meiner Arbeit über die europäischen Tefunocera-Arten (Verh. d, zool, bot. Ges. Wien, 1900. p. 335.) charakterisirte, und passen alle dort erwähnten Kennzeichen mit folgenden Ansnahmen anf' sie:

1. Die Orbitalborsten stehen in den Drilteln des Augenranrles (conf. Punkit A. a. I. c. p. 325.);

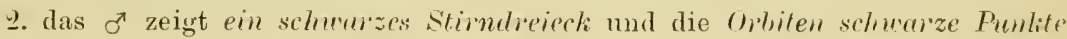
(I. c. p. 336. al. 12 von oben).

Durch letzteres Merkmal wird cine eigene Gruppe in der Gattung Tetumoceru gebildet, zu der ansser dieser Art noch 7\% punctifiem: Rosd. Atti. Soc. ital. Mil. 1868. p. 222. No. 11. gehört.

Von der Rondunischen Art, von der ich loc. cit. p. 3is irrthimmlich sagte, dass das ㅂ-te Fülılerglied länger als das 3-te sei, was nmgekelnt der Fall ist, unterscheidet sich Tet. Ko'tészii durch das Fehlen des Wurzelpunktes an der oberen Orbitalborste, durch den einfärbig rostgelben Hinterleib, Inreh die rostgelben Füsse, die bei functifromis am vorderen Beinpaare sammt der Schienenspitze, an den hinteren Paaren über die Hälfte schwärzlich sind, durch das Fehlen der Randmacrochreten an 4-ten Ringe, durch die entfernt stehenden Orbitalborsten, durch die hyalinen Flügel, während liondani ron seiner Art sagt: Alae fusco-flarelar;

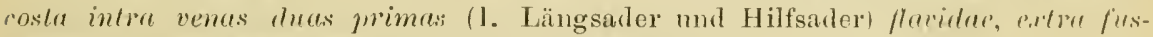
censconte, wais transwersis nigricante marginatis.

Das typische Exemplar befindet sich im ungarischen National-Museum und stammt aus Burdokova in Transbaikalien. (Exped. Zıchy, legit Csik1.)

Ich widme die Art dem hekannten ungarischen Dipterologen Dr. CoL. Kentész. 
In der Sammlung des ungarischen National-Museums befinden sich ferner $2 o^{x}$ einer echten Tetamorera-Art, welche ich für die Rondani'sche munrtifioms halte.

Das or besitzt ein schwarzes Wangendreieck, an der Wnrzel beider Orbitalborsten je einen schwarzen Wurzelpunkt und 2 schwarzbraune Seitenflecke an der Stirmmittelleiste. Die Abdominalsegmente sind oben breit schwärzlich und nur seitlich und hinten, sowie an den Aftergliedern rostgelb. Auch die Flügelzeichnung gleicht der von Rondani angegebeneu und stimmt mit einer intensiveren von fermaginea, nur sind die Längsadern nicht wie bei dieser zum grössten Theil gelb, sondern schwarz.

Die Färbung der Füsse habe ich oben erwähnt. Die Hinterschenkel besitzen vor der Spitze anssen und innen einen schwarzen Punkt.

Der 4-te und 5-te Hinterleibsring trägt eine Reihe deutlicher Randmacrochreten.

Die Orbitalborsten stehen in der oberen Augenrandhälfte. Alles übrige wie bei ferrugine'r.

Fundorte : Rákos-Csaba und Herkulesfürdö. (Dr. Kertész.)

Nachfolgend gebe ich eine Übersicht der mir bekannten Tetanocerenformen, welche wegen der Unkenntnis zahlreicher Löw'scher Typen kein abschliessendes Urtheil darstellt.

A) Schildchen mit 2 Borsten; Humerale, Presuturale, inneres und vorletztes äusseres Dorsocentralpaar felılend; Hinterschenkel verlängert, länger als der Hinterleib; Thorax lang und schmal ; Lunula umbedeckt, frei; Pleureu ohne Macrochreten.

I. 1 Orbitalborste; 9. Fülılerglied 2-mal so lang als das 3-te, griffelförmig schmal; Stirne eingesattelt, Augen vorgequollen; Hinterschenkel verdickt; hintere Querader schief nach einwärts gestellt; kleine Querader hinter der 1. Längsader.

Simpedon Latr. (sphegeus $\mathrm{F}_{\mathrm{AB} .}$ )

II. 2 Orbitalborsten; 2. Fühlerglied so lang wie das 3-te und auch so breit wie dieses, nicht griffelförmig; Hinterschenkel nicht verdickt; hintere Querader gerade gestellt; kieine Querader der Mündung der I. Lüngsader gegenüber.

Cylindria R. D. (obliterata $\mathrm{F}_{\mathrm{AB}}$.)

B) Schildchen mit 4. Randborsten; Humerale stets vorhanden; Hinterschenkel normal; Thorax gedrungen; Lunula frei oder bedeckt; Pleuren mit oder ohne Macrochæten.

I. Borste des vorne stielförmigen 3. Fühlergliedes griffelartig; Priesuturale vorhanden; 4 nach vorne kürzer werdende ïussere Dorsocentralborsten; 2 Orbitalborsten; Pleuren unbeborstet; Stirnmittelleiste oben breiter, trapezförmig; Hinterschenkel ohne Borsten; kleine Querader vor der Mündung der 1. Längsader. 
II. Arista des vorne nie stielartig verlängerten 3. Fülılergliedes nicht griffelartig dick; höchstens 2 postsuturale äussere Dorsocentralborsten; Stirnmittelleiste bandförmig; Hinterschenkel beborstet; kleine Querader der Mündung der 1. Längsader gegenüber.

1. Arista nackt oder anliegend licht pubescent; die Fiederfläche immer schmäler als die Breite des 3-ten Fühlergliedes; 2 Orbitalborsten.

a) Præsuturale, inneres und vorletztes äusseres Dorsocentralpaar fehlend; alle Pleuren behaart; Angen 2-bindig; Lunnla frei; hintere Querader in der Nitte bajonnettartig gebrochen.

Ilione HaLID.

b) Obige Borsten stets vorhanden.

(cucularia L. und rufa Panz.)

a) Arista fast nackt; 3. Fühlerglied olıne Borsten an der Spitze; hintere Qnerader ziemlich schief und stark S-förmig geschwungen.

Chione R. D. (Elgiva MG.)

* Lunula zum Theil frei; Vallarborsten vorhanden; alle Pleuren behaart; Augen mit 2 Binden.

Subgen. : Elgiva $\mathrm{I}_{\text {(i. }}$.

(albiseta Scop. und lineata $\mathrm{F}_{\mathrm{ALL}}$.)

** Lunula bedeckt: Vallarborsten fehlend; nur die Sternopleuren behaart; Angen einfärbig.

Subgen. : Hydromyia R. D. (dorsalis $\mathrm{F}_{\mathrm{AB} .}$ )

९) Arista deutlich pubescent, zum Theil gefiedert zu nennen; hintere Querader nicht stark schief und nicht stark geschwungen, meist blos bauchig; Angen mit 2 Binden.

Limnia (R. D.) Schin.

* 3. Fühlerglied am Ende nicht beborstet; Untergesicht nicht anffallend zurückweichend.

Limnia R. D. s. str.

(rufifrons $\mathrm{F}_{\mathrm{AB}}$, und unguicornis Scop.)

** 3. Fühlerglied am Ende beborstet; Untergesicht anffallend zurückweichend.

Coremacera RovD.

(marginata $\mathrm{F}_{\mathrm{AB}}$, catenata Lw., trilineata Lw.)*

2. Arista lang und abstehend gefiedert; die Fiederfläche so breit wie das 3-te Fühlerglied; Fiedern schwärzlich (excl. Lunigera Hend.) (cf. Verh. zool.bot. Ges. 1900.).

* teste Löw = Jammii Sonrs. Diese Art gleicht ansser der Beborstung des dritten Fühlergliedes nnd den gebänderten Augen im ganzen Halitus, in der liörper- und Flügelzeichnmo, der Verkürzung der Abdominalsegmente, der dunklen Bewimperung der Sehüppehen, der Lummla, in der ziemlich lang und abstehent gefiederten Fülılerborste so auffallend der Lunigero chrerophylli F., dass man das von der Beborstung des dritten Fühlergliedes hergenommene Merkmal nicht als generisch ansehen und die Art lieher zu Lunigera stellen möchte.

Prof. Mrk, dem ich ein Separatmm meiner Arbeit äber die enropäischen Arten der Gattung Tetanocer überschicktr, bemängelte den hylriden Namen Renoceru und den "Triviahnamen" Lanigera. In Übereinstimmung mit der Meinung Ronularis (Prodr. IV. p. 6): "Nomimu sunt signa, non defuntiones", finde ich mich nicht veranlasst diese beiden Namen zu emendiren. 
Zur geographischen Verbreitung der dort erwähnten Arten wäre nachzutragen: Verral : A List of British Diptera, London 1888. - Gobert : Catalogue des Diptères de France, Caen 1887.

Tetan. silvaticu Mg. - Österr. Schlesien (Kentész); Gobert ; Venral.

Tetan. unicolor Lw. - Mähren (Kertísz).

Tetan. laevifrons Lw. - GoBerT.

Tetun. ferruginea FaLt. - Russland, Kasan (leg. Csiki); Veiral; Gobert.

Tetan. clata F. - Österr. Schlesien (Kertész); Verral, Gober'r.

Lumigera chaeroplyylli F. - Verrat, Gobert.

Pherbina coryleti Scop. - Russland, Kasan (leg. Csiki); Verrar, Gobert.

Pherb. punctata F. - Mähren und Ungarn (ung. Nat. Museum, zahlr. Ex.).

Pherb. vittigera S. - Ung:un, zahlr. Exempl. (ung. Nat. Mus.); GoberT.

Irypetopt. punctulata Scop. - Russland, Sibirien, Cancasus (ung. Nat. Mus.). - Österr. Schlesien (Kertész); Verrat, Gobert.

Monochaetophora umbramem L. - VerRaL, GoberT.

(Separatim editum est die 15. Aprilis 1901.) 


\section{Ueber die systematische Stellung der Dipteren- gattungen Pseudopomyza Strobl u. Rhicnoëssa Lw.}

Von Friedrich Hendel in Wien.

(Mit 3 Figuren im Texte.)

Diese Gattung wurde vom Herrn P. Strobl im Jahrgang 1893 dieser Zeitung Seite 284 beschrieben und erhielt dort ihren Platz im Systeme bei den Drosophiliden oder fraglich Geomyziden.

Da ich sowohl die Type der Gattung, als auch das Stïck des Herrn P. Thalham $\mathrm{me}^{*}$ ) durch die Freundlichkeit dieser Herren untersuchen konnte, bin ich in der Lage, darüber meine Ansicht mittheilen zu können.

Die Chätotaxie ist richtig folgende:**) Orbitale 3, von gleicher Grösse, in einer Linie in den Augenranddritteln stehend und nach rïckwärts gebogen; Ocellare 2, stark, nach vorne gekrümmt; 2 lange Verticale jederseits und 2 kleine gekreuzte Postverticale nicht weit hinter den Ocellen.

Aeussere Dorso-Centrale 3+1. Die inneren stehen in drei Reihen, sind deutlich schwächer und so viel ich sehen kann, unregelmässig. Praescutellare fehlen. Prothoracale 1, Humerale 1, nach hinten gebogen, Praesuturale 1 und gleich hinter der Naht, etwas einwärts von voriger Borste noch 1 starke Intraalare. 2 Notopleurale, Supraalare undeutlich 3.

1 starke Mesopleurale in der Richtung der senkrechten Naht und darunter noch eine kleinere. Pleuren sonst nackt.

Schildchen mit 4 Borsten, die 2 apicalen viel länger.

Vorderhïften unter der Mitte mit 2 Borsten. Mittelschienen an der Spitze unten einen Dorn der in der Längsrichtung der Schiene nach abwärts geht. Präapicale 0. Hinterschenkel aussen an der Spitze einige Börstchen, Vorderschenkel in der Spitzenhälfte unten mit einer Borstenhaarreihe. Der Stiruvorderrand und die Periorbiten reichen bis z u den Fiihlerw u r eln vor, die Lunula ist ganz bedeckt. D i e Fliege ist also schizomet op.

Fulcrum nicht vortretend, Mundöffuung aber ziemlich gross. Der Rüssel liegt in der Ruhe ziemlich wagrecht, die Labellen sind dick und fleischig, zurïckgeschlagen.

*) Aliqua de Fauna Dipterologica Transsilvaniae, Coloczae 1902, pag. 24.

**) Die Type Stro b l's zeigt diese Chätotaxie nicht so, weil sie minder gut erhalten.

Wlener Entomologiache Zeitung, XXI. Jahrg., X. Пeft (10. December 1902). 
Die Fïhler sind nicht scheibenförmig, sondern fast kugelig, da sie von der Seite her kaum comprimirt sind.*) Stirne voll vorne gesehen fast so breit wie beide Augen neben den Fühlern, unten kaum verengt.

Das Abdomen hat 5 Segmente, wovon das 1. so lang wie die 2 folgenden ist, und die Legerölıre. Die Borsten der Ränder sind kurz.

Nun über die Verwandtschaft dieser Fliege.

Strobl stellt seine Gattung zu den Drosophiliden mit Rücksicht auf das Flügelgeäder. Betrachtet man den Flügel allein, so ist das Thier allerdings eine Drosophilide, denn die Costa ist eine Fortsetzung der ersten Längsader und vor der Mündung der letzteren abgebrochen, die Basalzellen fehlen oder sind rudimentär, - ich konnte eine angedeutete Analzelle entdecken - die Hilfsaderfalte hat ähnlichen Verlauf.

Betrachtet man aber das ganze Thier eingehend, so kommit man zu einem ganz anderen Resultat.

Die Drosophiliden sind nie schizometop, wenn auch die Periorbiten oft ziemlich weit nach vor reichen. Die meist aus der Reilhe herausgestellte, nach vorne gebogene Orbitale, welche auch für die kaum von den Drosophiliden zu tremnenden Geomyziden**)charakteristisch ist, fehlt bei Pseudopomyza, ebenso wie die für die vorgenannten Gruppen eigene starke Krümmung des vorderen Thoraxrückens und die mehr weniger deutliche Wölbung des Untergesichtes. Ebenso wäre die Bildung der Legeröhre für diesse Gruppen eine ganz ungewöhnliche.

Die vorhin erwähnte Aehnlichkeit des Flügeladerverlanfes zwischen Drosophiliden und Pseudopomyza muss aber zurïckstehen, wenn wir letztere mit Desmetopa Lw. vergleichen. Hier sehen wir vollständiges Uebereinstimmen des Aderverlaufes bis auf den Unterschied, dass eben die beiden Basalzellen bei J $_{\text {es- }}$ metopa nicht rudimentär sind. Die Costa setzt sich bei beiden Gattungen aus der 1. Längsader fort, verdickt sich dann auffallend und verdünnt sich dann plötzlich hinter der 2. Längsader. Der 1. Abschnitt der vor der 1. Längsader abgebrochenen Costa ist auch hinter der iVurzelquerader scheinbar abgebrochen

*) Aehnlich wio es bei A ct ora, $\mathrm{C}$ a n a ce etc., minder bei $\mathrm{Clusia}$ das F'all ist.

*:k) Siehe v. d. Wul p, Tijdschr. voor Entomol., 1871, pag. 199. 
und trägt mehrere Borsten. Die Queradern sind stark genähert, die 6. Längsader fehlt bei beiden Gattmugen ebenfalls, es ist nur die Axillartalte sichtbar. Durch das Abweichen der 5. Längsader nahe der Flügelwurzel vou ihrer Richtung bei Pseudopomyza sind anch ausserdem schon die Anlagen der Wurzelzellen gegeben.

Feruer ist Desmetopa ebenfalls schizometop; die Periorbiten reichen bis nach vorne. Die Fühlerbildung gleich tfrappirend der von Pseudopomyza. Das 3. Glied ist ebenfalls kugelig, die Borste ebenfalls wie bei Limosina, wie Strobl sagt.

Der Rüssel ist gleichfalls vorgestreckt, wagrecht. Der' Thorax und Beinban ist der gleiche. Die Legeröhre von Pseudo. pomyza ist für Agromyzinen nichts Abweichendes.
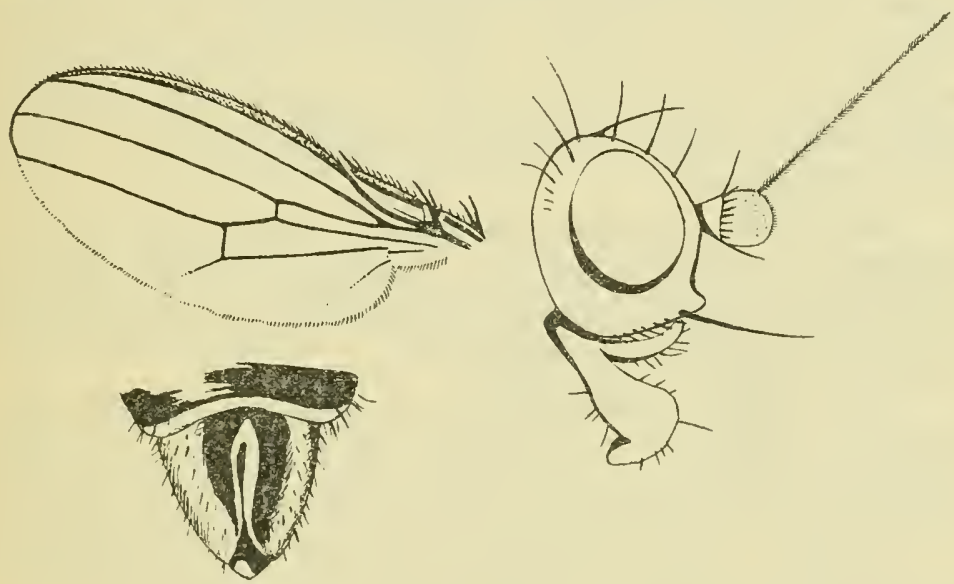

Ferner hat anch Pseudopomyza wie Desmetopa die kleinen anfgestellten Börstchen am Backenrande neben den Vibrissen.

Es ist also kein Zweitel mehr, dass Pseudopomyza zu den Agromyzinen (iucl. Milichinen) zu stellen ist.

Die nächst verwandte Gattung von Desmetopa ist aber nicht wiegewöhnlich angenommen wird Agromyza, sondern Rhicnoëssa Lw.

Obwohl Loew bereits in der Berl. Ent. Ztschr., 1872, pag. 124, in Index der Centurien Rhicnoëssa zu den Agromyzinen (incl. Milichinen) stellte, finden wir diese Gattung bei Verrall, Strobl und anderen Autoren bei ganz fremden Sectionen, wie Oponyziden und Geomyziden. Nur Bezzi weist ihr in seinen Contribuzioni etc. Bull. Soc. ent. ital., 1895, pag. 29 sep. den rechten Platz an.

Wlener Entomologische Zeltung, XXI. Jahrg., X. Heft (10. December 1902). 
Vergleicht man nämlich Desmetopa und Rhicnoëssa eingehend, so muss einem bei der grossen Verwandtschaft beider überraschen, dass L 0 ew dieselbe niclıt erkannte, da er $R h i$ cnoëssa zur Verwandtschaft Milichia, Desmetopa jedoch zu Agromyza stellte.

Rhicnoëssa hat denselben Aderlanf wie Desmetopa (Costa, 6. Längsader etc.). Beide sind schizometop wie al? e A grom y ziden, haben 4 Orbitale, denselben wagrechten Rüisel, mit hakig zurückgeschlagenen, verlängerten Labellen, die Reihe aufgestellter Börstchen am unteren Backenrande, die kugeligen Fülller, ja selbst die gleiche Bildung der Stirnstrieme: Form eines M.

Vom Ocellendreieck ziehen nämlich 2 beborstete Chitinleisten, die nach vorme hin convergiren oder sich selbst vereinigen, in der Stirnstrieme herab und lassen so einen mehr weniger dentlich M-förmigen Theil derselben frei, der bei Desmetopa schwarz gefärbt und daher auffälliger ist als das gelbe II von Rhicnoëssa.

Diese beiden beborsteten Leisten findet man auch bei Lobioptera*). Pseudopomyza Str., Desmetopa und Rhicnoëssa Lw. sind also die näclısten Verwandten und sind zu den Agromyziden, resp. Milichinen zu stellen.

Was endlich die Benennung der typischen Art von Pseudopomyza Str. anbelangt, so glanbe ich, dass nitidissima Str. nichts anderes ist als Opomyza atrimana Mg., Syst. Besclır. VI., pag. 106.

M e ig e n beschreibt zwar die Fühler und Mittelbeine als gelb, während das 3. Fühlerglied und die Mittelschenkel an der Spitze bei nitidissima Str. etwas gebräunt sind.

Das sind aber auch die einzigen Unterschiede. Die ganze iibrige Beschreibung $\mathrm{Me}$ igen's passt vollkommen auf nitidissima Str. und auf keine andere bis jetzt bekannte Fliege. So namentlich das über die Stirne, die Fühler, die Borste und über die "lange schwarze Legeröhre" am elliptischen Hinterleibe Gesagte.

\footnotetext{
*) Auch bei Limosina.
} 


\section{Kritische Bemerkungen zur Systematik der Muscidae acalypteratae.}

Vuil Friedrich Hendel in 11 in

\section{Ueder die Sectio Milichinae.}

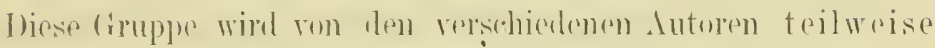

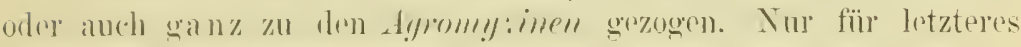

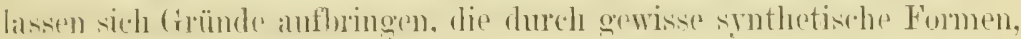

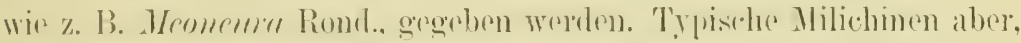

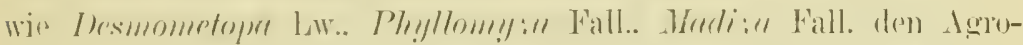

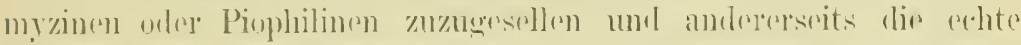

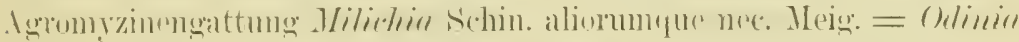

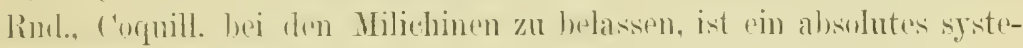
matisches: Umoling.

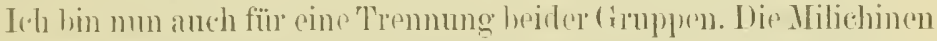
lassen sich durch folgende natürliche Jlertimales somblern: Das Koptprofil erinnert meln an die höheren Mnseden. I)ie Resluktion der Inter-

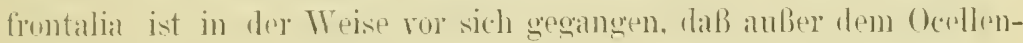

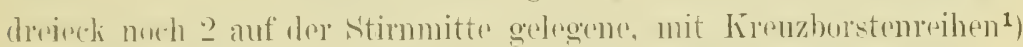

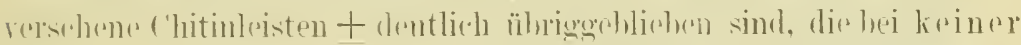

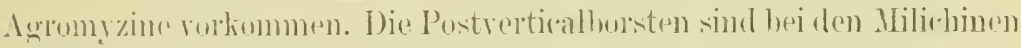

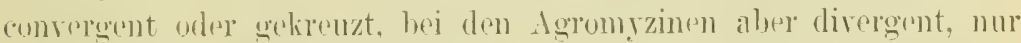
bri Mromenre fast parallel. Dio Analader fohlt allen Milichimen: dio bejlen Irurzelzellen sind klein und haben die Tejumg zu ver-

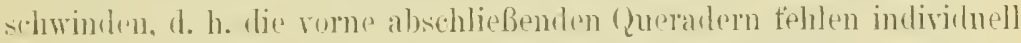
oder siml nur rudimentïr oder aber sie fehlen constant. I)ie ('usta ist

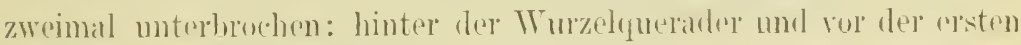

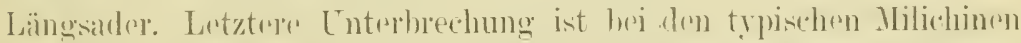

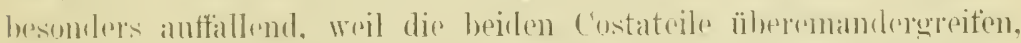

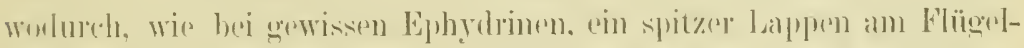

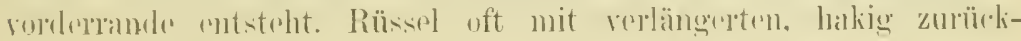
enchlongenem labollon.

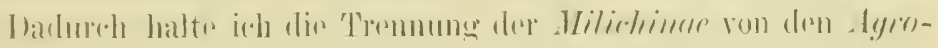
m!!! : imere fïl bererehtignt.

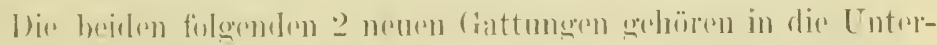

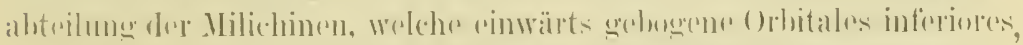

1) h m.

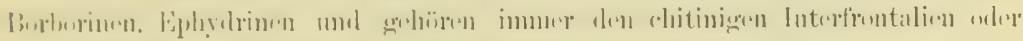

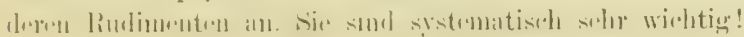

Wiener Entomologische Zeitung, XxII. Jahrg., lleft X (20. vezember 1903). 
einen spitzen Lappen am Flügelvorderrande, deutliehe Kreuzhörstchen tragende Interfontalrulimente, einen sillorschimmernden Hinterleil, mindestens beim or haben und deren letater Disedidalanlerabschnitt böchstens zirrimal so lamg als der rorlergahegnde ist.

Sie unterscheiden sich ron Milichia HIg. (Es liönnte auch Atrgyrites Latr. Wribem, da die Lepidupterengattung drgyritis:Hom. heibt. wie folgt:

A. Rüssed und Labedlen nicht rerlängert: Taster löffelförmig verbreitert, rorstehend; Mesopleuren nackit, :3 Stermopleuralborsten.

I. Augen behart, unter den Fühlern nicht genähert: Untergesicht daher wenig schmäler als beido Augen zusimmen. Stirne im Profil rorstrheme: Wangen deutlich sienthar, belaadt: Vibrissenrelien rorstelyend; Fühler fast unter der Augemmitte stehend: (orihitales superiores e-t +1 . Milichia Mg. (Type speciose Mg.)

II. Augen naklit, unter den Fühlern gemälurt; Untergesicht stark verengt, first nur $1 / 3$ eines Anges breit. Stime und Vibrissenedien nicht rorstehend: Vibrissenhorsten anfsteigend. Wangen fehlen; Fülıler über der Augemmitte. Orbitaless superiores $1+1$.

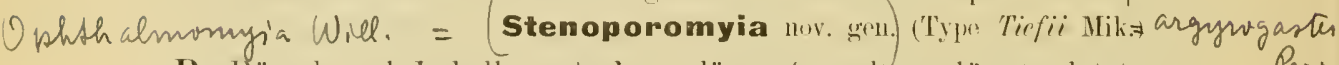

B. lï̈ssel und laibellen stark verlängert und rerdünnt: letztere finst so lang als der Mittelteil des Rüssels, knicartig zurücekgesedhlagen. Thister tidenartig, kurz, nicht rorstehend. :3 Itesopemallwersten, 22 Sternoplemrale.

Augen lehaart, unter den Fühlerm gemähert. Untergesicht verengt, sclumäler als 1 Ange, unter den Fühlern grubonartign rertieft. Wangen fehlen. Stime nicht. II metrand etwals rorstehemel. Fühler rotwas über der Augenmitte. Oblitales superioneres $2+1$.

Rhymchomilichia nor. gen. (Type ar!ygrophleney śchin.)

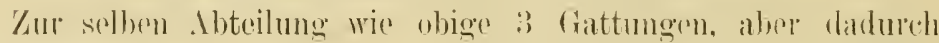

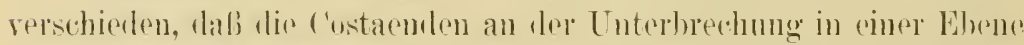
liegen, - weslialh koin vorsumgender lappen entsteht - dab das

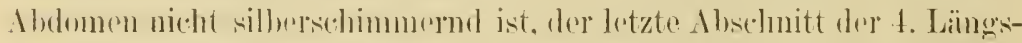
adere immer mohr als zwermal, mindestens dreimal so lange als dere

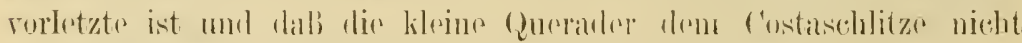
gegenüberliegt, sundern vorher steht, gohören fulgende 4 Generat.

A. Costa pricht bis zur Mündtung der t. Längsidler: Mrsopheuren

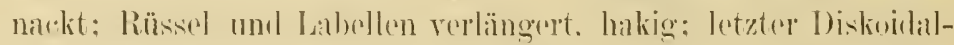
absethitt :3-31/2 mial so lang als der vorletete; Bisalzedlen gewöhnlich vorhinden, wemn anch klein.

I. Sentellare disergirend: 30 obitales superiores: drittes Antennenglied des $\jmath^{7}$ stark erweritert, fast viereckig. Angen behalart. 
Palpen anßerordentlich verlängert, breit, vorstehend. + Supraalare: Füller wher ser A ugemmitte.

Phyllomyza Fill. ${ }^{1}$ ) (Tyle semrienmis Fall.)

II. Seritellatre gekrenzt: 2 Orbitates superiores; 3. Fühlerglied des $\jmath^{x}$ nicht rergröbert: Angen nackt oder fast nackit: 3) Supraalare: Fühler unter der Augenmitte.

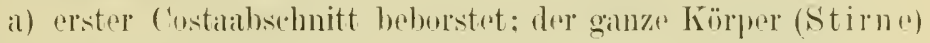
matt: Kreruzhorsten kräftig: die 2 oberen Orbitalen nach außn' geebogen.

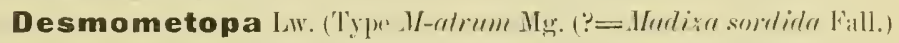

h) erster costaabschnitt nieht beborstet: ler ganze Kö̈rper glänzend, nackt, punktirt: Lúruzbörstehen der Stime zart: rine Orbitale nach oben, eine nach vorne gebogen.

Madiza Fall.2) ('Type ylabra Fall.)

B. Costa reicht nur bis zur 3. Längsader; Mesophleuren hehaart und mit 1 Borste: Rüssel und Labellen nicht verlängert, nicht hakig; Intzter Diskoidaladeralssehnitt gegen das Ende zu obliterirt, rireal l:3 mal so bang als ber vorige.

Meoneura Rund. (1856) (Tym olsenella Fall. ${ }^{3}$ )

Diess interessinnte und gute Gattumg des grobon Italieners worle seither von niemantem melur erkanut: wohl deshall, weil jener sie zu den Ocinina stellte. Fr mag hiezu, ebenso wie bei (cigmmopo Fall.) = Mosillus Latr., riner unzweifelhaften Ephydrine, durch das wohlentwiekelte, glänzende Ocollendreieck rerleitet worden sein. Die Künfund Flügelbildung alloin schon lälit dies nicht zn.

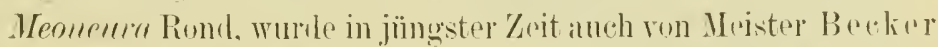
verkamnt und in desien degytischen Dipteren, 190:3, Seite 191 als

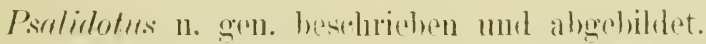

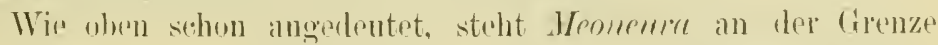
zwisehen Viliehinen und Agromyzinen. Ith ziehe sir aber wegen ther

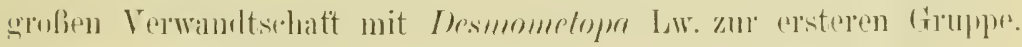

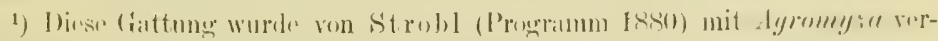

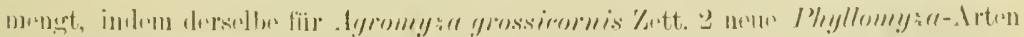

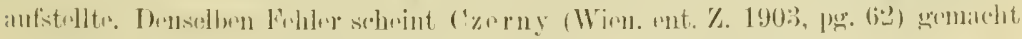

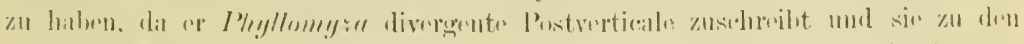

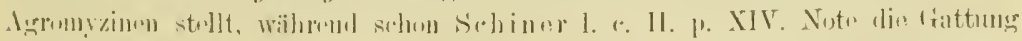
systromatixill ertalit hat.

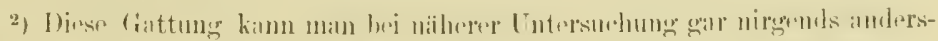
wohin stellen als nelen Iresmemetopu Iw.

3) bie Arten bedïrfon erst einer Revision. 


\section{Ueber eine neue Agromyzinengattung.}

Nath dem, was ich schon ringangs äbre Agromyzinen und

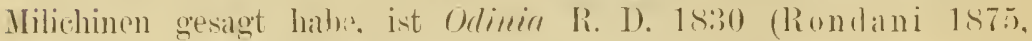

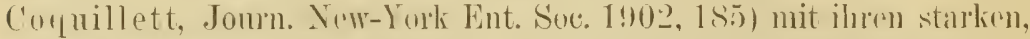
weit divergirenden Postrertioalen, dre somstigen Kopfbildung, mit ilurer cimmal unterbrochenen costa und der dentlichen Analader, suwe

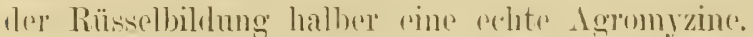

Bezüglich der Nomenelatur kann ieh mich nur Rondani und

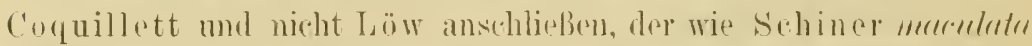

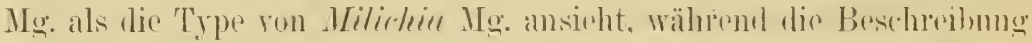

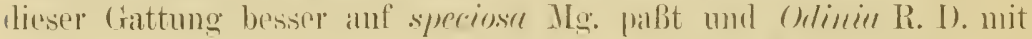

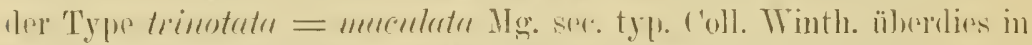

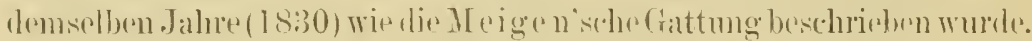

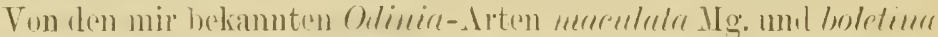

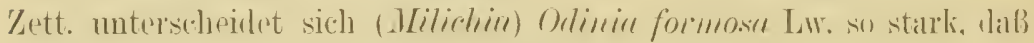
ich darauf dine neme Gattung grümıle.

()diniu R. 1 ).

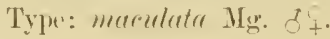

Mesoplenuren mackit.

Postrueticale stark mol kräftig entrickelt.

Dorsucentrale 5, Priascent. 2. Hum. 1. Praesut. 1. Notopl. ¿. Supraal. $2+1$ (1). Intraal. 2: Soutellare 4 , die apicalen gekreuzt.

Prothoracale stark: Nternoplerirale :3-t mebeneinander.

Nur die Mittelschienen mit einem Kranze ron Endspormen.

Mämmchen mit bis auf dir Hälfte

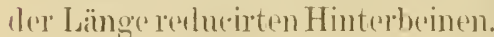
1)(ren Schonkel sind stark rele dickit, dir schirnen und 'Tarsem plattgerdrïclit.

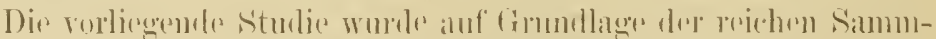

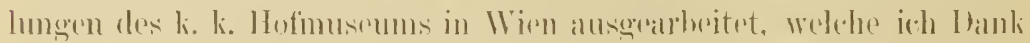

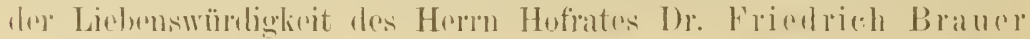

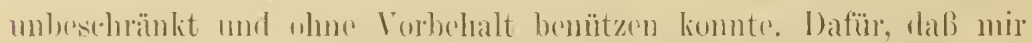

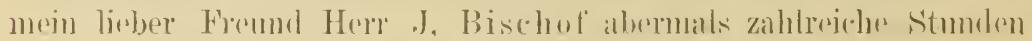
upforte. stei ihm horklichst gerlankit. 
P. pulchellum. - Schw. Berner Alpen, c. fr. (Bamberger).

P. depressum. - V. Unterer Fuchstobel und "Weisse Reute" bei Bregenz, in dem Substrate fest angepressten sterilen Rasen (Blnm., October 1900).

Amblystegium subtile. - V. Kennelbach (Blım.). - T. Ried bei Sterzing und am Höttingerberge bei Innsbruck, auf Buchen (Baer). - Mit Kapseln.

A. fulicinum. - Bos. Zwischen Brachythecium vivulare am rechten Vrbas-Ufer bei Jaice, steril (Kueucker).

A. varium. - T. Wilten-Amras, auf Mauern, c. fr. (Murr, H. B.).

Hypuum Halleri. - T. Bei der Capelle in Ebrenbachgraben bei Kitzbühel (Niessl). Lechthal: Vor Steeg auf Kalk (Baer). - V. Arlberg, Dreischwesternberg, $2100 \mathrm{~m}$ (Rompel). - S. Laidalpe bei Hofgastein (Pre ue r). - St. Felsen im Hartelsgraben im Gesäuse (Steidler, 1900). - Schw. Niederbauen-Kulm ad Seelisberg (Degeu). - Immer fruchtend.

H. chrysophyllum. - Mon. Džinovoberg bei Cettinje, auf Kalk, $800 m$ (Kn e ucker). - V. Achbett bei Kennelbach (BIum.). - Nur steril.

H. protensum. - T. Gschnitzthal und Trins, c. fr. (v. Kerner, W. U.).

H. vernicosum. - T. Pitzthal bei Wenns, $1000 \mathrm{~m}$, steril (Baer).

H. Wilsoni. - G. In uliginosis inter Jeziorki et Syczynam apud Chrzanowem, c. fr. (Schliephacke, 16./VI. 1865).

$H$. fluitans var. falcatum. T. Schwarzsee bei Kitzbühel, steril (Niessl).

$H$. decipiens. - T. Blaser $(2000 \mathrm{~m})$ in den Stubaieralpen, in schönen, sterilen Rasen (B a er).

H. commutatum. - U. Zwischen Mehadia und Herkulesbad, steril (Schierl). - Bos. Zwischen Jaice und Jezero, steril (Knencker). - D. Felsen bei den Kerkafällen, steril (Dr. Pa vlicsek, 1894). — 0.-0e. Gmunden: Im Aufstiege zum „Franzl im Holz", c. fr. (1898, !). - St. Liezen, c. fr. (Niessl). - T. Kitzbühel (Niessl). Wenns im Pitzthale $(1000 \mathrm{~m})$ und Sistrans, steril (Baer). Altenburg bei Kaltern nächst Bozen, steril (Pfaff). Poro bei Trient, auf Melaphyr, e. fr. (Michael de Sardagna, W. U.). - V. "Weisse Reute" bei Bregenz (Blum.).

H. irrigatum. - N.-Oe. Im I. Theile fehlt der genauere Fundort: Seeabfluss zu Lunz, steril, $600 m$ (Ke issler).

H. incurvatum. - T. Bei den Sillschluchten nächst Innsbruck, c. fr. (Benz, $1880)$.

H. Lindbergii. - Bos. 'Trebevićberg bei Sarajevo, steril (Schierl).

H. palustre var. subsphaericarpon. - Kt. Abfluss des Raibler Sees, c. fr. (Dr. Graef, 1884). - T. Innsbruck: Kirchebnergarten in der Sillgasse, steril (Benz, 1880).

H. palustre var. julaceum. - T. Padasterjoch bei Trins, c. fr. (Degen).

H. dilatatum. - T. Lisens (Selrain), am Gletscherbache, steril, $1700 \mathrm{~m}$ (Baer).

H. giganteum. - T. Bei Sterzing, steril (Pfaff).

H. sarmentosum. - T. Rosskogl bei Innsbruck, steril (v. Kerner).

Hylocomium loreum. - Viller Weg bei Innsbruck, schön fruchtend (Graf Sarnthein, W. U.). Kitzbühel: Seidlalpe, ca. $980 \mathrm{~m}$, c. fl. (NiessI). 
H. rugosum. - T. Südseite des Lanserkopfes bei Innsbruck (Baer). - 0.-Oe. Oberhalb Steyregg und bei Ramsau beim Gmundener See (!). Königsweg bei Urfahr und Katzbach bei Linz auf einem Dache (Stadlmann). Schw. Seelisberg: Niederbauen-Kulm (Degen). - Bos. Felsen an der Strasse bei "Da Riva“ nächst Sarajevo (Schierl). - Steril.

A nmerkung. Im I. Theile (vgl. diese ,Verhandlungen", Jahrg. L, 1900, S. 219-254) sind einige unliebsame Druckfehler unterlaufen: Statt „Felsenau“ steht manchmal "Helsenau“, statt der Neereshöhe $2100 \mathrm{~m}$ (Dreischwesteruberg in Vorarlberg) nur $2000 \mathrm{~m}$; S. 236 bei Splachnum sphaericum soll statt „Albulapass in der Schweiz" stehen: „Albunapass bei Arlberg"; statt "Kennelbach" wurde einige Male "Kemelbach", statt "Amerlugen" wurde "Amerlügen" und statt "Amras" auf den ersten Seiten "Ambras" stehen gelassen.

\title{
Ueber einige neue oder weniger bekannte europäische Muscaria schizometopa.
}

\author{
Von
}

\section{Friedrich Hendel.}

(Eingelaufen am 12. Jänner 1901.)

I. Ueber Lomacantha Rond., Psoudolomacantha nov, gen. und deren systematische Stellung.

Dass diese Gattung wegen einer Verwechslung der Type Rondani's ron Lomacantha parra R. den Bearbeitern der "ILuscaria schizometopa" unbekannt war und die in den „Vorarbeiten" erwähnte Gattung Lomatacantha R. (emend.), P. I, p. 98 und P. III, p. 124, zn Eggeria gehört, erwähnt Brauer in seinen "Nachträgen zu den Vorarbeiten etc." (Sitzungsber. der kais. Akad. der Wissensch. in Wien, Bd. CVII, S. 522) und gibt dort auch eine Beschreibung der wirklichen Type Rondani's.

Die einzige bis jetzt bekannte Art ist $L$. parra Rond. aus Parma (Italien).

In Sommer 1900 fing ich in Bisamberg bei Wien zwei Fliegen, von denen die eine sicher zu Lomacantha $R$. gestellt werden kann und mit den von B raue r, l. c., aus Niederösterreich erwähnten Exemplaren übereinstimmt, während die zweite blos verwandt mit dem Genus Lomacantha erscheint.

Alle drei Arten zeigen folgende Merkmale: Augen behaart, Backen schmal, böchstens $1 / 3$ der Augenhöhe, Vibrissen bis $1 / 3$ oder $1 / 2$ der Gesichtshöhe aufsteigend, apicale Schildchenborsten fehlend. 
Parra Rond. und Braueri nov. spec. besitzen übrigens beide einen sehr starken und laugen Randdorn am Flügel und platte Vordertarsen beim Weibchen.

Die Arten unterscheiden sich in folgender Weise:

A. (Lomacantha R.) Randdorn stark, Backen $1 / 4-1 / 3$ der Augenböhe, zweites Borstenglied nicht verlängert, Arista allmälig dünner werdend, Stirnborsten unten näher den Leisten als dem Auge, drei postsuturale Dorsocentralborsten, Hinterschienen ungleichborstig, Spitzenquerader gerade.

I. Zweites Fühlerglied kürzer als die Hälfte des dritten, Taster schwarz, Vibrissen bis zur Hälfte des Gesichtes aufsteigend, Backen fast $1 / 3$ der Augenhöhe breit. Stirnborsten bis zur Aristawurzel herabsteigend . . . . . . . . . . parra Roud.

II. Zweites Fühlerglied $2 / 3$ des dritten lang, Taster braun, an der Spitzenhälfte rothgelb, Vibrissen bis zum Drittel aufsteigend, Backen ${ }^{1 / 4}$ der Augenhöhe breit. Stirnborsten kaum bis zum Ende des zweiten Fühlergliedes herabreichend. Braueri nov. spec.

B. (Pseudolomacantha.) Randdorn rudimentär, Backen $1 / 6$ der Augenhöhe breit, Fübler deutlich über der Augenmitte sitzend, Stirnborsten unten näber dem Auge als den Leistenborsten, vier änssere Dorsoeentralborsten hinter der Quernaht, Hinterschienen gekämmt, Spitzenquerader wenig concar . . . . . pectinata nov. spec.

Lomacontha Brameri nov. spec. $q$.

Scheitel von Augenbreite, Augenränder von vorne gesehen nach abwärts fast parallel, Stirnstrieme schwarz, $2 / 3$ so breit als die unter den Macrochaeten sehr spärlich behaarten Orbiten. Gesichtsrand im Profil convex und dann concav, indem die nackten Wangen von der mässig vorstehenden Stirne nach unten zu fast linear werden; Backen $1 / 4$ der Augenhöhe breit, unten gerade, Kopfborsten alle ausserordentlich gross und kräftig, Stirnborsten einreihig, nicht ganz bis zum Ende des zweiten Füblergliedes herabgehend, unten deu Leisten genähert. Zwei Orbitalborsten, zwei Paare Scheitelborsten, das mittlere Paar nicht gekreuzt; Ocellarborsten stark, nach vorne gebogen; die ersten zwei Stirnborsten von oben, namentlich die zweite, stark und aufwärts gebogen. Circa sechs Borsten steigen auf den Vibrissenleisten bis $1 / 3$ der Höhe auf. Vibrissen stark, gekreuzt, unmittelbar neben dem Mundrande und in gleicher Höhe mit dem unteren Backenrande.

Die schwarzen Fühler der Augenmitte gegenüber, fast unter derselben sitzend; drittes Fühlerglied $1 \frac{1}{2}$ mal so lang wie das stark verlängerte zweite, Borste länger als die Fühler, allmälig dünner werdend, gebogen, deren zweites Glied deutlich sichtbar, jedoch nicht verlängert.

3 postsuturale innere und äussere Dorsocentralborsten, 1 Intraalare vor und 3 hinter der Quernaht, 3 Sternopleuralborsten. 
6 Schildehenborsten am Rande; die zwei änssersten marginalen neben der Spitze sehr lang und stark, divergiren und reichen nach rückwärts bis über das zweite Abdominalsegment hinaus.

Hinterleib kegelförmig wie bei Eutachina; erster und zweiter Ring mit zwei Borsten am Rande, dritter mit vollständiger Reihe; zweiter und dritter Ring mit zwei Discalmacrochaeten. Beine schwarz, ungemein lang und stark beborstet, wie überhaupt alle Borsten des Thieres von aussergewöhnlicher Länge und Stärke sind. Hinterschienen ungleichborstig. Vordertarsen des $q$ etwas erweitert und platt. Bauchsegmente ganz verdeckt.

Flügel hyalin, Randdorn lang und stark, Spitzenquerader ganz gerade, Beugung stumpfwinkelig, weit vor der Flügelspitze mündend. Hintere Querader näher dem Winkel. Dritte Längsader nur am Grunde beborstet.

Körper schwarz, dicht gelbgrau bestäubt. Rücken mit vier schwarzen Striemen, die mittleren linear, gehen etwas hinter die Quernaht; die seitlichen, an der Quernaht unterbrochen, sind doppelt so breit und gehen fast bis zum Schildchen, dieses ohne Roth, wie der Rïcken bestäubt. Hinterleib: Erster Ring und Mittellinie matt schwarz, die übrigen Ringe am Hinterrande glänzend schwarz.

Bisamberg bei Wien, September, anf Pastinaca sativa. - Kronstein und Weidlingau in Niederösterreich (Becher).

\section{Pseudolomacantha pectinata nov. spec. $\sigma^{7}$.}

Scheitel fast von Augenbreite, Augenränder von vorne gesehen nach abwärts fast parallel; Stirnstrieme schwarz, wenig schmäler als die unter den Borsten dicht behaarten Orbiten. Gesicht im Profile wie bei Lom. Braueri, Backen weniger als ein Sechstel der Augenhöhe breit, unten gerade. Stirnborsten einzeilig, nicht ganz bis zum Ende des zweiten Fühlergliedes herabreichend, unten dem Augenrande genähert. Orbitalborsten fehlen, zwei Paare Scheitelborsten $\left(\sigma^{7}\right)$ vorhanden, Ocellarborsten abgebrochen, Leistenborsten bis circa ein Drittel aufsteigend; Vibrissen gekreuzt, stark, unmittelbar neben dem Mundrande und in gleicher Höhe mit dem unteren Backenrande. Taster schwarz.

Die Fühler schwarz, deutlich über der Augenmitte inserirt. Drittes Fühlerglied etwas mehr als zweimal so lang wie das zweite, Borste bis über die Mitte verdickt und dann plötzlich dünner werdend, zweites Glied derselben dreimal so lang als breit.

Hinter der Quernaht des Rückens 3 innere und 4 äussere Dorsocentralborsten und 3 Intraalarborsten, 1 präsuturale Intraalare, 3 Sternopleuralborsten.

6 Schildchenborsten am Rande; die zwei äussersten neben der Spitze reichen bis zum Hinterrande des zweiten Abdominalsegmentes. Subapicale undentlich.

Hinterleib kegelförmig. Randmacrochaten wie bei Lom. Braueri; die Discalmacrochaeten in der Mitte des zweiterı und dritten Ringes stehen ungeordnet. Bauchsegmente unsichtbar. 
Beine schwarz, Klauen des $\sigma^{\nearrow}$ etwas länger als das letzte Tarsenglied; Hinterschienen aussen von oben bis unten mit gleichen und ziemlich langen Borsten gekämmt, in der Mitte der Reihe steht eine stärkere Macrochaete.

Flügel graulich hyalin, Randdorn rudimentär, fehlend; Spitzenquerader etwas concav, weit vor der Flügelspitze mündend; sonst wie bei Lom. Braueri.

Körper schwarz, schwach bläulichweiss bestäubt. Rücken mit vier gleichbreiten schwarzen Striemen, von denen die mittleren blos bis zur Queruaht gehen, die seitlichen dort unterbrochen sind. Schildehen schwarz. Hinterleib am 2.-4. Ringe mit Ausnahme der Mittellinie vorne weisslich bestäubt.

Bisamberg bei Wien, August.

Anmerkung. Braneri und pectinata haben bis zum Drittel der Gesichtshöhe aufsteigende Vibrissen, gehören also nicht mehr zu Myxexorista B. et B., II, S. 331, ${ }^{1}$ ) da bei dieser Gattung die Borsten mindestens bis zur Gesichtsmitte aufsteigen, sondern zu der Gruppe der Sectio Masicera B. et B. mit behaarten Augen und fehlenden apicalen Schildchenborsten (Bavaria B. et B.).

Trotz der behaarten Augen zeigen aber Lomacantha R. und Pseudolomacantha $\mathrm{m}$. die nächsten Beziehungen zu den mit Dexodes machairopsis B. et B. zunächst verwandten Arten dieser Gattung Brauer-Bergenstamm's, welche sich namentlich auf die aufsteigenden Vibrissen und das Fehlen der apicalen Schildchenborsten gründen. Die Augen dieser Dcxodes-Species sind aber nackt oder böchsteus pubescent, nie behaart. Besonders Pseudolomacantha pectinata $\mathrm{m}$. hat im Habitus auffallende Aebnlichkeit mit Dexodes machairopsis B. et B., wozu noch die verlängerten Klauen des $\sigma^{\lambda}$, die gleiche Abdominalchaetotaxie und die doppelten Scheitelborsten des $\sigma^{72}$ ) kommen. Sie unterscheidet sich aber leicht, abgesehen von der Augenbehaarung, der Scheitelbreite, der Aristaform, durch die unten geraden Backen, in deren Höhe auch die Vibrissen stehen, welch' letatere bei Dexodes immer deutlich hinaufgerückt sind, und durch vier äıssere Dorsocentralborsten.

Mit Pseudolomacantha nahe verwandt ist auch Bavaria mirabilis B. et B., I, S. 88; III, S. 114, und zwar durch Folgendes: Apicale Schildehenborsten fehlend, Leistenborsten circa 1/3 aufsteigend, Angen behaart; Vibrissen dicht am Mundrande, Fühlerborste bis zur Mitte dick, dann fein (Sectio Masicera). Abweichende Merkmale von Baiaria sind: Zweites Borstenglied kurz, Backen $1 / 2$ der Angenhöhe, drittes Fühlerglied viermal so lang als das zweite, Backen etwas unter die Vibrissen herabgehend, Klauen des ơ nicht verlängert.

Lecanipa patellifera Rond., III, p. 156 (B. et B., I, Taf. 3, Fig. 49) weist ebenfalls keine apicalen Schildchenborsten auf und scheint auch in der Kopfbildung ähnlich (Sectio Phorocera B. et B.).

Lomacantha Rond. erimert durch die beim $q$ platten Vordertarsen und die aufsteigenden Vibrissen an die Gattung Aporomyia R., welche fast rudi-

1) Conf. Zenillia R. D. (1830), p. 153; (1863) I, p. 471, mit libatrix als Type. - Ferner gehört zo Myxexorista B. et B. auch Nilea R. D. (1863), p. 275 , mit innoxia R. D., wahrscheinlich = fauna Rond.

2) Vergleiche weiter unten die Anmerkung bei Dexodes murinus. 
mentäre, haardünne Kreuzborsten am Schildehen zeigt. Die Klauen des $\sigma^{\nearrow}$ sind aber kurz. - Argyrophylax B. et B. zeigt blos Randmacrochaetel und vier Sternopleuralborsten, sowie nackte Augen.

\section{Dexodes murinus $\left(\sigma^{7}\right)$ nov. spec.}

Scheitel $2 / 3$ eines Auges breit, Augenränder von vorne gesehen nach abwärts mässig divergirend, Augen nackt, Stirnstrieme schwarz, etwas schmäler als die in Längsreihen behaarten Orbiten; Gesicht im Profile gerade, Backen 1/4 der Augenhöle breit, unten fast gerade; Vibrissen etwas über dem Mundrande stehend. Stirnborsten einreihig, mit einer Borste sogar unter die Aristawurzel und nnten den Augen genähert auf die Wangen herabreichend. Orbitalborsten fehlend, ein Paar Scheitelborsten, die obersten zwei Paare der Stirnborsten stark und nach hinten gebogen. Leistenborsten $1 / 4$ aufsteigend, Taster gegen das Ende etwas verdickt, rothgelb mit dunklerer Basis.

Fühler schwarz, über der Augenmitte sitzend; drittes Fühlerglied viermal so lang wie das zweite. Arista lang, gerade und abstehend, kaum bis zur Mitte verdickt, zweites Glied derselben sehr kurz.

Hinter der Quernaht des Rückens 3 innere und 4 äussere Dorsocentralborsten und 3 Intraalarborsten, 1 präsuturale Intraalare, 4 Sternoplenralborsten.

8 Schildchenborsten am Rande, die apicalen stark und gekreuzt, die nächststehenden marginalen lang und divergirend; zwei Subapicale stark und nach rückwärts gebogen.

Hinterleib kegelförmig, erster Ring mit zwei, zweiter mit sechs, dritter mit einer Reihe von Randmacrochaeten; die Discalmacrochaeten sind deutlich kürzer und ungeordnet, sie gleichen verstärkten Haaren.

Beine schwarz, Klauen und Pulvillen deutlich verlängert, Hinterschienen ungleichborstig.

Flügel gelblich hyalin, an der Basis deutlicb gelb, Randdorn rudimentär. Spitzenquerader fast gerade, ziemlich weit vor der Flügelspitze, dritte Längsader nur basal mit 2-3 Borsten.

Rückenschild schwarz, blanweisslich bestäubt, mit vier schwarzen Längslinien; Schildchen rothgelb, nur au der Basis schmal schwarz. Hinterleib ganz dicht und einfärbig gelblichgrau bestäubt, nur die Hinterränder bilden feine braune Linien. Seiten des Abdomens rötblich. Hypopyg eingezogen.

Nabresina, an der Adria, August 1900.

Anmerkung. Dexodes murinus unterscheidet sich von den bekannten Dexodes-Species durch die vier Sternopleuralborsten, welche blos noch interrupta R. Girsch., Entom. Nachr., 1899, S. 185, hat, den einfärbig mäusegrauen Hinterleib und die etwas unter die Aristawurzel herabreichenden Stirnborsten. Nach der Beschreibung zeigt einige Aehnlichkeit: Xylotachina ligniperdae B. et B., II, S. 342. Diese Art besitzt aber eine platte, nicht vorstehende Stirne, je ein Paar starke Discalmacrochaeten und nicht unter die Arista herab- 
reichende Stirnborsten. Ihre Chaetotaxie ist mir unbekannt, Dexodes interrupta R. Girsch. unterscheidet sich durch weniger herabreichende Stiruborsten, schwarzes Schildchen, andere Abdominalfärbung, bildet aber mit murinus in. eine eigene Gruppe, die sich durch vier Dorsocentral- und vier Sternopleuralborsten, sowie durch starke apicale Schildchenborsteu von derjenigen des D. machairopsis B. et B. unterscheidet und sich dadurch Argyrophylax B. et B. nähert.

Anschliessend möchte ich bemerken, dass mir Dexodes machairopsis B. et B. als Mischart erscheint. Unter den unbedingt in den Umfang der erwähnten Art gehörigen Individuen finden sich Männchen sowohl mit zwei Paaren als auch mit einem Pare Scheitelborsten, die auch in den, wenn überhaupt vorhandenen, immer feinen apicalen Schildchenborsten variiren, die gekreuzt und parallel sein können. Lophyromyia clausa B. et B., IV, S. 616 kommt hierbei nicht in Betracht.

\section{Allophorocera nov. gen.}

Die Stellung des Dexodes auripilus B. et B. bei dieser Gattung scheint mir nicht natürlich. Er ist vielmehr in die nächste Verwandtschaft der Gattung Paraphorocera B. et B., die eine gut begrenzte ist (Brauer, Girschner), zu bringen.

Ich stelle hiefür die Gattung Allophorocera auf.

Diagnose: Augen nackt oder höchstens pubescent, Leistenborsten bis zur Gesichtsmitte mehrreihig aufsteigend, mehrere gleich starke Vibrissen ïbereinander stehend. Scheitel bein o und $q$ breit, beide Geschlechter zwei Pare Scheitelborsten, nur das $q$ zwei Orbitalborsten. Backen breit ( $1 / 2$ Augenhöhe) und wulstig, ebenso die Vibrissenleisten. Arista bis über die Mitte gleich stark verdickt, dann dünn; drittes Fühlerglied lang (viermal zweites), apicale Schildchenborsten gekreuzt, halb aufgerichtet, aber nach rückwärts gebogen, drei Sternopleuralborsten, Macrochaeten discal und marginal. Klauen des $\sigma^{-7}$ so lang als das letzte Tarsenglied. Hypopyg. kugelig dick vortretend.

Paraphorocera B. et B. ${ }^{1}$ ) ist im Habitus sehr ähnlich, hat schmälere Backen, vier Sternopleuralborsten, aufgerichtete, nach vorne gebogene apicale Schildchenborsten, runde Haarflecke am dritten männlichen Bauchringe, kürzere Klauen und längere Fühler.

Allophorocera auvipila $B$. et $B$. hat nach der Beschreibung verlängerte Klauen, ein kurzes zweites Borstenglied und eine graue Färbung mit den gewöhnlichen Zeichnungen. Ich hielt daher meine Männchen vom Stilfserjoch in Tirol für eine neue Art (Paraphorocera Braneri i. l.), da die Klauen derselben nicht verlängert sind, das zweite Aristaglied 2-3mal so lang als breit und die Körperfärbung vorherrschend glänzend schwarz ist. Nach Ausicht der typischen Stücke im kais. Museum in Wien sah ich aber, dass meine Männchen mit denen von auripila übereinstimmen, obwohl bei letzteren das dritte Fühlerglied bei einigen Stücken unten eine Ecke aufweist, das zweite Aristaglied kürzer ist und

1) Vergleiche weiter unten die dipterologische Anmerkung Nr. 12. 


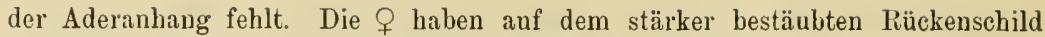
deutliche Längsstriemen und ein kurzes zweites Aristaglied.

Ich lasse hier die Beschreibung eines $\sigma^{7}$ als Ergänzung zu Brauer et Bergenstamm, 1. e., I, S. 316, folgen: Augen nackt, Scheitel $3 / 4$ des Auges breit, Augenränder von vorne gesehen nach unten ziemlich divergirend; Stirnstrieme dunkel rothbraun, so breit wie die Orbiten am Scheitel. Backen hinten herabgesenkt und unten stark beborstet. Stirne vorstehend, Wangen $1 / 2$ des horizontalen Augendurchmesser's breit. Hinterkopf hinter den Augen unten wulstig vortretend, greishaarig. Stirnborsten nugeordnet und den Leisten unten genähert bis zur Aristawurzel herabsteigend, die ersten drei oben stärker und nach anfwärts gebogen. Ocellarborsten nach vorne gebogen, stark. Fühler schwarz, hoch über der Augenmitte inserirt. Drittes Fühlerglied am Aussen- und Innenrande convex, daher fast länglich-eiförmig. Arista fast gekniet, bis $2 / 3$ ihrer Länge verdickt, dann plötzlich haardünn; zweites Glied derselben dreimal so lang als breit. Taster dünn, eylindrisch, rothgelb.

3 innere, 4 änssere Dorsocentralborsten, 3 Intraalare hinter, 1 vor der Naht. Erster und zweiter Abdominalring mit zwei Randmacrochaeten, dritter mit vollständiger Reihe; zweiter und dritter Ring mit mehreren Paaren ungeordneter Discalmacrochaeten.

Flügel glashell, erste Hinterrandzelle schmal offen, nicht weit vor der Flïgelspitze. Spitzenquerader concav, Beugung stumpfwinkelig; diesellue trägt beiderseits schräg nach abwärts einen gleich langen Aderanhang. Hintere Querader $2 / 3$ von der kleinen entfernt. Beine schwarz, Schienen nngleichborstig. Körper glänzend schwarz, Schultern etwas weisslich bestäubt, von Längsstriemen des Rückens kaum eine Spur. Vorderränder des 2.-4. Segmentes mit Ansnahme der Mittellinie bis zur Segmenthälfte weisslich bestäubt.

IV. Eupogona Rond., Atti Soc. It. Sc. Nat. di Milano, 1868, p. 588. B. et B., 1. c., I, S. 88 .

Die einzige Art (Masicera setifacies Rond., Prodr., IV, p. 30, 18) wird von Rondani in der synoptischen Tabelle nicht mit erwähnt, kann daher leicht übersehen werden.

Die Fliege ist meines Wissens bis jetzt nur ans Italien (Parma, Rondani), der Schweiz (Meyer-Dür) nnd Ungarn (Thalhammer, Faun. Reg. Hung., Budap., 1899, p. 44, 14) bekannt. Hiezu kommt noch Niederösterreich: Bisamberg bei Wien, wo ich sic im September 1900 fing.

Gezogen wurde sie von Rogenhofer, Wulp nud Brischke (Schriften der naturf. Gesellsch. zu Danzig, 1885, Bd. VI, S. 20, Tachina Papilionis) aus Papilio Machaon L. ${ }^{1}$ )

Das Insect ähnelt, wie schon $\mathrm{Brauer}$, der die Gattung zuerst ausführlich beschrieb und abbildete (1. c., Taf. I, Fig. 14, $\sigma^{\nearrow}$ und ( ), erwähnt, im Habitus

1) Verg1. Brauer et Bergenstamm, 1. c., IV, 1894, S. 552. 
sehr einer Miltogramma (Metopodia), besitzt aber keinen verengten Clypeus, keine Zinkenfalte, keine fein beharten, sondern beborstete Wangen. Dadurch unterscheidet sie sich auch von Chaetomyia B. et B., von Chaetolyga Rond. und von Winthemyia R. D., von letzterer ferner durch drei Sternopleuralborsten.

Apicale Schildchenborsten zart, gekreuzt, nach hinten gerichtet, 3 iunere und äussere Dorsocentralborsten, 3 Intraalarborsten hinter, 1 vor der Naht. Erster und zweiter Abdominalring mit zwei Randmacrochaeten, dritter mit vollständiger Reibe.

Hinterleib ausser der Längslinie einfärbig mäusegrau wie auch der gauze Körper.

Die Hinterschienen sind bei meinem $q$ entschieden gewimpert zu nennen, denn ausser den Schieneuenddornen und der stärkeren Mittelborste sind alle übrigen Borsten aussen von gleicher Länge.

$\mathrm{Ob}$ der Bewimperung der Hinterschienen überhaupt ein so hoher syste- matischer Werth beizumessen ist? Ich fand sie oft bei einer Art und daun bei beiden Geschlechtern variirend.

Dritte Längsader nur an der Basis mit 2-3 Borsten, mündet nicht weit vor der Flügelspitze. Hintere Querader circa $2 / 3$ vom Cubitus der vierten Längsader entferut.

\section{Parexorista tinctipennis ( $\left.\sigma^{7}\right)$ nov. spec.}

? cormuta Zett., Dipt. Scand., III, p. 1121, 118.

Scheitel $1 / 2$ der Augenbreite, Augenränder von vorne gesehen nach unten wenig divergirend, Stirnstrieme schwarz, so breit wie die Orbiten, diese unter den Borsten ziemlich behaart, Stirne ziemlich vorstehend, Gesicht im Profile geradrandig, Wangen nach unten schmäler werdeud, unten über die Backen mit wulstigem Rande vorstehend, Vibrissenleisten bis zu diesem Wulste mit wenigen Borsten besetzt; Backen 1/6 der Augenhöhe breit, unten gerade. Stirnborsten einreihig, den Leisten unten genähert, bis zur Borstenwurzel herabreichend; ein Paar aufrechte Scheitelborsten, ${ }^{1}$ ) erstes Stirnpaar oben stark, aufwärts gekrümmt. Chatotaxie wie bei Parexorista überhaupt. Fühler schwarz und anliegend, deutlich über der Augenmitte sitzend, drittes Glied mehr als sechsmal so lang wie das zweite. Borste so lang wie die Fühler, fast bis zur Mitte verdickt; zweites Glied derselben kurz, nicht verlängert; die Wurzel der Borste sitzt auffallend weit an der Aussenseite des dritten Fühlergliedes, so dass dieses an der Basis im Profile über die Aristawurzel und die Verbindungsstelle mit dem zweiten Gliede convex vorragt, zumal auch das dritte Glied am Vorderrande schwach concar ist. Taster schwarz, cylindrisch. Drei Sternopleuralborsten.

1) Alle mir bckannten Parexoristen haben beim ơ nur ein Paar Scheitelborsten. - Exarista (crinita Rond.) unterscheidet sich ausser den breiten Backen noch dadurch von Parexorista, dass sie beim $\sigma^{7}$ zwei Paare Scheitelbersten anfweist, wie zum Bei ele auch die Männchen der Gattung Masicera sens. B. et B. und viele andere. 
Hinterleib kegelförmig. Macrochaeten marginal und discal; erster und zweiter Ring mit einem Paare, dritter mit einer vollständigen Reihe von Randborsten, zweiter und dritter Ring mit zwei Paaren Discalborsten hintereinander. Beine schwarz, Hinterschienen unter gleich langen mit vielen längeren Borsten besetzt.

Körper glänzend braunschwarz, Rücken spärlich weiss bestäıbt, mit fünf schwarzen Längsstriemen, die äussersten breiter, die mittleren drei genähert und nur bis zur Naht reichend. Schildchen ohne Roth, glänzend; Abdomen am 2.-4. Ring in der Vorderhälfte mit Ausnahme der Mittellinie weisschillernd.

Flügel am Vorderrande und an den Längsadern intensiv gelblichbraun; dritte Längsader nur basal bedornt, Randdorn fehlend, Spitzenquerader stark concav nach der rechtwinkeligen Beugung.

Bisamberg bei Wien, September, auf Gebüsch.

Anmerkung. Nach der Synopsis der Arten in Brauer-Bergenstamm, II, S. 318, käme man auf mitis Mg., eine mir aus Niederösterreich wohl bekanıte Art, deren drittes Fühlerglied viel kürzer ist und deren Wangen ganz oben etwas behart sind. Nach Stein (Ent. Nachr., 1900, S. 15, Sep.) wäre diese Art identisch mit Westermanni Zett., III, p. 1120, 117. Da aber Zetterstedt, l. c., seiner Art ein sechsmal so langes drittes Fühlerglied als das zweite zuschreibt, so kann ich mich mit dieser Synonymie nicht einverstanden erklären (conf. auch Stein, Entom. Nachr., 1888, S. 214 und Mik, Wien. ent. Zeit., 1889, S. 166, nach dem sie mit temera Mg. zusammenfallen dürfte). Westermanni Zett. unterscheidet sich von oben beschriebener Art durch einen gelblichgrauen Hinterleib und blos vierstriemigen Thoraxrücken. Ein stark verlängertes drittes Fühlerglied besitzen noch linearicornis Zett., III, p. 1118, 115, ㅇ (drittes Fühlerglied viermal so lang wie das zweite, Rücken vierstriemig: nigra, subnitida), Bondsdorf Zett., XIII, p. 6111, 117-118 (drittes Fühlerglied fünfmal so ling wie das zweite, Rücken vierstriemig, aber Schienen und Schildchen roth), cormuta Zett., III, p. 1121, 118 (drittes Fühlerglied fünfmal so lang wie das zweite, Rücken fünfstriemig: nigra, subnitida) und spernenda Zett., III, p. 1122, 119, kaum von cornuta verschieden.

Mit mitis Mg. verwandt und durch längeres drittes Fühlerglied ausgezeichnet (viermal so lang als das zweite) ist magnicomis B. et B., II, S. 320, welche aber wie mitis einen viel breiteren Scheitel aufweist $(2 / 3-3 / 4$ des Auges) und nach Brauer und Strobl (Dipt. v. Steiermark, 1894, S. 21) fraglich das $\sigma^{\lambda}$ von mitis ist. Die Fühlerlänge scheint überhaupt nicht blos nach dem Geschlechte allein variabel $\mathrm{zu}$ sein.

Von allen angeführten Arten wäre blos die Beschreibung Zetterstedt's seiner cornuta ohne viel Widerspruch passend. Da aber Zetterstedt die Borste biarticulata nennt und die auffallende Tingirung der Flügel nicht erwähnt, benenne ich die Art neu.

Als eine Art, deren drittes Fühlerglied sechsmal so lang als das zweite ist, möchte ich noch die von Stein (Ent. Nachr., 1900) beschriebene heraclei Mg. erwähnen, zu welcher aber Meigen's Beschreibung (IV, p. 339, 172) nicht stimmt (drittes Fiihlerglied fast dreimal so lang wie das zweite). Sie zeigt ein rothes 
Schildchen. Stein's Beschreibung dieser Art stimmt fast vollkommen mit der von vivax Rond., Atti Soc. Sc. Nat. di Mil., XI, 1868, p. 38. Parma.

VI. Blepharidea unguiculata ( $\left.\sigma^{\lambda}\right)$ nov. spec. (? Pseudophorocera B. et B.).

Scheitel $2 / 3$ der Augenbreite, Backen weniger als $1 / 6$ der Augenhöhe, unten fast gerade; Vibrissen $1 / 3$ der Höbe aufsteigend, Orbitalborsten fehlend, ein Paar Scheitelborsten; drittes Fühlerglied schwarzbraun, dreimal so lang wie das zweite. Arista bis vor die Mitte verdickt, zweites Glied derselben so lang wie breit. Sechs Stirnborsten von der Fühlerwurzel an reichen deutlich unter die Aristawurzel herab, unten doppelreihig, oben einfach. Die ersten zwei Stirnborsten stark, anfwärts gebogen.

Blos drei innere und drei äussere Dorsocentralborsten (die anderen Arten zeigen vier äussere) hinter der Naht. Chaetotaxie sonst wie bei Bl. vulgaris Fall. (charakteristische Stellung der apicalen Schildchenborsten, drei Sternopleurale etc.).

Taster und Schildchen durchscheinend rothgelb. Körperfärbnng und Flügel sonst wie bei $\mathrm{Bl}$. vulgaris Fall. Die Kliuen sind aber länger als das letzte Tarsenglied. Randdorn des Flügels klein, aber sichtbar, nicht ganz rudimentär wie bei $B l$. vulgaris. Dritte Längsader nur basal bedornt.

Liezen, Steiermark, Angust.

Anmerkung. Vergleiche hiezu B. et B., I, S. 88 und 92; II, S. 338; III, S. 117 und 118, ferner Rondani, Prodr., I, p. 67, Note. Fraglich wäre auch die Varietät von Bl. vulgaris Fall., Meade, "Annotad list of British Tachinidae" (Ent. Mont. Mag., 1891, p. 326: "the palpi are often testaceons at their ends") hieher zu ziehen.

Durch die entschieden verlängerten Klanen wird die Stellung dieser Art bei der Gruppe Blepharidea B. et B. (Rond.) eine isolirte, obwohl anch Subgen. Ceratochaeta $B$, et $B$. in beiden Geschlechtern etwas verlängerte Klaven zeigt.

\section{Blepharidea (Anoxycampta Big. = Pseudoperichaeta B. et B.) hirta} Big., Bull. Soc. ent. Fr., V, 10, p. XL.

$\sigma^{7}$ (trotz der sehr kurzen Klanen und Pulvillen und der zwei Scheitelborsten): Scheitel $5 / 4$ des Auges breit, Stirnstrieme oben fast so breit wie der Scheitel, verjüngt sich nach vorne deutlich, roth; Orbitalborsten fehlen. Aenssere Stirnborstenreihe nur haarförmig und in der Mitte deutlich, 5-6 Stirnborsten unter der Fühlerwurzel reichen deutlich unter die Arista herab; Backen ca. ${ }^{1} / 3$ der Augenhöhe breit, Fühler anliegend.

Drittes Fühlerglied 5-6 mal so lang wie das zweite, Borste bis $7 \mathrm{u} 2 / 3$ verdickt, zweites Glied fast zweimal so lang wie breit. Taster schwarz, keulig. Schildchen am Rande roth.

Körper wegen der dichten Bestäubung kaum glänzend, Abdomen seitlich durchscheinend roth. Beine schwarz. Hinterschienen aussen fast gleichmässig ziemlich dicht gewimpert, nicht mit den langen starken Borsten wie bei vulgaris 
Fall. unregelmässig besetzt. Vibrissen bis über die Hälfte des Gesichtes aufsteigend.

Bisamberg, August. - Livland (Sintenis).

A nmerkung. Brauer (Sitzungsber. d. kais. Akad. d. Wissensch. in Wien, 1898, S. 505) stellte oben angeführte Synonymie nach der Type Bigot's fest, mit der Ausnahıne blos, dass er major B. et B. nur für „vielleicht gleich hirta Big." hält. Da aber die Höhe des Aufsteigens der Vibrissen namentlich bei den Blepharidea-Arten nicht allzu constant ist, glaube ich beide Arten für identisch balten zu müssen. Auch oben beschriebene forma rufoscutellata halte ich vorläufig für specifisch nicht verschieden, obgleich das zweite Aristaglied etwas verlängert, das Schildchen am Rande roth ist und die Hinterschienen gewimpert erscheinen. An. hirta wäre nach der Beschreibung Bigot's allein nie zu erkennen gerresen.

\section{Dipterologische Anmerkungen.}

1. Eurigaster Macq., sens. Rob.-Desv., Ann. Soc. entom. France, 1848, p. 435; Hist. nat., 1863, I, p. 595, deckt sich mit Pexopsis B. et B., I, S. 88.

2. Catagonia nemestrina Egg., B. et B., II, S. 348 (non Meig.), ist das Mäunchen von Exorista aberrans Rond., Prodr., III, p. 147, 38 (Parexorista ead., B. et B., II, S. 324).

Vergl. nuch Girschner (Entom. Nachr., 1899, S. 178, 10). Die Art ist in Bisamberg nicht selten.

Das $\sigma^{\pi}$ weicht im Habitus insoferne vom $ᄋ$ ab, als sein Thorax glänzend und nicht so stark bestäubt ist als beim $q$, bei dem die Längsstriemen bei weitem dentlicher sind. Die Taster des $q$ sind keulig, die des $\sigma^{\nwarrow}$ blos cylindrisch. Das Schildchen des letzteren ist gewöhulich schwarz, doch kann der Rand auch \pm roth sein, wie einige Exemplare beweisen. $\sigma^{\nearrow}$ und $q$ besitzen zwei Paare Scheitelborsten; apicale Schildchenborsten nach rorne gekrümmt, aufgerichtet; vier Sternopleuralborsten.

3. Labilogaster ${ }^{1}$ ) forcipata Meig. unterscheidet sich durch den Besitz von drei Sternopleuralborsten von den anderen zwei von Braner mit ihr vereinigten Subgenera Phaniomyia (biguttata Meig.) und Claivvillia (ocypterina S.), welche blos zwei solche Borsten haben. Die Gattung Phania besitzt gar nur eine Sternopleurale.

Das $\sigma^{7}$ von Clairvillia ocypterina S. kenne ich aus Bisamberg (August 1898) und aus der kais. Sammlung (B. et B., III, Note 107). Es hat verlängerte Klauen und Pulvillen.

$\sigma^{7}$. Drittes Fühlerglied zweimal so lang als das zweite, Taster cylindrisch, Flügel auffalleud heller als beim $ᄋ$; Backen linear, unten fast ganz gerade, Vibrisse kaum etwas höher als der Backenunterrand. Fühlerwurzel deutlich über

1) Labidogaster: Setae ocellares recurvatae, conf. Braner, Sitznngsber. der kais. Akad. der Wissensch. in Wien, 1898, S. 519. Ferner fehlen die inneren Dorsocentralborsten vor nnd hinter der Naht. Bei Clairvillia S. steht ferner die kleine Querader fast hinter der Mündung der ersten Längsader. 
die Augenmitte hinaufgerückt. Zwei Paare Scheitelborsten, Scheitel $2 / 3$ der Augenbreite; Stirne von vorne gesehen fast parallel (biguttata Meig., $\sigma^{7}$ : Ein Par Scheitelborsten, Scheitel 1/4 der Angenbreite, Augenränder von vorne gesehen nach unten stark divergirend und s-förmig geschwungen).

q. Drittes Fühlerglied mit dem zweiten fast gleich lang, kaum länger; Taster keulig, wie bei den meisten Formen der Sectio Phania B. et B.; Flügel wie Schiner beschreibt. Backen schon von der Vibrisse an convex herabgehend, hinten schmal. Fühlerbasis der Augenmitte gegenüber.

Die Verschiedenheit der Fühlerlänge und der Tasterform bei den Geschlechtern einer Art steht nicht vereiuzelt da. Sollte das $\sigma^{\nearrow}$ dennoch einer anderen Art angehören, mag sie longicornis heissen.

4. Meigenia incana Fabr., coll. Zett., teste P. Stein = egens Egg., Verh. der k. k. zool.-bot. Ges. in Wien, 1861, S. 213; B. et B., II, S. 310 (? = mutabilis Fall., Meig., IV, S. 403, 285). Für diese Art stimmt das nicht mehr, was Rondani, Prodr., III, p. 111 von seiner Gattung Spylosia, die schon Schiner erkannte, sagt: „scutellum apice setis duabus intermediis erectis et non decussatis." Die apicalen Schildchenborsten sind wohl aufgerichtet und nach vorne gebogen, kreuzen sich aber ganz an der Spitze und bleiben nicht parallel, wie bei den anderen Arten. Der Scheitel des $\sigma^{\pi}$ ist $2 / 3-3 / 4$ des Auges breit (bei bisignata $\sigma^{7} 1 / 2$, bei floralis $1 / 3$ ) und trägt zwei Pare Scheitelborsten (die anderen Arten nur ein Paar).

Hinterleib einfärbig mäusegrau ( $\sigma^{\top}$ und q) mit schwarzen Wurzelpunkten an den Macrochaeten. Meine Exemplare (die Art ist in Bisamberg bei Wien nicht selten) zeigen aber alle nur $\left(\sigma^{\top}\right.$ und $\left.\not\right)$ ein Paar Discalmacrochaeten auf jedem Ringe.

Vier deutliche Sternopleuralborsten. Erste Hinterrandzelle bei einigen Stücken am Rande geschlossen. Die Pubescenz der Augeu ist bei manchen Exemplaren sehr deutlich.

Auch die Fühlerwurzel sitzt bei egens Egg. hoch über der Augenmitte, während sie bei den anderen Arten der Mitte fast gegenüber steht.

5. Myiocera ferina Fall., S. hat vier äussere Dorsocentralborsten und drei Intraalarborsten hinter der Naht, Myiocera carinifrons Fall., S. je eine Borste weniger.

6. Frontina laeta Meig. und Roeselia antiqua Fall. zeigen an Stelle des gewöhnlichen Hypopleuralborstenfächers blos zwei einfache Borsten.

7. Das $\sigma^{\top}$ von Erigone consobrina Meig. (Brauer, Sitzungsber. der kais. Akad. der Wissensch. in Wien, 1898, S. 534, 6) besitzt blos zwei Sternopleuralborsten, das $q$ und beide Geschlechter von radium Fall. und connivens Zett. zum Beispiele drei solche Borsten.

8. Myiospila meditabunda Fall. var. alpina (Stilfserjoch in Tirol): Vier Sternopleurale, wie forma genuina; Thorax und Schildehen glänzend schwarz, nur längs der Dorsocentralreihe schmale weissliche Binden. Hinterleib: Erster Ring fast ganz schwarz; die zwei Mittelflecken des zweiten Ringes sehr breit, sie lassen seitlich nur schmälere Theile des Torgits frei, als sie breit sind; die-

Z. B. Ges. Bd. LI. 
jenigen des dritten Ringes sind schmäler. Flügel am Grunde mit intensiv schwarzbraun gesäumten Adern. (Vergl. E. Pokorny in diesen „Verhandlungen", 1887, S. 382.)

9. Für Parexorista confinis Fall. hat Robineau-Desvoidy (Hist. nat., 1863, I, p. 458) den Gattungsnamen Aplomyia gebraucht; Subgenus zu Parexorista B. et B.: Stirnborsten unter die Arista herabgehend, zweites Borstenglied und drittes Fühlerglied verlängert; Maerochaeten des Abdonens nur marginal, vier Sternopleuralborsten, Hinterschienen gekrümmt, Cubitus der vierten Längsader obne Zinkenfalte. $\sigma^{7}$ : Ein Paar Scheitelborsten, apicale Schildchenborsten gekreuzt, nach hinten gebogen. - Rondani stellte später (Atti Soc. Sc. nat. di Mil., 1868, p. 583) die Art zu seiner Gattung Tricholyga.

10. Gonia flaviceps Zett., Dipt. Scand., II, p. $1196=$ intervupta Rond., Prodr., III, p. 32 = flaviceps Schin., F. A., I, p. 443 = ead. Kow arz, Wr. Ent. Zeit., VII, S. 1. Gonia flaviceps Zett. hat schwärzliche Taster (nach Kowarz sogar schwarze) und besitzt keine Discalmacrochaeten am dritten Abdominalring. G. intervupta Rond. zeigt aber gelbe Taster und Discalmacrochaten am dritten Segmente.

Ein $\sigma^{7}$ (Hohe Salve, August, Tirol), welches vollkommen mehreren o von G. flaviceps Zett. des kais. Museums in Wien gleicht, weist nun keine Discalmacrochaeten, dagegen gelbliche 'Taster auf, bildet also den Uebergang. Das Vorhandensein oder Fehlen von nicht paarigen Discalmacrochaeten am dritten Ringe ist bei Tochinarien ein wenig constantes Merkmal. Es bleibt also blos die Farbe der Taster. Da dieselbe von Kowarz schwarz, von Zetterstedt schwärzlich genannt wird, da sie bei meinen Stücken graugelb, bei Rondani ${ }_{n}$ testaceus ${ }^{*}$ ist, so scheint mir auch lier der Uebergang angedeutet.

Den von mir erwähnten Mänuchen fehlen die weissen Randsäume am $\mathrm{Ab}$ domen ganz, das $\sigma^{\pi}$ des Kowarz hatte schmale weissliche Hinterrandbinden, während dieselben bei anderen Stücken \pm breit sind. Auch das $\delta^{\pi}$ des Zetterstedt hatte einen einfärbig glänzend schwarzen Hinterleib: $\left(\sigma^{\top}, \&\right)$ nigra, nitida, in \& vestigio vittarum albarum in thoracis antico et fasciarum 3 cinerascentium in abdomine.

11. Parexorista grossa B. et B., II, S. 323 ist eine ecbte Parexorista mit vorstehender Stirne, drei Sternopleuralborsten und kegelförmigem Abdomen. Sie kann daher nicht gleich sein Sisyropa glauca Meig., wie Stein, Entom. Nachr., 1900, S. 154, sagt.

12. Masicera senilis Meig., VII, S. $241,8=$ Andrina senilis R.-D. (1863), I, p. 836, und ist nicht identisch mit der Art Rondani's, daher auch Andrina R.-D. nicht als Synonym zn Paraphorocera zu ziehen ist. Senilis Meig. hat die dritte Längsader bis zur kleinen Querader beborstet und die erste Hinterrandzelle gestielt. Meigen stellte die Art nach Robineau-Desvoidy später zn seiner Gattung Clista.

13. Avihospita $\mathrm{Hend}$., Wr. Ent. Zeit., 1901, ist eine todtgeborne Gattnng, da sie zu Protocalliphora Hough, Entom. News Philad., 1899, synonym ist. Die Ursache ist ein bedauerlicher bibliographischer Fehler meinerseits. - Herrn P. 
Fr. Konow hat es gefallen, in Nr. 2 seiner jüngst ereirten Zeitschrift anlässlich eines Referates über meine Arbeit seiner ganz subjectiven Anschauung über Nomenclatur eine die Grenzen objectiver Kritik überschreitende Bemerkung beizufügen, die ich für meine Person hiermit zurückweise. Bezüglich des ja wirklich schlecht gebildeten Namens "Avihospita" mag sich Herr Konow aus dem oben eitirten Grunde trösten. Den belehrenden Hinweis auf Mik's Ansichten muss ich dankend ablehnen, da ich diese aus langem persönlichen Verkehre mit dem Verstorbenen selbst kenne, jedoch - wie ich auch unlängst in den Termész. Füzet., 1901 bemerkt babe - nicht immer mit ihnen übereinstimme.

\section{Eine neue Homopterenart aus Istrien.}

Von

Dr. L. Melichar.

(Mit zwei Abbildungen im Texte.)

(Eingelaufen am 4. Februar 1901.)

\section{Zyginella Graeffei nov. spec.}

Körper gelblichgrün. Scheitel, Pronotum und Schildchen gelblichgrün. Scheitel vorne stumpf abgerundet, um ein Viertel kürzer als das Pronotum, letzteres vor'ue bogig gewölbt, hinten gerade, glatt, glänzend. In der Mitte des Schildchens eine vertiefte Querlinie. Gesicht gelblichgrün, Augen schwarz. Flügeldecken gelblichgrün, im unteren Drittel meist hyalin, der Clavus bis auf seine Spitze zinnoberroth. Der Aussenrand der Deckflügel unterhalb der Wurzel beginnend bis zur Mitte schmal schwarz gesäumt, vom unteren Ende der
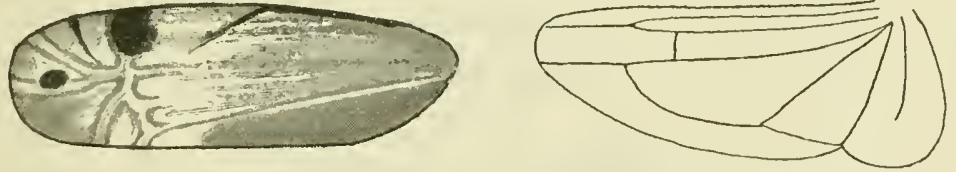

Umsäumung führt eine schiefe schwarze Linie in das Corium. Vier Apicalzellen, die Apicalnerven braun gesäumt, der äussere Apicalnerv gegabelt, in der Mitte der dreieckigen Zelle nahe dem inneren Aste ein schwarzer Punkt. In der Mitte der äusseren Apicalzelle geht vom Bogenrande ein schwarzer Strich fast bis zum gegabelten Apicalnerven und bildet einen falschen Quernerven. An dem äusseren Quernerven befindet sich eine grosse viereckige schwarze Makel. Flügel milehigweiss, von weisslichen Nerven durchzogen. Hinterleib unten grünlichgelb, mit einer schwarzen Längsmakel in der Mitte, oben schwarz, die Rückensegmente schmal gelb gesäumt. Beine blassgrün, die Klanen braun. 
$\sigma^{7}$. Genitalklappe fehlt. Genitalplatten schmal, nach hinten verschmälert, aneinandergeschlossen, das Ende aufwärts gebogen. Letztes Rückensegment schwarz, dessen Seitenlappen nach hinten und unten verschmälert, stumpf zingespitzt, kürzer als die Genitalplatten. Afterröhre blassgelb. Länge $3.5 \mathrm{~mm}$.

Diese durch die Randmakeln der Flügeldecken gekennzeichnete Art wurde von meinem Freunde Dr. E. Graeffe, welcher um die Erforschung der Homopterenfauna des Istrianer Gebietes sich grosse Verdienste erworben hat, bei Triest (Proseco) auf einer Lichenenart entdeckt.

Die drei bekannten Arten sind nach der nachstehenden Tabelle leicht zu bestimmen:

1. Auf den Flügeldecken ein am äusseren Quernerven anliegender grosser, fast viereckiger Randfleck. Länge $3: 5 \mathrm{~mm}$. Istrien . Z. Graeffei nov. spec.

- Auf den Flügeldecken kein schwarzer Randfleck; in der äusseren Apicalzelle zwei nach innen convergirende schwarze Randstriche . . . . . . . 2

2. Stirne beim $\sigma^{\top}$ einfarbig grün oder gelb, beim $q$ dicht über den Fühlern eine von einem Auge zum anderen ziehende schwarze, etwas nach oben ausgebogene Querlinie. Clypens schwarz. Clavus der Flügeldecken zinnoberroth. Länge $\left(\sigma^{7}\right.$, q) $3.5 \mathrm{~mm}$. Niederösterreich . . . . . Z. pulchra Löw

- Stirne bei beiden Geschlechtern einfärbig grün oder gelb. Clypeus gelb . 3

3. Clavus der Flügeldecken gelb. Länge $2.75 \mathrm{~mm}$. Croatien.

Z. albifrons Horv.

- Clavus der Flügeldecken, Hinterrand des Pronotum und ein Mittelfleck roth. Croatien . . . . . . . . . var. erubescens Horv.

\section{Baris Gudenusi nov. spec.}

Beschrieben von

\section{August Sehultze}

in Detmold.

(Eingelaufen am 25. Jänner 1901.)

In sectionem Baridis cuprirostris Fabr. pertinens, ab omnibus vero speciebus propinquis statura peroblongo-ovali, valde differre videtur.

Ovali-elongata, coeruleo-violacea, subnitida, antennis pedibusque nigris. Rostro subtenui, \& fere thoracis longitudine, aequabile curvato, supra subtilissime et sparsim, ad latera densius et paulo seriatim ruguloso-punctato, $\sigma^{\top}$ breviore, crassiore, lateribusque grossiore punctato, in utroque sexu nigro, saepiusque in basi metallescente. Prothorace subconico, lateribus ad apicem paululo curvatim coangustato, subtiliter et minus crebre, sat profunde punctato, 
(Aus der Zeitschrift für Hymenopterologie und Dipterologie. 1908. Heft 1.)

\section{Synopsis der bisher bekaunten Ti im ia-Arten. (Dipt.)}

Von Friedrich Hende $\mathrm{l}$ in Wien.

Herr Th. Becker hat in der Wiener entomol. Zeitung 1907 p. 108-118 eine Arbeit über die Gattung Timia Wied. publiziert, in welcher er zu den damals bekannten 5 Arten noch 7 neue hinzufügt. Da ich nun in der Lage bin, nóch weitere 7 Arten als neu zu beschreiben, habe ich die von Becker 1. c. gegebene Bestimmungstabelle erweitert und unter obigem Titel herausgegeben. Die neuen Arten stammen alle aus Transkaspien. Ich erhielt dieselben mit Ausnahme 3 Arten, welche sich in K. K. Museum unter einer Dipterenkollektion von Herrn E. Reitter aus Turkmenien befand, von Herrn Alex. von Jakowlew aus Jaroslawl.

Bezüglich der von Becker 1. c. p. 109 und 110 angegebenen Beborstung bei der Gattung möchte ich erwähnen, dass manche Arten eine, wenn auch schwache Orbitalborste besitzen und alle von mir beschriebenen Arten nur e in e hintere Dorsalborste am Rücken tragen.

1. Stirn gelb, mehr oder weniger punktiert, mit 2 von den Fühlergruben bis zum Scheitel durchlaufenden rotbraunen Streifen. Thoraxrücken von glänzend schwarzer Grundiarbe, mehr oder weniger grau bereift und fein punktiert . . . . . . . . 2.

- Stirn ohne die beiden rotbraunen Längsstreifen 9.

2. Schildchen ganz schwarz. Jakowlewi n. sp. ㅇ․

- Schildchen ganz oder teilweise gelb . . . . 3.

3. Hinterleib stark punktiert. Flügel wasserklar, aber Wurzel, Randmal und Spitze bräunlich gefärbt. Hinterleib glänzend schwarz, letzter Ring wenig länger als der vorhergehende. Schildchen gewölbt und etwas punktiert, an der Wurzelhälfte schwarz, Spitze gelbbraun. Beine glänzend schwarz, Kniee und Metatarsen gelblich. 5.5 mm lang. - Tibet. 
- Hinterleib nicht punktiert,Flügel wasserklar mit gelben Adern . . . . . . . . . . . . 4.

4. Schildchen glänzend gelb, gewölbt, ohne Punktierung . . . . . . . . . . . . . . . 5.

- Schildchen rostgelb, oben abgeplattet, runzelig punktiert, an der Wurzel schwarz. Hinterleib erzfarbig grün, glänzend; letzter Ring wenig länger als der vorletzte. Legeröhre schwarz. Beine rotgelb; Hüften, Spitze der Hinterschienen und letzte Tarsen gebräunt. 5,5--7,5 mm lang. - Tibet.

protuberans Becker ơo. Wien. entom. Zeit. 1907 p. 113.

5. Mesopleuren weisslich bestäubt. Vorderhüften und Vordertarsen schwärzlich. Hinterschienen gekrümmt und verdickt, unten (innen) lang gewimpert.

hirtipes ก. sp. $\sigma^{7} \%$.

- Mesopleuren glänzend schwarz. Hinterschienen normal . . . . . . . . . . . . . 6 .

6. Stirn verhältnismässig flach vorgestreckt. Gesicht mindestens um das anderthalbfache des horizontalen Augendurchmessers vortretend. Beine vorwiegend schwarz gefärbt. Fühler rotgelb. Hinterleib metallisch grün. Hinterkopf gelb. Stirn ohne Querfurche. Länge $6 \mathrm{~mm}$. - Alai-Giebirge, Süd-Sibirien.

Wien. entom. Zeit. 1907 p. 114.

monticola Becker ơ.

- Stirn steil abfallend. Gesicht höchstens um die Länge des horizontalen Augendurchmessers vorspringend 7.

7. Stirn in der Mitte mit einer Querfurche. Beine vorwiegend schwarz gefärbt. Hinterleib schwarz, ebenso der Hinterkopf. Länge $3,5 \mathrm{~mm}$. parva n. sp. $\sigma^{7}$.

- Stirn ohne Querfurche. Beine vorherrschend gelb 8.

8. Fühler, Taster, Hinterkopf und Vorderhüften schwarz. Letzter Hinterleibsring nicht verlängert. Länge 4-4,5 $\mathrm{mm}$.

nigriceps $\mathrm{n} . \mathrm{sp} . \mathrm{\sigma}^{\text {? }}$.

- Fühler, Taster, Hinterkopf und Vorderhüften rotgelb. Letzter Hinterleibsring verlängert. Länge 6-7 mm. Tibet.

turgida Becker ㅇ.

Wien. entom. Zeit. 1907 p. 114 .

9. Thoraxrücken glänzend, ohne Bestäubung . . . 10.

- Thoraxrücken bestäubt und punktiert . . . . 17. 
10. Thorax und Hinterleib rotgelb bis rostgelb . . 11 .

- Thorax und Hinterleib schwarz . . . . . . 13.

11. Fühler ganz gelb . . . . . . . . 12.

- Erstes und zweites Fühlerglied schwarz, das dritte gelb. Stirn gelb, wachsglänzend. Hinterleib rostgelb mit auf der Mitte unterbrochenen braunen Vorderrandbinden. Hinterrücken glänzend schwarz. Flügel farblos mit blassgelben Adern, Stirn mit einer flachen Querfurche, unpunktiert. Länge $3 \mathrm{~mm}$. - Kaschgar. dimidiata Becker ơ.

Wien. ent. Zeit. 1907 p. 115.

12. Hinterleib mit breitem schwarzen mittleren Längsstreifen. Stirn grob querrunzelig. Flügel schwach bräunlich getrübt. $7 \mathrm{~mm}$. - Kaschgar.

mellina Becker ot.

Wien. entom. Zeit. 1907 p. 116.

- Der ganze Körper glänzend rostgelb. 7-8 mm. Zentral-Asien. testacea Portschinsky ớq. Hor. Soc. ent. Ross., XXVI. 1891, p. 211.

13. Flügel wasserklar mit gelben Adern . . . . 14.

- Flügel nicht wasserklar . . . . . . . 16.

14. Stirn mit einer Querfurche. Schildchen schwarz. Beine pechschwarz, Kniee und Tarsen gelb. Länge $3,5 \mathrm{~mm}$.

Reitteri n. sp. ơo

- Stirn ohne Querfurche. Schildchen gelb . . . 15.

15. Kopf sehr stark aufgeblasen, Stirn 4 mal so breit als ein Auge, vorn mehr als um den horizontalen Augendurchmesser vorstehend. Rückenschild stark punktiert. 8-10 $\mathrm{mm}$ lang.

Klugi n. sp. $\sigma^{7}$ o .

- Kopf weniger aufgeblasen, Stirn daher nur 2 mal so breit als ein Auge, vorn weniger vorstehend als der horizontale Augendurchmesser beträgt. Rückenschild sehr spärlich punktiert. $5 \mathrm{~mm}$ lang.

carbonaria 11. sp. ơ.

16. Schenkel unten fein bedornt. Beine rotgelb: Hüften und Spitze der Schienen schwarz. Flügel weiss- 
gelblich mit brauner Costa und bräunlichem Salum längs derselben. - Süd-Russland. erythrocephala Wiedemann ơo. Aussereur. Zweifl. Ins., II. 564. 1830.

- Schenkel unbedornt. Hüften und Schenkel schwarz, Schienen und Tarsen pechbraun, Kniee rostgelb. Flügel gebräunt, an der Wurzelhälfte gelblich, längs der Costa stärker verdunkelt. Adern schwarzbraun, an der Basis gelb; ohne Legeröhre $8 \mathrm{~mm}$. Turkmenien.

nigripes Mik. ㅇ. Wien. ent. Zeit., V1ll. 201. 1889.

17. Flügel glashell mit gelben Adern, ohne braune Flecken. . . . . . . . . . . . 16.

- Flügelvorderrand schmal bräunlich gesäumt bis zum Spitzenfleck. Schulterbeule nebst vorderem Bruststück rot. Hinterleib glänzend schwarz mit rotgelben Hinterrandsäumen. Legeröhre und Beine rotgelb; ohne Legeröhre $9 \mathrm{~mm}$ lang. - Persien.

Wien, ent. Zeit., VIII. 186. 1889.

pulchra Röder \%.

18. Thorax glänzend schwarz mit grauer Bereifung. Hinterleib und Legeröhre glänzend schwarz. Fühler rotbraun. Grosse Art von 9-10 $\mathrm{mm}$ Länge. Turkmenien.

Wien. ent. Zeit., Vlll. 200. 1889.

Komarowi Mik. ơo.

- Thorax glänzend gelb mit weisslicher Bereifung. Hinterleib und Legeröhre glänzend rostgelb. Fühler schwarz; kleine Art von 4,5-5 mm Länge. - Tibet. canaliculata Becker ơ'o.

Wien. entom. Zeit. 1907. 117.

1. Timia hirtipes n. sp. $\sigma^{7} \circ$. Sammlung.

2 ㅈ 3 q aus Transkaspien, leg. Ahnger. Jakowlew's und meine

Kopf wachsgelb mit sehr steil abfallender Stirn. Das Untergesicht springt etwas weniger als die Hälite des wagrechten Augendurchmessers vor. Die Augen sind doppelt so hoch als lang, lotrecht gestellt. Die Stim ist sehr breit, $3 / 5$ der Kopfbreite, ohne Querfurche ; die Grundfärbung derselben ist glänzend rotgelb, welche Farbe aber durch eine dichte weisse Bestäubung verdeckt ist. Aus dieser Bestäubung treten 2 unbestäubte, nach oben hin etwas convergierende Streifen hervor, welche mit breiter Basis über den Fühlerwurzeln beginnen, nach oben hin gegen den schwarzen Ocellenhöcker sich verjüngen 
und dort mit einer ebensolchen unbestäubten Querbinde, welche die Stirn vom Hinterkopf trennt und von einem Auge zum anderen geht, zusammenlaufen. Zwischen und seitlich von diesen Stirnstriemen tritt die Grundfärbung nur in Form kleiner und sehr dicht nebeneinanderstehender Pünktchen an den Wurzeln der schwarzen, kurzen Behaarung zu Tage. Die Stirnseiten sind gerade so breit wie der von den Striemen eingenommene Mittelteil. Die Fühler und die Borste sind gelb, das 3. Fühlerglied manchmal braun. Die Fühlergruben nicht verdunkelt. Der zwischen den letzteren liegende leistenförmige Teil des Clypeus ist über dem Mundrande etwas engedrückt und tritt wenig vor. Der Rüssel ist voluminös, schwarz. Die Taster sind löffelförmig, an der Spitze breiter und behaart, ganz gelbrot. Das Fulcrum tritt wenig vor, ist schmal und gelbrot. - Im durchfallenden Lichte ist der ganze Hinterkopf rotgelb. Im auffallenden ist der Mittelteil um den Hals herum matt kastanienbraun, ein breiter Kreisring rund herum neben den Augen weiss bestäubt. Thorax von glänzend schwarzer Grundfarbe, am ganzen Rücken und an den Mesopleuren dicht weissgrau bestäubt und stark punktiert. Die Punktierung zeigt eine streifenartige Anordnung. Hinterrücken auch bestäubt. Das glänzend gelthe Schildchen ist stark gewölbt und zeigt nur am Seitenrande weisse Bestäubung mit Punkten. Nur 2 apicale, kurze Borsten. Schüppchen schneeweiss, Schwinger gelb. - Der Hinterleib ist metallisch grün, hell erscheinend und hat fast keine wahrnehmbare Punktierung. Alle Segmente ziemlich gleich lang, nur beim or ist der letzte Ring länger. Die Legeröhre des o 9 ist schwarz und $1 \frac{1}{2}$ mal so lang als das letzte Segment. Die Beine sind alle hell rotgelb; die Vorderhüften sind glänzend schwarzbraun, die Vorderschienen gegen das Ende gebräunt und die Vordertarsen schwärzlich. Bei einigen Stücken zeigt sich auf der Hinterseite der Vorderschenkel ein dunkler Wisch. Die Hinterschienen sind auffallend gekrümmt und verdickt und auf der Unter(Innen) Seite mit langen, schwarzen Haaren dicht gewimpert. Ebensolche Haarwimperreihen finden sich oben an der Spitzenhälfte der Hinterschenkel ziemlich dicht, dann posteroventral und anteroventral an den Mittelschenkeln, schwächer ventral an den Hinterschenkeln, Die stärkste Borstenreihe steht posteroventral an den Vorderschenkeln. Die Behaarung des ganzen Körpers ist schwarz und kurz. Die Flügel sind wasserklar mit 
gelben Adern. - Körperlänge 6-8 mm ; Flügel: 5,5 bis $6,5 \mathrm{~mm}$.

A n m e r ku ng: Timia hirtipes unterscheidet sich von protuberans Becker 1. durch die stark bestäubte, auch in der Mitte punktierte Stirn, 2. durch eine andere Färbung des Hinterkopfes, 3. durch bestäubte Schultern und Mesopleuren, 4. durch das gewölbte, ganz gelbe Schildchen, 5. durch die Behaaruug der Hinterschienen. - Von Timia turgida Becker unterscheidet sie sich 1. durch die bestäubten Mesopleuren, 2. durch das am Rande punktierte Schildchen, 3. durch den helleren Hinterleib, dessen letzter Ring beim 우 nicht verlängert ist, 4 . durch schwarze Vorderhüften und dunkle Vordertarsen, 5. durch andere Rückenpunktierung, 6. durch die Behaarung der Hinterschienen.

\section{Timia Jakowlewi n. sp. ‥}

3 ㅇ aus Transkaspien, leg. Reitter, 1894. Kaiserl. Museum in Wien. Kopf wachsgelb mit etwas weniger steil abfallender Stirn. Das Untergesicht springt aber dennoch nur um die Hälfte des wagrechten Augendurchmessers vor. Die lotrecht gestellten Augen sind nur 1 $1 \frac{1}{2}$ mal so hoch als lang. Die Stirn ist kaum die Hälfte des Kopfes breit, mit einer wenigstens angedeuteten Querfurche in der Mitte; die Grundfärbung derselben ist glänzend rotgelb, welche Färbung aber durch weisse Bestäubung zum Teile verdeckt ist. Die Behaarung der Stirn ist auffallend lang und rauh. *) Die unbestäubten Stirnstreifen der Mitte laufen parallel von den Fühlern zum Ocellenhöcker und sind in der Mitte am schmalsten, oben und unten breiter. Der Zwischenraum zwischen denselben ist weiss, unpunktiert, die Stirnseiten aber, welche schmaler sind. als die von den beiden Striemen eingenommene Fläche, sind ziemlich dicht punktiert. Der Ocellenhöcker und zwei Flecke der Stirn am oberen Augeneck sind glänzend schwarz. Fühler samt Arista sind schwarz. Die Fühlergruben sind verdunkelt. Der zwischen denselben liegende, leistenförmige Clypeusteil hat die Form wie bei hirtipes. Der Rüssel ist gross, schwarz; die löffelförmigen Taster sind auch schwarz. Das Fulcrum ist stärker entwickelt als bei hirtipes und glänzend schwarz. Der ganze Hinterkopf ist mit Ausnahme des gelben Cerebrales glänzend metallisch grünschwarz. Der ganze Thorax samt Schildchen ist von glänzend metallisch grünschwarzer Grundfarbe. Der Rücken ist matt bereift, auch die Schultern. Aus der Bereifung heben sich ungefähr 4 Punktlängsreihen in der Mitte und glänzende Längsstreifen an den Seiten deutlich ab. Auch der Hinterrücken ist matt. Die Pleuren sind mehr tiefschwarz als grün. Das glänzende Schild-

\footnotetext{
*) Daher besser bei Empyelocera, Loew.
} 
chen ist stark gewölbt und hat 4 lange Randborsten. Schüppchen weiss, Schwinger gelb. Der Hinterleib und die Legeröhre sind metallisch grün, dunkel, ohne wahrnehmbare Punktierung. Der erste Teil der Legeröhre ist ungefähr so lang wie das letzte der ziemlich gleichlangen Abdominalsegmente. An den Beinen sind die Hüften und die Schenkel mit Ausnahme der Kniee glänzend schwarz, die Schienen gelbrot, die Tarsen, namentlich die vorderen, gegen das Ende zu braun. Die Hinterschienen sind weder verdickt noch gewimpert. Mittelschenkel posteroventral und anteroventral mit Haarwimpern besetzt. Vorderschenkel posteroventral mit einer Borstenreihe. Hinterschenkel oben nur mit einigen Haaren. Die Flügel sind wasserklar mit gelben Adern. - Körperlänge: $5 \mathrm{~mm}$. Flügel: $4 \mathrm{~mm}$.

A n merkung: Diese Art ist von allen Arten mit den 2 rotgelben Stirnstriemen leicht durch das schwarze Schildchen kenntlich. Ich widme dieselbe Herrn A. von Jakowlew in Jaroslawl.

\section{Timia nigriceps ก. sp. $\sigma^{7}$.}

$2 \sigma^{7}$ aus Transkaspien, leg. Ahnger. Jakowlew's und meine Sammlung.

Kopf wachsgelb, mit noch etwas weniger steiler Stirn als bei Timia Jakowlewi. Das Untergesicht springt nur un die Hälfte des wagrechten Augendurchmessers vor. Die lotrecht gestellten Augen sind ein und einhalbmal so hoch als lang. Die Stirn ist die Hälfte des Kopfes breit, ohne Querfurche, und zienlich gewölbt; ihre Grundfärbung ist rotgelb. Die beiden Längsstreifen sind vorn über den Fühlern sehr breit, veriüngen sich nach oben und laufen dort mit einer ebenfalls roten Querbinde wie bei Tim. hirtipes - zusammen. Die bestäubten und dicht punktierten Stirnseiten sind nur die Hälite des von den Striemen eingenommenen Mittelteiles breit. Der Zwischenraum zwischen den Striemen ist unpunktiert weiss. Der Ocellenhöcker ist dunkler als die Querbinde am Scheitel. Die Fühler und der verdickte Wurzelteil der Borste sind schwarz. Die Fühlergruben sind bei dem einen Stücke verdunkelt. Der zwischen letzteren liegende Clypeusteil ist leistenförmig, über dem Mundrande etwas konkav und tritt mässig vor. Der Rüssel ist schwarz, die Labellen rot; die Taster sind schwarz, an der Spitze etwas verbreitert. Das Fulcrum tritt etwas vor, ist schmal und gelbrot. Der ganze Hinterkopf ist mit Ausnahme des roten Cerebrales tief schwarz. - Thorax von glänzend schwarzer Grundfarbe. Der ganze Rücken ist matt gelbgrau bestäubt und reihenweise punktiert. Die 
Pleuren glänzen. - Das Schildchen ist gewölbt, unpunktiert, gelb, nur die äusserste Basis ist schwarz. Es glänzt nur in der Mitte etwas und hat 4 lange schwarze Borsten. Schüppchen weiss, Schwinger gelb. Der Hinterleib ist glänzend metallisch grün ohne wahrnehmbare Punktierung. Alle Segmente von ziemlich gleicher Länge. Die Beine sind rotgelb, die Hüften schwarz. Die Vordertarsen sind etwas gebräunt und die Mittelschenkel posteround anteroventral gewimpert. Die Borstenreihe der Vorderschenkel ist deutlich entwickelt. Die Flügel sind wasserklar mit gelben Adern. - Länge: 4-4,5 mm ; Flügel: $3,5-4 \mathrm{~mm}$.

A nme rkung: Timia nigriceps steht der turgida Becker am nächsten, hat aber Hinterkepf, Fühler und Taster schwarz, überdies eine geringere Grösse. Empyelocera Camillae Mik hat bestäubte Pleuren.

4. Timia parva n. sp. $\sigma^{7}$.

I $\sigma^{\pi}$ aus Transkaspien, leg. Ahnger. Meine Sammlung.

Kopf wachsgelb. Die Stirn ist von den hier neu beschriebenen Arten am wenigsten steil. Das Untergesicht springt daher ungefähr um die Länge des horizontalen Augendurchmessers vor. Die lotrecht gestellten Augen sind wenig lang gestreckt, nur $1 \frac{1}{3}$ mal so hoch als lang. Die Stirn ist die Hälfie des Kopfes breit und hat ebenso wie Jakowlewi eine angedeutete Querfurche in der Mitte. Die roten Längsstreifen derselben laufen ziemlich parallel und sind nur vorn etwas verbreitert. Wie bei nigriceps sind die Scheitelquerbinde und der Ocellenhöcker gefärbt. Die bestäubten und spärlich punktierten Stirnseiten sind nur die Hälfte des von den Striemen eingenommenen Mittelteiles breit. Der Zwischenraum ist unpunktiert weiss. Fühler und Arista sind hell rotgelb. Der leistenförmige Clypeus ist über dem Mundrande konkav und springt oben ziemlich über die Augen vor. Der Rüssel ist schwarz, die Taster sind dunkel rotbraun. Das gebräunte Fulcrum ist nur wenig sichtbar. Der ganze Hinterkopf ist mit Ausnahme der schmalen roten Augenränder und des Cerebrales schwarz. - Der Thorax ist von glänzend schwarzer Grundfarbe und nur auf dem Rücken mässig dicht weisslich bereift. Rückwärts glänzt der Rücken zum Teile. Seine Punktierung ist reihenweise angeordnet. Die Schulterbeule ist nicht bestäubt. - Das Schildchen ist gewölbt, unpunktiert, glänzend gelb und hat 4 lange schwarze Randborsten. Schüppchen weiss, Schwinger 
gelb. - Der Hinterleib ist metallisch schwarz, kaum grünschimmernd, unpunktiert. Beine gelbrot, nur die Hüften und Basalhälften der Schenkel schwarz. Der Flügel ist glashell mit gelben Adern. - Länge 3,5 mm. Flügel : $2,5 \mathrm{~mm}$.

A nmerkung: Zum Teile schwarz gefärbte Schenkel hat nur noch Tim. monticola Becker, deren Clypeus aber bedeutend weiter vorspringt und deren Augen viel höher sind. Ausserdem hat diese Art einen gelben Hinterkopf und einen metallisch grünen Hinterleib. - Timia punctulata Becker hat keine wasserhellen Flügel. Ebenso Tim. nigripes Mik, deren Stirn überdies keine roten Längsstreifen zeigt.

\section{Timia Reitteri n. sp. ठㅇ.}

$1 \sigma^{\nearrow}$ I $q$ aus Transkaspien, leg. Ahnger. Meine Sammlung.

Kopf gelbrot; Stirn ziemlich steil abfallend, stark wachsglänzend, unbestäubt und unpunktiert, in der Mitte mit einer deutlichen Querfurche. Oben am Augeneck vor den Scheitelborsten je ein glänzend schwarzer Fleck. Ebenso ist der ganze Hinterkopf glänzend schwarz. Die Breite der Stirn kommt der halben Kopfbreife gleich. Eine Behaarung derselben ist kaum sichtbar. Der leistenartige Clypeus ist unten etwas konkav und springt oben nur um den halben wagrechten Augendurchmesser über die Augen vor. Am Mundrande ist er glänzend schwarz oder gelb und nur das Praelabrum schwarz. Rüssel und die relativ kurzen und fadenförmigen Taster schwarz. Die Fühler dagegen sind samt der Arista rotgelb. Die Augen sind lotrecht oval, rundlich, nicht viel höher als lang. - Thorax, Schildchen und Hinterleib glänzend metallisch schwarz. Der Rücken ist unbestäubt, hat aber durch eine äusserst feine Skulptur wenig Glanz. Eine deutliche Punktierung zeigt kein Körperteil. Das Schildchen ist stark gewölbt und hat 4 lange Randborsten. Der Hinterleib hat nur geringen grünlichen Schimmer. Das letzte Segment ist bei $\sigma^{7}$ und $q$ ungefähr $1^{1} \frac{1}{2}$ mal so lang als das vorhergehende. Der Basalteil der Legeröhre ist mit dem letzten Segmente gleich lang. Die Beine sind pechschwarz, die Kniee und die Tarsen gelbrot. Letztere gegen das Ende zu etwas verdunkelt. Die Flügel sind völlig wasserhell und haben gelbe Adern. - Länge 3,5 mıı. - Flügel $3 \mathrm{~mm}$.

A un in rkung: Ich widme diese Art Herrn Redakteur E. Reitter in Paskau, der seinerzeit eine ganze Serie neuer Ulidinen in Transkaspien 
sammeln liess. Dieselben befinden sich teils in der Collectio Mik, teils im K. K. Hofmuseum. - Tim. Reitteri gehört in die Verwandtschaft von erythrocephala Wied. und nigripes Mik, unterscheidet sich aber von beiden sofort durch die ganz wasserhellen Flügel mit den gelben Adern, überdies durch das schwarze Schildchen, von ersterer durch die viel ausgedehnter schwarz gefärbten Beine.

6. Timia Klugi n. sp. (Wiedem. in litt.) ơo.

Aus der Mongolei, leg. Leder. K. K. Museum u. Coll. Winthem.

Ganz von der Grösse und Gestalt der Timia Komarowi Mik, aber von derselben durch den unbestäubten Thoraxrücken, die breiteren Backen, die weiter vorstehende und auffallend runzelige Stirn merklich verschieden. Der ganze Kopf ist rotgelb und sehr stark aufgeblasen. Die Stirn steht um den horizontalen Augendurchmesser vor den Augen vor, ist $4 \mathrm{mal}$ so breit als ein Auge und nackt, glänzend. Ihre Fläclıe zeigt namentlich seitwärts starke Längsrunzeln, welche von feinen Querlinien geteilt werden, und in der Mitte eine grubigrunzelige Skulptur. Die Backen sind dem lotrechten Augendurchmesser an Breite gleich. Die Augen sind $1 \frac{1}{2}$ mal so hoch als lang. Der Ocellenhöcker ist schwarz. Die etwas gebräunten Fühler sitzen dem unteren Augenrande gerade gegenüber. Der Rüssel ist schwarz, die Taster sind braun und ziemlich breit, das Fulcrum schmal und gelb. - Der ganze Thorax und der Hinterleib sind glänzend metallisch blauschwarz; das Schildchen ist glänzend gelb, konvex und trägt nur 2 kurze Borsten. Der Rücken ist dicht mit Stichpunkten versehen, das Abdomen jedoch ganz glatt. Schüppchen weiss, Schwinger gelb. Die Hinterleibssegmente sind ziemlich gleich lang; die Legeröhre ist so lang wie die letzten 2 Segmente zusammen und von der Farbe des Abdomens. - Die Beine sind rotgelb, die Hüften schwarz. Die Spitzen der Vorder- und Hinterschienen, sowie die Füsse aller Beine sind braunschwarz. Nur die Mittelferse ist heller. Alle Schenkel sind unten kurz gedornt. Flügel völlig glasartig mit gelben Adern. - Länge: 8-10 mm, ohne Legeröhre. - Breite des Kopfes $3,5 \mathrm{~mm}$. - Flügel : $6-8 \mathrm{~mm}$.

7. Timia carbonaria n. sp. $\sigma^{x}$.

Aus dem Kaukasus, Araxesthal. Reitter. K. K. Museum.

Kopf ganz rotgelb bis auf die Schläfen an der oberen Augenecke und den Ocellenfleck. Die Stirn springt um 
die Hälfte des wagrechten Augendurchmessers vor, ist doppelt so breit als ein Auge, stark gewölbt, nackt, glänzend und dicht mit runzeliger Skulptur bedeckt. Die Backen sind etwas breiter als die Hälfte des lotrechten Augendurchmessers. Die Augen sind etwas höher als lang. Die Stirnrunzeln setzen sich bis auf die Backen fort. Die Fühler sind rotgelb, die Taster ebenfalls. Der Rüssel dagegen ist schwarz. - Der ganze Thorax und der Hinterleib sind glänzend schwarz. Nur der erstere zeigt wenige und zerstreute Stichpunkte. Schüppchen gelblichweiss, Schwinger gelb. Die Abschnitte des Hinterleibes zeigen bis auf den letzten, welcher den vorhergehenden um dessen Länge übertrifft, gleiche Länge. Die Beine sind pechbraun. Die Knie sind breit rotgelb, ohne scharfe Grenze. Die Füsse sind mit Ausnahme des dunklen letzten Gliedes gelbrot. Flügel wasserklar mit gelben Adern. - Länge: $5 \mathrm{~mm}$. - Flügel : $4 \mathrm{~mm}$ 

Separat-Abdruck aus den "Verhandlungen" der k. k. zoologisch-botanischen Gesellschaft in Wien (Jahrgang 1908). 



\title{
Nouvelle classification des mouches à deux ailes (Diptera L.).
}

\author{
D'après un plan tout nouveau \\ par
}

J. G. Meigen, Paris, an VIII (1800 v. s.).

Mit einem Kommentar herausgegeben von Friedrich Hendel (Wien).

(Eingelaufen am 11. Juni 1907.)

Diese Erstlingsarbeit Meigens gehört wohl zu den größten Seltenheiten der dipterologisehen Literatur und ist mir gegenwärtig außer dem Exemplare Osten-Sackens und meinem eigenen kein anderes zur Kemntuis gekommen. Dies mag auch die Ursache sein, daß sie den Fachkollegen bisher ganz unbekannt blieb und daß die darin beschriebenen Gattungen später gar nicht berticksichtigt, ja nicht einmal von Nomenklatoren zitiert wurden! Ein weiterer Grund scheint mir auch das Vorgehen Meigens selbst zu seim, der seine Arbeit fernerhin nie melı erwähnt und dic darin beschriebenen Gattungen drei Jahre später im II. Bande von Illigers „Magazin“ zum größten Teile umtauft. Da aber nach den Regeln der zoologischen Nomenklatur nach den Beschliissen des VI. internationalen Zoologenkongresses in Bern 1904 eine solche eigenmächtige Abänderung ohne Grund auch dem Autor nicht zusteht, hat diese seltene Erstlingsarbeit Meigens höchstes nomenklatorisches Interesse, da diejenigen Gattungsnamen derselben akzeptiert werden miissen, welche klar und deutlich das Genus erkemnen lassen.

Ich komme daher, schon mehrfach von Fachkollegen gedrängt, meinem in der Wiener Entom. Zeit., 1903, S. 58 gegebenen Versprechen nach und gebe hier aus meinem Exemplare, das Mcigen Chevrolat dedizierte, eine Reproduktion aller Gattungsbeschreibungen mit den Dentungen derselben nach unserer hentigen Nomenklatur.

Prof. Bezzi in Turin bin ieh zu großem Danke verpflichtet, denn er war es, der den Schliissel der Dentungen in Meigens 
zweiter Arbeit, jener in Illigers Magazin, fand. Vergleicht der Leser die in dieser Schrift gegebenen Beschreibungen mit jenen in der Nonvelle Classification, so kann er sich in den meisten Fällen schon durch den fast gleichen Wortlant von der Richtigkeit der von Bezzi und mir gegebenen Synonymie iiberzengen.

Ich labe zu diesem Zwecke unter jede Diagnose der Nouvelle Classification an erste Stelle die Gattung mit der Nummer und Seitenangabe ans Illigers Magazin gestellt und die dort angefiihrten typischen Arten, welche der Erstlingsarbeit fehlen, darunter gesetzt. Erst an zweiter Stelle ließ ich dann andere Synonyma folgen.

Jene Gattungsnamen, welche meiner Anschiauung nach heute zu Recht bestehen, sind fett gedruckt. Wie der Leser sich aber aus folgendem iiberzengen wird, entsteht durch die Annahme der alten Meigen schen Namen eine völlige "Revolution" in der dipterologischen Nomenklatur, die wohl sehr zu bedauern, aber leider nicht $\mathrm{zu}$ vermeiden ist. Fiat iustitia, pereat mundus! Ich kanm mich dem Inhalte der Osten-Sackenschen Arbeit: „Priorität oder Kontinuität" (Wiener Entom. Zeit., 1882, S. 193) nicht anschließen.

In der Nouvelle Classification sind nicht oder nur zweifelhaft folgende Gattungen aus Illigers Magazin, II, 1803 enthalten:

2. Corethra, p. 260 (Tipula culiciformis Deeg.).

26. Hexacantha, p. 264 (Stratiomys clavipes und 6-dentata Fab. $==$ Beris Latr., 1802.

32. Nemotelus, p. 265 (Nem. uliginosus Fab.).

34. Pachygaster, p. 266 (Nem. ater Panz.).

35. Acrocera, p. 266 (S. globosus Panz.).

36. Henops, p. 266 (S. gibbosus Fab.) = Ogcodes Latr., 1796.

38. Heptatoma, p. 266 (Tabanus Schaeff., Icon., Tab. 72, Fig. 6-8). Anmerkung 22.

42. Tanyglossa, p. 267 (Tab. haustellatus Fab.) = Pangonia Latr., 1794.

44. Phthiria, p. 268 (Bomb. pulicaris Mikan).

45. Conophorus, p. 268 (Bomb. maurus Mikan) = Ploas Latr.

46. Cytherea, p. 268 (Cyth. obscura Fab.) = Mutio Latr., 1796.

56. Dioctria, p. 270 (Asil. oelandinus, linearis, hyalipennis etc. Fab.). 
58. Toxophiora, p. 270.

64. Atherix, p. 271 (Rhagio diadema et cinctus F.).

67. Satyra, p. 272 (MTusca ungulata F.). Anm. 7.

73. Heliophilus, p. 273 (Syrph. sylvarum etc. F.).

76. Doros, p. 274 (S. conopseus F. et coarctatus Panz.).

83. Microdon, p. 275 (Mulio mutabilis F.).

84. Chrysotoxum, p. 275 (Mulio arcuatus et bicinctus F.).

85. Loxocera, p. 275 (Mulio ichneumoneus F.).

88. Trineura, p. 276.

90. Thyreophora, p. 276 (Musca cynophila Panz.).

93. Platystoma, p. 277 (MLusca seminationis F.).

96. Chamaemyia, p. 278.

98. Psila, p. 278.

99. Macrochira, p. 278 (Musca manicata F.) = Ochthera Latr., 1803.

101. Melanophora, p. 279 (M. grossificationis F.).

102. Leucostoma, p. 279.

103. Eriothrix, p. 279 (M. lateralis F.). Anm. 19.

104. Cylindromyia, p. 279 (M. brassicaria F.). Anm. 20.

107. Metopia, p. 280 (M. leucocephala Panz.).

108. Exorista, p. 280 (M. larvarum F.). Anm. 21.

109. Mriltogramia, p. 280.

111. Anthomyia, p. 280 (M. meditabunda, pluvialis etc. F.).

Welche Gattungen aus der Nonvelle Classification später im "Míagazin" nicht mehr enthalten sind, ist aus der folgenden Übersicht selbst zu entnehmen.

\section{Flabellifera. (S. 13.)}

Antennes à treize articulations: la première eylindrique; la seconde sphérique; la troisième un peu alongée; les suivantes avec des appendices en forme de peigne (le mâle), ou presque sphériques (la femelle). - Ailes à demi-étalées, lancéolées. - Les vers vivent dans les trones d'arbres pourris.

4 espèces.

= 15. Ctenophora Meig., p. 263.

Arten: Tip. pectinicornis, bimaculata, atrata, flaveolata ete. Fab. 
2. Tipula. (S. 14.)

Antennes à treize articulations: la première cylindrique; la seconde spluérique; les suivantes eylindriques, hérissées de poils i la base. - La tête alongée par devant. - Les jambes longues. - Les ailes ‘ demi-étalées. - Les vers vivent dans la terre.

14 espèces.

$=$ 12. Tipula L., p. 262.

Arten: T. simuata, Junata, hortorm, connicina, crocata etc. Fab.

3. Polymeda. (S. 14.)

Antennes ì seize articulations velues: la première cylindrique; les suivantes ovoïdes, diminuant en grandenr. - Les jambes longues. - Les ailes panachées, croisées.

11 espèces.

$=$ 10. Erioptera Meig., p. 262.

Kein Typus.

4. Liriope. (S. 14.)

Antennes ì seize artieulations, velues et legèrement liérissées de poils: la première petite, cylindrique; la seconde sphérique; la troisième longue, cylindrique; les suivantes ovoüdes.

2 espèces.

= 14. Ptychoptera Meig., p. 262.

Arten: Tip. contaminata, allimana.

5. Pales. (S. 14.)

Antennes i dix-neuf articulations: la première cylindrique; la seconde eyathiforme; la troisième cylindrique; les suivantes réniformes; vers l'extrémitė presque eylindriques, hérissée de poils.

1 espèce.

$=13$. Neplirotoma Meig., p. 262.

Art: Tip. dorsalis Fab.

6. Orithea. (S. 15.)

Antennes a quinze articulations: la première cylindrique; les antres sphériques. - Les jambes très longues, sans piquans.

1 espèce. 
7. Amplinome. (S. 15.)

Antennes a seize artieulations hérissées de poils: la première cylindrique; la seconde presque sphérique; les suivantes ovoïdes. - Les jambes longues. - Les ailes croisées.

5 espèces.

= 11. Limonia Meig., p. 262.

Arten: Tip. tripunctata, 6-punctata, 4-maculata, replicata, rivosa ete. Fab.

$=$ Limnotia Meig., 1818.

Anm. 1.

8. Petaurista. (S. 15.)

Antennes sétacées, légèrement velues; les denx premieres artieulations grôsses, presque sphériques; les suivantes oblongues, d'un nombre indéterminé. - Les ailes croisées. - Les ieux lissent mauquent.

\section{2 espèces.}

= 9. Trichocera Meig., p. 262.

Art: Tip. hiemalis Deeg.

\section{Euphrosyne. (S. 16.)}

Antennes deux fois longues comme le corps, très delićes, velıe: la première articulation sphérique; les suivantes eylindriques, d'un nombre indéterminé. - Les ailes croisées. - Les ienx lisses manquent.

1 espèce.

= S. Macrocera Meig., p. 261.

Art: Tip. longicornis?

Anm. 2.

10. Phryne. (S. 16.)

Antennes à seize articulations velues: la première cylindrique; les suivantes presque sphériques. - Sur le sommet de la tête, trois ieux lisses. - Les ailes eroisées.

5 espèees.

= 21. Anisopus Meig., p. 264. - Kein Typus.

- Rihyphus Latr., 1804. 


\section{Zelmira. (S. 16.)}

Antennes ì seize articulations presqu'égales, légèrement velues. - Les jambes garnies à l'extrêmité du tibia de deux piquans. Trois ieux lisses sur la tête, et d'inégale grandeur. - Les ailes croisées.

3 espèces.

$=20$. Platyura Meig., p. 264.

Kein Typus.

12. Fungivora. (S. 16.)

Antennes ì treize articulations: les deux prenières hérissées de poils roides; les suivantes velues. - Le tibia des jambes du milieu et postérieures armé de piquans. - Les icux lissent manquent. - Le corps comprimé. - Les ailes croisćes. - Les vers vivent dans les cliampignons.

6 espèces.

= 16. Mycetophila Meig., p. 263.

Arten: Tipula fungivora, agarici Deeg.

13. Lycoria. (S. 17.)

Antennes à seize articulations, légèrement velues: les deux premières plus grôsses que les suivantes qui sont cylindrique. Les ieux a réseau réniformes. - Trois ieux lisses sur le sommet. - Les ailes croisées.

6 espèces.

= 19. Sciara Meig., p. 263.

Art: Hirtea Thomae F.

\section{Tendipes. (S. 17.)}

Antennes filiformes: celles du mâle garnies de longs poils en forme de cône; celles de la femelle à six articulations, qui (à l'exception de la dernière) sont hérissées de poils à leur bâse. - Les ieux à réseau réniformes. - Les ieux lisses manquent. - Les jambes antérieures étendues. - Les ailes portées en toit. - Les vers (du moins en partie) vivent dans l'eau.

20 espèces. 
= 3. Chironomus Meig., p. 260.

Arten: Tip. plumosa, motitatrix, vibratoria etc. Fab.

\section{Pelopia. (S. 18.)}

Antemnes du mâle filiformes, garnies de longs poils en forme de cône; celle de la femelle à quinze articulations qui sont sphériques, seulement la dernière est plus grôsse et oblongue. - Les ieux à réseall réniformes. - Les ieux lisses manquent. - Les ailes portées en toit.

3 espèces.

= 4. Tanypus Meig., p. 261.

Arten: Tip. cincta F. et maculata Deeg.

Anm. 3.

\section{Helea. (S. 18.)}

Antennes filiformes a treize artieulations, dont les premières sont sphériques et les suivantes oblongues: celle dı mâle garnies de longs poils en forme de pinceau; celles de la femelle velues. Les ieux ì réseau réniformes. - Les ieux lisses manquent. - Les ailes portées en toit.

11 espeees.

= 5. Ceratopogon Meig., p. 261.

Art: Tip. barbicomis F.

17. Phalaemila. (S. 18.)

Antennes filiformes en grains: les deux premières articulations oblongutus, grôsses, glabres; les autres enfilées, hérissées de poils. - Les ailes velues, larges, portées en toit.

2 espèces.

$=7$. Trichoptera Meig., p. 261.

Arten: Tip. phalaenoides et hirta F.

- Psychoda Latr., 1796.

\section{Itonida. (S. 19.)}

Antennes longues ì vingt-quatre articulations, enfilées, lérissées de poils: la première grôsse, glabre.

2 espèces.

Z. B. Ges, 58. Bd. 
=6. Cecidomyia Meig., p. 261.

Art: Tip. pini Deeg.

19. Culex. (S. 19.)

Antennes filiformes, eomposées d'un grand nombre d'articulations plumenses (lc mâle), ou hérissées de poils ì la base (Ia femelle). - La trompe perpendienlaire. - Les ieux lisses manquent. - Les ailes croissées, garnies d'écailles. - Les vers vivent dans l'eau.

6 espèces.

$=1$. Culex L., p. 260.

Arten: Cul.pipiens, annulata $\mathrm{F}$.

20. Polyxena. (S. 19.)

Antennes à douze articulations, eylindriques, obtuses. - Les jambes longutes. - L'extrêmité du tibia armée de denx piquants. - Les ailes croisées.

1 espèce.

$=17$. Cordyla Meig., p. 262.

Kein Typus.

21. Melusina. (S. 19.)

Antennes en forme de fuseau, ì onze articulations. - Les ieux lisses manquent.

1 espèce.

$=18$. Atractocera Meig., p. 263.

Art: Tip. regelationis.

$=$ Simulium Latr., 1802.

22. Amasia. (S. 20.)

Antennes filiformes à onze articulations. - Les ieux à réseau ovales. - Sur le sommet trois ieux lisses.

1 espiece.

$=$ 22. Penthetria Meig., p. 264.

Kein Typus. 
23. Scathopse. (S. 20.)

Antennes à onze artieulations. - Les ieux à résean réniformes. - Sur le sommet trois ieux lisses. - Les ailes eroisées.

3 espèces.

= 23. Scathopse Geoffr., p. 264.

Art: Tip. Zatrinarum Deeg.

\section{Iirtea. (S. 20.)}

Antennes à neuf articulations. - Le tibia des jambes antérieures garni ì l'extrêmité d'un piquant. - Trois ieux lisses sur le sommet. - Les ailes eroisées. - Les vers vivent en terre.

9 espèces.

= 24. Hirtea Meig., p. 264.

Arten: Hirt. marci, pomonae ete. F.

= Bibio Geoffi., 1764.

\section{Philia. (S. 20.)}

Antemnes à neuf artienlations. - Le corselet armé de denx rangs de piquants. - Le tibia des jambes antérieures armé à l'extrêmité de sept piquans en forme de rayons. - Trois ieux lisses sur le sommet. - L Les ailes eroisées.

3 espèces.

= 25. Dilophus Meig., p. 264.

Kein Typus.

\section{Erinna. (S. 21.)}

Antennes eylindriques a trois articulations: la première eylindrique; la seeonde eyathiforme; la troisième légèrement divisée en huit pièces qui diminuent en longueur. - Éeussons sans piquans. - Les ailes eroisées. - Les vers vivent dans les trones d'arbres pourris.

2 espèees.

$=37$. Xylophagus Meig., p. 266.

Art: Nemotelus cinctus Deeg. 
27. Sicus. (S. 21.)

Antennes en forme de fer d'alène ì trois articulations: la première cylindrique; la seconde cyathiforme; la troisième légèrement diviscée en huit pièces, diminuant en grôsseur. - Écussons avec denx piquans. - Les ailes croisées.

3 espèces.

= 27. Sicus F., p. 265.

Art: Sic. ferrugineus Fabr.

= Coenomyia Latr., 1796.

\section{Eulalia. (S. 21.)}

Antennes cylindriques ả trois articulations: les denx premières de même grandeur, hérissées de poils; la troisième longue, légèrement divisée en cinq pièces. - Écusson armé de deux piquans. - Les ailes croisćes. - Les vers vivent dans l'eau.

5 espèces.

= 29. Odontomyia Meig., p. 265.

Arten: Strat. furcata, tigrina, hydroleon F.

\section{Stratiomys. (S. 22.)}

Antennes à trois articnlations: la première longue, eylindrique; la seconde petite, cyathiforme; la troisième longuc, plate, légèrement divisée en cinq pièces. - Écusson armé de deux piquans. - Les ailes croisées. - Les vers vivent dans l'eau.

5 espèces.

= 28. Stratiomys Geoffi., p. 265.

Arten: Strat. strigata, chamaeleon etc. Fabr.

\section{Potamida. (S. 22.)}

Antennes en forme de fer d'alène ì trois articulations: les deux premières petites, d'égale grandeur, hérissées de poils; la troisième longue, nue, diviséc légèrement en sept pièces. - Corselet et écusson armés de piquans. - Les ailes croisées.

1 espèce. 
$=30$. Clitellaria Meig., p. 265.

Art: Strat. ephippium Fab.

= Ephippium Latr., 1809.

\section{Hermione. (S. 22.)}

Autennes à trois articulations: la première longue, cylindrique; la seconde en eône renversé; la dernière avec un poil latéral simple. - Éensson armé de deux petits piquans. - Les ailes eroisées. 3 espèces.

= 31. Oxycera Meig., p. 265.

Arten: Strat. hypoleon et trilineata F.

$=$ Hypoleon Dumeril, 1801 (see. O.-S.).

\section{Ceria. (S. 23.)}

Antennes fléehués en eoude ì trois articulations: la première longue, eylindrique; les deux autres applaties, élargies; la dernière se termine en pointe aiguë.

1 espèce.

$=60$. Ceria F., p. 271.

Art: Cer. clavicornis F.

\section{Chrysops. (S. 23.)}

Antennes eylindriques a trois articulations: les deux premières d'égale longueur, hérissées de poils; la troisième légèrement divisée en plusieurs pièces. - Les ieux ì réseau d'un beau vert doré, tachetés. - Trois ieux lisses sur le sommet. - Les ailes ì demiétalées.

5 espèces.

= 39. Chrysops Neig., p. 267.

Art: Tab. caecutiens F.

\section{Chrysozona. (\$. 23.)}

Antennes en forme de fer d'alène i trois artienlations: la première oblongue; la seconde très-petite, cyathiforme; la troisième avec quelques incisions très-légères ver's l'extrêmité. - Les ieux 
à résean verds avee des bandes ondées. - Les ienx lisses manquent. - Les ailes à demi-étalées.

2 espèces.

= 40. Haematopota Meig., p. 267.

Art: Tab. pluvialis F.

35̃. Tabanus. (S. 24.)

Antennes à trois articulations: les denx premières cyathiformes; la troisième échanerée, articulée ì l'extrêmité. - Trompe perpendiculaire. - Les ailes à demi-étalée. - Les vers vivent en terre.

9 espèces.

= 41. Tabanus L., p. 267.

Arten: Tab. bovinus, morio, autumnalis, tropicus, bromius etc. F.

\section{Bilio. (S. 24.)}

Antennes en forme de fer d'alène à trois articulations: la première cylindrique; la seconde sphérique; la troisième conique. - Trois ieux lisses sur la tête. - Écusson sans piquans. - Les ailes ì demi-étalées. - Les vers vivent dans les trones d'arbres pourris.

5 espèces.

$=48$. Bitio F., p. 268.

Arten: B. nolititata, anilis, lugubris ete. F.

= Thereva Latr., 1796.

\section{Dionnaea. (S. 24.)}

Antennes en forme de fer d'alène à trois articulations: la premières oblongue; la seconde sphérique; la troisième conique. Trompe perpendiculaire. - Les ailes croisées, très-larges.

2 espèces.

= 49. Platyptera Meig., p. 269.

Arten: Empis borealis et platyptera Panz.

Anm. 4. 


\section{Empis. (S. 25.)}

Antennes en forme de fer d'alène à cinq articulations: la première eylindrique; la seconde presque sphérique; la troisième conique; les deux dernières petites. - Trompe perpendiculaire. Les ailes croisées.

24 espèces.

$=50$. Empis L., p. 269.

Arten: E. pennipes, livida etc. F.

$$
\text { 39. Asilus. (S. 25.) }
$$

Antennes en forme de fer d'alène ì cinq articulations: la première eylindrique; la seconde cyathiforme; la troisième longue, applatie, élargie au milieux; les quatrième et cinquième petites, en forme de poil roidi. - Trompe presque horizontale. - Les ailes croisées. - Les vers vivent en terre.

7 espèces.

= 54. Asilus L., p. 269.

Arten: As. craboniformis, barbatus, germanicus.

40. Lapria. (S. 25.)

Antennes it trois articulations: la première cylindrique, longue; la seconde cyathiforme; la troisième en forme de massue plate. Trompe presque horizontale. - Les ailes croisées. - Les vers vivent en terre.

5 espèces.

= 57. Lapheria Meig., p. 270.

Arten: As. gibbosus, gilvus, flavus, chinipuium, violaceus, marginatus ete. Fabr.

Anm. 5.

\section{1. $\operatorname{Erax}$ (S. 26.)}

Antennes à quatre articulations: la première cylindrique, longue; la seconde cyathiforme; la troisième longue, plate; la dernière petite. - Trompe presque horizontale. - Les ailes croisćes. 10 especes. 
$=$ 55. Dasypogon Meig., p. 270.

Arten: As. teutoms, diadema etc. Fab.

\section{Conops. (S. 26.)}

Antennes i trois articulations: la première cylindrique; les deux autres en forme de massue, terminée par une pointe articulée. - Trompe presque horizontale. - Les ailes croisées.

3 espèces.

$=59$. Conops L., p. 270.

Arten: C. macrocephala, aculeata, vittata, flavipes ete. Fab.

\section{Myopa. (S. 26.)}

Antennes eylindriques it trois articulations: la première petite; la seeonde cylindrique, velue; la troisième sphérique ou un pen ovoïde, garnie d'un petit poil articulé. - 'Trompe presque horizontale. - Tête gonflée. - Les ailes eroisées.

9 espèces.

$=61$. Myopa F., p. 271.

Arten: Mr. ferruginea, testacea F.

\section{Coryneta. (S. 27.)}

Antennes à deux articulations: la première petite, hérissée de poils; la seconde conique, terminée par un poil barbu. - Trompe perpendiculaire. - Cuisses des jambes du milien enflées. - Le tibia armé à l'extrêmité d'un piquant. - Les ailes eroisées.

3 espèces.

$=52$. Tachydromia Meig., p. 269.

Arten: IIusca cursitans, cimicoüdes Fab.

Anm. 6.

\section{Noeza. (S. 27.)}

Antennes à denx articulations: la première petite, hérissée de poils; la seconde conique, terminée par un poil barbu. - Trompe horizontale. - Les ailes eroisées.

3 espèces. 
$=51$. Hybos Meig., p. 269.

Kein Typus.

$$
\text { 46. Iphis. (S. 27.) }
$$

Antennes a trois articulations: la première ovoïde; la seconde eyathiforme, hérissée de poils; la troisième applatie, de figure variable, terminée par un poil légèrement barbu. - Tête hémisphérique. - Jambes alongées. - Tibia garni de petits poil roides dı côté intérieur. - Les ailes croisées. - Les vers vivent en terre.

6 espèces.

= Dolichopus Latr., 1796.

Anm. 7.

47. Surgus. (S. 28.)

Antennes à trois articulations: les denx premières courtes, hérissées de poils roides; la troisième en forme de palette avee trois incisions, terminée par un poil un peu barbu à la bâse. Les ienx châtains, bandés de violet. - Les ailes croisées. - Les vers vivent dans les bouses de vaches.

5 espèces.

= 33. Sargus Fab., p. 266.

Arten: S. cumarius, auratus ete. Fab.

\section{Iihagio. (S. 28.)}

Antennes à trois articulations: les deux premières sphériques; la troisième conique, terminée par un poil long, recourbé et barbu. - ''ête presque hémisphérique. - Les ieux sans bande. - Ailes à demi-étalées. - Les vers vivent en terre.

7 espèces.

$=63$. Rhagio F., 1775, p. 271.

Arten: Rh. scolopaceus, tringarius ete. Fab.

$=$ Leptis Fab., 1805.

Anm. 23.

$$
\text { 49. Anthrax. (S. 28.) }
$$

Antennes at trois articulations: la première cylindrique on un peu oblongue; la seconde sphérique; la troisième conique, terminée 
en pointe droite. - Tête sphérique. - Corps velı. - Les ailes étalées.

7 espèees.

$=47$. Anthrax Scop., p. 268.

Arten: A. maura, morio, hottentotta etc. F.

\section{Oestrus. (S. 29.)}

Antennes placées en deux eavités presque sphériques, à trois artieulations: la dernière garnie à l'extrêmité d'un poil simple. Les ailes un pen étalées. - Les vers vivent dans le eorps ou sous la peau des quadrupèdes.

3 espèces.

$=69$. Oestrus L., p. 272.

Arten: Oestr. Zovis, haemorrhoidalis etc. F.

\section{Bombylius. (S. 29.)}

Antennes $\dot{a}$ trois artieulations: la première eylindrique; la seconde sphérique; la troisième longue, plate, terminée en pointe. - Trompe horizontale, très-longue. - Tête sphérique. - Les ailes étalées.

6 espèces.

$=43$. Bombylius L., p. 267.

Arten: B. discolor, concolor, simuatus ete. F.

52. Omphrale. (S. 29.)

Antennes inclinées à deux articulations: la première eyathiforme; la seconde presque eylindrique, obtuse. - Le corps applati.

1 espèce.

$=70$. Iypselura Meig., p. 273.

Art: MIusca senilis F.

= Scenopinus Latr., 1803.

53. Clythia. (S. 30.)

Antennes à trois articulations: les deux premières cyathiformes, hérissées de poils; la troisième en palette, terminée par un 
poil simple. - Tarses des jambes postérieures élargies. - Ailes obtuses, croisées.

1 espèce.

$=65$. Platypeza Meig., p. 272.

Kein Typus.

54. Musidora. (S. 30.)

Antennes à trois articulations: les deux premières cyathiformes, hérissées de poils roides; la troisième en palette, terminée par un poil barbu. - Jambes longues, minces. - Ailes lancéolées, croisées.

2 espèces.

$=66$. Lonchoptera Meig., p. 272.

Kein Typus.

55. Cleona. (S. 30.)

Antemnes à trois articulations: les deux premières cyathiformes, hérissées; la troisième conique, terminée par un poil barbu. - Ailes lancéolées, croisées.

1 espèce.

?= Callimyia Meig., 1804 .

Anm. 8.

56. Cypsela. (S. 31.)

Antennes à deux articulations: la première petite, hérissée de poils; la seconde en palette ronde, garnie à la bâse d'un poil barbu. - Ailes croisées. - Tarses des jambes postérieures élargis. - Les vers vivent dans les cxcrémens et les cadavres.

4 espèces.

$=$ 89. Borborus Micig., p. 276.

Kein Typus.

57. Dorilas. (S. 31.)

Antennes ì deux articulations: la seconde inclinée, garnie à la bâse d'un poil simple. - 'Tête hémisplıérique. - Ailes croisées, obtuses.

1 espèce. 
$=71$. Microcera Meig., p. 273.

Kein Typus.

= Pipunculus Latr., 1802.

58. Atalanta. (S. 31.)

Antennes à trois articulations, en forme de cône, terminées par un poil barbu, recourbé. - Ailes croisées, obtuses.

1 espèce.

= 62. Clinocera Meig., p. 271.

Kein Typus.

$$
\text { 59. Tylos. (S. 31.) }
$$

Antemnes à deux articulations: la première petite; la seconde en palette ronde, avec un poil long et barbu à la bâse. - La tête prolongée en cône. - Jambes minces. - Les ailes croisées.

1 espèce.

$=$ ? 86. Micropeza Meig., p. 276.

Art: Musca corrigiolata Fab.

\section{Iihingia. (S. 32.)}

Antennes a trois articulations: la dernière en palette, avec un poil simple à la bâse. - La bouche prolongée en cône qui reçoit la trompe articulée. - Les ailes croisées.

1 espece.

$=72$. Rhingia Scop., p. 273.

Art: $T i l$. rostrata.

\section{Chrysogaster. (S. 32.)}

Antennes a trois articulations: la troisième en palette, avec IIn poil simple à la bâse. - Le front crénelé. - L'abdomen plat, ovale. - Les ailes croisées.

4 espèces.

$=80$. Chrysogaster Meig., p. 274.

Arten: Syrph. coemiteriorum, metallinus, umbrarum Fab. 


\section{Antiopa. (S. 32.)}

Antennes inelinées a trois artienlations: les deux premières petites, hérissées; la troisième longue, presque prismatique, garnie à la bâse d'un poil long, barbu. - Balaneiers nus. - Corps presque glabre. - Ailes croisées.

3 espèces.

?= 84. Chrysotoxum Meig., p. 275 (Bezzi).

\section{Thereva. (S. 33.)}

Antennes petites, perpendiculaires, à deux articulations de même grandeur, eylindriques: la seconde avec un poil simple ì la bâse. - Ailes larges. -- Balanciers eouverts d'une éeaille.

6 espèces.

= 91. Thereva Fab., p. 277.

Arten: Th. hemiptera, affinis etc. F.

= Allophora R. D., 1830.

\section{Syrphus. (S. 33.)}

Antennes a trois articulations: la dernière en palette avec un poil simple à la bâse. - Balanciers eouverts d'une petite écaille. - Ailes croisées. - Les vers vivent de pucerons.

45 especes.

= 81. Syrphus L., p. 275.

Arten: S. myrastri, ribesii, ruficomis, nectareus etc. Fab.

65. Tritonia. (S. 33.)

Antennes a trois articulations cylindriques: la troisième un peu compriméc avec un poil simple ì la bâse. - Ailes croisées. - Corps nu.

4 espèces.

$=74$. Spilomyia Meig., p. 273.

Arten: S. diophthalmus et vespiformis F.

Anm. 9. 
66. Zelima. (S. 34.)

Antennes it trois artienlations: la dernicre en palette oblongne, garnie d'un poil simple à la bâse. - Cuisses des jambes postérieures armées d'un rang' de piquans. - Ailes croisées.

2 espèces.

$=75$. Eumeros Meig., p. 273.

Arten: S. segnis, pipiens F.

$=$ Tylota Meig., 1822.

Anm. 10.

\section{Lampetia. (S. 34.)}

Antennes i trois articulations: la dernière en palette, garnic ¿̇ la bâse d'un poil simple. - Cuisses des jambes postérieures enflées, armées à l'extrômité d'une dent. - Les ailes ì demi-étalées.

3 espèces.

$=77$. Merodon Meig., p. 274.

Arten: S. equestris, curvipes F.

\section{Tubifera. (S. 34.)}

Antennes ì trois articnlations: la dernière en palette garnie à la bâse d'un poil ou simple, ou un peu barbı. - Cuisses des jambes postérieures un peu comprimées. - Ailes à demi-étalées, resplendissantes. - Les vers vivent dans l'can et les immondices. (Vers à queue de rat. Réaumur.)

12 espèces.

$=78$. Elophilus Meig., p. 274.

Arten: S. tenax, nemorum, floreus, pendulus Fab.

= Eristalis Latr., 1804.

Anm. 11.

\section{Cinxia. (S. 35.)}

Antennes à trois articulations: la dernière en palette, garnie ¿ la bâse d'un poil plumeux. - Ailes croisées.

4 espèces.

$=$ 79. Sericomyia Mcig., p. 274.

Arten: S. mussitans et lapponum F.

Anm. 11. 


\section{Penthesilea. (S. 35.)}

Antennes à trois articulations: la dernière en palette ovale, garnie ì la bâse d'un poil simple. - Cuisses des jambes postérieures enflées, sans piquans. - Ailes croisées.

1 espèce.

= Criorthina Meig., 1822.

Anm. 12.

\section{Trepidaria. (S. 35.)}

Antennes à deux articulations: la seconde oblongue, obtuse, garnie à la bâse d'un poil légèrement barbu. - Tête presque splhérique. - Front large. - Ailes redressées. - Corps cylindrique, glabre.

3 espèces.

= 87. Calobata Meig., p. 276.

Arten: Musca calobata Panz. et petronella F.

$=$ Ceyx Dumeril, 1801 (sec 0.-S.).

\section{Titania. (S. 35.)}

Antennes à deux articulations: la seconde oblongue, obtuse, garnie à la bâse d'un poil barbu. - Front large. - Ailes croisées. - Corps glabre, plat.

7 espèces.

= 97. Chlorops Meig., p. 278.

Kein Typus.

Anm. 13.

73. Scopeuma. (S. 36.)

Antennes id denx articulations: la seconde prismatique, un poil barbu à la bâse. - Front large. - Tête sphérique. - Corps velu. - Ailes croisées. - Les vers vivent dans les excréments. 7 espèces.

= 95. Scatophaga Meig., p. 277.

Art: Musca merdaria $\mathrm{k}$. 
74. Statinia. (S. 36.)

Antennes à deux articulations: la seconde échancrée, avec un poil plumeux à la bâse. - Tête sphérique. - Front large. Ailes croisées, réticulées.

3 espèces.

= 92. Dictya Meig., p. 277.

Arten: M. cucullaria, umbrarum F.

= Tetanocera Dum., 1798, sens. lat.

Anm. 24.

75. Euribia. (S. 36.)

Antennes à deux articulations: la seconde oblongue, avec un poil légèrement barbu à la bâse. - Front large. - Ailes croisées, tachetées et bandées. - Tarrière de la femelle longue, corneuse. - Les vers vivent dans les semences etc.

18 espèces.

= 94. Trypeta Meig., p. 277.

Arten: MI. arnicae, cerasi, urticae, artemisiae etc. $\mathrm{F}$. Anm. 14.

\section{Apivora. (S. 37.)}

Antennes ì deux articulations: la seconde prismatique, garnie ¿̇ la bâse d'un poil long, très-plumenx. - Bonche prolongée. Corps velu. - Les vers vivent dans les nids des bourdons et abeilles sanvages.

5 espèces.

$=82$. Pterocera Meig., p. 275.

Arten: S. inanis, pellucens, inflatus, bombylans etc. F.

= Volucella Geoffr., 1764.

\section{MIusca. (S. 37.)}

Antennes id deux articulations: la seconde prismatique, garnie ¿ la bâse d'un poil plumeux ou barbu. - Corps hérissé de poils. - Balanciers converts d'une écaille. - Les ver's vivent dans les cadavres, le fumier etc.

70 espèces. 
$=110$. Musca L., p. 281.

Arten: M. domestica, camaria, caesar etc. F.

78. Salpyga. (S. 37.)

Antemnes ì trois articulations: la dernière oblongue, avec un poil très-peu barbu ì la bâse. - Balanciers converts d'une écaille. - Corps hérissé de poils roides. - Ailes à demi-étalées.

6 espèces.

\section{Titia. (S. 38.)}

Antennes petites, à trois articulations, ovoïdes, de même grandeur: la dernière avec 1 n poil simple à la bâse. - Corps hérissé de poils. - Ailes à demi-étalées.

1 espèce.

\section{Salmacia. (S. 38.)}

Antennes à deux articulations: la seconde longue, prismatique, garnie à la bâse d'un poil simple, fléchi en coude. - Balanciers couverts d'une écaille. - Corps hérissé de poils roides.

1 espèce.

$=106$. Gonia Meig., p. 280.

Kein Typus.

\section{Echinodes. (S. 38.)}

Antennes à trois articulations: la dernière plate, élargie, avec un poil simple à la bâse articulé. - Corps hérissé de poils. Ailes à demi-étalées. - Les vers vivent dans les bouses des vaches.

5 espèces.

$?=103$. Eriothrix Meig., p. 279.

Art: Musca lateralis F.

= Oliviera R. D.

Anm. 19.

82. Larvaevora. (S. 38.)

Antennes à deux articulations: la seconde prismatique avec un poil simple à la bâse. - Corps hérissé de poils roides. -Ailes à demi-étalées. - Les vers vivent dans les chenilles ete.

25 espèces.

Z. B. Ges. 58. Bd. 
$=105$. Tachina Meig., p. 280.

Arten: MI. grossa, fera, lurida etc. F.

Anm. 16.

83. Rhodogyne. (S. 39.)

Antennes inclinées à trois articulations: la première petite; la seconde longtue, hérissée de poils; la troisième lancéolée, obtuse, avec un poil simple a la bâse. - Le corps glabre. - Ailes à demi-étalées.

2 espèces.

$=100$. Gymnosoma Meig., p. 278.

Art: $M \Gamma$. rotundata $\mathrm{F}$.

\section{Crocuta. (S. 39.)}

Antennes à deux articulations: la seconde longule, comprimée, obtuse, un poil simple à la bâse. - Trompe horizontale, articulée. - Ailes à demi-étalées.

1 espèce.

$=113$. Siphona Meig., p. $281=$ Bucentes Latr.

Anm. 15.

\section{Calirrhoe. (S. 39.)}

Antemnes à deux articulations: la seconde prismatiques, mn poil plımenx à la bâse. - Trompe horizontale. - Ieux ovales. - Ailes ì demi-étalées.

1 espèce.

$=$ Prosena St. Farg. et Serville, 1825 .

Anm. 17.

\section{Stomoxys. (S. 40.)}

Antennes à denx articulations: la seconde prismatique, un poil plumenx à la bâse. - Trompe horizontale. - Ienx réniformes. - Ailes ì demi-étalées.

1 espèce.

$=112$. Stomoxys, p. $2 \mathrm{~s} 1$. 
87. Hippobosca. (S. 40.)

Antennes très-petites, filiformes. - Trompe droite, filiforme. Corps plat. - Ailes un peu étalées.

3 espèces.

= 114. Hippobosca L., p. 281.

Sans antennes.

88. Cyanea. (S. 40.)

1 espèce.

Anm. 18.

\section{Anmerkungen.}

1. Amphinome Meigen ist durch Amphinoma Brug., Encyel. méth., 1789 (Vermes), präiokupiert, da nach den Regeln Schluß- $\eta$ gleich ist $\alpha$.

2. Diese Synonymie scheint mir persönlich nicht ganz sicher zu sein.

3. Tipula cincta ist eine Rhyphus-Art.

4. Empis platyptera gehört zu Rhamphomyia Meig., 1822.

5. Lapria wird wohl nur ein Druckfehler sein fiur Laphria.

6. Musca cursitans gehört zur Gattung Platypalpus Macqu., 1827.

7. Bezzi schreibt: "I Iphis kann sowohl 67. Satyra wie 68. Rhamphomyia sein. Jedenfalls ist es aber ein Synonym zu Dolichopus."

S. Bezzi sagt hier: "Kann nur Callimyia sein. Diese Gattung felılt in Illigers Magazin und ist erst 1804 in der Klassifikation zu finden."

9. Tritonia ist schon von Cuvier, Tabl. élém., 1798, an ein Molluskengenus vergeben.

10. Zelima ist gleich Eumerus Meig., 1803 und nach den angefuihrten typischen Arten auch gleich Xylota Meig., 1822 + Syritta St. Farg. et Serv., 1825. Eumerus Meig., 1822 entluält keine der zwei Arten Syrphus segnis und pipiens F. und miißte eigentlich neu benannt werden, da Eumerus 1803 unter die Synonyme fällt. Nach obigem hat aber auch Xylota Meig., 1822 fiir Syritta St. Farg. et Serv., 1825 einzutreten. Beachte auch den Sinn der folgenden Anmerkung.

11. Belïßt man den II eigenschen Namen Helophilus für die Arten Syrphus floreus und pendulus, obwohl Tubifera = Elophilus mit gleichem Umfange, so miißte damn auch konsequenterweise (Anı. 4) Platyptera Veig., 1803 für Thamphomyia Meig., 1822 (Anm.6), Tachydromyia Meig., 1803 fiil Platypalpus Nacqu., 1827, Scricomyia Meig., 1803 fiir Arctophila Schin., 1860 gesetzt werden, was meiner Ansicht nacl nicht richtig wäre, la eben die Namen in Illigers "Nagazin" mit Unrecht gegeben, d. h. umgeändert wurden und bloß Synonyme zu den älteren der Kalassifikation sind.

12. Bezzi schreibt: $?=73$. Heliophilus. Kann nur Criorrhinu ruficauda sein." 
13. In Illigers Magazin spricht Meigen von einer nackten Borste, was den 'Tatsachen entspricht. Ich behalte daher den Namen Chlorops bei.

14. Der Meigensche Gattungsbegriff Euribia = Trypeta umfaßt eigentlich die gauze Subfamilie Trypetinae, weshalb es sehr schwer ist, einen so alten Namen einer hentigen Gattung olme gewisse Bedenken zu geben. Die angefihrten typischen Arten gehüren der Reihe nach in folgende hentige Genera: I'ephritis, Rhagoletis, Ceroxys (Anacampta), Spilographa, worans ersichtlich ist, daß die Gattung Trypeta, wie wir sie heute anffassen, keine dieser vier Arten enthïlt. Da aber Meigen nach den vier Arten - ete. setzt, so könnte man diesem Umstande nicht allzuviel Wert beilegen, sich Loews Vorschlag anschließen und für die Arten mit gegitterten Flïgeln dann Tephritis Latr., 1804 beibehalten, für die Arten mit nicht gegitterten Flïgeln jedoch, welche ja anch unter den vier von Meigen bei Trypeta angeführten 'Typen die Mehrzahl bilden, den Namen Euribia (= Trypeta) annehmen. Die Subfamilie hieße daun statt Trypetinae jetzt nach Macquart Tephritinae. Trupanea Schrank, 1803 oder vielmehr nach Schiner von Guéttard, Mém. de l'acad. Paris (171, Nr. 4) kommt wegen der Jahreszahl 1756 nicht in Betracht.

15. Ich kann mich der Ansicht Speisers (Zeitschr. fiir wissensch. Insektenbiologie, 1905, S. 461) nicht anschließen und Siphona für Haematobia R. D. setzen, demn die Beschreibung Meigens in Illigers Magazin von einer "nackten" Arista und vou einem "wagrecht vorgestreckten, gebrochenen Riissel" paßt mur auf die bekannte Tachinidengattung, welche gleich ist mit Bucentes Latr., und nie auf Stomoxys stimulans Mg. oder eine andere StomoxysArt. Die von Meigen als Typus angeführte Stomoxys irritans F. ist eben nicht gleich der späteren St. stimulans, sondern ist eine Art der Gattung Siphona = Bucentes!

Auch Griinberg, „Die blutsaugenden Dipteren“, S. 160, Jena, 1907, gebrancht Siphona irrtiimlich fiir Haematobia R. D.

Bezzi, der nach seiner schriftlichen Mitteilung im Katalog der palïarktischen Dipteren, III, ebenfalls Speiser folgte, teilt jetzt meine Ansicht.

16. Larvaevora deckt sich mit Tachina im Umfange ganz, denn beide Genera enthalten fast die ganze Gruppe der Tachiniden. Die Musca grossa L. wird Larvaevora grossa heiBen miissen.

17. Die Gattung Callirrhoe findet in Illiger' Magazin kein Analogon. Ich halte sie aber nit Bestimmtheit für zugehörig zur Art Stomoxys siberita Filb., welche sich eben von den anderen Stomoxys-Arten, welche "nierenförmige" Augen liaben, durcl die ovale Form der Netzangen anszeichnet. II igen hat später seine Anschanung geändert und die Arten in einer Gattung belassen. Prosenc fällt daher unter die Synonyme.

15. Diese Gattung fehlt in Illigers Magazin. Bezzi meint, daß es sich vielleicht um Nycteribia oder Melophagus handelt.

19. Nach Bezzi vielleicht gleich Eriothrix Meigen, welcher Name fiir Oliviera R. D. zu setzen ist. 
20. Cylindromyia Meigen hat vor Ocyptera Latr., $180 t$ den Vorrang.

21. Exorista Meigen, 1803 hat also einen ganz anderen Umfang als im 7. Bande der "Systematischen Beschreibung" und hat fuir Eutachina BranerBergenst. einzutreten.

22. Meigen hat diesen Namen im 2. Bande seiner Systematischen Beschreibung, 1820 in Hexatoma abgeindert, also einen schon von Latreille 1809 vergebenen Namen mustatthafter Weise in Verwendung genommen, dafïr statt Hexatoma Latr. Anisomera Hffgg., 1818 gesetzt.

23. Fabricius entscheidet in der Systema antliat., Index, p. 19 völlig olne jeles Recht: „Rhagio, nomen generienm, ne cum Rhagium Eleutheratorum confundetur, in Leptis mutatum est." Bezzi, der im Katalog der paläarktischen Dipteren, II, Rhagio für Psammorycter (Vermileo) gebrauchte, schrieb mir, daß er es nun anch für richtiger halte, Rhagio fiir Leptis zu setzen.

24. Den Namen Dictyia Meig., 1803 hat Becker in Katalog der paliiarktischen Dipteren, IV, fïr meine Gattung Monochaetophora gemüß meiner Anregung angenommen. Ich halte aber nun meinen Genusnamen anfrecht, ra sich Dictya und Statinia mur als Synonyme zu Tetanocera darstellen. 



(Aus der Zeitschriit für Hymenopterologie und Dipterologie 1908. Heft 2.) 


\title{
Ueber die bisher bekannten Dorycera-Arten.
}

\author{
(Dipt.)
}

Von Friedrich Hendel in Wien.

1. Fühler sehr lang und dünn, länger als die halbe Kopflänge . . . . . . . . . . . . . . . 2.

- Fühler relativ kürzer und breiter, deutlich kürzer als die halbe Kopflänge ; 2. und 3. Fühlerglied höchstens zweimal so lang als breit. Percnomatia Loew.

2. 3. Fühlerglied ungefähr 3 mal so lang als das 2. und stark säbelförmig zugespitzt: das zweite Glied ist nur 1/2 mal so lang als breit. Machaerocora Rond. 
- 3. Fühlerglied kürzer als das zweite oder höchstens so lang wie dieses; das zweite Antennenglied ist stielförmig dünn und länger als seine 3 fache Breite.

Dorycera Meig.

\section{Machaerocera Rond.}

Typus und einzige Art: M. grandis Rond. - Italien und Südfrankreich. 1 \&; Länge ohne Fühler 9 111m. Flügel-L. $8 \mathrm{~mm}$.

Augen rund. Stirn eben, um den Durchmesser der Augen vor dieselben vorspringend, im Profile geradlinig, fast wagrecht. Kopf länger als hoch. Backen so breit wie das Auge, hinten olne Querbinde. Thorax und Hinterleib schmal; letzterer ohne Legeröhre ca. 3mal so lang als breit, parallelrandig. - Flügel milchig weiss; in der vorderen Hälfte mit ausgedehnten braunen Zellkernen zwischen den Längsadern. An der Flügelspitze liegen an den Enden der 2.-4. Längsadern mehr oder weniger zusammenfliessende braune Endsäume. Die beiden Queradem und die 5. Längsader sind braun umsäumt.

\section{Dorycera Meigen.}

1. Letzter Abschnitt der 4. Längsader dentlich aufwärts gebogen, mit dem vorletzten einen stumpfen Winkel bildend; erste Hinterrandzelle daher an der Spitze auffallend verengt. Augen rund. Stirn eben, um den Durchmesser der Augen vor dieselben vorstehend, im Profile geradlinig, fast wagrecht. 2. Fühlerglied 3 mal so lang als das 3., das allmählich in eine stımpfe Spitze übergeht. Arista hinter der Mitte. Kopf so lang wie hoch. Backen so breit wie das Auge, hinten mit einer schwarzen Querbinde. Thorax und Hinterleib schmal; letzterer ca. 2 mal so lang als breit und fast parallelrandig. Beim o glänzend schwarz mit grauer Mittellinie, beim o ausser der Mittellinie noch am 2.-5. Ringe mit grauen Querbinden an der Vorderhälfte der Segmente, welche von der Mittelbinde bis zum Seitenrande reichen. - Flügel beim o glashell, in der Spitzenhälfte mit Ausnahme eines hellen Fleckens unten in der 1. Hinterrandzelle schwarzbratn; beim o zeigt der Flügel zwischen allen Lüngsadern dunkle, streifenartige Längskerne zwischen den Adern in den Zellen und einen kleinen Spitzenfleck an der Mündung der 2. Längsader. Nur die kleine Querader merklich gesäumt. - Mehrere $\sigma^{\top}$ und o. - Länge ohne Fühler 
$10 \mathrm{~mm}$. - Flügel-L. $8 \mathrm{~mm}$. - Klein-Asien, Brussa, [Mann], Varna [Loew]*).

\section{D. maculipennis Macquart.}

- Letzter Abschnitt der 4. Längsader mit dem vorletzten fast in einer Geraden laufend, erste Hinterrandzelle daher nicht oder kaum merklich verengt. . . 2.

2. Hinterleib (q) mit schwarzen Querbinden gezeichnet. Es sind nämlich der erste und 2. Ring ganz, der 3. - 5. an der Basis grau bestäubt, welche Bestäubung hinten in eine Spitze ausgezogen ist. Das dritte Fühlerglied ist etwas kürzer als das zweite, verdünnt sich gegen die Spitze zu nur allmählich und ist im Profile lanzettförmig zugespitzt. Kopf und Augen wie bei $D$. graminum. - Länge $9 \mathrm{~mm}$. - Flügel: 7 mm. - Spanien.

D. scalaris**) Loew.

- Hinterleib ohne Querbinden, entweder glänzend schwarz mit einer grauen Mittellinie oder ganz grau.(o)3.

3. 3. Fühlerglied dem 2. ıngefähr an Länge gleich; es verdünnt sich plötzlich jenseits der Arista vor der Mitte und geht dann spitzig in fast gleicher Breite bis zum Ende. - Augen rund. Stirn eben, im Profile gerade und fast wagrecht, $ı \mathrm{~m}$ den Augendurchmesser vorstehend; Kopf so hoch wie lang. Backen fast so breit wie ein Auge, hinten ohne Querbinde. Thorax und Hinterleib schmal, letzterer ca. 2mal so lang als breit. - Flügel in der Vorderhälffte mit dunklen Längskernen in den Zellen und einem Spitzenflecke an der 2. Längsader. Von den Queradern ist nur die kleine merklich gesäumt. Diese Zeichnung ist beim ơ intensiver als beim ㅇ. Länge : 5-9 mm. - Flügel-L. $4-7 \mathrm{~mm}$.

D. graminum Fab.

3. Fülllerglied bedeutend kürzer als das zweite, nur allmählig in die Spitze übergehend.

4. Augen rund, Stirn um den Augendurchmesser über die Augen vorstehend. Kopf so hoch wie lang. 2. Fühlerglied fast doppelt so lang als das 3. - Flügel-

*) Das von Becker in seinem Kataloge angeführte Citat: Ortalis maculipennis Latr: bei L. Dufour, Ann. Soc. Ent. France, 1850, p. 145, Pl. 6. fig. 8 gehört nicht hierher, da die Abbildung eine echte, mit formosa Panzer verwandte Ortalis-Art darstellt.

*) Die mit einem Sternchen bezeichneten 3 Arten lagen mir nicht zur Untersuchung vor. 
zeichnung ähnlich jener von D. graminum Fab. Länge 6,5-7,5 mm. - Flügel 6-7 mm.- Varna. D. hybrida*) Loew.

- Augen länglich oval; Stirn weniger vorstehend; Kopf kürzer als hoch, Arten mit breiterem Thorax und Hinterleibe . . . . . . . . . . . . . 5.

5. Beine des $\sigma^{\top}$ fast ganz schwarz, diejenigen des 우 schwarz gefleckt. Stirn vorn über den Fühlern eben, nur mit einer glänzenden Stelle. 2. Fühlerglied 2mal so lang als das 3.; dieses mit abgestutzter Spitze und mit der Arista auf der Mitte. - Die Thoraxstriemen wachsglänzend; Hinterleib bei or und o mit einer ziemlich breiten grauen Längsstrieme. Beim o auch je eine Seitenstrieme an den umgeschlagenen Rändern, die beim ơ nur vorn erkennbar ist. Flügel graulich, mit sehr ausgedehnten und intensiven Längskernen in den Zellen, namentlich am Vorderrande, und einem Spitzenfleck an der 2. Längsader. Beide Queradern gesäumt. - Länge 9-10 mm. Flügel 7-8 mm. - Griechische Inseln. D. brevis Loew.

-- Beine gelb. Stirn vorn, über und neben den Fühlern mit einer glänzend-schwarzen Beule, welche auch im Profile deutlich vortritt. - 2. Fühlerglied fast 2 mal so lang als das 3.; dieses hat eine abgerundete Spitze und die Arista etwas hinter der Mitte. Die Thoraxstriemen glänzen auffallend, wodurch sich diese Art von allen andern sofort unterscheidet. Der ebenfalls stark glänzende Hinterleib hat blos eine schmale und nur aus Makeln zusammengesetzte Mittelstrieme. - Flügel $\sigma^{\top}$ o glasartig, in der Vorderhälfte braungelb und an der Mündung der 2. Längsader mit einem braunen Spitzenfleck von ziemlicher Ausdehnung. Die bei der Gattung gewöhnlichen Längskerne in den Zellen fehlen hier gänzlich. Länge 8-9 mm. - Flügel-L. 7--8 mm. - Corfı (Schmiedeknecht.) D. tuberculosa 11. sp.

\section{Percnomatia Loew.}

1. Flügel grau mit braunen Kernstreifen in den Zellen und einer Trübung der Spitze. Hinterleib glänzend schwarz, mit schmaler graugelber Mittellängslinie und ebensolchen Seitenstriemen am umgebogenen Rande. - Länge $6,5 \mathrm{~mm}$. Flügel 4,5 mm. - Algier.

Perc. griseipennis*) Becker ㅇ․ 
- Flügel glashell, ohne dunkle Längsstreifen zwischen den Adern. Abdomen oben ohne Längsstriemen. 2.

2. Hinterleib einfarbig gelbgrau bestäubt. Die Stirnseiten sind fast bis zu den Fühlern hin weisslich bereift. - Augen länglich oval. Stirn nur wenig und zwar beiläufig die Hältte des horizontalenAugendurchmessers über die Augen vortretend. Sie hat ähnlich wie Dorycera tuberculata jederseits eine, wenn auch kleinere Beule, die namentlich beim ơ deutlich erkennbar ist. Das 2. und das 3. Fühlerglied sind ungefähr gleich lang, ca. $1 \frac{1}{2}$ mal so lang als breit; das 3 . ist allmählich zugespitzt, vorn stumpf. Die Arista sitzt etwas vor der Mitte. - Länge 9-10 mm. - Flügel 7-9 $\mathrm{mm}$. - Corsica (Mann.) Perc. inornata Loew.

- Hinterleib gelbgrau bestäubt mit glänzend schwarzen, ziemlich breiten Hinterrandsäumen an den Segmenten. Die gramen Querbinden erweitern sich in der Mitte nacl hinten zu einer Längsstrieme, die über den ganzen Hinterleibsrücken verläuft. Die Stirnseiten sind nur oben am Scheitel neben den Augen weisslich bereift, vorn glänzend gelb. - Die Stirn steht weiter vor als bei inornata Loew und besitzt vorn keine Beulen. - Alles Uebrige wie bei $P$. inornata Loew. -- Länge $10 \mathrm{~mm}$. - Flügel $8,5 \mathrm{~mm}$. ớ. Jerusalem (Schmiedeknecht). $\quad$ Perc. judaea n. sp.

A n merk.: Ueber die Arten Robineall-Desvoidy's, welche Becker ohnehin im Katalog anführt, und über die fragliche Dorycera conspersa Walker aus Columbien weiss ich nichts anzugeben.

Das bei dieser kleinen Uebersicht benützte Material stammt aus dem k. k. Hofmuseum in Wien. 
VII. ANNALES NUSEI NATIONALIS HUNGARICLI. 1909.

\section{FRIEDRICH HENDEL,}

\section{ÏBER DIE GATTUNG EUXESTA, LOEW.} (DIPT.) 



\section{ÜBER DIE GATTUNG EUXESTA, LOEW. (DIPT.)}

\section{Von Friedrich Hendei.}

Im Folgenden möchte ich nicht etwa eine Monographie der EuxesluArten bringen, weil es mir hiezu im gegenwärtigen Augenblicke an Zeit und Material gebricht, sondern bloss eine Hilfstabelle zum Bestimmen der zahlreichen Arten, wie ich sie mir zur Determination des mir vorliegenden Materiales zurecht legte, sowie die Beschreibung der neuen Arten, welche mir aus dem Budapester und Wiener Museum, ferner aus der Sammlung des Herrn W. Schnuse zur Verfügung standen. Mit der Bestimmungstabelle glaube ich eine momentane Lücke bis zur künftigen monographischen Bearbeitung der Arten ausgefüllt und die Einreihung der neu von mir beschriebenen Species erleichtert zu haben.

Die von Schint: in den Novara-Dipteren beschriebenen Arten wurden nach den Typen neuerdings untersucht, ihre Beschreibung ergänzt und ihre eventuelle Synonymie festgestellt. Schiner's Gattung Amethysa, Macqu. entspricht den LoEw'schen Genera Euxesta plus Chaetopsis. Da ich nicht die Überzeugung habe, dass die afrikanische Fliege Amethysa fusciata eine Euxesta-Art ist, musste ich den Loew'schen Namen annehmen.

Bezüglich der generellen Merkmale und der Flügelabbildungen der neuen Arten vergleiche man aus Wrtsuan's "Genera Insectorum" die von mir bearbeitete Subfamilie Ulidinae.

\section{BESTIMMUNGSTABELIE DER ARTEN.}

Flügel ganz milchigweiss, ohne dunklere Flecke oder Binden.

No. 1. Eux. lactripennis, n. sp.

Flügel nie ganz milehigweiss oder hyalin.

1.

1. Flügel mit 4 dunkelbraunen Querbinden von verschiedener Form und Breite.

Flügel mit 2--4 dunklen Flecken am Vorderrande." _. _... 31.

Flügel zum grössten Teile dunkelbraun, von verschiedenen hellen Fenstern durchbrochen, die nie eine durchgehende Querbinde bilden. . ... ... 2.

1 Diese Arten stehen durch die gerade Subcosta, den stärker vorspringenden Zipfel der Analzelle, die Flügel. und Thoraxzeichnung den Acrosticta-Arten nahe 
2. Flügel bram, mit einer glashellen Bogeubinde vor der Spitze, einem ebensolchen Streifen von der Mündung der Subcosta bis zur kleinen Querader und einem glasigen 8-er-förmigen Fleck ror der Mündung der Posticalader. No. 2. Eux. lunatu, n. sp. Flügel mit kleinen glashellen Fensterchen gegittert.

3. Schildelıen, Beine und Hinterleib gelb. Körper metallischgrün.

4. Lunula samtschwarz. Lumula olne samtschwarzen Fleck.

5. Die dritte und viertc Flügelbinde an der Costa in dex Marginalzelle durch einen milchigweissen Fleck getrennt.

Die dritte und rierte Querbinde an der Costa rereinigt; der milchigweisse Fleck fehlt hier.

.. No. 4. Enx. stigmutias, LoEw. ${ }^{2}$

6. Vorderrand der Stirne über den Fühlern wulstig und stark glänzend. Fühler schwarzbraun, an der Basis abgesetzt hellrot. Die zweite Flügelquerbinde reicht dentlich über die vierte Längsader hinab.

No. 6. Enix. stigma, n. sp. Stirne vorne eben und matt. Fühler einfarbig rostrot. Die zweite Flügelbinde ist schon unter der Subcostalzelle verwaschen.

No. 5. Eux. elulu. Loew.

7. Hinterleib ganz oder teilweise gelb oder rotbraun. _ _ _ _ _... 8. Hinterleib einfärbig dunkel, meist metallisch glänzend. $\quad 11$.

8. Beine ganz gelb; Gesicht, Schildchen, die ersten zwei Segmente des Hinterleibes und tie Basis des dritten gelb. Die symmetrisch an der Flügelspitze liegende Binde schliesst mit der sehr sclımalen dritten einen dreilappigen hellen Zwischenraum ein. No. 7. Eux. junctu, Coquiluerr.

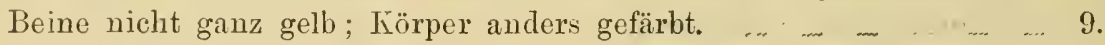

9. Die glashellen Zwischenräume zwischen den Querbindeu des Flügels sind breiter als die Binden selbst. Hinterleib rotbraun, die letzten Segmente

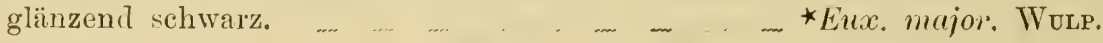
Die Zwischenräume sind schmäler als die dunklen Flügelbinden. _. 10.

10. Die glashellen Zwischenränme zu beiden Seiten der 3-ten Flügelquerbinde bogig begrenzt, schiefliegend. Die hintere Querader liegt inmitten der dritten Querbinde. _. _ _ _... _ _ Eux. abdominulis, Loww. Die glashellen Zwisclienränme zu beiden Seiten der dritten Querbinde geradlinig. parallel begrenzt, senkrecht auf der Costa stehend. Die hintere Querader liegt an der inneren Grenze der dritten Querbinde.

No. 8. Eux. Schineri, nom. nor.

$11 .^{3}$ Beine gelb oder rot oder rotbraun. Beine vorherrschend schwarz.

1 Die mit einen * versehenen Arten kenne ich nicht aus Autopsie.

2 Hieher käme man auch nach der Beschreibung der Ortalis punctifron: Thomson, Eugenies Resa, Dipt. p. 573.

" Hier ist es angezeigt nacheinander beiden Alternativen zu folgen! 
12. Costa in der Mitte nach rorne gewölbt. Radialader besteht aus zwei flachen Bogen. die in der Mitte unter einer nach vorne gerichteten Spitze zusammenstossen. No. 11. Eux. acutu, n. sp. Costa und Radialader normal. _ _.. _ _ _ _ _ _ _ _ _ _ _ _ 13. 13. Thorax und Hinterleib glänzend schlackenschwarz. Gesicht und Beine gelb. * Eux. scániucea, Loew. Thorax, Hinterleib und Gesicht metallisch grïnlich oder blau. ... ... 14. 14.' Die dritte und vierte Flügelquerbinde an der Costa getrennt ron einander.

Die dritte und vierte Flïgelquerbinde an der Costa verbunden; dritte Binde gleichbreit.

15. Dritte branne Querbinde des Flügels hinten verbreitert; der glashelle Zwischenranm hinter derselben schief und etwas gebogen. Die Queradern sind beinahe die doppelte Länge der hinteren Querader von einander entfernt.

*Eux. latifasciata, WuLp. Dritte Querbinde gleichbreit; der glashelle Zwischenraum hinter derselben gerade und senkrecht auf der Costa. Der Abstand der beiden Queradern kommt der Länge der hinteren Querader gleich.

No. 9. Eux. latifuscia, Schiner.

16. Die braune Spitzenbinde des Flügels breiter als der darorliegende parallelrandige, senkrechte glashelle Zwischenraum. Discoïdalzelle fast bis zur Wurzel dunkelbraun.

No. 10. Lux. Schnusei, n. sp. ${ }^{2}$ Die Spitzenbinde ist schmäler als der darorliegende glashelle Zwischenraum, der sich nach unten hin verbreitert. Discoïdalzelle im Wurzelciertel glashell.

*Eux. conserta, WULP. ${ }^{3}$

17. Radialader mit einer nach vorne gerichteten Spitze in der Mitte.

No, 11. Eux. acutu, n. sp.

Radialader ohne diese Spitze.

18 .

18. Gesicht und Scheitel aschgran. Thorax, Schildchen und Abdomen schwarz. Die vierte Flügelbinde ist ein Fleck, der weder die Flügelspitze, noch die Discoïdalader erreicht.

*Enx. nigricuns. WuLP.

Gesicht und Scheitel metallisch. Flügel mit einer vollständigen Spitzenquerbinde.

19. Die dunklen Querbinden des Flügels sind an der Costa nicht mit einander verbumden.

Die dritte und vierte Flügelınerbinde hängen vorne zusammeı. _- 22.

20. Zipfel der Analzelle schlank gleichbreit, dann zugespitzt, so lang wie die Analzelle und länger als der restliche Teil der Analader.

No. 12. Enx. Bilimeli, n. sp.

1 Hier wire anch Ortalis spothulata, Thousun, Eugenies Resa, Dipt. p. 574, mit gelbem Kopf und gleichfärbigen Fühlern und Beinen zu erwähnen.

2 Nicht wit der sehr älnliehen Eux. Schineri (= hasalis, Schrner) zu verwechseln!

:) Vergleiche mit liux. Annonue, FAB. 
Zipfel der Analzelle keilförmig. dreieckig, kürzer als die Analzelle und nur einen kleinen Teil der restlichen Analader lang. _ _ _ _ $20 \alpha$.

20 $\alpha$. Die zweite Flügelquerbinde ist unter der Discoïdalader sehr verwaschen und überschreitet die Posticalader nur etwas. Die Spitzenquerbinde liegt schief oben an der Spitze, reicht bis zur Discoïdalader, ist nur schmal und ron der dritten Binde an der Costa nur schmal getrennt.

No. 13. Eux. Macquarti, Schiner.

Die zweite Fliigelquerbinde geht bis zum Hinterrande des Flügels. 21.

21. Flïgelwurzel ganz schwarz. Fusswurzeln schwärzlich, nicht heller. Stirne nicht anffallend behaart. Epistom ziegelrot. ... _ _ Enx. atripes, Loew. Flügelwurzel glashell. Fusswurzeln heller, rot. Stirne ranhhaarig. Epistom stahlblau.

Eur. alternans, ${ }^{1}$ Loew.

22. Die vierte braune Querbinde des Flügels liegt symmetrisch an der Spitze.

Die Spitzenbinde ist nicht symmetrisch gelegen, sondern mehr nach aufwärts gerückt oder unter der Spitzenmitte aufgelöst. ... _.. _ _ _ _... 26.

23. Discoïdalzelle doppelt so lang als der letzte Abschnitt der Discoïdalader.

No. 14. Eux. acuticomis, n. sp.

Discoïdalzelle nicht oder nur wenig länger als der letzte Abschnitt der vierten Längsader.

24. Die hintere Querader liegt inmitten der dritten braunen Querbinde; metallisch blaue Art. Schwinger kreideweiss.

No. 15. Eux. Wettsleini, n. sp. Die hintere Querader liegt an der inneren Grenze der dritten Querbinde. 25. 25. Die zweite braune Flügelquerbinde ist ein hinten breiter werdender, nach aussen stark convexer Bogen. Costal- und Subcostalzelle ganz dunkelbraun.

No. 16. Eux. arcuuta, n. sp. Die zweite Querbinde ist senkrecht, sehr breit und gerade, die Costalzelle nur an der Spitze braun. _. _ ... _. . No. 10. Eux. Schnusei, n. sp.

26. Die dritte braune Querbinde ist oben sehr schmal. unten ausserordentlich stark erweitert. In der braunen Spitzenhälfte des Flügels liegt eine schmale glashelle Bogenbinde, die schief von oben und weiter inmen nach unten

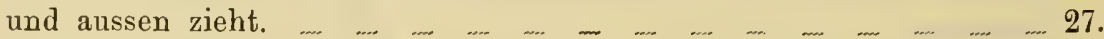

Die dritte braune Querbinde ist unten kaum breiter oder sogar schmä'er

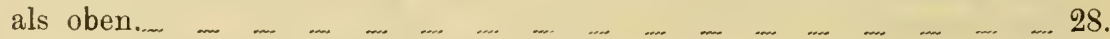

27.2 Die braune Spitzenbinde ist schmäler als der glashelle Zwischenraum davor. Aussenrand der zweiten braunen Querbinde convex.

Eux, sororcula, Wiedemans.

1 Mit dieser Art fällt Amethysa propinqua, Schiner, Norara Dipt. p. 283. 155. (1868) von Venezuela zusammen.

2 Ob die hieher gehörenden zwei Arten: Ortalis obliqua, Thomson, Eugenies Resa, Dipt., p. 574 und Herina decisa, WALkER, Trans. Ent. Soc. London, n. ser. IV. p. 227 (1856-1858) eigene Arten oder Synonyma sind, kann man nach der Beschreibung allein nicht entscheiden. 
Die Spitzenbinde ist breiter als der glashelle Zwischenraum davor. Aussenrand der zweiten Querbinde concav. No. 17. Eux. obliquestriata, n. sp. 28. Flügelwurzel schwarz. Kleine Querader auffallend weit vor der Mitte der Discoïdalzelle; diese viel kürzer als der letzte Abschnitt der Discoïdalader. Die zweite und dritte Flügelquerbinden sind schmale scharf begrenzte schwarze Streifen, die nach hinten stark divergieren. Schwinger und Schüppchen schwärzlich. _.. _. _ _ No. 18. Eux. insolita, n. sp. Änsserste Flügelwurzel glashell. Kleine Querader jenseits der Mitte der Discoïdalzelle, welche länger als der letzte Abschnitt der Discoïdalader ist.

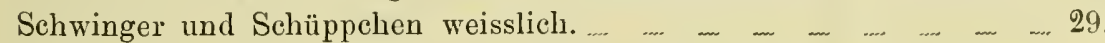

29. Die zweite braune Querbinde erreicht den Flügellinterrand nicht und ist ziemlich gleich breit. Die dritte Querbinde ist oben schmäler als der davorliegende glashelle Zwischenraum. _ _ _ _ Eux. Annonae, Fabricius Die zweite Querbinde erreicht ganz oder fast ganz den Flügelhinterrand. Die dritte Querbinde ist oben breiter als der glashelle Zwischenraum vorher.

30. Die zweite Querbinde verbreitert sich stark nach hinten zu, die dritte ist vorne schmäler als hinten. _.._ _ _ _ _ _ Eux. fascipennis, Wulp. Die zweite Querbinde ist ziemlich gleich breit, die dritte vorne breiter als hinten. . _ _ _ _ _ _ _ _... _ _ _ Eux. Thomae, Loew.

31. Aın Flügelvorderrande liegen vier braune Flecke. _ _ _ _.. _ _ _ _ 32 . Am Flügelvorderrande liegen nur 2-3 Flecke. _ _ _ _ _ _ ... 33.

32. Flügelwurzel glashell; der zweite Costafleck reicht unten bis in die vordere Basalzelle hinein; der dritte Fleck liegt weit jenseits der Mündung der Subcosta. *Eux. quatemaria. LoEw. Flügelwurzel schwarz; der zweite Costafleck reicht nicht in die Basalzelle hinüber; der dritte Fleck liegt an der Mündung der Subcosta.

Eux. calligyna, Віяот.

33. ${ }^{1}$ Flügel am Vorderrande mit zwei fleckenartigen Querbinden; die bis zur Discoïdalader herabreichen; eine von der Subcostalzelle herabgehend, die andere vor der Flügelspitze gelegen. _ _ _ _ _ Eux. binotata, Loww. Am Vorderrande des Flügels liegen 2-3 Flecke, die nie weit nach hinten reichen und nie das Aussehen von Querbinden haben. _.. _ _ _ 34 .

34. Hinterleib teilweise gelb gefärbt. _ _ _.. _ _ _ ... _ _ _ ... 35. Abdomen einfärbig glänzend schwarz oder metallischgrün oder blau. 40.

35. Clypens stahlblau. 36 . Clypeus und Beine gelb. _. _ _ _. _ _ _ _ _ _ _ _ _ _ _ _ 39.

36. Lunula samtschwarz. No. 20. Enx. maculata, n. sp. Lunula von der Farbe des Clypeus, weisslich bereift. _ _ _ _.. _ 37. 37. Costalzelle in der Mitte glashell. Beine metallisch schwarz, Knie und

1 Hieher käme man auch bei der mir unbekannten Euxesta (Ortulis) basalis, WalKER, Insect. Saunders., Dipt. Vol. IV. p. 373 (1852): Nigro.cyanea; caput fulvum; antennæ luteæ; abdomen basi ferrugineum, $f$ apice luteum attenuatum: pedes fulvi; alæ hyalinæ, basi fulvæ, ritta antica interrupta fusca.- United States. 
Fusswurzeln rot. Endhälfte des letzten Hinterleibsabschnittes des $q$ und Basis der Legeröhre gelb. _ .... _... _ _ _ _ _... Eux. notata. Wiedem. Costalzelle ganz braun. _ _ _ _ _... _ _... _ _..... _ _ _ _ 38. 38. Hüften und Schenkel gelb, Schienen schwärzlich. Abdomen schwarz, erstes Glied des Oripositors an der Wurzel gelb. *Eur. apiculis, Williston. Hüften und Beine schwarz, Metatarsen bräunlich. Das vierte und fünfte Tergit des Abdomens und das ganze Basalglied des O\ipositors gelb.

* Eux. mulchella, Cresson.

39. Costal- und Subcostalzelle schwarz. Die ersten zwei Abdominaltergite gelb.

*En.x. Willisloni, Coquiliett.

Costalzelle in der Spitzenhälfte glashell. Die Hinterränder des dritten und der folgenden Tergite gelb. _ _... _ _ _ ... _ _ * Eux. minom. Cresson.

4.0. Beine gelb.

Beine vorherrschend schwärzlich.

41. An den schwarzen Vorderfïssen ist der Metatarsus mit Ausnahme der Spitze gelb. Vorderschenkel an der Spitze mit einem schwärzlichen Fleck.

No. 19. Eux. spoliatu, Loew. Vorderfüsse ganz schwarz. Vorderschenkel an der Wurzel schwarz.

*Eux. laticejs, Wulp.

42. Unmittelbar ror der Flügelspitze liegt ein schwarzer kleiner Fleck, der rom Vorderrande bis etwas über die Cubitalader hinabreicht, die Spitze der Marginalzelle bedeckt, die der Submarginalzelle aber ganz frei lässt.

* Eux. pusio, Loew.

Der schwarze Apicalfleck des Flügels bedeckt auch die Spitze der Submarginalzelle.

43. Der Apicalfleck des Flügels ist sehr gross und fast so lang wie der letzte Alsschnitt der Discoïdalader. An die schwarze Subcostalzelle schliesst sich unten ein bis zur Discoïdalader reichender Fleck an.

Eux. rostulis, Fabricius.

Apicalfleck klein, kaum die Hälfte des letzten Discoildaladerabschnittes lang. Das schwarze Randmal kanm nach hinten zu rer]ängert.

*Eux. nitidiventris. Loew.

\section{BESCHREIBLNG DER ARTEN.}

\section{Euxesta lacteipennis, n. sp.}

$1 \sigma^{\top}$ aus Bolivien (Mapiri; Jänner); Coll. Schnuse.

Stime rotbram, in der Mitte glänzend, am Augen̈rande weisslich, ror den Ocellen etwas konkav, sehr kurz und spärlich belaart. Lunulà, Clypeus und, Prrelabrum grün, unter den Fühlern weisslich bereift. Backengrube rothraun, oben und unten feinweiss gerandet, in der Mitte mit einem weissen Querstrichlein. Fühler rotgelb. Oberer Hinterkopf blàugrün, unterer treiss bestäubt. Rüssel und Taster bräunlich. Thorax 
und Schildchen dunkel bläulichgrün. Rücken vor der Quernaht stärker bereift. An den Quernahtästen liegen dunklere Querbinden. Pleuren auch etwas bereift. Hinterleib schwärzlichgrün, glänzencler als der Thorax.

Vorderhüften hellgelb, weisslich bereift. Schenkel mit Ausnahme der gelben línie schwarz, blaugrünschimmernd; Vorder- und Hinterschienen ebenso, die mittleren am Ende breit gelb. Vorderfüsse schwarz, jene der beiden hinteren Paare rotgelb.

Flügel einfärbig milchigweiss, mit hellen Adern. Subliosta geradlinig mündend. Kleine Querader deutlich jenseits der Mitte der Discoïdalzelle. Flügeladerung wie bei den Arten mit bloss gefleckter Kosta.

Kööperlänge $4 \mathrm{~mm}$. - Flügel $3 \mathrm{~mm}$ lang.

\section{Euxesta lunata, n. sp.}

$1 q$ aus Peru (Meshagua: November); Coll. SuHnuse.

Dunkel stahlblau. Rotbraun sind: die wachsglänzende Stirnstrieme, die an der Spitze etwas dunkleren Fühler, die Taster und der Rüssel, ausserdem die schmalen Backengruben (Wangen). Scheitel stark glänzend, blau. Obere Hälfte des Clypeus deutlich weiss bereift. Bebaarung der Vorderstirne schütter, aber am Rande ziemlich lang. Rücken und Schildchen kaum bestäubt, glänzend, mit einem Stiche ins Stahlgrüne; Pleuren mehr blau. Hinterleib einschliesslich des Ovipositors einfärbig glänzend schwarz mit violetten Reflexen.

Beine rötlich pechbraun; die äussersten Kniespitzen, die Gegend um die Schenkelringe und die Füsse etwas heller rotbrann. Metallischer Schimmer fehlt vollständig.

Flügel dunkelbraun. Flügelbasis mit Ausnahme einer braunen Wurzelquerbinde über der Schulterquerader glashell. Im Braunen des Flügels liegen 3 glashelle Flecke: ein spitz trapezförmiger hinter der Mündung der Subcosta bis hinab an die vierte Längsader — seine innere Grenze läuft senkrecht nach abwärts, gerade über die kleine Querader - ein bogen- oder mondförmiger vor der Flügelspitze, welche braun bleibt, und endlich ein ovaler, der zur Hälfte in der Discoïdal-, zur anderen Hälfte in der dritten Hinterrandzelle liegt. Die kleine Querader liegt weit vor der Mitte der Discoïdalzelle und die erste Hinterrandzelle ist fast vollkommen parallelrandig.

Körper $3 \cdot 5 \mathrm{~mm}$, Flügel $2.5 \mathrm{~mm}$ lang. 


\section{Euxesta geminata, n. sp.}

5 ơ $q$. Peru (Meshagua; September, Oktober); Coll. Schnuse.

Nur mit Euxesta fenestrata, Coquilletr vergleichbar. Körper metallisch grün. Stirne etwas schmäler als ein Auge, nur an den grünlichen Augenrändern länger behaart, Strieme und Backengruben hell rotbraun. Scheitelplatten und Ocellendreieck glänzend metallisch grün; von gleicher Farbe der auf seiner ganzen Fläche mässig weisslich bestäubte Clypeus. Peristomalien in gewisser Beleuchtung hell bereift und am Rande relativ lang beborstet. Fühler und Taster rot, erstere an der Wurzel und am Oberrande verdunkelt. Drittes Fühlerglied mit abgerundeter Spitze und etwas concavem Oberrande.

Rücken und Schildchen ziemlich glänzend, mit zartem rotfarbigem Tomente bedeckt.

Hinterleib schwärzlich, matter als der Thorax-Rücken, mit schwachem blauen oder sogar violetten Schimmer in der Mitte. Das erste Glied des Ovipositors ist gleichfarbig, von der Gestalt eines Dreiecks, das etwas spitzer als ein gleichseitiges ist.

Hüften, Knie und Füsse rotbraun. Schenkel und Schienen dunkelpechbraun, mit deutlichem Metallschimmer an der Oberseite.

Flügel mit Ausnahme der gelblich hyalinen Basis, die nur an der Wurzelquerader eine Verdunkelung zeigt, schwarzbraun.

Die Discoïdalzelle und der darunter liegende Flügelteil erscheinen nur vor dunklem Hintergrunde hellbraun, in durchfallendem Lichte dagegen gleichfalls gelblich hyalin. Bei ersterer Beleuchtung treten aus der Flügelfläche neun kreisrunde, milchigweisse Flecke hervor. Je ein Paar liegt an der Radialader, in der Verlängerung der hinteren Querader; dann in der Mitte des letzten Discoïdaladerabschnittes und endlich an dem Ende der Posticalader, noch vor der Querader. Die zwei Kreispunkte liegen immer übereinander und werden durch die betreffende Längsader von einander getrennt. Ausser diesen sechs Flecken liegen noch drei gerade untereinander und zwar der erste unmittelbar hinter der Mündung der Sublosta in der Marginalzelle, der zweite in der Submarginalzelle und der dritte hinter der kleinen Querader in der ersten Hinterrandzelle. Im durchfallenden Lichte ist diese Zeichnung viel undeutlicher wahrzunehmen.

Schüppchen und Schwinger gelblich. Körper olne Legeröhre $4 \mathrm{~mm}$, F'ügel $3 \mathrm{~mm}$ lang.

A nmerkung. Eux. fenestrata, Coqu. hat Schildchen, Beine und Hinterleib gelb, ist aber nebst unserer Art die einzige mit gefensterter Flügelzeichnung. 


\section{Euxesta stigmatias, LoEw.}

Berlin. Ent. Zeit., Vol. XI. p. 310. 12. (1867).

Zu den schon bekannten Fundorten kann Peru (Callanga), Paraguay (Asuncion) und Bolivien (Mapiri) hinzugefügt werden. (Ungar. NationalMuseum). Die Loww'sche Abbildung des Flïgels l. c. Fig. 18 zeigt denselben im durchfallenden Lichte. Gegen dunklen Hintergrund gehalten erscheinen in den glashellen Zwischenräumen zu beiden Seiten der dritten schwarzen Querbinde schmälere milchigweisse Bänder, die den Flügelhinterrand nicht erreichen. Zipfel der Analzelle kräftig.

\section{Euxesta eluta, Loww.}

Berlin. Ent. Zeit., Vol. XI. p. 312. 13. (1867).

Mit dieser Art ist die Amethysa Amunnae, Schiner, Novara-Dipt. p. 283, 154, wie die Typen des k. k. Hofmuseum ausweisen, identisch. Mir liegt die Art auch aus Argentinien (Lules; Ungar. National-Museum), Bolivien (Cordilleren, 2-3000 m, Mai; Coll. Schnuse) und Peru vor. Die Loww'sche Flügelzeichnung zeigt die milchigen Teile des Flügels, wie sie gegen dunkleren Hintergrund gesehen werden können. Im durchfallenden Lichte sind bloss die dunkler braun gezeichneten Partien vom hyalinen Teile unterscheidbar. Zipfel der Analzelle schlank.

\section{Euxesta stigma, n. sp.}

2 ơ $q$ aus Peru (Urubambafluss; Oktober); Coll. Schnuse.

Der Eux. eluta, Loew sehr nahe stehend. Torderrand der Stirne über den Fühler wulstig, konvex und stark glänzend rotbraun. Clypeus und Prælabrum grünlich blau, ersterer oben weisslich bereift. Zwischen den Fühlerwurzeln ein samtschwarzer Fleck, der unten quadratisch begrenzt ist. Backengruben weiss schimmernd, mit einer dunklen abstechenden Mittelbinde, parallel zum Augenrande. Fühler schwarzbraun; Wurzel des dritten Gliedes abgesetzt rotgelb. Unterer Hinterkopf weiss bereift.

Pleuren grünlich und stahlblau. Hinterleib dunkel. Erstes Glied des Ovipositors gleichfarbig mit dem Hinterleib, ein- und einhalbmal so lang wie breit. Die dunklen Teile der Beine violett schimmernd. Basis der Vorderschenkel gelb. Mittelschienen ganz dunkel.

Im übrigen gilt Loew's Beschreibung der Eux. clulu.

Die Flügelzeichnung, welche nur sichtbar wird, wenn man gegen einen dunklen Hintergrund sieht, gleicht fast jener von E. eluta. Die 
zweite, breite Querbinde reicht aber weiter nach abwärts, etwas über die vierte Längsader hinaus, während sie bei eluta mehr einem breiten, nach hinten verwaschenen Costalflecke gleicht. Die darauf folgende milchige Querbinde ist bei stigma oben breiter, verschmälert sich nach linten zu und liegt mehr schief als bei eluta.

\section{Euxesta juncta, CoquilletT.}

Proc. Ent. Soc. Wash., Tol. VI. p. 95 (1904).

1 q aus Peru (Meshagua; September); Coll. Schnuse.

Zur Beschreibung Coquiluetr's möchte ich noch Folgendes hinzufügen: Rücken der geringen Bestäubung halber ziemlich glänzend. Der metallisch dunkle Teil des Hinterleibs, sowie das erste Glied des Ovipositors, welches schlank dreieckig ist, glänzen metallisch violett und zeigen keinen Reif. Die zweite Flügelquerbinde beginnt oben mit der Breite der Subcostalzelle und zieht sich erweiternd bis zum Hinterrande. Ihre innere Grenze ist gerade, ihre äussere unter der Subcosta ebenfalls und berührt die kleine Querader. Beide stehen auf der Costa schief. Die dritte Binde ist schmal, gleichbreit, durchgehend, steht senkrecht und hat die hintere Querader an der Innengrenze. Die symmetrisch an der Flügelspitze liegende vierte Binde hängt mit der dritten oben kaum, am Hinterrande aber deutlich, wenn auch etwas verwaschen zusammen und ist schmäler als der davorliegende glashelle Zwischenraum, der sich an der dritten Längsader am weitesten gegen die Flügelspitze ausstreckt. Die Analzelle hat eine fast kaum sichtbar vortretende, sehr kleine Spitze.

\section{Euxesta Schineri, nom. nov.}

Amethysa basalis, Schiner, Novara-Dipteren, p. 284.157 (nec Walker).

Die Suhiner'schen Stiicke stammen aus Venezuela. In der Coll. Schnuse sind Stücke aus Bolivien (Mapiri; Jänner, April) und Peru (Meshagua; Olitober).

Der Schiner'schen Beschreibung wäre Folgendes hinzufügen : Stirne merklich schmäler als ein Auge, ganz matt rotbraun, weisslich bestäubt. Angenränder weiss. Behaarung der Strieme ziemlich rauh und lang. Scheitelplatten metallisch blau. Clypeus stahlblau, oben weiss bestäubt. Taster rot. Thoraxrücken ziemlich dicht weisslich bereift. Schildchen auch bei den zwei Typen nicht rostgelb, sondern mit dem Rücken gleichfarbig. Die Hinterleibsbasis ist oft nur sehr schmal gelb gefärbt. Die Vorderbeine sind heller rotbraun als die hinteren Paare. Hüften 
rot. Das erste Glied des Ovipositor's ist wie der Hinterleil, glänzend violettschwarz.

Euxestu Schineri steht der Eux. Schunsei sehr nahe. Man vergleiche die Anmerkung bei letzterer Art.

\section{Euxesta latifascia, Schinkr.}

Schiner, Novara-Dipteren, p. 283. 156 (1868). - Venezuela.

Die beiden Typen-Stücke sind ziemlich verschimmelt. Die Stirne der Art ist merklich schmäler als ein Auge, hell rotbraun und schütter behaart. Die eng zusammengedrängten Scheitelplatten und Ocellendreieck metallisch blan. Fühler und Taster gelbrot. Das dritte Antennenglied dunkler. Clypeus metallisch blau.

Thorax und Schildchen metallischgrün. Pïcken etwas bräunlich bereift.

Hinterleib glänzend blauschwarz, an der Wurzel und am ersten Gliede des Ovipositors durchscheinend rötlich. Dies hat aber seinen Grund in der Unreife der zwei Stücke.

Beine rotbraun, Schenkel und Schienen in der Mitte ausgedelnt dunkler braun, Füsse heller, mehr gelbrot.

Flügel mit vier braunen, ganz isolierten und durchgehenden Querbinden. Man könnte auch sagen: Flügel jenseits des glashellen Wurzelteiles bis zur Flügelspitze dunkelbraun mit zwei gleichbreiten glashellen Querbinden in der Mitte dieser Fläche. Die basale geht zwischen den beiden genäherten Queradern durch, berührt die kleine deutlich und die hintere fast. Die distale Querbinde ist nur durch einen brannen, senkrechten Parallelstreifen von der ersten getrennt, der schmäler als die glashellen Zwischenräume ist. Schrner schreibt irrtümlich. dass die dritte und vierte bramne Binde am Torderrande zusammenhängen, was nirlıt der Fall ist. Man vergleiche meine Abbildung in den Genera Insectorum, Subfam. Ulidinue.

\section{Euxesta Schnusei, n. sp.}

$6 c^{\prime} q$ aus Peru (Meshagua; Olitober-November); Coll. Scunuse.

Steht in der Flügelzeichnung am nächsten der Eur. lusalix, Scus. Stirne so breit wie ein Auge, ziemlich gewölbt, lang und rauh behaart. Die rote Stricme ist auf einem Längsstreifen in dro Mitte und am Augenrande weisslich bereift, matt, dazwischen strejfnförmig wachsglänzend. Scheitelplatten und Ocellendreiechi hell stahlblau. Fühler. Backengruben, manclımal auch der äusserste Mundrand, ferner die Mitte 
des Prælabrums und die Taster rostrot. Clypeus stahlblau, unter den Fühlern weiss bestäubt. Thorax und Schildchen dunkel blaugrün, an den Pleuren glänzend, auf dem Rücken durch ein schütteres fuchsrotes Toment wenig glänzend. Hinter den Quernahtästen ein brauner Wisch. Von allen mir bekannten Arten hat diese den schlankesten Körperbau, sind Thorax und Hinterleib am schmälsten. Dadurch erinnert Eux. Schrusei an die Chaetopsis-Arten.

Hinterleib glänzend schwärzlich, mit etwas grünlichem Schimmer. Das erste Glied des Ovipositors herzförmig, ziemlich breit, etwas länger als breit.

Hüften rotgelb, vordere an der Aussenseite etwas grünlich schimmernd. Beine pechbraun, Schenkel an der Wurzel und an der Spitze oft ziemlich breit rot; manchmal auch nur die äussersten Knie rot. Metallglanz an denselben sehr gering. Füsse rot, die vordersten oft verdunkelt.

Flügel mit 4 breiten, braunen durchgehenden Querbinden. Die zweite ist die breiteste. Ihre äussere Grenze ist eine Linie von der Mündung der Subcosta über die kleine Querader zum Hinterrande; ihre innere Grenze gelit hart an den Basalzellen vorüber. Die 3. und 4. Binde erfüllen die ganze Flügelspitze jenseits der hinteren Querader, die an der inneren Grenze liegt, und lassen nur einen glashellen Streifen in der Mitte frei, der senkrecht auf den Adern steht, so breit wie die 3. Binde, aber schmäler als die 4. ist und oben nur die 2. Längsader berührt; seine untere Grenze ist bräunlich verwaschen.

Schüppchen bräunlich, Schwinger gelb.

Körper 5-6 mm, Flügel 4-5 $\mathrm{mm}$ lang.

A n merkung. Euxesla (basalis Schiner) = Schineri nom. nov, hat einen an der Wurzel gelben Hinterleib und plumperen Körperbau. Ihre Backen und Stirne sind schmäler, das Epistom weniger convex und weniger vorspringend. Der glashelle senkrechte Zwischenraum zwischen der 2. und 3. Binde ist streifenförmig gleichbreit, schmäler als die dritte und die gleichbreite 4. Binde. Bei Eux. Schnusei ist obiger Zwischenraum oben merklich breiter als unten, so breit als die dritte Binde, welche wieder schmäler als die 4. ist.

Der Zipfel der Analzelle springt bei letzterer deutlich über die Zelle vor, während er bei Eux. Schineri nicht stärker als der obere convexe Teil der Analzelle vortritt. Diese Art ist auch konstant etwas kleiner und hat kürzere, breitere Flügel.

\section{Euxesta acuta, n. sp.}

$1 \sigma^{7}$ aus Peru (Callanga); Ungar. National-Museum.

Stirne schmäler als ein Auge; spärlich und auch an den Seiten wenig auffallend belıart. Strieme, Fühler und Backengruben matt rot- 
gelb; Scheitelplatten und Ocellendreieck wie der obere Hinterkopf glänzend metallisch blau. Clypeus und das grosse Prælabrum, sowie die Taster hellgelb, seidenartig glänzend. Thorax und Schildchen schwärzlich, mit geringem metallisch grünen Schimmer. Rücken von einem bräunlichen Tomente ziemlich matt. Der Hinterleib erscheint nur glänzend schwarz oder pechbraun. Beine einfärbig pechbraun mit geringem Metallglanz, Hüften und Knie etwas heller, mehr rotbraun. Füsse nicht lichter. - Aderung sehr charakteristisch. Costa in der Mitte merklich verdickt und convex vorgewölbt. Radialader aus zwei flachen Bogen bestehend, die in der Ader unter einer nach vorne gerichteten Spitze zusammenstossen. Flügel bräunlich hyalin mit 4 dunkleren, verwaschenen Querbinden, deren Grenzen sehr undeutlich sind. Die zweite beginnt mit der braunen Subcostalzelle und geht senkrecht und gerade nach hinten, sich merklich verbreiternd. Die dritte geht über die hintere Querader, ist ziemlich gleichbreit und etwas nach aussen convex; sie ist schmal und durchgehend. Die vierte Binde hängt mit der dritten vorne nicht zusammen, liegt mehr über als an der Spitze, reicht bis unter die Discoïdalader herab und hat eine sehr verwaschene innere Grenze. Schüppchen braun, Schwinger gelb.

liörper und Flügel kaum $3 \mathrm{~mm}$ lang.

\section{Euxesta Bilimeki, n. sp.}

$1 \sigma^{\pi}$, Mexico (Quadalup), leg. Bilmme; k. k. Museum Wien.

Auf diese Art stimmt das, was Loww über die Euxesta Annonce, FAB. schreibt. Der Thoraxrücken hat aber eine bräunliche Bestäubung. Der wichtigste Unterschied liegt in der Flügeladerung und -zeichnung. Durch den langen, schlanken Zipfel der Analzelle ist unsere Art von allen anderen charakterisiert. Dieser Zipfel ist so lange wie die Analzelle selbst und länger als der bis zum Flügelhinterrande gehende Rest dèr Analader. Er ist scharf abgesetzt, gleichbreit, schlank, dann zugespitzt und durch eine rechtwinkelig gebogene Querader mit der Analzelle vorne verbunden.

Die Flügelzeichnung besteht aus 4 isolierten braunen Querbinden. Die zweite liegt unter der schwarzbraunen Subcostalzelle, wird nach hinten breiter und lichter, erreicht den Hinterrand des Flügels nicht ganz, da sie hinter der Posticalader verwaschen wird. Sie ist innen convex, aussen gerade und senkrecht auf die Costa begrenzt. Letztere Grenze berührt fast die kleine Querader. Die dritte Querbinde ist an der Discoïdalader ebenso breit wie die zweite. die vierte oder Spitzenbinde wenig schmäler. Die glashellen, milchig schimmernden Zwischen. 
räume sind in ihrer Mitte nur ein Geringes schmäler als die braunen Binden. Die dritte braune Querbinde ist an der Costa etwas schmäler als an der 4. Längsader; die hintere Querader liegt schief inmitten dieser Binde. Die Spitzenbinde ist vollständig isoliert und liegt fast symmetrisch; sie ist nur etwas mehr nach oben geschoben.

Schüppchen weisslich, Schwinger gelb.

Körper $5 \mathrm{~mm}$, Flügel $4 \mathrm{~mm}$ lang.

\section{Euxesta Macquarti, ${ }^{1}$ Schiner.}

Schiner, Novara-Dipt. p. 282. 152. (1868). - Venezuela.

Stirne wenig schmäler als ein Auge. Strieme gelbrot, etwas glänzend, lang und rauh behaart, am Augenrande weisslich. Scheitelplatten hell metallisch blau. Fühler, Backengruben. Epistom, Prælabrum und 'Taster gelbrot, der obere 'Teil des Clypeus metallisch blau, etwas weisslich bereift. Thorax von hellerem metallischen Grün, auf dem Rücken und dem Schildchen etwas rötlich bereift. Hinterleib schwarz; grïn, ziemlich glänzend.

Huften und Beine rotbraun. Schenkel in der Mitte zum grössten Teile, Schienen in geringerem Masse schwärzlich, metallisch grün schimmernd. Tarsen gegen die Spitze zu dunkler.

Zu dem ïbeı die Flügelzeichnung schon in der Tabelle Gesagten ist hinzuzufügen: Die 2. braune Querbinde ist oben sehr schmal und wird unten doppelt so hreit wie oben. Die 3. Binde ist ganz gerade, senkrecht, gleichbreit, sehr schmal und nur die Hälfte des davorliegenden glashellen Zwischenraumes breit. Die Spitzenquerbinde ist auf einem sehr schmalen Raum an der Costa deutlich von der dritten Querbinde getrennt. Die Mündungen der Mediastina und Subcosta liegen so nahe beisammen, dass diese Adern dort zusammenfliessen. Hileine Querader auf der Mitte der Discoïdalze\}le. Erste Hinterrandzelle durch die bauchig aufgebogene Discoïdalader an der Spitze ziemlich stark verengt. Die hintere Querader liegt inmitten des dritten braunen Querloandes. Discoïdalzelle länger als der letzte Abschnitt der Discö̈dalitler. Zipfel der Analzelle schlank und spitz, so lang wie die halbe Zelle. Bei Eur. Ammomar ist er gerade so lang, aber stumpfer.

Schwinger und Schüppchen rotgelb.

Körper $5 \mathrm{~mm}$, Hlügel $4 \mathrm{~mm}$ lang.

1 In Falle als die Lrophora aenea, Maquart, Dipt. exot., II (3) p. zug, tal. 30, fig. 7 wirklich dieşe Art ist, müsste der. Schner'sche Name weichen. Sicher ist es keineswegs ! 


\section{Euxesta acuticornis, n. sp.}

1 q aus Paraguay (Asuncion); Ungar. National-Museum.

Stirne so breit wie ein Auge, rotbramn, ziemlich rauh behaart. Ocellendreieck und Scheitelplatten stark glänzend, schwarz. Ebenso ist der Hinterleib samt Legeröhre und der Thorax mit dem Schildchen schwarz, selbst letzterer nur mit einem kaum merklichen grünen Schimmer. Wangen, Backengruben und Taster rostrot. Desgleichen die Fühler, deren drittes Glied aber oben und an der Spitze braun ist und eine ziemlich merkliche scharfe Ecke oben an der Spitze aufweist. Der Clypeus ist glänzend blauschwarz, unter den Fühlern weiss bereift. Die Fühler sitzen unter der Augenmitte.

Der Rücken glänzt weniger als die Pleuren. Hüften rostrot. Beine mit Ausnahme der roten Knie glänzend schwarzbraun.

Hinterleib mit wenig Glanz. Erstes Glied des Ovipositors sehr breit und stumpf, so lang wie der halbe Hinterleib, aber nicht viel länger als breit.

Flügel mit 4 Querbinden. Die zweite ist ausserordentlich breit und erfüllt den ganzen Flügelraum ungefähr von den Basalzellen an bis zur kleinen Querader und vom Vorder- bis zum Hinterrande des Flügels. Diese Binde ist umso breiter, als die Discoïdalzelle hier ausserordentlich verlängert und die Hälfte des Flügels lang ist und die kleine Querader erst im letzten Drittel dieser Zelle steht. Costalzelle glashell. Die 3. Querbinde ist gleichbreit, etwas schmäler als der davorliegende helle Zwischenraum, aber von gleicher Gestalt wio dieser, nämlich nach aussen etwas convex. Die 4. Querbinde liegt symmetrisch an der Spitze des Flügels, hängt am Vorder- und Hinterrande mit der 3. Querbinde, an deren Innenrande die hintere Querader liegt, zusammen und lässt einen schmäleren, isolierten glashellen Zwischenraum mit der vorhergehenden Binde frei. Zipfel der Analzelle kurz und stumpf.

Schüppchen bräunlich, Schwinger gelblich.

Körperlänge ohne Legerölre $4 \mathrm{~mm}$., Flügellänge $3 \mathrm{~mm}$.

\section{Euxesta Wettsteini, n. sp.}

$4 o^{7} q$ aus Brasilien (Exped. Wettstein). Hofmuseum Wien und Ungar. National-Museum.

Aus der nächsten Verwandtschaft von Eux. Ammonae F. und fasipemis, WuLP.

Der ganze Körper blau, mehr weniger dicht weisslich bereift, ohne jedes Grün. Stirne schmäler als bei den verwandten Arten, streifen- 
förmig. Strieme, Fühler, Backengruben und Taster hell rotbraun. Beborstung wie bei Eux. Anmonce, F. Clypeus unter den Fühlern etwas weisslich bestäubt. Rücken und Hinterleib mit wenig Glanz. Auf letzterem zeigt sich in gewisser Beleuchtung auch noch ein violettbrauner Reif. Thorax hellblau. Erstes Glied des Oripositors mit dem Abdomen gleichfärbig, so lang wie breit.

Beine von der Körperfürbung. Hüften teilweise, dann auch die Knie rötlich. Hie und da, besonders an den Schienen und den Fusswurzeln tritt eine rotbraune Grundfärbung unter dem metallisch Blauen hervor.

Flügel mit 4 dunkelbraunen, scliarf abgesetzten Querbinden, die bis an den Hinterrand reichen und dort kaum lichter werden. Die Zeichnung gleicht mehr der von Eux. fascipennis, Woup als jener von Eux. Annonae, F. Die zweite Binde ist hinten stark verbreitert. Der Zwischenraum zwischen ihr und der nächsten Querbinde ist unten stark verschmälert. Die dritte Binde selbst ist fast gleichbreit, geradlinig begrenzt und steht vollkommen senkrecht, nicht schief wie bei fascipennis. Die vierte oder Spitzenquerbinde liegt nicht oben an der Spitze, sondern genau am äussersten Ende und symmetrisch um die Cubitalader. Der helle Zwischenraum vor derselben ist nicht breiter als diese Binde und in der Mitte am breitesten. Zipfel der Analzelle kurz, aber schlank, die schliessende Querader stark hineingebogen.

Schüppchen liell bräunlich, Schwingerkopf kreideweiss.

Körper ohne Legeröhre und Flügel $4 \mathrm{~mm}$ lang.

\section{Euxesta arcuata, n. sp.}

$2 q$ aus Peru (Urubambafluss; November und 'Dezember); Coll. Schnuse.

Körper pechbraun, teilweise glänzend, nur an den Scheitelplatten metallisch blau schimmernd. Stirne fast so breit wie ein Auge, kurzhaarig, wie die Wangen und Backengruben rotbraun; an den Augenrändern und oben am Clypeus, unter den Fühlern, weiss bereift.

Fühler dunkelbraun, an der Wurzel etwas heller. Drittes Glied mit geradem Oberrande und ziemlich deutlicher scharfer Ecke oben an der Spitze. Fpistom auch etwas metallisch schimmernd. Rücken und Schildchen ziemlich matt, mit einem Stich ins Olivengrüne.

Hinterleib ebenfalls nur wenig glänzend. Erstes Glied des Ovipositor's mit dem Abdomen gleichfarbig, von der Gestalt eines gleichseitigen Dreiecks. Beine und Hüften pechbraun, Knie kanm heller.

Flügel glashell mit vier braunen Querbinden. Costal- und Sub- 
costalzelle ganz dunkelbraun. Die zweite Querbinde hat eine halbkreisförmige Gestalt, beginnt schmal und dunkel unter der Mündung der Mediastina, biegt bis zur Berührung mit der kleinen Querader nach aussen und wendet sich nun, immer breiter und etwas heller werdend, zum Hinterrande. Sie geht gerade durch die Mitte der Discoïdalzelle. Die dritte Querbinde ist sehr schmal, ziemlich, gleichbreit, senkrecht auf die Costa und geht den Flügel hindurch; an ihrer Innengrenze liegt die hintere Querader. Der symmetrisch gelegene Spitzensaum ist an seiner breitesten Stelle an der Spitze nur ein Drittel des davorliegenden gerade balbkreisförmigen glashellen Zwischenraumes breit und hängt oben und unten sehr schmal mit der dritten Querbinde zusammen.

Schüppchen braun. Schwingerkopf dunkelbraun.

Körper ohne Legeröbre und Flügel $3 \% \mathrm{~mm}$ lang.

Anmerkung. Diese Art und Eux. acuticornis zeichnen sich durch ein scharfes drittes Antennenglied aus und bilden gleichsam einen Übergang zu Chaetopsis. Die Arten dieser Gattung uuterscheiden sich aber ansserdem durch die viel schlankere Gestalt des Leibes, während die Euxesta-Arten einen melır plumperen Eindruck machen.

\section{Euxesta obliquestriata, n. sp.}

$60^{7} q$ aus Brasilien, Bolivien und Paraguay. Ungar. NationalMuseum, Wiener Hofmuseum, Coll. Schnuse.

Der Eux. sororculı, Wied. und Eux. latifasiutu, Wulp äusserst nahe stehend und leicht mit ihnen zu verwechseln. Von der ersten Art unterscheidet sie der immer etwas konkave nicht konvexe Aussenrand der zweiten braunen Flügelquerbinde, die Form der dritten Querbinde, welche unten viel breiter wird und die hintere Querader fast in der Mitte, nicht am Innenrande, enthält und die viel breitere Spitzenquerbinde, die stets breiter als der vorhergehende schmale, helle Zwischenraum ist.

Bei sorormulu ist der Zwischenraum zwischen der zweiten und dritten Binde schiefer und so gebogen, dass seine Concavität innen liegt. Der Costalsaum ist schmäler als der davorliegende Zwischenraum.

Eux. latifasciata, WubP unterscheidet sich nach der Beschreibung und Abbildung durch hinten rotes Schildchen und rote Beine, während die neue Art in allen sonstigen Eigenschaften mit der Loww'schen Beschreibung der Eux. sororculu harmoniert. Die Flügelzeichnung der WuLP'schen Art stimmt so ziemlich auf unsere Art, bis auf die Form des vor der Flügelspitze liegenden glashellen Bandes, welches seine Concavität aussen statt innen hat. 
Körper ohne Ovipositor und Flügel 4-5 mm lang.

Anmerkung. Eux. sororcula, Wied. hat Schnuse auch in Bolivien gesam. melt. Desgleichen Eux. Annonae. Fab.

\section{Euxesta insolita, n. sp.}

$1 \sigma^{\pi}$, Peru (Vilcanota); Ungar. National-Museum.

Eine durch Flügeladerung und -Zeichnung einzige Art dieser Gattung.

Stime etwas schmäler als im Auge. Strieme rotbraun, wachsglänzend, nur vorne und am Augenrande mit einigen längeren Borsten. Scheitelplatten und Ocellendreieck dunkel metallischgrün. Fühler, Wangen, Taster und Bockengruben dunkelrot. Drittes Antennenglied gegen die Spitze zu dunkler, zweimal so lang wie breit, oben ziemlich gerade. Clypeus, Prælabrum und Rïssel dunkel, schwarzgrün; Clypeus oben nur etwas weisslich bereift.

Thoraxschildchen schwarz, etwas grünlich metallisch schimmernd, Rücken wenig glänzend.

Hinterleib schwarz, kaum etwas glänzend, fast matt.

Hüften und die ganzen Beine einfärbig, pechbraun.

Radialader fast gerade, nur über der hinteren Querader mit einer schwachen Welle und an der Mündung etwas herabgebogen. Erste Hinterrandzelle fast parallel, kaum etwas verengt an der Spitze. Die kleine Querader steht auffallend weit vor der Mitte der Discoïdalzelle. Diese selbst ist beträchtlich kürzer als der letzte Abschnitt der Discoïdalader. Der Winkel der hinteren Querader mit der Posticalader ist ein spitzer.

Flügelwurzel, mit Ausnahme eines schiefen Spitzenfleckes der Costalzelle und der Basalzellen, ganz schwarzbraun. Über die Flügelmitte ziehen zwei schmale, scharf begrenzte und gerade Querbinden, die nach hinten divergieren. Die erste geht vom schwarzen Randmale schief nach unten und einwärts, hat die kleine Querader an der äusseren Grenze und kreuzt die Analader in der Mitte. Die zweite Querbinde steht dagegen senkrecht auf der Costa, schliesst die hintere Querader ein und teilt den Flügel in zwei Hälften. Mit ihr hängt vorne an der Costa eine schmale Spitzenbinde zusammen, die bis zur vierten Längsader reicht und gegen die Flügelspitze hin wenig breiter wird.

Schwinger und Schüppchen schwarzbraun.

Körper- und Flügellänge wenig üher $3 \mathrm{~mm}$. 


\section{Euxesta spoliata, Loww.}

Loww, Berl. entomol. Zeit., Vol. XI. p. 29s. (1867).

$50 \%$ aus Brasilien (Exped. Wetrsters) und Argentinien; Ungar. National-Museum.

LoEw's Beschreibung wäre zu ergänzen: Bei einigen Stücken sind auch die sonst grünlichbrannen Scheitelplatten ganz gelb. Die glänzende Stirne hat in der Mitte eine deutliche Querfurche. Kopf von vorne betrachtet zweimal so breit wie hoch. Der Augenrandwinkel neben den Fühlerwurzeln fast ein rechter. Clypeus weisslich bereift, Backengruben seidenartig weiss schimmernd. Die braune Spitze der Mittel-, seltener auch der Hinterschenkel fehlt manchmal. Seite 299, Zeile 3 der oben zitierten Beschreibung Loww's soll es statt "Hinterschienen". "Torderfüsse» heissen. Die Mittel- und Hinterfüsse sind rotgell, gegen die Spitze zu dunkler.

Das erste Glied des Ovipositors ist mit dem Hinterleibe gleichfärbig, viel schmäler als derselbe, an der Wurzel wenig breiter als an der Spitze, in der Mitte etwas verbreitert und zweimal so lang als dort breit.

Nur die Spitze der Subcostalzelle braun. Auf den Spitzenfleck passt wohl die Beschreibung, nicht aber die Abbildung Loew's.

Körper $4 \mathrm{~mm}$, Flügel $3 \mathrm{~mm}$ lang.

\section{Euxesta maculata, 11. sp.}

4 q aus Bolivien (Mapiri; Dezember und Jänner) und Peru (Meshagua; Oktober, November); Coll. Schnuse.

Stirne wenig schmäler als ein Auge. Strieme glänzend rotgelb, nach oben oft etwas dunkler, zerstreut, kurz beluart, in der Mitte mit einer seichten Quermulde; am Augenrande, an den Wangen sind die sonst roten Backengruben weiss hereift. Scheitelplatten goldgrün, ebenso der Clypeus und das Prælabrum. Lumula strmtschurm. Taster rotbraun. Fühler leuchtend rotgelb.

Thorax. Schildchen und Hinterleib metallisch grün, glänzend, nur auf dem Thoraxiücken durch schwachen Reif von geringerem Glanze, Hinten in den Quernahtästen am Präalarcallus schwach violettschwarz. Der Hinterleib glänzt am stärksten und schimmert bei einigen Stücken oben in der Mitte violett. Erstes Glied des Ovipositors violettschmarz.

Hüften und Beine glänzend schwarz, etwas metallisch; nur die Wurzeln der zwei hinteren Beinpaare rötlich.

Flügel glashell. Wurzel und Subcostalzelle gelblich. Ein kleiner 
schwarzbrauner Fleck in und unter der Spitze der Costalzelle. Ein schwarzbrauner Fleck an der Flügelspitze, so lang wie die Hälfte des letzten Discoidaladerabschnittes. Er erfüllt die Spitzen der Marginalund Submarginalzelle, hat am Innenrande an der Radialader eine rechtwinkelige Stufe und reicht nur bis in die Mitte der ersten Hinterrandzelle. - Schüppchen und Schwinger gelblich.

Körperlänge ohne Legeröhre $4 \mathrm{~mm}$. - Flügel $3 \mathrm{~mm}$ lang.

\section{Fragliche oder mir unbekannte Euxesta-Arten.}

1. Euxesta aryentina, Brétges, An. Mus. Buen.-Aires, (3) IV. p. 342 (1904). Herrn Dr. Kertész verdanke ich die mir unzugänglich gewesene Beschreibung dieser Art, deren lateinische Diagnose lautet:

"Nigra; antennis ferrugineis, capite, coxis, metatarsisque obscure ferrugineis, alis fuscis, 4-fasciato-albis: fasciis $2^{\mathrm{a}} 3^{\mathrm{a}}$ que marginem versus paulatim amplioribus, fascia $4^{\text {a }}$ ante apicem alæ sita, leniter curvata, costam marginemque haud attingente. Long. corp.: $4^{1} / 3 \mathrm{~mm} . "$

Nach dieser Diagnose und der etwas zu klein geratenen Flügelabbildung der Art, Fig. 4, käme man bei Benützung meiner Tabelle auf Punkt 22. Da nicht mit Gewissheit zu sagen ist, ob die braune Spitzenquerbinde des Flügels symmetrisch gelegen ist oder nicht, wären also die Arten Eux. Wettsteini, Schnusei, sororcula und obliquestriata zu vergleichen. Von allen diesen unterscheidet sich aber argentina dadurch, dass die glasshellen Zwischenräume zwischen den braunen Querbinden 1 bis 3 nach hinten breiter werden und dass die 2. braune Querbinde ungefähr die Breite der sie begrenzenden, eben vorhergenannten glashellen Bänder besitzt, während sie bei obigen 4 Arten bei weitem breiter ist. BrÉTHes vergleicht seine Art nur mit Eux. abdominalis, Loew, deren Flïgelzeichnung sehr ähnlich ist. Die hellen Zwischenräume sind aber bei dieser Art schmäler als die dunklen Querbinden und der Hinterleib ist an der Basis stets ockergelb.

2. Euxesta (Ortalis) basalis, Walker, in der Note bei Punkt 33 ler Tabelle erwähnt, wurde von Coquildett, Journ. N. Y. Ent. Soc., Vol. VIII, p. 24 (1900) wieder in Nord-Amerika aufgefunden, aber nicht eingehender beschrieben.

3. Herina decisu, WaLKer, in der Fussnote bei Punkt 27 der Tabelle zitiert, ist sicher eine Euxesta-Art. Ob sie ein Synonym zu Eux. sororcula, WiEd. oder obliquestriata oder eine eigene Art ist, kann nach der Beschreibung allein nicht entschieden werden.

" $q$ : Blackish green; head ferruginous; antennæ reddish; abdomen 
black; legs black; knees and tarsi ferruginous; wings black, white at the base and with 3 white bands; one near the base, the 2. just within the discal, transverse vein, the 3 . oblique and subapical; halteres whitish.

L. of the body 2 lin. - Wings 5 lin.» Brasilien.

4. Herinu intrulens, WaLker, Trans. Entom. Soc. Lond., n. ser. IV. p. $228(1856-1858)$.

" $q$ : Bluish black; head dark blue; ferrugineous in front; abdomen attenuated at the tip; legs black; tarsi testaceous at the base; wings white, with 4 bands which are blackish along the costa, pale grey hindward; 3. and 4. bands connected on the costa; halteres whitish.

L. of the body $1 \frac{3}{4}$ lin. - $21 / 2$ lin. Valley of the Amazon."

Wahrseheinlich dieselbe Art wie Euxesta Annonae, FABR.

5. Ortalis leucomelas, Warker, Trans. Ent. Soc. Lond., n. ser. V, p. 325 (IS60).

"Blackish-green; antennæ and legs black; tarsi piceons, wings white, with 4 black bands; first band near the base; 2. broad, much dilated hindward; third narrow, also dilated hindward; 4. costal, joining the 3. at much beyond half the length of the costa and extending thence to a little beyond the tip of the wing; discal transverse vein parted by one-fourth of its length from the border, and by more than twice its length from præbrachial transverse vein; halteres white.

L. of the body $2^{1} / 2$ lin. - Wings 4 lines. South-America."

Höchst wahrscheinlich eine Euxesta-Art!

6. Amethysa intermedia, Lynch-Arribalzaga, Stett. Entomol. Zeitg. Vol. 42, p. 191 (1881).

"A. Macquarti et propinquae, Schin. maxime affinis, sed differt prima pedibus nigris et 2. fascia obscura, 3. alarum cum 4. s. apicali antice conjuncta. Long. o 3 , ๆ $4.5 \mathrm{~mm}$.

Caput obsolete albo-pruinosum; frons obscure ferruginea, nigrosetosa, vertex epistomaque viridi-nigra, nitida; antennæ ferruginæ, articulo tertio cum stylo fusco. Thorax viridi-nigra, leviter chalybescens interdum parum auratus, obsolete albopruinosus, breviter nigro-setosus; pedes nigro-picei, nitidi, breviter nigro-setulosi, femoribus anticis extus viridescentibus, trochanteribus genibusque perparum ferrugineis, metatarsis posterioribus testaceis; alæ limpidæ, venis fuscis, fasciis 4 nigrofuscis ornatæ; prima subbasali, 2. omnibus latiore, completa, inter basin et nervulum transversum primum ista, siti contigua, postice amplicata et satis dilutiore, in margine postico alæ cum sequenti anguste conjuncta, 3. quoque completa, nervulum transversum 2. includente, ad marginem costalem cum 4. anguste conjuncta, quarta apicali; halteres ferruginei. Abdomen nigrum, nitidum, breviter nigro-setulosum.» 
Diese aus Pio-Colorado, Patagonien, beschriebene Art scheint der Eux. Amonae, Fab. sehr nahe zu stehen. Dieser Artenkreis ist überhaupt noch lange nicht vollständig bekannt.

7. Ortalis platystoma, Thomson, Eugenies Resa. Dipt. p. 572, 239 (1868). - Wulp, Biolog. Centr.-Amer., Dipt. Vol. II, p. 397.

Aus Panama. - Ich halte diese Art für identisch mit Eux. spoliata, Loew.

S. Ortalis obliqua, Thomson, Eugenies Resa, Dipt. p. 574, 241 (1868). Von dieser Art gilt das Gleiche, was ich von Herina lecisa, WaLKer gesagt habe. Sie stammt aus Peru.

9. Ortalis punctifrons, Thomson, 1. c. p. 573, 240 (1868) und

10. Ortalis spathulata, Thonson, 1. c. p. 574, 942, beide aus Puna, Indien.

Ich halte beide Arten für echte Euxesta-Arten und vermute deshalb, dass die Vaterlandsangabe Puna ein Irrtum ist. Aus dem asiatischen Faunengebiete ist bisher keine echte Euxesta-Art bekannt geworden. Auch

11. Euxesta primu, Osten-Sacken, Ann. Mus. Gen., Vol. XVI, p. 470 (1S81) aus Celebes und Neu-Guinea, siehe Kertész, Termész. Füz., Vol. XXII, p. $18 S$ (1S79), ist eine ron Euxesta verschiedene, wenn auch nahestehende Ulidinen-Gattung. Desgleichen ist

12. Euxesta farvula, Wulp, Termész. Füz. Vol. XX, p. 141 (1897) aus Ceylon keine Euxesta-Art, überhaupt keine Ortalidine, sondern eine Tephritine, wie sie von Meisere auch in der Tijdschr. v. Entom., Vol. 51, p. 126 (1908) aus Semarang angeführt wird. Sie gehört in das Genus Acidia im Sinne Loww's und ist den zwei afrikanischen Arten Acidia melania, Bezzi und Acidia (Ortalis) Sanctae-Mariae, Bigot nahestehend. Ich sah die Wulp'sche Type aus dem Ungar. National-Museum. 


(Sonderabdruck aus dem »Zoologischen Anzeiger « Bd. XXXIV. Nr. 20/21 vom 10. August 1909.)

\section{Revision der Chrysomyza-Arten (Dipt.).}

Von Friedrich Hendel, Wien.

(Mit 8 Figuren.)

Zu allererst wurde diese Gattung von Fallén in seiner »Nova Diptera disponendi methodus", Tundae 1810 p. 11. Nr. 33 als Physiphora beschrieben und den Syrphiden zugesellt. Im Jahre 1817 änderte Fallén in seinen Dipteris Sueeiae Namen und systematische Stellung der Gattung, taufte sie wegen Vergebung des Namens Physiphora in Chrysomyza um und stellte sie num neben das Genus Scenopimus.

Was nun die nomenelatorisehe Seite dieser Frage, die ja allein nur mehr in Betracht kommt, anbelangt, so gibt es nach C. C. Sherborns Index Animalium, 1902 vor Fallén weder ein Genus Physiphora, noch ein Genus Pliysophora, wie die richtige Sehreibweise lauten würde, sondern nur eine Coelenteraten-Gattung. Plyyssophora P. Forskail, Descr. Animal. 1775. 119, welehe in allen andern Nomenelatoren und zoologischen Handbiichern emendiert als Phy/sophora Forsk. mit ungenauen Angaben zitiert wird. Auch Poehe macht in seinem Supplement zu C. O. Waterhouses Index Zoologieus (Zool. Annalen, II. S. 322, 1908) auf die ursprüngliche Schreibweise aufmerksam und zitiert: Physsophora Forskal, Descr. Animal., 1775 p. XXV (cf. p. 112). Da aber die bekannte Röhrenquallengattung ihren Namen nur von ıũoc, Blase und 'pogź(1) erhalten haben kann, folglich richtig geschrieben ebenfalls wie die Fallénsche Gattung Physophora heißt, muß unsre Dipteren-Gat- 
tung Chry:omy:a genannt werden, es wollte denn jemand Plyysiphora bestehen lassen.

Der viel jüngere Name Chloria Schiner, der hier und da auch heute noch gebraucht wird, hat aus den schon von Loew eimmal im Jahrb. der k. k. gelehrt. Gesellschaft in Krakau 1870 S. 13 für den Gebrauch des Namens Anthomyia geltend gemachten Gründen keine Berechtigung.

Ich gehe nun gleich auf die Beschreibung der Arten ïber, weil ich eine genaue Charakteristik der Gattung, sowie Mitteilungen ïber die Biologie derselben ohnehin für die Genera Ulidinamm vorbereite.

Bestimmungstabelle.

Erste Hinterrandzelle vor dem Flügelrande geschlossen, oder deutlich gestielt

Erste Hinterrandzelle offen oder erst am Rande geschlossen

1) Hinterleib ausgedehnt glänzend gelb gefärbt. Erste Hinterrandzelle nicht gestielt

3. Clr. flavipes Karsch.

Hinterleib einfarbig metallisch grün oder blau

2) Epistom, Prälabrum und Taster schwarz. Scheitelplatten grün oder blau

Fpistom, Prälabrum und Taster gelb. Scheitelplatten gelb, nie metallisch .

2. Chr. africana n. sp.

3) Vorderfüße ganz schwarz

Metatarsus der Vorderfüße fast ganz weißlich .

4) Rarlial- und Cubitalader schwach, aber merklich gebogen; der letzte Abschnitt der Discoidalader bis zur Mïndung ganz gleichnäßig gebogen. Schildchen kurz, oben deutlich gewölbt, an der Spitze abgerundet

7. Chr. ehalybea 11. sp.

2. und 3. Längsader gerade oder fast gerade; der letzte Abschnitt der 4. Längsader hinter der Querader ausgebaucht, dann aber bis zur Mündung gerade. Schildchen länger, oben etwas abgeflacht, an der Spitze kantig. . . 6. Chr smaragdina Loew.

5) Kopf ganz schwarz, ohne Rot. Fiihler fast so lang wie das Untergesicht; 3. Glied gut zweimal so lang wie breit, oben gerade. 6) - Kopf ganz oder zum gröliten T'eil rotgelb. Fühler kurz, 3. Glied oval, ein und einhalbmal so lang wie breit, oben konvex. Rücken matt ziseliert

4. Chr. demandata Fabricins.

6) Rücken glänzend, wie poliert. Von den 4 Stirnlängsleisten über der Querfurche sind die äußeren merklich länger als die zwei mittleren. Schildchen gewölbt. Stirn vorn ohne Punkte.

8. Chr. longicomis $\mathrm{n}$. sp.

Rücken matt. Alle 4 Stirnleisten von gleicher Länge. Schildchen abgeflacht. Stirn vorn punktiert.

5. Chr. tarsasa Macquart. 
Anmerkung: Ulidia smaragdi Walker, List. Dipt. Brit. Mus., Vol. 4 p. 1059, aus unbekanntem Vaterlande, gehört in die Verwandtschaft der Chrys. demandata Fab. Die Beschreibung bietet keine Anhaltspunkte, sie als besondere Art zu unterscheiden, ja gestattet die Identifikation mit einer dunkelköpfigen Form der Fabriciusschen Art. Sicherheit kamn natiirlich nur eine Untersuchung der 'Type in London bringen.

\section{Chrys. aenea Fabricius.}

Musea aenea Fabricius, Ent. Syst. IV. p. 335.98 (1794).

Sareus aeneus Fabr., Syst. Antl. p. 257.5 (1805).

Itlidia acnea Wiedemann, Außereur. zweifl. Ins. Bd. II. p. 566. 2 (1830).

clausc Macquart, Dipt. exot. II. 3. p. 251, Pl. 33. 9 (1843).

Chloria clausa v. d. Wulp. Tijdschr. v. Entom. XXIII. p. 180. 41. Pl. 11. 3.

Uliulia melanopsis Walker, List. Dip,t. Brit. Mus. Pt. 4.1058 (1849).

- livergens Walker, Dipt. Saund. Pt. IV.p. 397 (1852).

- fulieeps Walker, Trans. Entom. Soc. Lond. n. ser. IV. p. 227 (1857).

Chloria clausa de Meijere, Tijdschr. v. Entom. IJ. p. 125 (1908).

Scheitelplatten, Ocellenhöcker und oberer Hinterkopf goldgrin, Cerebrale und der ïbrige Kopf glänzend rotgelb. Stirn so breit wie ein Auge, selten dunkler, mehr rotbraun, häufiger noch mit deutlichem blauen oder grünlichem Metallschimmer. Alle Übergangsnïancen vom hellen Gelb bis zum dunkleren Rot, vom Fehlen des Metallglanzes bis zum Vorherrschen desselben treten in der Stirnfïrbung auf. Stirnaugenränder vor den Scheitelplatten von einem nach vorn keilförmig zugespitzten weißhestüubten Streifen begrenzt; derselbe wird nur neben den Fühlerwurzeln schmal unterbrochen und setzt sich an den Wangen als feine weiße Linie um die Angen herum fort. Über der in der Stirnhälfte gelegenen Querfurche der Stirn liegen vor und zwischen den Scheitelplatten vier ungefähr gleichlange und gleichgroße erhabene Längsleisten, die sich deutlich und scharf abheben. Ein Börstchen jederseits am Augenrande, noch vor den grünen Scheitelplatten, und 1 Ocellarbörstchen sehr schwach entwickelt. Scheitel- und Postvertikalpaar normal. Clypeus im Profil gebrochen - der untere Teil - Epistom - nicht stärker als der obere vortretend. Epistom in der Mitte in verschiedener Ausdehnung, aber immer merklich glänzend schwarz oder schwarzbram. Der obere Clypens, über der Querfurche und unter den Fühlern dicht weiß bestäubt. Lunula glänzend gelb. Prälabrum, 'Taster und Rïssel dunkelbraun bis schwarz. Augenbandierung nach Figiu 4.

Fühler rotgelb, merklich kiurzer als das Untergesicht. Drittes Antennenglied manchmal an Oberrande gelorännt, von elliptischer Gestalt, $1{ }^{1} / 2$ mal so lang wie breit.

Thorax hell goldgriin, nie stark verdunkelt, mit rötlichem oder auf „lem Rücken und auch den Plouren blauem Schimmer. Rüicken ziem- 
lich glänzend, aber nicht poliert, sonderu durch eine feine Ziselierung etwas matt. Das rötlich schimmernde Schildchen oben etwas gewölbt.

Hüften und Beine rotgelb. Alle Schenkel mit einem dunkelbraunen Wisch in der Mitte, oder nur das eine oder das andre Paar gefleckt oder alle ganz gelb. Vorderschienen in verschiedener Ausdehnung von der W urzel her dunkel braun gefürbt. Vorderfüße mit Ausnahme des weißgelben Metatarsus schwärzlich. Vorderschenkel unten in der Spitzenhälfte mit fünf schwarzen Dörnchen besetzt.

Erste Hinterrandzelle vor dem Rande geschlossen und gestielt. Dieser Stiel erscheint als eine Fortsetzung der Discoidalader und bildet mit der Costa einen ungefähr rechten Winkel. Der letzte Abschnitt der Discoidal-sowie der Cubitalader sind ziemlich gleichmäßig und gleichstark bis zur Vereinigung gebogen. Radialader sehr schwach, aber doch merkbar gebogen. Schüppchen und Schwinger weißlich bis gelblich.

Hinterleib glänzend goldgrün, an den Seiten und auf dem etwas verlängerten 5. Tergit schwach ziseliert, in der Mitte glatt poliert. In der Mitte herrscht blawer und violetter Schimmer vor, an den Rändern rötlicher. Erstes Glied des Ovipositors kurz trapezförmig, kürzer als breit, violett schimmernd. Hypopyg und letztes Sternit des or rotgelb. Körper ohne Legeröhre 4-6 mm, Fliigel 3,5-4,5 mm lang.

Geogr. Verbreitung: Mir liegen Stücke vor aus Java, Hinterund Vorderindien, Formosa, Borneo und Mauritius.

Ich habe im Wiener Hofmuseum den Sargus acneus Fab. der Wiedemannschen Sammlung, sowie 2 Typen von Bigot der Ulidia clausu Macquart gesehen.

Die drei oben angeführten Wa lkerschen Arten lialte ich nach den Beschreibungen für ziemlich sichere Synonyma.

\section{Chrys. africana n. sp.}

Chrysomy a clausa Karsch, Berl. Entom. Zeit. XXXI. S. 379 (1887). Bezzi, Bull. Soc. Ent. Ital. XXXIX. p. 132 (1907).

Ocellenhöcker metallisch griin, Scheitelplatten jedoch immer wie das Cerebrale glänzend rotgelb. Oberer Hinterkopf goldgrün. Stirne wie der ganze Kopf glänzend rotgelb, bei keinem der mir vorliegenden 21 Stiicke verdunkelt oder mit Metallschimmer versehen. Die weißbestäubten Stellen wie bei acnea F., auch die Unterbrechungsstelle an den Wangen neben den Fiihlerwurzeln erscheint wie ein dunkler Punkt. Die vier erhabenen Längsleisten in der oberen Stimlälfte sind viel weniger scharf differenziert und heben sich wenig deutlich von der Stirnfläche ab; dasselbe gilt von den Gesichts- und Backenleisten. Clypeus relativ stärker gekielt als bei aenca, oben in gleicher Weise bestäubt, unten aber immer, ebenso wie Prälabrum und 'Taster hell 
rotgelb. Im Profil tritt die Stirn und der Clypens etwas stärker vor die Augen hervor, als dies bei nenea der Fall ist; auch die Backen sind etwas stärker aufgeblasen. Fühler hell rotgelb, in der Länge und Form wie bei aenea. Augenbandierung nach Fig. 8.

Thorax und Schildehen hell goldig grün, nie merklich verdunkelt, mit mehr oder weniger ausgebreitetem blauen Schimmer. Rötlicher Metallglanz fehlt stets, wodurch sich diese Art von aenea, deren Schildchen stets rötlich glänzt, auch unterscheidet. Das Schildelıen ist oben ganz eben abgeflacht.

Hüften und Beine hell rotgelb, nur die Vorderschienen an der Wurzel etwas gebräunt. Vorderfüße mit Ausnahme des weißlichen Metatarsus schwärzlich. Vorderschenkel wie bei aenea bedornt.

Erste Hinterrandzelle gesehlossen und gestielt. Der Stiel steht auf der Costa senkrecht. Der letzte Absehnitt der Discoidal- und Cubitalarler für sich gleichmäßig, aber beide nicht gleichstark gebogen, da die Ausbauchung der letzteren Ader etwas stärker gekriimmt ist.

Ilinterleib glänzend goldgrün, in der Mitte mit stärkerem Glanze, wie poliert, und blauem Schimmer. Erstes Glied des Ovipositors kurz trapezförmig, kürzer als breit, dunkel schwarzblau. Hypopyg und letztes Sternit des or metallisch grün.

Körper ohne Legeröhre 5-6 mm, Flügel 4-4,5 mm lang.

Geogr: Verbreitung: Ostafrika, Assab.

\section{Chrys. flavipes Karsch.}

Chrysomy:a flaripes Karsch, Berl. ent. Zeit. Vol. XXXI. s. 380 (1887).

Bezzi, Bull. Soc. Lint. Ital. Vol. 39. p. 138. 207 (1901).

Karseh sagt von dieser Art nur folgendes: „Das Berliner Museum besitzt eine zweite afrikanische, noch kleinere Chrysom!y:a-Art vom Senegal: Chr. flavipes in litt. Bei dieser ist die erste Hinterrandzelle nicht gestielt, sondern es biegt die Vorderrandader vor der Flügelspitze in die Fliigelftiche ein und trifft so mit der Spitze der ersten Hinterrandzelle zusammen, daß der Flügehrand über die Zelle frei vorragt. "

Da diese kurze Charakteristik auf meine Art zutrifft, glaube ich obigen Namen amnehmen zu dïrfen.

Kopf in bezug auf Form und Färbung wie bei africana, nur erseheinen mir die Augen etwas rundlicher. Augenbandierung nach Figur 7.

Ebenso ist der Thorax mit dem Sehildchen wie bei dieser Art gefürbt. Das Schildchen ist oben aber nicht so stark abgeflacht.

Hiiften und Beine hell rotgelb. Vorderschienen an der Spitze braun; Vorderfiiße schwarz, deren Ferse weißlich. Vorderschenkel mit meist fünf kurzen schwarzen Dornen unten in der Spitzenhälfte. 
Zweite und 3. Längsader fast ganz gerade. Die 4. Längsader biegt allmählich zur dritten auf und vereinigt sich mit derselben, eine stumpfe abgerundete Spitze der ersten Hinterrandzelle bildend, in demselben Punkte, wo die vom häutigen Flügelrande etwas abgeriickte Costa mit der Cubitalader zusammenstößt. Die 1. Hinterrandzelle ist also wohl vor dem Rande geschlossen, aber eigentlich nicht gestielt, da hier der Stiel die Fortsetzung der Costa ist und mit dieser keinen Winkel bildet wie bei den zwei andern Arten.

Hinterleib glänzend rotgelb mit schwachem grünen Metallschimmer. Drittes und 4. Tergit nur seitlich oder ganz goldgrïn, fünftes wieder rotgelb, manchmal aber stark griin schimmernd. 1. Glied des Ovipositors kurz trapezförmig, hellgelb. Hypopyg und Bauch gelb.

Körper ohne Legeröhre und Fliigel $3 \mathrm{~mm}$ lang.

Geogr. Verbreitung: Senegal (K arsch), Ägypten (Schmiedeknecht), Ostafrika, Assab. $4 \sigma^{\top}$ 오.

Bezzi loc. cit. schreibt: »Una femmina colle tibie rosse, ma coi femori neri, perciò è dubbio se appartenga veramente a questa specie.*

\section{Chrys. demandata Fabricius.}

Musea demandata Fabricius, Entom. Syst. Suppl. p. 564 (1798).

Ulidia demandata Meigen, System. Beschr. Vol. 5. S. 386.1 (1826).

Chrysomyaa splendida Fallén, Dipt. Suec. Scenop. p. 4. 1 (1817).

Chloria demandata Schiner, Fauna Austr. Vol. 2. p. 86 (1864).

Ausführlichere Zitate siehe in Genera Insectorum, Subfam. Ulidinae. Eine Ulidia bicolor Macquart gibt es nicht!

Eine in der Färbung sehr variable Art. Da aber verschieden gefärbte Tiere am gleichen Standort gefunden werden, kann man von geographischen Varietäten nicht sprechen.

Am Kopfe ist der obere Hinterkopf, die Scheitelplatten und der Ocellenhöcker immer heller oder dunkler metallisch grün. Der uibrige Teil des Kopfes, wie Cerebrale, Stirn, Untergesicht, Backen usw., ist bei den hellsten Stiicken rotgelb, auch die Fühler können ganz hell rotgelb sein, um in allen Übergängen und Abstufungen gelbrot, rot, rotbraun bis fast schwarzbraun zu werden. Im letzteren Falle treten an den verdunkelten Stellen meist auch metallisch grïne Schimmer oder Reflexe auf. Die Verdunkelung beginnt gleichzeitig im oberen Teile der Stirn und dann auf dem Epistom und kann verschiedene Ausdehnung annehmen. An dieser Verdunkelung nehmen auch die Fiihler Anteil. Das 3. Glied ist an Oberrande meist etwas gebräunt, kann aber ausgedehnt braun erscheinen. Es ist kurz oval.

Stirn fast etwas breiter als ein Auge. Die 4 Längswiilste iiber der Querfurche der Mitte sind nicht sehr deutlich differenziert, nur flach.

Die seitlichen reichen etwas weiter nach vorn als die zwei mittleren, 
undeutlich voneinander getrennten. Die weiße Bestäubung der Stirn und Wangen ist die gleiche wie bei aenea Fabr. Das Profil des Clypeus zeigt eine gebrochene oder konkave Linie, ähnlich jener von aenea Fab. Auch hier tritt der Mundrand nicht oder kaum über die Insertionsstelle der Fühler vor. Der Teil des Clypeus iiber der Querfurche ist dicht weiß bestäubt, die Lunula jedoch glänzend. Wangen und Backengruben in der Regel mindestens rötlich. Prälabrum rotgelb bis schwarz. Taster nie hellrot, dunkelrot bis schwarzbraun.

Thorax und Schildchen smaragdgrün, goldig schimmernd, sogar oft blau, dann in verschiedenen Nïancen bis ins dunkle Olivengriin, ja ins metallisch Schwarzbraune übergehend. Der Rücken ist nie glänzend poliert, sondern immer äußerst fein ziseliert, daher etwas matt. Das Schildchen ist oben abgeflacht. Bei den meisten Stiicken ist der Ruicken vor dem Schildchen in der Mitte oder seitlich etwas eingedrückt. Die feinen Punktreihen in der Linie der Dorsocentralborsten, dureh feine Härchen hervorgerufen, treten bei den hellgrïnen Exemplaren als rote Längslinien hervor. Auch in der Mitte zwischen beiden liegt dann gewöhnlich eine hinten abgekürzte, breitere rote Längsstrieme.

Hiiften und Beine glänzend dunkel rotbraun bis schwarz, meist mit deutlichem violetten Metallschimmer, namentlich an den Schenkeln. Die Fiiße der hinteren Beinpaare weißlich gelb, die des vorderen Paares schwarz, mit Ausnahme des gelblich weißen, nur an der Spitze schwarzen Metatarsus. Vorderschenkel unten in der Spitzenhälfte mit gewöhnlich sechs kurzen schwarzen Börstchen besetzt.

Erste Hinterrandzelle an der Miindung fast geschlossen. Radialund Culbitalader schwach, aber deutlich gebogen. Der letzte Abschnitt der Discoidalader ist vor der Mitte ausgebaucht, dann aber bis zur Mündung hin fast gerade.

Hinterleib glänzend schwarzgrï bis schwarz. Das 1. Glied des Ovipositors und meist auch das letzte Abdominalsegment schwarz, oft violett schimmernd. Hypopyg schwarz. - Körper $4-5$ mm, Flügel $3-4 \mathrm{~mm}$ lang.

Geogr. Verbreitung: Mir liegen Stücke vor aus Europa, Ägypten, Ostafrika, Kapland, Vorderindien. - Zitiert wurde die Art aus ganz Europa, Nord- und Ostafrika, Kanar. Inseln, Seichellen und Nordamerika. Es ist also kein Zweifel, daß wir es mit einer über den ganzen Erdball verbreiteten Art zu tun haben.

\section{Chrys. tarsate Macquart.}

M a cqu art, Diptères exotiques, Suppl. 4. p. $301 / 1850$.

Kopf glänzend schwarz, mit violettem Metallschimmer. Stirn etwas breiter als ein Auge, mit vier ganz gleichgroßen und gleichlangen 
Längswïlsten ïber der Querrinne der Mitte. Die Vorderhälfte der Stirn, besonders der Vorder- und Seitenrand, deutlich fein punktiert. Die weile Bestäubung am Augenrand und an den Wangen wie bei aenea Fab. Clypeus im Profil kaum etwas konkav, fast ganz gerade, in der oberen Hälfte mit Ausnahme der glänzenden Lunula weiß bereift. Backengruben und Cerebrale etwas rötlich durchscheinend. Prälabrum und Taster auch schwarz. - Füller fast so lang wie das Untergesicht, schwarzbraun. Drittes Glied länglich, gut zweimal so lang wie breit, oben fast gerade. Augenbandierung nach Figur 2.

Thoraxrïcken und Schildchen blangrin, durch Ziselierung ganz matt, nicht glänzend. 3 Längsstriemen sind angedeutet. Schildchen oben flach. Mesopleuren heller matt grün, nur an den Nähten glänzend.

Hinterleib einfarbig glänzend schwarz. Erstes Glied des Ovipositor's von gewöhnlicher Form, violettschwarz.

Beine und Hüften glänzend metallisch schwarz. Vorderfiiße schwarz, Metatarsus mit Ausnahme der Spitze gelblichweiß. Die Füße der beiden hinteren Beinpaare rötlich gelblich, an der Spitze dunkler.

Erste Hinterrandzelle am Rande stark verengt, aber deutlich offen, nicht so stark wie bei demumdatu Fab. verjïngt. Radial-, noch mehr aber die Cubitalader gerade gestreckt. Der letzte Abschnitt der Discoidalader ist der ganzen Tünge nach fast gleichmäßig stark gebogen und nur vor der Mitte kaum merklich stärker bauchig.

Körper olme Legeröhre $5 \mathrm{~mm}$, Flïgel $4 \mathrm{~mm}$ lang.

Geogr. Verbreitung: 1 \& aus Kapland von Dr. Brauns gesammelt. Macquart erwähnt die Insel Bourbon als Fundort.

\section{Chrys. smaragdina Loew.}

Loew, Sitzber. Akad. Berlin 1852. S. 661. Nr. 33 (Utidia).

Peter's Reise, Mosamb, Zool. Vol. V. S. 32 (1862 (Ulidia).

Zeitschu. f. ges. Naturw. V. 42. S. 109 (1873) (Chrysomy;a).

Syn. Thidia mifrons Walker, Nintomologist, Vol. V. p. 345. 84 (Ulidiu) (1871).

Bezzi, Bull. Soc. Ent. Ital. Y. 39. p. 138. 208 (1908).

In Aussehen der demandatu ähnlicher als der gleichfalls schwarzfiiligen chalyburu. Stirn, Junula, Wangen und Backengruben rotbraun, bald heller, bald dunkler. Scheitelplatten und Ocellendreieck metallisch griin, wie der obere Hinterkopf; der untere ist glänzend braunschwarz. Der (Quereindruck der Stirn und die vier fast gleichgroßen erhabenen Längsleisten ïber demselben zienlich deutlich ausgeprägt. Unter den Scheitelplatten auf der Stirn jederseits ein keilförniger weißbestäubter Fleck, der sich nach unten verjüngt, als feine weiße Linie um die Augen herumläuft und neben den Fiihlerwurzeln einen oben und unten durch ein weißes Querstrichlein begrenzten dunklen Punkt einschließt. - Clypeus glänzend pechbraun, auf dem Epistom metallisch grün schimmernd, 
über der in der Mitte liegenden Querfurche, unter den Fühlern, weiß bestäubt, im Profil unten nicht stärker als die Stirn vorspringend, mälig konkav gebrochen. Prälabrum, Rüssel und Taster dunkel, schwarzbraun. Augenbandierung nach Figur 3.

Fühler rotbraun; das 3. Glied derselben verdunkelt, bald mehr, bald weniger; in Größe und Form wie bei demandata Fab.

Thorax und Schildchen heller oder dunkler smaragdgrïn, wie bei der Fabriciusschen Art durch Ziselierung ziemlich matt. Manchmal auf dem Riicken und Schildchen vorherrschend blau; ersterer immer mit drei grïn oder rotschimmernden Längslinien in der Mitte, letzteres oben etwas abgeflacht aber nicht ganz eben wie bei demandata.

Hinterleib glänzend grïn- oder blauschwarz, oder vorn mit olivgriinem, weiter hinten dann mit blauem Schimmer. 1. Glied der Legerölıre meist blauschwarz, kurz trapezförmig, breiter als lang. Banch und Hypopyg schwärzlich.

Hüften und Beine, auch der Metatarsus der Vorderfiiße schwarzbraun, ohne Metallschimmer oder nur mit Spuren desselben an den Schenkeln; die äufersten Knnie rötlich; die Füßje der hinteren Beinpaare sind gelb.

Erste Hinterrandzelle am Rande fast geschlossen. Radial- und Cubitalader schwach gebogen. Der letzte Abschnitt der Discoidalader hinter der Querader stark ausgebaucht, dann aber bis zur Mündung fast ganz gerade.

Körper ohne Legeröhre 4-5 mm, Flügel 3-4 mm lang.

Geogr. Verbreitung: Mosambik (Loew), Ägypten (Walker); 7 or $Q$ aus Ostafrika - Katona - und Kapland liegen mir vor.

Anmerkung: Die Synonymie mit der Walkerschen Art stellte Loew am angegebenen Orte in der Zeitschr. f. ges. Naturw. fest. Dort sagt er auch: "Chrysom. smaragdina steht der demandata Fabr. sehr nahe, unterscheidet sich von derselben aber durch die ganz und gar schwarzen Vorderfïße, während bei allen Abänderungen der Chrys. demandatu das 1 . Glied derselben nur an der Spitze schwarz gefürbt ist. «

\section{Chrys. chalybea n. sp.}

Kopf glänzend bramnschwarz, nur die Vorderhälfte der Stirn, die Wangen und die Backengruben rotbraun. In der Mitte des Stirnaugenrandes und neben den Fühlerwurzeln an den Wangen ein weiß bereifter kleiner Fleck. Von den gewöhnlichen vier erhabenen Tü̈ngsleisten über dem Quereindruck auf der Stirnmitte ist kaum eine Spur wahrzunehmen. Charakteristisch für diese Art ist besonders das Gesichtsprofil. Die Querfurche des Clypeus befindet sich über der Mitte und der darunter befindliche Teil, das Epistom, springt viel stärker als bei allen 
andern Arten, das heißt ein merkliches Stiick über die Fühlerwurzeln vor. - Fühler rotbraun, 3. Glied, namentlich am Oberrande verdunkelt, ziemlich schlanker als bei demandata $\mathrm{F}$., am Oberrande weniger abgerundet. Prälabrum, Rïssel und Taster schwarzbraun. Augenbandierung nach Figur 6.

Thorax und Schildchen schwarz, stahlgriin bis stahllblau schimmernd. Rücken etwas matt ziseliert, Schildchen deutlich gewölbt.

Hüften und Beine, auch der Metatarsus der Vorderbeine, pechbraun, olne Metallschimmer. Die Füße der zwei hinteren Beimpaare sind gelb, deren Kunie rotbraun.

Die 1. Hinterrandzelle ist am Fliigelrande selbst geschlossen. Die 3. und 4. Längsader stoßen unter sehr spitzem Winkel in einem Punkte an der Costa zusammen. Radial- und Cubitalader schwach, aber deutlich gebogen. Der letzte Abschnitt der Discoidalader ist fast ganz gerade oder seiner ganzen Länge nach gleichmäßig schwach gebogen, nirgends stärker ansgebaucht.

Hinterleib schwarz, stark glänzend, meist dunkelblau, seltener stahlgrün schimmernd. Erstes Glied des Ovipositors gleichfarbig, trapezförmig, fast so lang wie breit. Bauch und Hypopyg pechbram.

Körper olıne Legeröhre $4-4,5$ mm, Flïgel 3,5 mm lang.

Geogr. Verbreitung: $5 \sigma^{\top}+$ aus Sary Yasy (März) in Turkmenien.

Anmerkung: Diese Art unterscheidet sich von smaragdina Loew durch die Form und Lünge des 3. Fühlergliedes, die fast glatte Stirn, den größeren Glanz des Rückens, den Verlauf des letzten Discoidaladerabschnittes, namentlich aber durch das größere und stärker vorspringende Epistom hinlänglich.

\section{Chrys. longiromis n. sp.}

Kopf ganz glänzend schwarz. Stirn etwas breiter als ein Auge, bläulich oder violett metallisch schimmernd. Stirnaugenränder und Wangen wie bei acrea Fab. weiß gesïumt und nit dem gleichen oben und unten weiß eingefaßten dunklen Fleckchen zwischen den Fühlerwurzehn und Auge. Von den vier erhabenen Längsleisten in der Stirnmitte sind die mittleren verkürzt, die seitlichen nach vorn hin etwas verlïngert. Clypeus in der Form wie bei acnea, aber im Profile sehr wenig konkav. Lunula und Backengruben etwas rötlich. Clypeus unter den Fühlern weiß bestäubt. Unter der Lunula zeigt sich ein Y-förmiger weißbestïubter Fleck.

Prälabrum, Taster und Rüssel glänzend schwarz. Augenbandierung nach Figur 1. 
Fühler dunkel rotbraun, fast so lang wie das Untergesicht, lang oval, gut zweimal so lang wie breit, oben gerade.

Thorax dunkel sehwarzgrün, anf dem Rücken glänzend, wie poliert, oft blau oder violett schimmernd. Schildehen und 1. Glied des Ovipositors immer violettschwarz, ersteres oben deutlich gewölbt..

Hüften und Beine glänzend violettschwarz, Füße weißlichgelb, Vorderfüße schwarz, die Ferse derselben mit Ausnahme der äußersten Spitzen gelblichweilß. Vorderschenkel in der Spitzenhälfte mit meist vier kurzen, gebrechlichen, keineswegs dornenartigen Börstehen besetzt.

Erste Hinterrandzelle an der Fliigelspitze fast geschlossen. Radialund Cubitalader auffallend gerade, erstere vor ihrer Mündung merklich nach aufwärts zur Costa gebogen, wodurch die Submarginalzelle dort erweitert erscheint. Der letzte Abschnitt der Discoidalader ist hinter der hinteren Querader stark ausgebaucht, dann aber bis zur Mündung fast gerade.

Hinterleib glänzend schwarzgriin, dunkel, wie der Thorax. Die Oberseite oft in der Mitte stellenweise blan oder violett schimmernd. Das 1. Glied des Ovipositors ist etwas herzförmig, stumpf, breiter als lang. Banch und Hypopyg glänzend schwarz.

Körper 4-5 mm, Flïgel 3-4 $\mathrm{mm}$ lang.

Geogr. Verbreitung: $25 \mathrm{or}^{\mathbf{T}}$ ㅇ aus Formosa und Ceylon.

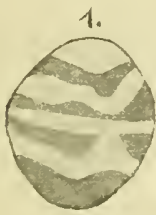

5 .

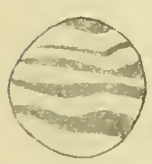

2.

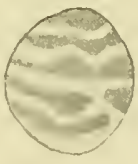

6.

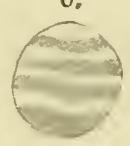

3.

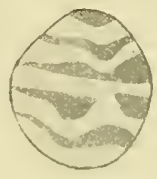

z.

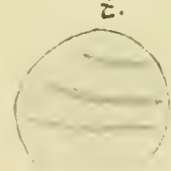

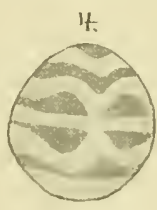

8.

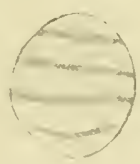

Augenzeichnung der Arten; links ist die Vorderseite der Augen.

fig. 1. longicomis n. sp. Fig. 2. tarsata Maçu. Fig. 3. smaraydina Lnew.

Hig. 4. aenere Fab. Fig. 5. demamlate Fab. Fig. (i. chulybure n. sp. Fig. 7. flavipes Karsch. Fig. 8. africana n. sp. 



\section{Drei neue holometope Musciden aus Asien.}

Von Friedrich Hendel in Wien.

\section{Trigonometopus monochaeta n. sp.}

5 ठ․, Formosa (Takilo: April, Mai). L'ngar. Nationamuseum.

Die Unterschicale von Tr. frontalis Meig. sind folgende: Nur cine Frontorbitalborste: Postvertikalborsten fehlen. Ier vordere Stirnrand tritt nicht ïber die Augen vor: dagegen springt der Clypeus, der die Gestalt eines scharfen längskieles hat, stark zwischen und muter den Fiilulern vor und zeigt im Profile eine sanft S-förmig geschwungene Linic. Ilie Augen sind breiter und vorne nicht zugespitzt, sondern abgestutzt. Tr. frontalis hat zwei Orbitalbolsten, ein I'ostrertikalpalu; der vordere Stirmand springt ein ziemliches Stuick ïber dic Angen vor, der fast Hache Clypens weicht damn in einer im P'rofile greraden Linie zuriick.

Selur auffallend ist auch die Flïgelzeichnung. Der Flïgel ist milchig weiß; hievon heben sich die schwarzbraumen Längsadern 3 und 4 sowic die ebensolchen Queradern dentlich ab. Tor der Flitgelspitze geht ein schiefliegender bramer Wisch von der zweiten his zur vierten Länģsader. 'Zwischen diesen Ader'n ist der äubere Saum desselben konkar ansgerandet. Dic kleine Querader liegt jenseits der Mitte der Diskoidalzelle, die hintere vor der Mitte der letzten zwei Diskoidaladerabschnitte, die keinen Aderanhang zeigen.

Der Kïrper der Fliege ist hell matt-ockergelb. Das Ozellendreiech ist schwarz. Scheitelplatten weiblich bestänbt. Torne an der Stirne zwei größere, hinten neben dem Ozellendreieck zwei kleinere braune Flecke. Neben den Fïhlerwurzeln ein kleines brames Wangendreieck. Rimnen des Clypeus gebäunt. 'Thoraxrieken in der Zentralregion und auf dem Schildchen etwas weiblich bereift. Über die Mitte des Riickens läuft eine bramne Doppellinie, die nach hinten etwas konvergiert und sich anf dem Schildchen vereinigt. Seiten des Piickens brännlich.

Die Hinterleibstergite sind an der Basis dunkler als an Hinterrandle.

Sternoplemralnalıt dunkel gesämnt. - Schwinger und Schïp)chen gelb.

Körperlänge $3 \cdot 5 \mathrm{~mm}$. - Flïgcllänge $3 \mathrm{~mm}$.

Wiener Entomologische Zeitung, XXYII. Jahrg., Heft 」II (15. April 1909). 


\section{Tetanocera amurensis $n . \mathrm{sp}$.}

1 O, Mmumebiet, Chelasso: leg. Schrenk. K. k. Museum. In der ron mir publizierten ..Synopsis der paläarktischen 'Tetanocera-Arten", Zeitschr. für Hymenopt. nnd Dipterologie. 1903, pag. 35 bis 37, läßt sich diese Lit neben 'Tet. hyalipennis Ros. (laevifrons Loew) unterbringen.

Aufer mit letzterer Art würde $T$. amurensis nur noch mit $T$. silvatica Meig. zu vergleichen sein. T. hyalipennis hat eine in ihrer ganzen Austehnung glänzend gelbe Stirne: bei 'T. siltatica hebt sich ein schar begrenztes, mattgelbes riereck in der Mitte al), welches einen glänzenden Vorderrand und ebensolche Ingenränder anf der Stirntläche freilälst. T. amurensis zeigt auf der glänzenden Stirne nur jederseits neben den Ozellen eine kleine, dreieckige, aber deutlich wahrnehmbare matte Stelle, deren Spitze nach vorn gerichtet ist. C̈ber die nene Art gilt mit einigen Ausmahmen dasselbe, was ich in den ., Yerh. tler Zool. Botun. Gesellschatt, Wien, 1900, par. 338. iiber 'T. laevifrons Loew. geschrieben habe. 'T. amurensis hat aber ein angedentetes braunes Wangendreieck und stärker glänzenden und deutlicher gestrienten Thoraxriicken als jene Art. Kürperlänge ohme Fiihler $8 \mathrm{~mm}$. Flïgel $75 \mathrm{~mm}$.

\section{Seperlon violaceus n. sp.}

1 O, aus Hongkong, leg. Frauenfeld 1867. K. k. Musemu.

Von allen bisher aus der Region bekannten Irten die einzige, welche durch die Fürbung dem Sepedon sphegens Fab. ähnlich sieht.

Diese beiden drten sind sogar auf den ersten Blick ziemlich leicht zu verwechseln, da sie in den meisten P'unkten übereinstimnen und sich nur durch Folgendes mit Bestimmtheit unterscheiden:

Bei S. sphegeus sint die Fliigel schon von der Wurzel an ziemlich gleichmäbig braungelb tingiert, was allmählich in den diunkleren Schatten der Flügelspitze ïbergeht. Bei s. violacens ist jerlorh die Wurzelhälfte des Flïgels glashell, die Spitzenhälfte jenseits der kleinen unerader plïtzlich rauchbraum. S. violaceus hat ferner das erste Fuihlerglied nicht schwarz, sondern rot mul die Beine heller gelb, nie so satt rot wie $S$. sphegeus.

Kö̈rperlänge ohne Fïhler und Flügellänge $7 \mathrm{~mm}$. 


\section{Über eine Dipterengattung mit turmartigem Scheitel, Traginops Coquillett.}

Von Friedrich Hendel in Wien.

Mit zwei Figuren im Texte.

Wir sind durch $H$. L oew bereits mit zwei fliegengattungen bekannt gemacht worden, die ebenfalls einen turmartigen Höcker in der Ozellengegend aufweisen. Es sind dies die in Siidafrika nnd Ostindien verbreitete Gattung Cestrotus Loew und die scither nicht wieder aufgefundene Drepanephora horvida Loew aus Cevlon. Beide. Genera gehören in die Acalyptratengruppe der Lauxaninae und wurden von mir in den Genera Insectorum, Fasc. 68 anf Tatel 3. Fig. 33, und Tafel 1, Fig. 1, abgebildet. Hiezu kommt noch als 3. rattung: Pyrgometopa Kert., ein Drosophilinengenus aus P'eru. beschrieben in den T'ermés\%. Fiiz., Vol. 24, pg. 419 (1901).

Vergleicht man die hier beigefiigten Figuren mit dem Bilde von Cestrotus, so glanbt man auf den ersten Blick mahe Verwandte vor sich zu haben. Bei genauerer Untersuchung stellt sich jedoch heraus, dafo die von Coy uillett anfgestellte Gattung Traginops eine echte Agromyzine ist, also in die unmittelbare Nähe unserer heimischen (rattungen Odinia R. 1)., Neoalticomerus Hend., Agromyza Fall., Phytomyza Fall. und Cerodonta Rond. ${ }^{1}$ ) gehört.

Coquillett hat seine Gattumg in den Entomoligical Ners 1900 , p. 429, beschrieben und sagt dort von ihr, nearest related to Milichia. Damit wäre Milichia im Schinerschen Sinne anfgefalbt und nicht in mserem luentigen. Ich habe in meinen ..Kritischen Bemerkungen zur Systematik" der Milichinen und Agromyzinen (Vergl. diese Zeitg., Jahrgang 1903, p. 249) die Griinde angeführt, welche mich zur 'Trennung beider (iruppen bewogen haben. Wenn diesbeziiglich auch in neneren Arbeiten, wie z. B. in Williston, Manual of $\mathrm{N}$. Amer. Diptera, 3. Ell. 1908, eine Scheidme der Gattungen nach diesem l'rinzipe nicht durchgefïhrt wurde, so ist wohl im allgemeinen blof eine mangelhafte Durcharbeitung der betreffenden Materie daran schuld oder die ungenügenden Charakteristiken der Gattungen, welche eine Einreihung ummöglich machten.

Traginops Coquillett fehlen die Interfrontalrudimente, die Kreuzbörstehen der Stirne. die hakig zurïickgeschlagenen Labellen ver Mi-

1) Cerodonta Rond., Dipt. Ital. Prodr. IV, p. 10 (1861), hat vor Caratomyza Schiner, Wien. ent. Monatsch. VI, p. 434 (186\%), die Prioritit. Bisher gehranchte man immer den Schinerschen Namen! 
lichinen; dagegen sind die Postvertikalborsten stark divergent und die Analader deutich vorhanden; alles Kennzeichen der echten Igromyzinen.

Zur Charakteristik der Gattung möchte ich noch hinzufügen: Stirne so breit wie ein Auge, fast parallelrandig, vorne nur wenig schmäler und dort fürr die Lunula stark hogig ausgerandet. Die Scheitel- und Wangenplatten liängen zusammen, die Fliegen sind also wie alle Agronyzinen schizometop. An den Periorbiten sind ein Paar einwärts gebogene untere und zwei l'are aufwärts gebogene obere Frontorbitalborsten zu sehen. Der tumartig erhobene 'Teil ist das Ozellendreieck ( In te r frout a li a R. D.). Fs trägt vorne eine Ozelle nnd in riemlicher Entfernung davon seitlich an Höcker je eine der beiden anderen. Am Gipfel, hinter der vordersten Ozelle, sitzt dis starke, nach vorne gebogene und divergierende Ozellarborstenpatar. Die Stirnstrieme schiebt sich oben jederseits als schmaler Ist zwischen die streifenförmigen P'eriorbiten und den (Izellenhöcker bis zum Scheitel empor. Ein I'aar konvergierende imnere und ein Paar divergierende äuljere Scheitelborsten. Postrertikalparar kräftig, stark divergierend, in ziemlicher Entfernung hinter den Höcker inseriert. Lunula grolj. Stirnspaltenäste stark divergierend, dem Augenrande genähert, von den Gesichtsleisten (Facialia) entfernt. Diese begrenzen emen oben unter den Fühlern etwas ausgehöhlten und dazwischen sanft erhabenen Klypeus, dessen Mundrand (Epistom) anderseits wieder vorspringt. Die nackten konkaven Backengruben (Mediana P. D.) simd oben von den anfangs durch die Stirnspaltenäste geschiedenen und dann unten un die Augen lerumbiegrenden Wangen, unten von den behaarten und am Rande gerade unter den Augen mit zwei nach aufwärts gekriimmten Borsten versehenen, rom Hinterkopf hervorbiegenden Peristomalien deutlich abgegrenzt. Die I'eristomalien (Backenleisten) rereinigen sich mit den Fazialien unter scharfen Winkel unmittelbar neben dem Mundrande (Vibrisseneck) und tragen dort ainige $(2-3)$ gegeneinander gebogene Vibrissen. Die hinten etwas lrerabgesenkten Backen sind zwei Drittel des lotrechten Augendurchmessers breit und hinten mit einer fast lotrechten Reihe von mehreren lrerabgebogenen Borsten besetzt. Der obere Hinterkopf ist oben fiur den 'Thorax konkav ausgehölitt.

Die Fïhler sind kurz, geneigt. Firstes (ilied selır kurz; zweites etwas läıger, oben mit einer dentlich abstehenden Borste; drittes fast scheibenrund, kürzer als breit, mit einer von der Basis des dritten (aliedes etwas entfernten, geneigten, pubeszenten oder kurz gefiederten Arista. 
Riissel mittellang. labellen kurz, nicht verlängert und hakig zurtickgeschlagen. Die 'laster scheinen mix etwas verbreitert zu sein. Sie sind unten beborstet. Prälabrum aubergewiihnlich grob und stark vortretend. Mundrand in die Höhe gezogen.

Thorax etwas länger als breit, viereckig, oben mäbig gewölbt, vorne abschüissig. (irundbeharung des Riickens kurz und zerstreut, nicht in Längseihen geordnet. Quernahtäste vor den Seitemmitten, nach oben und rome aufsteigend, in der Mitte breit gretremnt. I'leuren allmählich gewölbt. - Ieborstung: Humeralcallus mit drei verschieden gerichteten Borsten: Notoplemale $2 ; 1: 1$ Suplablare 4: l'rïsuturale 1: Dorsozentrale $3-1$; 1 Präskutellarpar. - Schildchen fast die Hälfte des Rïickens lang, eiförnnig, oben behaart und ziemlich abgeflacht, nit vier fast parallelen orler auch gekleuzten Raudborsten. - P'leuren nackt, ohne Grumdbehasung'. Nur die Sternopleuren, die am Oberrande drei starke, nach aufwärts gebogene Borsten in gleichen $\mathrm{Ab}$ ständen nebeneinander tragen, haben einige zerstreute Bürstchen. Eine (riclleicht abnornal zwei) starke I'rothorakalborste.

Hinterleib breit eiförmig, mit sechs gleichlangen sichtbaren Ringen bei $\sigma^{2}$ und $\bigcirc$. '/ählt man den letzten Ring des $\sigma^{2}$ zum folgenden kugeligen Teil als Hypopyg, so hat das ó nur füinf Ringe. Ovipositor nicht sichtbar. Behaarung kurz. Ritudborsten kurz, seitlich etwas verlängert, mauffällig.

Beine von normaler Länge und Stärke. Torderhüften anch vorne etwas beborstet. Vorderschenkel posterodorsal und posteroventral mit einer Reihe langer Borsten. Präapikalborsten der Schienen kurz, aber deutlich. Mittelschienen immen nur mit einem längeren Sporn.

Fliigel mit dunklerer Fleckenzeichnung. Kosta vor der Miindung der Subkosta etwas verdickt und dort durch ein Randbörstehen verziert; hinter dieser Verdickung zusammengeschnïrt und dann wieder an der Mündung der crsten Längader auffallend verdickt. Sic reicht bis zur Diskoidalader, ist aber linter der Kubitalader schon sehr diinn. Die Mediastina ist fein und diimm und verschwindet vor ihrer Miindung in die Kosta; sie liegt eng neben der Subkosta. Diese Längsader ist sehr stark und mindet in einer Verdickung im ersten Flügeldrittel, noch vor der kleinen Querader. Die iibrigen Längsadern fast gerade, wie das Bild zeigt. Kleine (unerader etwas schief, der hinteren genähert, in der Nähe der Flïgelmitte. Hintere Querader gerade oder etwas bauchig gebogen. Wurzelzellen deutlich abgegrenzt. Analzelle vorne bauchig. Analader deutlich. Axillarfalte fehlt.

bie beiden Irten lassen sich wic folgt muterscheiden:

1. Arista pubeszent, fast nackt. Lunula weilo, ungefleckt. Rüicken punktiert. Die Flügelzeichnung besteht aus isolierten, größeren und 
kleineren r'unden granen Flecken. I'leuren mit zwei braunen Längsbinden. Nordamerika (Georgia). T. irrorata Coquillett.

2. Irista gefiedert. Lumula mit einem schwarzen MittelHeck. liiicken grobgefleckt. Die Flïgelzeichnung besteht aus einer mitrinander zusammenhängenden, gitterartig durchbrochenen granen Zeichnung, Plemren in gelben Pingen bram gefleckt. T. clathrata n. sp.

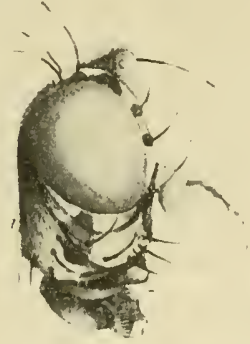
Siidamerika.

Mir liegen beide Arten vor.

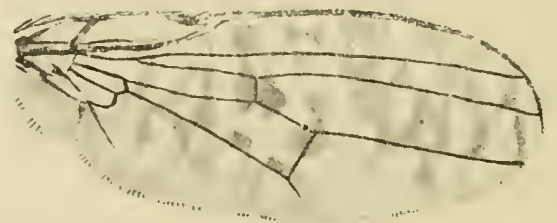

Traginops clathrata Hendel.

'Traginops clathrata n. sp. 1 o aus Perm, Vilcanoti uncl P'araguay (Ungar. Nat.-ILuseum).

Stirnstrieme dunkelbraum, vorne rot. Periorbiten und Ozellendreieck ockergelb. Der Höcker schwarz. An den Wmrzeln aller Kopfborsten schwarze Flecke. Lumula weif mit samtschwarzem Mitteltleck. Ein hufeisenförmiger Fleck am Mundrande dunkelbraun, daneben ockergelb. Ebenso Wangen und Backen. Ingen purpurnviolett, mit zwei hellgrïnen Querbinden in der Mitte. Am Ingenunterrand rin grober branner Fleck. Ebenso ist das Vibrisseneck braun. Unterer Hinterkopf grau. Fiihler gelbrot. am Vorderrande des dritten Gliedes manchmal gebräunt. Arista braun. T'aster und Labellen rotbraun.

Thorax und Schildchen dicht ockergelb bestäubt. Riicken in der Mitte mit einer dunkelbraunen Längsstrieme, die sich gabehnd aut das Schildchen ïbertritt. Daneben jederseits eine Längsreihe von vier grofen rlunkelbraunen Flecken an den Wurzeln der vier Dorsozentralborsten. I)ie vorletzten dieser Flecke hängen mit der Mittelstrieme zusammen. Noch weiter auswärts je ein Längsfleck und eine Makel hinter der Quernaht in der Richtung der Intraalaren. Iußerdem noch Flecke, an den Borsten seitlich am 'Thorax und einer' über dem Humeralcallus. Schildchenborsten der Spitze gekreuzt. Pleuren braun gefleckt. Hinterleib pechbraun, wachsglänzend. Hinterränder der Tergite an den Seiten weifograu gesäumt; ansgedehnter am 4. und 5. Tergit. Beine: Schenkel bramn, an der Spitze rotgelb. Schienen und Tarsen rotgelb. erstere mit zwei braunen Ringen. Fliigel weißlich, mit granem (ritterwerk. - Schwinger gelb, Schiippchen braun gewimpert. Körperlänge: $4 \mathrm{~mm}$, Fliigellänge: $4 \mathrm{~mm}$. 


\section{Meigens Erstlingsarbeit über Dipteren.}

Ton Friedrich Thendel in Wien.

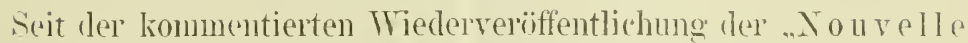
Classification" (1800) in den Terhandlungen der k. K. \%ool.bot. Fesellschalt in Wien (1908), in welchel ich die Reaktivierme.

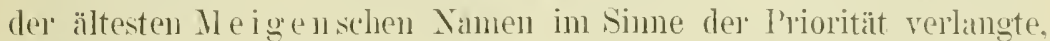
hat sich noch wenigg Gelegenheit ergeben, dic stellumgnahnus des dipterologischen Fachkollegen liezu kemnen zu lruen.

Daf I'rof. II. Iiezzi, der Terfechter der strengsten I'riorität. fïir die Wiederammalme eintrat, ist mohl selbstresständlich.

Eine gewiehtige und wirksmo 'Tat fiil die dufnahme sle

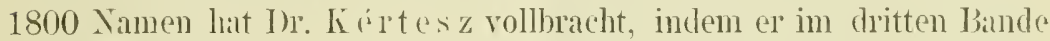
des Catalogus I) iptrol'nu die liebei in Betracht lommenten General der ..Nouvelle Classification" akzeptierte.

Aus brieflichen Vitteilmngen anderer dutoren halor ich teils Znstimnung, teils Milvergnügen, teils Ablehnumg konstatielen kïnnen.

Wir miissen also die diptelologische Literatur dej nächsten Zukunft abwarteı, um zu erkemen. wofiur sich die Mehrahl der Dipterolosen entscleidet, ob für Kontimitüt odev für Priorität. Hotfen wir. dallo sich die Erkenntuis allgemein Pahn bricht, dal, die Stabilität der

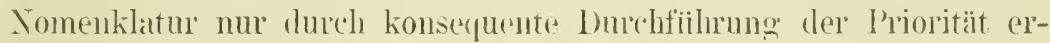
langt worden kann. Dieses Prinzip latte ich in Luge, als irh sagte: F'int justitia, pereat mundus!."

"Justice to whom, or to what?:" fragt nämlich I'rot. Aldric: h i11. "Canadian Entomologist", pas. 373 (1908). Hier die Antwort!

Pereat mundus! - Ei ist begreiflich, dill man Namen, die ainem in Fleisch und Plut iibergegangen sind, nicht leichten Herzens iiber Bord wirft und iiher die Notwendigkeit, eine ganze lieihe neur Samen annehmen zu müssen, nicht entziickt ist. Mein langjähriges Zögernn mit der Wielelveröffentlichung der ..Touv. Classification "illustriert ja dieses Geftihl des Mißbehagens, dab die Menschen bei Störungen in altgewohnten Gebräuchen beschleicht, zur Fenügc und jerler wird cin Beharrungsvermögen in altrn /Austande menschlich begreiflich finden. Ich landelte aber im Simne obigen Zitates, als ich lie Erstlingsurbeit Mrigens wierler cler öftentlichkeit iibergab.

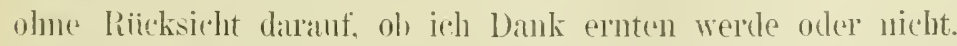

I'rof.' Williston wendet sich nännlich in der dritten Erlition seint's Mannal of $\mathrm{X}$. Amer. Hiptera (1908) palg. 390 folgendermalien all mixh: .Mr. Hondel rould have deserved the thanks of a lony suffering public had he withledr these copries instead of regublishing.:

Wiener Fntomologische Zeitung, XXVII. Jahrg., Meft 1 (1. Februar 1909). 
Der erste. der die Dblehmung der $1800 \mathrm{er}$ Namen mit (iriunden motiviert, ist I'rof. Aldrich. Derselbe hat im Oktoberheft des .. Canadian Entomologist". nachlem er semer' subjektiven L'nlust iiher mein Postulat kräftig Ausdruck gegeben hat - woriiber ich ilın aher alls obenerwähntem Grunde gar nicht böse hin - objektiv Folgendes gegen die Amahme iles alten Me igenschen Namen vorwehracht: Die Gattungsnamen seien ungiltig, demn sie wären unter Bedingungen gegeben worden, welche gegen die internationalen Regreln der zoologischen Nomenklatur verstoßen.

Der von Aldricll herangezogenc Artikel 25 der "Regeln" (6. Kongreb, Bern 1904) lantet: .. Giltiger Name ciner Gattung oder Art kamu nur derjenige Name sein. mit dem sie zuerst bezeichnet worden ist, unter der Bedingung,

a) dali dieser Name in Begleitung einer Kiennzeichnung vesittentlicht worden ist und i) daf der Autor den Frundsätzen der binären Nomenklatur folgte.

Irof. Aldrich meint nun, die 1800er Gattungsdefinitionen intsprächen weder dem P'unkte $\propto$ noch dem Punkte ß.

Dem Punkte a nicht, weil sie förmlich nomina nuda seien.

Ich hätte die Mehrzahl der ('Gattungen erst mit Hilfe der Arbeit Meigens atts dem Jahre 1803 deuten können. Dem l'unkte \& nicht. dia $\backslash[$ eigen nur Gattungen beschreibe mul keine Irten. also dic hinäre Nomenklatur nieht befolge.

Dem ist Folgendes zu entgegnen:

II eigen heschreiht in der ..Nouvelle Classification" 88 reneral. Davon sind 24 solche von älteren Autoren - Ifeigen respektiert also dic L i n né sche Regel - mol drei schon heute gïltige M e ig ensche. Es b]eiben also 61 neue Gattungsnamen.

Wer von aufmerksamen Lesern der Reimprimation wïrde aber nicht sofort aus der Beschreibung allein die Gattungen Erinna Éulalia, Potamida, Chrysozona, Cypsela, Tubifera, Scopeuma, Statinia, Euribia erkennen, wer wiirde Apivora, Larvaevora, Rhodog!ne und Crocuta fïr nomina muda erklären?

Diese 13 rrattungen sind cin Drittel der 39 BrachycerenGattungen, welche also sofort ex descriptione erkannt werden können. Andere Genera sind rielleicht schweres erkennhar, immerhin aber deutbar, andere wurden erst im Vergleidhe mit der Arbeit in Illigers Nagazin gredentet oder waren nicht erkembar. Aber auch letztere bleiben eben bis jetzt unerkannte (rattungen und keineswegs nomina meda: Dic Kennzeichnmm feblt nicht. 
Dal's die Arbeit vom Jalne 1803 zur Deutung beniitzt wurde, kam um so weniger als Hindernis der Anerkennung betrachtet werden, als die Methode, durch welche ich zum Ziele gelangte, einwandfiei ist und indirekte Deutungen schon des öfteren gemacht wurden. (Ader sind die Gattungsdiagnosen der von Aldrich anerkannten Arbeit des Jahres 1803 klarer? Wurden viele dersellsen nicht erst später durch die .Systemat. Beschreibung" uns nälıer geebraht? Weisen wir vielleicht jene Artnamen zuriick, welche erst durch 'Typenuntersuchungen gedeutet werden komnten? In wievielen Fïllen ist die Deutung gar nur eine traditionelle!

Meiner Überzeugung nach ist dem I'unkte $\%$ des Artikels 25) in der ...Nonv. Class." also vollkommen Geniige geleistet worden.

Artikel 2 der Regeln heilst: „Die wissenschaftliche lienemung der Tiere ist für die Untergattung und alle übergeordneten fruppen uninominal, für die Art binominal, für die Enterart trinominal."

Ia II igen nur Gattungen beschreibt, die Arten nur der Zalul nach angibt und in der Torrede seine kleine Arbeit nur als l'rodro. mus, die Gattungen enthaltend, eines angekiindigten später'n Werkes bezeichnet, kann man doch nicht behaupten, er hätte dabei die binäre Nomenklatur, die sich ja bloß auf Arten bezichen kann, auljeracht welassen! Dalj Gattmosnamen anch olme Angabe des Typus in lietracht gezogen werden miissen. ist alls dem Ratschlag $x$ des Artikels 28 ersichtlich.

Damit glaube ich auch den zweiten objektiven Einwand, den I'rof. Aldrich in Bezug auf die internationalen Regaln der Xomenklatur machte, genügend widerlegt zu hahen.

Die (rattungen del" .. Nonvelle Classification" antsprechen den in den Riegeln aufgestellten Bedingmugen und haben die l'riorität folglich miissen sie angenommen werden. Wemn $\mathrm{ll}$ eigen später die Xanen eigenmächtig umändlerte, so handelte er gregren dir Regeh. yoradeso wie es gegen die Regehn verstibit, diese crumdlos abgeändorten Namen weiter beizubehalten.

Ein anderer, volt manchen Dipterologen gentachter Einwand ist der, dals die ,Nouvelle Classification“ ja nur in zwei Exemplaren bekannt sei, die Gattungen eigentlich nicht publik zeworden wären.

Ich bin iberzeugt, daf ebenso wie Herr l'rof. Heyden ein Exemplar in seines Bibliothek entdeckte, wovon el mir fremillich litteilung machte, noch manche andere Fachkollegen diese fieilich scltene Sichrift in Museen oder anderen Bibliotheken auffinden werden. Dur'd welche Zahl wird demn das Minimmm der Luflage einer Mbhandlung 
angegeben, damit die darin besehrichenen Formen als mit Recht „publiziert" gelten können?

Zum Schlnsse möchte ich norh einen Irrtum des Herrn I'rof. Aldrich berichtigen, der in cinem zweiten Artikel, im Noremberhefte des ..Canadian Entomologist" 1908, zum Ausdruck kommt.

Ans einer Bemerkung des Herrn Prof. Bezzi, welche derselbe bei einer Lezension des dritten Bandes des Catalogus Dipterorum in dieser Zeitschrift machte, glanbt Herr 1ldrich ammehmen zn diirfen. Bezzi akzeptiere wohl die $1800 \mathrm{er}$ Namen, obgleich auch er rlie nicht völlige C̈bereinstimmung derseliben mit den internationalen Regeln konstatiere. Eine briefliche Nitteilung l'rof. Bezzis an mich korrigiert diese falsche Auffassung dahin, dafo sich obige Bemerkung keineswegs auf die Gattungen der .. Nouvelle Classification" bezieht, die anch nach Bezzis Anschumung den Regeln entsprechen, sondern anf andere Tatsachen, die Schreibung der Artnamen hetreffend u. s. w.

Hiemit schliefie irh meine Verteidigung, indem ich weiterhin in Rohe die Entscheidung der Zukunft iiberlasse. Vielleirlit entscheidet schon die lebende Generation! Alea jactu est!

Während der Drucklegrung dieses Artikels sind Äuberungen zweiex lervorragender Inipterologen über unseren Gegenstand erfolgt, die ich nicht iibergehen möichte.

Herr D. W. Coun illett widerlegt in einem Aufsatze "Meigen's first paper on Dipterc" rom I)ezember 1908, Canad. Lintomol., die Ald richschen Argunente gegen die Inwendung des 1800er Namen als intuimliche aus den Gesetzen des internationalen fodex selbst und tritt damit an die Seite der I'rioritätsanhänger.

Herr f. H. Verrall dagegen bleibt bedanerlicherweise anf seinem konservativen standpunkte und erklärt im soeben erschicnenen zweiten Bande seines wahhaft monumentalen Werkes „British Flies" p. 772, "that none of the genera (1800) wore founded in accordance with binomial law". Auberdem glaubt er (p. 285), jeder Lutor habe das sonderbare Recht, eine, ja sogall zwei nomenklatorische Fruilggeburten desselben Themas zn machen, Im dann später die erste durch die zweite und diese endlich durch ein nun gliicklich ausgereiftes Werk zu ersetzen. Ist das nicht das Ende der P'riorität und dex Kontimuität : 


\title{
Ein verschollener Asilus Centraleuropa's.
}

\author{
(Ein dipterologischer Beitrag.)
}

Von Friedrich Hendel in Wien.

Ob man die von Loe w in seiner Monographie der Asiliden zur Erleichterung der Artbestimmung der zahlreichen europäischen Arten aufgestellten und von anderen Autoren und ihm selbst später ohne Rücksicht auf die geographische Verbreitung neu als Gattungen hinzugeftigten Gruppen der Gattung Asilus s. str. als natürliche Auflösung in engere selbständige Genera auffasst oder uicht, scheint ziemlich gleichgiltig dem Umstande gegenïber, dass ihr Bestand - und wenn er anch vorläufig nur manchmal auf ein einziges und selbst wieder nur dem einen Geschlechte zukommendes, ausgezeichnetes Merkmal basirt ist, und demgemäss von keinem natürlich tremnenden Gattungscriterium die Rede sein kann - bei Thieren von solcher Gleichartigkeit in Körperbane eine genauere Fixirung der Formen ermöglicht, indem unterscheidende Merkmale in der Beschreibung berüicksichtigt werden müssen, die bei der weiteren Begrenzung des Gattungsbegriffes verloren gingen.

Wemn Loe w*) die Zusprechung des Gattungsrechtes in der Zukunft an seine Gruppen voraussah, so erfüllte er später selbst seine Vorhersehung. Ihm tolgten dann Schine $\mathrm{r}^{* *}$ ) nach seiner Fauma und seinem Katalog und zahlreiche andere Autoren.

Hält man aber daran fest, dass eine natürliche Gattung nur "eine Reihe von Arten umfasst, welche durch Fehlen von Zwischenformen aus der Verbindung mit anderen Artemreihen getreten ist",***) dann können viele Loew'sche Gruppen als solche nicht betrachtet werden.

So sagt z. B. L o e w selbst: „Es ist nicht ganz leicht, eine scharfe Grenzlinie zwischen diesen (den buntbeinigen Dysmachus-Arten) und den buntbeinigen Eutolmus-Arten zu ziehen."

*) Linnaea Entomol. III. pag. 400.

*) "Verzeichniss der bis jetzt publicirten Asiliden." Verh. Zool.- Bot. Gesellsch. Band XVI. pag. 695 sq.

*) Prof. Dr. F. B r a u e r : "Vorarbeiten zu einer Monographie de Muscaria schizometopa." Pars. I. Denkschr. k. Ak. math. nat. Cl. Bd. LVI. pag. 70.

Wiener Entomologische Zeitung, XVIII. Jahrg., IV. Ileft (30. April 1899). 
Die Lage der Endlamellchen der Legeröhre stimmen bei beiden Gattungen iiberein, und in der Beborstung und Behaarung des Thoraxrïckens weichen eben nur die typischen Formen ab.

Den 1848 als Dysmachus (Lophonotus) apiculatus beschriebenen Asilus stellt er 1871*) zu Eutolmus als scheiubar passender untergebracht; Eutolmus graecus "scheint" ilım kein Dysmachus zu sein. Die von Schiner als Tolmerus corsicus**) beschriebene Art "duirtte" nach L o e w trotzdem, dass Behaarung und Beborstung des Thoraxrückens sehr derjenigen eines Dysmachus gleichen, "vielleicht" besser in die Gattung Eutolmus untergebracht sein.

In der Wirklichkeit gibt es eben Zwischenformen zwischen den Gattungen Eutolmus und Dysmachus, über deren Stellung man absolut im Zweifel ist. Beide Gattungen bilden sichtbal eine ununterbrochene Artenreihe, die in der Gattung Machimus, deren Stellung nur auf die Lage der Endlamellen der Legeröhre des q begrindet ist, ihre Fortsetzung findet. - Sc h in e r hatte beide Gruppen in seiner Fanna vereinigt; später führt er sie getrennt und schliesslich wieder als Gattmingen anf.**)

Ohme das o kann kein Asilus zu Eutolmus oder Machimus gestellt werden. Die für die $\sigma^{\top}$ beider Gattungen als charakteristisch bezeichnete zipfelartige Verlängerung oder Behaarung des 8. Hinterleibsabschnittes ist bei einigen Arten (z. B. apicatus) kaum zu sehen, während Asilus inconstans ơ einen Zipfel besitzt, aber trotzdem zu Epistriptus gestellt werden muss, und Asilus (Dysmachus) bimucronatus dort eine schopfartige Belıarung anfweist.

Was ferner As. (Mochtherus) farinosus anbelangt, so liat er durch anliegende kurze Behaarung bedeckte Beine und musste deshalb zu Epitriptus gestellt werden.

Man erimert sich da unwillkürlich an den von Da rwin melirfach citirten Satz L i n n é's, dass die Merkmale nicht die Gattung, sondern die Gattung die Merkmale geben sollen.

Aus allem aber geht hervor, dass gewisse, bis jetzt als Gattungen aufgefasste Gruppen keine solchen sind, sondern

*) Dr. H. L o e w : „Beschreibungen emrop. Dipteren“ Bd. II. pag. 143.

**) „Nene oder weniger bekannte Asiliden des k. Zool. Hofkabinets zu Wien " Verin. Zool.-Bot. Gesellsch. Bd. XVII. pag. 409.

***:*) Verzeichniss der bis jet\%t publicirten Asiliden." Verh. Zool.-Botan. Gesellsch. Bd. XVI. pag. 695 sq. 
nur Artengr'uppen, die anf solche typische Grundformen*) basirt wurden, welche die meisten Merkmale jeder Grnppe zeigen, um welche sich die Arten aber nicht nn terb rochen, und oft anch niclıt natürlich reihen. „In einer bestimmten Zeitperiode aber können Gattungen etc. nur dann festgehalten werden, wenn sie nicht durch lebende Zwischenformen in ihren Charakteren verbunien wer(len. “**) "Denn er'st das Erlöschen von Zwischenformen macht die scharfe Charakteristik einer Gruppe möglich. "**)

Die nachträgliche Auffassung der Gruppen als Gattungen geht ans dem Bestreben hervor, hier ebenso wie andernorts die grossen Genera in engere anfzulösen, was aber bis jetzt noch nicht glïcklich durchgeführt werden konnte. Die Anflösung geschah nicht etwa deshalb, weil man nene Verschiedenheiten entdeckt hatte, sondern weil zahlreiche nene Arten hinzukamen, welche die alte Gattung anderen gegenibber zu gross er'scheinen liess.

Die Gleichartigkeit im äusseren Körperbau, die geringen Abweichnngen in nur untergeordneten, uns nicht sonderlich in die Angen springenden Nerkmalen bei grosser Arten- und Individuenzahl nebst allgemeiner geographischer Verbreitung beweist in dieser sonst ziemlich scharf nmrissenen Gattung eben nur deren entwickhugsgeschichtliche Jugend, ilne jetzige Blïthezeit. Die sich entwickehten Extreme sind noch nicht isolirt, die Mittelformen noch vorhanden.

Asilus apicatus Lw. Limn. Entomol. III. Bd., 1848, pag. 464 spec. 14, Gruppe des Asilus rufibarlis. Eutolmus ơ'

Asilus apicatus Lw., Sehin, Fanna Austr. I. pag. 149, ơ- - Gruppe: Eutolmus und Machimus Lw.

Asilus apicatus Lw, Sehin., Catal. system. Dipt. Eur. pag. 34. Gruppe: Eutolmus.

Eutolmus apicatus Lw, Schin., Verzeichniss der bis jetzt publicirten Asiliden. - Verh. Zool.-Bot. Ges. Wien, Bd XII. pag. 718. Gattung: Eutolmus.

*) Cf. D a r w i n, 14, Cap.

**) Prof. Dr. Fr. B r a u e r: "Systemat. zool. Studien", Sitzber. d. k. Ak. d. W. math. nat. Cl Bd. LCI. I. Abth, pag. 255 et 250.

Wienex Entomologisehe Zeitung, XV111. Jahrg., IV. Heft (8 '. April 1899). 
Asilus apicatus Lw., Palm, Beitrag zur Dipteren-Fanna Tirols. Verh. Zool.-Bot. Ges. Wien, Bd. XIX pag. 416. - Grupue: Eutolmus.

(Asilus apicutus Walk. = Japhria Reimwardti Wied. noth V a n d e r W u l p, Tijdschr. Ent. 2, VII.)

L o e w, der nur das o kannte, gibt als Vaterland dieser Art Tirol und die Schweiz an. Sch in e r war die Art mbekannt. Eine weitere Erwähnung der Art geschieht endlich durch P a $1 \mathrm{~m}$ ïber ilnr Vorkommen in Tirol, leider olne Angabe, ob anch das o gefangen wurde. Seitdem war dieser Asilus verschollen.

Ich fing die Art in beiden Geschlechtern Ende Juli bis Anfang September im "Schindergraben" am Bisamberg bei Wien, wo sie nach Art, des Asilus albiceps Meig. immer am Boden sass. Sie ist sehr schen. Ein $q$, das eine Sarcophaga in den Klanen trug, liess sich erst recht weit treiben, bevor ich es erhaschen konnte. Die Exemplare falle!l durch ihr dunkles Colorit auf.

L 0 e w's Beschreibung stimmt in allen Punkten mit meinem einzigen, etwas abgeriebenen Mämnchen überein. Der 8. Hinterleibsring ist an der Unterseite ganz dentlich glänzend schwalz; sein Unterrand ist kaum erweitert, nur mit schwarzen und wenigen rostgelben Haaren schwach gewimpert. Dis mittelgrosse Hypogygimm ist glänzend schwarz. Die Beharmmg desselben mit Ausnahme der Oberseite nur rostgelblich.

Ich lasse nun zum Vergleiche die Beschreibung des bisher unbekannten Weibchens etwas ansfïhrlicher folgen:

Der stark vortretende Gesichtshöcker nimmt etwa ${ }_{1 / 4}^{3 /}$ der Gesichtslänge ein. Der ihn bedeckende Knebelbart äusserst stark und dicht, aus borstenartigen Haaren von der Länge der grössten Thoraxborsten bestelend; er ist fast ganz schwar'z an der Ober- und Vorderseite des Höckers, unten aber rostgelblich (bei meinem o') bis bremend rostroth (bei einigen q). Backenbart und Behaarung des Hinterkopfes ron derselben Farbe, wie die jeweilig unterste Behaarung des Ilöcker's. Behaarung der Stirn und der beiden ersten Fï̈llerglieder schwarz. Das 1. Fühlerglied bei frischen Exemplaren gleich dem Untergesichte mit goldgelbem Tomente besetzt. Die Borsten am hinteren Angenrande sind zahlreich nnd schwarz. Die Behaarung der Taster ist auffallend lang, stark und schwarz. 
Behaarmng und Beborstung der Oberseite des Mesothorax ist verhältnissmässig fein mud fast durchwegs schwarz. Die Borsten sind nur schwarz, anf der Längsmitte in zwei regelmässigen, an Rande der Mittelstriemen verlanfenden Reihen geordnet, welche nach vorn etwas uiber die Qnernaht hinansgehen. Die zarte Beharmung der Brustseiten und des Schildchens ist schwarz und $₹$ elb gemischt. Das letztere am Rande mit zahlreichen schwarzen Borsten besetzt. - Beleuchtet man den 'Thoraxriicken ganz von vorn, so zeigt sich die dentliche, scharfbegrenzte, nach hinten wenig verschmälerte Mittelstrieme, mit einer ebenso deutlichen gelb bestänbten Halbirungslinie ihrer ganzen bis zum letzten Thoraxdrittel reichenden Länge nach. Seitenstriemen bei gleicher Belenchtung weniger dunkel als die Nittelstrieme, aber dentlich. Von dem vordersten der drei Flecken nur ein keilförmiges Fleckchen ïbrig. Der dritte endigt in der Höhe der Mittelstrieme. Die Bestänbung des übrigen Thorax ist eine grangelbliche oder weissgrane. Hinterleib von hinten betrachtet matt schwarz. Die scharf abgesetzten Hinterrandsäıme und die Seitenränder mit weisslichem oder gelblichem Schimmer, so dass auf jedem Ringe ein fast halbkreisförmiger dunkler Discus iibrig bleibt. - Der Banch ist matt schwarggran. - Die Behaarung des Hinterleibes kurz. Die Discalbehaarung, sowie die bedeutend längere aber zarte Behaarmong des Banches anf den vorderen Ringen gelblich, auf den hinteren schwarz und viel kürzer. - Die ersten drei Ringe sind an den Seiten und am Banche ziemlich lang und fein rostgelb behaart. Die Marginalborsten sind sckwarz und nehmen nach hinten zu an Grösse ab, bis sie von der ïbrigen Behaarung kaum mehr zu unterscheiden sind. - Die glänzend schwalze Legeröhre ist etwas länger als die letzten zwei Hinterleibssegmente zusammen; sie ist der ganzen Länge nach zusammengedrückt, schmal und säbelförmig spitzig. Der Oberrand des ersten Oberstïckes ganz gerade, das Unterstück unter der Grenze des zweiten Oberstïckes schwach S-förmig geschwungen. Das zweite Oberstiick und die freien, griffelförmigen, grobpunktirten Lamellen sclıwach abwärts gebogen. Die Lamellen von der Länge des zweiten Oberstiickes, dieses kamı die Hälfte des ersten lang. Letzteres dentlich querrunzelig. Die Behaarung der Legeröhre deutlich, ziemlich lang und schwarz, diejenige der Lamellen röthlich. - Die Beine 
sind ganz schwarz. Die Härchen erscheinen mir aber mit Ansnahme derjenigen an der Innenseite der Schienen rostgelblich und nicht schwarz. Die gewöhnlichen Schillerstellen sind lenchtend rotlifilzig. Die Hüften, namentlich die vorderen, haben eine sehr dichte Beharung, die gelbweiss bis brennend rostroth ist. Diese Behaarung dehnt sich auch auf die Unterseite der vorderen Schenkel ans; nur sind derselben an den Vorderschenkeln gegen die Spitze hin gleich lange schwarze Haare beigemengt. Unterseite der Vorderschenkel wie beim $\sigma^{7}$ ohne Stachelborsten. Solche finden sich nu an der Oberseite der Vorder- und der Vorderseite der Mittelschenkel in spärlicher Anzahl und von schwarzer Farbe. - Die Fliigel sind glasartig, an der Spitze bräunlichgrall abgegrenzt getrübt und reichen fast bis zum Hinterleibsende. Die Trübung reicht an der. Fliigelspitze, indem sie sich den Adern vollkommen anschliesst, nicht ganz bis zur Wurzel der zweiten Unterrandzelle, erstreckt sich in den beiden vor ihr liegenden Zellen streifenartig viel weiter, füllt die zweite Hinterrandzelle etwa zu $2 / 3$ aus und lässt um die dritte und fünfte dentliche helle Säume. Die Adern sind dunkelbraın.

A n m e r k ung 1. Die auf der Aussenseite der Hüften stehende Borste, ebenso die oberste Hypopleuralborste schwarz oder gelbweiss; manchmal bei demselben Individum an den beiden Huften versehieden. Metapleuralborstenkranz schwarz und gelb gemischt Körperlänge des $\sigma^{7} 17$, des $Q$ P $16-20 \mathrm{~mm}$.

A n m e $\mathrm{r}^{\mathrm{k}}$ u n g 2. Nach der Gestaltung der weiblichen Legeröhre muss diese Art nun in die Nähe von Asilus modestus Lw. zur Gruppe Machimus gestellt werden. Die Beschreibung, die Loew (Linn. Entont. Bd. IV. pag. 51) von einem einzigen schlecht conservirten $q$ als Asilus lugens gibt, passt fast ganz auf das \& von upicatus, nur wird der Knebelbart unten bloss gelblichweiss, die lange Beharung der Vorderschenkel unten ganz schwarz angegeben. As. cyanopus Lw., pag. 53, (nach $10^{7}$ ans 0esterreich beschrieben) unterscheidet sich nach der Beschreibung durch den weiter hinaufreichenden Höcker des Untergesichtes, den glänzend sehwarzen \&. Hinterleibsring und die fast netalliseh blausehwaruen Beine; As. modestus Lw., pag. 55, durch die glänzend schwarzen Seitenflecke des dritten und folgenden Hinterleibsringes, durch zahlreiche weisse Haare am ersten Fühlergliede und weisse Beluarung des Sehildchens. 





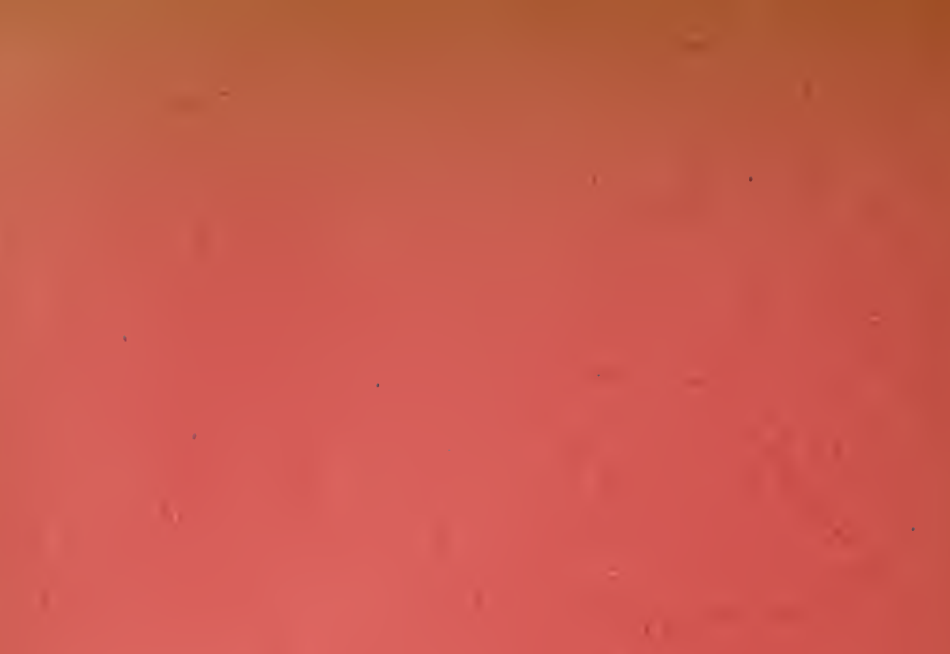

$+$

(n)

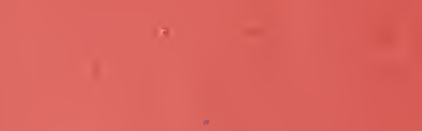

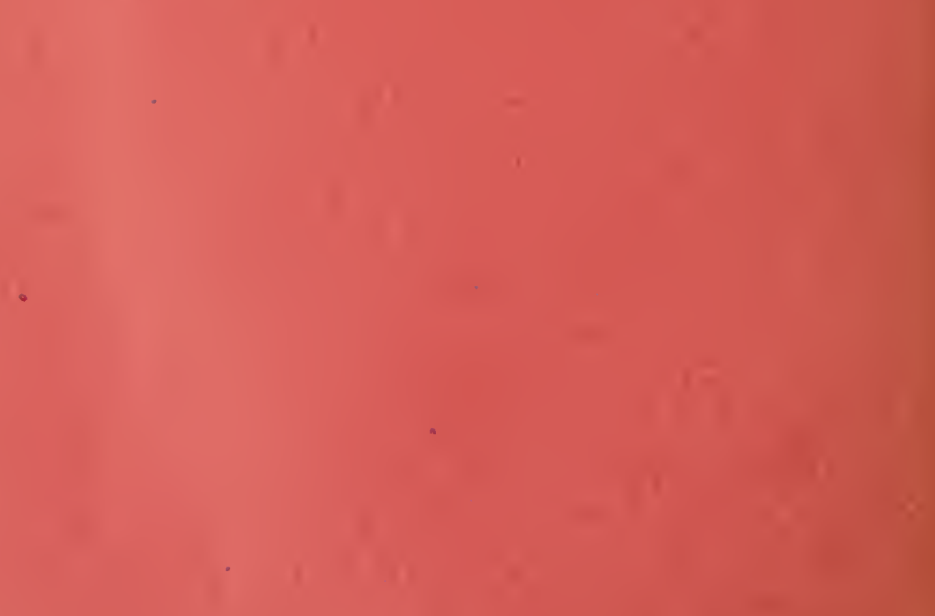




\section{Übersicht \\ der bisher bekannten Arten der Pterocallinen. (Dipt.)}

\section{Von Friedrich Hendel, Wien.}

Nach der Bearbeitung der Pyrgotinen als eines Teiles der grofsen Aciphoreen-Gruppe der Diptera acalyptrata (79. Fascic. Genera Insectorum, 1908) habe ich jene der Pterocallinen-Gattungen begonnen.

Das überaus reiche Studienmaterial, das mir diesmal wider Erwarten zu Gebote stand, verdanke ich fast ausschliefslich einer einzigen Person - Herrn Wilhelm Schnuse in Dresden, der mir alle seine in Bolivia und Peru gesammelten und, wie sich merkwürdigerweise herausstellte, $\mathrm{zu}^{2} / 3$ aus Pterocallinen bestehenden Ortalidinen in selbstloser Weise zur Bearbeitung überliefs. Seinem Sammeleifer ist es hauptsächlich zu danken, dafs die Zahl der bekannten Arten und Gattungen und damit unsere Formenkenntnis dieser Gruppe so stark vermehrt wurde. Aber auch im ungarischen National-Museum fanden sich viele neue Arten.

Wir kannten bisher 6 Gattungen mit 19 Arten, mit Ausnahme der Gattung Psaeroptera, welche ich nicht hierher rechne und die wahrscheinlich mit dem neu von Cresson errichteten Hiatus zusammenfällt. Die folgende Arbeit gibt aber schon eine Übersicht über 18 Gattungen mit 86 Arten.

Mit Ausnahme dreier paläarktischer und ein paar nearktischer Formen gehören alle übrigen Arten dem neotropischen Faunengebiete an.

Vorliegende Arbeit enthält die Auseinandersetzung aller Arten der Pterocallinen und bildet somit die Basis und nötige Ergänzung zur Bearbeitung und Abbildung der Gattungen, welche in Wytsmans Sammelwerk erscheinen wird. Da dort ohnehin alle Zitate und Synonyme aufgezählt werden, habe ich diese Arbeit nicht damit beschwert, deren Zweck ja die leichte Bestimmung dieser in Farben und Formen so prächtigen Fliegen ist.

Dafs ich in den Verwaltern der Dipterensammlungen des Wiener und des Budapester Museums, den Herren A. Handlirsch und C. Kértesz, die dankenswerteste Unterstützung fand, ist ja selbstverständlich.

\section{Analytische Übersicht der Gattungen.}

1. Beide Queradern sind schief und laufen parallel; die hintere bildet mit der Discoidalader einen stumpfen Winkel 2. 
Die Queradern nicht parallel; die hintere bildet mit der Discoidalader einen spitzen, mit der Posticalader einen stumpfen Winkel . . . . . . . . . . . 6.

2. Kleine Querader jenseits der Mitte der Discoidalzelle, näher der Flügelspitze. . . . . . . . . . . . 3.

Kleine Querader vor der Mitte der Discoidalzelle, näher der Wurzel

3. Stirne gekörnt. Subcosta vor der Mündung plötzlich steil zur Costa aufgebogen . . . II. Chondrometopum n. g.

Stirne glatt. Subcosta allmählich unter sehr spitzem Winkel in die Costa mündend. . . . . . . . . . 4.

4. Der spitze Zipfel der Analzelle überragt die hintere Basalzelle nicht . . . . . . IV. Xanthacrona Wulp.

Der spitze Zipfel der Analzelle überragt deutlich die hintere Basallzelle . . . . . . . III. Myennis Rob.-Desv.

5. Dritte und vierte Längsader gegen die Mündung zu divergierend. Subcosta vor der Mündung zuerst abwärts, dann steil aufwärts gebogen. Stirne glatt. I. Megalaemyia n. g.

6. Kleine Querader auf oder vor der Mitte der Discoidalzelle. 7. Ḱleine Querader deutlich jenseits der Mitte der Discoidalzelle . . . . . . . . . . . 10.

7. Erste Hinterrandzelle in der Mitte stark zitronenförmig erweitert, so breit wie der halbe Flügel, gegen die Spitze zu aber wieder verjüngt. Die Discoidalzelle ist dadurch so stark nach abwärts gebogen, dafs die hintere Querader als eine unmittelbare Fortsetzung der Posticalader erscheint und dem Flügelhinterrande fast parallel läuft.

XIII. Elapata n. g.

Erste Hinterrandzelle normal,Discoidalzelle nicht gekrümmt. 8.

8. Kopf in der Längsachse zusammengedrückt, Augen daher lotrecht oval

Kopf im Profile so hoch wie lang, nicht zusammengedrückt. Augen länger als hoch . XVII. Ophthalmoptera n. g.

9. Mundrand ohne Vibrisse. Die Frontorbitalborsten stehen schief nebeneinander. Randmal des $\sigma^{\pi}$ stark erweitert.

VI. Dasymetopa Loew.

Mundrand mit einer kräftigen Vibrisse. Orbitalborsten hintereinander. Subcostalzelle des $\sigma^{7}$ nicht grölser als beim ㅇ.

VII. Rhyparella n. g.

10. Analzelle in eine auffallend schmale Spitze ausgezogen, die mindestens so lang wie die Analzelle selbst ist . 11 .

Analzelle ohne Spitze oder nur mit einem kurzen, keilförmigen Zipfel . . . . . . . . . . . . . 13. 
11. Flügelvorder- und -Hinterrand parallel. VIII. Pterocalla Rond. Vorder- und Hinterrand des Flügels nie parallel . . 12.

12. Stirne mit einer Grube vor den Ocellen. Die verengte Spitze der ersten Hinterrandzelle ist aufwärts gebogen.

XV. Bothrometopa n. g.

Stirne ohne Grube. Erste Hinterrandzelle gerade.

X. Callopistromyia Hend.

13. Anallappen des Flügels mit einer auffallenden Ecke vorspringend.

Thoraxrücken mit einer breiten Längsgrube in der Mitte.

XVIII. Goniaea n. g.

Anallappen abgerundet, normal. Thoraxrücken ohne Grube. 14.

14. Clypeus im Profile mit konvexem Buckel zwischen und unter den Fühlern vortretend. Dritte und vierte Längsader vor der Mündung aufwärts gebogen. XIV. Cyrtomostoma n. g.

Clypeus ohne Buckel. Dritte und vierte Längsader nicht aufwärts gebogen . . . . . . . . . 15 .

15. Arista lang und ziemlich weitläufig gefiedert. Analzelle bauchig begrenzt. Erste Hinterrandzelle an der Spitze verengt. Zweite Längsader zweimal wellig geschwungen.

XI. Pterocerina n. g.

Arista nie gefiedert, nackt oder höchstens behaart. . 16 .

16. $\sigma^{7}$ : Vorderschenkel unten höckerartig erweitert; Vordertarsen verkürzt. q: Das basale Doppelsegment des Hinterleibes so lang wie der halbe, das Wurzelglied der Legeröhre so lang wie der ganze Hinterleib und so breit wie dieser.

XVI. Coscinum n. g.

$\sigma^{7}$ : Vorderbeine normal. 우 Legeröhre kürzer und schmäler als der Hinterleib, dessen Wurzelsegmente nicht verlängert sind

17. Analzelle bauchig begrenzt. Radialader am Ende wellig aufwärts gebogen. Flügel gegittert.

XII. Paragorgopsis Gigl. Tos.

Analzelle mit kurzer, aber deutlicher Spitze. Radialader nicht aufwärts gebogen. Flügel mit Querbinden . . . 18.

18. Kopf kuglig, hinten ausgehöhlt. Augen rund. Drittes Fühlerglied fast kreisrund . . IX. Pseudotephritis Johnson. Kopf flach, hinten stark ausgehöhlt. Augen lotrecht oval. Drittes Fühlerglied länglichrund. V. Terpnomyia n. g.

\section{Genus: Megalaemyia n. g.}

1. Der Rand an der Flügelspitze schwarz. Hintere Basalzelle oben geradlinig begrenzt . . . . . . . . 2 .

Ein sichelförmiger Rand an der Flügelspitze glashell. Hintere Basalzelle oben erweitert . 6. 
2. Analzelle dunkel, mit einem glashellen Punkte in der Mitte. 3. Analzelle ganz glashell. Spitzenhälfte des Flügels glashell, mit einer geraden Querbinde über die hintere Querader und einem Costalsaume . . . . . 6. M. costalis $\mathrm{n}$. $\mathrm{sp}$.

3. Hinterleib mit gekörnter Oberfläche . . . . . . 4. Hinterleib glatt, poliert. Thorax glänzend schwarz, mit 2 weifsen Längsstriemen in der Mitte. 3. M. albostriata n. sp.

4. Rücken auf grauer Bestäubung schwarz punktiert. Flügel hinter der Posticalader glashell . . . . . . . . . 5 .

Rücken des Thorax nicht punktiert. Flügel hinter der Posticalader noch braun . . . . . . 1. M. Elsae n. sp.

5. Der glashelle Teil der Submarginalzelle mit 2 braunen Querbändchen, die bis an die Cubitalader herabreichen.

2. M. punctulata n. sp.

Obige 2 Querbinden fehlen. Der braune Costalsaum geht um die ganze Flügelspitze herum . *M. radiata $\mathrm{n}$. $\mathrm{sp}$.

6. An der kleinen Querader ein helles Fenster. . . . 7.

An der kleinen Querader kein Fenster. Von der Basalhälfte der Discoidalzelle zieht eine bogenförmige Binde in die dritte Hinterrandzelle hinüber . 4. M. bestifer $\mathrm{n}$. $\mathrm{sp}$.

7. Untergesicht mit einem weifsen Querbande. Flügel hell nufsbraun . . . . . . 5. M. fenestellata $\mathrm{n} . \mathrm{sp}$. Untergesicht einfarbig dunkelbraun. Flügel schwarzbraun. * M. marginata n. sp.

\section{Megalaemyia Elsae n. sp.}

$6 \sigma^{7} q$, Bolivia (Mapiri, Sarampioni; Februar und März). Peru (Urubambaflufs, September). Coll. Schnus e.

Stirnstrieme hell rotbraun bis schwarzbraun, oder das Rot ist nur längs der Mitte sichtbar; mit Fettglanz und kurzer, aber ziemlich rauher, an den Orbiten etwas längerer Grundbehaarung. Ocellendreieck und Scheitelplatten glänzend schwarz, weifslich bestäubt. Die Augenränder um das ganze Auge herum weifsschimmernd. Clypeus heller oder dunkler braun, ebenso wie die rötlichen Wangen und Backen weifs bereift, besonders beim $q$. Mundrand manchmal heller gefärbt. Hinterkopf schwärzlich. Augen einfarbig hell rotbraun.

Fïhler dunkel braunrot. Prälabrum schwärzlich. Die Taster und der Rüssel, mit Ausnahme des glänzend schwarzen Kinnes, rotbraun bis dunkelbraun.

Thorax und Schildchen glänzend braunschwarz. In gewisser

* Die Beschreibung der mit einem Sternchen versehenen Arten folgt im Anhange. 
Beleuchtung erscheint das Schildchen und der Rücken vor der Quernaht in rotbraunem Schimmer, der Rücken hinter der Naht mit gelblichen Reflexen, was durch ein feines Toment hervorgebracht wird.

Die Pleuren haben über der Sternopleuralnaht einen milchigweilsen Schimmer.

Hüften und Beine glänzend braunschwarz. Füfse leuchtend hell gelbrot.

Hinterleib glänzend pechbraun oder schwarz, mit winzigen Grübchen, die dicht nebeneinander stehen und teilweise zusammenfliefsen, über und über bedeckt, wodurch die Oberfläche ein granuliertes Aussehen erhält. Der Hinterrand des dritten Tergits ist an den Seiten etwas verkürzt oder ausgeschweift, so dals zwischen dem dritten und vierten Tergit ein seitliches, unten durch die weiche Bindehaut begrenztes Grübchen entsteht, welches mit einer weifslichen oder gelben wachsähnlichen Masse, klumpenartig gehäuft, erfüllt ist. Erstes Glied der Legeröhre kurz und nicht breit, von der Form eines gleichseitigen Dreiecks.

Von den 2 Arten, deren Flügelspitzensaum auch noch schwarz ist, unterscheidet sich diese Art in der Flügelzeichnung durch Folgendes: Die braunschwarze Farbe herrscht weitaus vor. Vor der Mündung der Mediastina liegen an der Costa 3 helle, trapezförmige Flecke, nicht blofs einer.

Die erste Hinterrandzelle ist vor der Spitze verengt und dann erst wieder erweitert. In den braunen, gegen die Flügelspitze heller werdenden Hinterrandzellen 1 und 2 liegt hinter der hinteren Querader je eine helle schiefe Querbinde. Bei den anderen Arten sind diese Zellen glashell. Der Flügel ist auch hinter der Posticalader noch ausgedehnt braun gefärbt. Das Ende der dritten Längsader ist nach aufwärts gebogen.

Schüppchen hell bräunlich. Schwinger weifsgelb.

Körperlänge ơ $4 \mathrm{~mm}$, $\uparrow 4,5 \mathrm{~mm}$. Flügel $4 \mathrm{~mm}$.

2. Megalaemyia punctulata n. sp.

2 \&, Bolivia (Mapiri, Januar). Coll. S c hn us e.

Stirnstrieme rotbraun; Stime im übrigen wie bei $\boldsymbol{M}$. Elsae.

Das Untergesicht gleicht mit seiner silberweifsen Querbinde jedoch $M$. albostriata. Augen bläulich metallisch grün, oben und unten, sowie 2 wagrechte Querbinden über die Mitte verlaufend, purpurviolett.

Fühler rostrot, desgleichen die Taster, deren Spitzen braun sind. Rüssel und Prälabrum dunkler braun.

Thorax und Schildchen glänzend schwarzbraun, an den Pleuren lichter. Der Rücken ist mit einer weifsgrauen Bestäubung, 
welche in gerade Längsreihen geordnete schwarze Punkte der Grundfarbe freiläfst, dicht bedeckt. Pleuren oben mit einem milchweifs schimmernden Längsbande.

Hinterleib glänzend schwarzbraun, mit granulierter Oberfläche. Die Skulptur wird aber nicht wie bei $M$. Elsae durch Vertiefungen, sondern durch winzige halbkuglige Konvexitäten erzeugt. Erstes Glied der Legeröhre wie bei der zuletzt genannten Art.

Hüften und Beine wie bei $\boldsymbol{M}$. albostriata gefärbt.

M. punctulata unterscheidet sich in der Flügelzeichnung von den beiden zum Vergleiche herangezogenen Arten durch das Fehlen der glashellen Punkte in der Rand- und Unterrandzelle, sowie durch die ganz glashelle dritte Hinterrandzelle. Das Ende der dritten Längsader ist nach aufwärts gebogen.

Da sich die Flügel aller Megulaemyia-Arten nicht so gut beschreiben wie abbilden lassen, verweise ich auf die von mir ausgeführten Tafeln der Genera Insectorum, Subfam. Pterocallinae.

Schüppchen braungelb. Schwinger hellgelb.

Körper- und Flügellänge ungefähr $4 \mathrm{~mm}$.

\section{Megalaemyia albostriata n. sp.}

$6 \sigma^{7}+$, Bolivia (Mapiri, Januar-März); Peru (Meshagna, September). Coll. Schnuse.

Stirnstrieme dunkelbraun, oben vor den durch Bestäubung und Glanz hell erscheinenden Scheitelplatten und Ocellendreieck schwar'z, vorne in der Mitte mit weifslichem Schimmer. Behaarung kurz und fein. Orbiten rund herum weifs eingefalst. Ebenso ist das ganze Untergesicht unter den Augen, dann quer über dem Mundrande silberweifs. Die unteren Backen, sowie der Hinterkopf jedoch sind glänzend schwarz. Der Clypeus ist matt braun. Angen wie bei $\boldsymbol{M}$. punctulata.

Füller dunkel braunrot. Das dritte Glied derselben meist noch dunkler. Rüssel und Taster wie bei M. Elsae. Desgleichen auch der Thorax und das Schildchen. Auf dem Rücken sind aber aufserdem, wenn derselbe von rückwärts betrachtet wird, zwei hinten abgekürzte, weifsschimmernde Längsstriemen in der Linie der Dorsozentralen zu sehen.

Hüften und Schenkel dunkelbraun, Schienen allmählich heller rotbraun, Füfse noch heller, gelbrot.

Hinterleib pechbraun, glatt poliert, stark glänzend, beim or mit ähnlichen Gruben wie bei M. Elsae. Erstes Glied der Legeröhre spitz dreieckig, länger, aber nicht breiter als bei $M$. Elsae.

Im Flügel unterscheidet sich diese Art von den 2 nächstverwandten Arten dadurch, dafs zwischen der ersten und zweiten Längsader an der Costa 2 dreieckige helle Flecke liegen und 
dafs von der aufgebogenen Radialader ausgehend nur eine dunkle Querbinde die Cubitalader berührt ${ }^{1}$ ). Schüppchen braun, Schwinger hellgelb.

Körperlänge $3-4 \mathrm{~mm}$. - Flügel $3,5-4 \mathrm{~mm}$.

\section{Megalaemyia bestifer n. sp.}

4 ๙7, Peru (Meshagna, Urubambaflufs; September), Coll. $\mathrm{Schnuse.}$

Stirnstrieme dunkel rotbraun, wenig glänzend und kurz schwarz behaart. Scheitelplatten und oberer Hinterkopf, ebenso der Clypeus dunkelbraun, wachsglänzend. Wangen, Backen und unterer Hinterkopf rötlich braun. Fühler noch dunkler rotbraun als die Stirne.

Arista mit Ausnahme des etwas verdickten Wurzeldrittels fein und kurz, aber deutlich behaart. Augen einfarbig dunkel stahlgrün.

Rüssel mit seinen Anhängern dunkelbraun, Taster etwas rötlich.

Thorax und Hinterleib dunkelbraun, nur wachsglänzend.

Rücken mit einem dünnen rotbraunen Tomente gleichmäfsig bedeckt.

Hüften und Beine dunkel rotbraun, Schienen heller, noch mehr aber die Tarsen.

Die Behaarung des Hinterleibes ist hellgelb.

Flügel schwarzbraun. Kleine Querader ohne helles Fenster, höchstens selbst glashell. Von der dunklen Wurzelhälfte der Discoidalzelle zielıt ein bogenförmiges Band bis zur Mündung der Analader herab. Erste Hinterrandzelle vor der Spitze etwas verengt, dann wieder erweitert.

Schïppchen bräunlich. Schwinger gelb.

Alle 4 Stücke, die mir vorliegen, sind mehr oder weniger ölig geworden! Die Beschreibung bedarf daher noch der Ergänzung.

Körperlänge und Flügel 2,5- $3 \mathrm{~mm}$.

Anmerkung: Diese, die folgende Art und M. marginata unterscheiden sich von den vorhergehenden aufser in der Flügelzeichnung noch durch einige andere Merkmale, so dafs ihr Verbleiben in der Gattung Megalaemyia nur ein provisorisches ist. Ihre Mediastina ist vor der Mündung ahgebrochen und geht nur als Falte zur Costa, welche an dieser Stelle etwas verdünnt erscheint. Dadurch entsteht

1) Die hintere Querader bildet mit der Discoidalader wohl einen stumpfen Winkel, jedoch mit der Posticalader keinen spitzen, sondern auch wieder einen stumpfen Winkel, was daher kommt, dal's sie eben nicht gerade, sondern in der Mitte bauchig gebogen ist. Das Ende der dritten Längsader ist nach abwärts gebogen. 
eine Ähnlichkeit mit den Tephritinen. Aufserdem besitzen sie 2 Paare Dorsozentralborsten und aufgerichtete, gekreuzte Borsten an der Schildchenspitze, während die anderen Arten nur 1 Paar Dorsozentralborsten und parallele oder etwas divergierende Schildchenborsten baben. Mit Tephritinen haben wir es deshalb nicht zu tuin, weil untere Frontorbitalborsten vollständig fehlen. Flügeladerung und -Zeichnung, Kopfbau und die sonstige Organisation bringen diese Fliegen im übrigen in die unmittelbare Nähe der typischen Megalaemyiaarten.

\section{Megalaemyia fenestellata n. sp.}

1 q, Mexico (Orizaba, November). K. K. Museum in Wien (leg. Bilimek).

Stirnstrieme rot, fein und kurz behaart. Der untere Teil der Backen und des Hinterkopfes gelbrot. Die weifse Querbinde des Untergesichts und die übrige Kopffärbung wie bei $\boldsymbol{M}$. albostriata.

Fühler rotbraun, das dritte Glied am dunkelsten. Arista wie bei $\boldsymbol{M}$. bestifer. Die Augen scheinen einfarbig rotbraun zu sein.

Rüssel mit seinen Anhängen rostrot.

Thorax und Schildchen dunkel rotbraun, der Rücken mit Ausnahme der Seiten jedoch schwarzbraun und etwas graulich bereift.

Hüften und Beine rotgelb. Schenkel gegen die Knie zu mehr braun werdend.

Hinterleib schwarzbraun, an der Wurzel etwas rötlich. Die Oberflächenskulptur ähnelt jener der M. Elsae. Das erste Glied des Ovipositors ist sehr kurz, stumpf dreieckig und ron rötlicher Farbe.

Flügel nufsbraun. An der kleinen Querader liegt ein helles Fenster. Die Discoidalzelle ist ganz glashell und die dritte Hinterrandzelle ebenfalls. Die erste Hinterrandzelle ist jenseits der hinteren Querader ïberall gleich breit.

Schüppchen bräunlich. Schwinger?

Körperlänge und Flügel $3 \mathrm{~mm}$.

$$
\text { 6. Meyalaemyia costalis n. sp. }
$$

1 q, Bolivia (Mapiri, Januar). Coll. S chnuse.

Da mir nur 1 einziges, etwas fettig gewordenes $q$ vorliegt, kann ich ganz verlärsliche Farbenangaben nicht machen.

Kopf samt den Fühlern gelbrot. Eine weifsschimmernde Binde quer über das Untergesicht scheint mir vorhanden zu sein. Augen?

Auch Prälabrum, Rüssel und Taster sind hell rostrot. 
Thorax und Hinterleib glänzend pechbraun. Schulterbeulen und Schildchen rotbraun. Der Rücken des Thorax ist von einer ockrigen Bestäubung etwas matt.

Hüften und Beine rotbraun; letztere gegen das Ende zu immer heller werdend. Das erste Glied der Legeröhre ist schlank und spitz dreieckig and fast so lang wie der ganze Hinterleib.

Im Flügelgeäder weicht diese Art nicht unbeträchtlich vom Gattungstypus ab. Bei allen Arten ist die Radialader auffallend wellig geschwungen oder doch vor der Mündung bogig nach aufwärts gebogen; hier ist sie jedoch ganz gerade und macht nur vor dem Ende eine kaum merkliche Biegung nach unten. Nur auch noch bei $\boldsymbol{M}$. fenestellata sind die Endabschnitte der dritten und vierten Längsändern fast gerade und parallel, sonst in verschiedener, charakteristischer Weise gebogen. Die hintere Querader ist wie bei der albostriata bauchig gebogen. Der in der Tabelle erwähnte Costalsaum geht von der Mündung der auf der Costa senkrecht stehenden Querbinde bis zur Mündung der Discoidalader. Die Querbinde hängt am Flügelhinterrande mit der Spitze eines braunen rechtwinkligen Dreiecks zusammen, dessen Katheden die Costa von der Wurzel bis zur Mündung der Subcosta und von dort eine Linie im rechten Winkel nach abwärts sind, und dessen Hypotenuse eine geschwungene Linie bildet, welche die Basalzellen, die Wurzel der Discoidalzelle und die Wurzelhälfte der dritten Hinterrandzelle noch glashell lälst. Ein glashelles Dreieck liegt im Randmale, ein heller Fleck in der Costalzelle.

Die kleine Querader steht auf der Mitte der Discoidalzelle, bei allen anderen Arten vor derselben.

Schüppchen und Schwinger rotbraun.

Körperlänge $4 \mathrm{~mm}$. Flügel $3 \mathrm{~mm}$.

\section{Genus: Chondrometopum n. g.}

7. Chondrometopum arcuatum n. sp.

1 , Peru (Pichis, Pto. Bermudes, Dezember). Coll. Schnuse.

Die auffallend breite, gekörnte Stirne ist rotbraun, mit kaum merklicher Grundbehaarung. Die Scheitelplatten und der obere Hinterkopf erscheinen noch dunkler. Der ganze untere Kopfteil ist von glänzend gelber Grundfärbung, am Clypeus, an den Wangen und an den vorderen Backen jedoch dicht weifs bereift. Augen einfarbig smaragdgrün, mit schwachem rötlichen Schimmer.

Fühler und Taster gelbrot. Praelabrum kaum sichtbar. Rüssel braun.

Der ganze Thorax und der Hinterleib dunkel pechbraun, mit 
Wachsglanz, an manchen Stellen rötlich durchscheinend. Legeröhre hellgelb, das erste Glied derselben kurz trapezförmig.

Beine von der Farbe des Thorax. Die Schienen gegen die Spitze zu und die Tarsen rotgelb.

Flügel glasig, mit einem bogenförmigen, schmalen schwarzen Bande an der Spitze, welches vom Flügelhinterrande iiber die schiefe hintere Querader zur Costa und längs derselben bis über die Mündung der Discoidalader hinausläuft. Ebenfalls schwarz ist die Flügelbasis über der Discoidalader bis zu der mit obigem Ringbande parallelen Grenze, die von der Mündung der Subcosta bis knapp hinter die kleine Querader verläuft. In diesem schwarzen Felde liegt ein ovaler glasheller Fleck wenig hinter dem Ursprung der Radialader in der Unterrandzelle und ein dreieckiger, ebensolcher Fleck in Randmale, mit der Spitze gegen die kleine Querader zu.

Schwinger gelblich weifs.

Körperlänge mit Legeröhre (erstes Glied) 4,5 mm. Flügel $4 \mathrm{~mm}$.

\section{Genus : Myennis Rob.-Desv.}

Essai sur les Myodaires p. 717 (1830).

1. Erste und zweite Längsader siud über der kleinen Querader durch eine schiefe Querader verbunden. . . . 6. Obige Querader fehlt . . . . . . . . . 2.

2. Beide Queradern sind ungefähr die Länge der hinteren Querader voneinander entfernt. Erste Hinterrandzelle in rer Nitte verengt . . . . 14. M. scutellaris Wied.

Queradern viel stärker genähert. Erste Hinterrandzelle in der Mitte nicht verengt . . . . . . . . . 3.

3. Glänzend schwarze Arten, mit schwarzen Flïgelquerbinden. 4 .

Arten von nicht glänzend schwarzer Grundfarbe und mit hellbraunen Flügelquerbinden . . . . . . . 5.

4. Gesicht grau, mit 3 braunen Querlinien. Der Apicalfleck des Flügels isoliert . . . 11. M. sibirica Portschinsky.

Gesicht einfarbig weifs. Der Apicalfleck des Flügels ist an der Costa mit den übrigen Querbinden verbunden.

10. M. nigra n. sp.

5. In der Randzelle liegt ein isolierter brauner Fleck. Schenkel verdunkelt. Stirne grau. Hinterleibsbasis hellbraun.

8. M. octopunctata Coqueb.

Der Randzellenfleck bildet die unmittelbare Fortsetzung der Spitzenbinde. Schenkel und Stirne hellgelb. Hinterleibsbasis orangerot . . . . . 9. M. tricolor $\mathrm{n}$. sp. 
6. Die beiden dunklen Säume der Queradern bilden eine einzige Querbinde, weil die Adern fast übereinander stehen. Thorax längsgestriemt . . • . . . . . . . . 7.

Die Säume der beiden ziemlich voneinander entfernten Queradern bilden zusammen keine Querbinde. Thorax quergestriemt . . . . . . . 13. M. zebra n. sp.

7. Hinterleib glänzend schwarzbraun.

12. 1 . appendiculata n. sp.

Hinterleib metallisch blau und violett.

*M. cyaneiventris n. sp.

8. Myennis octopunctata, Coquebert

[= Myennis fasciata Fabricius, Syst. Antl. p. 210. 19 (1805)].

L oew hat schon in den Monogr. N. A. Dipt., Vol. VIII, p. 58 darauf hingewiesen, dals die von $\mathrm{Coquebert}$ in der Illustratio iconographica Insectorum, Decas tertia, Paris 1804, p. 110 (Tab. XXIV, Fig. 17 a b c) beschriebene und abgebildete Musca octopunctata sehr wahrscheinlich mit unserer Myemis fasciate Fab. zusammenfällt. Er nimmt diese Synonymie jedoch nicht an, weil der namengebende Charakter nicht existieren soll. Coq u e b e rt schreibt: „.. . thorace marula clorsali grisea quadrata, punctis orto niyris." ..... "Thorax antice linea recta utrinque brevi, vigra; macula grisea quadrata in area nigra, punctis octo nigris in lineas 2 transiersas, paralleles dispositis."

Ich kann nur sagen, dals diese Beschreibung vollständig auf M. fasciata Fab. palst, welche Art vor dem Schildchen jenen quadratischen grauen Fleck und auf demselben $6-8$ schwärzliche Wurzelpunkte an den Borsten in 2 Querreihen zeigt.

Was mich aber vollends bestimmt, obigen Namen anzunehmen, ist die treffliche und so charakteristische Abbildung der Flügelzeichnung $\mathrm{Coqueberts,} \mathrm{welche} \mathrm{den} \mathrm{auch} \mathrm{schon} \mathrm{in} \mathrm{der} \mathrm{Be-}$ schreibung erwähnten braunen Fleck in der Randzelle deutlich zeigt. Man vergleiche nur die Photographie $\mathrm{Loews}$ in dessen "Bohrfliegen", Tafel XVI, 3.

Auch $\mathrm{R}$ ondan $\mathrm{i}$ hat in seinem Prodromus den Namen Myemis octopunctata Coqueb. schon angenommen. Schimmer.

Die Angen dieser Art sind im Leben grün mit violettem

$$
\text { 9. Myennis tricolor n. sp. }
$$

8 우 aus Sary Yasy in Turkmenien. K. K. Museum in Wien.

Kopf matt hellrot, nur Hinterkopf an den Seiten und das kleine Ocellendreieck weilsgrau. Intergesicht weilslich bestäubt. Stirne dentlich mit kurzen, schwarzen Haaren bedeckt, so breit 
wie ein Auge. Clypeus im Profile konkav. Fühler und Taster rotgelb, ebenso der Rüssel. Arista nackt. Taster etwas verbreitert. Rüssel rotbraun. Augen smaragdgrün mit blauem und violettem Schimmer.

Thorax glänzend schwarz, dicht grau bestäubt. Der Rücken ist innerhalb der Linien der Dorsozentralborsten auf einer breiten Strieme von vorne bis hinten hellgrau, seitlich davon abgesetzt sepiabraun, welche Färbung nach unten heller wird und hinten in der Supraalargegend die glänzend schwarze Grundfärbung hervortreten lärst.

Schulterbeulen rötlich, grau bestäubt; ebenso sind die Pleuren mit grauer, minder dichter und nach rückwärts noch dünner werdender Bestäubung bedeckt. Hinterrücken glänzend schwarz. Schildchen glänzend gelb, an den Seiten breit schwarz und nur oben schwach bestäubt.

Hinterleib dreifarbig: orange, weifs, schwarz. Das erste und zweite Tergit sind orange, ziemlich glänzend, die folgenden von glänzend schwarzer Grundfärbung, die aber in der Hinterhälfte des zweiten und der vorderen des dritten silberweifs, sowie am ganzen fünften Segmente grauweifs, dazwischen matt sepiabraun bestäubt ist. Der dritte und noch mehr der vierte Ring lassen aber seitlich das glänzende Grundschwarz hervortreten.

Erstes Glied der Legeröhre des $q$ fast so lang wie der Hinterleib, gelbrot, breit lanzettförmig. Genitaltergite des or rot und klein, kuglig.

Schüppchen weifs, Schwinger gelb. - Beine und Hüften ganz gell.

Flügel rein glashell, mit 4 hellbraunen, schiefen, parallelen, durchgehenden Querbinden. Die beiden ersten hängen an der Costa zusammen; die erste verläuft über die Basalzellen und die Analader; die dritte, isolierte, beginnt im Randmale und geht ïber die beiden Queradern, die zweite liegt in der Mitte zwischen der ersten und dritten Binde, die vierte liegt an der Flügelspitze.

$\sigma^{7}$ : Körper- und Flügellänge 4,5 $\mathrm{mm},-q: 5 \mathrm{~mm}$. Legeröhre $2 \mathrm{~mm}$.

\section{Myenuis nigra n. sp.}

1 ๙ Schnuse.

Stirne matt hellrot, mit kurzer, schwarzer, abstehender Grundbehaarung. Clypeus mit Prälabrum seidenartig weils. Backen unter dem Auge kastanienbraun. Hinterkopf dunkelgrau, an den Orbiten weils schimmernd.

Fühler und die verbreiterten Taster gelbrot, Rüssel schwarz. 
Im Vergleiche mit $\boldsymbol{M}$. octopunctata Coqueb. ist der Kopf viel stärker zusammengedrückt; die Augen sind daher viel höher und kürzer im Durchmesser. Auch das Profil des Clypeus ist nur wenig konkav und die Spitzenhälfte der Arista deutlich pubescent. Angen hell olivengrïn, am Vorderrande dunkel purpurn schimmernd, nach hinten verwischt.

Thorax, Hïften, Beine und Abdomen von glänzend pechbrauner Grundfärbung. Am Rücken ist der Teil vor der Quernaht, mit Ausnahme des Humeralcallus, und eine Querbinde etwas vor dem Schildchen weifs bereift. Dieser weilse Reif zieht auch auf die Pleuren herab und überzieht den Vorderteil der Mesound Sternopleuren.

Der Hinterrand des zweiten und der vordere des dritten Abdominaltergits sind ebenfalls schmal weifs bestäubt.

An den Beinen sind die Knie rötlich, die Schienen heller braun als die Schenkel, und die Tarsen sogar rostrot.

Flügel glashell mit 4 schiefen schwarzbraunen Binden. Die erste läuft längs der Costa von der Wurzel bis zur Mündung der Discoidalader und ist nur an der Subcosta etwas zusammengeschnïrt. Die zweite, die über die beiden genäherten Queradern führt, entspringt aus der ersten vom Randmale her, oder besser gesagt, ist die eigentliche Fortsetzung des Costalsaumes von der Wurzel her. Die dritte Binde läfst die hintere Basalzelle noch frei, wird aber dann unten von der Posticalader begrenzt, welche sie erst hinter der Mitte überschreitet. An der Mündung dieser Längsader stofsen die zweite und dritte Binde fast zusammen. Als vierte Binde kann man den verdunkelten Flügelteil hinter der Längsfalte der Axillarzelle auffassen. - Die Subcosta mündet nicht geradlinig unter sehr spitzem Winkel, sondern in einem steilen Bogen, wodurch das Randmal noch gröfser wird. Die beiden Queradern sind wie bei $M$. octopunctata genähert. Die hintere ist aber in der Mitte gebogen. Dritte und vierte Längsader gegen die Mündung zu parallel. Spitze der Analzelle nur kurz.

Schüppchen schneeweifs, Schwinger gelbweifs.

Körper- und Flügellänge 4,5 mm.

11. Myennis sibirica Portschinsky.

Horae Soc. Ent. Ross., V. XXVI. p. 213, T. 1 fig. 10 (1892).

Ich kenne die Art nicht. Die Beschreibung lautet:

․ Nigra, nitida; fronte lata fuscescenti-grisea, vitta transversa fusca, faciei griseae lineis tribus transversis fuscis, genis antennisque fusco-rufescentibus; thorace in medio lateribusque griseo-micante; scutello nigro, nitido, setis 4 marginalibus instructo; abdomine nigro, nitido, segmentis: secundo basi late 
tertioque anguste griseo-micantibus; oviducto lato, nigro, nitido, longitudine segmentis duobus ultimis subaequali; pedibus fusconigris, tibiis pallidioribus tarsisque sordide flavidis; alis hyalinis, costa basi latissime, macula apicali fasciisque tribus obliquotransversis atris.

Long. 6,5 $\mathrm{mm}$. - Patria: Sibirica.

\section{Myenus appendiculata n. sp.}

5 o $q$, Brasilien (Rio Grande do Sul). K. K. Hof-Museum Wien. - Paraguay. Ungar. National-Museum.

Kopf matt gelbrot, Clypeus heller, seidenglänzend; Stirne manchmal ins Rotbraune verdunkelt. Letztere an den Augenrändern, auf einer schmalen, sich verjüngenden Mittellinie vom schwarzen Ocellenhöcker bis zum Vorderrande und beiderseits des Ocellenhöckers selbst goldgelb bestäubt. Grundbehaarung derselben schwarz und kurz. Augen am Vorder- und Hinterrande dunkel violettpurpurn, in der Mitte als ovaler Längskern grün.

Fühler rostrot; drittes Glied derselben oft dunkler braun. Arista nackt. Im Vergleiche mit $\boldsymbol{M}$. octopunctata und $\boldsymbol{M}$. migra steht die Art in bezug auf Konkavität des Clypeus, Flachheit des Kopfes und Form der Augen zwischen denselben.

Backen unter dem Auge mit einem dunkelbraunen Fleck. Die verbreiterten Taster, das Prälabrum und die Labellen rostrot; der Rüssel jedoch sonst glänzend schwarz. Hinterkopf rotbraun, oben dunkler, an den Orbiten goldig bestäubt.

Thorax von glänzend dunkel rotbrauner Färbung, die an den Pleuren heller wird. Von derselben wird auf dem Rücken von einer goldgelben dichten Bestäubung folgende dunkle Längsstriemenzeichnung freigelassen: eine feine Nittellinie hinter der Quernaht; seitlich davon dann je eine breitere, durchgehende, nur ganz vorne doppelte Längsstrieme in der Linie der Dorsozentralborsten; noch weiter seitlich davon je ein Punkt und ein gröfserer Fleck hinter dem Humeralcallus und vor der Naht, und hinter derselben eine vorne zusammenhängende, U-förmige Doppelstrieme bis zum Schildchen. Letzteres ist unbestäubt oder fast so.

Hinterleib glänzend schwarzbraun. Das erste Glied der Legeröhre ist stumpf trapezförmig und halb so lang wie der Hinterleib.

Beine dunkel rostbraun, Knie und Tarsen heller.

Flügel glasig durchsichtig, mit schwarzen, schmalen Querbinden: Äufserste Wurzel schwarzbraun. Eine Bogenbinde läuft von der Costa einerseits bis zur Mündung der Discoidalader, anderseits in gleicher Krümmung über die Mündung der Mediastina und die Queradern der Basal- und Analzelle. Eine Querbinde endlich geht über die beiden Queradern zum Randmal und schliefst 
unter demselben auch die überzählige Querader zwischen der ersten und zweiten Längsader ein. Beim ơ ist das Randmal (Subcostalzelle) durch eine konvexe Ausbiegung der Costa stark erweitert und in der Mitte heller gefärbt. Die dritte und vierte Längsader konvergieren etwas gegen die Mündung zu. Der Zipfel der Analzelle ist nur kurz. Die zweite Längsader ist bei dieser und der folgenden Art vor dem Ende viel weiter nach aufwärts gebogen als bei den übrigen Spezies. - Schüppchen schwarz gerandet und gewimpert. Schwinger gelb.

Körper- und Flügellänge $5-5,5 \mathrm{~mm}$.

\section{Hyennis zebra n. sp.}

1 오, Brasilien (Rio Grande do Sul). K. K. Hof-Museum Wien.

Kopf braunrot. Stirne oben mit 2 breiten, ungefähr hufeisenförmigen dunkelbraunen Flecken, die sich in der Mitte fast $\mathrm{zu}$ einer Querbinde vereinigen. Grundbehaarung derselben und Kopfbau wie bei der vorigen Art. Backen unter dem Auge mit einem dunkelbraunen Fleck. Hinterkopf unten und auf dem Cerebrale rostrot, sonst dunkelbraun.

Fühler rostrot, Arista nackt. Prälabrum und die verbreiterten Taster rostrot; der Rüssel schwarzbraun mit glänzendem Kinne. Augen grün, mit purpurnem Unterrande und 2 breiten wagrechten Purpurbinden in der Mitte.

Grundfarbe des Thorax glänzend schwarzbraun, an den Pleuren heller, mehr ins Rotbraune gehend. Der Rücken und die Mesopleuren sind von einer dichten goldgelben Bestäubung bedeckt, welche eine dunkelbraune, matte Querstreifung, aus drei hufeisenförmigen Binden gebildet, hervortreten lälst. Die Mitte des ersten Bogens liegt ganz vorne, hinter dem Kopfe, und seine Schenkel laufen mit Überspringung des Humeralcallus über die Notopleuralnaht. Die zweite Bogenbinde läuft genau über die Quernaht, und der dritte Hufeisenbogen liegt parallel mit den vorderen und im gleichen Abstande hinter dem zweiten. Seine Schenkel berühren die Seiten der Schildchenbasis. Schildchen glänzend schwarzbraun, kaum bestäubt.

Hüften und Beine pechbraun. Sçhenkelwurzeln und Knie rostbraun, Tarsen viel heller, rostgelb.

Hinterleib mit Ausnahme der gelbroten Wurzel und des ebensolchen Vorderrandes des zweiten und dritten Tergits glänzend pechbraun. Eine weils bestäubte Mittellinie ist angedeutet. Die dunklen Stellen sind von einem zarten weifsen Reife bedeckt, der eine dichte Punktierung der Grundfarbe hervortreten läfst. Legeröhre heller, rotbraun, herzförmig nnd kürzer als der halbe Hinterleib. 
Flügelzeichnung und Aderung wie bei der vorigen Art, nur dafs die über die Queradern laufende Binde an der Discoidalader wegen der Entfernung der beiden Queradern, welche gröfser ist als die Länge der hinteren, breit unterbrochen ist. Diese gröfsere Entfernung der beiden Queradern wird zum Unterschiede von allen Myenmis-Arten dadurch hervorgebracht, dafs die hintere Querader schief nach auswärts geneigt ist, wodurch der Abstand von der kleinen an der Discoidalader gröfser, der Winkel mit dieser Ader jedoch kleiner wird. Trotzdem also der untere Winkel der Discoidalzelle daher ein stumpfer ist, kann diese Art doch in keine andere Gattung gebracht werden, weil sie in allen übrigen Punkten eine echte Myenmis-Art darstellt.

Körper- und Flügellänge $6 \mathrm{~mm}$.

\section{Genus : Xanthacrona Wulp.}

Biologia Centr. Amer., Dipt. II, p. 392 (1899).

15. Xanthacrona bipustulata Wulp.

Biologia Centr. Amer., Dipt. II, p. 393. T. X. 29 (1899).

25 or 웅, Peru (Meshagna, Urubambaflufs, August bis November), Bolivia (Mapiri, Jänner). Coll. S chnuse. - Paraguay. Ungar. National-Museum. Brasilien. Hof-Museum in Wien.

Unter dem mir vorliegenden Materiale lassen sich 2 Varietäten unterscheiden. Die erste hat die Flügelquerbinde über die beiden Queradern und den Costalsaum von der Wurzel bis über die Mündung der Discoidalader hinans von hellbrauner Farbe und einen ausgedehnten rotgelben Längswisch in der Randzelle und darüber hinaus bis zur Flügelspitze. Die andere Varietät hat oben genannte Flügelzeichnung tief schwarzbraun, ohne jedes Gelb oder nur mit Resten derselben darin. Zugleich ist zu beobachten, dafs das grofse, aufgeblasene Schildchen bei der ersten Varietät durch eine Längsfurche deutlich in 2 kuglige Hälften geteilt wird, was bei der zweiten Varietät kaum angedeutet ist. Bei manchen Stücken trägt oft noch jede Hälfte aufgetürmte warzenartige Beulen. Solche wurden von $\mathrm{Cresson}$, Entomol. News, 1908 p. 97, Pl. 6, Fig. 2-3, für eine eigene Art, X. tuberosa aus Paramaribo, gehalten. Da aber allmähliche Übergänge vorhanden sind und beide Formen in Copula gefangen wurden, kann von einer Trennung nicht die Rede sein.

Der Hinterleib ist manchmal ganz glänzend schwarz, manchmal an der Basis in verschiedener Ausdehnung gelb, oder auch an den folgenden Tergiten in verschiedener Breite in Form von Querbinden oder unregelmälsig gelb. 
Auch die Pleuren und die sonst gelben Beine können in verschiedenem Grade gebräunt sein.

Die Augen sind im Leben smaragdgrün, am Hinterrande dunkelblau oder violett schimmernd.

Körperlänge $4-6 \mathrm{~mm}$. Flügel $5-6 \mathrm{~mm}$.

Schildchenborsten sind 4 vorhanden, nicht 2 , wie von $\mathrm{Wulp}$ und als Unterscheidungsmerkmal in Willistons Manual of W. A. Diptera, 3. Ed. 1908, p. 277 angegeben wird. Von dem Autor ist diese Gattung nicht erkannt worden, delın er bildet p. 283 Fig. 13 den Flügel eines or unter anderen Tephritinen ab, trotz der bei dieser Gruppe ganz anders verlaufenden Mediastina.

* Xanthacrona phyllochaeta n. sp., siehe Anhang!

\section{Genus: Terpnomyia n. g.}

16. Terpnomyia angustifrons n. sp.

6 o7 o, Bolivia (Mapiri, Januar), Peru (Pichis, Pto. Yessup, Dezember und Januar). Coll. Schnuse.

Kopf von vorne betrachtet mit langer schmaler Stirne und gleichbreiten schmalen, hohen Augen. Stirne kurz und zart, aber ziemlich dicht behaart, in der Mitte wachs- bis rotgelb, vorne und hinten gesättigter, an den Orbiten breit seidenartig weils, sowie auch die Wangen, der Clypeus, das Prälabrum und der hintere Teil der Backen respekt. der untere Hinterkopf. Cerebrale gelblich, oberer Hinterkopf ganz dunkel, aber hell aschgrau bestäubt. Backen unter dem Auge mit einem rotbraunen Fleck. Clypeus im Profile fast ganz gerade und lotrecht." Augen hellgrün mit rotem oder violettem Schimmer, namentlich am Vorderrande.

Fühler hell rötlich gelb. Arista fast nackt. Drittes Fühlerglied länglich oval und erreicht fast mit seiner Spitze den Mundrand.

Taster verbreitert, rotgelb. Rüssel gelbbraun.

Thorax, Schildchen und Hinterleib von glänzend pechbrauner Grundfarbe. Der Rücken, der Prothorax, die Mesopleuren und der vordere Teil der Sternopleuren hell aschgrau bestäubt. Von der glänzend braunen Beule des Rückens hinter dem Quernahtast (Präalarcallus) zieht sich ein rotbrauner Reif zur Rückenmitte empor. Schildchen ebenfalls bereift.

Hüfte und Beine gelbrot, mit etwas verdunkelten Schienenspitzen, oder rotbraun, mit helleren Knien und Tarsen.

Die Wurzel des Hinterleibes ist manchmal etwas rötlich. Die Hinterränder des ersten und zweiten Ringes gelb. Beim o 
ist der dritte Ring etwas länger als einer der übrigen. Das erste Glied der Legeröhre ist so lang wie der halbe Hinterleib, an der Wurzel herzförmig, von spitzdreieckiger Gèstalt.

Das Randmal des $\sigma^{7}$ ist durch sanfte Biegungen der Costa und Subcosta deutlich erweitert. Radialader zweimal wellig geschwungen.

Die Flügelzeichnung besteht zunächst aus einer auffallenden V-förmigen braunen Binde, deren Scheitel an der Mündung der Posticalader liegt. Der basale Arm des V zieht über die Wurzelhälfte der Discoidalzelle nach oben hinauf zur Flügelbasis, der distale Schenkel über die hintere Querader senkrecht zur Costa, biegt dort um und läuft als Costalsaum bis zur Discoidaladermündung. Beim $\sigma^{7}$ ist das Randmal und 1 Teil des Costalsaumes gelb, beim $q$ alles braun. Von der Mündung der Subcosta kann sich die Färbung des Randmales als Querbinde bis auf die kleine Querader herabsenken oder schon früher abbrechen. Auch der Axillarlappen ist braun. Schüppchen hellbraun. Schwinger gelb.

Körperlänge $4,5-6 \mathrm{~mm}$. Flügel $4,5-5,5 \mathrm{~mm}$.

\section{Terpnomyia latifrons n. sp.}

4 q. Bolivia (Mapiri, Januar bis März), Peru (Urubambaflufs, November). Coll. S chnus e.

Kopf von vorne betrachtet viel breiter als hoch, mit vorgequollenen Augen. Stirne doppelt so breit wie ein Auge, sehr zerstreut kurz behaart. Über den Fühlern eine halbkreisförmig nach oben begrenzte Konvexität, welche wie die Scheitelplatten glänzend schwarzbraun ist und ein gelbes Mittelband trägt.

Der vertiefte Teil der Stirne matt rotgelb. Hinterkopf oben jederseits glänzend schwarzbraun. Das ganze Untergesicht hell wachsgelb, mit 2 parallelen schwarzen Querbinden. Die obere, viel breitere liegt unmittelbar unter den Fühlern und geht von Auge zu Auge, die untere zieht als Bogen vom unteren Augenrande des einen Auges über die Backen und den Mundrand bis wieder zum anderen Ange und wird nur an den Gesichtsleisten und in der Mitte über dem Mundrande schmal unterbrochen. Auch das Prälabrum ist oben schwarz. In Profile ist der Clypeus stark konkav, der Mundrand daher vorstehend.

Fühler rostrot, drittes Glied etwas dunkler. Arista fein und kurz behaart, pubescent. Die verbreiterten Taster rostrot. Rüssel braun. Augen grün, mit purpurnem Unterrande und 2 etwas schiefen purpurnen Querbinden in der Mitte.

Thorax, Schildchen und Hinterleib glänzend pechbraun. Rücken in der Zentralregion der ganzen Länge nach seidenartig graugelb bestäubt. 
Nur hinter der Quernaht zeigt sich ein rotbrauner Schimmer, der vor dem Schildchen aber wieder verschwindet. Aus dieser Bestäubung treten 3 hinten abgekürzte Längslinien der dunklen Grundfarbe hervor. Die helle Bestäubung zieht sich nur als schmales Querband vorne im Quernahtaste herab, während die Rückenseiten unbereift bleiben.

Pleuren und. Vorderhüften schütter weifsgrau bereift, daher hell und dunkel schillernd. Am Vorderrande der Tergite 3-5 liegt eine weifsgrane matte Binde, welche in der Mitte spitzenartig auf den Hinterrand des vorhergehenden Tergites vorgezogen ist. Nanchmal fehlt sie auf den hinteren Ringen. Das erste Glied des Ovipositors ist ungefähr zweimal so lang als breit, fast so lang wie der Hinterleib und schlank zugespitzt.

Hüften, Knie und Füfse rotbraun; der Rest der Beine schwarzbraun.

Radialader gerade, schief nach aufwärts gehend. Erste Hinterrandzelle an der Spitze etwas verengt, bei $T$. angustifrons parallelrandig. Während bei dieser Art die hintere Querader kaum ilhre eigene Länge von der kleinen entfernt ist, beträgt der Abstand bei T. latifrons die doppelte Länge der hinteren Querader. Der Zipfel der Analzelle ist bei T. latifrons so kurz, dafs er leicht übersehen werden kann, während er bei T. angustifrons kräftig als Spitze vorspringt.

Die Flügelzeichnung ist dieselbe wie beim of der vorhergehenden Art. Der proximale Schenkel der V-förmigen Binde ist. aber steiler aufgebogen, so dals er schon vor der Flügelwurzel die Costa an der Mündung der Mediastina erreicht, sich aber dort in 2-3 Flecke auflöst. Der distale Schenkel und der Costasaum sind viel breiter als bei $T$. angustifrons.

Das Randinal ist glashell. Nur von der Mündung der Subcosta geht eine schmale Querbinde senkrecht nach abwärts und schliefst die kleine Querader ein. Über die Analader zieht ein brauner Wisch, der auch die Analzelle erfüllt. Schwinger und Schüppchen weifsgelb.

Körperlänge $7 \mathrm{~mm}$. Flügel $5 \mathrm{~mm}$.

Anmerkung: Ich hahe diese Art mit der vorhergehenden in einer Gattung vereint, weil sie die gleiche Flügelzeichnung und einen, wenn auch schwachen Zipfel an der Analzelle besitzt und die Radialader an Ende nicht aufwärts gebogen ist. Ich mufs aber gestehen, dals der ganze Kopfbau dieser Art (die breite vertiefte Stirne, die vorgequollenen Angen, deren Unterrand fast wagrecht ist, die breiten Backen, der konkave Clypeus) der Gattung Paragorgopsis entspricht und nicht jenem von Terpmomyia aneyestifrons. 
$\mathrm{Zu}$ diesem Vorgehen bestimmte mich die leichtere Determinierung der Art bei der Gattung Terpnomyia. Ihre Stellung hier ist aber nur eine künstliche und provisorische.

3 weitere Arten und die Tabelle siehe im Anhang.

\section{Genus : Dasymetopa Loew.}

Berl. Ent. Zeit. Vol. XI. p. 285 (1867).

1. Flügel glashell, mit 2 schwarzen Längsbinden längs der ersten und vierten Längsader in der Wurzelhälfte und 2 schwarzen Querbinden, von der Mündung der Subcosta einerseits zur hinteren Querader und anderseits längs der Costa zur Mündung der Discoidalader. Randmal gelb.

24. D. stigma n. sp.

Flügel nicht glashell, sondern vorherrschend braun oder gelblich, ohne schmale schwarze Querbinden . . . 2.

2. Flügel ohne gelbe Färbung, grau hyalin mit ausgedehnten rauchbraunen Längswischen. Unmittelbar hinter der Mündung der Subcosta ein runder glasheller Fleck.

19. D. fumipenis n. $\mathrm{sp}$.

Flügel teilweise gelb gefärbt . . . . . . . 3 .

3. Flügel vorherrschend gelb, verwaschen, mit glasigen Stellen und braunen Flecken an der Spitze des Flügels, in der Costal- und Subcostalzelle, am letzten Abschnitt der Discoidalader, an den Queradern, dann in der Marginal- und Discoidalzelle. . . . . . *D. luteipennis n. sp.

Flügel aufser den gelben Stellen mit grofsen braunen, nie blofs punktartigen Partien. . . . . . . . 4.

4. Costalzelle ohne dunklen Kernfleck. An der Mündung der Radialader ist der Flügelrand hell. Hinter der Posticalader ist kein Braun mehr zu sehen.

18. D. ochracea n. sp.

Costalzelle mit dunklem Kernflecke. Der Flügel ist an der Mündung der Radialader und noch jenseits der Posticalader dunkelbraun . . . . . . . . . . . 5.

5. Flügel mit scharf begrenzten, regelmäfsig angeordneten glashellen Fenstern in der Spitzenhälfte . . . . . 6.

Flügel unregelmälsigg gelb- und braunscheckig, ohne geordnete helle Fenster.

6. Zwischen den Fühlerwurzeln ein samtschwarzer Punkt. Stirne gelb mit einer roten Querbinde.

23. D. nigropunctata n. sp. Lunula unpunktiert. Stirne einfarbig gelb . . . . 7 . 
7. Flügel mit 7 hellen Fenstern in keilförmiger Anordnung.

20. D. septempunctata n. sp.

Flügel mit 10 hellen Fenstern, ein streifenförmiges Querband bildend . . . . . . . . . * D. fenestrata n. sp.

8. Discoidalzelle in der Mitte und unmittelbar neben der hinteren Querader braun, sonst gelblich. 21. D. lutulenta Loew. Discoidalzelle ganz braun, ohne gelb.

22. D. sordida n. sp.

18. Dasymetopa ochracea n. sp.

$2 \sigma^{7}$, Bolivia (Mapiri, Januar), Peru (Meshagua, Oktober). Coll. Schnuse.

Kopf des or stark verbreitert, viel breiter als der Thorax, flach gedrückt. Stirne vorne ungefähr $1 \frac{1}{2}$ mal so breit wie ein Auge, oben etwas breiter; in der Mitte stark konkav, dicht und fein mittellang, centripetal behaart.

Der ganze Kopf matt goldockergelb, nur der Clypeus weifs schimmernd.

Ocellarborsten nach vorne gebogen. Untere Augenränder fast wagerecht; der Augenwinkel neben den Fühlern ein rechter. Augen smaragdgrün, mit tiefem und leuchtendem ultramarinblauen Schimmer.

Fühler rotgelb. Arista fast nackt. Das schmale Prälabrum, die verbreiterten Taster und der Rüssel gleichfarbig mit dem iilrrigen Kopfe.

Thorax und Schildchen mit Ausnahme der rötlichen Schultern und des Schildchenrandes von dunkelbrauner Grundfarbe, überall dicht goldockrig bestäubt. Pleuren vorne und unten gelbgrau bereift. Von hinten betrachtet treten auf dem Rïcken 2 dunkle Linien in der Richtung der Dorsozentralborsten und dazwischen noch 3 ebensolche, hinten aber abgekïrzte Linien auf.

Hüften und Beine ockergelb. Vorderhüften und Vorderfülse verküirzt.

Hinterleib glänzend sepiabraun. Der dritte Ring verlängert, länger als die matten und dunkleren folgenden 2 Segmente zusammen, welche, wie auch schon das dritte Tergit, an den Seiten und am Hinterrande lang und dicht bewimpert sind.

Randmal (Subcostalzelle) des $\sigma^{7}$ aufserordentlich stark erweitert und lang. Die Subcosta mündet ungefähr der hinteren Querader gegenüber. Die Radialader ist nicht wellenförmig geschwungen, sondern nur allmählich bogenförmig zur Costa aufgebogen.

Der Flügel ist gelb hyalin. Die Spitzenhälfte rauchbraun; nur ein trapezförmiger Fleck beiderseits der Mündung der Radial 
ader und von demselben eine gewundene schmale Binde herab bis in die dritte Hinterrandszelle gelb. Ein schmaler brauner Längswisch schliefst die kleine Querader ein und erfüllt den grölsten Teil der Discoidalzelle von der Wurzel an. Die Grenzen der braunen Zeichnung sind verwischt. Schwinger und Schüppchen gelb.

Körper- und Flügellänge $6 \mathrm{~mm}$.

\section{Dasymetopa fumipennis n. sp.}

$1 \sigma^{7}$, Peru (Pichis, Januar). Coll. S chnuse.

Kopf in Form und Farbe wie bei D. stigma.

Thorax, Schildchen und Hinterleib von dunkler Grundfarbe, dicht ockergelb bestäubt. Hinterleib leider verschrumpft.

Hüften und Beine rotgelb.

Flügel in der Aderung wie bei $D$. ochracea, nur dafs die Radialader über der kleinen Querader einen schwachen Bug nach unten hat. Der Flügel ist zum grölsten Teile rauchbraun, nur an der Wurzel, am Hinterrande und auf einem zentral in der Mitte gelegenen Wische grau hyalin. Hinter der Subcosta liegt am Vorderrande des Flügels ein runder heller Fleck. Das hellere Grau und das dunklere Braun gehen allmählich ineinander über.

Schüppchen und Schwinger gelblich.

Körper- und Flügellänge $3,5 \mathrm{~mm}$.

\section{Dasymetopa septempunctata n. sp.}

6 o, Peru (Meshagua, September, Oktober). Coll. Schnuse. Bolivia. Ungar. National-Museum.

Kopf bei allen 6 Stücken flach und verbreitert, breiter als der Thorax. Stirne so breit wie 1 Auge, vorne nur etwas verengt. Konkavität derselben seicht. Ocellarborsten nach vorne gebogen. Härchen zentripetal gerichtet, gegen die Mitte zu. Kopf gelb. Der Clypeus und das ganze Untergesicht weifs schimmernd. Unterrand der Augen wie bei $D$. ochracea.

Alle übrigen Körperteile wie bei $D$. variegata gefärbt. Das erste Glied des Ovipositors ist aber länger, spitz dreieckig.

Flügel gelb hyalin, jenseits der Wurzelzellen zum gröfsten Teile schwarzbraun, mit 7 regelmälsig angeordneten gelben Flecken von fast rechteckiger Gestalt. Einer in der Marginalzelle, 2 in der Submarginal- und in der ersten Hinterrandzelle, 2 unter der Discoidalader zu beiden Seiten der Querader. Der helle Fleck, der die Mündung der Mediastina umgibt, reicht als heller Zipfel in die Marginalzelle hinein. Costalzellenfleck wie bei $D$. variegata. Radialader kaum merklich wellig geschwungen. Schwinger und Schüppchen gelb.

Körper $7 \mathrm{~mm}$. Flügel $6 \mathrm{~mm}$. 


\section{Dasymetop a lutulenta Loew.}

Berl. Ent. Zeit. Vol. XI. p. 285. T. II. Fig. 1 (1867).

$3 \sigma^{7}$, Peru (Meshagua, Pichis; September, Oktober, Januar). Coll. Schnuse. - Surinam, Loew.

Wie wenig die Stirnbreite resp. die Verbreiterung des Kopfes konstant ist, beweist uns diese Art in gleicher Weise wie die Paragorgopsis-Arten. Ja hier machen wir die sonderbare Beobachtung, dafs von den 3 Stücken gerade 1 o einen verbreiterten Kopf besitzt, während das $\sigma^{7}$ normalköpfig bleibt.

Der Kopf dieses $q$ ist breiter als der Thorax und flachgedrückt. Seine Stirne ist zweimal so breit als 1 Auge und parallelrandig, in Behaarung und Färbung gleich jener von D. ochracea, nur dals die Ocellarborsten nach hinten gebogen sind. Die Konkavität ist seichter. Die unteren Augenränder sind stärker geneigt und bilden, nach der Stirnmitte hin verlängert, einen rechten Winkel. Bei der schmalstirnigen, normalköpfigen Art ist die Stirne schmäler als ein Auge und vorne etwas verengt, sonst aber in allem gleich. Clypeus ockergelb.

Thorax, Schildchen, Beine wie bei $D$. ochracea. Rücken ungestriemt.

Hinterleib gelblichgrau, etwas glänzend, mit rotbraunen, in der Mitte nach vorne erweiterten Hinterrandsäumen an den Tergiten. Der Hinterleib des einen $\sigma^{7}$ ist vertrocknet. Das erste Glied der Legeröhre hat ungefähr die Gestalt eines gleichseitigen Dreiecks und ist einfarbig dunkelbraun.

Flügel gelblichhyalin, braun gescheckt. Costalzelle ungefähr in der Mitte mit einem braunen Flecke an der Costa, der sich als Wisch schief nach abwärts bis in die vordere Basalzelle hinabzieht. Spitze des Randmales (= Subcostalzelle) schwarzbraun, ebenfalls etwas nach unten ausgewischt. Flügelspitze breit braun. In der Mitte der Discoidalzelle ein breiter brauner, oben die kleine Querader einschliefsender Fleck, weiter auswärts ein gleichgrofser an der hinteren Querader, welcher sich nach oben streifenartig bis an die Radialader fortsetzt. Beide Flecke sind durch das Braun der dritten Hinterrandzelle miteinander verbunden.

Randmal des $\sigma^{7}$ ist wie bei $D$. ochracea erweitert. Die Radialader zeigt aber eine deutliche wellenartige Biegung.

Schwinger and Schüppchen gelb.

Körper 5-6 mm, Flügel $5 \mathrm{~mm}$.

\section{Dasymetopa sordida n. sp.}

$1 \sigma^{7}$, Bolivia (Mapiri; Januar). Coll. S chn us e.

Kopf des einen Stückes nicht breiter als gewöhnlich, mit schmaler Stirne. Letztere ist vorne schmäler als ein Auge, in 
der Mitte deutlich konkav, wie bei den anderen Arten behaart und von graugelber Farbe. Augenränder und Scheitel mehr grau. Das ganze Untergesicht (Clypeus, Wangen und Backengruben) silberweifs schimmernd. Augen?

Fühler rostrot, drittes Glied oben braun. Arista fast nackt. Taster ockergelb, Rüssel braun.

Der ganze Körper von dunkelbrauner Grundfarbe. Thorax und Schildchen gelbgrau bestäubt. Hinterleib nur wachsglänzend. In der Richtung der Dorsozentralborsten des Rückens erscheinen dunkle Längslinien.

Hüften und Beine ockergelb. Schenkel stellenweise gebräunt.

Flügel nur unter der Längsfalte (sulcus, Girschn.) der dritten Hinterrandzelle glashell, sonst oben gelblich und unten braun, welche beiden Farben im allgemeinen durch die Cubitalader getrennt werden. Ein kleiner brauner Kern liegt in der Costalzelle. Spitze der Subcostalzelle dunkelbrann, ebenso die Flügelspitze. Vor der Bräunung der letzteren zieht sich ein unregelmälsiger hellerer Wisch der Grundfarbe von der Mündung der Subcosta bis zum Flügelhinterrande herab. Analzelle wieder gelb. Subcostalzelle des $\sigma^{7}$ stark erweitert. Radialader flach wellig geschwungen.

Schüppchen und Schwinger gelblich.

Köörper- und Flügellänge $4 \mathrm{~mm}$.

\section{Dasymetopa nigropunctata n. sp.}

2 , Bolivia (Mapiri; Februar). Coll. Schnuse. - Peru. Ungar. National-Museum.

Kopf flachgedrückt, etwas breiter als der Thorax. Stirne vorne etwas verengt und wenig schmäler als ein Ange, gelb, vor den grauen Scheitelplatten mit einer breiten rostroten Querbinde zwischen den Augen, die sich in der Mitte etwas nach vorne in eine Spitze auszielit.

Lunula zwischen den Fühlern mit einer kreisrunden, samtschwarzen Makel. Untergesicht gelb, Clypeus etwas verdunkelt. Cerebrale gelb, oberer Hinterkopf grau.

Fühler und Taster gelb, Prälabrum etwas grau, Rüssel braun.

Thorax, Schildchen und Hinterleib von dunkelbrauner Grundfarbe, aber dicht gelblichgrau bestäubt. Die 2 feinen Längslinien des Rückens nur undeutlich sichtbar. Dagegen ist die Noto- und Mesopleuralnaht verwaschen braun gesäumt. Schildchen am Rande rötlich.

Hüften und Beine rötlich gelb.

Hinterleib mit dunkler graubraunen schmalen Hinterraud- 
säumen an den Tergiten 3-5. Erstes Glied des Ovipositors dunkelgraubraun, wachsglänzend, etwas länger als breit.

Flügel gelblich und grau hyalin, braun gefleckt. Als Fortsetzung des braunen Kernes der Costalzelle erscheint eine breite, kurze Querbinde bis zur Discoidalader nach abwärts. Der braune Saum der kleinen Querader zieht sich, breiter werdend, durch die Mitte der Discoidalzelle hindurch bis über die Posticalader hinaus. Der braune, schmale Saum der hinteren Querader hängt durch eine an Breite immer zunehmende gebogene Querbinde mit dem Spitzenfleck der Subcostalzelle zusammen. Diese Querbinde schliefst in der Unterrandzelle ein quadratisches helles Fenster ein. Ein gleiches Fenster liegt durch ein braunes Quadrat getrennt etwas weiter distalwärts in derselben Zelle, dann gleich darunter in der ersten Hinterrandzelle und endlich über obigem braunen Quadrat in der Marginalzelle. Flügelspitze braun.

Schwinger und Schüppchen gelb.

Körperlänge $6 \mathrm{~mm}$, Flügel $5 \mathrm{~mm}$.

\section{Dasymetopa stigma n. sp.}

1 ๙ॅ, Bolivia (Mapiri; Februar). Coll. Schnuse.

Kopf kaum breiter als der Thorax, jedoch immer noch breiter als hoch und flachgedrückt. Stirne schmäler als ein Auge, vorne sehr wenig verengt, sehr kurz und fein behaart. Ocellarborsten nach rückwärts geboger. Kopffärbung, Winkel der Augenränder, Fühler und Taster wie bei D. lutulenta. Augen hellgrün, mit blatem und rötlichem Schimmer.

Thorax, Schildchen und Hinterleib pechbraun. Rücken und Schildchen dicht braungran bestäubt. Hinterleib des einen Stückes etwas verschrumpft. Prothorax und Pleuren vorne schwach weifslich bereift.

Hüften und Beine rotgelb. Schienen und Schenkel der beiden hinteren Paare pechbraun; ebenso deren Tarsen gegen das Ende zu verdunkelt.

Flügel glashell. Von der Flügelwurzel gehen zwei schmale sich verjüngende schwarzbraune Längsbinden neben der Subcosta und Discoidalader bis zur Flügelmitte. Von der Mündung der Subcosta zieht eine ebensolche Querbinde über die hintere Querader zum Hinterrande und ein schmaler Costalsaum bis zur Mündung der Discoidalader. Die durch eine starke Ausbauchung der ersten Längsader nach unten erweiterte Subcostalzelle ist gelb gefärbt. Die Radialader ist etwas wellig geschwungen. Die kleine Querader liegt näher der Flügelwurzel als bei den anderen Arten. Die erste Hinterrandzelle ist gegen die Spitze hin all- 
mählich stark verjüngt; die hintere Querader einfach gebogen. Die Spitze der Analzelle ist nur klein. hellgelb.

Schüppchen braun gerandet und gewimpert. Schwinger

Körper- und Flügellänge $5 \mathrm{~mm}$.

\section{Genus : Rhyparel/a n. g.}

25. Rhyparella decempunctata $\mathrm{n}$. sp.

4 or $q$, Bolivia (Marpiri; Januar). Coll. S chnuse.

Stirne rotgelb, rauh schwarzhaarig. Die Haare an den Stirnorbiten vor den Frontorbitalborsten sind fast borstenähnlich entwickelt (tephritinenartig). Ocellendreieck und Scheitelplatten gelbgrau.

Clypeus hell gelbgrau, ebenso Wangen und Backen.

Fühler rötlich gelb, drittes Glied derselben am Oberrande manchmal gebräunt. Arisła fast nackt. Augen einfarbig smaragdgrün, violettschimmernd.

Thorax, mit Ausnahme des rötlichen Schildchens, und Hinterleib von dunkelbrauner Farbe. Rücken, die oberen Pleuren und das Schildchen dicht ockergelb bestäubt. In der Richtung der Dorsozentralborsten tritt je eine feine dunkle Linie auf. Pleuren unten und vorne gelbgrau.

Hüften und Beine rötlich gelb.

Hinterleib dunkelbraun, wachsglänzend, kaum sichtbar bestäubt. Erstes Glied des Ovipositors etwas länger als breit, mit herzförmiger Wurzel.

Flügel im Wurzeldrittel glashell, sonst schwarzbraun. An der Mündung der Mediastina liegt ein viereckiger glasheller Fleck und je ein gleichgrofser darunter in der Marginalzelle, sowie auch in der Discoidalzelle. 7 gleiche viereckige glashelle Flecke liegen in der Flügelspitze. Einer knapp hinter der Mündung der Subcosta, einer unmittelbar darunter in der Submarginalzelle und einer weiter auswärts in derselben Zelle. Zwischen die beiden Flecke der Submarginalzelle fällt jener der ersten Hinterrandzelle, der über der hinteren Querader liegt, während ein zweiter weiter gegen die Wurzel hin gerückt ist. Je ein Fleck liegt dann zu beiden Seiten der hinteren Querader.

Schüppchen bräunlich, Schwinger gelb.

Körper- und Flügellänge $4 \mathrm{~mm}$.

* Rhyparella novempunctata n. sp., siehe Anhang. 


\section{Genus : Pterocalla Rondani.}

Esame Ditteri Brasiliani, p. 23, Torino 1848.

Analzelle mit kurzer breiter Spitze. Vorder- und Hinterrand des Flügels nicht parallel. Augen einfarbig. (Subgenus: Pseudopteroralla n. subg.) . . . . . . . . . 1.

Analzelle in eine lange, schmale Spitze ausgezogen, welche so lang wie die Analzelle selbst ist. Vorder- und Hinterrand des Flügels parallel. Augen bandiert. (Subgenus: Pterocalla Rond. s. str.). . . . . . . . . . 3.

1. Spitzenteil des Flügels honiggelb. Radialader an der Mündung ohne dunklen Fleck . . . . . . . . . . 2.

Flïgelspitze nicht honiggelb. Radialader an der Mündung mit dunklem Randfleck. Zu beiden Seiten der kleinen Querader liegt je ein Augenfleck.

$$
\text { 26. Pterocalla olscura Wiedem. }
$$

2. Die gelbe Flügelspitze olıne Augenflecke; je ein solcher liegt zu beiden Seiten der kleinen Querader. Vordere Basalzelle ohne hyaline Flecken. 27. Pterocalla scutellata Schin.

Die gelbe Flügelspitze mit 3 Augenflecken, einer über und 2 unter der Cubitalader. Vordere Basalzelle mit einer Reihe hyaliner Flecken . . 28. Pterocalla fenestrata Wulp. ${ }^{1}$ )

3. Flügel an der Spitze mit sternförmig angeordneter dunkler Zeichnung . . . . . . *Pt. radiata n. sp. Flügel ohne solche Zeichnung. . . . . . . . . 4.

4. Discoidalzelle o hne dunklere Punkte oder Querstreifen. 5. Discoidalzelle m it dunkleren Punkten oder Querstreifen. 9.

๖. Hinterleib nit Ausnahıne des dicht ockergelb bestäubten zweiten Tergits glänzend pechbraun.

$$
\text { *Pt. niticliventris n. } \mathrm{sp} \text {. }
$$

Hinterleib ganz matt bestäubt . . . . . . . . 6 .

6. Radialader an der Mündung ohne dunklen Fleck. Die Posticalader bildet vor der hinteren Querader die Grenze zwischen dem braunen und dem hyalinen Teil des Flügels . 8.

Radialader mit dunklem Fleck an der Mündung. Der braune Teil des Flügels reicht vor der hinteren Querader weit über die Posticalader hinaus und erreicht fast den Flügelhinterrand .

7. Pleuren tief dunkelbraun, mit einer grell goldgelben, breiten Längsbinde. Mündung der Radialader um mehr als $90^{\circ}$ aufgebogen. . . . 36. Pterocalla striata n. sp.

1) Biol. Centr. Amer., Dipt. II. p. 394, T. X. 30 (1899) Mexico. 
Pleuren rötlichbraun, unauffällig ockrig gefleckt oder die Mesopleuren mit '2 graugelben Längsstreifen. Mündung der Radialader um weniger als $90^{\circ}$ aufgebogen.

37. Pterocalla quadrata Wulp.

8. Radialader mit einem glashellen Flecke an der Mündung. Flügelspitze mit 4 Augenflecken in 2 Reihen. 2 untere, entfernt voneinander in der ersten Hinterrandzelle stehend, und 2 obere in der Cubitalzelle, so genähert, dafs sie $\mathrm{z}$ wischen die 2 unteren fallen. Flügel nur in der vorderen Basalzelle mit dunkleren Flecken.

38. Pterocalla bella Gigl. Tos. ${ }^{1}$ )

Radialader ohne hyalinen Fleck. Flügelspitze mit 5 Augenflecken in 3 Reihen: 2 obere in der Cubitalzelle durch einen augenlosen Fleck getrennt, 3 untere in der ersten Hinterrandzelle, wovon 2 in einer Reihe liegen, aber gegen die 2 oberen um halbe Distanz nach aufsen gerückt sind, während der dritte untere Fleck unter dem äufsersten der rorhergehenden Reihe liegt. Ein Flügelgitter ist in allen Zellen zwischen der ersten bis vierten Längsader erkennbar.

39. Pterocalla oculata $\mathrm{n}$. $\mathrm{sp}$.

9. Radial- und Cubitalader gerade. Flügel ohne Augenflecke.

35. Pterocalla strigula Loew. ${ }^{2}$ )

Obige Längsader wellenartig geschwungen. Flügel mit Augenflecken . . . . . . . . . . . . 10 .

10. Rücken mit 4 Querreihen grofser dunkelbrauner Flecken, die hinten am gröfsten und pantoffelförmig (o) sind oder ganz zusammenfliefsen $\left(\sigma^{7}\right)$; Punkte fehlen dazwischen. $\sigma^{7}$ mit gefiederten Hintertarsen und durch Herabbiegen der Subcosta aufsergewöhnlich erweitertem Randmale.

34. Pterocalla plumitarsis n. sp.

Rücken nur mit kleinen Flecken, welche die helle Grundfarbe vorherrschen lassen, und dunkleren Punkten dazwischen. $\sigma^{7}$ ohne gefiederte Hinterfülse . . . . . . 11.

11. Radialader mit dunklem Mündungsfleck . . . . 12. Radialader ohne dunklen Mündungsfleck. $\sigma^{7}$ : Flügel in der Mitte mit einem breiten, hellen, rostgelben Längswisch, Hintertarsen verbreitert, die letzten 2 silberschimmernd. Flügel bei $\sigma^{7}$ und $q$ mit $4-5$ Augenflecken: 2 in der Cubitalzelle, durch einen augenlosen Fleck getrennt, und 3 darunter in der ersten Hinterrandzelle.

33. Pterocalla tarsata Schiner.

1) Ditteri del Messico, P. IV. p. 39, Pl. fig. 11 (1895) Mexico.

$\left.{ }^{2}\right)$ Monogr. Dipt. N. Am., P. III. p. 133, T. VIII. 30 (1873) Georgia, N. Amer. 
12. Flügel mit 5 Angenflecken. Einer in der Randzelle unter dem glashellen Mündungsflecke der Subcosta, einer in der Cubital- und 3 in der ersten Hinderrandzelle. Der Flügel erscheint als hellgefleckt auf dunklem Grunde.

32. Pterocalla reticulata n. sp.

Flügel nur mit 3 Angenflecken, wovon nie einer in der Randzelle steht . . . . . . . . . . . 13.

13. Flügel viermal so lang wie breit. Kleine Querader und Mündung der Subcosta liegen erst im dritten Viertel des Flïgels gegen die Spitze zu. Die 2 Augenflecke der ersten Hinterrandzelle liegen beide jenseits der Mitte des Oberrandes, der erste der beiden genau unter dem Ange der Unterrandzelle . . . 30. Pterocalla angustipennis n. sp.

Flügel höchstens dreimal so lang wie breit. Kleine Querader und Mündung der Subcosta liegen im zweiten Drittel des Flügels. Die 2 Augenflecke der ersten Hinterrandzelle liegen in den Dritteln der Zelle, jener der Unterrandzelle über der Mitte des Abstandes der beiden letztgenannten . . . . . . . . . . 14.

14. Cubitalzelle ohne runde schwärzliche Flecke hinter dem Augenfleck. Das Braun des Flügels erscheint dunkelgefleckt. Beine einfarbig gelb. Costa des $\sigma^{7}$ in der Mitte bein Randmale gerade . . . . . . . . . . 15.

Cubitalzelle mit 3 dunklen Flecken jenseits des Augenfleckes. Das Braun des Flügels erscheint genetzt. Schenkel und Schienen gefleckt. Costa des or am Randmale konvex ausgebuchtet . . . 31. Pterocalla costalis Wulp. ${ }^{1}$ )

15. Dritte Hinterrandzelle fast ganz braun, unter der Posticalader dunkler gefleckt . . . 29. Pt. ocellate Fab.

Hinter der Posticalader nur ein schmaler brauner ganz ungefleckter Saum . . . . . . *Pt. punctata n. sp.

26. Pterocalla obscura Wiedemann.

Aulsereurop. Zweifl., II. p. 499. 35 (1830).

$7 \sigma^{\nearrow}$ ㅇ, Bolivia (Mapiri, Januar bis Februar), Peru (Urubambaflufs, September, Vilcanota). Coll. S chn us e. Ungar. NationalMuseum.

Stirne vorne verschmälert und dort deutlich schmäler als ein Auge. Die Strieme derselben kupferrot schimmernd. Der ganze Kopf sonst einfarbig matt rostrot oder rotbraun. Auf dem Clypeus jederseits über dem Mundrande ein glänzendes Höckerchen.

2) Biol. Cent. Amer., Dipt. II. p. 396, Pl. XI. 5 u. 6 (1899) Mexico. 
Drittes Fühlerglied dunkler braun. Rüssel und Anhänge haben die Farbe des Kopfes. Augen smaragdgrün, mit blauem Schimmer.

Thorax und Schildchen rötlich kaffeebraun. Rücken unregelmäfsig mit dunkleren Wurzelpünktchen bedeckt. Schildchen mit je einem grofsen schwärzlichen Fleck seitlich zwischen den 2 Borsten und mit 2 parallel liegenden bräunlichen, eiförmigen oben auf dem Rücken.

Hinterleib (ㅇ) glänzend rotbraun. Vom dritten Tergit an mit glänzend schwarzem Seiten- und Hinterrand, mit dem auch 3 rundliche, glänzend schwarze Flecken verbunden sind, welche eine Querreihe bilden. Erstes Glied des Ovipositors glänzend rotbraun, herzförmig, ziemlich schmal und wenig länger als breit. Der Hinterleib des einzigen or ist verschrumpft; doch ist eine Verlängerung des letzten Tergites deutlich zu erkennen. lichter.

Hüften und Beine etwas heller als der Thorax; Füfse noch

Das Randmal des or ist nur wenig durch ein schwaches, kaum merkliches Abwärtsbiegen der Subcosta erweitert. Die Radialader ist vor der Mündung auffallend stark wellig oder S-förmig geschwungen und vor der Mündung ganz steil aufgebogen. Erste Hinterrandzelle an der Spitze verengt. Hintere Querader ziemlich schief, nur etwas geschwungen, manchmal fast gerade und nur ungefähr $2 / 3$ ihrer eigenen Lünge von der kleinen Querader entfernt, vor welcher die Discoidalader stark nach abwärts gebogen ist.

Flügel einfarbig kaffeebraun, mit einem grofsen schwärzlichen Fleck vor der Mündung der Radialader, je einem Angenflecke in gleichem Abstande jederseits der kleinen Querader und einem schwärzlichen runden Punkt vor der Mündung der Cubitalader. Diesem Punkte liegt ein noch kleineres Pünktchen, gerade an der Biegung der Discoidalader zur Verengung der ersten Hinterrandzelle, gegenüber. Zweite Hinterrandzelle braun, nur mit einem hellen Pankte am Flügelrande. Das Braun des Flügels reicht überall über die Posticalader hinaus.

Schüppchen dunkelbraun, heller gewimpert. Schwinger rot.

Körper $5-6 \mathrm{~mm}$. Flügel $6-7 \mathrm{~mm}$ lang, weniger als die Hälfte davon breit.

27. Pterocalla scutellata Schiner.

Novara Dipteren p. 286 (1868).

13 ơ 오, Bolivia (Mapiri, Januar bis März, Snapi), Peru (Meshagua, Oktober; Callanga). Coll. S c h n u s e. Ungar. NationalMuseum. 
Die Schinersche, auf 1 웅 begründete Beschreibung bedarf der Ergänzung. Kopf und Thorax genau wie bei Pt. obscura Wied. beschrieben. Die Pleuren sind aber bei den meisten Stücken dunkelbraun and dann gleichfalls die Hüften und Beine mit Ansnahme der hellen Füfse.

Schildchen vorherrschend glänzend schwarz. Erstes Glied des Ovipositors schmal, herzförmig, wenig länger als breit. Es erscheint wie bei Pt. obscura vom Hinterleibe abgesetzt.

Beim 우 glänzt der ganze Hinterleib. Beim or zeigen die gleichlangen dritten und vierten Tergite mit Ausnahme eines glänzenden, manchmal vertieften Mittelquerstreifens eine äufserst feine nadelrissige Skulptur. Das fünfte Tergit ist nicht verlängert. Die Wurzeltergite sind unter dem Schildchen etwas eingedrückt.

Angen smaragdgrün, hinten mit tiefblauem Schimmer.

Die honiggelbe Spitze des Flügels liegt jenseits einer Linie von der Mündung der Subcosta über die Spitze der Discoidalzelle zum Hinterrande. Der Aderverlauf gleicht vollkommen dem von Pt. obscura Wied.

Bei keinem Exemplare kann ich jedoch ein „braunes Fleckchen im gelben Spitzendrittel des Flügels" finden.

Körper 5-6,5 mm. Flügel $5-6,5 \mathrm{~mm}$ lang, die Hälfte davon breit.

29. Pterocalla orellata Fabricius.

$$
\text { Syst. Antl. p. 330. } 1 \text { (1805). }
$$

$12 \sigma^{7}$ ㅇ, Bolivia (Mapiri, März), Peru (Urubambaflufs, September bis November; Vilcanota, Callanga), Argentinien (Tucuman, November). Coll. Schnuse. Ungar. National-Museum.

Unter den mir vorliegenden Stücken kann ich 2 Varietäten unterscheiden.

Bei der ersten ist die Stirne bei $\sigma^{7}$ und 우 oben viel schmäler als ein Auge, vorne nur die Hälfte eines Auges breit. Der Rücken des o hat 4 dunkelbraune Längsstriemen; die äufseren, in der Linie der Dorsozentralen, sind an der Quernaht unterbrochen, die beiden mittleren, in der Linie der inneren Dorsozentralborsten verlaufenden, sind hinten alggekürzt. Der Rücken and das Schildchen zeigen aufser den Wurzelpunkten der Haare und Borsten keine anderen Punkte. Beim $q$ sind die Längsstriemen nur angedeutet und liegt an der Unterbrechungsstelle der äufseren Binde ein brauner Punkt.

Bei der zweiten Varietät ist die Stirne oben so breit wie ein Auge, vorne neben den Fühlern schmäler als ein solches. Der Rücken des ơ zeigt nur den Teil der äufseren Längsbinden hinter der Quernaht, jener des 우 keine Längsbinden, sondern 2 Quer- 
reihen von 4 und 2 brąunen runden Punkten, an der Quernaht und dann weiter hinten. Diese Punktreihen können auch beim $\sigma^{7}$ vorkommen. Das Schildchen hat meist 2 braune Flecke auf der Mitte.

In allen übrigen Punkten stimmen beide Varietäten vollkommen überein. Die Stirne ist wie bei Pt. angustipemis gezeichnet, nur dafs die 2 konvergierenden Striche der Stirnmitte sehr wenig oder gar nicht wahrnehmbar sind. Augen grün mit blatem Schiller. Etwas über der Mitte eine schmale hellgrüne wagerechte Querbinde.

Auch sonst gleicht Pt. ocellata Fabr. ganz obengenannter Art, so dals ich nur die Unterschiede beider hervorhebe:

Den Tergiten des Hinterleibes fehlt der Mittelfleck am Hinterrande und die Punktierung am Vorderrande der Wurzelsegmente. Das erste Glied der Legeröhre hat die Gestalt eines gleichseitigen Dreiecks. Beim ơ ist nur das zweite Segment länger als eines der übrigen.

Im Flügel überschreitet das Braune als breiter Saum die ganze Länge der Posticalader und erreicht den Hinterrand. An der Grenze desselben gegen den viel kleineren hyalinen Teil der dritten Hinterrandzelle liegt ein runder heller Punkt. Die hintere Querader liegt schief, ist fast gerade und nur ihre eigene Länge von der kleinen Querader entfernt. Das Randmal des o7 ist nicht merklich vergröfsert.

Körperlänge $5-7 \mathrm{~mm}$. Flügellänge $7-8 \mathrm{~mm}$, Flügelbreite $2,5-3 \mathrm{~mm}$.

\section{Pterocalla angustipennis n. sp.}

1 \&, Bolivia (Songo). Ungarisches National-Museum.

Stime so breit wie ein Auge, fein und kurz behaart, matt hell goldockrig bestäubt, an den Orbiten wenig heller. Aufser je 3 runden dunkelbraunen Flecken jederseits am Angenrande, wovon die 2 oberen an den Wurzeln der Orbital- und Scheitelborste liegen, noch ein Paar schiefer, nach unten konvergierender Striche in der Stirnmitte. Das ganze Untergesicht rostbraun, hell goldockrig bestäubt, stellenweise von dunklen Schillerflecken unterbrochen, besonders an den Backen. Augen wie bei der vorhergehenden Art gefärbt.

Fühler hell rostgelb, Taster nnd Prälabrum rostbraun, Rüssel dunkler braun.

Thorax, Schildchen, Hinterleib von dunkel rotbrauner Grundfarbe, überall dicht ockergelb bestäubt. Da der Rücken meines einzigen Stückes fettig geworden ist, so sehe ich nur runde braune Wurzelpunkte an den rückwärtigen Borsten. Schildchen 
aufser den Punkten an den Borsten noch mit 2 runden Flecken auf der Mitte.

Hinterleib mit Wurzelpünktchen an den Haaren und je einer Querreihe von 4 braunen runden Flecken am Vorderrande der Tergite 2-6. Aufserdem haben die Ringe $3-5$ einen kleineren Mittelfleck am Hinterrande.

Das erste Glied der Legeröhre ist ockrig und braun punktiert und ist kürzer als breit.

Hüften und Beine rotgelb. Schenkel etwas punktiert und unten mit 2 dunkleren Schillerflecken.

Der Flïgel ist auffallend lang, schmal und parallelrandig; braun mit Querreihen dicht nebeneinanderstehender, quergestell ter dunklerer Striche zwischen der ersten bis zur fünften Längsader und noch jenseits der letzteren. Das Braune des Flügels läfst den gröfsten Teil der dritten Hinterrandzelle frei und überschreitet die Endhälfte der Posticalader nur durch kurze Zähne, nicht aber als ein den Hinterrand erreichender Saum. Das Helle der zweiten Hinterrandzelle beschränkt sich auf 2 kleine Flecke, die am Flügelrande nur schmal kommunizieren. Die Lage der 3 Augenflecke gibt bereits die Tabelle an. Die Radialader ist gegen das Ende zu deutlich wellig geschwungen und vor der Mündung, die ein breiter brauner Fleck einsäumt, steil aufwärts gebogen. Die hintere Querader liegt schief, ist nur schwach S-förmig geschwungen und $3 / 2$ mal ihre Länge von der kleinen entfernt.

Schüppchen und Schwinger wie bei Pt. oculata.

Körperlänge $5 \mathrm{~mm}$. Flügel $8 \mathrm{~mm}$ lang, $2 \mathrm{~mm}$ breit.

\section{Pterocalla reticulata n. sp.}

2 ㅇ, Peru (Vilcanota), Paraguay (S. Bernardino, März). Ungarisches National-Museum.

Stirne ebenso breit wie ein Auge, vorne schmäler, ziemlich rauh behaart; in der Mitte mit 2 durch eine feine gelbe Mittellinie getrennten rotbraunen Längsbinden, neben welchen die Orbiten auch wieder gelb bestäubt sind. Scheitelplatten grau. An der Wurzel der Orbitalborste und weiter vorne am Augenrande ein dunkelbrauner, rundlicher Fleck. Untergesicht wie bei Pt. oculata, aber dunkler bestäubt.

Fühler rotbraun, an der Wurzel heller. Ebenso Rüssel und Taster rotbraun. Augen grün, ınit blauem Schimmer zu beiden Seiten einer wagrechten hellgrünen Querbinde. Man könnte auch sagen: grün, mit 2 blauen Querbinden.

Thorax, Schildchen und Hinterleib von rötlich brauner Grundfarbe, überall dicht ockergelb bestäubt. An den Wurzeln der Borsten und Haare dunkelbraune Punkte und Pünktchen. Auf 
dem Thoraxrücken vor den Dorsozentralborsten 3 Querreihen aus je 4 oder 6 (die mittlere Reihe) runden dunkelbraunen Punkten. Auf der Mitte des Schildchens 2 runde Flecke.

Hinterleib auf den Tergiten gleichmäfsig fein punktiert und am Vorderrande derselben, vom zweiten angefangen, mit einer Querreihe von 4 dunkelbraunen Flecken geziert. Erstes Glied des Ovipositors kaum so lang als an der herzförmigen Wurzel breit, ockergelb und dicht braun punktiert.

Hüften und Beine gelbrot. Schenkel punktiert, unten mit 2 braunen Flecken.

Radialader deutlich geschwungen, vor der einen dunkelbraunen, runden Fleck tragenden Mündung steil nach aufwärts gebogen. Hintere Querader wenig schief und kaum gebogen, ${ }^{4} / 3$ ihrer eigenen Länge von der kleinen Querader entfernt.

Flügel mit Ausnahme eines kleinen Teiles vor und hinter der Analader dunkelbraun und unter der Subcosta auf dem ganzen Flügel mit Längsreihen dicht nebeneinanderstehender dunkelbrauner Punkte, die nur an der Flügelspitze fehlen, besetzt. Zwischen den dunklen Flecken ist aber die Grundfarbe heller als an den ungefleckten Stellen vorne und an der Spitze, wodurch der Flügel das Aussehen erhält, als ob er hell gefleckt wäre. Noch hinter der Analader stehen 2 kleine braune Punkte. Die zweite Hinterrandzelle zeigt am Flügelrande nur 2 kleine weifse runde Flecke. Das Braune des Flügels reicht überall über die Posticalader hinüber und erreicht sogar den Flügelhinterrand der dritten Hinterrandzelle, die dort an der Grenze des Braunen einen runden weilsen Fleck zeigt. Die 5 Augenflecke, deren dunkle Umrandung ziemlich verwaschen ist, haben folgende Stellung: einer in der Randzelle, einer in der Unterrandzelle weiter abwärts und drei in der ersten Hinterrandzelle, deren äufserster mit den 2 vorbezeichneten Flecken in einer Geraden liegt, während der innerste unter den Randzellenfleck fällt und der dritte weiter unten im Zwischenraume zwischen den beiden oberen Augenflecken derselben Zelle steht.

Schüppchen braun, heller gewimpert. Schwinger gelb.

Körperlänge $3,5-4 \mathrm{~mm}$, Flügel $4-5 \mathrm{~mm}$.

33. Pterocalla tarsata Schiner.

Novara-Dipteren p. 287, $\sigma^{7}=$ Pt. Rondanii Schiner $\&$, ibidem.

11 o $^{7}$, Peru (Meshagua, Unini, Oktober; Laristal 2-3000 m, August; Callanga); Bolivia (Mapiri, Februar; Songo). Coll. Schnuse. Ungarisches National-Museum.

Stirne schmäler als ein Auge, hell rotbraun. Ein Fleckchen seitlich neben den Fühlerwurzeln und die ganze Stirne mit Ausnahme des braunen Vorderrandes sonst weifslich bereift. Ocellen- 
dreieck und die breite Umrandung der Scheitelplatten, manchmal anch nur ein Querbändchen vor jeder Platte, rot- bis schwarzbraun. Ein Querband unter den Fühlern dunkelbraun. Der ganze darunter liegende Teil des Untergesichts samt den Backen silberweifsschimmernd. Augen wie bei Pt. ocellata Fab.

Fühler heller oder dunkler rot; ebenso die Taster.

Die dichte Bestäubung des Thorax und Schildchens ist ockergelb bis gelbgran. Auf dem Rücken finden sich unter den feinen dunklen Wurzelpünktchen der Haare und den gröfseren Punkten an den Borsten noch 4 Querreihen von je 4 rundlichen, ungefähr gleichgrofsen Flecken; die zweite Querreihe allein hat 5 Flecke. Über die Pleuren geht von der Vorderhüfte an ein oben und unten dunkelbraun gesäumtes, gelb bestäubtes Längsband.

Der mit dem Thoraxrücken gleichfarbige Hinterleib hat viele braune Pünktchen und vom dritten Tergite an am Vorderrande je eine Querreihe von meist 6 dunkelbraunen Flecken. Das zweite Tergit trägt nur 2 Flecke. Das erste Glied des Ovipositors ist auch punktiert und hat die Form eines gleichseitigen Dreiecks. Das vierte Tergit des $\sigma^{7}$ ist viel länger als die vorhergehenden, fast so lang wie der halbe Hinterleib.

Hüften und Schenkel dunkelrotbraun, Knie und Schienen heller, noch heller die Tarsen. An den hintersten Füfsen des or ist die lichte Ferse lang und schmal; die folgenden 4 Glieder sind etwas verbreitert und samtschwarz, die zwei letzten davon silberschimmernd.

Flügel braun, mit Längsreihen dunkler Flecke zwischen den Lüngsadern 1-5. In der Unterrandzelle befinden sich jenseits der kleinen Querader 5 rundliche schwarzbraune Flecke in einer Reihe, von welchen der erste über der Querader und der fünfte an der Flügelspitze am kleinsten sind, der zweite und vierte haben ein helles Auge, welches beim or oft dem zweiten runden Fleck fehlt; der Mittelfleck ist elliptisch und immer augenlos. In der ersten Hinterrandzelle liegen 3 Augenflecke; 2 oben, 1 unten. Der schmale helle Raum am Rande der zweiten Hinterrandzelle wird durch den Zahn des Braunen nicht vollständig in 2 Teile getrennt. Jenseits der Mitte der Discoidalzelle greift das Braune nur als ein schmaler Saum, mit einem kurzen Zahn, über die Posticalarler hinaus.

Das Randmal des or ist sowohl durch eine Konvexität der Costa, als auch durch ein Abwärtsbiegen der Subcosta erweitert, aber bei weitem nicht so stark wie bei Pt. plumitarsis.

Der zentrale Teil des Braunen im Flügel wird beim or durch eine rotgelbe oder bräunliche Farbe verdrängt. Die Radialader ist schwach wellig geschwungen und vor der fleckenlosen Mündung 
nach aufwärts gebogen $\left(45^{\circ}\right)$. Die hintere Querader steht sehr schief, ist sehr wenig gebogen und um $1^{1 /} / 2$ ihrer eigenen Länge von der kleinen Querader entfernt.

Schüppchen dunkelbraun, rot gewimpert. Schwinger gelb.

Körperlänge $4-5 \mathrm{~mm}$, Flügel $5-5,5 \mathrm{~mm}$.

\section{Pterocalla plumitarsis n. sp.}

9 ơ + , Bolivia (Mapiri, Januar bis März; Songo). Coll. $\mathrm{Schnuse.} \mathrm{Ungarisches} \mathrm{National-Museum.}$

Stirne so breit wie ein Auge, kurz und fein behaart, matt ockrig bestäubt, in der Mitte mehr rötlich, an den Seiten heller goldgelb. Je ein Paar dunkelbrauner, runder Flecke an den Wurzeln der inneren Scheitel- und der Orbitalborsten; ein gleiches Paar liegt angedeutet an vordersten Drittel des Augenrandes. Die vordere Hälfte der Stirne ist, mit Ausnahme des goldgelben Fleckes zwischen Fühlerwurzel und Auge, dunkler gelbrot. Endlich liegen zwischen den Orbitalborsten in der Stirnmitte 2 langovale braune, nach vorne konvergierende Flecke.

Das ganze Untergesicht hell rostrot, nur am Augenrande und auf dem Clypeus hell goldgelb bereift. Letzterer mit einem braunen Querbande in der Mitte. Am unteren Augenrande liegen zwei kleine, am unteren Hinterkopfe ein gröfserer dunkelbrauner Schillerfleck.

Fühler gelbrot, Prälabrum und'Taster rotgelb, Rüssel braun, sein Kinn glänzend pechbraun. Angen bläulichgrün, Unterrand und 2 wagrechte Querbinden violettpurpurn.

Thorax, Schildchen und Abdomen von schwarzbrauner Grundfarbe. Die beiden ersten goldockrig bestäubt und mit grofsen, dunkelbraunen Flecken bedeckt. Beim $q$ sind die Rückenflecke in 4 Querreihen geordnet. In der ersten stehen 5, in der zweiten bis vierten 4 Flecke. Die Flecken der letzten, etwas gebogenen Reihe sind am grölsten und pantoffelförmig. Aufserdem sind dunkelbraune Flecke am Humeralcallus und in der Suturaldepression zu sehen. Beim $\sigma^{7}$ sind die 2 letzten Rückenquerbinden zusammengeflossen, so dals die hintere Rückenhälfte einfarbig braun erscheint. Schildchen aufser den 2 Apicalpunkten mit schwarzbraunen Flecken an den Seiten, welche in der Mitte auf den Rücken herüberbiegen. Beim or ist es fast braun.

Hinterleib (o) ohne Pünktchen, nur mit dunklen grofsen Flecken, welche an vierten bis sechsten Tergite vorherrschen und von der gelben Bestäubung nur 3 längliche quergestellte Flecke in der Mitte und je ein kleines Strichlein seitlich am Vorderrande freilassen. Das dritte Tergit ist vorherrschend gelb bestäubt und hat eine Querreihe dunkler Flecke am Hinterrande, die den 
vorderen Rand nicht erreichen. Das erste Glied des Ovipositors ist herzförmig, ungefähr so lang wie breit und von glänzend pechbrauner Farbe.

Der Hinterleib des $\sigma^{7}$ ist an der Wurzel etwas gelbrot, sonst glänzend schwarzbraun.

Hüften und Beine rotgelb. Das Spitzenviertel bis -drittel der Hinterschenkel braun; seltener ist dies an den Mittelschenkeln der Fall.

Beim $\sigma^{7}$ sind die 4 Endglieder der Hinterfüfse etwas verbreitert und seitlich mit gekrümmten schwarzen, an den Spitzen gelblichen Haaren lang gefiedert.

Das Flügelrandmal des $\sigma^{7}$ ist durch Abwärtsbiegen der Subcosta sehr stark erweitert. Die Radialader ist kaum merklich geschwungen, vor der unverdunkelten Mündung aber deutlich nach aufwärts gebogen $\left(45^{\circ}\right)$. Die hintere Querader steht ziemlich schief, ist stark S-förmig geschwungen und um $4 / 3$ ihrer eigenen Längre von der kleinen Querader entfernt.

Flügel braun mit Längsreihen dunkler Flecke zwischen den Adern 1-5, welche beim $q$ stärker als beim $\sigma^{7}$ hervortreten, immer aber sehr deutlich sind und regelmäfsig verteilt sind. Je ein Paar gleichweit entfernter Augenpunkte liegt in der Unterrandund ersten Hinterrandzelie, wobei das untere Paar gegen das obere um halbe Distanz gegen die Spitze zu verschoben ist. Das Auge des innersten der 4 Flecke ist manchmal rudimentär. Das Helle der zweiten Hinterrandzelle wird durch einen Zahn des Brammen in einen gröfseren inneren und kleineren äufseren Fleck am Flügelrande geteilt. Die Posticalader bildet die untere Grenze des Braunen jenseits der Mitte der Discoidalzelle.

Schwinger und Schüppchen wie bei Pt. oculata.

Körper $7-8 \mathrm{~mm}$, Flügel $8-9 \mathrm{~mm}$ lang, $1 / 3$ davon breit.

36. Pterocalla striata n. sp.

1 q, Peru (Vilcanota). Ungarisches National-Museum.

Steht der Pt. quadrata Wulp äufserst nahe und ist nur durch folgende Unterschiede zu erkennen:

Der Rücken ist nur in der Mitte dicht goldockrig bestäubt und zeigt dort nur 2 Punkte hinter und 4 Punkte als Querreihe auf der Quernaht, aufserdem Wurzelpunkte an Borsten und Haaren. Eine breite, tief kastanienbraune Binde fafst den Rückenschild vorne und an den Seiten, längs der Notopleuralnaht ein. Von gleicher Farbe sind die Pleuren unter einer glänzend goldgelben Längsbinde, die von den Vorderhüften bis unter die Flügelwurzel zieht. Humeralcallus oben und unten von einem goldigen Bogen eingefafst. Schildchen vorherrschend schwarzbraun. 
Die Stirne ist lebhafter gefärbt; von den Fühlern bis zur Orbitalborste tief rotbraun, nur durch eine gelbliche Mittellinie oben etwas geteilt. Clypeus dunkelbraun. Über den Mundrand und die Backen zieht eine scharf sich abhebende goldige Querbinde, deren Fortsetzung obige Pleurenbinde darstellt. Fühler noch dunkler braun. Augen grün, mit dunkelviolettem Schimmer und einer wagrechten hellgrüinen Querbinde etwas über der Mitte.

Hinterleib dunkler', namentlich an der Wurzel. Die 4 braunen Flecke stehen erst an dem vierten Tergit. Das erste Glied der Legeröhre ist etwas punktiert.

Flügel g'enau wie bei Pt. quadrata Wulp, nur dunkler. Die Radialader ist an der Mündung noch mehr als um einen rechten Winkel aufgebogen und zeigt dort einen viel weiter ausgedehnten schwarzbraunen Fleck.

Vorder- und Hinterschenkel braun, namentlich erstere ziemlich verdunkelt.

\section{Pterocalla quadrata Wulp.}

Biol. Centr. Amer., Dipt. II. p. 394. Pl. Xl. 1 (1899).

11 ơ $q$, Bolivia (Mapiri, Januar bis März), Peru (Urubambaflufs, September; Callanga), Brasilien. Coll. S chnuse. Coll. W int he m. Ungarisches National-Museum.

Stirne oben so breit wie ein Auge, vorne neben den Fühlern schmäler, von rotbrauner Grundfarbe, ziemlich rauh behaart; an den Orbiten hell gelblich bereift. Die Wurzeln der Borsten stehen anf dunkelbraunen Punkten; ein ebensolcher Punkt weiter rorne am Augenrande. Scheitelplatten und Ocellendreieck hell bereift. Untergesicht von dunkelbrauner Farbe. Lunula, der Mundrand und die Backen gelb bestäubt, letztere teilweise dunkelschillernd. Augen grün, tief blauschimmernd, mit einer schmalen hellgrünen Querbinde, die wagrecht etwas über der Mitte liegt.

Fühler rot, das dritte Glied dunkler braun. Die hellbraunen Taster stehen etwas vor. Rüssel dunkelbraun.

Thorax, Schildchen und Hinterleib von dunkelbrauner Grundfarbe, dicht ockergelb bestäubt. Rücken mit 3 Querreihen von 4, 6 und hinten 2 kleinen runden braunen Flecken. Wurzelpunkte fehlen meist den Härchen und sind nur an den Borsten immer vorhanden. Beim $\sigma^{r}$ ist der ganze Rücken und das Schildchen von einem silbrigen Tomente bedeckt, welches nur die Wurzelpunkte der Schildchenborsten, deren apicale zu einem grölseren braunen Fleck zusammenfliefsen, frei läfst. Auf der Oberseite ist das Schildchen bei $\sigma^{7}$ und $q$ ungefleckt.

Hüften und Beine einfarbig gelbrot. 
Hinterleib des $q$ an der Wurzel oft heller rotbraun. Aufser den Wurzelpünktchen an den Haaren liegen vom dritten Tergite an am Vorderrande der Ringe je 4 runde, ziemlich grofse braune Flecke. Das erste Glied der Legeröhre ist glänzend pechbraun, oft heller und hat die Gestalt eines gleichseitigen Dreiecks mit etwas konvexen Seiten. Beim or sind die ersten 3 Segmente matt hellgelb, ebenfalls wie der Rücken silbrigschimmernd. Kein Ring ist verlängert.

Randmal des or nicht erweitert. Radialader deutlich wellig geschwungen und vor der Mündung steil nach aufwärts gebogen. An dieser Stelle liegt ein grofser schwarzbrauner Fleck. Hintere Querader liegt wenig schief, ist fast gerade und ungefähr $5 / 4$ mal ihre eigene Länge von der kleinen entfernt.

Flügel hellbraun, nur in der vorderen Basalzelle mit ein paar wenig deutlichen dunkleren Querflecken gezeichnet. Zwischen diesen Flecken und an der Flügelspitze ist das Braun oft bis zum Ockergelb erhellt. Die hellen Punkte in der zweiten und dritten Hinterrandzelle und die hintere Grenze des Braunen wie bei Pt. reticulata. 3-4 Augenflecke. 2 am Oberrande der ersten Hinterrandzelle, einer in der Mitte zwischen diesen darüber in der Unterrandzelle und sehr selten einer darunter, ebenfalls noch in der ersten Hinterrandzelle. Bei manchen Stücken zeigt sich auch in der änfsersten Spitze der Unterrandzelle ein kleiner dunkler Fleck.

Schüppchen und Schwinger wie bei $P$ t. reticulata.

Körper- und Flügellänge $4-5 \mathrm{~mm}$.

A n merkung: Aus der Beschreibung und Abbildung des Flügels von Pterocalla undulata Cresson, Trans. Amer. Ent. Soc. Washington, XXXII. p. 283 (1906), aus Mexiko kann ich keine Verschiedenheit von der Art van der Wulps herausfinden, weshalb ich die Cressonsche Art als Synonym hierher stelle.

\section{Pterocalla oculata n. sp.}

3 б $\sigma^{7}$, Peru (Callanga); ungar. National-Museum.

Stirne so breit wie ein Auge, kurz und fein behaart, matt rötlich goldgelb bestäubt. An den Wurzeln der inneren Scheitelborsten und der weiter vorne stehenden Orbitalborsten je 1 Paar rotbrauner, runder Flecke. Ein gleiches Fleckenpaar liegt, stark genähert, in der Stirnmitte. Die Lunula und 1 Fleck zwischen Auge und Fühlerwurzel hellgelb schimmernd. Darüber ist der Vorderrand der Stirne rotbraun. Clypeus, Wangen, Backen und Prälabrum von roter Grundfarbe, aber dicht hell goldgelb bestäubt. Hier und da zeigt sich die Grundfarbe an den Backen als dunkler Schiller. Augen wie bei Pt. plumitarsis gefärbt.

Fühler und Taster rotgelb. Kinn des Rüssels glänzend 
schwarzbraun. Thorax, Schildchen und Abdomen von dunkelbrauner Grundfarbe, überall aber dicht ockergelb bestäubt. Diese Bestäubung wird am Thorax durch unregelmälsig stehende, dunkelbraune, kleine Wurzelpunkte an den Härchen und den Borsten unterbrochen, welche hier und da zu Flecken zusammenfliefsen. Auf der Mitte des Schildchenrückens ist meistens ein hufeisenförmiger brauner Fleck zu sehen. Die Zeichnung des Hinterleibes besteht aus einer über die Ringmitte der hinteren Segmente verlanfenden Querbinde, die sich aus mehr oder weniger deutlich zusammengeflossenen 4 Doppelflecken zusammensetzt, welche anderseits durch feine Pünktchen mit dem Hinterrande des Tergits verbunden werden. Beim $\sigma^{7}$ sind die 4 Doppelflecke mehr als beim $q$ aufgelöst. Der vierte Ring desselben ist auf die halbe Hinterleibslänge vergrölsert. Erstes Glied der Legeröhre herzförmig, nur so lang als breit, braun punktiert wie der Hinterleib. Hüften und Beine gelbrot, weifslich bereift. Die mittleren und hinteren Schenkel sind mit Ansnahme der breiten Spitzen verdunkelt, bräunlich.

Das Flügelrandmal des $\sigma^{7}$ ist durch Abwärtsbiegen der Subcosta stark verbreitert. Die Radialader ist nur schwach wellig geschwungen und vor der Mündung kaum merklich aufgebogen. Die hintere Querader steht nicht sehr schief, ist sehr schwach S-förmig geschwungen und um ihre doppelte Länge von der kleinen Querader entfernt.

Flügel braun mit Längsreihen dunkler Flecke zwischen den Längsadern $1-4$. Die dunkelsten in der vorderen Basalzelle (7-8 Flecke) und in der Unterrandzelle (3 Flecke, zwischen welchen dann die 2 Augenflecke liegen). Zweite Hinterrandzelle in der unteren Hälfte glashell, die braune Grenze ist zweibuchtig.

Schwinger gelb. Schüppchen dunkelbraun, gelb gewimpert. Körperlänge $6 \mathrm{~mm}$. Flügel $7 \mathrm{~mm}$ lang, $2 \mathrm{~mm}$ breit.

\section{Genus: Pseudotephritis Johnson. ${ }^{1}$ )}

(= Stictocephala Loew., praeoc.)

Entomol. News Philad., XIII. p. 144 (1902).

2 Orbitalborsten. An der Analader liegen 2 schwarzbraune Flecken. Anal- und hintere Basalzelle glashell . . 1.

1 Orbitalborste. Analader ungefleckt. Anal- und hintere Basalzelle schwarzbraun . . . . . . . . . 2.

1) 4 nordamerikanische Arten, deren Beschreibungen bei Loew, Monogr. N. Am. Dipt., Part III zu finden sind. 
1. Flügelspitze mit einem braunen Flecke an der Mündung der dritten und vierten Längsader. Flügel braun und gelb gefleckt . . . . . . 40 Pseudotephritis vau Say.

Flügelspitze glashell. Flügel nur braunfleckig, ohne Gelb.

41. Pseudotephritis corticalis Loew.

2. Der Saum der hinteren Querader verbindet sich mit der von der Mündung der Subcosta herabgehenden Querbinde in eine einzige zusammenhängende. Schienenspitzen und Mitte der Hinterschienen mit braunem Ringe.

42. Pseudotephritis cribrum Loew.

Der Saum der hinteren Querader isoliert von obiger Querbinde. Beine einfarbig gelb. 43. Pseudotephritis cribellum Loew ${ }^{1}$ ).

\section{Genus: Callopistromyia Hendel.}

(= Callopistria, Loew, praeoc.)

Wiener entomol. Zeit. p. 98 (1907).

44. Callopistromyia annulipes, Maequart

Dipt. exot, Spl. V. p. 121 (1855), Nort-Amerika.

XI. Genus: Pterocerina n. g.

Hintere Querader aufserordentlich schief gestellt; Flügel stark zugespitzt. (Subgenus Sympaectria n. sbg.) . . . 1.

Hintere Querader fast senkrecht auf der Discoidalader stehend; Flügel an der Spitze abgerundet. . . . . . . 2.

1. Beine gelb. Flügel in Wurzeldrittel glashell, dann schief abgegrenzt schwarzbraun, mit glashellen Längskernen zwischen den Längsadern vor der Flügelspitze. Randmal und der Zellenteil darunter glashell.

45. Pt. acutipenis n. sp.

Beine zum gröfsten Teil pechbraun. Flügel hyalin mit braungesäumten Queradern, einem braunen Querbändchen zwischen den Queradern, von der zweiten bis fast zur vierten Längsader reichend. Die Costa ist bis zur Mündung der Discoidalader gelbbraun gesäunt. 46. Pt. stylata n. sp.

2. Flügel vorherrschend schwarzbraun, mit glashellen Flecken oder Bändern . . . . . . . . . . . 3. Flügel hyalin, mit dunkleren Flecken oder Querbändern.

1) Zwei mir aus Bezzis Sammlung vorliegende Exemplare haben die Flügelzeichnung von $P$. cribellum, die Beinfärbung von $P$. cribrum, weshalb mir die Verschiedenheit beider Arten zweifellaft ist. 
3. Untergesicht glänzend schwarz, unter den Fühlern weifs bestänbt. Ein eiförmiger schwarzbrauner Fleck erfüllt ${ }^{2}{ }_{3}$ des Flügels von der Spitze an, reicht unten noch in die Discoidalzelle und umschliefst beide Queradern. Vor der Flügelspitze liegt in der Unterrandzelle ein glashelles Fenster und unter demselben ein kleineres, mehr oder weniger verwischtes in der ersten Hinterrandzelle.

47. Pt. fenestrata n. sp.

Untergesicht gelb oder rostrot 4.

4. Untergesicht unter den Augen der ganzen Breite nach samtartig rostrot, darüber abgegrenzt gelblich. Flügel ganz schwarzbraun, mit Ausnahme des Randmales und eines glashellen, keilförmigen Fleckens an der Costa, von der Mündung der ersten Längsader mit der Spitze schief nach aufsen . . . . . . 48. Pt. nigripennis n. sp.

Untergesicht gelb. Flügel mit Ausnahme des Basisdrittels schwarzbraun, mit 2 glashellen Querbinden: die erste vor der kleinen Querader von der ersten bis zur vierten Längsader gehend, die zweite durchgehend, von der Mündung der Subcosta zwischen den beiden Queradern hindurch zum Hinterrande. . . . 49. Pt. clarifascia n. sp.

5. Flügel mit drei auffallenden, tief schwarzbraunen Flecken in der Randzelle, welche an der Costa zusammenhängen. Backen dunkelbraun; Untergesicht gelbweifs; Vorderhüften schwarz . . . . . . 50. Pt. angulata n. sp.

Flügel mit dunklen Querbinden . . . . . . . . 6.

6. Flügel aufser den 4 Querbinden am ganzen Vorderrande tief rotgelb. Fühler und eine breite Querbinde unter denselben feurig rostrot. Mundrand weilslich.

51. Pt. colorata $\sigma^{7}$ n. sp.

Flügel längs der Costa nicht rotgelb . . . . . 7.

7. Thorax gelb oder wenigstens dicht gelb bestänbt. Schenkel ganz oder zum grölsten Teile gelb . . . . . . 8.

Thorax und Schenkel schwarz . . . . . . 11.

8. Thorax glänzend gelb . . . . . . . . . . 9 .

Thorax nur gelb bestäubt, von dunkler Grundfarbe 10 .

9. Die Flügelquerbinde über die kleine Querader geht bis über

die Posticalader hinaus. Clypeus glänzend gelb. Legeröhre lang . . . . . . 52. Pt. fermuginea n. sp.

Die zweite Querbinde endet gleich unter der kleinen Querader. Clypeus mattgelb. Legeröhre kurz.

53. Pt. ochracea n.' sp. 
10. Flügel nur mit 2 schwarzbraunen Binden im Spitzendrittel, die unten und oben zusammenfliefsen. Schenkelspitzen und Schienen schwarzbraun. Scheitel schwarz.

54. Pt. Lifasciata n. sp.

Flügel mit 4 Querbinden, welche zum Teile unterbrochen sind. Schenkel und Schienen gelb, auch der Scheitel.

55. Pt. interrupta n. sp.

11. Flügel nur mit 3 Querbinden, die basale fehlt. Untergesicht glänzend schwarz . . . 56. Pt. trifasciata n. sp.

Flügel mit 4 Querbinden . . . . . . . . 12.

12. Untergesicht gelb. . . . . . . . . . . 13 .

Untergesicht schwarz oder braun . . . . . . 14.

13. Die beiden ersten Querbinden hängen an der Posticalader zusammen. Vorderhüften gelb. Clypeus unter den Fühlern weifs bestäubt. . . . . .57. Pt. furcata n. sp.

Die beiden ersten Querbinden vereinigen sich nicht. Vorderhïften braunschwarz. Untergesicht unter den Fühlern rostrot . . . . . 51. Pt. colorata ㅇ, n. sp.

14. Die zweite und dritte Flügelbinde konvergieren nach unten, die erste reicht bis zur Discoidalader. Die Querbinden sind an der Costa nicht miteinander verbunden.

58. Pt. picer n. sp.

Die zweite und dritte Binde laufen parallel, die erste geht über die Posticalader hinaus. Die Querbinden sind an der Costa durcl einen Saum miteinander verbunden.

59. Pt. migripes n. sp.

45. Pt. acutipenuis n. sp.

6 or, Peru (Urubambaflufs, 23. IX.), Bolivia (Mapiri, Sarampioni, $700 \mathrm{~m}$, 18. III. und S. Carlos, $800 \mathrm{~m}, 21$. I.) Coll. $\mathrm{Sch}$ u use.

Stirne seidenartig gelbrot, Scheitelplatten und Ocellendreieck schwach glänzend braungrau. Clypeus hellgelb, weils schimmernd. Fühler und Backen unter den Augen matt gelbrot. Hinterkopf oben an den Orbiten schwarz, grau bestäubt, unten weifsgelb schimmernd.

Prälabrum, Rüssel und die wenig verbreiterten Taster rotgelb.

Augen hellgrün, unten blau, oben rötlich schimmernd.

Thorax und Schildchen von schwärzlicher Grundfarbe, lückenlos dicht graugelb bestäubt. Rücken und Schilḋchen mit schwachem Glanze, letzteres an der Spitze mehr oder weniger rotgelb. Auf dem Rücken erscheinen in gewisser Beleuchtung zwei voneinander entfernte dunkle Längslinien. Schulterbeulen rötlich.

Beine und Hüften gelb. - Hinterleib gelb, die Tergite meist schon vom zweiten an glänzend braun bis schwarz. 
Flügel von allen Arten am spitzigsten. Hintere Querader sehr schief gestellt. Eine breite schwarzbraune Querbinde durchzieht schief den Flügel. Thre innere Grenze beginnt von der Mündung der Mediastinalader und geht über die Wurzel der Analader hinaus; ihre äufsere Grenze, welche durch die Verlängerung der hinteren Querader zur Costa gegeben erscheint, ist nicht scharf, sondern entsendet dunkle Längsstreifen nach aufsen, welche die Flügelspitze mit Ausnahme von hellen, dazwischenliegenden Längskernen, namentlich zwischen der zweiten bis vierten Längsader, ausfüllen. Flïgelwurzel, sowie auch das Randmal und der ganze darunterliegende Zellenteil glashell.

Schwinger und Schüppchen gelb.

Körper- und Flügellänge $3,5-4 \mathrm{~mm}$.

\section{Pt. stylata n. sp.}

2 ㅇ, Peru (Meshagua, Urubambafturs, 29. IX. und 4. X.). Coll. S c h n u se.

Stirne seidenartig gelbrot, Scheitelplatten und Ocellendreieck glänzend braun. Untergesicht ganz gelbrot, etwas weifs schimmernd.

Hinterkopf oben an den Orbiten braun, überall weifsgelb, bestäubt, am intensivsten unten. Backen und Fühler gesättigter rotbraun. Augen am unteren Rande hellgrün, oben violett purpurn; Grenze zwischen beiden Farben nicht scharf.

Rüssel, Prälabrum und Taster rotgelb.

Thorax und Schildchen von glänzend schwarzbrauner Grundfarbe, aber ganz graubraun bestäubt. Rücken und namentlich das Schildchen schwach glänzend. In der Richtung der Dorsozentralborsten wird in gewisser Beleuchtung jederseits eine dunkle Längslinie sichtbar. Quernahtäste und Supraalarregion des Riickens durch das Hervortreten der Grundfarbe dunkler erscheinend. Schulterbeule rötlich.

Hüften und Schenkelringe rotgelb; Schenkel pechbraun, an der Wurzel etwas gelb, ebenso die äufsersten Kniespitzen: Schienen pechbraun; Füfse gelb, gegen das Ende zu schwärzlich.

Hinterleib glänzend gelb. 2 Hinterrandflecke am zweiten Tergit und alle folgenden vier mit Ausnahme der gelben Vorderecken glänzend schwarzbraun. Legeröhre (erstes Glied) etwas länger als der Hinterleib, mit herzförmiger Basis und schlanker Spitze, mit breit herzförmiger Basis und konkaven Seiten, am breiten Wurzelteile gelbrot, hinten schwarz, zweimal so lang wie die grörste Breite.

Flügel weniger spitz als bei acutipennis, hintere Querader aber sehr schief gestellt und etwas bauchig nach aufsen gebogen. 
Von der Flügelwurzel zieht sich ein schmaler braungelber Costalsaum bis zur Flügelspitze, die hinter der hinteren Querader in der ersten und zweiten Hinterrandzelle verwaschen braun getrübt ist. Das Randmal und die Säumung der beiden Queradern ist braun. Ein Rudiment einer braunen Querbinde zeigt sich ungefähr in der Mitte zwischen den beiden Queradern von der zweiten bis zur vierten Längsader. - Schwinger und Schüppchen gelb.

Körperlänge mit Legeröhre $9 \mathrm{~mm}$. - Flügel $8 \mathrm{~mm}$.

\section{Pt. fenestrata n. sp.}

9 o7, Bolivia (Mapiri, Sarampioni, $700 \mathrm{~m} ; 1$ 10.-16. III., 3. IV.), Peru (Urubambafufs, 16. IX. Umahuankilia). Coll. S chn us e.

Stirne seidenartig gelbrot, manchmal vorne und an den Seiten in verschiedener Ausdehnung in Schwarz übergehend, an den Augenrändern weifs schimmernd. Scheitelplatten und Ocellendreieck glänzend schwarz. Das ganze Untergesicht schwarz. Clypens zwischen den Augen und Augenrändern weifs bestäubt, Backen und der vorspringende Mundrand tief samtschwarz. Hinterkopf oben dunkelbraun, unten gelblich, am Auge und hinter den schwarzen Backen dicht weifs bestänbt. Ange dunkler olivengrün, violettpurpurn schimmernd.

Fühler gelbrot. Prälabrum, Rüssel und die sehr breiten Taster mattschwarz, Bindehaut gelb.

Thorax und Schildchen glänzend braunschwarz von Grundfärbung. Die braungraue Bestäubung des Rückens läIst die Schulterbeulen, Streifen unten an den Quernahtästen, 2 ovale, verwischt begrenzte Lüngsflecke in der Mitte des Rückens und die Gegend vor dem Schildchen frei und zieht sich, intensiver werdend, schief auf die Mesopleuren herab, auf welchen sie ein Dreieck im oberen Hinterecke bildet. Prothorax weifs schimmernd. Schildchen kaum merklich bestäubt.

Hüften hellbraun, die vorderen weifs schimmernd. Beine pechbraun bis schwarz, die Füfse der hinteren Beinpaare gelblich.

Das basale Doppelsegment des Hinterleibes und die Vorderecken des dritten Tergits breit rotgelb, die übrigen Tergite glänzend schwarzbraun. Manchmal ist auch der Vorderrand des dritten Tergites noch schmal gelb. Gewöhnlich ist auch das fünfte Tergit in verschiedener Helligkeit gelb gefärbt, was aber ins ganz dunkle Braun übergehen kann. Auch das vierte Tergit zeigt seitlich einen mehr oder weniger deutlichen Stich ins Gelbliche. Sternite vorherrschend gelb.

Flügel glasig hyalin. Ein grofser, eiförmiger, braunschwarzer Fleck an der Costa erfüllt weit mehr als die Spitzenhälfte des 
Flügels. Er beginnt unter der Mündung der Mediastinalader, das Randmal aber nur an der Spitze verdunkelnd, reicht nach hinten nur bis zur Mitte der Discoidalzelle und vereinigt sich mit dem breiten Saume der hinteren Querader. Gegen die Flügelspitze ist die Färbung weniger dunkel und wird dort von einem grofsen glashellen Fleck unterbrochen, der sich von der Mitte der Randzelle bis zur Mitte der ersten Hinterrandzelle nach hinten erstreckt. Von diesem Flecke ist aber in der Randzelle meist fast gar nichts zu sehen und der grolse, helle Fleck der Unterrandzelle wird dann durch einen Saum an der Cubitalader mehr oder weniger von jenem etwas verwischten in der ersten Hinterrandzelle getrennt. Auch am Aufsenrande der zweiten Hinterrandzelle ist ein hellerer Raum unterscheidbar.

Schwinger gelb, Schüppchen weifslich.

Körper- und Flügellänge $5-6,5 \mathrm{~mm}$.

\section{Pt. nigripennis n. sp.}

$2 \sigma^{7}$, Bolivia (Mapiri, Sarampioni, $700 \mathrm{~m}$; 13. III. und 4. IV.). Coll. Schnuse.

Stirne seidenartig rostrot, am Vorderrande heller, mehr gelb. Scheitelplatten und Ocellendreieck dunkel, wachsartig glänzend. Die Backen und ein gleichbreiter Saum unter den Augen, quer über den Clypeus, samtartig rotbraun. Ein Querband darüber unter den Fühlerwurzeln weifsgelb bestäubt. Fühler rotgelb, drittes Glied derselben hinter der Borste rotbraun. Hinterkopf oben dunkel, unten gelb, licht bestäubt. Augen etwas dunkler smaragdgrün, oben violett, unten hellblan schimmernd.

Prälabrum und die breiten Taster rotbraun, Rüssel dunkelbraun.

Thorax und Schildchen glänzend schwarzbraun, am ganzen Rücken, am Schildchen und an den Pleuren bis zur Sternopleuralnaht herab dicht ockergelb bestänbt. Der vertiefte Vorderteil der Mesopleuren ist noch tief dunkelbraun. Der Humeralcallus und ein breiter Rand des Schildchens sind rötlich durchscheinend. In der Reihe der Dorsozentralborsten sind je eine schwarze feine Längslinie in gewisser Beleuchtung sichtbar.

Vorderhüften samtschwarz, alle Schenkelringe und die hinteren Hüften gelbrot. Schenkel mit Ansnahme der schmal roten Knie pechschwarz. Schienen rotbraun, an der Basis, namentlich an den vordersten Schienen dunkelbraun. Füfse rotbraun, die vordersten an der Wurzel dunkler.

Hinterleib schwarzbraun, glänzend. Das hasale Doppelsegment, die Vorderecken des dritten Tergites in geringer Ausdehnung und 
vielleicht auch ein schmaler Vorderrandraum an demselben Tergit rotgelb.

Sternite vorherrschend gelb.

Flügel intensiv schwarzbraun, nach hinten gegen die Analzelle zu heller werdend. Vorderrand bis einschliefslich des Randmales hellbraun. An der Costa liegt mit seiner Basis bei der Mündung der ersten Längsader ein keilförmiger glasheller Fleck, der mit seiner Spitze schief nach aufsen und hinten in den tiefen Bogen der Radialader hineinreicht. Unter der Posticalader liegt im dritten Viertel derselben ein verwaschener hellerer Fleck.

Schwinger und Schüppchen gelblich.

Körper- und Flügellänge $5 \mathrm{~mm}$.

\section{Pt. clarifascia n. sp.}

6 o , Bolivia (Mapiri, Sarampioni, $700 \mathrm{~m}$; 23. II. bis 1. IV.), Peru (Meshagna, Urubambafluls; 7. X.). Coll. S c hnusse.

Stirne seidenartig rotgelb. Ocellendreieck und Scheitelplatten glänzend dunkelbraun, etwas bestäubt. Clypeus und Backen tiefer gelbrot, in gewisser Richtung weifs schimmernd. Hinterkopf oben verdunkelt, unten gelb. - Fühler gelbrot. Augen hell olivengrün, purpurn schillernd.

Prälabrum und die ziemlich verbreiterten Taster gelbrot, Rïssel mehr rotbraun.

Thorax von glänzend schwarzbrauner, Schildchen von dunkel rotbrauner Grundfärbung, beide ganz ockergelb bestäubt. Diese Bestäubung ist am Schildchen und unter der Sternopleuralnaht am schüttersten. Auf dem Rï̈cken zeigen sich die 2 gewöhnlichen schwarzen Längslinien. Die Mesopleuren sind vorne, in der Vertiefung kastanienbraun. Prothorax weils schimmernd.

Vorderhüften dunkelbraun, weifslich schimmernd. Beine pechbraun. Die beiden hinteren Hüften und Füfse, sowie die äufsersten Knie und Schienenspitzen rotbraun. Bei mauchen Stücken ist die rotbraune Färbung ausgedehnter, ja sogar vorherrschend.

Das basale Doppelsegment des Hinterleibes, ein schmaler Vorderrandsaum und die Vorderecken des dritten Tergites rotgelb, der übrige Teil glänzend schwarzbraun. Bauch zum grölsten Teile gelb. Legeröhre kurz und breit, nur so lang wie die grörste eigene Breite und so lang als der halbe Hinterleib; schwarzbraun.

Flügel hyalin, etwas bräunlich tingiert. Vorderrandzelle ganz und Randzelle mit Ausnahme der dunkleren Spitze gelblich. Der ganze Spitzenteil des Flügels, welcher über einer von der Gahel der Radialader bis zur Mündung der Posticalader gelegenen Geraden liegt, ist tief schwarzbraun und wird von 2 glashellen 
Bändern durchbrochen: Ein Band von Flecken beginnt an der Mündung der Subcosta, zieht zwischen den beiden Queradern hindurch bis zum Hinterrande des Flügels und ist in der Unterrandzelle in verschiedener Breite unterbrochen. Die erste Reihe heller Flecke beginnt unter der Mitte des Randmales, endet vor der kleinen Querader an der Posticalader und kann in gleicher Weise unterbrochen sein. - Schwinger gelb, Schüppchen weifsgelb.

Körperlänge mit Legeröhre $6-7 \mathrm{~mm}$. Flügel $5-6,5 \mathrm{~mm}$.

50. Pt. angulata n. sp.

1 or, Bolivia (Mapiri, Sarampioni, $700 \mathrm{~m} ; 11$. III.). Coll. $\mathrm{Schnuse}$.

Stirne seidenartig gelb, Ocellendreieck und Scheitelplatten dunkelgrau, etwas glänzend. Clypeus seidenartig weifs. Backen unter dem Auge samtartig sepiabraun. Hinterkopf oben verdunkelt, unten hinter den Backen gelblichweifs. Fühler gelb. Augen?

Rüssel, Prälabrum und Taster hellgelb.

Thorax und Schildchen von glänzend schwarzbrauner Grundfärbung. Eine graue Bestäubung zeigt sich: in geringer Dichte auf dem Rücken, von 2 feinen Längslinien in der Richtung der Dorsozentralborsten unterbrochen und hinter den Quernahtästen seitlich die Grundfärbung kaum verdeckend, und dichter werdend in einem Dreiecke im oberen Hinterecke der Mesopleuren. Prothorax weifslich schimmernd. Schulterbeulen rötlich.

Vorderbeine samt Hüften und die Hinterbeine dunkelbraun, Mittelbeine gelb.

Hinterleib rötlichgelb, an den Seiten des dritten bis fünften Tergites in unregelmälsiger Abgrenzung pechbraun.

Flügel weifslich hyalin mit braun gesäumten Queradern und 3 tief schwarzbraunen Querflecken in der Randzelle, die an der Costa durch einen schmalen Saum verbunden sind. Der erste Fleck ist ein rechtwinkliger Haken, dessen Scheitel der Mündung der Subcosta gegenüber an der zweiten Längsader liegt. Der kürzere Schenkel geht zur Costa hinauf und erfüllt noch die Spitze des sonst glashellen Randmales, der längere zieht basalwärts längs der Radialader bis etwas über die kleine Querader hinaus. Der zweite Fleck reicht als Querbinde bis zur Cubitalader herab; der dritte geht als Costalsaum bis zur Mündung der Radialader und von dort, die glashelle Flügelspitze freilassend, als Schatten bis in die erste Hinterrandzelle hinein. Hinter und weniger ausgedehnt vor der kleinen Querader zeigen sich schwache bräunliche Wolken.

Schüppchen und Schwinger gelblichweifs.

Körper- und Flügellänge $5 \mathrm{~mm}$. 


\section{Pt. colorata n. sp.}

16 우으, Bolivia (Mapiri, Sarampioni, $700 \mathrm{~m}$; 31. I., 18. und 23. II., 16. III.), Peru (Ucayaliflufs; 24. X. - PachiteaMündung; 22. XI.). Coll. S chnus e.

Stirne vorne seidenartig hellgelb, in der oberen Hälfte allmählich rot werdend. Scheitelplatten und Ocellendreieck wie bei trifasciata gebildet, braun. Augenränder heller gefärbt.

Fühler und eine Querbinde unter denselben feurig rostrot, samtartig. Scharf hebt sich davon ein seidenweifser Ring ab, der vom Mundrande bis zur Linie des unteren Augenrandes hinaufreicht. Hinterkopf oben schwarz, namentlich an rlen Augenrändern dicht weifs bestäubt. Augen smaragdgrün, in der Mitte mit tiefblauem, oben, unten und hinten mit purpurviolettem, abwechselndem Schiller.

Prälabrum weifsgelb, Rïssel und die etwas verbreiterten Taster pechbraun.

Thorax und Schildehen von glänzend dunkelbrauner Grundfärbung, am Rücken mehr schwarz, an den Pleuren unten heller werdend, zum gröfsten Teile aber gelblichgrau bestäubt. Diese Bestäubung wird am Rücken nur an den Quernahtästen schmal unterbrochen, reicht, die ganze obere Hälfte der Pleuren bedeckend, fast bis zur Sternopleuralnaht nach abwärts - darunter scharf abstechend tiefbraun - und ist am Schildchen am schüttersten. In einer gewissen Beleuchtung lassen sich auf dem Rücken zwischen einer braunen Mittellinie und 2 feinen tiefbraunen Seitenlinien 2 aschgraue Längsstriemen unterscheiden. Schultern und Prothorax rötlich. Bei manchen Stücken ist auch das Schildchen, wenigstens unten, und der Metathorax ausgedehnt gelblichrot gefärbt.

Vorderhüften samtschwarz, alle Schenkelringe und die hinteren Hüften, sowie die Fülse gelbrot. Schenkel, mit Ausnahme des Spitzendrittels, und Schienen vor der Spitze schwarzbraun; an ausgedehntesten und am intensivsten am vordersten Beinpaare.

Am Hinterleibe sind beim 우 das basale Doppelsegment, breite Vorderecken und ein schmaler Vorderrandsaum am dritten, schmale Vorderecken am vierten Tergit, dann das fünfte und sechste Tergit rotgelb, das dritte und vierte Tergit, sowie Hinterrandsäume an den beiden letzten Ringen glänzend schwarz oder schwarzbraun. Der Bauch ist gelb. Das Gelb am dritten Ringe ist weils bestäubt und viel dichter noch jenes am fünften. Die Legeröhre (erstes Glied) ist deutlich kürzer als der Hinterleib, rotgelb mit schwärzlicher Spitze und weniger schlank als bei trifasciata. Sie ist dreieckig mit herzförmiger Basis und kaum länger als die gröfste Breite. 
Beim or ist das Gelb am dritten Tergite sogar vorherrschend; am vierten ist ebenfalls ein gelber Vorderrandsaum zu sehen und der gelbe fünfte Ring ist stark silberig bestäubt.

Flügel des $\sigma^{7}$ bräunlich hyalin, am Vorderrande breit intensiv rotgelb gefärbt, mit 4 zum Teile in Flecken aufgelösten Querbinden. Die erste beginnt vor der Mündung der Mediastinalader als dunkler Fleck, bricht unter der Subcosta ab und findet seine Fortsetzung erst unter der Discoidalader, ohne den Hinterrand des Flügels zu berühren. Die zweite Binde liegt vor der Mündung der Subcosta und endet, in der Mitte verschwommen, als Saum der kleinen Querader. Die dritte und vierte Binde hängen über der Mündung der Radialader teilweise zusammen; die dritte zieht, mit der zweiten nach unten konvergierend, über die hintere Querader zum Flügelrande, die vierte mit einer vorspringenden Stufe an der Spitze der ersten Hinterrandzelle etwas bis über die Discoidalader hinaus. Hinter der Wurzelquerader liegt an der Costa bis in die vordere Basalzelle herab ein brauner Fleck.

Beim of fehlt der gelbe Saum. Die Querbinden sind viel intensiver braun und nicht in Flecke aufgelöst. Die Verbindung der dritten und vierten Binde an der Costa ist vollständig und erfüllt die ganze Spitze der Randzelle.

Schwinger und Schüppchen gelb.

Köörperlänge $5-6 \mathrm{~mm} \sigma^{7}$, + mit Legeröhre $6-8 \mathrm{~mm}$. Flügel $5-7 \mathrm{~mm}$.

\section{Pt. ferruginea n. sp.}

1 ㅇ, Peru (Meshagua, Urubambaflufs; 2. X.). Coll. S c h n u s e.

Stirne, Wangen und Backen seidenartig rotgelb, letztere weifsschimmernd.

Ocellendreieck und Scheitelplatten glänzend gelb, ebenso wie der Hinterkopf, der nur unten weifs bestänbt ist. Fühler rotgelb. Clypeus glänzend rotgelb. Von gleicher Farbe sind auch das Prälabrum, die verbreiterten Taster und der Rüssel. Augen hellolivengrün mit violettem Schimmer.

Auch der Thorax, das Schildchen, die Beine und der Hinterleib sind von glänzend rotgelber Farbe. Der Rücken zeigt in gewisser Beleuclıtung Spuren von Längslinien, das Schildchen ein dunkelbraunes Längsband von der Basis bis zur Spitze.

Die Schienen tragen unmittelbar vor der Spitze einen dunkelbraunen Ring und verdunkeln sich mit Ausnahme der mittleren immer mehr gegen die Spitze zu. Metatarsus gelblichweils, Spitze desselben und die folgenden Fufsglieder schwärzlich.

Hinterleib mit dunkelbraunen Hinterrandbinden vom zweiten bis sechsten Tergit. Die am zweiten Ringe ist in der Mitte 
etwas verjüngt, jene am dritten und vierten ebendort nach vorne erweitert. Der fünfte und sechste Tergit sind beinahe ganz schwarzbraun. Legeröhre rotgelb, gegen die Spitze zu gebräunt. Erstes Glied derselben spitz dreieckig, fast so lang wie der Hinterleib und fast zweimal so lang wie breit.

Bauch vorherrschend gelb.

Flügel gelblich hyalin mit 4 dunkelbraunen Querbinden, wovon die ersten 3 gerade und parallel sind. Die erste ist schwach entwickelt und geht von der Mündung der Mediastina bis zur Discoidalader; die zweite geht von der Spitze des Randmales über die kleine Querader und bis über die Posticalader hinaus. Die dritte Binde ist breiter, zieht über die hintere Querader hin und ist durch die braune Spitze der Randzelle mit der vierten, eigentlich mehr einen breiten Spitzenfleck darstellenden Querbinde verbunden.

Schüppchen und Schwinger gelb.

Körperlänge mit Legeröhre $7,5 \mathrm{~mm}$. - Flügel $6 \mathrm{~mm}$.

\section{Pt. ochracea n. sp.}

2 오, Pern (Meshagua, Urubambaflufs; 17. III., 30. IX.). Coll. Se h n u se.

Wie ferruginea, nur mit folgenden Unterschieden: Clypeus weils bestäubt. Auch der Thoraxrücken und die Pleuren sind etwas bestäubt und glänzen nicht so stark wie bei fermuginea. Der Mittelfleck des Schildchens ist ausgedehnter. Die Schienen sind gelb, der dunkle Ring vor der Spitze derselben ist sehr schmal, der Metatarsus ist nicht auffallend heller als die folgenden Glieder. Augen hellgrün, mit blauem und violettem Schiller.

Die Hinterrandbinden der Abdominaltergite beginnen erst am dritten Ringe und sind in der Mitte am breitesten. Das Basalglied der Legeröhre ist wenig länger als breit und etwas länger der halbe Hinterleib.

Am verschiedensten ist die Lagerung der 4 Flügelquerbinden. Die erste geht von der Mündung der Mediastina, nach hinten breiter werdend, bis über die Posticalader hinaus, die zweite von der Spitze des Randmales bis zur Discoidalader an die kleine Querader. Die dritte Binde und der braune Spitzenfleck liegen wie bei ferruginea, nur ist letzterer etwas ausgedehnter. Die ersten 3 Binden laufen nicht parallel, sondern würden sich verlängert fast im Flügelhinterrande treffen.

Körperlänge mit Legeröhre $6 \mathrm{~mm}$. - Flügel $5 \mathrm{~mm}$.

$$
\text { 54. Pt. bifasciata n. sp. }
$$

3 ㅇ, Peru (Urubamaflufs; 10. II.). Coll. S c hn us e.

Stirne seidenartig gelbrot, am Augenrande weils schimmernd. Scheitelplatten und Ocellendreieck glänzend schwarz, ebenso der 
obere Hinterkopf, etwas graulich bestäubt. Untergesicht dunkelbraun, weifs bereift. Backen rostrot, in gewisser Richtung seidenartig weifsschimmernd.

Fühler gelbrot. Prälabrum und Rüssel braun, die verbreiterten Taster rotgelb. Augen hellgrün, oben mehr violett, unten hellblauschimmernd.

Thorax von glänzend dunkelbrauner Grundfärbung, überall ziemlich dicht ockergelb bestäubt. Am Rücken können von vorne betrachtet 2 feine schwarze Längslinien in der Richtung der Dorsozentralen und dazwischen nur ganz vorne 2 dunkle Keilflecken gesehen werden. Schulterbeulen und Schildchen rotgelb.

Hüften und Beine gelb. Spitzenhälfte der Schenkel und die Schienen braunschwarz. Tarsen wieder heller.

Das basale Doppelsegment des Hinterleibes und die Vorderecken des dritten Ringes rotgelb, die folgenden Segmente glänzend schwarzbraun. Legeröhre gelb, in der Mitte und an der Spitze schwarz, die Hälfte des Abdomens lang und nur so lang wie breit.

Bauch vorherrschend gelb.

Flügel gelblich hyalin mit nur 2 schwarzbraunen Querbinden an der Flügelspitze, die vorne und hinten sich vereinigen und so einen steifenförmigen hellen Raum einschliefsen. Die erste der beiden Binden läuft über die hintere Querader. Auch die kleine Querader ist braun gesäumt. Dort, wo sonst die ersten beiden Querbinden liegen, sind an der Costa gelbe Flecke sichtbar.

Schwinger und Schüppchen gelb.

Körperlänge samt Legeröhre $6 \mathrm{~mm}$. - Flügel $5 \mathrm{~mm}$.

\section{Pt. interruptu n. sp.}

7 q, Peru (Urubambaflufs, 24. IX.) und Bolivia (MapiriSarampioni, $700 \mathrm{~m}$, Januar bis März). Coll. Schnu se.

Stirne, Clypeus und Backen matt seidenartig gelbrot. Augenränder und Wangen weifslichschimmernd. Scheitelplatten, Ocellendreieck und Cerebrale glänzend dunkelgelb, Hinterkopf oben grau.

Fühler, Prälabrum, die verbreiterten Taster und der Rüssel gelbrot. Augen hellgrün, oben mehr rot, unten mehr blau schillernd.

Thorax von dunkelbrauner, glänzender Grundfarbe, überall ziemlich dicht ockergelb bestäubt. Rücken mit den 2 feinen, dunklen Längslinien. Die Gegend an den Schultern, an den Seiten des Rückens und des Schildchens von rotgelber Grundfärbung.

Hüften und Beine rotgelb. Vorder- und Hinterschienen mit einem verwischten dunklen Ring vor der Spitze. Tarsen etwas verdunkelt.

Hinterleib rotgelb. Ein schmaler Hinterrandsaum am zweiten 
Ringe pechbraun. Die folgenden Ringe haben einen trapezförmigen jechbraunen Mittelfleck, welcher nur dreieckige, gelbe Vorderecken von der Grundfarbe freiläIst. Legeröhre gelb, gegen die Spitze zu braun. Basalglied derselben so lang wie der halbe Hinterleib und wenig länger als breit.

Bauch gelb.

Flügel graulich hyalin mit 4 schwarzbraunen Querbinden. Die erste Binde besteht aus einer Reihe von 3 braunen Flecken unter der ersten, vierten und fünften Längsader, von welchen der erste am hellsten ist und der Mündung der Mediastina gegenüber liegt. Die zweite geht von der Spitze des Randmales bis zur Discoidalader an die kleine Querader. Die dritte Binde hängt an der Costa mit dem Spitzenflecke zusammen und erreicht die Discoidalader hinter der hinteren Querader, mit dem breiten Saume derselben eine Stufe bildend. In der Mitte der zweiten Hinterrandzelle liegt ein etwas verwaschener brauner Fleck, mit welchem die oben genannte dritte Binde ebenfalls durch einen Saum an der Discoidalader stufenförmig zusammenhängt.

Schüppchen und Schwinger gelb.

Körperlänge mit Legeröhre $3,5-4,5 \mathrm{~mm}$. - Flügel 4,5 bis $5, \dot{\mathrm{j}} \mathrm{mm}$.

\section{Pt. trifasciata n. sp.}

7 q, Peru (Urubambaflufs, Umahuankilia; 15. IX. und Meshagua, 7. X.), Bolivia (Mapiri, S. Ernesto, $800 \mathrm{~m}$; 25. III. - Sarampioni, $700 \mathrm{~m}$; 8. III. - Chimate, $650 \mathrm{~m}$; 15. I.). Coll. Schnuse.

Stirne seidenartig gelbrot, Augenränder weifs. Scheitelplatten und Ocellendreieck scharf differenziert, glänzend schwarz. Die ersteren tragen nur die oberste der beiden Orbitalborsten. Clypeus glänzend schwarz, unter den Fühlern weils bestäubt. Backen unter den Augen tiefbraun, seidenartig weilsschimmernd. Hinterkopf schwarz, namentlich an den Augenrändern dicht weifs bestäubt. Augen dunkelgrün, mit braunviolettem Schimmer.

Fühler gelbrot. - Prälabrum, Rüssel und die ziemlich verbreiterten Taster schwarz.

Thorax und Schildchen von glänzend schwarzer Grundfarbe. Dieselbe wird nur durch 2 Querbinden von hellockerfarbiger Bestäubung verdeckt, welche an den Quernalitästen des Rückens breit getrennt bleiben, in der Mittellinie aber durch einen schmalen Streifen zusammenhängen. Die erste dieser Querbinden bedeckt den ganzen Vorderrücken bis zur Quernalıt, mit Ausnahme der Schulterschwielen und zieht sich, intensiver werdend, schief auf die Mesopleuren herab, anf denen sie ein Dreieck im borsten- 
tragenden oberen Hinterecke bildet. Die zweite Querbinde ist mehr ein Fleck vor dem Schildchen, dessen Bestäubung gegen die Flügelwurzel herab spärlicher wird. Prothorax weifsschimmernd.

Beine schwarz oder pechbraun; die äufsersten Kniespitzen, die Schenkelringe und die Füfse der beiden letzten Beinpaare rotgelb. Vorderhüften hellbrann, meist bestäubt.

Hinterleib glänzend schwarz. Das basale Doppelsegment und die Vorderecken des dritten Tergites gelb bis rotgelb. Erstes Glied der Legeröhre länger als der Hinterleib, spitz dreieckig, etwas hinter der Wurzel so breit wie das vorletzte, fünfte Segment. Sie ist an der Wurzelhälfte gelb, gegen die Spitze zu schwarz, zweimal so lang wie breit. Sternite gelb.

Die bräunlich hyalinen Flügel haben 3 dunkelbraune Querbinden, welche durch einen gleichfarbigen Saum an der Costa, der auch schon das ganze Randmal erfüllt, verbunden sind. Die erste läuft senkrecht herab über die kleine Querader, aber nur wenig über dieselbe hinaus (bis zur Längsfalte in der Discoidalzelle); die zweite zieht über die hintere Querader bis zum Hinterrande des Flügels, die dritte nimmt ungefähr die äufsere Hälfte des durch die zweite Querbinde abgeschnittenen Spitzenteiles ein und wird unter der Discoidalader verwaschen. Die Querbinden laufen parallel zueinander. Flügelwurzel glashell.

Schwinger, Schüppchen und Behaarung derselben gelb.

Körperlänge mit Wurzelteil der Legeröhre 8-10 mm. Flügel $6-7,5 \mathrm{~mm}$.

57. Pt. furcata n. sp.

2 , Bolivia (Mapiri, Sarampioni, $700 \mathrm{~m}$; 31. I. bis 18. II.). Coll. S chnuse.

Stirne seidenartig gelbrot, an den Augenrändern fein weifsschimmernd. Ocellendreieck und Scheitelplatten dunkelbraun, etwas glänzend. Fühler gelbrot, Clypeus rotgeb, weifslich bereift, namentlich oben unter den Fühlem. Backen gelbrot, in gewisser Richtung weifsschimmernd.

Hinterkopf oben dunkelbraun, unten gelb und liell bestäubt. Augen hell olivengrün, purpurschimmernd.

Prälabrum und die verbreiterten Taster gelbrot. Rüssel schwarzbraun mit helleren Labellen.

Thorax und Schildchen von glänzend schwarzer Grundfarbe, mit Ausnahme des Schildchens am Rücken und den Pleuren bis zur Sternopleuralnaht relativ dicht ockergelb bestäubt. Anf dem Rücken treten in gewisser Belenchtung die 2 gewöhnlichen schwarzen Längslinien in der Richtung der Dorsozentralborsten und dazwischen ein breiteres braunes Längsband, ferner seitlich 
hinter den Quernahtästen dunkelbraune Mondflecken hervor. Die vertiefte Stelle der Mesopleuren ist kastanienbraun, die Schulterbeulen sind rot.

Vorderhüften und alle Schenkelringe gelb. Schenkel und Schienen, mit Ausnahme der äufsersten Knie, die gelb sind, pechbraun. Mittelschienen an der Wurzel und Aufsenseite rotbraun, ebenso die Füfse der 2 hinteren Beinpaare. Vordertarsen schwärzlich.

Hinterleib mit der Legeröhre glänzend pechlraun. Das basale Doppelsegment, ein schmaler Vorderrandsaum und die Vorderecken des dritten Tergites rotgelb. Legeröhre (erstes Glied) kurz und breit, ein Drittel des Hinterleibes lang, breiter als lang.

Flügel hyalin mit 4 dunkelbraunen Querbinden. Die erste, breiteste, liegt vor der Mündung der Mediastinalader und zieht so nach abwärts, dafs sie sich mit der von der Mündung der Subcosta über die kleine Querader laufenden zweiten Binde an und hinter der Posticalader vereinigt. Die dritte Binde läuft parallel mit der zweiten vom Vorder- zum Hinterrande des Flügels ïber die hintere Querader und steht an der Costa mit dem bis zur Mündung der Discoidalader sich hinziehenden Randsaume in Verbindung. An der Mitte des letzten Abschnittes der Discoidalader liegt ein isolierter brauner Fleck. Schwinger gelb. Schüppchen weifslich.

Körperlänge mit Legeröhre $7 \mathrm{~mm}$. - Flügel $5,5 \mathrm{~mm}$.

$$
\text { 58. Pt. picea n. sp. }
$$

2 or + , Bolivia (Mapiri, Sarampioni, $700 \mathrm{~m}$; 3. II.). Coll. $\mathrm{Schnuse.}$

Kopf wie bei 14 . Clypeus aber ganz braunschwar\% und unter den Fühlern weifsschimmernd. Fühler rotbraun, drittes Glied ziemlich dunkel. Augen grün, violettschimmernd.

Thorax und Schildchen glänzend braunschwarz. Die graue Bereifung ist so zart, dafs sie nur an den Seiten des Rückens in den Vertiefungen merkbar ist. Schulterbeulen rötlich.

Die ganzen Hüften und Beine glänzend pechbraun.

Hinterleib mit Ausnahme des etwas helleren Doppelsegmentes der Wurzel glänzend schwarzbraun. Legeröhre (erstes Glied) nur im durchfallenden Lichte an der Basis dunkel rotbraun, sonst schwarzbraum. Sie ist etwas länger als breit und so lang wie der halbe Ilinterleib.

Flügel hyalin mit 4 schmalen, schwarzbraunen Querbinden. Die erste geht von der Nündung der Nediastinalader bis über die Posticalader hinaus; die zweite von der Mü̈ndung der Subcosta über die kleine Querader durch das letzte Drittel der Discoidalzelle bis zur Posticalader; die dritte vom Vorder- bis zum 
Hinterrande des Flïgels über die hintere Querader und die vierte Binde als schmaler Vorderrandsaum bis etwas über die Discoidalader hinaus. Die dritte und vierte Binde sind aber an der Costa getrennt voneinander.

Schwinger gelh, Schüppchen weifslich.

Körperlänge $o^{7} 5 \mathrm{~mm}$, + mit Legeröhre $6 \mathrm{~mm}$. Flügel $5 \mathrm{~mm}$.

\section{Pt. nigripes n. sp.}

4 \&, Bolivia (Mapiri, Sarampioni, $700 \mathrm{~m}$; 11. I. bis 16. III.). Coll. Schnuse.

Stirne seidenartig hellgelb, Ocellendreieck und Scheitelplatten dunkelbraun, etwas glänzend. Augenränder weifsschimmernd. Clypeus glänzend braun bis braunschwarz, nur unten an den Seiten gelb. Wangen gelb, Backen unter den Augen samtartig kastanienbraun, in gewisser Richtung seidenartig weifsschimmernd. Hinterkopf unten gelb, weils bestäubt, oben dunkelbraun. Fühler rotgelb. Augen dunkler grïn, violettschimmernd.

Prälabrum von der Farbe des Clypeus, die verbreiterten Taster hell- bis dunkelbraun, Rüssel schwarzbraun.

Thorax und Schildchen glänzend braunschwarz. Der Rücken ist vor der Quernaht gelblich grau bestäubt. Diese Bestäubung bildet ein Querband and zieht sich schief nach hinten auf die Mesopleuren herab, deren oberes Hintereck sie erfüllt. Hinter den Quernahtästen heginnt die Bestäubung nicht gleich wieder, sondern läfst die Grundfarbe in der Mitte in geringerer, an den Seiten in gröfserer Ausdehnung sichtbar werden. 2 feine dunkle Längslinien wie gewöhnlich vorhanden. Das Schildchen ist unbestäubt, ebenso der etwas rötliche Humeralcallus.

Hüften und Beine pechbraun. Die äufsersten Knnie und die Wurzel der hinteren Tarsen etwas rötlichbraun.

Am Hinterleibe ist das basale Doppelsegment, mit Ausnahme dessen schwarzer Hinterecken, und der schmale Vorderrand und die Vorderecken des dritten Tergits rotgelb, der übrige Teil glänzend pechbraun. Legeröhre an der Wurzelhälfte rotgelb, an Rande und gegen die Spitze zu schwarzbraun. Erstes Glied derselben hat eine herzförmige Basis und eine schlanke Spitze und ist zweimal so lang wie breit und wenig kürzer als der Hinterleib.

Flügel hyalin mit 4 schmalen schwarzbraunen Querbinden: Die erste geht von der Mündung der Mediastinalader bis zur Discoidalader; die zweite von der Mündung der Subcosta über die kleine Querader durch die Mitte der Discoidalzelle und üher die Posticalader hinaus; die dritte vom Vorder- bis zum Hinterrande über die hintere Querader und die vierte Binde als schmaler Vorderrandsaum von der dritten Binde an bis in die Spitze der 
ersten Hinterrandzelle. Auch die zweite Binde ist an der Costa durch einen dünnen Streifen mit der dritten verbunden.

Schwinger gelb, Schüppchen weilslich.

Körperlänge mit Legeröhre $5-7 \mathrm{~mm}$. - Flügel $4-5 \mathrm{~mm}$.

\section{Genus : Paragorgopsis Gig1.-Tos.}

Boll. Mus. Torin., Vol. VIII, No. 158, p. 12 (1893).

1. Die hellen Gitterfenster der Flügel ohne dunklen Zentralkern . . . . . . . . . . . . . . 2.

Die hellen Gitterfenster der Flügel mit dunklem Kerne in der Mitte

2. Spitzenhälfte der Discoidalzelle nur mit einem hellen Flecke. In der Randzelle liegen nur 2 helle Flecke; je einer unter den Mündungen der Mediastina und der Subcosta 60. P. maculata Gigl.-Tos.

In der Spitzenhälfte der Discoidalzelle liegen 3 helle Flecke. In der Randzelle sind aufser obigen 2 Fenstern noch andere zu sehen . . . . . . . . . . . . . 3 .

3. Erste Hinterrandzelle mit zahlreichen hellen Flecken, zweite jedoch nur mit einem einzigen 61. $P$. clathrata n. sp. Erste und zweite Hinterrandzelle mit 2-3 hellen Flecken

62. P. Schmusei n. sp.

4. Dritte Hinterrandzelle an der Basis von Gitterflecken unterbrochen. Discoidalzelle in der Spitzenhälfte mit über 10 kleinen hellen Flecken . . . 63. P. cancellata n. sp.

Dritte Hinterrandzelle an der Wurzel ganz glashell. Discoidalzelle in ganzen nur mit höchstens 5 grofsen hellen Flecken 64. P. mallea n. sp.

60. Paragorgopsis maculata Gigl.-Tos.

Boll. Mus. Torin., Vol. ViII, No. 158, p. 12 (1893).

18 우, Peru (Urubambafluls, September bis Oktober), Bolivia (Mapiri, Januar, März). Coll. S chnuse. - Surinam, Paraguay. Ungar. National-Museum.

Der flachgedrückte Kopf kann beim or so stark verbreitert sein, dafs er um die Hälfte breiter als hoch und $2^{1} / 2$ mal so breit als lang ist. Die Stirne des or ist gewöhnlich der doppelten, die des $q$ der einfachen Augenbreite gleich. Doch gibt es auch $\sigma^{7}$, deren Kopf kaum breiter als der der $q$ ist.

Die Stirne ist hell- bis dunkelgelb. Periorlbiten und Ocellendreieck sind dunkelbraun und immer etwas glänzend, beim ơ verbreitern sie sich auch mit dem Kopfe. Bei manchen Stücken 
zeigen sich auf der Stirne auch rotbraune Stellen, namentlich neben den Ocellen. Augenränder weifslich schimmernd.

Von allen übrigen Arten unterscheidet sich diese Art durch die Stärke der Stimbehaarung, nicht blofs in der Mitte der Stirne, sondern namentlich auch an den Seiten, unter den 2 Orbitalborsten. Dort stehen nach unten schwächer werdende Borsten, die oben noch nach rückwärts, weiter unten jedoch schon einwärts gebogen sind und als untere Orbitalborsten (wie bei den Tephritinen) bezeichnet werden können.

Clypeus weifslich bis rotgelb. Backen die Hälfte der Augenhöhe breit, unter dem Ange mit einem in gewisser Richtung dunkel spiegelnden Fleck. Hinterkopf rotgelb, nur oben neben dem Cerebrale grau. Im Profile steht der Mundrand etwas vor. Augen grün, mit einer dunkelpurpurnen wagrechten Querbinde vom Vorderrande des Auges bis zur Mitte. Über dieser Querbinde und in der hinteren Hälfte des Auges herrscht ein dunkler violetter Schimmer vor. Leider liefs sich die Augenfärbung nur bei einem Stücke mehr hervorrufen, so dafs ich obiger Angaben nicht ganz sicher bin.

Fühler hellgelb bis gelbrot. Drittes Glied manchmal dunkler. Arista nur äufserst kurz nnd zart pubescent. Prälabrum und die verbreiterten Taster weirsgelb bis rostrot, Rüssel gelb bis braun.

Thorax von pechbrauner Grundfärbung, überall dicht ockergelb bestäubt. Diese Bestäubung ist auf dem Rücken und auf den Mesopleuren von zahlreichen, an den Wurzeln der Härchen liegenden Punkten der Grundfarbe unterbrochen. Auf dem Rücken sind ferner einige Querreihen dunkelbrauner Flecken zu sehen. Je einer hinter dem Humeralcallus, 5 Flecke in einer Querreihe über der Quernaht, 2 weitere hinten und endlich 6 an den Wurzeln der Randborsten vor dem Schildchen, welches am Rande rötlich ist und nur in gewisser Beleuchtung oben gelb bereift erscheint.

Hinterleib glänzend pechbraun, an der Wurzel etwas gelb gefärbt. Bei den meisten Stücken sehe ich an dem Vorderrande des dritten bis fünften Tergits eine in der Mitte unterbrochene weifsbereifte Querbinde. Legeröhre kürzer als die Hälfte des Hinterleibes, herzförmig zugespitzt, ungefähr doppelt so lang als breit. Hüften und Beine rotgelb. Schenkel, namentlich die hinteren, vor der Spitze verdunkelt. Schienen mit 2 braunen Ringen.

Flügel schwarzbraun, von rundlichen, glasigen Flecken durchbrochen. Von diesen seien erwähnt: je einer unmittelbar hinter den Mündungen der Mediastina und Subcosta. Ersterer reicht anch in die Randzelle hinüber. 3 Flecken in der Unterrandzelle, 2 über der kleinen Querader, einer an der Flügelspitze. Dieser kann auch fehlen. Je ein runder Fleck zu beiden Seiten der 
kleinen Querader; einer über der hinteren Qnerader in der ersten Hinterrandzelle; 2 gleichfalls in der zweiten, 3 in der dritten Hinderrandzelle. 2 Fenster in der Discoidalzelle; einer davon basal, der andere unter der kleinen Querader gelegen.

Beim or sind die erste und zweite Längsader vor der Mündung znerst bauchig nach abwärts und dann steil zum Rande anfgebogen. Das Randmal ist daher stark erweitert. Beim $q$ ist das Randmal normal und die zweite Längsader nur flach wellig geschwungen. Schüppchen und Schwinger gelb.

Körperlänge $3,5-6,5 \mathrm{~mm}$. - Flïgel $3,5-6 \mathrm{~mm}$.

\section{Paragorgopsis clathrata n. sp.}

4 or 오, Bolivia (Mapiri, 800-1000 m hoch, Februar bis Vlärz), Peru (Urubambaflufs, Oktober). Coll. S c h n us e.

Bei dem einzigen $\sigma^{7}$, das mir vorliegt, ist der Kopf so stark verbreitert, dals er gut zweimal so breit wie hoch ist. Seine Stirne ist weitaus breiter als der doppelte Angendurchmesser, während jene des 우 diesem ungefähr gleich kommt oder denselben bis $1 \mathrm{~m}$ die Hälfte übertrifft.

Die Stirne ist glatter als bei maculata und aufser den Borsten nur kurz behaart. Untere Orbitalborsten fehlen. Die Färbung des Kopfes gleicht jener der dunklen Strïcke von maculata. Backen ohne dunklen Fleck unter dem Ange. Der stark glänzende Hinterkopf stärker vorgequollen als beim Gattungstypus. Auch der Clypeus ist im Profile viel stärker konkav und am Mundrande oft verdmkelt. Fühler und Rüssel wie bei P. maculute.

Augen wie bei $P$. cancellata.

Thorax von pechbrauner Grundfarbe, graugelb bestäubt, aber noch wachsglänzend. Nur auf dem Rücken sieht man schwarze Wurzelpunkte an den Borsten und Haaren, die mehr grane Bestänbnung der Pleuren ist unpunktiert. Die Rückenzeichnung besteht in je einem grofsen dunkelbraunen Fleck hinter der Schulterbeule, einer ebensolchen breiten Bogenquerbinde genau iiber die Quernaht verlanfend und einem rechteckigen Flecke in der Mitte des hinter der Naht liegenden Rückenteiles. Dieser Fleck steht mit der Bogenbinde durch eine Längslinie in Verbindung, wodurch eine ankerähnliche Figur entsteht. Schildchen nur am Rande bestäubt.

Hinterleib einfarbig glänzend pechbraun, an der Wurzel gewöhnlich gelbrot. Erstes Glied der Legeröhre wie bei maculata geformt.

Hüften gelbrot. Ebenso fast die ganze Spitzenhälfte der 
Vorder- und die Knie der hinteren Schenkel, sowie die Füfse der hinteren Beinpaare. Alles übrige glänzend schwarzbraun.

Die Flügelzeichnung erhält durch Folgendes ihr Gepräge: Vor der Mündung der Mediastina beginnt ein gegen den Hinterrand immer breiter werdendes dunkelbraunes Querband, das kein helles Fenster enthält. Ein zweites solches Querband lärst sich von der Mündung der Subcosta abwärts, die hintere Querader einschliefsend, bis zum Hinterrande unterscheiden. Zwischen diesen beiden dunklen Querbinden liegt ein durch je 3 helle viereckige Fenster zwischen den Längsadern 1 bis 5 gebildetes, ziemlich regelmälsiges Gitterband. Ein ähnliches Gitterband folgt hinter der zweiten Querbinde, das aber in der Rand- und der zweiten Hinterrandzelle nur einen hellen Fleck aufweist. Das Randmal des $\sigma^{7}$ ist kaum gröfser als das des $?$, seine Radialader vorne aher stärker aufgebogen. - Schüppchen braun, Schwinger gelb.

Körperlänge $6-7 \mathrm{~mm}$. Flügel $5-6 \mathrm{~mm}$.

\section{Paragorgopsis Schnusei n. sp.}

6 or $^{7}$, Bolivia (Mapiri, 700-800 m, Januar bis März). Coll. Schnuse.

Diese Art steht dem Gattungstypus am nächsten, so dafs ich nur die Unterschiede anführe. Der Kopf ist bei den mir vorliegenden Stücken nie so hell gefärbt wie bei maculata. Der Backenfleck ist aber heller, nur dunkel rotgelb spiegelnd. Die Grundbehaarung der Stirne ist nur kurz und fein, nie borstenähnlich. Augen bläulich grün, mit einem violettpurpurnen dunklen Schimmer.

Die Pleuren sind unpunktiert. Von dunklen Rückenflecken sind nur zu sehen: 1 kleiner hinter der Schulterbeule, punktförmig; je 1 Paar gröfserer Flecke an den Quernahtästen, in der Linie der Intraalaren, und 1 unregelmäfsiger Fleck in der Suturaldepression.

Hinterleib glänzend pechbraun ohne weifsliche Querbinden. Legerölrre (erstes Glied) etwas länger als breit, an der Wurzel herzförmig.

Das basale Doppelsegment ist zum gröfsten Teile gelbrot.

Hüften und Beine rostrot; 2 braune Schienenringe kaum angedeutet. Hinterschenkel oft dunkler.

Die Flügelzeichnung unterscheidet sich konstant durch folgendes: In der Spitze der Randzelle liegt 1 heller Fleck. Aufser dem kleinen Basalflecke liegen in der Discoidalzelle 3 ungleich grofse Flecke in der Spitzenhälfte. Zweite Hinterrandzelle mit einem grofsen Mittelflecke und 2 kleinen Seitenflecken. Dritte Hinterrandzelle nur mit 2 Flecken. 
Die Schüppchen sind dunkel gerandet und gewimpert, bei P. maculata hell.

Bei dem einzigen $\sigma^{7}$ verlaufen die ersten beiden Längsadern wie beim Typus, das Randmal wird sogar noch durch eine kleine Konvexität der Costa erweitert. Bei diesem Stücke enthalten die schwarzbraunen Flügelpartien hellbraune Zellenkerne, so dafs die Längsadern wie dunkel gesäumt erscheinen. Ich messe dieser Verschiedenheit aber keine Bedeutung bei.

Körperlänge $5-7 \mathrm{~mm}$. Flügel $6-6,5 \mathrm{~mm}$.

Anmerkung: Dem Entdecker der zahlreichen schönen Dipteren mit Dank gewidmet.

63. Paragorgopsis cancellata n. sp.

1 , Peru (Meshagua, Urubambaflufs, September). Coll. $\mathrm{Sch}$ cuse.

Das einzige $q$ gleicht dem bei $P$. mallea unter Var. $\alpha$ beschriebenen bis auf folgende Unterschiede.

Der Clypeus ist einfärbig gelbrot, weniger glänzend, im Profile aber stärker konkav. Das erste Glied des Ovipositors ist viel länger; zweimal so lang wie breit und so lang wie der ganze Hinterleib. Die Schüppchen sind braun gerandet. Das Flügelgitter ist viel dichter, die dunklen Zentralkerne der viereckigen, glasigen Fenster haben keine rundliche Gestalt, sondern Kreuzform und sind meist durch den einen oder anderen Kreuzarm mit dem Rahmen verbunden. Die schwarzbraune Querbinde der Wurzelhälfte beginnt ebenfalls vor der Mediastina, ist gut doppelt so breit wie bei $P$. mallea beider Varietäten, zeigt aber unter der Radialader kein helles Fenster mehr und erreicht ganz den Hinterrand. Letzteres ist bei $P$. mallea nicht der Fall. Das beste Kennzeichen ist aber die Gitterung auch in der Wurzel der dritten Hinterrandzelle hinter der Analzelle und das dichte Gitterwerk in der Discoidalzelle. Die Augen sind bläulich goldgrün und haben 2 breite wagrechte Querbinden, sowie Ober- und Unterrand dunkelviolett purpurn. Je eine schmale grüne Binde der Grundfarbe durchkreuzt obige Querbinden sowohl parallel den Stirn- als auch den Hinterhauptsorbiten.

Körperlänge (mit Legeröhre) 9,5 mm. Flügel $7 \mathrm{~mm}$.

\section{Paragorgopsis mallea n. sp.}

9 or 온, Peru (Meshagua, Urubambaflu[s, Oktober, November), Bolivia (Mapiri, S. Carlos, Januar). Coll. Schnuse.

Alle 9 Stück scheinen mir einer einzigen Art anzugehören und nur Variationen derselben vorzustellen.

Als Typus fasse ich die nachbeschriebene Form auf. $\sigma^{7}$ : Der 
Kopf ist aufsergewöhnlich verbreitert, ïber zweimal so breit wie hoch. Die Stirne viermal so breit wie 1 Auge, fast kalıl, selbst die Kopfborsten sehr schwach entwickelt. Die Strieme und das Cerebrale sind gelbrot, die querliegrenden, wachsglänzenden Scheitelplatten dunkler braun und in gewisser Beleuchtung grau bereift. Ocellenhöcker schwarz. Clypeus glänzend pechbraun, welche Färbung sich auch auf die matt werdenden Backen hinüberzieht. Letztere werden jedoch an der scharfen Seitenkante des Kopfes unter dem Auge gelbrot, wie der ganze untere Hinterkopf, während der obere dunkelbraun ist. Die Fühler sind so weit voneinander entfernt, dafs sie in den Dritteln der Stirnbreite stehen (was übrigens auch beim or von $P$. clathrata der Fall ist). Die Wurzelglieder und die als nackt zu bezeichnende Arista sind rostrot, das dritte Glied ist dunkler, Jraun.

Clypeus, die verbreiterten Taster und die Labellen rostrot, das Kinn glänzend schwarz. Augen wie bei Parag. cancellata.

Thorax von glänzend pechbrauner Grundfarbe, auf dem Rücken und den Pleuren bis zur Sternopleuralnaht herab dicht goldockrig bestäubt. Diese Bestäubung wird auf dem Rücken von zahlreichen Punkten der Grundfarbe durchbrochen, welche in der Mitte, zwischen zwei in der Linie der Dorsozentralborsten durchschimmernden schwarzen Längsbinden in Längsreihen geordnet sind. Schulterbeulen schwarz. Eine dunkle Bogenquerbinde über der Quernaht samt einem damit zusammenhängenden Fleck dahinter, geben dieselbe ankerähnliche Zeichnung wie bei $P$. clathrata.

Vordere Mesopleuren dunkel.

Vorderhüften, Wurzelhälfte der keulig verdickten Vorderschenkel, Basisdrittel der Mittelschenkel, alle Knie und die Fülse der hinteren Beinpaare rostrot. Der übrige Teil der Beine pechbraun.

Hinterleib pechbraun, an der Wurzel breit rotgelb. Vorderränder der Tergite und damit zusammenhängend ein in der Mitte etwas nach vorne erweiterter Hinterrandsaum des vorhergehenden Tergites, gelb, matt bereift.

Flügel glasig durchsichtig. Die Spitzenlälfte wird von einem durch senkrecht sich kreuzende, schwarzbraune Quer- und Längslinien gebildeten Gitterwerke, dessen Fenster dunkle Zentralkeme einschliefsen, gebildet. Charakteristisch erscheint mir ein schiefes dunkelbraunes Band, das, von der Flügelwurzel herkommend, hinter der Wurzelquerader nach abwärts biegt und durch die Mitte der Posticalader noch in die dritte Hinterrandzelle hinüberreicht, ohne jedoch den Flügelhinterrand $\mathrm{zu}$ berühren.

Schüppchen und Schwinger gelb.

Körperlänge $5 \mathrm{~mm}$. - Kopfbreite $4 \mathrm{~mm}$. - Flügel $5,5 \mathrm{~mm}$. 
Die gleiche Flügelzeichnung wie obiges $\sigma^{7}$ haben 3 o und 2 normalköpfige $\sigma^{7}$.

Das $q$ hat normalen Kopf, vorne goldgelb bestäubte Scheitelplatten, unter welchen die Stirne verdunkelt ist, hell rostrote Fühler, einen glänzend gelben Clypens, der nur auf einer Mittellinie und in den Seitenrinnen schwarzbraun ist. Die Mesopleuren sind wie der Rücken punktiert, was beim or nicht der Fall ist. Der Rückenfleck hinter der dunklen Quernahtbinde fehlt.

An den Schenkeln ist die rote Färbung an der Spitze breiter, an der Wurzel schmäler als beim $\sigma^{7}$. Der Ovipositor (erstes Glied) ist dreieckig, ungeführ $1^{1} / 4$ mal so lang wie breit und wenig länger als der halbe Hinterleib.

Die beiden normalköpfigen $\sigma^{7}$ gleichen den $q$ in allen Merkmalen. Nur der Clypeus und das schildförmige Prälabrum sind seidenartig weifslich, der erstere im Profil fast gerade, während er beim $q$ ziemlich konkav ist.

Körperlänge $\sigma^{7} 4,5 \mathrm{~mm}$, 우 5,5 $\mathrm{mm}$. - Flügel 5-5,5 $\mathrm{mm}$.

$\mathrm{Da}$ auch bei $P$. maculata $\sigma^{7}$ mit normalem Kopfe bis zu solchen mit ziemlich verbreiterter Stirne vorkommen und auch das Profil des Clypeus, sowie dessen Farbe Abstufungen unterworfen sind, so zweifle ich nicht, dafs obige $3 \sigma^{7}$ und die $3 q$ zusammengehören. (Var. $\alpha$.)

Etwas anderes ist es mit $2 \sigma^{7}$ und 1 o, welche sich durch die Flügelzeichnung etwas unterscheiden (Var. $\beta$ ). Bei denselben beginnt nämlich die oben erwähnte schiefe Querbinde der Wurzelhälfte des Flügels nicht an der Wurzel, sondern vor der Mündung der Mediastina, und geht also viel weniger schief, aber desto breiter gegen den Flügelhinterrand, einige helle Fensterchen einschliefsend; dieselben fallen namentlich in der Discoidalzelle auf und kommen bei Var. $\alpha$ nicht vor.

Der Thoraxrücken zeigt aufser den dunklen Punkten, die in der Mitte in Längsreihen geordnet sind, keine Zeichnung. Die Pleuren sind unpunktiert.

Über dem Mundrande stehen 2 schwarze Punkte. Auch die Schüppchen sind dunkler gerandet und gewimpert.

Beim $\sigma^{7}$ sind Hüften und Beine rotgelb, die Vorder- und Hinterschienen und die Spitzen der Hinterschenkel dunkelbraun, die Vordertarsen verdunkelt. Aufserdem ist das Durchsichtige des Flügels ausgesprochen gelb.

Die Beine des $q$ gleichen jenen des $q$ der Var. $\alpha$. Der Flïgel ist glasig hyalin.

Ich vermute unter Var. $\beta$ eine eigene Art, die sich beim Untersuchen gröfseren Materiales deutlicher erkennen lassen wird. 
XIII. Genus : Elapata n. g.

65. Elapata remipes n. sp.

$3 \sigma^{7}$, Peru (Meshagua, Urubambaflufs, Oktober). Coll. Schnuse.

Stirne rotgelb, zum Teile goldschimmernd; kurz behaart. Scheitelplatten und Ocellendreieck glänzend schwarzbraun. Unter den Fühlern eine silbrige Querbinde von einem Auge zum andern. Auch die Fühler fallen in diesen Silberschimmer hinein. Das ganze Untergesicht darunter, das ist unter den wagrecht liegenden unteren Augenrändern, samtartig kupferrot, mit weifsen Reflexen, namentlich am Clypeus. Die Backen erscheinen oft in weinrotem Schimmer. Unterer Hinterkopf gelb. Obere Augenorbiten braun. Augen oben purpurn, metallisch glänzend, am Unterrande bläulich smaragdgrün.

Fühler gelbrot. Arista beiderseits weitläufig gefiedert. Prälabrum, die verbreiterten Taster und der Rüssel gelbrot.

Thorax und Schildchen mit Ausnahme der rötlichen Schultergegend glänzend dunkelbraun. Der Rücken, die Vorderbrust und am wenigsten das Schildchen sind mit einem zarten goldockrigen Tomente bereift.

Hüften und Tarsen hell gelbrot. Vorderschenkel gelbrot, mit einer braunschwarzen Längsstrieme unten und vorne (anteroventral). Vorderschienen gelbrot, mit einer gleichen Strieme postero-dorsal. Mittelschenkel im Wurzeldrittel, ja bis zur Hälfte, Hinterschenkel in geringerer Ausdehnung gelb, sonst schwarzbraun. Die schwarze Färbung kann auch hier in Längsstriemen auftreten. Schienen mit Ausnahme der Spitzen und der Knie schwarzbraun.

Die Vorderfüfse des or ( $q$ unbekannt) sind wie die Hüften stark verlängert, aufserdem jedoch seitlich komprimiert und verbreitert, und tragen am Ende der Glieder und am ganzen vierten und fünften Gliede seitlich lanzettliche, hornige Blättchen.

Hinterleib an der Wurzel gelb, sonst glänzend pechbraun.

Flügel längs der Costa von der Basis bis zur Spitze gelbrot gesäumt, am Hinterrande rauchbraun, in der Mitte glashell. Vor der Mündung der Posticalader liegen beiderseits je ein schwarzbrauner Fleck oder Längswisch. Die dritte Längsader ist hinter der kleinen Querader dunkel gesäumt. In der Mitte der zitronenförmig erweiterten ersten Hinterrandzelle liegt ein schwarzer Punkt.

Schüppchen und Schwinger gelb.

Körper- und Flügellänge $6-7 \mathrm{~mm}$.

XIV. Genus: Cyrtomostoma n. g.

66. Cyrtomostoma gigas n. sp.

8 or 옹, Bolivia (Mapiri, Sarampioni, $700 \mathrm{~m}$; Januar bis März). Coll. Schnuse. 
Stirne matt rotgelb ljis gelbrot, gegen den Scheitel zu dunkler werdend, aufser den Borsten mittellang schwarz behaart, vorne neben den Augenrändern goldig schimmernd. Scheitelplatten und Ocellendreieck glänzend dunkelgelb bis rotbraun; ebenso der ganze Hinterkopf, der unten an den Seiten und dann an den Augenrändern gelbschimmernd bereift ist und nur oben an den Orbiten dunkelbraun sein kann.

Clypeus, Wangen und Backen beim or matt samtschwarz mit weifsem oder auch gelblichem Schimmer in gewisser Beleuchtung.

Fühlergruben intensiv weifsschimmernd. Nur der Teil des Clypeus über und zwischen den Fühlern, oder noch etwas darunter ist meist noch rotgelb. Beim $q$ sind obige Teile gelbrot. Blofs die Fühlergruben und ein Schatten unter dem Auge auf den Backen sind schwarz. Der weifsliche Schimmer des ganzen Untergesichts, einem Seidenglanze gleich, ist auch dem $q$ eigen. Augen einfarbig violettbraun.

Fühler rostrot, deren drittes Glied manchmal verdunkelt. Arista kurz und fein behaart.

Prälabrum schwarzbraun. Taster verbreitert, rostrot. Rüssel heller oder dunkler rotbraun.

Thoraxrücken, mit Ausnahme der rotgelben Schultern, und das Schildchen braun, ziemlich glänzend, von weifslichen bis goldgelben Schillerflecken ein wechselndes Aussehen erhaltend. Von allen Seiten können aber zwei durchgehende dunkle Längsstriemen in der Linie der Dorsozentralen und je eine abgekürzte seitlich davon hinter der Quernaht unterschieden werden. Die Pleuren werden nach unten $\overline{z u}$ heller und sind durch lichtere Bestäubung fleckig.

Hüften und Beine rotgelb. Schienen, namentlich die hinteren Paare, mehr braun; Tarsen meist auch dunkler als die Schenkel.

Hinterleib an der Wurzel, am Seitenrande und zum gröfsten Teile auf dein Bauche rotgelb, auf dem Rücken schwarzbraun, beim or heller und mehr glänzend als beim $q$. Die Querbinden lassen sich besonders gut bei letzterem wahrnehmen und bestehen aus weifsgrauer Bereifung. Hiervon werden die Wurzelsegmente und der Vorderrand des dritten Tergits, sowie die Tergite 5 und 6 bedeckt. Der Saum am dritten Tergit erweitert sich an. den Seiten fleckenartig nach hinten. Der Basalteil der Legeröhre gleicht fast einem Sechseck, so stumpf ist die Spitze. Er ist fast so breit wie der Hinterleib, über die Hälfte desselben lang und ebenso lang als breit.

Flügel glasig oder gelblich hyalin. Randmal braun. Ein dunkelbrauner Fleck in der Gabel der Radialader. Von der Mündung der Subcosta eine dunkelbraune Querbinde bis zum oberen Ende 
der nur schmal dunkel gesäumten hinteren Querader. Damit hängt an der Costa ein die ganze Spitze einfassender Randsaum zusammen. Von der Spitze des Randmals geht eine zweistufige Querbinde zur kleinen Querader, deren kräftiger Saum eben die zweite Stufe bildet. Das Randmal des or ist durch eine Konvexität der Costa etwas erweitert.

Schüppchen hell, Schwinger gelb.

Körperlänge $\sigma^{7} 11-13 \mathrm{~mm}$, \& mit Legeröhre $13 \mathrm{~mm}$; Flügel $13-15 \mathrm{~mm}$.

\section{Genus: Bothrometopa n. g.}

67. Bothrometopa gamma n. sp.

1 व7, Peru (Urubambaflufs, September). Coll. Schnus e.

Stirne vorne, vor der Grube matt rötlich braun, hellgrauschimmernd, mit mittellangen, schwarzen Haaren, die nach aufwärts gebogen sind, dicht bedeckt. Die Stirngrube matt braun. Am hinteren Augenecke, das ist hier auch vor den Scheitelplatten, liegt ein weifser Fleck. Der stark hinter den Augen vorgequollene Hinterkopf, sowie die Scheitelplatten glänzend braun. Clypeus an den Fühlerwurzeln gelb, unten matt weifslich. Wangen, Backen und unterer Hinterkopf gelb. Ocellar- und Postvertikalborsten fehlen.

Fülıler gelb. Arista fast nackt. Prälabrum und Rüssel braun. Die verbreiterten Taster gelbrot. Augen einfarbig metallisch olivengrün, schwach rötlich schimmernd.

Thorax und Schildchen glänzend dunkelbraun. Schultergegend heller. Auf dem Rücken erscheinen, schief von hinten betrachtet, zwei sehr schlanke, gleichschenklige Dreiecke aus weifser Bestäubung. Ihre Basen nehmen fast die ganze vordere Rückenbreite nebeneinander ein, ihre Höhen sind als scharfe dunkle Linien in der Richtung der Dorsozentralen zu sehen und ihre Spitzen reichen bis auf die Schildchenseiten hinüber. Aufserdem sind noch bestäubt oder bereift: die Supraalargegend und die Vorderseite der Brust.

Vorderhüften gelblich. Beine braun; die vordersten heller als die hinteren.

Ilinterleib einfarbig glänzend schwarzbraun.

Flügel glasig durchsichtig. Eine dunkelbraune Binde beginnt breit an der Wurzel, erfüllt die Basalzellen, läuft längs der Posticalader zum Flügelhinterrand, biegt im Bogen auf, schliefst die hintere Querader ein und gabelt sich über derselben. Der eine Gabelarm mündet zwischen der ersten und zweiten, der andere zwischen der dritten und vierten Längsader am Vorderrande. 
Ebenfalls aus der dunklen Wurzel entspringt eine andere Längsbinde, die in ihrem weiteren Verlaufe ungefähr von der ersten and dritten Längsader begrenzt wird und mit einem die kleine Querader weit umfassenden Fleck, von dem ein trapezförmiger in die Mitte des grofsen Randmales hinüberreicht, plötzlich endet. Im Gabelaste der zweiten und dritten Längsader liegt ein gelber Längswisch. Das Randmal ist durch Abwärtsbiegen der Subcosta erweitert. Eine überzählige Querader fehlt.

Schüppchen schneeweifs. Schwinger dunkelbraun.

Körperlänge $6 \mathrm{~mm}$. - Flügellänge $7 \mathrm{~mm}$.

\section{Bothrometopa determinata Walker.}

Herina determinata Walker, Trans. Entomol. Soc. Lond. n. s. IV. p. 227 (1856-58).

4 , Peru (Meshagua, Urubambaflufs; September und Oktober), Bolivia (Mapiri, S. Ernesto; März). Coll. S c h n us e.

Bei dem mir nur vorliegenden $q$ ist die Vertiefung der Stime ror den Ocellen nur auf eine seichte Mulde reduziert, aber dennoch wahrnehmbar und namentlich durch die im Vergleiche zur Vorderstirne viel schütterere Behaarung kenntlich. Im Vergleiche mit B. gamma springt die Stirne im Profile viel weniger vor, weshalb auch anderseits das Untergesicht, welches hier mehr konkav als dort erscheint, weniger zurückweicht.

Sonst ist die Stirne mattgelb bis kupferrot; die Scheitelplatten, das Ocellendreieck und die oberen Augenorbiten glänzend dunkelbraun. Wangen, Backen und Clypeus braungelb, letzterer weifslich bereift. Ocellar- und Postvertikalborsten vorhanden.

Fühler braunrot, Wurzelglieder oft heller. Arista fast nackt. Irälabrum, Rüssellabellen und die verbreiterten Taster heller oder dunkler rotbrau. Augen wie bei der vorigen Art gefärbt.

Thorax und Schildchen glänzend dunkelbraun. Auf dem Rücken sieht man folgende Zeichnung durch weifslichgraue Bestäubung hervorgebracht: Je einen Bogenfleck hinter der Schulterbeule; eine nach vorne gebogene Querbinde in der Verlängerung der Quernahtäste und 2 abgekürzte Längsbinden hinter der Naht in der Linie der Dorsozentralen. Die Vorderseite der Brust ist etwas fuchsrot bereift.

Hüften und Tarsen rotbraun, Schenkel und Schienen pechbraun. Hinterleib glänzend schwarzbraun. Eine schmale hellgraue Vorderrandbinde am vierten und eine an den Seiten etwas verbreiterte am dritten Tergit.

Frstes Glied des Ovipositors kurz, von der Form eines gleichseitigen Dreiecks. Der Flügel zeigt dieselbe Bogenbinde wie B. gamma, welche über die Posticalader läuft, sich dann am 
Hinterrande nach aufwärts biegt und über der Querader gabelt. Die Zeichnung wird aber dadurch anders, dafs eine über die kleine Querader gehende, auf dem Vorderrande fast senkrecht stehende Querader, sich mit obiger Bogenbinde am Hinterrande vereinigt, während bei $B$. gamma parallel mit der schwarzen Bogenbinde eine glashelle durch die Discoidalzelle hindurchzieht.

Bei $B$. determinata biegt sich die über die kleine Querader ziehende Querbinde an der Costa gegen die Flügelspitze hin um und wird durch eine parallel mit ihr von der Mündung der Mediastina bis zur Posticalis gehende glashelle Binde vom Schwarzbraun der Flügelwurzel getrennt.

Randmal (o) nicht aufsergewöhnlich verbreitert. Zweite und dritte Längsader sind in der Verlängerung der hinteren Querader durch eine Querader verbunden. - Schüppchen weifs. Schwinger braun.

Körperlänge $6 \mathrm{~mm}$. - Flügel $8 \mathrm{~mm}$.

\section{Genus : Coscinum n. g.}

69. Coscinum clavipes n. sp.

2 구오, Peru (Urubamba- und Ucayaliflufs; September bis Oktober). Coll. Schnuse.

Kopf nnattrötlich ockergelb. Stirnstrieme etwas leuchtender; kurz, aber rauh behaart. Scheitelplatten matt bestäubt. Augenränder weifsschimmernd. Clypeus, namentlich unter den Fühlern, und die Wangen schütter weifslich bereift. Augen dunkelrotbraun, grünlich und rötlich metallisch schimmernd.

Fühler gelbrot. Drittes Glied oben und an der Spitze braun. Arista fein und dicht mittellang behaart. Prälabrum, die verbreiterten Taster und der Rüssel gelbrot.

Der ganze Thorax, mit Ausnahme des Schildchenrandes und der Schultergegend, die rötlich sind, wohl von dunkelbrauner Grundfarbe, aber überall äufserst dicht und gleichnälsig goldockrig bestäubt.

Hüften und Beine rotgelb, die vorderen dunkler. Vorderschienen und Hinterseite (Aufsenseite) der Vorderschenkel des $\sigma^{7}$ zum Teile noch dunkler rotbraun. Vordertarsen des $\sigma^{7}$ verkürzt und verbreitert. Vorderschenkel verdickt und unten mit einer kurzbeborsteten, höckerartigen Erweiterung basalwärts.

Hinterleib an der Wurzel rotgelb, dann hellbraun mit lichteren Hinterrandsäumen. Der rotgelbe Ovipositor hat eine herzförmige Basis.

Flügel mit Ausnahme der glashellen Wurzel dunkelbraun, von farblosen runden Flecken regelmäfsig durchbrochen. Davon 
liegen 4 in der Vorderrand-, je 3 in der Unterrand-, ersten Hinterrand- und Discoidalzelle und je 2 in der zweiten und dritten Hinterrandzelle am Flügelrande.

Schüppchen und Schwinger rotgelb.

Körperlänge ơ 6, ㅇ (mit dem ersten Gliede der Legeröhre) $8 \mathrm{~mm}$. - Flügel $6 \mathrm{~mm}$.

\section{Genus: Ophthalmoptera n. g.}

1. Hinterleib metallisch violett, mit gekörnter Oberfläche.

* Ophthalm. elegans n. sp.

Hinterleib glänzend pechbraun, glatt . . . . . . 2.

2. Flügel ungefähr dreimal so lang als breit. Oberer Winkel der Discoidalzelle an der Querader spitzig. Flügel mit 5 Augen . . . . 70. Ophthalm. longipemis n. sp.

Flügel ungefähr zweimal so lang als breit. Oberer Winkel der Discoidalzelle stumpf. Flügel mit 2 Augen.

71. Ophthalm. bipunctata $\mathrm{n}$. $\mathrm{sp}$.

70. Ophthalmoptera longipennis n. sp.

$1 \sigma^{7}$, Bolivia (Songo). Ungar. National-Museum.

Stirne seidenartig rotgelb, fast kahl. Scheitelplatten und Ocellendreieck glänzend braun, etwas bestäubt. Clypeus unter den Fühlern gelb. Das ganze Untergesicht (Clypeus und Wangen) unter einer durch die unteren, wagrechten Augenränder gegebeneu Geraden silberweifs glänzend. Hinterkopf unten, dann die Backen unter den silberweifsen Wangen und Augenorbiten glänzend gelb.

Fühler rotgelb. Drittes Glied an der Spitzenhälfte etwas gebräunt. Arista fast nackt. Das schmale Prälabrum, die verbreiterten Taster und der Rüssel rotgelb. Augen bläulichgrün, in den oberen $4 / 5$ purpurn. Parallel mit der Grenze eine wagrechte purpurne Querbinde etwas unter der Mitte.

Thorax, Schildchen, Hüften und Beine glänzend rotgelb.

Rïcken und Schildchenseiten mit sehr wenig auffallendem, gelblichem Reife dünn bedeckt. Pleuren unter der Notopleuralnaht mit einem aus weifser Bestäubung gebildeten, ziemlich breiten Längsbande.

Hinterleib an der Wurzel und an Banche rotgelb, sonst glänzend pechbraun.

Flügel zum grölsten Teile dunkelbraun. Helle Flecke liegen an den Mündungen der Mediastina und Subcosta, 5 dunkel umrandete Augenflecke auf gelblichem Grunde in der Flügelspitze. Die 4 äufseren bilden ein Kreuz; 2 davon liegen über, einer unter der Cubitalader und der vierte unter der Radialader. 
Der fünfte innerste Angenfleck liegt auch unter der Cubitalader, in gleichem Abstand wie die 3 hinter ihm die Ader von oben oder unten berührenden Augenflecke untereinander. Vom untersten Augenfleck erweitert sich das helle Zentrum, dunkel umrandet, bis zum Flügelhinterrande nach abwärts. Aufserdem finden sich noch glashelle Partien in der Wurzelhälfte der ersten Hinterrandzelle, in der Mitte der Discoidal- und dritten Hinterrandzelle. Axillar- und Flügellappen farblos. Schüppchen bräunlich, Schwinger hellgelb.

Körperlänge $6 \mathrm{~mm}$. - Flügel $8 \mathrm{~mm}$.

\section{Ophthalmopterabipunetatan. sp.}

3 o , Peru (Meshagua, September). Coll. Schnuse.Bolivia. Ungar. National-Museum.

Stirne so breit wie ein Auge, seidenartig gelb, nur kurz und zerstreut fein behaart. Scheitelplatten und Ocellendreieck glänzend schwarzbraun. Clypeus ockergelb, über dem Nundrande hraun. Eine silberweifse Querbinde zieht über den Mundrand und über die Backen hin. Fühler rotgelb, das dritte Glied derselben am Oberrande etwas gebräunt. Arista fast nackt. Prälabrum braun; die verbreiterten Taster gelbrot.

Augen bläulichgrün, mit 2 über die Nitte laufenden wagrechten purpurmen Querbinden.

Thorax, Schildchen und Hinterleib glänzend schwarzbraun.

Rücken und Schildchen etwas rötlich bestäubt. Pleuren unter der Notopleuralnaht mit einer breiten silberglänzenden Längsbinde. Erstes Glied der Legeröhre von der Gestalt eines gleichseitigen Dreieckes, an der Basis etwas herzförmig, rötlich durchscheinend.

Hüften und Beine einfarbig rotgelb.

Flïgel in der oberen Wurzelhälfte schwarzbraun, in der oberen Spitzenhälfte gelb, mit 2 dunkel umrandeten glashellen Augenflecken in der Unterrandzelle, parallel der Costa. Das Gelb der Flügelspitze und die hintere Querader sind braun eingefarst. An den Mündungen der Mediastina und der Subcosta liegen helle Flecke; unter demjenigen der Subcosta noch $1-2$ helle, kleine Punkte in der Randzelle.

Diese Art unterscheidet sich von 0 . longipemis durch die viel kürzeren und daher breiteren Flügel und noch mehr durch die Lage der hinteren Querader, die bei $O$. longipennis oben schief nach aufsen, bei unserer Art aber schief nach einwärts geneigt ist.

Da aber vor allem der Kopfbau, sowie auch die übrigen 
generellen Merkmale übereinstimmen, können beide Arten in eine Gattung vereinigt werden.

Schwinger und Schüppchen wie bei O. longipemis.

Körperlänge $3 \mathrm{~mm}$. - Flügel $3,5 \mathrm{~mm}$.

\section{Genus : Goniaea n. g.}

72. Goniaea foveolata n. sp.

1 ๙ॅ, Bolivia (Songo). Ungar. National-Museum.

Stirne goldgelb, hellfilzig, kahl; Borsten rudimentäl. Vertikale nnd Postvertikale auf den Hinterkopf hinabgerückt. Backen, Wangen und Clypeus ebenfalls goldgelb; letzterer in den Fühlergruben etwas braun, erstere unter den Augen mit einem braunen Spiegelfleck. Fühler gelbrot. Arista nackt. Prälabrum, die verbreiterten Taster und der Rüssel rotbraun. Hinterkopf nur oben, hinter den Augen dunkler. Augen violettpurpurn, mit einem langovalen, schief von oben nach unten, im Höhendurchmesser liegenden blaugrünen Mittelflecke.

Thorax von dunkel rotbrauner Grundfarbe, am Rïcken vor der Quernaht matt schwarzbraun. Schulterbeulen, Quernahtäste, deren Fortsetzung in der Mitte des Rückens durch die scharf abgegrenzte Längsgrube des Rückens, der Hintermandsaum der Grube, die Supraalargegend und die Mesopleuren oben und längs der Naht ockergelb bestänbt.

Pleuren unten, Hüften und Beine heller, rötlichbrann.

Schildchen ungewöhnlich grofs, etwas anfgerichtet, an der Wurzel sehr breit, dann dreieckig zugespitzt; rotgelb, durchscheinend, unten an den Seiten mit je einem dunkelbraunen Längsfleck.

Hinterleib an der Wurzel rotgelb. Vom zweiten Ringe an dunkel metallisch, grünlich stahlblau glänzend, in gewisser Richtung wie mit einem roten Reif bedeckt erscheinend. Längs der Mitte eine undeutliche weilshestäubte Linie.

Flügel in der Mitte glashell, hinten graulich, vorne intensiv rotgelb. Durch dieses Gelb zieht von der Wurzel, im allgemeinen längs der Subcosta, ein unregelmälsig begrenzter braunschwarzer Längswisch bis in die Randzelle. Der scliarfeckige Anallappen mit einem schwärzlichen Punkt im Scheitel. Schüppchen und Schwinger gelb.

Körperlänge und Flügel ungefähr $8 \mathrm{~mm}$. 


\section{Nachtrag.}

Legala emyia radiata n. sp.

3 o, Bolivia (Songo). Ungar. National-Museum.

Diese Art steht der Meg. punctulata so nahe, dafs ich blofs die nnterscheidenden Merkmale anführe.

Die Bestäubung des Untergesichtsquerbandes und des Rückens ist mehr gelblich, das Schildchen in der Mitte dunkelbraun.

Der wichtigste Unterschied liegt in der Flügelzeichnung. Das glashelle Dreieck in der Submarginalzelle ist kleiner und liegt knapp hinter der Mündung der Mediastina, jenes in der Marginalzelle kürzer und gleichseitig. Die beiden schwarzen Querbändchen, die vor der Flügelspitze die Radial- mit der Cubitalader verbinden, fehlen hier. Die schwarze hufeisenförmige Binde, die bei prnctulata von der Mündung der Discoidalader bis zur Flügelmitte anfsteigt und sich dann wieder über die hintere Querader herabsenkt, besteht hier aus 2 geraden Winkelschenkeln, deren Scheitel in der Radialader, ungefähr unter der Spitze des glashellen Dreiecks der Marginalzelle liegt. Der glashelle Fleck hinter der kleinen Querader dehnt sich bis zur Querbinde über die hintere Querader aus. Die Costa ist über der Submarginalzelle konvex emporgebogen. Die Radialader biegt sich hinter der hinteren Querader noch viel steiler auf und läuft dann mit der Costa parallel. Augen im Leben grün, mit purpurnem Unterrande und 2 Purpurquerbinden in der Mitte.

Schienen und Fülse sind gelb. Die Grölse ist die gleiche.

\section{Meyala emia marginata n. sp.}

$1 \sigma^{7}$ aus Peru (Callanga). Ungar. National-Museum.

Der Mleg. bestifer äufserst ähnlich, aber namentlich durch folgende Unterschiede in der Flügelzeichnung verschieden: hinter der Wurzelquerader ist nur ein ganz kleiner heller Punkt zu sehen. Die glashelle, spitzige Querbinde hinter der hinteren Querader dringt mit der äufsersten Spitze noch über die Cubitalader hinaus in die Submarginalzelle ein. Der helle Punkt in letzterer Zelle fehlt. Dagegen liegt ein helles Fensterchen an der kleinen Querader und ein ebensolcher Punkt fast genan darüber an der Radialader. Die Discoidalzelle ist fast ganz glashell, mur an der äufsersten Wurzel braun. Von dort zieht ein schmales schiefes Band über das erste Drittel des Unterrandes dieser Zelle in die dritte Hinterrandzelle bis zur Falte zwischen Anal- und Posticalader. Bei Meg. bestifer ist die ganze Wurzelhälfte der Discoidalzelle braun und ein bogiges Band zieht über die Mitte der Zelle bis zur Mündung der Analader. Die Radialader ist bei moryinate 
vor der Mündung nicht so stark zur Costa aufgebogen wie bei Meg. bestifor.

Alles übrige wie bei Meg. bestifer. Augen im Leben wahrscheinlich einfarbig grünlich.

\section{Myennis cyaneiventris n. sp.}

1 ons Bolivia (Songo). Ungar. National-Museum.

Steht der $\boldsymbol{M}$. appendiculata sehr nahe. Augen im Leben wie bei dieser Art gezeichnet. Stirne samtartig rotgelb, in der Mitte mit einem mit der Spitze nach vorne gerichteten braunen Dreiecke, ohne Grundbehaarung; Kopfborsten sehr kurz. Wangen, Backen nnd unterer Hinterkopf rotgelb, seidenartig schimmernd. Unter dem Auge ein brauner Fleck. Clypeus bräunlichgelb, in der Mitte jederseits ein rundlicher brauner Fleck. Lunula braun. Fühler rotgelb. Das dritte Glied fehlt. Prälabrum und die verbreiterten Taster rostrot. Rüssel rotbraun.

Thorax pechbraun, Pleuren, Schildchen und Supraalargegend glänzend, sonst matt. Zwei breite Längsstreifen am Rücken, die Gegend vor dem Schildchen, die Quernahtäste, die Umgebung des Humeralcallus, das obere Eck der Mesopleuren und das Postscutellum goldgelb bestäubt. Nein Exemplar ist etwas fettig geworden. Schildchen viel grölser als bei allen anderen Arten, aufgeblasen, mit äufserst kurzer heller Pubescenz bedeckt, an der Spitze gelb, vierborstig; die seitlichen Borsten sehr kurz. Hüften und Beine glänzend rötlich pechbraun, die äufsersten Knie und die Tarsen kaum etwas heller.

Hinterleib mit 5 sichtbaren, fast gleichlangen Ringen, der sechste ist kaum sichtbar, an der Wurzelhälfte hellstahlblau, etwas glänzend, gegen die Spitze zu mehr violettschimmernd und matt, wie bereift. Die Grenze zwischen erstem und zweitem Tergit ist weifslich. Das erste Glied des Ovipositors ist glänzend schwarz, schlank dreieckig, ungefähr zweimal so lang wie an der Basis breit.

Der Flügel gleicht jenem des $q$ von $M$. appendiculatu mit folgenden Unterschieden: Der schwarzbraune Saum der Subcostalzelle ist mit dem dunklen Braun der Flïgelwurzel verbunden, das sich bis über die Basalzellen hin verbreitert und nur die hintere Basalzelle und die Analzelle frei lälst. Die beiden Queradern sind noch melı genähert und bilden fast eine Linie. Die überzählige Querader zwischen der Subcosta und der Radialader erreicht erstere Längsader nicht ganz.

Schwinger hellgelb. Schüppchen braun gerandet.

Körper ohne Legeröhre und Flügel $7 \mathrm{~mm}$ lang. 
Yanthariona phyllochaetan. sp.

7 의 Paraguay. Ungar. National-Museum.

Augen im Leben hellgrün, blauschimmernd, mit 2 schmalen, vorne abgekürzten Querbinden in der Mitte.

Stirne samtartig rotgelb bis gelbrot, am Augenrande und den Wangen auffallend seidenartig weifsschimmernd. Kopf sonst glänzend gelb. Ocellengegend schwarz. Die auf den Scheitelplatten stehende Orbitalborste ist blattartig erweitert. Die längeren Börstchen weiter unten am Stirnaugenrande sind nicht nach einwärts, sondern nach auswärts gebogen. Lumula matt gelb. Clypeus glänzend zrelb, in der Mitte mit einer hufeisenförmigen ziemlich tiefen Querfurche, unter welcher das Epistom merklich im Profile vortritt. Auch der Quere nach ist der Clypeus viel stärker gewölbt als bei der $\mathrm{Wulp}$ schen Art, Prälabrum breiter, glänzend. Backenleisten am Rande schwarz. Backengruben samtartig rot. Fühler gelbrot, am Vorderrande gebräunt und etwas konkav. Rüssel und Taster rostgelb.

Thorax, Schildchen und Hinterleib rotgelb, sehr stark glänzend. Rücken mit 4 braunen bis schwarzen Längsstriemen, die vorne und hinten etwas abgekürzt sind und in der Mitte einen etwas breiteren Abstand haben. Die äufsersten Striemen sind an der Quernaht unterbrochen. Sternopleuren meist schwarzbraun. Das aufgeblasene halbkreisförmig umrissene Schildchen hat 2 schwarze Seitenflecke.

Die Grundbehaarung des Rückens ist so lang, dafs derselhe nur mit Borstenharen bedeckt erscheint. Die 2 hintersten Dorsozentralborsten sind wie die Frontorbitalborste blattartig erweitert. Vor denselben stehen auf dem gelben Zwischenraume zwischen den dunklen Längsstriemen noch einige Borstenhaare bis vorne hin. Ebenso sind auf dem gelben Mittelstreifen des Rückens vorne in der Fortsetzungslinie des Präscutellarpaares mehrere Borstenlaarpaare $\mathrm{zu}$ sehen. Aber auch in der Intraalarlinie sind hinter und vor der Quernaht borstenartige Haare vorhanden. Schildchen vierborstig. - Ocellarborsten klein.

Hinterleib hellgelb, von der Wurzel her in grölserer oder geringerer Ausdehnung gebräunt, stärker beim $q$, minder beim $\sigma^{\top}$. Die Tergite $3-5$ haben beim $q$ ziemlich gleiche Länge, das sechste ist kurz. Beim or ist das dritte Tergit etwas verlängert. Ovipositor und Beine wie bei $X$. bipustulata Wulp.

Die Flügelzeichnung charakterisiert sich dadurch, dafs die Costalzelle in der Wurzelhälfte glashell ist und dafs der braune Costalsaum nicht bis zur Radialader herabreicht, sondern nur die Subcostalzelle erfüllt und dann erst nach und nach wieder breiter wird. Datlurch wird die über die Queradern laufende, 
Querlinde, welche an der Radialader endet, vom Costalsaume durch die glashelle Marginalzelle isoliert. Mit Ansnahme des Verlaufes der Radialader, welche nicht nach aufwärts gebogen der Costa genähert ist, sondern näher der Cubitalader, fast mit derselben parallel läuft, gleicht das Geäder sonst jenem des Typus. - Schïppchen dunkler gerandet. Schwinger hellgelb.

Körperlänge ohne Legeröhre $4-5 \mathrm{~mm}$. - Flügel 3,5 bis $4, \check{\mathrm{j}} \mathrm{mm}$.

\section{Pterocalla nitidicentris n. sp.}

1 o aus Paraguay. Ungarisches National-Museum.

Augen im Leben smaragdgrün mit bläulichem Schimmer, unbandiert. Kopf im Profile nicht so stark zusanmengedrückt als bei den anderen Arten; die Augen erscheinen daher fast rundlich. Die Stirne verengt sich merklich nach vorne und ist neben den Fühlern deutlich schmäler als ein Auge. Die Fühler sitzen genau der Augenmitte gegenüber. Die Stirne ist in der Vorderhälfte matt ockergelb, oben mehr grau. Scheitelplatten und Ocellendreieck, sowie der obere Hinterkopf aschgrau. Die sehr lange und starke Frontorbitalborste steht in der Mitte des Augenrandes, also sehr weit vorne. Lunula und ein Fleck neben den Fühlerwurzeln hellgelb. Clypeus unter den Fühlern mattbraun. Über das Epistom und die Backen zieht ein silberweilses Querband. Der Mundrand tritt nicht vor. - Fühler an der Wurzel rotgelb, das dritte Glied oben zum gröfsten Teile braun. Sie sind etwas hürzer als gewöhnlich. Das dritte Antennenglied ist kaum länger als breit und reicht mit der Spitze bis zur oberen Grenze des silberigen Querbandes.

Thoraxrücken und Schildchen gelbgrau bestäubt. Zeichnnng wegen Fettigseins unrleutlich. Humeralcallus und Suturaldepression rotgelb.

Pleuren hell aschgrau bestänbt. Längs der Notopleural- und Sternopleuralnaht läuft eine kastanienbranne Längsbinde. Schildchen eiförmig, mäfsig gewölbt, vierborstig.

Beine einfarbig hell rötlichgelb.

Hinterleib glänzend pechbraun, mit Ausnahme des dritten, hell gelblichgran bestäubten Tergites.

Subcostalzelle des o7 durch eine schwache Konvexität der Costa und ein starkes Nach-unten-Biegen der Subcosta aufsergewöhnlich erweitert. Radialarler mälsig wellig geschwungen, am Ende aber sehr steil zur Costa aufgebogen, mit dunklem Mündungsfleck. Discoidal- und Cubitalader wellig, erste Hinterrandzelle an der Mündung nicht verengt. Hintere Querader nur etwas bauchig, mit der Discoirlalader einen Winkel von $60^{\circ}$ bildend; ilu 
Abstand von der kleinen Querader ist $1 \frac{1}{2}$ mal so lang wie die hintere Querader selbst. Der spitze Zipfel der Analzelle ist schlank und in gleicher. Weise von der Zelle abgeschnürt wie bei den echten Pterocalla-Arten, aber viel kürzer wie bei diesen Species, nur so lang wie die die Analzelle vorne begrenzende Querader. Der Flügel ist einfarbig nufsbraun, olhne jedwede dunklere Strichlierung oder Punktierung. Vor der Mediastina und hinter der Subcosta liegen an der Randrippe glashelle Fleckchen; unter letzterem ein dunkelbrauner Wisch. 3 Augenflecke liegen an den Vierteln des letzten Cubitaladerabschnittes, der zweite oben in der Submarginalzelle, der erste und dritte darunter in der ersten Hinterrandzelle. Die zweite Hinterrandzelle ist braun; ein kleiner Punkt an der Flügelrandmitte und ein etwas gröfserer viereckiger Fleck an der Posticalader glashell. Das Braun des Flügels tritt nur in der Gestalt von 3 Zähnen unter die Posticalader hinab. Axillarlappen ganz glashell.

Körperlänge fast $4 \mathrm{~mm}$. - Flügel $4,5 \mathrm{~mm}$.

\section{Pterocalla punctata n. sp.}

$4 \sigma^{7}+$, Bolivia (Songo); Paraguay. Ungarisches National-Museum.

Leicht mit Pt. ocellata $F$. zn verwechseln. Stirne etwas breiter und anffallender gefärbt. Lunula und daneben jederseits ein Fleck zwischen Auge und Fühlerwurzel hell gelbgrau; darüber ist die Vorderstirne tief braunrot. Die Scheitelplatten sind ebenfalls hell gelbgrau bestäubt und tragen je 2 schwarzbraune Punkte an den Wurzeln der Orbital- und Scheitelborsten. In der Stirnmitte liegen zwei schräge rotbraune Strichelchen, die durch eine helle Linie vom Ocellendreieck her getrennt werden. Clypeus heller und mehr grau als bei Pt. ocellata und mit einer braunen Querbinde über dem Mundrande, die bei genannter Art fehlt. Augen im Leben grün, blauschimmernd: in der Mitte zwischen 2 roten Reflexen ein hellgrünes Querband.

Thoraxrücken hell ockerig bestäubt, in der Mitte ohne Längslinien. Eine Querreihe von 4 braunen Punkten vor, eine solche von 6 auf und endlich ein Paar gröfserer Punkte hinter der Quernaht. Überdies braune Wurzelpunkte an den Borsten und Flecken an den Rückenseiten.

Hinterleib ähnlich wie bei Pt. ocellata gezeichnet, nur ist die feine Punktierung viel ausgedehnter und dichter und liegen die 4 braunen Flecke des dritten Tergites in gleichen Abständen nebeneinander, nicht in der Mitte durch einen breiteren Zwischenraum von einander getrennt. Vorderschenkel bräunlich.

Die auffallendsten Unterschiede bietet jedoch die Flügelzeichnung beider Arten. Bei Pt. munctata sind die Querstriche 
zwischen den Längsadern viel kürzer, mehr punktförmig, und kleiner, nicht so auffallend wie bei Pt. ocellata. Bei dieser Art liegen unter der Posticalader im braunen Saume noch 4--5 dunkle Striche, welche bei unserer Art fehlen. Hier ist der Axillarlappen mit Ausnahme des äufsersten Winkels zwischen Analader und Axillarfalte ganz glashell, während er bei Pt. ocellata in der ganzen Wurzelhälfte, auch hinter der Falte graulich ist und unter dem Zipfel der Analzelle 2 dunklere Flecke zeigt. Bei Pt. punctata ist der Abstand der beiden Queradern an der Discoidalader länger als die nicht so stark geneigte und etwas bauchige hintere Querader, bei Pt. ocellata dagegen kürzer als die stark schief liegende, fast gerade hintere Querader. Die Augenflecken liaben bei beiden Arten die gleiche Lage, bei letztgenannter Art aber eine bedeutendere Gröfse, so dafs der Fleck in der Submarginalzelle beinahe so breit wie die Zelle selbst ist, während er bei Pt. punctata ungefähr die halbe Zellbreite als Durchmesser hat.

Körperlänge $4,5-5 \mathrm{~mm}$. - Flügellänge ungefähr $5 \mathrm{~mm}$.

$$
\text { Pterocalla radiata n. sp. }
$$

2 or $q$ Bolivia (Songo, Coroico). Ungarisches National-Museum. Augen im Leben grün; in der Mitte mit einer hellgrünen Querbinde zwischen violetten Reflexen.

Stirne vorne so breit wie ein Auge, oben breiter. Die Frontorbitalborste steht etwas weiter vorne und die Scheitelplatten sind etwas länger als gewöhnlich. Die sehr schwachen Ocellarborsten divergieren nach seitwärts und sind aufgerichtet. Die Grundbehaarung der Stirne ist sehr kurz und zerstrent. Stirne, Thorax und Hinterleib beim or dicht hellgrau, fast kreideweifs bestäubt. Beim o ist die Bestäubung mehr gelblich- oder bräunlichgrau. Stirne dunkelbraun gefleckt; 3 rundliche Flecke an der Scheitelkante, und zwar an den Scheitelborsten und am Ocellenhöcker; je ein ebensolcher an der Basis der Frontorbitalborste. Aufserdem liegen noch 2 hellere Flecke zwischen diesen Borsten auf der Stirnmitte. Diese Flecke und je ein gröfserer an Vorderrande der Stirne, wo dieselbe in die Wangen übergeht, sind mehr weniger verwischt und rötlich. Lunula und Wangen dunkelrotbraun. Ebenso ein Wisch am unteren Hinterkopf. Clypeus etwas mehr ausgehöhlt als gewöhnlich, oben unter den Fühlern schwarzbraun, matt, unten am Mundrand wie das übrige Untergesicht hellgelblichweils bestäubt. Fühler einfarbig rötlichbraun. Drittes Antennenglied fast scheibenrund. Tasterspitzen schwarzbralin. Backen ein Drittel der Augenhöhe breit.

Thoraxrücken in der Mitte mit runden braunen Flecken ver- 
ziert. Ganz an den Seiten liegen gröfsere, weniger abgerundete Flecke vor und hinter dem Humeralcallus, ferner vor und hinter der Flügelwurzel. Die runden Flecke bilden 3 Querreihen, wovon die ersten zwei je 4 , die letzte aber nur 2 Punkte enthält. Schildchen fast halbkreisförmig, mit 4 Borsten und braunen Wurzelflecken an denselben. Pleuren mit grofsen rundlichen braunen Flecken.

Am Hinterleibe des $\sigma^{7}$ ist das zweite Tergit verlängert. Das erste Glied des Ovipositors ist so lang wie breit und herzförmig, wie der Hinterleib bestäubt und punktiert Vom dritten Ringe an sind die Hinterrändel braun punktiert. Das zweite Tergit hat in der Vorderhälfte 2, die folgenden aber 4 runde braune Flecke in einer Querreihe. Beine bräunlichgelb. Schenkel etwas grau bereift und vor der Spitze mit einem verwaschenen braunen Ring. Schienen mit 2 undeutlichen rötlichen Ringen. Tarsen hell. Flügel von dem aller bekannten Arten durch die strahlige Zeichnung an der Spitze unterschieden, die sich besser im Bilde darstellen als beschreiben lälst. Ein Mittellängswisch von der Wurzel bis zur Hälfte der ersten Hinterrandzelle dunkelbraun, mit dunkleren Flecken in Längsreihen zwischen den Längsadern 1 bis 5. Kleine Querader durchsichtig. Costa auch beim ơ gerade. Subcostalzelle normal, nicht besonder's erweitert. Subcosta nackt, nicht weit hinter der Flügelmitte mündend. Radialader vor der steil aufsteigenden Mündung nach oben ausgebaucht und dort mit einem grofsen tief dunkelrotbraunen Fleck verziert, der zum grörsten Teile in der Submarginalzelle liegt und ein glashelles Auge einschliefst. Dieser Augenfleck bildet mit den 3 anderen der ersten Hinterrandzelle ein schiefliegendes Rechteck. Die Discoidalader biegt hinter der hinteren Querader aufwärts, verengt dadurch die erste Hinterrandzelle auffallend und geht dann mit der ziemlich geraden Cubitalader stark divergierend zum Flügelrande. Queradern stark genähert. Hintere schief und mäfsig S-förmig gebogen. Die schlanke Spitze unten an der Analzelle ist fast so lang wie die Zelle selbst. Gegen den Rand zu divergierende Y-förmige schwarzbraune Strahlenpaare liegen hinter der Subcostamündung, an der Radial-, Cubital- und Posticalader und in der Mitte der zweiten Hinterrandzelle. Unter der Posticalader ist der Saum des Braunen zahnartig ausgezackt. Schüppchen braun, Schwinger gelb.

Körperlänge $4-5 \mathrm{~mm}$. - Flügellänge $5-6 \mathrm{~mm}$.

$$
\text { Dasymetopa luteipennis n. sp. }
$$

$1 \sigma^{\top}$, Peru (Vilcanota). Ungar. National-Museum.

In der Kopfform gleichfalls der D. sordida ähnlich. Stirne 
matt rotgelb; Scheitelplatten und oberer Hinterkopf ockergelb. Fühler, Rüssel und Taster gelbrot. Thorax und Schildchen dicht ockergelb bestäubt. Sternopleuren grau. Hüften und Beine rotgelb. Hinterleib dunkelbraun, wachsglänzend, nur wenig bereift.

Subcostalzelle durch eine Konvexität der Costa und durch eine Ausbauchung der Subcostalader stark erweitert. Die kleine Querader steht ungefähr in der Mitte der Discoidalzelle, die hintere auf der vierten Längsader fast senkrecht, so dafs der untere Winkel der Discoidalzelle noch gerade stumpf ist. Die Subcostalzelle und die Flügelmitte ist ockergelb, die äufserste Basis, die Zellenspitzen am Flügelrande und der Hinterrand glashell. Dunkler braune Flecken von geringer aber verschiedener GröIse liegen vor der Mündung der Mediastina, an derjenigen der Subcosta, an der Costa zwischen der ersten und zweiten Längsader und an der Flügelspitze. Vier solcher Flecke am letzten Abschnitte der Discoidalader von der kleinen Querader an, ein geteilter in der Spitze der Discoidalzelle und ein Wisch in der Mitte der ersten Hinterrandzelle. Anfserdem ist die hintere Querader braun gesäumt.

Körperlänge $3,5 \mathrm{~mm}$. - Flügellänge $3,5 \mathrm{~mm}$.

\section{Dasymetopa fenestrata n. sp.}

1 q aus Peru (Vilcanota). Ungar. National-Museum.

Kopfform wie bei $D$. sordida. Der Kopf weniger von vorne her zusammengedrückt als bei den andern Arten, die Stirne schmäler als ein Auge. Stirne matt rotgelb, Scheitelplatten und oberer Hinterkopf graulich, Cerebrale gelb. Clypeus und Backen weifsschimmernd, unterer Hinterkopf gelb. Fühler rotgelb. Ebenso der Rüssel und seine Anhänge. Thorax dicht gelblichgrau bestäubt. Sternopleuren aschgrau, Humeralcallus und Schildchen rotgelb. Hüften und Beine rotgelb. Hinterleib dunkelbraun, wenig bereift, daher etwas glänzend. Erstes Glied des Ovipositors mit herzförmiger Basis, so lang wie breit.

Flügel mit Ausnahme des Basisdrittels ranchbraun, mit 10 viereckigen glashellen Fenstern: 3 über der zweiten, 2 über der lritten, 3 über der vierten Längsader und 2 neben der hinteren Querader. Die Spitze der Costal- und Subcostalzelle ist dunkelbraun. Die Subcosta ist nackt.

Körper ohne Ovipositor $4 \mathrm{~mm}$. - Flügel 4,5 mm lang.

Rhyparella novempunctata n. sp.

1 o aus Bolivia (Mapini; Januar); Koll. S chnuse.

Diese Art unterscheidet sich von $R$. decempenctata durch folgendes: Scheitelplatten, oberer Hinterkopf, Pleuren, Rïcken und 
Schildchen dicht aschgrau bestäubt. Nur die Gegend an der Notopleuralnaht ist etwas bräunlich tingiert.

Flügelbasis und Costalzelle gelblich, nicht glashell. Der helle Zwischenraum zwischen den 2 braunen Flecken der Costalzelle bei decempunctata fehlt und ist auch braun; desgleichen der quadratische Fleck an der Basis der Discoidalzelle. Die beiden glashellen Flecke an der Mündung der Mediastina liegen nicht senkrecht untereinander, ein Rechteck bildend, sondern schief und bilden zusammen ein schiefes Parallelogramm. Die Anordnung der 7 glashellen, rechteckigen Fensterchen an der Flügelspitze ist die gleiche wie bei 10-punctata, nur der äufsere Fleck der Submarginalzelle ist dem inneren vielmehr genähert, so dafs der dunkle Zwischenraum nur die Hälfte des Fensters breit wird. Der braune Hinterleib ist in der vorderen Hälfte der Tergite gelblichgrau bestäubt, was ohne scharfe Grenzen in den dunkleren Hinterrand übergeht. Das glänzend braune erste Glied des Ovipositor's ist $1^{1 /}$ mal so lang' wie breit, lanzettförmig und länger als der halbe Hinterleib.

Körper ohne Legeröhre und Flügel $5 \mathrm{~mm}$ lang.

Die 5 Terpnomyia-Arten lassen sich wie folgt unterscheiden:

1. Zwischen den Fühlerwurzeln ein grofser samtschwarzer Fleck.

Analzelle bauchig begrenzt. . .17. T. latifrons n. sp.

Clypeus ohne schwarzen Fleck. Analzelle unten mit kurzer aber dentlicher Spitze . . . . . . . • . 2.

2. Augren doppelt so hoch wie lang. Die 2 mittleren Flügelquerbinden vereinigen sich am Flügelhinterrande.

16. $T$. angustifrons $\mathrm{n}$. $\mathrm{sp}$.

Augen rundlich. Querbinden isoliert . . . . . 3.

3. Cubitalader nackt. Costa in der Mitte konvex.

T. costalis n. sp.

Cubitalader beborstet. Costa gerade . . . . . 4 .

4. Erste Hinterrandzelle an der Spitze verengt. Der schmale

Spitzenfleck des Flügels hängt an der Costa mit der dritten Querbinde zusammen. . . . T. nitens n. sp. Erste Hinterrandzelle ïberall gleichbreit. Der breite SpitzenFleck des Flügels isoliert . . . . T. bicolor n. sp.

$$
\text { Terpnomyia bicolor n. sp. }
$$

1 q, Peru (Callanga). Ungar. National-Museum.

Stirne seidenartig gelbrot, mit kurzer Grundbehaarung, auch vorne etwas breiter als, ein Auge. Scheitelplatten, Ozellendreieck und oberer Hinterkopf mit Ausnahme des gelblichen Cerebrales dunkelbraun, wachsglänzend. Die 2 Orbitalborsten sind nach 
vorne gerückt und stehen fast in den Stirndritteln. Kopfform wie bei der Gattung Pterorerina. Wangen, Backen und unterer Hinterkopf zitronengelb; Clypeus weifslichgelb. Fühler rostrot, am Oberrande gebräunt. Arista pubescent. Taster rotgelb, Rüssel pechbraun. Augen einfarbig bell olivengrüu mit rötlichem Schimmer.

Thorax und Schildchen sepiabraun, Schultergegend rötlich. Rücken ziemlich glänzend, etwas lichter bestäubt. Diese Bestäubung ist an den Quernahtästen dichter und bildet in der Mitte zwei helle Längsstreifen. Pleuren ziemlich dicht graulich bestäubt.

Hiiften und Beine hell rotbraun, die hinteren etwas dunkler. Auch die Vorder- und Hinterschienen sind gegen die Śpitze zu dunkler.

Das basale Doppelsegment des Hinterleibes mit Ausnahme je eines schwärzlichen Hinterrandfleckes links und rechts am 2. Tergit, sowie die Basis des dritten und vierten Ringes gelb, sonst glänzend schwarzbraun.

Das erste Glied des Ovipositor's ist so lang wie der halbe Hinterleib und von gleicher Farbe wie dieser, an der Basis und Spitze gleichbreit, in der Mitte erweitert, gleich den Längsschnitte eines Fasses.

Die Flügelzeichnung ähnelt jener von Pterocerina rolorata of sehr. Die erste Querbinde ist aber vorne schmäler, erfüllt nur die äufserste Spitze der Costalzelle und ist hinten breiter und erreicht den Flügelrand am Ende der Posticalader. Die zweite Querbinde ist nur linienartig schmal und zieht vom proximalen Ende der scluwarzen Subcostalzellenspitze zur kleinen Querader. Die dritte Binde ist unten breiter und hat einen konvexen Innenrand. Die Spitzenbinde ist ganz isoliert, durch einen hinten etwas breiter werdenden glashellen Zwischenraum von der dritten Querbinde getrennt.

Auch das Geäder ähnlich wie bei der genannten PterocerincArt, nur die erste Hinterrandzelle fast gleichbreit streifenförmig. Subcosta der ganzen Länge nach lang beborstet. Cubitalader von der Wurzel bis über die kleine Querader hinaus schütter beborstet. Schüppchen bräunlichweils. Schwinger gelb.

Körper ohne Legeröhre und Flügel $6 \mathrm{~mm}$ lang.

$$
\text { Terpuomyia costalis n. sp. }
$$

$1 \sigma^{7}$ aus Bolivia (Songo). Ungar. National-Museum.

Kopfform wie bei ' $T$ : bicolor, Stirne aber noch breiter, Backen $1_{1}$ des lotrechten Augendurchmessers, nicht blofs $1 / 4$ wie bei dieser Art breit; die 2 Orbitalborsten stehen in der oberen Stirnrandhälfte. Der Clypeus ist im Profile fast gerade, tritt aber weiter über die Augen vor. Stirne; Wangen und Backen matt rotgelb; 
noch gesättigter die Fühler und die Taster. Clypens weifsgelb. Scheitelplatten und oberer Hinterliopf glänzend hellbraun, unterer Hinterkopf glänzend gelb. Rüssel rotbraun. Die Augen scheinen einfarbig grün mit blauem Schimmer zu sein.

Thorax und Schildchen hell rotbraun, oben etwas verdunkelt. Rücken nur mit Spuren dunklerer Längsstriemen, glänzend, nur mit schr zartem gelben Tomente bedeckt. Pleuren dichter gelbgratu bereift.

Hüften und Beine dunkel rotgelb. Alle Schenkel in der Mitte braun. Die hinteren Schienenpaare mit je 2 braunen Ringen, unter dem hellen Knie und an der Spitze. Vorderschienen und -Fülse dunkelbraun. Hintere Fülse gegen das Ende zu verdunkelt.

Hinterleib glänzend pechbraun. Die Basalhälfte bis zur Mitte des dritten Tergits rotgelb.

Charakteristisch für diese Art ist, dafs die Costa im stumpfen Winkel, dessen Scheitel etwas vor der Mündung der Subcosta liegt, gebrnchen erscheint. Die Radialader ist stark wellig geschwungen, die gerade Cubitalader nackt, die vierte Längsader vor der Mündung etwas aufgebogen, die Subcosta der ganzen Länge nach dicht beborstet. Auf der Flügelmitte liegt eine abgekürzte braune Querbinde, welche auf der sehr scliefen kleinen Querader beginnt und unter der Mündung der Subcosta endet; an der Radialader ist sie unterbrochen. In gleichen Abständen vor und hinter dieser Binde liegt je eine breite, in der Mitte spindelförmig erweiterte ganz durchgehende Querbinde, die beide mit den verjuingten Spitzen einerseits die Costa, anderseits etwas konvergierend und breiter den Hinterrand berühren. Das ganze Spitzendrittel des Flügels ist dunkelbraun, die innere Grenze desselben unter der Cubitalader verwaschen. Subcostalzelle hell. Zweite und dritte Längsader gelb g'esäunt. - Schüppchen helIbraun. Schwinger gelb.

Körper $6 \mathrm{~mm}$. - Flügel $7 \mathrm{~mm}$ lang.

$$
\text { Terpuomyia uitens n. sp. }
$$

3 ㅇ aus Bolivia (Songo). Ungar. National-Museum.

Kopfform wie bei $T$. bicolor. Stirne so breit wie 1 Auge. Backen fast die Hälfte der Augenhöhe breit. Die 2 Frontorbitalborsten stehen in der oberen Stirnhälfte. Strieme der Stirne matt rotbraun, in gewisser Richtung weifsschillernd, vor den glänzend dunkelbraunen Scheitelplatten rerdunkelt, am Augenrande weifs gesäumt. Das ganze Untergesicht braun; der Clypeus dicht weifslich bestäubt; die Backengruben weifsschillernd, sonst tief rotbraun. Epistom im Profile etwas vorspringend. Fühler und 
Taster rostrot. Arista nackt. Oberer Hinterkopf dunkelbraun, unterer rötlich, weifs bereift. Augen im Leben grün, blauschimmernd, mit 2 schmalen roten Querbinden in der Mitte und rotem Unterrande.

Thorax und Hinterleib glïnzend kaffeebrauı. Rücken dicht hell gelblichgrau bestäubt, mit dunklen Punkten an den Borsten und den in Reihen gestellten Hadren. Aufserdem tritt die braune Grundfarbe in 3 hinten abgekürzten Längsstriemen in der Mitte und in Querstriemen in den Quernahtästen hervor. Schultern rötlich. Schildchen nur in der Mitte bestäubt. Pleuren dünn grau bereift. Beine pechbraun; die Knie, die Vorderhüften und die Füfse der 2 hinteren Beinpaare heller rotbraun.

Nur an der äufsersten Basis des Hinterleibes ist eine gelbe Färbung wahmehmbar. Das glänzend dunkelbraune erste Glied des Ovipositors ist schlank lanzettförmig, fast dreimal so lang wie breit und so lang wie der Hinterleib.

Die Flügelzeichnung ähnelt der von T. bicolor. Die erste, dritte und die Spitzenquerbinde sind aber viel schmäler als bei dieser Art und auch schmäler als die hellen Zwischenräume, was bei $T$. bicolor nicht der Fall ist. Die erste Binde ist fast gleich breit und hat unter der Subcosta 1 helles Fenster. Hinter der zweiten Querbinde liegt mnter der Mündung der Subcosta ein schwarzer Punkt in der Marginalzelle, der bei T. bicolor nur angedeutet ist. Der Innenrand der dritten Binde ist konkav. Die vierte Binde stellt einen mit der vorhergehenden zusammenhängenden Costalsaum dar, der bis unter die Discoidalader herabreicht. Der letzte Abschnitt dieser Längsader ist gerade, nicht wie bei bicolor geschwungen, konvergiert ziemlich stark zur Cubitalader und ist doppelt so lang wie der Alsstand der beiden Queradern, der bei bicolor kaum $1 \frac{1}{2}$ mal so lang ist. Die Subcosta ist nur jenseits der Mediastinamündung behaart, die Cubitalader nur an der Wurzel beborstet. -- Schüppchen braun, Schwinger gelb.

Körper ohme Legeröhre und Flügel 4,5 mn lang.

$$
\text { Ophthalmoptera eleyans n. sp. }
$$

6 o , Bolivia (Songo), Veneznela. Ungar. National-Museum und Coll. W in the $m$ in Wien. ${ }^{\text {) }}$ )

Stirne vorne merklich schmäler als 1 Auge; Strieme matt gelbrot, vorne meist in gröfserer Ausdehnung verdunkelt, etwas weifslich bereift, fein kurz und schwarz behaart. Ocellendreieck, Scheitelplatten und oberer Hinterkopf dunkel stahlblau. Clypeus unter den Fühlern, sowie die Wangen rotbraun. Über den Mund-

1) Ortalis gentilis Loew in litt. 
rand und die Backengruben zieht ein silberweilses Querband. Unterer Hinterkopf gelbrot, glänzend. - Fühler rotbraun; ebenso die Taster. Angen im Leben hellgrün mit blauem Schimmer und 2 schmalen roten Querbinden in der Mitte.

Thorax und Schildchen schwarzbraun, metallisch violett schimmernd. Der Rücken zeight in gewisser Beleuchtung einen fuchsroten Reif. Die Gegend des Prothoracalstigmas ist weifs bestäubt.

Hinterleib schwarzviolett, stark metallisch glänzend, auf der Oberseite dicht mit körniger Skulptur versehen. Das fünfte Tergit ist etwas kürzer als das vierte, das sechste fast ganz versteckt. Das erste Glied des Ovipositors hat die Farbe des Hinterleibs, eine herzförmige Basis und ist ungefähr so lang wie breit.

Beine rötlich gelb, Mittel- und Hinterschenkel vorherrschend braun, Vorder- und Hinterschienen an den beiden Enden gebräunt.

Das Flügelgeäder ähnelt in seinem Verlaufe mehr jenem von O. bipnnctata als dem von O. lomgipennis. Die dritte und vierte Längsader divergieren an den Mündungen. Auffallend ist der Verlauf der Radialader, die vor der Mündung eine starke Ausbauchung nach oben hin erfährt. Die hintere Querader liegt dermafsen schief, dafs der untere Winkel der Discoidalzelle stumpf ist, wem auch nicht in gleichem Malse wie bei $O$. longipemis. Flügel in der Wurzelhälfte über der Discoidalader dunkelbraun. Ein kleiner weifser Fleck an der Mündung der Mediastina, ein glashelles Dreieck an der Costa hinter der Subcosta, ein ebensolcher Punkt unter der Mündung letzterer Längsader in der Marginalzelle. Spitzenteil des Flïgels gelb, Randsaum braun, ebenso der Saum eines gebogenen glasigen Streifens im Gelben, der fast parallel mit der Costa in der Nähe der Flügelspitze von der zweiten bis zur dritten Längsader reicht. Hintere Querader breit braun gesäunt. Der glashelle Teil der zweiten Hinterrandzelle reicht mit einer oben abgerundeten Spitze bis an die Cubitalzelle heran und ist schmal braun gerändert. Ein glasheller Fleck liegt jenseits der kleinen Querader in der ersten Hinterrandzelle. Der hintere Flügel ist glashell. Die Subcosta ist mikroskopisch kurz behaart.

Schüppchen bräunlich. Schwinger rotgelb.

Körperlänge ohne Legeröhre und Flügellänge $6 \mathrm{~mm}$. 

6

-
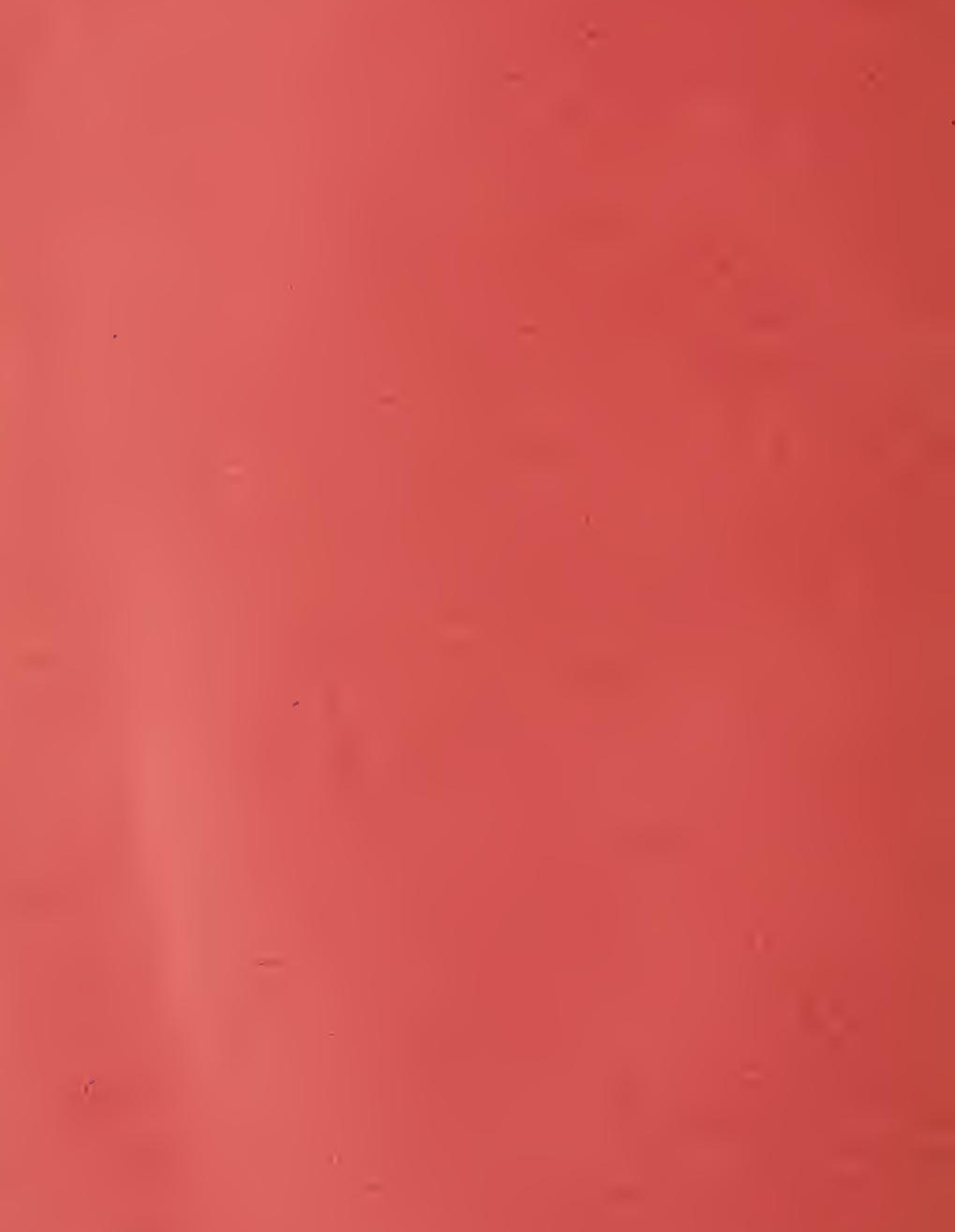

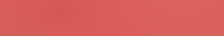

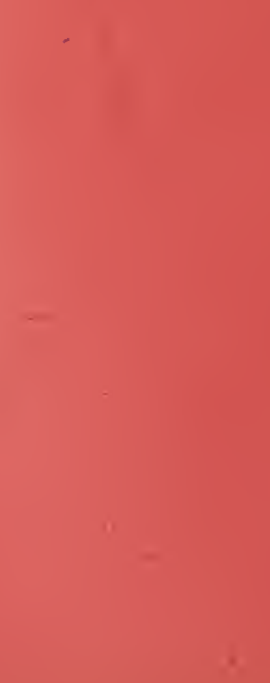

n 

2

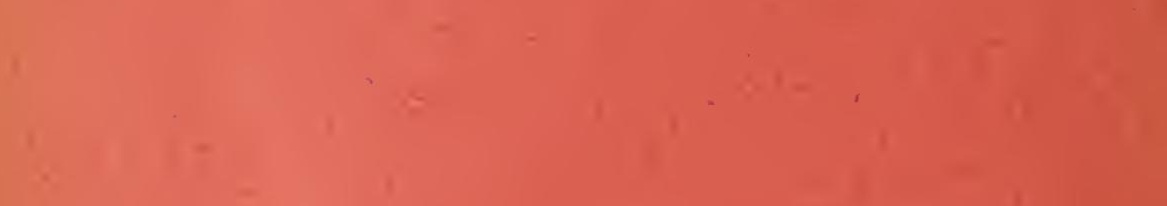

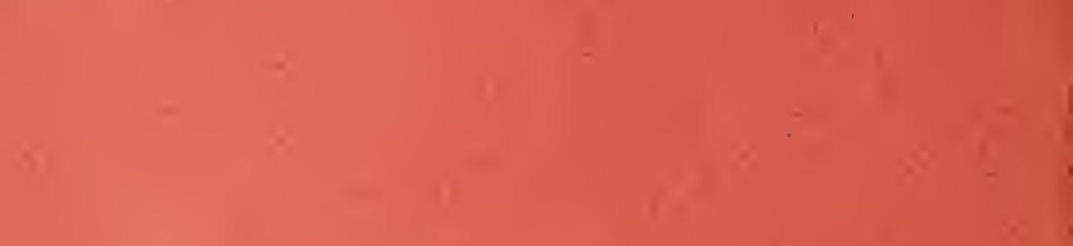

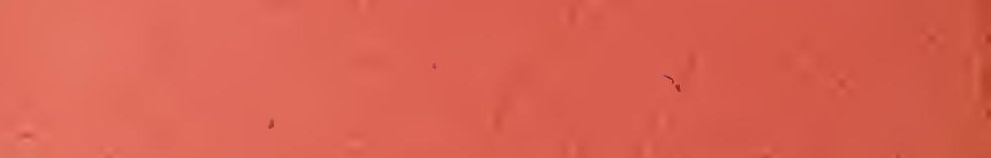

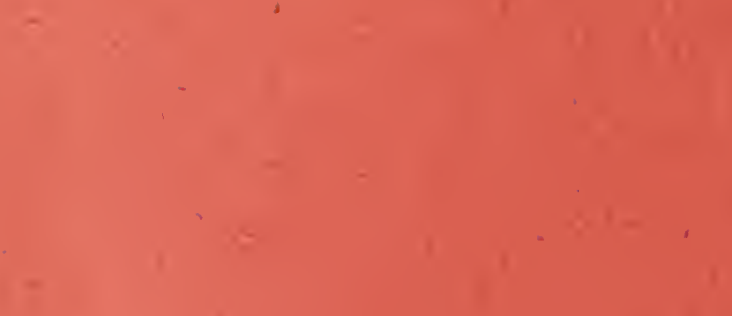

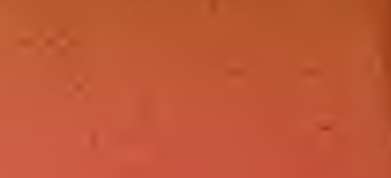

$y+\frac{1}{2}+2$

ta․

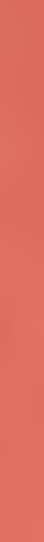

$=-1$

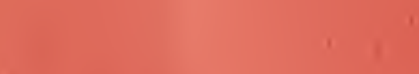
(1) -10

112

$\therefore$ 


\section{Über eine neue paläarktische Cordylurinen-Gattung. (Dipt.)}

\section{Von Friedrich Hendel, Wien.}

Unter den von Leder im Jahre 1892 in der nördlichen Mongolei gesammelten Dipteren des Wiener Hofmuseums fand ich eine Cordylurinenform, welche durch ihre ganz eigentümliche und vereinzelt dastehende Kopfform, sowie durch eine merkwürdige Kombination von Merkmalen der verschiedenen Cordylurinensippen meine Aufmerksamkeit auf sich zog.

Bei Benutzung der B e cke r schen Scatomyziden-Monographie (1894) ergibt sich, dafs unsere Gattung die Beborstung der Sippe Cordylurinae, die Färbung und Tasterform der Hydromyzince und den Legeapparat der Norellinae besitzt. Immerhin läfst sie sich nach der Tabelle für diese „Unterabteilungen" bei den Cordylurinen einreihen, obwohl man dann eigentlich keine Gattung zum näheren Vergleiche heranziehen kann.

Da die Legeröhre an der Spitze feilenartig geriffelt und der sichtbare Endteil unten sogar gedörnelt ist, ganz wie bei der Gattung Norellia, so kann man mit grofser Wahrscheinlichkeit vermuten, dafs die Fliege ihre Verwandlung in Pflanzen durchmacht.

So leben nach Ge r cke (Verh. d. Verein. f. naturw. Unterh. in Hamburg, Bd. 5 p. 68, 1880) die Larven von Norellic spinimana Mg. und Cnemopogon apicalis Meigen im Stengel von Rumex aquaticus L., nach demselben Autor und nach de Meijere (Tijdschr. v. Entomol., vol. 38 p. 33, 1895) jene von Hydronyza livens Fall. minierend in Nupharblättern. Andere Phytophagen unter den Cordylurinen gehören zur Gattung Parallelomma Becker. So zog ich selbst aus Blasen von Majanthemum bifolinm D. C., Polygonatum multiflorum und Paris quadrifolia die Parallelomma media Becker in unserem Schlesien. Parallelomma albipes Fall., sehr häufig in der Wiener Gegend, wurde von $\mathrm{K}$ al t e $\mathrm{nbach}$ aufser aus Polygonatum multiflorum noch aus Orchis mascula, Ophrys fuciflora, Listera ovata und Convallaria majalis gezogen; siehe dessen "Pflanzenfeinde".

$\mathrm{Kal}$ te $\mathrm{nbach}$ zog ferner noch Cnemopogon apicalis Meig. aus der Schafgarbe und seine Cordylura convallariae ans dem Salomonssiegel. Letztere Art hält Brischke unwahrscheinlicherweise für Parallelomma allipes Meig. var. bilineata („Die Blattminierer in Danzigs Umgebung" 1880 p. 52)

Mit diesen Bemerkungen wollte ich nur meine Vermutung, die neue Gattung sei eine phytophage, plausibel machen, ohne eine Vollständigkeit in der Aufzählung anzustreben. 
Nebenbei möchte ich nur anführen, dals nach zweifelhaften Beobachtungen, die $\mathrm{Braner}$ in den "Zweiflüglern des Kaiserl. Museum" Pars 3 p. 93, 1883, zitiert, Norellia spimimana auch aus Larven von Authomyia versicolor und Cnemopogon apicalis aus Raupen von Noctua phraynitilis gezüchtet worden sein sollen. Ich bezweifle diese Angaben sehr!

Was die Kopfform der mongolischen Fliege anbelangt, so hat sie unter rlen Cordylurinen nicht ihresgleichen. Wer unsere Maromychia agrestis Fall. oder noch besser unsere Deriosoma longifacies Rond. zu vergleichen Gelegenheit hat, kann sich an diesen Tachinarien am besten eine Vorstellung vom Kopfe und Untergesicht der unten beschriebenen Art machen. Die Abbildungen, die Bra ur und Bergenstam m im ersten Teile der "Vor"arbeiten zu einer Monographie der Muscaria Schizometopa" auf Tafel VII in den Figuren 146 und 148 von den 2 genannten Arten gibt, ebenso wie die Figur 147, Megaprosopus rufiventris Mcqu. aus Mexiko, veranschaulichen aber auch schon ziemlich gut die für eine Corlylurine abweichende Clypeusgestaltung.

Ich nenne die neue Gattung

\section{Mirocordylura n. gen.}

Stirne wagrecht, so breit wie die doppelte Augenbreite (o oder noch etwas darüber ( $(q)$, parallelrandig. Die Scheitelplatten sind die Hälfte der dazwischenliegenden Strieme breit $\left(\sigma^{\top}\right)$ oder schmäler (o) und gehen nach vorne zu allmählich in die etwas schmäleren Wangenplatten ohne Absatz über. Striome unbehaart, oben durch das eindringende Ocellendreieck, das einen deutlichen Höcker trägt, ziemlich stark gegabelt. Der Vorderrand der Strieme und der Stirne also überhaupt ist wulstig über die deutlich sichtbare Lunula anfgestülpt. Wangen ein Drittel des ganzen Untergesichtes breit. Im Profile tritt die Stirne wegen der breiten Wangen merklich vor die Augen vor und bildet mit dem zurückweichenden Untergesichte einen spitzen "Stirnwinkel“. Die Stirnspalte läfst, wie schon gesagt, oben eine dentliche Lunula über den Fühlern frei und biegt dann in 2 fast parallelen Ästen herab, knapp neben den Gesichts- (Facialia) und Backenleisten verlaufend. Ihre Enden liegen in der Höhe des unteren Mundrandes und nicht, wie gewöhnlich, in jener der Vibrissenecke. Die Gesichtsleisten sind scharf und wulstig abgesetzt, verengen den Clypeus etwas in seiner Mitte und stofsen dort mit den etwas nach oben konvergierend aufsteigenden Backenleisten in einem deutlichen Vibrisseneck zusammen. Der von diesen Leisten eingeschlossene Clypeus erhält cladurch eine biskuitartige Form. Charakteristisch ist also, dals das Vibrisseneck hoch über dem unteren Mundrande in der 
Mitte des Clypeus liegt, dafs dieser dort etwas verengt wirl und unter dieser Stelle dann zwischen den Peristomalien nach hinten stärker als der obere Teil zurückweicht. Der zwischen den Facialien liegende Teil ist etwas vertieft, im Profile schwach konkav, der Quere nach sanft gewölbt. Der zwischen den Backenleisten liegende Teil ist fast eben und könnte für den inneren Nundrand gehalten werden, wenn nicht die Lage des deutlich vortretenden Prälabrums den untersten äufseren Mundrand vom Vibrisseneck weit nach abwärts verlegen würde. Auch die stärkere Chitinisierung dieses als Epistom zu bezeichnenden Teiles spricht für meine Ansicht.

Hält man an der normalen Lagenbeziehung zwischen den Enden der Stirnspaltenäste und den Vibrissenecken als den unteren Enden der Facialien fest, dann müfste man in diesem Falle die Gesichtsleisten bis zum untersten äufseren Mundrande annehmen und dort erst die Peristomalien beginnen lassen. Eine Begründung scheint diese Deutung durch die verschiedene Richtung der Leistenborsten $\mathrm{zu}$ erhalten. Über dem Mundrande, also noch innerhalb der Spaltenäste, sind die 6 nicht ganz gleich starken Vibrissenborsten nach unten und einwärts gebogen, unterhalb dieser Grenzen jedoch nach oben und aufsen.

Die Backen sind fast so breit wie der vertikale Augendurchmesser und verjüngen sich allmählich nach unten, so dafs das Kopfprofil durch ein mit der Spitze nach unten gerichtetes Dreieck schematisiert werden kann. Der behaarte Teil der Backen ist ganz auf den unteren Hinterkopf zurückgedrängt und unten nur auf die beborsteten, zum Vibrissenerk aufsteigenden Backenleisten beschränkt. Den gröfsten Teil nehmen also die nackten, hiel flachen und ebenen Backengruben (mediana R. D.) ein, die mit den Wangen zusammenfliefsen. Die vordere Grenze des behaarten unteren Hinterkopfes läuft hinter dem Auge fast lotrecht nach abwärts zur tiefsten Stelle des Kopfes. Der Hinterkopf ist gewölbt, oben mit den fast flachen Cerebrale weniger, unten stärker. Dort tritt er auch merklich hinter den Augen hervor.

Beborstung des Kopfes: Wangenplatten meist mit 6 nach vorn und einwärts gebogenen unteren Frontorbitalborsten (= Striemenborsten oder Frontalborsten bei Townsend u. a.); Scheitelplatten mit 3 oberen Frontorbitalborsten, die mit den unteren nicht in einer Reihe, sondern etwas gegen den Angenrand hin gerückt stehen. Die oberste derselben ist nach auswärts, die vorderen 2 sind nach vorn gebogen. Letztere würden den mittleren Frontorbitalborsten $\mathrm{T}$ own sends, und nur die oberste den "oberen" Frontorbitalborsten dieses Autors entsprechen ${ }^{1}$ ). -

2) Ch. T. Townsend, The taxonomy of the Muscoïlean Flies, 1908. 
Ocellarborsten lang und kräftig, nach vorn divergierend. Sie stehen hinter der ersten Ocelle. Scheitelborsten stark: die inneren gekreuzt, die äufseren divergierend. Die auffallenden langen Postvertikalen stehen wenig hinter den Vertikalen, an der Basis genähert und mit der Spitze sehr stark nach aufsen gebogen. Nur die Occipito-Zentralborste, das ist jene kleine Borste gleich unter den inneren Scheitelborsten, vorhanden.

Fühler kurz, stark geneigt, etwas über der Augenmitte inseriert nnd dem unteren Augenrande ungefähr gegenüber endend, an den Wurzeln stark genähert. Erstes Glied klein, aber deutlich; zweites oben mit dem Innenrande das dritte etwas überragend und dort unter kleineren mit einer langen abstehenden Borste verselren; drittes Glied elliptisch, am Oberrande schwach konkav, ungefähr zweimal so lang wie breit. Die nackte Borste steht im Wurzeldrittel des Oberrandes und ist an der Basis spindelförmig verdickt.

Taster auffallend lang und stark verbreitert, namentlich an der Unterseite dicht behaart. Rüssel schlank, stark chitinisiert (Kinn) und mit kleinen, zurückgeschlagenen Labellen.

Thoraxrücken von oben besehen rechteckig, wenig länger als breit. Quernahtäste etwas vor der Mitte senkrecht aufsteigend, in der Medianlinie ein merkliches Stück voneinander getrennt. Schildchen in gleicher Ebene liegend, eiförmig zugespitzt, ca. 1/4 des Rückens lang, oben gewöllbt und kurz behaart. Postalarcallus deutlich abgesetzt.

Pleuren ziemlich gleichmäfsig gewölbt, Mesopleuren vorn nicht viel eingedrückt.

Beborstung; Rücken: 3 äufsere Dorsocentrale hinter, 2-3 vor der Naht, 1 Präscutellarpaar; 2 Längssreihen kurzer Härchen in der Medianlinie (Acrosticalbörstchen); 2 Humerale, 1 Posthumerale oben, 1 Präsuturale, 2 Notopleurale, 1 Borste auf dem Postalarcallus, 2 Borsten davor in einer Linie zur Präsnturalen und 2 Borsten darunter, weiter nach aufsen zu. Also aufser der Postalaren noch 4 Supraalare in 2 Reihen. - 1 Schildchenborsten, die an der Spitze gekreuzt. - Je 1 starke Prothoracalund Stigmaticalborste; 3 Mesopleurale oben, 1 Sternopleurale oben und hinten. Meso- und Sternopleuren behaart.

Beine von mittlerer Länge, stark, mit etwas verdickten Schenkeln. Vorderschenkel posterodorsal mit 2, posteroventral mit 1 Längsreihe langer Borsten unter der besonders aufsen und unten ziemlich dichten und langen Behaarung. Mittelschenkel unten dicht kurzhaarig, vorn mit einer Längsreihe kurzer Borsten und posterodorsal mit einer starken Borste vor der Spitze. Hinterschenkel vorn mit einer Reihe längerer Borsten und an der Spitze darüber noch ca. 3 Borsten anterodorsal. Anteroventral jenseits 
der Mitte 3-4 lange Borsten. - Mittel- und Hinterschienen am Ende mit einem Kranze von 4-5 längeren und einigen kürzeren Endspornen (darunter die Präapicalborste). Aufserdem: Vorderschenkel ad 3-4, pd 1 ( $\left.\sigma^{7} 0\right)$, pv 2; Mittelschenkel ad 2, pd 1 ( $\left.\sigma^{7} 0\right)$, pv 1; Hinterschenkel ad 3, pd 3 Borsten. Vorderhïften breit und rel. kurz, vorn in der Unterhälfte beborstet. Fülse normal. Beim or sind die Klauen länger als beim $q$.

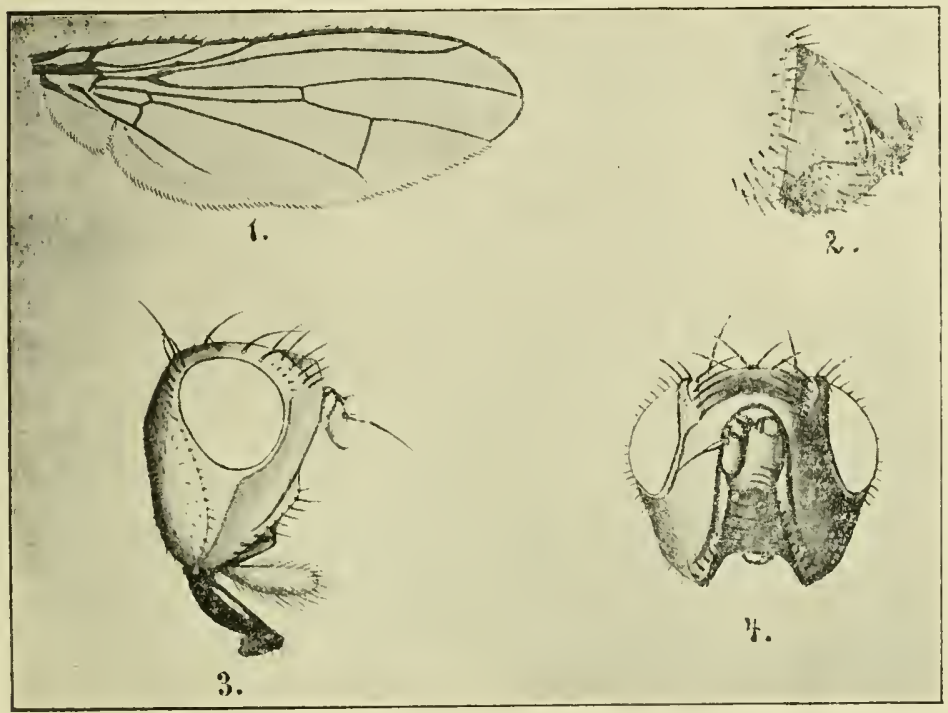

Hinterleib etwas länger als der Thorax, beim or streifenförmig mit kolbigen Genitalien, fünfringlig, beim o schlank elliptisch, sechsringlig. Das fünfte Segment des ơ ist stark verlängert; auf dasselbe folgen die 2 Genitaltergite. Der erste derselben ist am linken Seitenrande asymmetrisch abgeschnitten, der zweite wird unten durch 2 grofse gewölbte Klappen, wie gewöhnlich bei den Cordylurinen, völlig geschlossen.

Beim o sind die Ringe mit Ausnahme des kürzeren sechsten von ziemlich gleicher Länge. Den Legeapparat zeigt die Abbildung. Er stellt eine Sägevorrichtung dar. - Randmacrochaeten sind nur an den hinteren Hinterleibsringen länger und stärker entwickelt.

Flügeladerung aus der Abbildung ersichtlich. Ich möchte nur hinzufügen, dafs die Costa sehr zart gedörnelt und vor der Nediastina abgebrochen ist. Gleich hinter der Wurzel und etwas jenseits der Schulterquerader ist sie verdünnt.

Die typische und einzige Art heirst 
782 Hendel, Uber eine neue paläarktische Cordylurinen-Gattung.

$$
\text { Mirocordylura longifacies n. sp. }
$$

Vorherrschend matt rötlich-ockergelb, auch die Flügel wïstenfarbig. Stimstrieme mehr rot, das Untergesicht nelır gelb. Wangen-, Scheitel- und Ocellenplatten heller bestäubt, ebenso der Hinterkopf. Fühler und Taster gelb. Rüssel pechbraun. Borsten schwarz. Haare der Taster und des unteren Hinterkopfes gelb. Jederseits aine Stelle am Scheitel, auf welchen die Vertikalborsten stehen, der Zentralteil des Thoraxrückens, der untere Teil der Sterno- und Hypopleuren, die Mitte des Hinterrückens, sowie die Tergite des Abdomens, letztere aber in verschiedener Ausdelnung, vou schwärzlicher Grundfarbe, die aber mit gelblichem Reife überleckt ist. Gewöhnlich sind nur die Vorderränder der Tergite 2 -5 dunkel, seltener dehnt sich diese Färbung fast bis zum Hinterrande aus. - Beine rötlichgelb, ebenso die Schüppchen und Schwinger. Flügel intensiv rotgelb tingiert. Behaarung des Körpers und der Beine schwarz, nur an den Vorderhüften und Schüpprehen gelblich.

Körper mit den Genitalien 7-9 mm, Flügel $6-8 \mathrm{~mm}$ lang.

1. Flïgel.

$$
\text { Erklärung der Abbildungen. }
$$

2. Ovipositor hinter den sechsten noch sichtbaren Segmente. Das basale Doppelsegment wird für 2 Ringe gezählt. Unter den behaarten Cerci des Endsegmentes sieht man den gedörnelten Teil. Unmittelbar darunter seine aufsen feilenartig geriffelte Scheide.

3. Lopf des $q$ im Profil.

4. liopf iles $q$ von vorn. 




\section{Namensänderung. (Dipt.)}

Herr Dr. H. A. Kra u $\int \mathrm{s}$ in Tübingen, der bekannte Orthopterologe, machte mir die freundliche Mitteilung, dafs schon C. Stå 1 in der Recensio Orthopt. Vol. 1 p. 35 und 56 (1873) ein Acridiiden-Genus Goniaea aus Australien aufgestellt hat. Dies war mir entgangen. Ich nenne daher mein gleichnamiges Pterocallinen-Genus, das ich im Beihefte dieser Zeitschrift (1909) p. 71 beschrieb, Goniaeola.

Noch einige Druckfehler meiner im Beihefte d. J. erschienenen "Übersicht der Pterocallinen" möchte ich richtig stellen. Seite 14, Zeile 6 von oben: "Sibiria" statt "Sibirica".

" 17, 8 " 8 "N. Amer." statt "W. A. .

52: „Pt. interrupta n. sp." statt „Pt. interruptu“.

" 55, bei der Art Pt. picea, n. sp. lies ${ }_{n}$ Kopf wie bei 59. Pt. nigripes" anstatt ${ }_{n}$ Kopf wie bei $14^{4}$.

Friedrich Hendel. 



\title{
Beitrag zur Kenntnis der Ulidiinen (Dipt.).
}

\author{
Von Friedrich Hendel, Wien.
}

Sonderabdruck aus der „Wiener Entomologischen Zeitung“, XXVIII. Jahrgang 1909. 



\section{Beitrag zur Kenntnis der Ulidiinen (Dipt.).}

Von Friedrich Hendel, Wien.

Gern hätte ich sämtlich bisher bekannt gewordene Ulidiinen in ähnlicher Weise wie die I'terocallinen in einer Arbeit zusammengefaßt, da ich aber die Loe w'schen Typen nicht vergleichen konnte, blieb mir nur der von mir eingeschlagene Weg ïbrig. Ich schloß also vorderhand die Gattung Ulidia Meig. aus meinen Betrachtungen aus und wandte mich nur jenen Gattungen zu, wo mir kein Typenmangel Schwierigkeiten entgegenstellte. So war es mir dennoch möglich, Übersichten iiber alle artenreichen Genera zu geben und unsere Kenntnis durch zahlreiche neue Formen, fuir die ich auch einige neue Gattungen errichten mußte, zu erweitern.

Eine „Synopsis der bisher bekannten Timia-Arten" publizierte ich 1908 in der Zeitschr. für syst. Hymen. und Dipterol. Leider hatte ich damals die Empyelocera-Arten nicht mit aufgenommen. Nach meiner jetzigen Erkenntnis sind nämlich die Arten beider Gattungen nicht von einander zu trennen. Loew kannte gar keine echte Timia-Art und vergleicht seine Gattung Empyelocera deshalb auch nur mit Chrysomyza.

Eine Auseinandersetzung der Euxesta-Arten erschien in den Annalen des ungar. Nation. Nuseums 1909 p. 151-172 und eine „Revision der Chrysomyza-Arten" in Zoolog. Anzeiger 1909 p. 612-622.

Hier lasse ich die Bearbeitungen der restlichen Gattungen folgen, über deren Arten ich etwas Neues zu sagen habe. Bezüglich der ausfïhrlichen Gattungsbeschreibungen und der Abbildungen aller hier beschriebener Arten verweise ich auf die Genera Insectorum, Subfam. Ulidiinae.

Zum Schluf möchte ich einer angenehmen Pflicht geniige leisten, indem ich allen jenen Dank sage, welche meine Arbeit durch Ühersendung von Material förderten. Von öffentlichen Museen ist es aufer denen von Wien und Budapest das United States Nat.Museum in Washington, von dem ich durch die hoch anzuschlagende Vermittlung der Herren Dr. L. O. II oward und D. W. Coquillett alle von mir erbetenen Dipteren zum Studium erhielt. Man sicht also, daß es doch noch modern denkende Musealverwaltungen gibt!

Von Privatsammlungen standen mir die des Herrn W. S c b n u se, mit den in Bolivia und Peru gesammelten Fliegen und jene des Herrn Prof. M. Bezzi, welcher mir auch die von A. A. Barbiellini in Brasilien erbeuteten Clidiinen zur Verfügung stellte, zu Gebote. 


\section{Die Acrosticta-Arten.}

Beine rotgelb, nur die Fußspitzen braun. Subkostalzelle und ein Spitzenfleck des Fliigels, der vor der Spitze der Radialader beginnt und zwischen der Kubital- und Diskoidalader endet, braunschwarz. Kostalzelle nur lichtbraun. Körper matt dunkelgrün.

Acr. fulvipes Coquillett, Nordamerika.

Beine nie ganz rotgelb, höchstens die Vorderschenkel, sonst rotbraun bis schwarz

1. Die ersten drei Hinterleibsabschnitte blutrot. Ovipositor metallisch schwarz. Schwingerkopf schwarz. Der braunschwarze Spitzenfleck des Fliigels reicht unten an die Diskoidalader hinan. Beine ganz schwarz. Kostal- und Subkostalzelle braunschwarz.

Acr. dichroa Loew, Nordamerika.

Die ersten drei Abdominalsegmente nicht blutrot

2. Schwingerkopf hell, gelblich oder weiblich. Die rote Stim mit kleinen Hohlpunkten, die in der Stirnmitte am tiefsten sind, bedeckt. Die Umwallungen derselben fließen zu Querrunzeln zusammen

3

Schwingerkopf schwärzlich. Die schwarzbraune Stirn von hinten bis vorn gleichmäßig dicht mit großen, tiefen Hohlpunkten bedeckt, die keine Querrunzeln erzeugen. Vorderfersen rötlich. Kostal- und Subkostalzelle gleichmäßig schwarzbraun

5

3. Vorderfüße ganz schwarz. Der Spitzentleck des Flïgels endet zwischen der dritten und vierten Längsader

Vorderfersen, mit Ausnahme der Spitze, rötlich. Der Spitzenfleck des Fliigels berïhrt hinten die Diskoidalader. Kostalund Subkostalzelle ganz schwarzbraun. Hinterleibsende und Ovipositor hell gelbrot.

Acr. ruficauda n. sp.

4. Kostal- und Subkostalzelle gleichmäßig braunschwarz. Drittes Abdominaltergit des $Q$ den größten Teil des Hinterleibes einnelımend, die folgenden Segmente verdeckend. Vorderschenkel rotbraun bis schwarzbraun.

Acr. scrobiculata Loew. Kostalzelle nur an der Wurzel braun, sonst fast glashell; Subkostalzelle braun. Drittes und viertes Abdominalsegment des o fast gleichlang. Vorderschenkel rotgelb.

Acr. pallipes Grimshaw.

5. Letzter Abschnitt der Diskoidalader so lang wie der vorletzte. Acr. foveolata Loew. Letzter Abschnitt der 4. Längsader ein- und einhalbmal so lang wie der vorletzte.

Acr. profunda n. sp. 
Anmerkung: Acrosticta bicolor Cresson, Trams. Americ. Ent. Soc., Vol. 32, p. 285, Tafel 6, Fig. 8-10 (1906), ist lieine AcrostictaArt, sondern gehört einer nenen Gattung an. Abweichend ist nicht nur das Kopfprofil, sondern auch die glatte Stirn, der "gekörnte" Hinterleib u. a. m.

\section{Acrost. scrobiculata Loew.}

Loew, Berl. Entom. Zeitschr. Vol. XI, p. 293 (1867).

Mir liegen die Loew schen Typen der Kollektio Winthem vor'; es sind dies zwei $q$ aus Brasilien. Ferner habe ich noch ein $q$ untersucht, das Herr W. Schnuse in Peru (Pichis; Dezember) sammelte, und eines aus Brasilien (Fruhstorfer).

Dieses letztgenannte Stïck weicht nur in der Beinfärbung etwas ab, indem die Vorderhïften und Vorderschenkel nicht wie bei den Typen nur teilweise, namentlich an der Innenseite, rötlich sind, sondern mit Ausnahme eines dunkleren Wisches vor der Spitze an der Außenseite ganz hell rotbraun gefärbt sind. Anch das dritte Antennenglied ist fast ganz hellrot und die Taster an der Spitze etwas rötlich.

Die Loewsche Beschreibung bedarf nm noch in bezug auf die Länge der Abdominaltergite eine Ergänzung. Das auf das basale Doppelsegment folgende dritte Tergit ist nämlich so stark verlängert, dals es die folgenden Tergite fast ganz ïberdeckt und unmittelbar an die Legeröhre zu grenzen scheint.

\section{Acrost. pallipes Grimshaw.}

Grimshaw, Fauna Hawaiiensis, Dipt., p. 44 (1901).

Diese auf den Hawaiischen Inseln entdeckte Art habe ich in $8 \delta^{\circ}$ O aus Bolivi a (Songo und Mapiri; Mai) und Peru (Ucayalifluf; Oktober) vor mir. Ungar. Nation. Museun und Koll. Schnuse.

Der Acr. scrobiculata Loew sehr ähnlich und in allem mit folgenden Unterschieden gleich: Vorderhiuften und -schenkel ganz hell rotgelb. Das auf das basale Doppelsegment folgende dritte Abdominaltergit nur wenig länger als das folgende vierte, das an den Ovipositor zu grenzen scheint. Das erste Glied des letzteren kurz, breit herzförmig, kamm länger als breit und an der Wurzel viel breiter als an der Spitze. Bei scrobiculate ist es länglich oval, schlank, ein und einhalbmal so lang wie in der Nitte, wo die größte Breite ist, breit und an der Wurzel kaum breiter als an der Spitze. 
Die Kostalzelle ist nur an der Wurzel dunkler braun, sonst ziemlich hell ausgewaschen. Die Subkostalzelle ist dann wieder etwas gesättigter tingiert. Der dunkelbraune Spitzenfleck des Flïgels hat die gleiche schiefe Lage und dieselbe Begrenzung wie bei der Loewschen Art, nur ist er kleiner und schmäler und erfüllt nur die äußerste Spitze der Marginalzelle, meist derart, daß die Kosta dort nicht ganz berïhrt wird.

\section{Acrost. ruficauda n. sp.}

9 ठ $q$ aus Peru (Vilcanota) und Bolivia (Mapiri; Jänner). Ungar. Nationalmuseum und Koll. Schnuse.

Stirn nicht wie bei scrobiculata und pallipes vollkommen parallelrandig, sondern vorn deutlich verschmälert und dort dann schmäler als eine Augenbreite. Strieme glänzend gelbrot, hinten manchmal dunkler rotbraun. Der Vorderrand derselben ist nur schwach mit Hohlpunkten versehen, die Mitte zeigt einige deutliche Querrunzeln. Die Stirn ist also nicht so stark grubig-runzelig wie bei scrobiculata. Scheitelplatten und Ozellendreieck glänzend blau, Augenränder weil gesäumt. Wangen und Backengruben rot. Klypeus metallisch blaugr'ün, oben weißlich bestäubt, Epistom oft, Prälabrum meist gelbrot, mit Netallschimmer. Taster braun, an der Spitze rötlich. Fühler rot, drittes Glied derselben gegen die Spitze zu dunkler.

Thorax und Hinterleib wie bei den anderen Arten gefärbt.

Hiiften und Beine glänzend pechbraun. Vorlerhiiften und -knie etwas rötlich; Schenkelspitzen der hinteren Beinpaare sowie deren Füiße rötlich. Vorderfüße mit Ausnahme des roten Metatarsus schwärzlich.

Hinterleibssegmente und Ovipositor wie bei scrobiculata geformt. Der Hinterrand des langen dritten Tergits, die darunter versteckten folgenden und das Basalglied der Legeröhre brennend rotgelb.

Das dritte 'Tergit zeigt sehr feine Querrillen, die wenig auffallen und ist beim $\sigma^{\pi}$, ebenso wie bei pallipes Grims., ungefähr so lang wie die folgenden zwei Tergite 4 und 5 zusammengenommen.

Am Flïgel fällt uns die abgerundete Spitze, an der nicht wie gewöhnlich die 4., sondern die 3. Längsader mïndet, ferner die besonders lange Subliostalzelle und der lange letzte Abschnitt der Diskoidalader auf. Kostal- und Subkostalzelle gleichmäßig schwarzbraun. Der schwarzbraune Spitzenfleck ist unter allen Arten

am gröbten und berührt unten die Diskoidalader. Er erfüllt schief die Spitze der Marginalzelle, die Hälfte des Kostaabsehnittes zwischen 
den Längsadern 1 und 2 beriihrend, maclit innen unter der Radialader eine Stufe und steht dann auf den Längsadern 3 und 4 senkrecht. Schwingerkopf gelblich oder rötlich.

Körper ohne Legeröhre und Flügel $3-4 \mathrm{~mm}$ lang.

\section{Acrost. profunda n. sp.}

1 đ’ aus Bolivia (Songo).

Diese Art und Acrost. foreolata Loew (Type Loews aus del Koll. Winthem) haben außer den im Punkte 2 der Bestimmungstabelle angegebenen Merkmalen noch folgende gemeinsam: Ihr Profil des Ḱlypeus ist fast gerade, nicht so deutlich konkav wie bei den anderen Gattungsgenossen; das dritte Antennenglied ist etwas länger und schmäler, oben und unten fast geradlinig begrenzt; die Stirn ist oben etwas breiter und im allgemeinen viel rauher behaart.

Die von Loew gegebene Beschreibung seiner Acr. foveolata paßt mit folgenden Unterschieden vollständig auf die neue Art.

Das Ozellendreieck deutlich stahlblau. Bei foveolata steht die kleine Querader auf der Mitte der Discoidalzelle nnd ist der letzte Abschnitt der Discoidalader mit dem vorletzten gleich lang. Bei profunda dagegen liegt die kleine Querader deutlich jenseits der Discoidalzellenmitte und ist der letzte Abschnitt der 4. Längsader gut ein- und einhalbmal so lang wie der vorhergehende. Auch der braune Spitzentleck des Flügels ist länger und breiter, innen aber anch fast senkrecht und nicht schief begrenzt. $\mathrm{Er}$ erfüllt einen größeren Teil der Marginalzellenspitze als bei foveolata und reicht unten fast an die Discoidalader hinan. Die 'lrennung bildet nur ein etwas hellerer Schatten.

Von den 5 vor dem Hypopyg sichtbaren Segmenten des $\sigma^{\top}$ Abdomens ist das 4. etwas verlängert. - Körper und Flïge $4 \mathrm{~mm}$ lang.

Bei Acr. foveolata Loew $\&$ (das $\sigma^{\pi}$ kenne ich nicht) ist las dritte Hinterleibstergit zweimal so lang als das folgende vierte, das an den Ovipositor zu grenzen scheint. Das erste Glied der Legeröhre hat den Cmriß eines gleichseitigen Dreieckes mit etwas konvexen Seiten.

\section{Cenchrometopa (n. g.) curvinervis $\mathrm{n}$. sp.}

1 O aus Peru (Urubanbatlub; September). Koll. Schnuse.

Stim ein- und einhalbmal so breit wie ein Auge, rauh schwarzharrig, fast parallelrandig, glänzend, dunkelrotbraun, mit Ausnahme 
der glatten Scheitelplatten dicht mit großen und relativ tiefen Hohlpunkten besetzt, also grubig uneben. Zerebrale rotbraun, Scheitelplatten und oberer Hinterkopf glänzend schwarz. Wangen, Backengruben und ein lanzettförmiger Längstleck zwischen den Fühlern goldfilzig. Lunula sonst glänzend rotgelb. Der unter den Fiihlern ausgehöhlte Klypeus dunkelbraun, etwas gelblich bestäubt. Facialien neben der Stirnspalte dunkel rotbraun. Unterer Hinterkopf rotgelb, matt bestäubt. Die kurzen Fühler sind mit Ausnahme des schwarzen ersten Gliedes rostrot. Prälabrum dunkelbraun. Die bei dem Stiicke allein sichtbaren, verbreiterten Tasterspitzen sind rot, weibschimmernd. Riïssel schwarzbram. Augen wie poliert, einfarbig rotbraun.

Thorax und Schildchen glänzend blauschwarz; ein Streifen quer vor dem Schildchen, die Präsuturaldepression und ein verwaschener Streifen längs der Mesopleuralnaht herab auf die Pleuren, bis zu den Mittelhiiften hellgelb filzig. Die Pleuren sind iibrigens fast ganz mit einem gleichen Tomente spärlich bedeckt und schimmern dann bei gewisser Beleuchtung an dieser oder jener Stelle.

Vorderhüften rotbraun, weiß schimmernd. Beine glänzend metallisch blauschwarz, an den Schenkeln hie und da weißlich tomentiert, die äußersten Knnie rotbraun. Alle Fißße, mit Ausnahme der dunkleren Spitzen, hell rotgelb.

Vorderbeine etwas verkiirzt. Schienen seitlich kompreß, etwas gebogen und unter der Iitte am breitesten.

Hinterleib glänzend violett schwarz. Erstes Glied des Ovipositors spitz dreieckig, etwas länger als breit.

Fliigel glashell. Kostalzelle nur von der Flïgelwurzel an bis etwas iiber die Schulterquerader hinaus dunkelbraun. Subkostalzelle schwärzlich. Die Fliigelfalte darunter bis zur Gabel der 2. und 3. Längsader verwaschen braun gefärbt. Schief oben an der Flïgelspitze liegt ein großer dunkelbramer Fleck, der bis in die Mitte zwischen der 3. und 4. Längsader hinabreicht. Seme innere Grenze ist schief, macht an der Radialis eine Stufe und beriihrt ungefähr die Mitte des Kostaabschnittes zwischen der Subkosta und der Radialis.

Schiippchen gelb, Schwinger schwärzlich.

Körper ohne Legeröhre $65 \mathrm{~mm}$, Flïgel $6 \mathrm{~mm}$ lang.

Anmerkung: Cenchrometopa hat folgende wesentliche Ierkmale: grubige, seln breite Stirn, ausgehöhltes Untergesicht, dritte und vierte Längsader vor der Niündung nach aufwärts gebogen und merklich vor der Flïgolspitze mïndend. 


\section{Siopa (n. g.) longicornis n. sp.}

\section{$8 \delta^{T} P$ aus Peru (Neshagua; Oktober), Koll. Schnuse.}

Stirn merklich breiter als ein Auge, parallelrandig, samt dem Cerebrale rotgelb oder gelbrot. Der iibrige Hinterkopf ist sonst schwärzlich, mit metallisch grïnem Schimmer, der sich auch auf die Scheitelplatten hinüberzieht. Die glänzende Stirn ist mit Ausnahme der glatten Scheitelplatten dicht mit Hohlpunkten besetzt und daher grubig uneben. Ozellenhöcker schwarz. Ein Ozellendreieck reicht mit der Spitze bis zum Stirnvorderrande. Seine Schenkel sind in der oberen Hälfte als schwarze Linien, auf welchen etwa ein Dutzend kurze schwarze Börstchen stehen, besonders gekennzeichnet. -- Wangen und Backengruben gelb, seidenartig weiß schimmernd. Stirn im Profile kaum vortretend. Klypeus mit einer scharfen Querrinne in der Mitte, im Profile also winkelig gebrochen, mit ziemlich stark vortretendem Epistom. Der Klypeusteil iiber der Querfurche weiß bereift, zwischen den Fühlern braum. Der schmale Streifen der Lunula gelb. Das glänzend gelbe Epistom zeigt unter der Furche seitlich je einen braunen Fleck. Unterer Hinterkopf rotgelb, dicht weiß bestäubt. An der Grenze desselben gegen die Backengrube liegt ein bräunlicher Fleck gerade unter dem Auge. Prälabrum und Taster gelb. Riissel braun. - Fühler länger als das Untergesicht, mit den Spitzen den unteren Mundrand ïberragend. Das besonders stark verlängerte 3 . Glied fast linear und ungefähr viermal so lang wie breit.

Thorax und Schildchen dunkel metallisch blaugrün, mit blauen und violetten Reflexen. Rücken, mit Ausnahme des Schildchens, durch ein gelbliches Toment ziemlich matt, mit einem unmittelbar hinter der Quernaht befindlichen dunkelbraunen Bogenquerbande, welches sich seitwärts am Präalarcallus ziemlich verbreitert und eine Mittellängsstrieme bis zum Schildchen nach hinten aussendet. Pleuren oben weniger bereift als unten. - Hinterleih stark glänzend goldgrün. Diese Farbe ist jedoch nur seitlich sichthar; breite Tergithinterränder und Riickenfläche sind dunkel blauviolett. Das erste Glied des Ovipositors ist dem Ruicken gleichfarbig und hat die Gestalt eines etwas ahgeschnittenen, zugespitzten Dreieckes.

Vorderschenkel und die Spitzenhälfte der hinteren Schenkelpaare gelbrot, die Wurzelhälfte der letzteren glänzend pechbraun. Hiiften und Schienen sowie die Vorderfüße etwas lichter, mehr rötlich braun. Die Füßje der hinteren Beine hell gelblich, nur gegen die Spitze etwas verdunkelt. 
Fliigel hyalin, nur gegen dunklen Grund betrachtet etwas rauchbraun tingiert; die Wurzel erscheint dann leuchtend gelb. Fliigelvorderrand von der Wurzel bis inklusive Subkostalzelle schwarzbraun. An der Spitze des Flïgels liegt ein großer schwarzbrauner Fleck, der unten die Diskoidalader beriihrt. Seine schiefe Innengrenze liegt an der Kosta in der Verlängerung der hinteren Querader, unten aber etwas jenseits der Mitte des letzten Diskoidalalderabschmittes.

Schwinger und Schiippchen gelb.

Körperlänge $5-7 \mathrm{~mm}$, Flïgel $4-5.5 \mathrm{~mm}$.

Anmerkung: Siopa steht der Gattung Acrosticta nahe, hat aber ein verlängertes lineares drittes Antennenglied und ein bis nach vor'n hin reichendes, an den Seiten mit Börstchenreihen versehenes Ozellendreieck.

\section{Die Gattungen Chaetopsis Loew und Stenomyia Loew.}

Ist es schon nach den Typen beider Gattungen schwer, durchgreifende Unterschiede zwischen denselben zu finden, so verwischen die neuentdeckten Formen auch die spärlichen Differenzen vollends.

Chaetopsis acnea Wied. hat einen, durch eine spitzwinkelig gebrochene Querader an der Analzelle gebildeten spitzen, ziemlich lang iiber die Zelle vortretenden Zipfel, eine im Profile nur wenig vorspringende Stirn und einen stumpfen Stirnwinkel, ferner eine ar- Aralfalte am Fligel.

Stenomyia tenuis Loew dagegen hat eine Analzelle, die vorm durch eine nur im stumpfen Winkel gebogene Querader begrenzt wird und deren Zipfel wenig spitz ist und nur etwas iiber die Zelle vorsteht; ferner eine im Profile stärker vortretende Stirn und bei stärkerem Zurückweichen des Klypeus auch einen spitzen Stirnwinkel. Eine Anatfalte fehlt.

Durch die Fühlerform werden keine generellen Unterschiede bedingt.

Die oben angegebenen Unterschiede in der Kopf- und Flügelbildung werden durch die vier neuen Arten vollständig ausgeglichen, so dal ich beide Gattungen in eine vereinigen muls.

Die die Analzelle vorn abschließende Querader ist bald stärker, bald schwächer in Winkel gebogen und steht bald steiler und bald schiefer. Der Stirnwinkel ist bei der einen Art spitz, bei der anderen ein rechter, bei der dritten ein stumpfer. Die Awalfalte fellt, ist 
nur angedeutet oder deutlich sichtbar. Ebenso ist das dritte Fiihlerglied mehr oder weniger am Oberrande ausgeschnitten, die Vorderecke mehr oder weniger spitz abgesetzt. Endlich kann auch die in geringem Grade wechselnde Schlankheit des Körpers als Merkmal nicht gebraucht werden.

Veränderliche Merkmale sind ferner die Breite der Stirn, der Verlauf der Stirnränder zueinander, das Gesichtsprofil, die Richtung des Epistomes und die Beborstung der Vorderstirn.

Aber auch die Gattung Hypoectu (longula) Loew, von der ich außer der Type im Wiener Museum noch ein Stiick aus S. Paulo in Brasilien, von A. A. B a r b i ell in i gesammelt, gesehen habe, unterscheidet sich blop durch die am spitzen Zipfel offene Analzelle und die plötzlich stumpf endende Analader, welche sich nicht als Falte bis zum Fliigelhinterrand fortsetzt. Es ist nicht ganz sicher, ob das auch konstante Merkmale sind. Die Figur 23 der Tafel der Berliner Entom. Zeitschr. 1867, gibt diese Verliältnisse falsch wieder, indem die Analzelle ja wie bei Chaetopsis geschlossen erscheint.

Anderseits ist auch ein Übergang zur Gattung Euxesta Loew zu konstatieren, der durch Arten wie Eux. acuticomis und arcuatr (Hendel, Ann. Mus. Nat. Hung., Vol. 8, p. 158 und 159, 1909) mit mehr weniger scharfem dritten Antennenglied gegeben wird.

\section{Die Chatopsis-Arten.}

Stirn vorn schmäler als ein Auge, gegen den Scheitel hinauf zu noch weiter stark verschmälert. Epistom winkelig vortretend 1

- Stirn parallehrandig, ungefähr von Augenbreite 2

1. Flïgel mit vier schma len, brannen Querbinden, die gegen den Fliigelhinterrand hin konvergieren. Kleine Querader auf der Mitte der Diskoidalzelle

Chaet. praeceps n. sp.

Flïgel nicht bandiert, vorherrschend hell graubraun und weil verwaschen, Flügelspitze dunkelbraun, Randmal gelb. Kleine Querader jenseits der Mitte der Diskoidalzelle

Chaet. mucronata n. sp.

2. Fliigel mit dreibreiten bramen, parallelen und senkrechten Querbinden; eine Wurzelquerbinde fehlt 3 - Fliigel nie bandiert, dunkler und heller bran nit weiß verwaschen

3. Die erste Querbinde des Fliigels ist so breit, daf sie den Ramm zwischen der kleinen Querader und den Wurzelzellen fast ganz ausfüllt. Die hintere Querader liegt am Innenrande 
der 2. Querbinde. Analzelle unten ohne spitz vorspringenden Zipfel (Stenomyia).

Chaet. laticauda n. sp.

- Die erste Querbinde füllt nur die distale Hälfte des obigen Raumes aus. Die hintere Querader liegt inmitten der zweiten Querbinde. Die Analzelle ist unten in einen die Zelle stark iiberragenden spitzen Zipfel ausgezogen (Chaetopsis) 4

4. Zweite und dritte Fliigelquerbinde vorn verbunden. Fühler braunschwarz mit hellerer Wurzel. Größere Art

Chaet. aenea Wiedem.

- Zweite und dritte Querbinde vorn getrennt. Fühler ganz rotgelb. Kleinere Art

Chaet. debilis Loew.

5. Beine einfarbig gelbrot. Gegen dunkleren Hintergrund gehalten erscheint der Flïgel hell rötlich braun, die Fliigelspitze an den drei Längsadermündungen dunkelbraun, eine Querbinde unmittelbar davor milchweiß

- Beine vorherrschend metallisch schwarz

Chaet. apicalis Johnson.

6. Flügel mit Ausnahme der weißen Wurzel dunkelbraun. Zwischen den beiden Queradern zieht eine deutliche weibe Querbinde durch, von vorn bis hinten. Ein heller Fleck in der ersten Hinterrandzelle

Chaet. angusta n. sp.

- Fliigel ohne weiße durchgehende Mittelquerbinde. Nur ein Wisch unter der schwärzlichen Subkostalzelle und die obere Hälfte der Flitgelspitze dunkelbraun, die ganze untere Flügelhälfte hell graubraun. Ein heller Fleck an der Postikalader.

Chaet. tenuis Loew.

\section{Chatopsis apicalis Johnson.}

Entomol. News, Philad., Vol. XI, p. 326 (1900).

$2 \sigma^{7}$ aus Georgia, Nordamerika; k. k. Museum in Wien.

Diese Art ist in der Kopfform und Flïgeladerung dem Chaetopsis-Typus ganz gleich.

Sehr charakteristisch ist für dieselbe die schon in der dichotomischen Tabelle angegebene Flügelzeichnung.

Über die allgemein bekannte Chaetopsis aenea Wiedem. brauche ich nichts zu sagen.

\section{Chatopsis mucronata n. sp.}

$1 \delta^{\top}$ aus Brasilien (S. Paulo), gesammelt von A. A. Barbiellini. Stirn nach oben hin merklich verschmälert, vorn etwas schmäler als eine Augenbreite, oben am Scheitel nur ungefähr die 
Hälfte eines Auges breit. Strieme seidenartig gelbrot; Augenränder sehr breit weif schimmernd, fast ein Drittel der Stirn breit. Vorn und an den Seitenrändern der Stirn nur wenige Börstchen, noch kürzer als bei laticauda. Die Frontorbitalborste und das Ozellarborstenpaar sind aber relativ länger und stärker als bei allen anderen Arten. Die durch die Stirnverschmälerung aneinander geriickten Scheitelplatten und Ozellendreieck hellgriin, etwas weißlich bereift, ebenso der ganze Hinterkopf. Wangen und Backengruben rot. Klypeus blaugriun, oben weiß bereift. Im Profile tritt die Stirn nicht mehr als bei Chaet. aenea Wied. iiber die Augen vor; unter einer Querfurche des anfangs unter den Fïhlern zuriickweichenden Klypeus tritt aber das Epistom (Mundrand) wieder merklich winkelig vor. Der Stirn-, winkel ist ein stumpfer, das Klypeusprofil eine gebrochene Linie. Prälabrum kaum sichtbar. Taster rostrot. Fühlerform wie bei temis Loew. Fïhler hell rostrot, nur die äußerste Spitze etwas dunkler.

Thorax hell metallisch grün. Riicken rötlich schimmernd, etwas matt bereift. Das ebene Schildchen und die glänzenden Pleuren mehr blau. Hinterleib glänzend dunkelgrïn, nach hinten zu blauschwarz und endlich ganz schwarz werdend.

Hüften und Schenkel metallisch grïn. Schenkelringe, Knie, Schienen und Füße gelbrot. Schienen aber in der Mitte ausgedelnnt verdunkelt und mit grïnem Schimmer.

Gegen dunklen Hintergrund gehalten, zeigt der Flïgel folgende zusammentließende Zeichnung: milchweiß erscheint die Wurzel mit der Kostalzelle und den beiden Wurzelzellen, ferner ein großes gleichseitiges Dreieck, dessen Basis jenseits der Subkostaniindung an der Kosta und dessen Spitze in der Mitte zwischen den zwei Queradern an der. Diskoidalader liegt, endlich ein runder Fleck an der Postikalader vor der hinteren Querader. Der ganze iibrige Fliigel ist hell rauchbraun, was im durchfallenden Lichte von obigen milchweißen Flecken kaum unterschieden werden kann. Die obere Spitzenhälfte des Fliigels jenseits des weißen Dreieckes bis etwas iiber die Diskoidalader herab dunkelbraun. In der ersten Hinterrandzelle liegt in der Mitte eines hellen dünnen Längswisches ein lichterer Fleck. Subkostalzelle und der darunter befindliche Teil gelblich. Adern rotgelb, in Braunen schwarz. Die Querader vorn an der Analzelle scharf gebrochen, fast wie bei Chaet. aenea Wied. Der Zipfol der Zelle ist aber kleiner als bei diese Art. Kleine Querader deutlich jenseits der Vitte der Diskoidalzelle. Schiippchen und Schwinger gelblichweiß. Körper $5 \mathrm{~mm}$, Fliigel $4 \mathrm{~mm}$ lang. 


\section{Chaetopsis praeceps n. sp.}

2 q aus Brasilien (S. Paulo), gesanmelt von A. A. B a rb i ell i n i. Stirn schmal, vorn nur die Hälfte eines Auges breit, nach oben hin noch bis auf den dritten Teil einer Augenbreite verschmälert. Strieme matt gelbrot, die weil schimmernden Augenränder ein Drittel der Stirn breit. Vorn und an den Augenrändern nur wenige Börstchen (ungefähr 1+4). Die aneinander gerïckten Scheitelplatten und Ozellendreieck blaugriun, weißlich bereift; ebenso der Hinterkopf. Die äufere Scheitelborste fehlt hier wegen der Enge des Scheitels. Wangen und Backengruben rot. Klypeus blaugriin, unter den Fühlern weißlich bereift. Stirnwinkel ein stumpfer; Klypeusprofil gleich dem von Ch. mucronata, weil auch hier das Epistom winkelig vortritt. Prälabrum fast versteckt. Form der Fiihler wie bei tenuis Lw., nur ist die Spitze des dritten Gliedes noch stärker differenziert und gleicht fast einem aufsitzenden Dorne. Der Farbe nach sind die Fühler hell gelbrot, desgleichen die Taster.

Thorax und Schildchen hell blaugriin, ziemlich dicht weißlich bestäubt. Pleuren mit mehr Blau. Hinterleib glänzend dunkelgriin, nach linten zu dunkler werdend. Beim anderen Stiicke ist das Abdomen nur wenig dunkler blaugriin als der Thorax. Erstes Glied des Ovipositors viel schmäler als der Hinterleib, länger als breit, dreieckig zugespitzt.

Hiiften und Beine metallisch blaugruin, Füße gelbrot, gegen das Ende zu dunkler werdend. Schienen etwas rötlich durchscheinend.

Flïgel gegen dunklen Hintergrund milchig weif erscheinend, mit vier braunen schmalen Querbinden. Die erste an der Schulterquerader. Die zweite, senkrechte, von der Submarginalzelle zum IInterrande, fast die kleine Querader erreichend. Die dritte schließt die schiefe hintere Querader ein, ist gerade und gleichbreit und hat vorn von der zweiten Querbinde den doppelten Abstand wie am Hinterrande. Die vierte läuft von der Spitze der ersten Hinterrandzelle, wo sie am breitesten ist, immer schmäler werdend längs des Flïgelrandes bis zur Mündung der Postikalader, wo sie sich mit der dritten Binde vereinigt. Aber auch am Fliigelvorderrande hängen beide Querbinden durch einen sehr schmalen Saum zusammen. Die kleine Querader liegt iiber der Mitte der Diskoidalzelle. Die Radialader ist dort, wo sie die dritte Querbinde kreuzt, etwas eingebogen. I) Querader vorn an der Analzelle ist spitzwinkelig gebrochen, der Zipfel der Zelle selbst aber nur sehr kurz. Schïppchen und Schwinger uelblich.

Körper ohne Legerölne $4 \mathrm{~mm}$, Flïgel $3 \mathrm{~mm}$ lang. 


\section{t. Chaetopsis (Stenomyia) tenuis Loew.}

Berlin. Entom. Zeitschr., Vol. XI, p. 321 (1867).

20 o aus Florida; Unit. States Nit.-Mfus. Washington.

Der Loewschen Beschreibung fiige ich nur. Folgendes an. Stirn parallelrandig, so breit wie ein Auge. Strieme unter den Ozellen wie bei Chaet. angusta etwas vertieft. Stirnwinkel ein spitzer. Die Stirn tritt merklich ïber die Augen vor, der Klypeus weicht im Profile wieder greradlinig zuriick. Epistom nicht abgesetzt.

Gegen dunklen Hintergrund gehalten, erscheint die Flïgelwurzel mit der Kostal- und den Basalzellen sowie ein ungefähr trapezförmiger Fleck in der IIitte des Fligelvorderrandes, dessen breitere Basis der Kubitalader aufsitzt und endlich ein wenig deutlicher, rundlicher Fleck an der Posticalis vor der hinteren Querader milchwe ib. Der iibrige Teil des Flügels unter der Kubitalader sehr hell graubraun, die obere Fluigelspitzenhälfte aber, jenseits des weifen Trapezes, sowie die diesseits desselben gelegene Submarginalzelle dunkelbraun. Der Übergang des dunklen in das hellere Braun allmählich verwaschen.

\section{う. Chaetopsis (Stenomyia) laticauda 11. sp.}

1 Q aus Paraguay (Puerto Max), ungar. Nation.-Nuseum. Stirn etwas breiter als ein Auge, parallehandig; Strieme rotbraun, wachsglänzend, in der Mitte vor'n und an Augenrande nur mit wenigen Börstchen. Augenränder breit weiß bestäubt. Ozellendreieck und Scheitelplatten wie der ganze Hinterkopf schwarzgriin. Die Stim springt im Profile etwas weniger als bei Chaet. (Stenom.) tenuis Loew vor; der Stirnwinkel ist schon ein Rechter. - Wangen und Backengrube rot. Klypeus dunkelgriin, im Profile gerade, zuruickweichend, genau wie Loew von seiner Art beschreibt; Epistom gar nicht abgesetzt. Prälabrum kaum sichtbar. Taster rostrot. Fühler ron der Form wie bei tenuis Loew, rostrot. Drittes Glied derselben in der Spitzenhälfte verdunkelt.

Thorax und Hinterleib dïster schwarzgriin, mäbig glänzend Das ebene Schildchen fast schwarz. Hinterleib nach hinten dunkler und matter werdend. Das erste Glied des Ovipositors schwarz, auffallend breit, so breit wie der Hinterleib, etwas länger als breit und sehr stumpf abgeschnitten. Bei Ch. tenuis Loew ist dasselbe länger und schärfer zugespitzt.

Beine schwarz, die vorleren mit grinem Metallschimmer. Schenkelringe, äuljerste Kniespitzen, Schienenspitzen und Fïße gelbrot. IIüften nur etwas riötlich durchseheinend. 
Fliigelzeichnung in der Anlage wie bei Chaet. aenea Wied., also aus drei schwarzbraunen Querbinden bestehend. Die erste reicht von der sehr dunklen Subkostalzelle bis zum Hinterrande, ist nur ganz hinten etwas heller und berihrt einerseits fast die Wurzelzellen, anderseits fast die kleine Querader. Die zweite und dritte Querbinde hängen vorn breit zusammen. An der senkrechten geraden inneren Grenze liegt die lintere Querader - zwischen beiden Queradern also ein glasheller Parallelstreifen der Quere nach. Der glashelle Zwischenraum zwischen der 2. und 3. Querbinde ist senkrecht, erreicht den Hinterrand, oben kaum die Radialader und ist etwas schmäler als eine der beiden dunklen Binden. Die Flügelwurzel ist ganz glashell, ohne jede Tingierung. Flugeladerung und Form der Analzelle wie bei Chaet. (Stenomyia) tenuis Loew.

Schüppchen weif, Schwinger gelb.

Kö̈rper ohne Legeröhre $5 \mathrm{~mm}$, Flïgel $3.5 \mathrm{~mm}$ lang.

\section{Chaetopsis (Stenomyia) angusta n. sp.}

2 o $q$ aus Brasilien (S. Paulo), gesammelt von A. A. Barbiellini.

Stirn parallelrandig, etwas breiter als ein Auge. Strieme ganz dunkelrotbraun, etwas glänzend und gewölbt, vor den Ozellen mit einer kaum merklichen, flachen Vertiefung, nur an den breit weiß gesäumten Augenrändern mit einigen Börstchen besetzt. Scheitelplatten, Ozellendreieck und der ganze Hinterkopf dunkel olivengrün, weißlich bereift. Wangen und Backengruben dunkelrot. Klypeus blaugrün, unter den Fiihlern weiß bereift. Im Profile tritt die Stirn nur wenig über die Augen vor, nicht mehr als bei $C h$. aenea Wied. Der Klypeus dagegen tritt viel stärker als bei dieser Art zurïck und ist nur ganz sanft konkav, ohne winkelig abgesetztes Epistom. Der Stirnwinkel ist ungefähr ein Rechter. Prälabrum nur wenig sichtbar. Taster dunkel rotbraun. Fühler bei beiden Stiicken abgebrochen. Erstes Glied derselben hellrot.

Thorax schwärzlich olivengriun, nur an den Pleuren etwas stärker glänzend. Schildchen schwarz, ziemlich eben. Hinterleib stärker als bei laticauda, weniger aber als bei mucronata glänzend, metallisch schwarz, vorne noch deutlich griunlich und damn auch violett schimmernd. Beim $\subsetneq$ ganz pechschwarz. Erstes Glied des Ovipositors wie bei Ch. laticauda geformt. im Verhältnisse kaum etwas kleiner. Hïften und Beine metallisch schwarz. 
Schienenspitzen und Füße, an den vordersten nur der Metatarsus mit Ausnahme der Spitze, gelbrot.

Gegen dunklen Hintergrund gehalten, zeigt der Fliigel folgende Zeichnung: Die Fliigelwurzel mit der Kostalzelle und den Wurzelzellen sowie eine oben etwas breitere Querbinde in der Flügelmitte, deren senkrechter fast gerader Außenrand nur etwas vor der hinteren Querader liegt, während der sanft gebogene imnere von der Mïndung der Subkosta nach hinten verläuft, ohne die kleine Querader zu erreichen, sind milchig weiß. Die Flïgelspitze, mit Ausnahme eines hellen rundlichen Fleckes in der ersten Hinterrandzelle, sowie der ganze Raum unter dem schwarzbraunen Randmale zwischen den zwei milchweißen Teilen sind dunkelbraun. Adern rotgelb, im Braunen schwarz. Die Querader vorn an der Analzelle wie bei Chaet. tennis Loew nur im stumpten Winkel gebogen. der Zipfel der Analzelle nur klein. Kleine Querader weit jenseits der Mitte der Diskoidalzelle.

Schiippchen und Schwinger rostgelb.

Körper ohne Legeröhre $5.5 \mathrm{~mm}$, Flïgel $4 \mathrm{~mm}$ lang.

\section{Paraphyola (n. g.) angustifrons n. sp.}

9 万o aus P'eru (Neshagua, Oktober; Pichis, Dezember); Kioll. Sehnuse.

Stirn vorn neben den Fühlern ungefähr so breit wie die halbe Augenbreite, nach oben hin aber noch viel schmäler werdend. Strieme matt gelbrot, am Augenrande ziemlich breit weiß schimmernd, kurz und schwach beborstet, vorn in der Mitte noch kräftiger als an den Orbiten. Die Ozellenplatte ist mit den Scheitelplatten wegen der starken Verengung des Vertex eng zusammengedrängt und gleich dem Hinterkopfe blaugrün mit weißlicher Bereifung. Äußere Scheitelborste fehlt. Stirn im Profile beinahe gar nicht vor die Augen vortretend. Wangen und Backengruben sehr schmal, an die Augen gedrängt, rot. Klypeus blaugriin, iiber der Querrinne in der Nitte weiß bereift. Lunula rötlicb. Der Klypeusteil unter der Querrinne (Epistom) tritt winkelig vor, aber weder so stark noch in gleichem Maße konvex wie bei der Gattung Aspistomella. Auch die Peristomalienborsten sind schwächer. Prälabrum dunkel; Taster verbreitert, rotgelb; Rüissel schwärzlich. - Fühler in der Größe und Gestalt wie bei Aspistomella; das dritte Glied ist auch etwa zweimal so lang wie breit, am Oberrande aber kaum merklich konkav.

Thorax und Schildchen glänzend goldig olivengrün, Riicken etwas rötlich bestïubt. Hinterriicken dunkel. Hinterleib an der 
Basis gelbrot, sonst metallisch dunkelgriin, am Hinterrande der Tergite violettschwarz, auch schon am zweiten. In gewisser Beleuchtung erscheint der ganze Hinterleib durch einen zarten Reif einfarbig matt bräunlich, während er sonst ziemlich glänzt. Erstes Glied des Ovipositors gleichfarbig, fast kürzer als breit, herzförmig, wenig breiter als die Hinterleibsspitze.

Beine wie bei Aspistom. heteroptera gefärbt. Die Vorderhiiften sind jedoch zum grö̈ßten Teile metallisch gr'in, an der Vorderseite weiß bestäubt und die Fiiße von hellerem Rotgelb.

Fliigel lang und schmal, vorherrschend schwarzbramn. Flïgelwurzel, die Kostalzelle mit Ausnahme der Spitze und die Basalzellen glashell. Ein braunes Querband iber die Schulterquerader. Jenseits der Nündung der Subkosta liegt ein großes hyalines Dreieck mit der Basis an der Kosta, mit der Spitze nach unten hin, gerade hinter der kleinen Querader etwas in die Diskoidalzelle hineinreichend. Vor der dunklen Flïgelspitze liegt eine ähnliche glashelle Bogenbinde wie bei Aspistom. lobioptera. Sie ist aher hier viel weniger schief und breiter.

Die kleine Querader liegt deutlich vor der Mitte der Diskoidalzelle. Die letzten beiden Abschnitte der Diskoidalader sind ungefähr gleich lang, der letzte kaum länger als die halbe Diskoidalzelle. Der Winkel der Posticalis mit der hinteren Querader ist stumpf. Die Radialis und Kubitalis sind deutlich zweimal wellig geschwungen.

Schïppchen und Schwinger gelblich.

Körperlänge ohne Legeröhre $455-5.5 \mathrm{~mm}$. Flügel $4-5 \mathrm{~mm}$.

Anmerkung: Paraphyola ist durch die außergewöhnlich enge Stirn und die parallel mit dem Flïgelhinterrande auslanfende Analader gekennzeichnet.

\section{Paraphyola crucifera n. sp.}

1 O aus Peru (Meshagua; November). Koll. Schnuse.

Gleicht mit folgenden Unterschierlen der vorigen Art.

Hiiften und Beine einfarbig rotgelb. Hinterleib an der Wrurzel anch gelbrot, sonst aber glänzend schwarzgriun, ohne jeden Reif, am Riicken violett schimmernd.

Der Fliigel ist stark verschieden gezeichnet und auch abweichend geadert. Fliigelwurzel, mit der Kostalzelle und den beiden Basalzellen glashell. Über die Schulterquerader eine verwischte braune Qnerbinde. Der übrige Flïgel ist dunkelbramn mit vier glashellen Fenstern, zwei gröbere an der Kosta, zwei kleinere an Hinterrande. 
Der zwischen diesen vier hellen Flecken liegende braune Teil hat die Gestalt eines Kr'euzes. Der erste Kostalfleck wird innen durch eine Linie von der Mündung der Subkosta bis knapp vor der kleinen Querader zur Diskoidalader, distal durch eine fast Senkrechte auf die Kosta, welche zwischen den beiden Queradern die Diskoidalis trifft, begrenzt. Der zweite, äußere Kostalfleck ist etwas kleiner und endet in der Nitte der ersten Hinterrandzelle, während der erste mit der untersten Spitze sogar etwas in die Diskoidalzelle hineinragt. Die proximale Grenze des zweiten glasigen Kostafleckes liegt in der Verlängerung der hinteren Querader. Die beiden hyalinen Flecke des Hinterrandes sind kreisförmig und von gleicher Gröfe. Der eine liegt an der Posticalis, gerade unter dem ersten Kostafleck, der äußere in der zweiten Hinterrandzelle, deren Mitte gerade von immen beriillrend.

Die kleine Querader liegt weit jenseits der Diskoidalzellenmitte. Der letzte Abschnitt der Diskoidalader ist gut dreimal so lang wie der vorletzte und so lang wie die ganze Diskoidalzelle. Der Winkel der Posticalis mit der hinteren Querader ist spitz. Radialis und Cubitalis nur einmal wellig geschwungen.

Körper $5 \mathrm{~mm}$, Flïgel $4 \mathrm{~mm}$ lang.

\section{Polyteloptera (n. g.) apotropa n. sp.} biellini.

õ $\sigma^{\nearrow}$ Q aus Brasilien (S. Paulo), gesammelt von A. A. Bar-

Die neue Gattung ist sofort daran zu erkennen, dafo beide Flïgelqueradern weit jenseits der Flïgelmitte liegen, die hintere wenig vor der Mliindung der Radialader steht und der letzte Abschnitt der Liskoidalader kürzer als der vorletzte ist.

Die Gesantfärbung ist ein schönes, tiefes Stahlblau. - Die Stirn ist vorn neben den Fühlern etwas schmäler als ein Auge und verjüngt sich gegen den Scheitel zu bis auf die Hälfte der Augenbreite. Strieme matt rotbraun, an den Augenrändern nur schmal weiloschimmernd, vorn und an den Seitenrändern lang und stark beborstet. Äußere Scheitelborsten nur klein, die ïbrigen Kopfborsten sehr stark. Scheitelplatten und Ozellendreieck zusammengedrängt, stahlblau und wie der Hinterkopf, aber spärlicher weiß bestäubt. Fiihler gelbrot, unter der Augenmitte sitzend. Drittes Glied oben stark ausgebuchtet, vorn mit spitzer Vorlerecke. Wangen und Backengruben rotbraun. Klypeus stahlblau, oben wie die Lunula weißlich bereift. Im Profile tritt die Stirn kaum etwas vor, der 
Stirnwinkel ist ein sehr stumpfer. In der Mitte des Klypeus eine Querfurche. Der untere Teil tritt als Epistom winkelig vor. I'rälabrum stahlblau, breit sichtbar. Taster rotbraun.

Der Thoraxrïicken ist etwas weiblich bereift, das Schildchen fast schwarz, oben vollkommen eben. Die Pleuren glänzen stark und haben etwas violetten Schimmer.

Der Hinterleih ist dunkler blau als der Thorax, matter und wird nach hinten zu immer noch dunkler und matter, fast schwarz. Das erste Glied der Legeröhre ist schmäler als der Hinterleib, so lang wie breit, dreieckig zugespitzt, nur wenig abgestutzt.

Hiiften dunkel rotbraun, metallisch schimmernd. Schenkel dunkel stahlblau. Alle Schienen und die Vorderfüße schwarzbraun, die übrigen Tarsen rotbraun, gegen das Ende zu etwas verdunkelt.

Flügel mit keulenförmigem Unrisse, vor der Spitze an breitesten. Flügelwurzel mit der Kostalzelle und den Wurzelzellen glashell, nur über die Schulterquerader herab zieht eine schwarzbraune Querbinde. Der ganze iibrige Flügel ist tief schwarzbraun und hat zwei schiefe glashelle Querbinden an der Spitze, die von unten und außen nach vorn und oben, gegen die Mündung der Subkosta hin, ziehen, nach ohen immer schmäler werden, durch einen schmäleren braunen Streifen von einander getrennt werten und noch einen schmalen Kostalsaum freilassen, der von dem genannten braunen Streifen an, an Breite etwas wachsend, bis unter die Mündung der 4. Längsater hinabzieht. Die große breite Mitteltläche des Flügels bildet ein dunkelbraunes Trapez. Schwinger und Schüppchen gelblich

Körper ohme Legeröhre $5-55 \mathrm{~mm}$, Flügel $4-4.5 \mathrm{~mm}$ lang.

\section{Aspistomella (n. g.) lobioptera n. sp.}

3 Q aus Bolivi a (Mapiri ; Jämer und April) und Peru (UcayaliHuß; (Oktober). Koll. Schnuse.

Stirn nur wenig schmäler als ein Auge, parallelrandig: Strieme rotbraun, etwas glänzend, in der Mitte schwächer, am Rande lang und stark beborstet und hier auch weiß bestäubt. Ozellendreieck und Scheitelplatten glänzend stahlblau, ebenso der Hinterkopf, letzterer aber weißlich bereift. Äußere Scheitelborste vorhanden. Im Profile tritt rie Stirn nur ganz wenig vor die Augen vor; Stirnwinkel sehr stumpf. - Wangen und Backengruben sehr schmal, an die Augen gerlrängt, rot. Klypeus dunkel stahlblau, oben unter den Fïhlem weißlich bereift, unten, am Iundrande manchmal rot durchscheinend. In oberen Inittel seiner Höhe wird er von einer scharfen 
Rimne durchyuert, unter welcher das Epistom (die unteren zwei Drittel des Klypeus) als gewölbter Schild weit nach vorn und unten hin vorspringt. Peristomalienborsten auffallend lang und stark. Prälabrum rot, blau schimmernd. Taster gelbrot, stark verbreitert und beborstet. Rüssel schwarz. - Die Fühler erreichen die Mitte des Epistoms und sind gelbrot. Das dritte Glied ist länglich oval, vorn abgerundet.

Thorax und Schildchen diister schwarzgrïn, glänzend. Der Rücken dagegen ist mit einem feinen braunen Tomente bedeckt. Schildchen und Hinterricken fast schwarz. Hinterleib glänzend violettschwarz. Erstes Glied des Ovipositor's schmäler als der Hinterleib, von der Gestalt eines gleichseitigen Dreieckes, an der Spitze etwas abgestutzt.

Vorderhiiften gelblichrot, nur oben und außen schwärzlich. Beine glänzend pechschwarz. Schenkelringe, die Basis der Schenkel, die äußersten Krne- und Schienenspitzen sowie die Fïße der beiden hinteren Beinpaare mit Ausnahme der Spitze rotbraun.

Flïgel groß und breit, vorherrschend schwarzhraun. Glashell ist die Wurzel mit der Kostalzelle und den Wurzelzellen, jedoch mit Ausnahme eines braunen Querbandes iiber die Schulterquerader, der dunkelbraunen Kostalzellenspitze und des Anallappens und der Alula, die hellbraun sind. Im Braunen des Flïgels liegen ferner noch folgende glashelle Figuren: ein Dreieck knapp hinter der Mïndung der Subkosta, ein klemer Halbkreis hinter der kleinen Querader, ein größerer Kreisabschnitt in der Mitte des Flïgelhinterrandes vor der Posticalis und endlich ein schmaler flacher Bogen vor der dunklen Fliigelspitze, der bald hinter der Subkosta beginnt und sich bis in die Spitze der zweiten Hinterrandzelle hinabzieht.

Die kleine Querader liegt jenseits der Subkostamiundung, etwas vor der Mitte der Diskoidalzelle und des Flügels ïberhaupt. Der letzte Abschnitt der Diskoidalader ist nur wenig länger als der vorletzte und die Hälfte der Diskoidalzelle. Hintere Querader gerade und fast senkrecht. Die Querarler vorn an der Mnalzelle stark spitz winkelig hineingebogen. Der Analzellenzipfel kurz, aber schlank und spitzig. Flïgelhinterrand gleichmäßjig konvex gebogen.

Schiippchen und Schwinger gelblich.

Körper ohne Ovipositor 4.5-5.5 mm, Flïgel 4-5 $\mathrm{mm}$ lang.

Anmerkung: Das Genus Aspistomella ist durch den vorspringenden spitzen Flïgellappen an der Mediastina und das schildartig gewölbte Epistom genügend charakterisiert.

Wiener Entomologische Zeitung, XXVIII. Jahrg., Heft VII und VIII (25. September 1909). 


\section{Aspistomella heteroptera n. sp.}

8 q aus ' 'er u (Meshagua; Oktober und Jänner); Koll. S c h n use.

Stirn vorn neben den Fiihlern merklich schmäler als ein Auge, nach oben hin aber bis auf die halbe Augenbreite verschmälert; Strieme rotbraun, matt, am Augenrande schr breit weif schimmernd die Beborstung derselben ist bei weitem kürzer und schwächer als bei lobioptera, namentlich am Augenrande, während sie vorn in der Mitte fast kräftiger als seitlich ist. Ozellenplatte, Scheitelplatten und der ganze Hinterkopf grimblau, etwas bereift. Äußere Scheitelborste fehlt. Stirnwinkel im Profile, Wangen und Backengruben wie bei lobioptera, letztere aber stark silberschimmernd. - Klypeus in der Form ebenfalls wie bei voriger Art, nur geht die Querrinne durch die Nitte. Oberhalb derselhen ist der Ḱlypeus mit der Lunula samtschwarz, unterhalb metallisch blaugrün, am Mundrande etwas rot durchscheinend. Die Peristomalienborsten sind kürzer als bei lobiopter $u$. I'rälabrum grïn, die verbreiterten Taster dunkelbraun, Rüssel schwarz, Labellen rot. Fiihler braunschwarz, von gleicher Länge und Form wie bei lobioptera.

Thorax und Schildehen glänzend goldig olivengriun, Rïcken etwas fuchsigrot bestäubt. Hinterriicken fast schwarz. Hinterleib dunkler griin als der Thorax, am basalen Doppelsegment rotgelb, am 3. und 4. Tergit an der Wurzelhälfte weißlich bereift, am Hinterrand violett und mit einer feinen unbestäubten medianen Längslinie. Ovipositor wie bei lobioptera, etwas bereift.

Beine metallisch grïn; Hüften, Schenkelringe, Kinie, Schienenspitzen und alle Füiße mit Ausnalme der verdunkelten Spitzen gelbrot.

Flïgel so lang wie der ganze Körper und dadurch, dab der Hinterrand vor der Spitze konkav statt konvex ist, eigentümlich zugespitzt. Die Färbung ist in der Anlage die gleiche wie bei der vorigen Art, nur die glashellen Figuren im Braunen jenseits der hellen Wurzel sind verschieden. Das glasige Dreieck gleich jenseits der Mediastinamündung ist breiter und reicht mit seiner Spitze unten nicht nur etwas über die Radialader, sondern bis an die Postikalader hinab. Fast parallel mit dem Vorderrande des Flïgels ist eine kaum geboggene hyaline Querbinde, die in der Spitzenhälfte der 2. Hinterrandzelle beginnt und sehr schief iber die Längsadern 4 und 3 hinlaufend in der Submarginalzelle ïber der hinteren Querader endet. Unten wird sie durch einen mit dem Braunen zusammenhängenden schmäleren Zahn begrenzt. Dieser wieder bildet die eine Kathete eines hyalinen Dreieckes, dessen andere Kathete etwas jenseits der 
hinteren Querader und parallel mit iln liegt und das bis zum Hinterrande des Flügels reicht.

Die kleine Querader liegt der Suhkostamündung gegenüher, auffallend weit vor der Mitte der Diskoidalzelle und des Fliigels iiherhaupt. Der letzte Abschnitt der Diskoidalader ist beinalse doppelt so lang wie der vorletzte und ebensolang wie die ganze Diskoidalzelle. Hintere Querader sanft S-förmig geschwungen und etwas schief. Die Querader der Mnalzelle ist weniger stark spitzwinkelig gebrochen. Die erste Hinterrandzelle ist im letzten Irittel plötzlich etwas erweitert, an der Spitze aber wieder verengt, nicht allmählich rerjiingt wie bei lobioptera.

Schïppehen und Schwinger gelb.

Körper olne Legeröhre $5 \mathrm{~mm}$, Flïgel $55 \mathrm{~mm}$ lang.

\section{Oedopa ascriptiva 11. sp.}

$2 \delta^{\pi} \bigcirc$ aus S. Colorado, Nordamerika.

Da die neue Art der Oedopa capito Loew äuferst ähnlich ist, führe ich blok die Unterschiede von letztgenamnter Art an.

Die Gesamtfärbung macht einen aschgrauen, dunkleren Eindruck als die gelbliche, wüstenfarbige der Oed. capito. Die schwärzliche Querhinde der Stirn ist fast gerade, kaum etwas gebogen, der darïberliegrende Stirnteil dichter mit viel größeren dunklen Wurzelpiinktchen besetzt, welche an der Scheitelkante zu einer zweiten dunkleı Querbinde zwischen den beiden oberen Augenecken zusammentliefen. Die bei Oed. capito unpunktierte Vorderstirn ist hier ebenfalls durch kleine schwärzliche Pünktchen an den Haarwurzehn geziert. Der Hinterkopf ist in der Mitte ansgedehnter schwärzlich gefärbt. Der dunkle Querstrich unter den Fïhlern ist markierter und tritt kräftig auf die Wangen ïher. Die Backen sind in den unteren zwei Drittehn deutlich mit ziemlich langen schwarzen Härchen besetzt, welche teilweise ebenfalls dunkle Wurzelpünktchen haben. Bei Oed. capito sind die Backen nackt oder fast nackt; anch der braune Strich, parallel mit dem unteren Augenrande an den hinteren Iacken, fehlt der Loew schen Art.

An asclograuen Thorax sind die Längshinden der Pleuren breiter und dunkler, die P'unktierung zwischen den Längsstriemen des Riickens dichter. Der Hinterleib ist oben gleichfalls ziemlich dicht mit dunklen Wurzelpünktchen besetzt. Beim o zeigen sich zwei nicht scharf abgegrenzte dunklere und etwas glänzende Läng's- 
striemen, die ïber den ganzen Hinterleib verlanfen. Das erste Glied des Ovipositors ist mit dem Hinterleibe gleich gefärbt.

Vorderhüften rötlich grelb, außen grau. Schenkelringe rotgelb. Alle Schenkel, mit Ausnahme der gelhen Spitze, schwärzlich, dicht aschgrau bestäubt und dunkel punktiert, nur hie und da etwas rötlich durehseheinend. Die Schienenringe sind sehr dunkel und scharf ausseprägt.

Submarginalzelle in der Spitzenhälfte schwarzbraun. Bei Oed. capito ist diese Zelle ganz glashell.

Anmerkung: Die Abweichmgen dieser Art von Oed. capito, die ich in mehreren Stiicken aus verschiedenen schon bekannten Lokalitäten besitze, scheinen nir spezifische zu sein. Schon dem Habitus nach kann man beide Formen von einander unterscheiden.

Die dritte bis jetzt bekannte Art., Oed. elegans Giglio-Tos, kenne ich nur ans der Beschreibung. Durch die Flïgelzeichnung - ,alis maculis parvis fuscis plurimis omnino adspersis" — ist sie wohl leicht kenntlich.

\section{Stictomyia longicornis Bigot.}

Diese Art liegt mir in mehreren Stücken ans Mexiko (St. Fe), von Bilimek gesammelt, und in einem Exemplar aus N e l- M exiko, welches mir Herr E. T. Cresson jr. freundlichst mitteilte, vor. Letzteres Stiick unterscheidet sich in folgenden P'unkten von den mexikanischen Tieren: Die Fiihler sind nicht ganz einfarbig dunkelbramn, sondern an den Wurzelgliedern und der Basis des dritten Gliedes rötlichgelb. Die bei Betrachtung gegen dunklen Hintergrund sichtbar werdenden weißen Punkte des Flïgels sind größer und weniger zahlreich.

\section{Axiologina (n. g.) ferrum-equinum n. sp.}

o’ 9, Peru (Ieshagua; November, Dezember), Kóll. Sc hnuse, und Brasilien, Exped. Wettstein.

Stirn schmäler als ein Inge, parallelrandig, ziemlich gleichmäßig rauh behaart. Strieme dunkel rotbraum, matt; Augenränder fein weils eingefaft. Scheitelplatten, Ozellendreieck und oberer Hinterkopf glänzend schwarz, metallisch grün oder blauschimmernd. Ebenso das Untergesicht. Wangen und Backengruben rot. K'lypeus unter den Fühlern weißlich bereift. Fïhler dunkelbraun, an der Iasis ausgedehnt rötlich: 3. Glied länglich oval. Prälabrum sehr grof, hoch und breit, metallisch schwarz. Rïissel und die etwas rerbreiterten 'Taster' schwarz, letztere borstig. 
Thorax glänzend grün- oder blauschwarz, auf dem Rïcken durch eine bräunliche Bestäubung ziemlich matt. Die Quernalitïste, der Supraalareallus sowie der Hinterrand des Schildchens metallisch braun. Die Oberseite des Schildchens lichter bereift.

Hinterleib schwarzbraun, wenig glänzend. Der 4. Ring etwas länger als die übrigen. Erstes Glied des Ovipositors kiirzer als breit, stark abgestutzt.

Hiiften und Beine pechbraun. Knie schmal rotbraun. Vorderfiilje dunkelrotbraun, die hinteren gelbrot.

Flïgel glashell mit vier schmalen, schwarzbraunen Querbinden. Die zwei mittleren biegen an der Kosta zusammen und vereinigen sich zu einem hufeisenförmigen Fleck. Die vierte Binde liegt oben an der Flügelspitze, die erste an der Flïgelwurzel.

Subkosta nicht konkav, sondern konvex aufgebogen in die Kosta miindend. Radialader im Endteil mit der Kosta parallel laufend. Kleine Querader in der Nähe der Basis der Diskoidalzelle gelegen. Analzelle unten mit einer schlanken Spitze.

Schüppchen braun, Schwinger schwärzlich.

Körper $3.5 \mathrm{~mm}$, Fliigel $3 \mathrm{~mm}$ lang.

Anmerkung: Die Gattung Axiologina kennzeichnet sich durch das eigentümliche Flügelgeäder geniigend.

\section{Eumecosomyia (n. g.) gracilis Coquillett.}

Epiplatea gracilis, Coqu. Journ. N. York Ent. Soc. Vol. 8. p. 25 (1900).

$6 \delta^{\top}$ \& aus $\mathrm{C}$ uba (Havanna), Haïti (Santo Domingo), Brasilien (Iguape), Paraguay. Coquilletts Stiicke sind aus Mexiko.

Zur Originalbeschreibung möchte ich noch hinzufïgen: die ersten zwei Fiihlerglieder nicht ganz sclwarz, sondern die distale Hälfte des zweiten schon rotgelb. Beine nicht blob einfarbig rotgelb, sonderm die Vorderschienen in verschiedener Ausdehnung gebräunt, die Vorderfüße mit Ausnahme des Endgliedes und der Spitzen der anderen Glieder dunkelbraun. Die hinteren Schienen haben vor der Spitze einen braunen Fleck resp. Iiing.

Die Gattung Eumecosomyia unterscheidet sich von allen Ulidiinen durch die rundliche Analzelle, die fehlende Analader und den rudimentären Anallappen.

Epiplatea ist eine Richardinen-Gattung ohne Beborstumg der unteren Stirn. mit ovalem. nicht zugespitztem 3. Fiihlerglied mol einem zwischen deutlichen Fïhlergruben gekielten Kilypeus. Auch 
ist die Stirn im Gegensatze oben breiter als unten und die Analadler und der Lappen deutlich entwickelt.

\section{Eumecosomyia lacteivittata 11 sp.}

$2 \delta^{\nearrow}$ aus Mexiko (Orizaba; März); leg. Bilimek. Wiener Hofmuseum.

Stirn vorn so breit wie ein Auge, mach oben hin stark verschmälert, aber in ganzen etwas breiter als wie bei gracilis; Strieme gelbrot, am Augenrande weilb bereift, dort und vorne in der Nitte beborstet. Scheitelplatten, Ozellendreieck und oberer Hinterkopf metallisch blau. Wangen und Backengruben gelbrot. Klypens winkelig' gebrochen, metallisch blau, oben weiflich bereift, Lunula ebenfalls. Fiiluler und Taster rotgelb.

Thorax blaugrïn, Riiicken etwas bräunlich bereift. Hinterleib dunkelschwarzgriin, etwas rötlich durchscheinend.

Hiiften grelbrot. Beine metallisch blaugriin. Knie, Schienenspitzen und Füße rot.

Flügel in der Spitzenhälfte brann. Die innere Grenze derselben ist bogig konvex: ihre Enden oben und unten an den Fliigelrändern liegen in der Verlängerung der hinteren Querader, der Bauch in der Mitte zwischen den beiden Queradern. In der Basishälfte des Fliigels liegt ein dreieckiger brauner Fleck, dessen Spitze das braune Randmal, dessen Basis der Hinterrand des Flügels ist. Der äulbere Schenkel dieses Dreieckes berührt die kleine Querader, der innere lälst gerade noch die Wurzelzellen frei. Fliigelwurzel gelblich. In der Fliigelmitte erscheint der glashelle Zwischenraum gegen dunklen Hintergrund als oben und unten erweiterte milchweiße Querbinde.

Schïppchen und Schwinger gelblichweib.

Im iibrigen gleicht die Art gan\% der Eumecos. gracilis Coru., so namentlich in der Kopf- und Fühlerform und in der Flügeladerung:

Die Unterschiede beider Arten liegen im samtschwarzen LunulaHeck und in der anderen Bein- und Flügelfärbung bei gracilis.

Auch die Grölje ist bei beiden Arten gleich, Körper- und Fliigellänge $455-5 \mathrm{~mm}$. 




\section{Über acalyptrate Musciden.}

Von Friedrich Hendel in Wien.

Mit Tafel I.

Sonderabdruck aus der „Wiener Entomologischen Zeitung“, XXIX. Jahrgang 1910. 



\section{Über acalyptrate Musciden.}

Von Friedrich Hendel in Wien.

Mit Tafel I.

\section{Subfam. Ortalidinae. Gruppe Ortalidina.}

\section{Zwei neue palüarktische Dorycera-Arten.}

In meiner synoptischen Übersicht der bisher bekannten DoryceraArten, Zeitschr. f. Hymenopt. u. Dipterol., 1908, p. 104, hatte ich als neu die Dorycera tuberculosa u. die Pernomatia judaea beschrieben. Ich kinn num abermals zwei neue Spezies bekanntmachen, die eine aus der Sammlung des Herrn Kollegen Lichtwardt, die zweite aus der Kollektion des verstorbenen Prof. J. Mik, im k. k. Hofmuseum.

\section{Dorycera nitida n. sp.}

$2 \sigma^{\pi}$ aus Ak-Chehir (1900) in Anatolien. Loll. Lichtwardt. Diese Art steht durch Kopf und Fühlerform der Dor. tuberculosa Hend. und auch der Dor. brevis Loew am nächsten, unterscheidet sich aber von allen Arten leicht dadurch, daß der ganze Körper glänzend schwarz ist und nur der Thoraxrücken zwei wenig auffallende schmale weißliche Längsbinden in den Linien der Dorsozentralborsten zeigt, die dunkel punktiert und vorn iiber dem Humeralcallus etwas erweitert sind, riickwärts das Schildchen aber nicht erreichen. Zwischen ihnen ist in der Medianlinie ein vorn und hinten abgekürzter weißlicher Strich, in gewisser Beleuchtung aber sind drei derartige, nach vorn konvergierende feine Linien sichtbar. Alle diese Bestäubungen verhindern aber nicht, daß der Riicken als vorherrschend glänzend schwarz aussieht, was sonst bei keiner anderen Art der Fall ist. Überdies sind auch die Pleuren und das Schildchen ganz unbestäubt und glänzend. Der Hinterleib erscheint nur durch die feine, aus Querrunzeln bestehende Skulptur der Tergite etwas matter.

Der Kopf ähnelt sehr dem del Dor. tuberculosa Hend. Wie bei dieser Art ist er etwas höher als lang, hat lotrecht ovale Augen und keine ehene, sondern eine unter den Ozellen etwas konkave, vorn aber ïber den Fühlern wieder aufgewölbte Stirn. Kei tuberculosa nimmt diese Konvexität des Stirnvorderrandes zwischen Fïhler und Auge sogar Beulenform an, was bei der neuen Art aber nicht del 
Fall ist. Auch steht bei derselben die Stirn viel weniger, kaum den halben horizontalen Augendurchmesser vor die Augen vor. Stirn in der Mitte gelbrot, wachsglänzend, mit einer dunkleren Medianlinie vor deı Ozellen; der ganze Hinterkopf, die Ozellen- und Scheitelplatten glänzend schwarz; Augenränder dunkelrotbraun, stark glänzend, nach vorn hin und aul die Wangen herab etwas heller werdend. Backen gelbrot, unter den Auge mit einem grolien dunklen Fleck, ohne scharfe Begrenzung. Kilypens gelbrot, nur in den Fühlergruben bis zum Mundrand linienartig glänzend schwarz. Fiihler rotgelb, drittes Glied rot, an der spitze gebräunt. Zweites Glied duinn und schlank, gut dreimal so lang wie breit, merklich schmäler als das dritte, was bei tuberculosa nicht der Fall ist. Das dritte Glied hat länglich eiförmige Gestalt und ist $2 / 3$ des zweiten ling. Die Arista stelit medial.

Bei D. tuberculosa Hend. ist das Cerebrale weiß bestäubt; es glänzen nur die Ozellen- und Scheitelplatten, die Angenränder sind ebenfalls bestäubt und nur an den Beulen kommt der Glanz wieder zuII Vorschein.

Die rotgelbe Stirnmitte ist ganz matt. Die Wangen, der Ḱlypeus und die Backen sind rotgelb. I)er Längskiel des Untergesichts zeigt hier einen schwarzen Fleck unter den Fühlern und jede Rinne der letzteren nur eiı kleines schwärzliches Strichılchen. Der ganze Augenumfang ist zart weif bereift, zwischen Fühler und Auge liegt unter der Beule ein schwärzliclser Querstrich. Auch die Backen zeigen einen solchen unter den Augen. Der ganze untere Hinterkopf ist hier rotgelb und nur der obere wie bei nitida selswarz.

Der ganze Körper ist wohl auch von glänzend schwarzer Grundfarbe, aber der Glanz durch die vorherrschende, wenn auch zarte weißliche Bestäubung zurïickgedräıgt. 'Thoraxrüicken mit sechs breiteren, stark glänzenden Längsstriemen der Grundfarbe in der Bestäubung, die hinter dem glänzenden Humeralcallus an dichtesten ist. Schildchen oben in der Mitte, Pleuren in ilnrer Gänze zart bereift. Am glänzend schwarzen Hinterleib sehe icls bei einem besonders gut erhaltenen Stiicke $\left(\sigma^{\top}\right)$ eine weifgraue Querbinde an der Grenze des 1. und 2. Tergits, je eine spitz dreieckige solche Makel in der Mitte des 3. bis 5 . Tergits, nit der Basis dem Torderrande anliegend.

Bei D. nitida sind die Beine nicht einfarbig rotgelb, wie bei tuberculosa, sondern die Schenkel mit Ausuahme einer breiten Spitze schwarz.

In Flïgel unterscheidet sich nitida ebenfills von allen anderen Arten, ausgenommen die folgende, indem derselbe mit Ausnalme der 
schwach angerauchten Spitzen der Längsadern 2 bis 4 einfach gelblich hyalin erscheint.

Kö̈per $7 \mathrm{~mm}$, Flügel $6 \mathrm{~mm}$ lang.

\section{Dorycera caucasica n. sp.}

20 O aus Derbent und l'alysch im Kaukasus, Mai 1885 , k. k. Hofmuseum.

I)urch die Form des dritten Antennengliedes, das sich jenseits der Arista plötzlich verjüngt und zuspitzt, der D. graminum Fab. ähnlich. Das dritte Fühlerglied ist aber nur wenig länger als die Hälfte des zweiten, die Augen sind deutlich senkrecht oval, die Stim ist nicht eben, sondern wie bei tuberculosa Hend. geformt und vorn seitlich mit Beulen versehen; sie steht $2 / 3$ des wagrechten Augendurchmessers vor die Augen vor.

Die Stirnmitte ist matt rotgelb und enthält eine schwarze Mittellinie. Oberer Hinterkopf mit Ausnahme des rotgelben Cerebrales, sowie die Ozellen- und Scheitelplatten und die Stimbeulen glänzend schwarz. Augenränder weiß bestäubt. Unterer Hinterkopf, Wangen, Backen und Klypeus rotgelb. Unter jedem Fühler in der limne ein keilförmiger schwarzer Fleck und darunter ein ebensolcher Strich. Zwischen Fühler und Auge, sowie unter dem letzteren auf den Backen ein schwärzhicher Strich. Aber auch der Wangenrand an den Fazialien ist geschwärzt. Fühler wie bei $D$. nitida gefärbt. Das zweite Glied ist schlank, etwa riermal so lang wie breit. Die Arista steht vor der Mitte.

Thorax, Schillchen und Hinterleib glänzend schwarz. Thoraxrïcken sehr dicht grau bestänbt, mit sechs schmalen Längslinien der Grundfarbe. Schildchen oben wie der Rücken mattgrau. Ein Streifen von dem Humeralcallus bis zur Flïgelwurzel glänzend schwarz. Darunter sind die I'leuren weißlichgram bereift.

Beine rotgelb, Fiibe an der Spitze gebräunt.

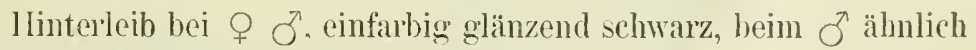
wie bei $D$. nitida mit sehr fein querrunzelig ziselierten T'ergiten.

Flügel intensiv gelblich tingiert. Die Längsadern an der Flügelspitze. besonders die Radialis, merklich angerancht. I)ie Tingierung ler Flïgelthäche ist entschieden auffallender als bei nitida, aber schwächer als bei tuberculosa.

Körper $75 \mathrm{~mm}$, Flïgel $6 \mathrm{~mm}$ lang. 


\section{Gruppe Ulidiina.}

\section{Timia planiceps n. sp.}

2 ○ đ’aus Tscherwach, März 1887, T'urkmenien. K. k. Hofmuseum, Wien.

Bei Beniitzung meiner ,Synopsis der bisher bekannten TimiaArten“, Zeitschrift f. Hym. und Dipterol., 1908, p. 1, wïrde diese Ar auf Punkt 2, "Schildchen ganz schwarz", fiihren. Aber weder die dort angefïhrte Timia Jakowlewi Hend. noch die in der Synopsis noch nicht einbezogenen Empyelocera-Arten mit schwarzen Schildchen können mit der neuen Art verwechselt werden, deren Kopf so stark von vorn her zusammengedriickt, daher so flach ist, daf er und die Augen im Profil gut zweimal so hoch wie lang sind.

Kopf wachsgelb, mit sehr steil abfallender Stirn. Das Untergesicht tritt nur etwa $1 / 3$ des wagrechten Augendurchmessers vor die lotrecht gestellten Augen vor. Die Stirn ist die Hälfte des Kopfes breit, ohne Querfurche, von rotgelber Grundfarbe, die in zwei fast parallelen und gleichbreiten medianen Längsstreifen und zahlreichen Wurzelpiinktchen der kurzen und zarten schwarzen Grundbehaarung sichthar bleibt, sonst aber in dem mit den zwei roten Längsstreifen gleichbreiten und fast unpunktierten Zwischenraum der Mitte und den seitlichen Stirndritteln an den Augen dicht weißlich bestäubt ist. Ozellenfleck und die kurzen Scheitelplatten glänzend schwarzbraun. Scheitelkante ziemlich scharf. Cerebrale gelbrot. Hinterkopf in der Mitte und oben schwarz, licht bestäubt.

Fühler schwarzbraun. Klypeus relativ flach, nicht stärker als die Stirn vortretend. Rüssel und die langborstigen Taster schwarzbraun, letztere an der Wurzel rot. Fulcrum hell rotgelb.

Thorax und Schildchen von glänzend metallisch grün-schwarzer Grundfarbe, Riicken und Schildchen dicht, Hinterrïcken und obere Plemen weniger dicht, untere Pleuren nicht hell gelblich-grau bestäubt. Rüicken und Schildchen sind dicht mit Wurzelpiunktchen der Grundfarbe an den Haaren bedeckt.

Während die Stirnbehaarung sehr kurz ist, sind der Rïcken, namentlich aber die Oberseite des Schildchens, sowie die Ränder der Mesopleuren und Stemopleuren lang, ja man kann sagen borstig behaart, wodurch diese Art vor allem charakterisiert wird.

Auch die Beborstmng ist nicht wie gewöhnlich bei den Timien rudimentär, sondern wohl entwickelt. Am Kopfe sieht man 1 bis 2 Frontorbitale, 1 Ozellarpaar, 1 inneres und ein äußeres Vertikalpaar und ein kleines, paralleles Postvertikalpaar; am Thorax 1 Humerale, 

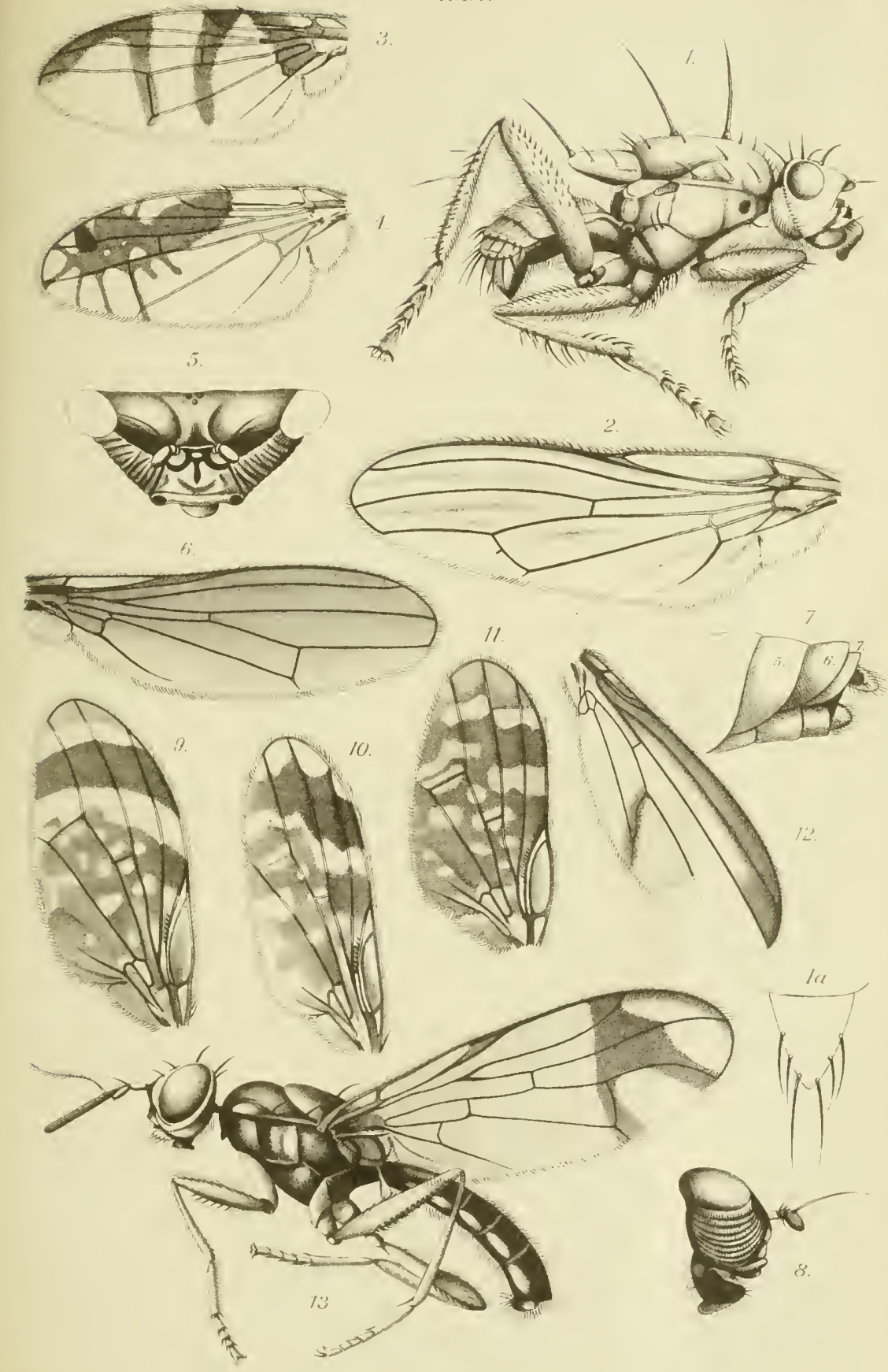

2 Notopleurale, 3 Supratilire, 1 I'aar Dorsozentrale und l'rïskutellare, 1 deutliche Irothorakale, mehrere Mesopleurale an der Naht und eine stärkere Borste unter den Borstenharen oben an den Sternoplemren. Das gewölhte Schildchen hat anBerdem 4 lange Randborstem.

Hinterleib glänzend metallisch blaugriin, ziemlich hell für eine Timia, ohne Punktierung. Das erste Glied des Uripositors hat den gleichen Schimmer, scheint aber rötlich durch und ist ein- und einhalbmal so lang wie das letzte Segment des Abdomens, breiter als lang, hinten sehr stumpf. Die schwarze Beharung des Hinterleibes ist gregen dic Spitze zu ziemlich rauh. Beine normal beborstet. Die Sehenkel sind mit Ausnalme des Spitzendrittels glänzend schwarzgriun, sonst wie dic Schienen und Füße rotgelb. Dic Spitzen der vordersten Schienen und Fübe sind merklich gebräunt. Hiiften schwarz. Schiippchen und Schwinger gelblich. Flügel wasserklar mit gelhen Arler'll.

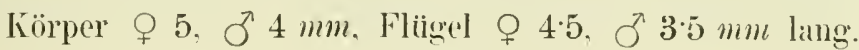

\section{Subfam. Tephritinae. 1)}

Urophora tenuis n. sp.

Q రૅ aus Kungruily, April 1887, Turkmenien. K. k. Hofmuseum, Wien.

Diese und die nächste Art gehören zu der Gruppe mit querbandierten Flïgehn und schwarzen, nur an der Spitze grelben Schenkeln. Von allen bekannten Arten unterscheiden sie sich aber dadurch, dab die Discoidalis merklich vor der Flügelspitze mündet und die braune Spitzenquerbinde gerade an rler Spitze endet und nicht unter dieselbe herabreicht und daß die erste Hinterrandzelle an der Mündung ganz merklich verengt ist.

Den Fligel der Ur. tenuis zeigt Fig. 3, Taf. I. Die erste Querbinde ist an der Mnalader nicht herabgezogen und beriulnt die zweite gerade erst an der Kosta; beide sind an Flïgelvorderrande durch eine rostbraune Stelle getrennt. Die zweite Querbinde ist gebogen. verschmälert sich nach hinten, ohne den Flig gelhinterrand zu erreichen, ist anßen und hinten scharf begrenzt, nicht verwaschem und an den Längsadern nicht ausgezackt. Das letztere gilt auch von der dritten Querbinde, die ganz gerade ist und sich an Hinterrande spitzig zusammenzieht. Die apikale Querbinde reicht, wie schon gesagt, nur bis zur Fliigelspitze, und ganz wenig unter die Discoidalis

1) Nimmt man den ältesten Gattungsnamen, so muß man mit Czerny Euribiinae schreiben. 
herab. Der glashelle 'Zwischenraum zwischen ihn und der 3. Binde reicht unten etwas in die Submarginalzelle hinein. I)ie Farbe der Querbinden ist ein tiefes Braun; sonst ist der Flïgel glashell, an der Wurzel etwas gelblich tingiert.

Stirnstriene gelb, vorn oft rotgelb. Ozellenplatte, die Augenränder, die Lunula, die Wangen und Backen weiligelb, porzellanartig gläızend. Fiihler, Taster mond Riissel rotgelb, letzterer noch etwas länger als bei Lr. quadrifasciata Mg. und auch gekniet. Hinterkopf ganz schwallz.

I) Ke Körperfürbung wie sonst bei den Urophora-Arten. Der Riicken ist ziemlich dicht gelblichgrau bestäubt. Das Schildchen ist fast gamz gelb, nul an den Seiten der Basis ein wenig schwärzlich. Schienen und Tarsen ganz hell rotgelb. Die Legeröhre ist so lang oder fast etwas länger als der Hinterleib.

Kö̈rper ohne Legeröhre etwas über $3 \mathrm{~mm}$, Flügel $3 \mathrm{~mm}$ lang.

\section{Urophora nigricornis n. sp.}

万o aus Ober-Murgab, April 1887. Turkmenien. K. k. Hofmuseum, Wien.

Steht der $U$ r. temis seln nahe. Ihr fehlt aber die erste F l ü gू e l y u e r b i nde v o l l st ä n d i g. Die Analzellen sind ganz glashell nur der Vorderrand des Flügels ist an der Flügelbasis rötlichgelh tingiert. Die zweite Querbinde ist gerarde, noch schmäler als bei $L r$. tenuis und erreicht ganz den Hinterrand. Bei einem Stiicke bricht sie schon unter der Discoidalis ab. Auch die dritte Querbinde ist gerade und streifenförmig. Der glashelle Zwischenraum zwischen beiden ist oben hreiter als unten, oben viermal, unten dreimal so breit wie eine der (uerbinden. I)ie apikale Binde hat dieselbe Lage wie bei temuis, der grlashelle Zwischenraum ror ihr reicht aber bis in die Marginalzelle hincin.

Fühler tief braunschwalz. Die Legeröhre ist länger als der Hinterleib. Die Art ist etwas gröber als $U_{r}$. tenuis, in allen iibrigen Ierkmalen ihr aber gleich.

\section{Urellia ang'ur Frfld, var. tridens 11. v.}

Frauenfeld, Sitzber. k. Akad. Wissensch. Wien, XXII. Bd., p. 556 , Taf., Fig. 10 (1856). - Loew, Berlin. Ent. Zeitschr., Vol. V, 1. 304, Taf. 2, Fig. 30 (1861).

3 万o ron Ober-Murgab, Turkmenien. April 1887. k. k. Hofimuseum, Wien. 
I) von beiden Autoren von der auf der Halbinsel Sinai gefangenen Tephritine gegebene Beschreibung stimmt mit Ansnahme einiger Verschiedenheiten der Fliigelzeichnung ganz auf einige Fliegen aus Turkmenien, so dals ich in letzteren nur eine Varietät der Fratuenfeldschen Art erblicken kann. Diese Verschiedenheiten bestehen, wenn man meine Figur 4, Taf. I, betraclitet, darin, dafo rom Aderabschnitt der Discoidalis zwischen den (Qnerarlem drei und nicht blob zwei Bindenrudimente in die Diskoidalzelle hineinragen und dafo aubiser dem groben glashellen Fleck an dem genannten Arlerabschnitt in der ersten Hinterrandzelle noch ein bis zwei helle Punkte zu sehen sind. Auch die Größje der 'Inrkmenischen Fliegen ist etwas größer,

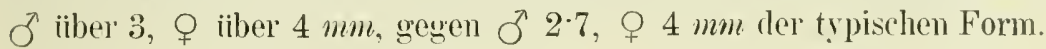

Ich hätte diese Form noch eher für eine selbständige Art gehalten. wenn ich nicht an einer Reihe von Stïcken der I'rellia stellata Fiiessl. von derselben Lokalität und ans Kileinasien (Erdschias. I)r. P e nther) ein vollständiges Übergehen der Flügelzeichnung in jene der Urellia decora Loew ans Suidafrika konstatiert hätte, so dafo mir auch letztere Art nur eine Varietät zu sein scheint.

\section{Meracanthomyia nom. nov.}

für Meracantha, Nacquart, I)ipteres exotiqnes, Suppl. IV, p. 285, l'l. 26, Fig. 9 (1850), präokkupiert durch Meracantha, Kirby, Faun. Boreal. Amer., IV. I. 237 (1837) (Tenebrionidae).

Diese Dacinengattung wurde meines Wissens seit Maryuart von keinem Dipterologen mehr aufgefunden. Loew hielt sie in den Monogr. of $\mathrm{N}$. Amer. Dipt., Ýol. 3, p. 23, für eine Richardiine, korrigiert aber auf p. 70 diese Auffassung, ohme einen anderen bestimmten Platz im System anzugeben. Van der Wulp zählt sie in seinem Catalogne of the descr. I)ipt. from S. Isia (1896), pag. 193, wohl bei den T'ephritinen auf, aber nicht in der Nachbarschaft von Dacus und Ceratitis, wohin sie gehören wiirde.

Nir liegt eine nene Art aus Ceylon vor, die olne jeden Zweifel in die Macpuartsche Gattung gehört.

\section{Merac. gamma n. sp.}

$1 \delta^{\nearrow}$ aus Ceylon. K. k. Hofinuseum, Wien.

Die Stirn ist sehr schmal, oben nur die Hälfte eines Anges breit, nach vorn hin wenig breiter werdend, der quere nach etwas konkav, vorn fïr die grolie, vortretende Lunula bogig ausgeschnitten, 
oben die eng zusammengedrängten (zellen ganz an der Scheitelkante tragend. Der Farbe nach ist sie gelbrot, nach oben hinauf immer: dunkler bis schwarz, wie der obere Hinterkopf, gefärbt. Javon heben sich die weiblichen Scheitelplatten. die an der Spitze vorn je eine obere Frontorbitalborste tragen. und die weiljgelben Augenränder scharf ab. Ozollarborsten und Postvertikalborsten fehlen. Von den zwei Scheitelborstenpaaren sind die inneren parallel. Untere Frontorbitalborsten sind zwei nach innen geneigte Paare vorhanden. Lumula umi Klypeus glänzend schwarz, letzterer aber unter den Fühlern und seitlich am Rande gelb. Wangen, Backen und unterer Hinterkopf gelb. I'nter dem Auge auf den Backen ein schwarzer Fleck. Die Stirn und der Klypeus stehen in I'rofil etwas vor die Angen vor: letzterer ist im Profil winklig gebrochen. am Mumdrande emporgezogen und vortretend, der Quere nach stark gewölbt. Wangen und Backen sehr schmal. Oberer Hinterkopf ziemlich Hach. unterer gewölbt. Augen länglich oval, etwas schief gestellt.

Fihhler aufergewöhnlich verlängert, vorgestreckt; alle drei Glieder selı dentlich. Erstes (ilied eiförmig, so lang wie das zweite, mit demselben ein schwaches Kune bildend; zweites oben ausgeschnitten und die Wurzel des dritten umfassend. an der Wurzel mit einer langen abstehenden Borste versehen: drittes Glied linear und schmal. allein schon länger als der Lopf́, mit basaler, an der Basis verdickter und dann fein und kurz gefiederter Arista. Die ersten zwei Gilieder der Fiihler rotgelb, das dritte schwarzbraun. Riissel und Taster rotgelb.

Thorax länger als hreit, mit einer vollständigen, anch die Thoraxmitte tief durchfurchenden Quernaht. Schildchen ein Viertel des Riickeus lang, spitz dreieckig, oben Hach. zwciborstig. Anf dem Thorax sieht man 2 Notopleurale, 2 Supraalare und 1 Mesopleurale.

Der Farbe mach ist der 'Tholax glänzend pechbram. C̈ber die Rïckenmitte verläuft eine lichtere, durch Bestäubung und hellere, rote Grundfarbe erzeugte Längsbinde. Her Humeralcallus und die Stigmengegend, sowie die Mesopleuren neben der Naht porzellanweiß. Die Lateralgegend des Rückens, namentlich an und hinter der Quermaht gelbrot, desgleichen das nur oben in der Mitte braune schildchen. Der Riticken und das Schildchen verlieren durch die kurze, anliegende helle Behaarung etwas von ihrem Glanze und erscheinen auch wie fein punktiert. Des glänzend pechschwarze Hinterleib ist länger als der 'Thorax, schmal, gegen die Basis hin allmählich verschmälert, flaumig, hell behaart, nur wenig von olen her zusammengedrickt. J as rundliche Hypopyg ist nur sehr klein. 
Die rotgelhen Beine sind lang und schlank, die Schenkel etwals vardickt, die mittleren jedoch merklich stärker und auffallend länger als die anderen. Die Vorder'- und Hinterschenkel sind auf' der Unterscite nur in der Spitzenhälfte, die mittleren aber fast der ganzen Länge nach mit kuzen schwarzen Dornen zweizeilig besetzt. Mittelsthienen innen mit einem Endsporn. Die Wrureln der beiden hinteren lieinpaare sowie die Spitze der Hinterschenkel rotbramn. Yorder-und Mittelhiiften gelb.

Das Fliigelgeäder zeigt die Abbildung besser als es Worte beschreiben kömnen. Der Flïgel ist ganz glashell mit bramen Adern; die Subkostalzelle sowie die Fliigelzeichnung an der Spitze sind rotbraun. Inie Subkosta und die Gabelstelle der Cubitalis sind beborstet. schwinger und Schiippehen weilogelb.

Körper ohne Fühler $8 \mathrm{~mm}$. Fiihler $2 \mathrm{~mm}$, Flïgel $7 \mathrm{~mm}$ lang.

Anmerkung. Die Il acquart sche Merac. maculipennis 1. e. atus Indien unterscheidet sich auber durch spezifische Färbung durch atheichende Länge der zwei antemnalen Wurzelglieder und namentlich durch die Form der ersten Hinterrandzelle, wolche durch gerade Längsader'n begrenzt wird, und durch die Gleichleit der letzten zwei Abschnitte der Ibiscoidalis.

\section{Subfam. Sciomyzinae. Gruppe Sciomyzina.}

\section{Ïber Sciomyza virgata Haliday.}

For einigen Jahren saudte mir Herr A uste m rom Brit. Mnseum in London einige $\delta^{\top}$ und $q$ einer ans der Emgebung von London stammenden Sciomyza-Art, welche mir bei der .. Revision der paläarktischen sciomyziden" 1902 noch nicht bekannt war. I)iese englische Art steht der von mir als Ditcenia Lichtwardti p. 68 loc. cit. beschriebenen, besser aber wohl bej der Gattung Sciomyza unterzubingrenden Fliege sehr mahe. Ich folge damit einer Anregung des englischen I)ipterologen und genialen Illustrators der ..Pritish Flies“, J. E. ('o ll i in. durch dessen Pielegstiicke ich anch in Kenntnis gesetzt wurle, dalo die in Velralls List of British Diptera, 1901, p. 31. aufgezählte Sciomyza virgata Haliday gleich der von 1 usten gesammelten Fliege ist. Iannit escheint auch die von mir l. e. p. 42 gemalde Notiz berichtigt, in der List sei pallidiventris Fall. mit rufivcntris Schin. verwechsolt: ich sah die echte Sciom. pallidiventris Fall. alls Eugland.

Amelers steht die Sarche, ob wir den Halidayschen Namen fiij die mir nun vorliegende Art annehmen diisfen. Ich habe in 
meiner Monographie Sciom. virgata als Synonym zu pallidinentris Fall. gresetzt. Dazu bewogn mich nebst dem Übereinstimmen der kurzen Haliday schen Beschreibung mit der von Fallén charakterisierten Fliege namentlich die Angabe "the naked arista of this species (virgata) should be particularly observed". Das stimmte mir danals nur auf pallidiventris Fall., weil mir die nene Art nicht bekannt war, deren Arista gleichfills fist nackt ist und die anch in der Gröbe, Körper und Flïgel bis $6 \mathrm{~mm}$ lang, melır den Ha li d a y schen Jaßen gerecht wirl, als die nur $3.5 \mathrm{~mm}$ lange pallidiventris Fall. Aber auch die von $\mathrm{Halliday} \mathrm{gekennzeichnete} \mathrm{Beinfärbung} \mathrm{palit} \mathrm{besser}$ auf die mir newe drt als im allgemeinen auf die Fallénsche. bei der bei manchen Stiicken anch die Schenkel und Schienen stärker gebräunt sein kïmnen. Freilich gilbt es wieder Exemplare, anf welche die Halida y sche Beschreibung der Beine vollinhaltlich palit. Nimmt man aber als wahrseheinlich an, dak Haliday die in England nicht seltene achte Sc. pallidiventivis Fall. wohl gekannt haben mag, so seheint die Dentung der mir bisher nur ans Englind bekimnt gewoldenen Alt als Sciom. virgata Hal. als nicht zol gewaght.

Aber anch die Beschreibung der Sciom. albicarpa Rondani möchte ich, namentlich wegen der darin angegebenen zwei Jerkmale: "ein schwärzlicher I'unkt zwischen Fïhlerwurzel und Augge und die beiden Queradern dunkel gesäumt", anf dlie englische Art beziehen. Sie stimmt auch sonst ganz gut!

Sciom. virgata Haliday (= albicarpa Iiond.) will ich nm im Vergleich mit der ihr am nächsten stehenden Art Sc.Lichtuardti cluarakterisieren. Beide Arten haben in der Verlängerung der Ozellenplatte nach rorn hin eine zugespitzte, silberschimmernde Strieme. welche aber mehr eine Zeichnung als eine feste Chitinleiste ist, weshall) ich die beiden Arten zur Gattung Sciomyza und nicht zn Ditaenia stelle, wie oben angedeutet.

Sciom. Lichtwardti Hendel.

Stirnvorderrand wie die ganze Striene samtartig, matt rotgelb, sehr fein und zerstreut behiart.

Stim beim ơ neben den Fiihlern dentlich schmäler als ein Auge, beim $O$ kaum breiter als ein Auge.

Zwischen Fühler und Auge fehlt ein dunkleser Fleck.
Sciom. virgata Haliday.

Stirnvorderrand breit wachsartig glänzend, relativ dicht und rauh behart.

Stirn beim of so breit wie (in Auge, beim $q$ deutlich breiter.

o mit tieforelbem. O mit schwärzlichem Fleck zwischen Fiihlern und Auge. 
Mrista pubeszent.

'Thoraxricken in der Zentralu. Lateralgegend einfarbig aschgrau. Desgleichen die I'leuren.

2-3 Pteropleuralborsten in ciner Reihe.

Hinterschenkel des ơ unten kiılum länger behaart.

Flügel glashell mit gelben Adern. Anch die kleine Querater gelb.
Arista nackt oder fast nackt.

Lateralgegend deutlicher gelblich als die mehr grane Zentralregion. I'leuren gelblichgrau, oben mit einer meist deutlichen bramen Binde.

Vier Pteroplemale, ein unregelmäßiges Viereck bildont.

Hinterschenkel des o kimz buirstenartig behaart.

Fliigel an der Kosta linter der Mediastina etwas quebräunt. Beide Queradern dunkel gerandet, die kleine tief schwarz gefärbt.

Sonst ist bei $S c$. virgata der gelblichgraue Thoraxricken mit vier dunkleren Längsstriemen, wovon die seitlichen vorn abgekiirzt sind, gezeichnet.

Die Beine sind gelb. Die Vorderschienen an der Spitze etwas tiefer gelb. Beim $O$ ist der Metatarsus der Vorderfiiße weifgelb, an der Spitze und die folgenden 4 Glieder schwarzbraun. Beim ơ sind die Vorderfïlo fast ginz gelb, nur gegen die Spitze hin etwas dunkler.

Die Sciom. scutellaris Roser wird in der "List of Brit. Diptera" als Sciom. pallidicarpa Rondani aufgezählt. Ich kam dem aher nicht zustimmen, da Rondani ja die Rosersche Art gekannt und auch wut beschrieben hat. Sciom. pallidicarpa steht dagegen der Sciom. Lichtwardti jedenfalls sehr nahe, unterscheidet sich aher nach der Beschreibung durch die nicht roten Schultern. Ohne die Ronda n ische 'Type gesehen zu haben, läbt sich wohl kein sicheres ITrteil fällen!

\section{Subfam. Helomyzinae. Gruppe Leriina.}

\section{Thyveophorella, eine nene Gattung der Helomyzinae.}

Unter den undeterminierten Dipteren der Winthemschen Sammlung in Wien entdeckte ich ein Stïck aus Brasilien, das durch die Länge und Stärke der Borsten auf Kopf, Schildchen und Thoraxriicken - man betrachte die Riickenborsten der Figur 1. 'T'afel I, die anfgerichteten Spiefien gleichen - auffiel. Die sonderbare Kopfgestaltung mit dem grublig rertieften Klypeus, dem stark rol'springenden Epistom, die kleinen runden Iugen, die Fïhlerform, die 
stilk beborsteten Mittel- und Hinterschienen, diss verlängerte Schild(hen, dic kaum beborstete Kosta, die eng beisammen verlanfenden Längsadern Mediastina und Subkosta, die vorn nicht banchig, sondern grerade begrenzte. unten nicht zuriickweichende, sondern rechteckige Analzelle, das alles sind Merkmale, die sich nicht so schnell unter einen Hut bringen lassen.

Da ich mich von dem systematischen Werte des Index-Charakters .. I'ostvertikalborsten gekreuzt" im Laufe meiner Studien genügend iiberzeugt habe, kommen nur die Subfamilien der Acalyptratengruppe in Betracht, welche diese Borstenstellung zeigen.

Die Subfamilie der Coelopinae ${ }^{1}$ ) hat wohl anch eine ähnliche Kopfform wie Ihyseophorella, namentlich auch beborstete Schienen und eine nicht bauchige, sondem minten eckige Anatzelle. Auch die Fußendglieder sind im Vergleiche mit den anderen vergrößert. Ein wesentliches Merkmal der Coelopinae scheint mir aber ror allem die ganz absonderliche Flachheit des ganzen Leibes. die geringe Höhe der Brust und damit rerbunden das Ausgrehöhltsein derselhen an ten Pleuren über den Vorderhüften zu sein, ein Nlerkmal, das nicht in (ntferntesten auf Thyreophorella past. Auch zeight diese Gattung am I'ibrisseneck nur eine einzige, starke Borste, während die Coelopinen dort und an den Peristomalien eine Reihe gleichstarker Hatrre anfweisen.

Kommt also die Gruppe der Coelopinae nicht in Betracht, so bleibt unter allen anderen mit gekreuzten Postvertikalen nur diejenige der Helomyzinae und zwar die Untergruppe Leriina derselhen, in welche unsere Gattung eingereiht werden kann. Freilich zeigt keine der mir bekannten Helomyzinengattungen eine ähnliche Kombination der eingangs aufgezählten Charaktere der Thyreophorella, doch der Monograph dieser Gruppe. Herr Abt L. Czerny, schrieb mir nach Untersnchung der Fliege, daß die Gesichtsbildung derselben der bisher noch nicht charakterisierten Borboropsis fulviceps Strobl gleiche und er sie unbedingt für eine Leriine halte. Die dem Kollegen $\mathrm{Czer}_{\text {r }}$ ïbersandte Fliege war aber nicht das brasilianische stiick, sondern dic IV iedemannsche Type del Scatophaga diadema aus Montevideo, welche ich erst später als zur gleichen Gattung gehörig erkannt hatte und die vielleicht gar bloß das andere Geschlecht darstellt.

Wi edemann schreibt am Schlusse seiner Beschreibung: ..Im lierliner Inseum unter der Bezeichnung Diacia diademu, wohin anch die emropäische $M$. furcata Fab. gezählt wird."

1) Ich wähle diesen Namen, weil Coelopa die verbreitetste und älteste Gattung dieser Gruppe ist und nicht Malacomy za Hal. (= Phycodroma Stenh. nach ('zerny.) 
Darans ist deutlich zu erkemen, dab die Scat. diadema fïr eine zıI Thyrcophora gehörige Art gehalten wurde. Veramlassung hiezu kann dlas verlängerte. spitze Schildchen geben, das aber bei den 'Thyreophorinen eine wesentlich andere Gestalt hat. Da aber diese (iruppe divergente l'ostrertikale besitzt, kommt sie in meinen Augen nicht in Betracht.

\section{Thyreophorella 11 . gen.}

Stirn fast wagrecht, gut dreimal so breit wie ein Auge, parallellandig. Ozollenplatte allein dentlich differenziert. kurz und klein, wamz oben am Scheitel, die 3 l'mntangen nicht weit voneinander entfernt. Die Stirn ist mit ihrem Vorder'ande etwas ïber die Wurzeln der Fiihler vorgezogen, bildet dort im Profile mit dem Klypeus eimen ungefälır rechten Winkel, ist der Länge mach nicht, der Quere nach mäbjg gewölbt mud geht oben ohne scharfe Scheitelkante in allmählicher Wölbung in den konvexen Hinterkopf iiber. Ihre Grundbehaarung ist kurz und fällt wenig auf. Die Wangen und Backen sind außerordentlich breit, erstere 2 I)rittel, letztere 3 Inittel des Durchmesser's der völlig runden Angen breit, beide nackt. Die Grenze des behaarten mol etwas wulstigen muteren Hinterkopfes ist als eine schicfe Linie hinter den Angen bis zum tiefsten l'unkt des Kopfes scharf abgesteckt.

Der Klypeus liegt vertieft, linter den Stirnvorder- und den Seitenrand der Wangen zuriickgezogen, so dals nm das dritte Glied der Intemen sichtbar bleilot. Was ist der Fall bei einem od und einem $q$, wälnend die Type der Scat. diadema Wied., ein $q$, ein eben ausweschlüpttes Stuich mit Resten der Stirnblase in der Spalte iiber den Fiihlern einen nicht versenkten Klypeus wie die anderen 2 Stiicke zeigt. Der Klypeus ist im I'rofile winkelig gebrochen, das Epistom minten tritt stark, fast wagrecht vor. In der Längsmitte wird er von cinem scharfen Kiele durchzogen, an dessen beiden Seiten muldenartige Vertiefungen fiur die Fühler liegen. Yon vorn geselsen ist der Yundrand stark in die Höhe gezogen, fast in die Linie des mnteren Angenrandes, seine seitlichen liegrenzungen sind die seln kurz belatarten Peristomalien bis zum Vibrisseneck, das jederseits seitlich neben dem Mundrande liegt. l)as Epistom tritt aber noch iiber das Vibrisseneck hinaus vor und umschliclist ein deutlich rorstehendes. wenn anch kleines L'rälabrum. Dic Äste der Stimspalte divergieren rtwas nach monten und biegen beim ó auch noch etwas iiluer den Vibrissen anf die Backengruben $11 m$. 
Die Fiihler sind kurz, teilweise versteckt, aber abstehend. Das erste (ilied ist becherartig, kurz aber breit; das zweite kleiner und schmäler, oben anch mit einer längeren abstehenden Borste versehen; das dritte grolo, von abgerundet beilförmiger Gestalt. Der Oberrand ist gerade, der Enterand hat eine rechtwinklige Ecke, die grerade so wie die vordere Spitze abgermondet ist. Arista an der Wurzel stark spindelig verdickt, damn dïnn, iiberall fist nackt: sie steht etwas vor der Mitte des Oberrandes.

I)er Riissel ist grolo, hat starkes, horniges Kinm und zuriickgrelegte breite Labellen. Die Taster sind von normaler Länge, aber von ziemlicher und fast gleicher Breite, mnten und an der Spitze langhorstig.

Beborstung. C : 2 Frontorbitalborsten in der oberen stimhälfte, hintereinander. Das vordere l'aar aubergewölmlich lang mnd stark, mehr nach andien als nach vorn gebogen; das hintere Par schwächer, nach hinten und anljen gebogen. Ozellan'palar stark und lang, nach rorn geneigt und stark divergierend. Beide Scheitelborstenpare stehen noch innerhalb der Verlängermng der Stinnangenränder, die inneren, stark gegeneinander geneigten ror den divergierenden änferen. Die Postvertikalen sind lang und stark und mit den Spitzen gekrenzt. Am Vibrisseneck eine einzige starke Borste. Unterer Hinterkopf lang wollig behart.

Thorax. Dorsozentralborsten 3 Paar linter der Naht. mit Ausnahme des letzten I'ares vor dem schildchen senkrecht infgerichtet, außerordentlich verlängert und stachelartigg verdickt. Vor der Quernaht nur jederseits aine Reihe von eirea 5, mach rorn hin an Gröbe abnehmender Borsten. I'räskntellare fehlen. Nkrostichalbörstchen zweireihig, nur rorn sichtbar. Humerale 1; Notoplemrale 2; Präsutmale 1: Supraalare 3; Intrahmmerale 1, ibber der hinteren Notoplenralborste; Schildchenborsten 6 , jene 2 an der Spitze auch spiefförmig.

Eine starke Prothorakale, 1 Stigmatikitborste. Mesopleuren sogar unbehaart, nackt. 2 sternoplemalborsten mebeneinander.

1)ie Beborstmng der o mterscheidet sich dadurch, dals die Borsten nirgends die spiefform ammehmen, aber doch länger. wenn anch dïnner sind als die nicht verdickten des o $\sigma^{7}$. Her Hamptunterschierl besteht in der Zahl der Dorsozentralborsten, die beim $q 4+2$ beträgt, und in dem Torkommen eines Präskutellarpaares.

Der 'Thorax ist hoch und gewöllt, an den Plemen rorn nicht eingedriickt. Der Riicken ist etwas länger als breit, das verlïngerte Schildchen ungefäln die Hälfte des Riiickens lang, beim ó kiirzer 
und nur so lanğ wie breit, beim O länger und merklich länger als an der Basis breit, ron dreieckiger Gestalt mit abgerundeter Spitze. I)ie Quernahtäste des Riickens steigen sehr schief ron hinten nach vorn auf.

Der Hinterleib ist ungrefähr so lang wie der Thorax olme schililchen oder fast küirzer, von eiförmiger, gewölbter (iestalt. 1)as batsale Doppelsegrnent ist fist die IIälfte des Abdomens lang. Juf dasselbe folgen beim of noch 3 , beim $q$ noch 5 sichthare Iinge. Beim $\sigma^{\pi}$ sind die Hinterränder des 4. und 5. T'ergits nit einem líranze abstehender, besonders seitlich sehr starker und langrer, nar'l unten gebogener Borsten besetzt. Das darunter liegende Hypopyg hat rine stumpf kegelige Gestalt. Beim o sind die hinteren 'T'rerite nu' mit langen Borstenhaaren ziemlich dicht besetzt.

Beine mittellang, aber sehr krättig. Schenkel etwas rerdickt. schienen borstig. Vorderschenkel mit Ausnahme der Vorder-(Innen-) seite mit langen feinen Haaren dicht abstehend bedeckt. Unter diesen. besonders beim ơ wolligen Hatren sind posterodorsal und -ventral je eine Längsreihe etwas stïrkerer Borstenhatare erkennbar. Nittel- und Hinterschenkel rorn kurz rauhhaarig, posteroventral fein loarig grewimpert, erstere an der Hinterseite mit 3-4 zur Spitze aufsteigenden und gebogenen kurzen fiorsten besetzt. Torderschienen aufer der I'uäapikalen olne Borsten, nur etwas läng̣er als gewölnulich behart. Mittelsehienen ald und pd mit 3-4 langen und starken Borsten, zwischen welchen namentlich beim ơ noch einige kürzere auftreten kömnen. besetzt. Anberdem hat die Schienenspitze rund herum einen ganzen Kranz borstenutiger Sporne, zu welchen ventral ror der Spitze noch einige starke, geksiumte hinzukommen. Hinterschienen außer der Präapikalen ad mit 3-4 kiirzeren, aber starken liorstelı, pd mit meist 3 Borsten in der oberen llälfte, wovon die gerade etwas iiber der Schienenmitte stehende durch ihre besondere Längre auffällt. Füße kräftig, die Glieder an ramole dornigg, das letzte Glied relativ sehr grob. Klanen stark, l'ulvillen normal.

Fliigel grof und sehr lang. Kostil in der Mitte beim on nit sehr kurzen und zarten, alıer doch deutlich wahruehmbaren Börstehen besetzt, beim o minder gut oder kaum merklich beborstet. Yor der Miindung der Mediastina ist die Kosta eingeschniurt. Dic subkosta mindet wenig hinter der Flïgelmitte mol in sehr geringer Entfernung vor ihr die in ilırer ganzen Längge gretrennte, aloer enun dancbenlaufende nud erst gegen das Ende hin etwas diverwierende Mediastina. I)ie Suhlostalzelle ist daher sehr schmal und an der 
Spitze durch Zusammenlanfen der Länğgadern hornig. Die Kostalzelle dagegen ist von besonderer Breite und luänge. Die Längsadern 2-4 sind sanft gebogen und fast parallel zu einander. Die erste Hinterrandzelle ist gegen den Flügelrand lin etwas verengt. Die kleine Querader steht etwas schief, unter der Mündung der Subkosta und jenseits der Mitte der Diskoidalzelle. Die hintere Querader steht sehr schief, der Winkel mit der Posticalis ist ein selur stumpfer. Die Basalzellen sind grofo. Die Analzelle wird vorn durch eine gerade Querader geschlossen, die mit der Mnalis unten einen rechten Winkel bildet. Die Analader erreicht den Fliigelrand nicht wamz.

'Typische Irt

\section{Thyreophorella diadema Wiedemamn.}

O Scatophaga diadema, $\left.{ }^{1}\right)$ Wiedem., Aubereurop. Zweitl. Ins., Vol. II, 1. 448. 4 (1830). - o Thyreophorella ruficeps Hendel in litt. 2 o als Typen in der Wiedemannschen Sammlung des Wiener Hofmuseums ans M ontevideo und 1 on ans Brisilien, Koll. Winthen.

Das Mämnchen kammte ich zuerst und hatte es schon als Thyr. ruficeps beschrieben, als ich beim Betrachten der Wiedemannschen Art in derselben einen rattmosgenossen entdeckte. Bei einor grenaneren Vergleichung der Tiere zeigten sich mir folgende Lnterschiede des $\sigma^{7}$ vom $q: 1$. die stachelartige Borstenbildung des Riickens, Sichildehens und Kopfes, 2. die verschiedene Zahl der Dorsozentralborsten, 3. das Fehlen des Präskutellarpares und 4. die germgere Länge des Schildchens. Da aber diese Tuterschiede teils ( 1 u. 4) anf Geschlechtsdimorphismus, teils (2 und 3 ) anf individueller Variation berulen kömmen und die Fliegen sonst in Färbung und Gestaltung sehr gat iibereinstimmen, aulierdem nur ein eimziges of rorliegt, will ich dirselben vorlänfig nur als Geschlechter ein und derselben Irt auffissen.

Kopf rotgelb bis gelbrot, oberer Hinterkopt, Ozellen- und Scheitelplatten bis zur oberen Orbitalborste schwarz, mäljig glänzend: Mittelstrieme der Stirn ein Drittel derselben breit und vorn etwas verjiungt, mattschwarz. Wangen und Backen weibschimmernd. Fühlel schwarz. Mittelleiste und Mundrand des Klypens schwarzbram, ebenso das l'rälabrum, der Riissel mol die Spitzenhältte der 'T'aster.

Der ganze Kïrper granlichsehwarz, nit stellenweise braunen Reftexen und geringem Glanze. Hypopyg gelbrot. Beine glänzend

1) Das 'Tier, das Rondani in seinen Dipteris exot., Arch. Zool. Iodena, Vol. 3, p. 35 (1863) als Scatina diadema Wied. aus Lahrador bestimmte, wird wohl eine Scopeumı-Art, ganz wahrscheinlich aber nicht die obige Spezies sein. 
schwarz, alle Fubghieder an der W'urzel rötlich, an ausgedehntesten der Metatarsus. Flizgel gleichmäßig granlichhyalin mit rotbramen Adern. Der Aderambang der binteren Querader ist nur beim ơ sichthar. Schwinger bräunlich mit dunklerem Kopfe. Schïppehen braun gerandet und gewimpert.

Körper o $9 \mathrm{~mm}$, q $6-7 \mathrm{~mm}$ : Flïgel o $10 \mathrm{~mm}$, q 7 bis 8 mm lang.

\section{Subfam. Lauxaniinae.}

\section{Die Gattumg Cestrotus Loew.}

As ich in den Genera Insectortum. Subfam. Lauxan i inae, p. 12. die Charakteristik dieser durch einen turmartigen scheitel auffallenden Gattung schrieb, kannte ich nur die ostindische Irt C. frontulis Kertész. Seitdem latte ich Gelegenheit, anch vier afrikanische Arten kemnen zu lernen, so daf ich die damals gregrebene (iattungscharakteristik etwas aweitern muf.

I Bei allen mir bekannten afrikanischen Formen ist der Stirnhöcker niedriger unl stmmpfer, das ['ntergesicht nicht so stark vortretend wie bei C. frontalis Kert. (Bei der Charakteristik iieser und der folgenden Gattungen habe ich den Genera latuxan iin a rum die Linie der Gesichtsleisten (facialia) und der danit zusammenhängenden Backenleisten (peristomalia) irrtumlich als Stirnspaltenausläufer bezeichnet. Die Spaltenäste laufen wohl knapp neben den Fazialien, enden aber immer früher und biegen nie unter den Augen nach hinten herum. Das tun eben die Backenleisten, deren Linie in meinen Figuren deutlich erkembar ist.)

Fühler stark geneigt. kurz. Das dritte Glied ist oval. höchstens zweimal so lang wie breit. Die basale Arista ist auffallend lang und abstehend gefiedert.

Das Prälabrum ist viel kleiner als bei frontalis, schmäler mor tritt nur etwas iber den unteren Mundrand hervor.

Die Ozellarborsten kömnen anch parallel oder etwas divergierend und auch oberhalh des Stirnhöckers inseriert sein.

Lei $C$. oculatus ist die rräsuturale sehr schwatch, aber die I'räiapikalborste del Hinterschienen stark entwickelt. Letzteres ist anch bei C. megacephalus und tibialis der Fall. C. striatus wieder hat 2 sternopleural-, alle Afrikaner l'räskutellarborsten.

Bei dem schmaltligedigen $C$. oculatus ist die Cubitalis nackt. bei den anderen Arten in der Wu'zelhïlfte heborstet. 
Iieim Vergleiche der Beschreibung vou Ephydra pictipennis Wiedemann, Außerenrop. '/weitt. Ins., Bd. II, p. 593 rom Kap mit ler im k. k. Hofinnsenm befindlichen Fliege stellte sich nachträglich herans, dafo beide nicht zusammengehören. Die Loewsche Type befindet sich in Westermanns Sammlung und ist schr wahrscheinlich doch eine Cestrotus-Art.

Sic wiirle zu den Arten mit gelber Stim zu stellen sein, sich aber dadurch ron denselben nnterscheiden, dab die Höckerspitze glänzend schwarz, nicht gelb, ist und auber den grolien schwarzen P'unkten an den Höckerseiten noch je ein kleiner. tiefschwarzer Punkt zwischen Fiihler mnd Auge liegt.

\section{Ubersicht der Arten.}

Stirne weiblich oder hellgelb, nur oben anı Cerebrale und beiderseits am Höcker braun oder schwärzlich getteckt.

- Stime grau und brauntleckig, in der ganzen Vorderhälfte samtschwarz, mit 4-6 weißen und 2 gelben Flecken, die Höckerspitze glänzend schwarz.

1. Ostindische Art. Schildchen glänzend dunkelbraun, die Seiten hellbraun, die Spitze schwar\%. Der Lntergesichtshöcker springt um den wagrechten Augendurchmesser vor die Angen vor. Der Stirnhöcker ist ein Drittel der Augenhöhe hoch.

Cestrotus frontalis Kertész.

- Afrikimische Arten. Schildchen gelb, oben in der Mitte braun. Der Untergesichtshöcker und der Stirnhöcker treten nur einen greringen Bruchteil des entsprechenden Augendurchmessers über die Augren vor.

2. Mit jeder der beiden vor'n am Stimböcker liegenden dunkelbramen Makeln ist eine gleichfarbige am Stimaugenrande verbunden, die in der Mitte ein kleines ovales, weil tomentiertes Fleckehen besitzt, anf dem die vordere der 2 Frontorbitalborsten steht. - Kopf und Thorax von hell ockerbrauner Grundfarbe, stellenweise zart weibgranlich bereift. Wangen gelb, Gesichtsleisten schmal, schwar\%. Klypeus mit etwas dunkleren bramen Flecken, ebenso die Batcken. Fïhler gelb, Basalglieder braun. Arista lang abstehend gefiedert. Thoraxricken oben matt, in der Mitte mit zwei dunkleren, rotbramen Längsstriemen, die sich an der Anßenseite neben der (quemaht dreieckig, vor dem schildchen aber rechteckig arweitern. Auch hinter der (gnernaht 
an den 'Thoraxseiten zwei ïbereinamderliegende bratue Längsstreifchen. Humeralcallus gelb, dariber ein bramer Fleck. Unter der Notopleuralnaht eine braune Längsbinde von der schulter bis zur Fliigelwurel. Hinterleib bram, mit dunkleren Hinterrandhinden und graulicher Bestäubung der basalhälfte der 'T'ergite. Ireine grell. Schenkel mit Ausnahme der Spitze hellbraun. Schienen mit einem bramen Ringe an del Basis und an der Spitze. Tarsen gegen das Ende zu grebrännt. Flügel, wie 'T'ufel 1, Fig. 10 zeigt. Schwinger gelb.

Körper $6 \mathrm{~mm}$, Flügel $5.5 \mathrm{~mm}$ lang.

1 万' aus siidafikil, 8. XI. 1896 (I)unkersbosh). Dr. l'enther, k. k. Hofmuseum Wien. Cestrotus oculatus n. sp.

- Der Stirnhöcker trägt jederseits nur die eine schwarze Makel, die zweite, einen weißen Augenfleck einschließende, fehlt. Aschgrau. Thoraxricken mit 6 braunen Makeln. Hinterleib schwäızlich.

Körper $4 \mathrm{~mm}$, Flïgel $5 \mathrm{~mm}$ lang. (Nach Loew.)

Cestrotus turritus Loew.

3. Untergesicht rötlich, weil\} bestäubt.

- Untergesicht schwärzlich, weiß bestäubt.

5 .

4. Beine schwärzlich, Knie und schienenwurzel rötlich. Hinterschienen mit einem breiten, aber verwaschenen braunen linge in der Mitte. Flïgel ohne scharfrandige, isolierte schwarze Querbinde vor der Spitze, sondern ähnlich wie Figur 11, Tafel I. weils und schwarzscheckig.

Kö̈rper und Flügel nach Loew $4 \mathrm{~mm}$.

Cestrotus variegatus Loew.

- Schenkel mit Ausnahme der rotgelben Spitze dunkel rotbram, atlisen grau bereift. Schienen und Füife rotgelb, erstere an der biasis und an der Spitze mit einem bramnen linge, letztere gegen das Ende zu gebräunt. Flïgel nach Figur 9, Tatel I, mit eimer schwarzen, scharf abgegrenzten und isolierten, am Rande nicht ausgezackten Bogenquerbinde vor der Spitze. Die samtschwarze Vorderstinn mit 6 weißen Tomentflecken, 4 an den Wurzeln der Frontorbitalborsten, 2 zwischen Fülller und Augenrand. Auch die Lunula weilsschimmernd. Fülıler gelb, Basalglieder braun. 3. Glied oben etwas verlunkelt. Aristal besonders lange und abstehend grefiedert. Wangen und Backen grau. Hinterkopf und Oberstirn matt grau und braunscheckig. 'T'holax schwärzlich, aschgrau bestäubt. Riucken mit groben rotbranen Flecken un- 
regehmälig gezeichmet, bei dem einzigen Stiicke nicht gut (r'kennbar. Schildclen an liande rötlich, hell bestäubt. oben in der Mitte braum. Abdomen wie bei oculatus gefärbt. Schwinger gelh. Kö̈rper und Fliigel $4 \mathrm{~mm}$ lang.

1 J aus siudafrika, 8. XI. 1896 (Dunkersbosh). Ir. l'enther, k. k. Hofmusem, Wien. Cestrotus striatus n. sp.

5. Beine schwärzlich, aschgrau bestäubt, Knie und Wurzel der" Füße rötlich. Epistom unter den Backen schwärzlichgrau. Vorderhiiften grau. Der'santschwarze Streifen der Vorderstirn ist deutlich höher als seine halbe Breite, die weiben 'Tomentflecke der' Frontorbitalborsten sind durch den schwarzen Grund breit getrennt von einander. Fliigel wie Fig. 11, Tafel I, die schwänzliche Zeichnung iiberwiegt gegeniiber dem graulichhyalinen Grunde.

Körper und Fliigel ungefälı $4 \mathrm{~mm}$ lang.

2 Stiicke vom K a p, Typen L o ew s, k. k. Hofmuseum, Wien.

\section{Cestrotus megacephalus Loew.}

- Beine mit rotgelben Schienen und Tarsen, erstere nit rinem schwarzen Ringe an der Spitze, letztere gegen das Ende hiu gebräunt. Epistom unter den Backen rot. Vorderhiiften rot. Irer samtschwarze Streifen der Vorderstirn ist gut zweimal so breit wie hoch, die weißlichen Tomenttlecke der 2 genäherten Frontorbitalborsten beriihren einander. Flïgel in der Anlage der Zeichmumg genau wie bei megacephalus, nur hält sich das schwärzliche mit dem hyalinen Grunde in der Ausdehnung so ziemlich das Gleichgewicht, der Flügel erscheint entschieden heller.

Kürper und Flïgel $4 \mathrm{~mm}$ lang.

2 Stücke aus der Erythräa, Typen liezzis aus dessen Sammlung.

Cestrotus tibialis Bezzi.

Bull. Soc. Ent. Ital., Vol. 39, p. 126 (1908).

\section{Physogenia (Physegenua) congruens 11. sp.}

$2 \sigma^{\pi}$ ans I'eru, Sammlung B. Lichtwalt in Berlin.

Von den drei mit Sicherheit bekannten siidamerikanischen Arten steht der neuen Art die Phys. facialis Wiedem. aus Brasilien am nächsten und unterscheidet sich vor allem durch die bleichgelben Beine, während bei Phys. congruens alle Schienen und die Vorderfiißße schwarzbraun sind.

Beziiglich der Gestalt eḷscheint unsere Art im Vergleiche mit dem Gattungstypus viel plumper, der Thorax breiter und höher. der Hinterleih kïrzer und breiter. I as Ḱlỵpeusprofil ist weniger konvex, 
tritt anch nach rorn kaum ïber die Augees vor, wohl aber nach unten in gleichem Malje wie hei Ph. villatu Macyu. Das zugespitzte dritte Antennenglied ist kiirzer als bei dieser drt und oben sogar wtwas konvex gerandet, die Arista ist merklich kiiryer und feiner grefiedert, die Fiederbreite kommt nur jener des dritten Fühlergliedes shleich. Man ziche zum Vergleiche die Figuren 14-16 auf Tafel I der .. Genera Lamxanimarm" heran.

Der ganze leib ist von glänzend rotgellber (numlfarbe. Die punktförmige Ozellenplatte, zwei ovale Flecke, parallel nebeneinumler in den lritteln der Stirnbreite rorn ïber den Fiihlern, worauf die vorderen, nach cinwärts grebogenen Frontorbitalborsten stehen, sowie zwei pirallele, nach unten ctwas breiter werdende Vittellängsstriemen unter den Fühler'n, die auch auf das Prälabrum ibertreten, schwarzbramm. Anf dem 'Thoraxtiicken zwei weit voneinander entfernte, schwarzbratune Lüngsstriemen in der Linie der Dorsozentralborsten, die sich vorn etwas erweitern. Auf dem gelben Kasischenraum innerhalh, dirser Gtriemen stehen sechs Längsreihen von Hatren.

\%weites 'Terwit des Abdomens jederseits am llinterrande mit eino' dunkelbramen bis schwarzen Makel; drittes T'ergit mit Ausnalme eines schmalen streifens am Vorderrande fast ganz schwarz. Viertes bis sechstes 'Tergit mit einer' schwarzen Vittelbinde und schwarzen Seitentfecken ron verschiedener Ausdehnung. Banch gelb.

licine gelb, alle Schienen und Vorderfiilie schwärzlich.

Fligel gelblich hyalin. Sublostalzelle, ein breiter Sutum der linteren Querader und das Spitzendrittel des Fliigels rauchbraun. In letzterem ist noch eine intensivere Säumung der längsaderenden hrmerkbar, die an der Radialis an weitesten basalwärts vordringt. sichiippchen bram gerandet. Schwinger hellgellb.

Kïrper und Flïgel $6 \mathrm{~mm}$ lang.

\section{Procrita sigma n. sp.} in lintill.

1 q von Costa Rica alus der Sammlume Is. Lichtwardt

Diese Art hat mit der bisher bekannten Pr.pectina Hend. aus Mexiko den spitzen Stirnwinkel, die wagrecht ovalen Augen und die an der Basis auflallend verschmälerte Flïgelform, so dab Axillarlappen, Alula und Analader verkïmmert sind, sowie die lage der hinteren Gurader anf oder noch vor der Flïgehnitte gemein und kimn deshalb sehr wohl als ein weiterer Vertreter dieser neotropischen Gattung hetrarlatet werden, obwohl einigr Abweichmoen rorlanden sind. 
to ist das dritte Fühlerglied ca, dreimal so lang wic breit. geradrandig, gegen die runde spitze hin etwas verjingt mol trägt eine besonders oben seln lang und alsstehend getiederte basale drista.

I) a das cinzige Stiick etwas zerdriickt ist. kamn ich die Riuckentbeborstmog hinten nicht erkennen. Das schildchen ist breiter. fast halbkreisförmig und länger als ein Inittel des Riuckens. Den Hintersehienen fehlen die Präapilialen. Inic Mittelschenkel haben vorn in der Spitzenhälfte vier Borsten in einer Längsreihe. Die Cubitalis ist nicht wellig geschwmgen. Die Queradern sind noch weiter basalwärts geriickt. die hintere S-förmig gebogen und ganz aubcrgewöhnlich schief gestellt, so dal die Diskoidalzelle unten einen spitzen Zipfel hat.

Die ganze Fliege ist glänzend liellgelb. Der kleine (bollentlecti und die spitze des dritten Fühlergliedes sind sehwar\%. Der Hinterleih seheint etwas dunkler zu sein, ist aher auch rerdrïckt.

Flïgrel glishell. der ganze Kostalrand bis etwas unter die Radialis herab, sowie die Längsaderenden in der Flïgelspitze und die schicfe Qnerader schwarzbraun gresäumt.

Küirper und Flügel ca. $35-4$ mm lang.

\section{Poecilohetacrus albolineatus n. sp.}

1 a aus Siidafrika, Viktoria (1888). K k. Jofmuseum, IIiell.

I) neve Art steht den anstralischen $P$. Schineri Hendel in (irstalt und Färbung seln nahe mol ist habituell dureh letztere schon

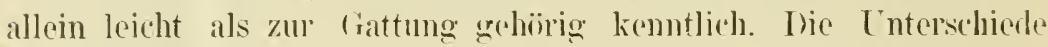
sind folgende:

Lie Stirn ist parallelrandig und nur wenig schmäler als die halbe Kopfbreite. Der Klypens ist sehwach konvex und hat iiber dem Mundrande eine Querfurche, die seitlich noch vertieft ist. Ias I'rïlabrum ist gröljer. Das vordere Orbitalborstempaar ist viel wenigrel zusanmengeneigt, die Ozelluwborsten fehlen ganz. Das dritte Fiihlerglied ist oben dentlich konkav, unten konvex, zreimal so lang wic breit. Der Thoraxrïeken zeight auber der Beborstung gar keine frundbehaarung. Am Humeralcallus sind zwei Borsten inseriert, die einc ist nach ohen und hinten. die andere nach auben und hinten gebogen. Das thache ebene schildchen ist sehr grof und breit, die Hälfte des Riickens lang. von viereckig abgermudeter Gestalt.

Stirnstrieme samtartig rotbram. Angemränder der Stirn und des Hinterkoptes, sowie die Wangen lenchtend weib. Als Fortsetzung der Stimangenränder verlanfen in gleichem Abstande parallel zueinanter zwei gleichweife Längsstriemen iiher die Thoraxrïckenmitte 
nnd die schildehenseiten. Klypeus gränzend hellbrann, Epistom und l'rïlabrum, sowie der mntere Hinterkopf gänzend pechbrams.

Fïhler rotgelb, drittes Glied an der spitze verdunkelt. Aristat fast natckt. 'Tastel' und Rii.ssel ganz dunkel. Thorax mud schildchen kaffeebram mit Wachsglanz. Durch beide Mesopleuren geht die Nadn, weslalb ich sie nicht gut betrachten kimn. Längs der Sternopleuralnaht veräuft eine weife Iängsbinde, aber atuch die zwei weiben Binden der Mesopleuren kamn ich vorn, wo die Natel nicht steckt, ('kennens.

Hiiften und beine lotgelb, nm die :3 Wrmzelglienled der Vorderfiile schwärzlich.

Ilinterleib schwarz, stark glänzend. - Flïgel welblich tingiert. Die kleine ouerader steht etwas hintel der Mitte der Dishoidalyelle. Körper und Flïgel is mm lang.

\section{Subfam. Eurychoromyinae.}

\section{Eurychoromyia 11. gुetr.,}

(rin inolierter (impupentypus acalyptrater Musciden.

Kopf der (quere nach Achius-artig rerbreitert (Fig. 5) und S), breiter als die länge des Thoraxrickens sant dem Schildchen und $5 /$ snal so breit wie hoch. Ton oben gesehen hat er die Form einer an don spitzen stark abgerundeten Mondsichel, mit der konkaren seite drm liumpfe ansitzend: von vorn betrachtet, die restalt eines gleichwhenkeligen 'Tapezes, dessen obere l'arallelseite ca. dreimal so lang wie die nutere am Mundrande ist. Die kleinen, fast wagrecht ovalen Angen liegen an den oberen koken und sind stark konvex. Ile stimbreite ist oben am scheitel der fiinffachen, vorn neben den Fiihlern der vierfachen Ingenbreite weich. Die Stirn selbst ist välig mackt, unbehadrt und borstenlos, glatt glänzend und chitinisiert und (iogentlich der Länge nach in drei 'Teile goteilt. 1) m mittlere Teil, ant llem ganz oben am scheitel die drej orellen eng zusimmenyedrängt stehen, ist eine Fortsotzmm des Cerabrales voun scheitel her, entspricht der ()zellenplatte und rodede inden er sich rerjüngt, his zum Torderande der stim vor. Die viel breiteren seitenteile

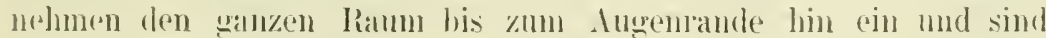

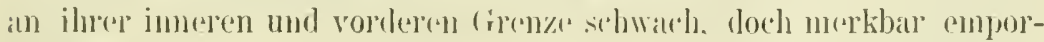
(qewïll)t.

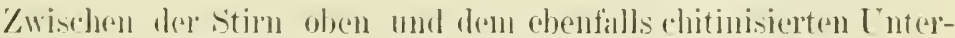

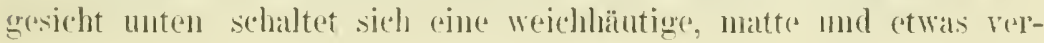


tieft liegende strieme ein, die die Tremmung yun von einum bis zum anderen duge durchtiihrt. Ich halte dafiir, dab diese Strieme funktionell Ersaty fiir die sonst normal rorkommende Strieme der Stim bietet. Von der Stirnspalte ist nu eine kurze Strecke geral. iber den Fiblerwurzeln bemerkbar. Unmittelbar dartiber ist aber auch schon ein schmaler Striemenstreifen zu sehen, der in der Mitte etwas in den Vorderrand der (Ozellenplatte eindringt und an den Sciten sich zunächst plïtzlich erweitert, um diunn allmählich schmäler werdem! zum unteren Stirnaugeneck emporzusteigen. In diese zwei seitlichen Striementeile verliert sich je ein Ast der Stirnspalte, ohne wie sonst zuerst nach abwärts zu gehen und sich dann unter dem Ange in der Backengrube (mediana R. I).) zu verlaufen.

Der Abstand der Fïhlerwurzeln voneinander beträgt ungefälı I/4 der vorderen stirnbreite und eben so breit ist oben der Ḱlypens. der in gleicher Höhe und Wölbong mit den benachbarten Wancen und Backen liegt. Die grut erkennbaren Gesichtsleisten gehen als gerade Linien mälbig divergierend bis zu den Ecken des fast wagrechten Mundrandes, die durch etwas wulstiges Vortreten der nackten Backenleisten gebildet werden. Die Wïlhung des ganzen Lntergesichtes ist der Quere nach eine schwache und gleichmäfige und nur der Länge nach im Klypensprofil durch Hache Höcker, aher anch nicht bei allen Stiicken gleich dentlich, gestört.

I) Seitenteile des Untergesichtes neben dem Klypeus sind nut den Backen nur eine Fortsetzung der Chitinplatte des unteren Hinterkopfes, daher nicht den normalen Wangen homolog. Sie sind in P'rofile gesehen deutlich höher als der lotrechte Augendurchmesser. Der obere Hinterkopf ist fïr den Thorax konkily ausgehöhlt; dir Scheitelkante der Stirn ist aber nur am Cerebrale scharf, seitlich davon abgerundet.

Die Fiihler sind rorgestreckt und kurz. Das arste (ilied ist deutlich sichtbar, ja sogar länger als das zweite, das oben eine ab). stehende borste hat. Dits dritte rilied ist länglich oval und (a). zweimal so lang wie breit. Die basale Arista ist gegen die Wurel hin etwats stärker und in der Wurzelhälfte zart pubeszent.

Das Prälabrum ist schmal, aher ziemlich loch und von vorn und im I'rotile dentlich sichthar. Die Taster erreichen mit ihren Spitzen den Mundrand nicht, sind küz und fadenförmig, schwach behorstet. Der Riissel ist ziemlich volmminös und hat breite zurieckgreschlagene Labellen.

Der Thorax hat fast die Gestalt einer Kugel. so gleichmälig ist er am Rïrken und an den Plenren gewölht. Der Riicken ist 
quatratisch, sogar ein wenig kiirzer als latng. hat in der Mitte zwei vertiefte Längslinien. die vorn mod hinten al)gekiirzt sind und scitlich ron den etwas vor der Thoraxmitte senkrecht anfsteigenden (burrmahtästen getroffen werlen. Das schildchen ist breit und kur\%, nur ${ }_{1}$ t des liiichens lang, wulstig gewölht und sehr stumpf. Die Pleuren sind stark der Länge nach verkiüzt, namentlich in der Vorderhälfte und in der Stiomatikalgegend iber den Torderhiiften kaum sichthar rertieft. Sehr merkwiirdig erscheint die Lage der Mesoplenrahnaht vor ler 'Thorixmitte, ferner, dals die Nesoplenren böher als lang sind und der 'Thorax an den Mittel- und Hinterhiiften nirht untel' das untere Ende der Vorderhiiften herabgesenkt ist, sondern in rrogenteile etwas emporgehoben erscheint.

Während der Kopt gar keine Reborstung zeigt, kümncen am Thorax haarfömige Borsten als 2 Notopleurale, 1 Iorsozentrale, 4 Schildchenborsten und 1 dentliche Sternopleurale bezeichuct werden. Auch an der Mesopleuralnaht stehen Härchen.

Der Hinterleil) ( \& ) ist sehr breit eiförmig. von oben her zusammengedriickt und aus 7 siclitbaren Segmenten znsammengesetzt. Das siebente ist schmal und tritt wenig ror. Die T'ergite greifen mit breiten Rändern auf die Bauchtläche herum, $2 / 3$ derselben eimehmend. Im Zwischenraume sieht man von der Bindehant eingeschlosseme, sehr schmale Sternite, wovon nui die letzten drei die Tergite beriburen. Hinter dem siebenten Segmente sieht man oben die zwei Cercides Endsegmentes. unten die älmlich gestaltete und beborstete untere Legeklappe vorragen.

Beine mittellang und kläftig. Alle Schienen, namentlich die mittleren und noch mehr die hinteren stark seitlich komprimiert und kreissegmentartig erweitert. Ihr Innenrand ist gerade, ihr Aufenrand ein Bogen. Nur die Vorderfiilie sind länger als die Schienen, die beiden hinteren blob 2/; derselben lang. Nirgends sicht man eine dentliche Borste orler eimen Sporn. Die Vorderhiiften haben normale. Form und Gröbse, die hinteren sind relativ sehr klein und kugelig. Die Sichenkel sind gerade mol rerdickẹn sich allmählich gregen die spitze hin.

I)ie Fliigelform mol Adermg ist am besten ats der Figur 6 eísichtlich. Die Kosta ist gerade, nirgends unterbrochen oder geknickt und leicht bis zur Müindung der Discoidalis. Die Mediastina ist vollständig getremnt und stark, Dic Subkostil selbst bei stärkerer Verwröferung nackt. l)ie Analzelle wird rorn durch eine grerarle (2neraller abgeschlossen, die Analader erreicht den Flïgehrand nicht. 
Nach dem ersten Eindruck, den die Fliege macht, kömnte man ror allem an eine Ortalidine im weiteren Sinne denken. Dis Fehlen von Präapikalborsten an den Schienen, die Beborstung im allgemeinen, die Fliigeladerung und andere Charaktere wïrden eine solche Deutung ganz wohl zulassen, zumal ja gerade bei dieser Muscidengruppe sehr häufig bizarr geformte Köpfe beobachtet werken kïnnen, wenn nicht das wesentlichste Merkmal - die dreigliedrige, hornige Legeröhre des $q$ hier fehlen wiirde. Die Bildung des weiblichen Hinterleibes weicht aber so weit von einer Legeröhre ab, dalb an die Gruppe (ler mit hornigem Ovipositor ausgestatteten Acalyptraten, wie Ortalidinen, Tephritinen, Lonchaeinen nicht gedacht werden kann. Indelseits weist der Legeapparat von Eurychoromyia aber auf die Sciomyzinen und 'Tetanocerinen hin, mit welcher Gruppe auch noch die kuze, wenig herabreichende Stirnspalte, die wenig spezitizierte Glicderung des Untergesichtes, die seichten Fazialien u. s. w., das Fehlen der Vibrissen. sowie teilweise die starke Entwicklung der Ozellenplatte gemeinsame Merkmale sind. Da aber die Sciomyzinen deutliche I'räapikalborsten und an den Mittelschienenenden einen ganzen Líranz von Spornen besitzen, Eurychoromyia wieder anderseits mehrere nicht bei Sciomyzinen rorkommende Eigenheiten aufweist, liann ich unsere ( 'attung auch hier nicht einzwängen.

Erschwert wird die Erkenntnis der systematischen Zugehörigheit besonders durch die spärliche Beborstung des neuen 'l'ieres. Kopfborsten fehlen ja ganz und Thoraxborsten fast ganz. Im ibrigen wissen wir über die rerwandtsehaftlichen Beziehungen der verschiedenen Acalyptratengruppen, iiber die iiberhaupt wertvollen Charalitere und deren Anwendung zur Herstellung natiirlicher Gruppen so wenig und ïber die Biologie derselben eigentlich noch gar nichts, so dalj es mir vor der Hand am niitzlichsten erscheint, die Gattung Eurychoromyia in ihrer Isoliertheit zu belassen. Wiirde ich sie in eine der bestehenden Gruppen unnatiirlicher Weise eimreihen. so wïrle ich sie der Gefahr aussetzen, von keinem der folgenden I)ipterologen erkannt zu werden.

Die speziellste Eigentïmlichkeit des neuen Genus ist die weichhäutige, quer ïber die Fühler hinweg von einem zum anderen Auge ziehende bandförmige strieme, mit der aulsergewöhnlich kurzen, in sie auslaufenden Stimspalte. Fine solche strieme hat keine der bis jetzt bekannten Acalyptratengruppen. 


\section{Eurychoromyia mallea n. sp.}

4 Q, alus Bolivia (Mapiri: Sarampioni, 700 m), Jänner und Yärz 1903: Sammlung W. Śchnuse in Dresden.

Kopf, Thorax und Hinterleib glänzend pechbsaum, ebenso die Beine. Letztere aber etwas rötlich durchscheinend und mit breit gelben Wurzeln der basalen Fufgglieder der beiden hinteren Beinpaare. Erstes Fühlerglied helbraun, die anderen schwarybrum. Die bogige Querstrieme unter der Stirn ist ulatt samtschwarz. Die StimHäche hat ebenfalls oft rötlichen Schein. Die in Figur 5 und 8 darwestellte Zeichmung der Backen wird durch ein goldiges Toment herrorgerufen und täuscht Querrunzeln vor. Auch der pechbraune Klypens ist ziemlich stark tomentielt; seine Zeichmung unter den Fiihlern ist aber mattschwarz und wird nicht durch die Grundfärbung hervornerufen.

Die I'leuren sind nur sehr schwach bereift. Die Seitenränder des 3. und der folgenden Tergite sind oben und unten durch in Reihen grestellte gelbe Tomentflecken hell punktiert.

Flïgel ziemlich intensiv und gleichmäßig rauchbraun tingiert, nur an der Basis und in der Subkostalzelle deutlich dunkler. Die Idem sind dunkel, die Schüppchen schwärzlich und ebenso lang gewimpert, die Schwinger hell roterelb.

Kö̈rper und Flïgel $5 \mathrm{~mm}$ ling; Kopf $25 \mathrm{~mm}$ breit.

Erklärung del' 'Tafel I.

1. Thyreophorella diadema Wiedemann, ō.

1a. Schildchen des $q$.

2. Flïgel dieser Art.

3. Flügel von Urophora tenuis n. sp.

4. Flügel von Urellia augur Fiffd. var. tridens.

ə. Eurychoromyia mallea n. sp. (nov. gen.), Kopf von rorn.

6. Fliigel, 7. Hinterleibsende des $\bigcirc, 8$. Kopf im Profile.

9. Cestrotus striatus 11. sp., Flügel.

10. Cestrotus oculatus n. sp., Fliigel.

11. Cestrotus megacephalus Loew, Fliigel.

12. Piocrita sigma n. sp., Fliigel.

13. Meracanthomyia yamma n. sp., ð’. 


Teschen.

K. u. K. Hof buchdruckerei Karl Procbaska. 


\section{Über die Nomenklatur der Acalyptratengattungen nach Th. Beckers Katalog der paläarktischen Dipteren, Bd. 4.}

\section{Ton Friedrich Hendel.}

Durch eine mir von Herrn D. W. Coquillett sochen freundlichst mitgeteilte Studie "The Type-species of the NorthA mer. Genera of Diptera," Proc. U. S. Nat. Nus. v. 37, pag. 499-647, 1910, sehe ich mich veranlafit, die Gattungsbenennungen der paläarktischen Mruscidae Acalypteratae, wie sie Th. Becker im 4. Bde. des I)ipterenkataloges veröffentlicht hat, zu revidieren und das Resultat dieser Durchsicht hier zu publizieren.

Ich habe mich hiebei aus Griunden der leichteren Orientierung' an die Reihenfolge des Kataloges gehalten und Coquilletts Ansicht, wo sie seine ureigene ist, inmer angeführt. Die iihrigen Bemerkungen haben als meine zu gelten.

Die Fälle, in welchen ich mit Couluillett nicht ïbereinstimme, möchte ich, soweit sie nicht später erwähnt werden, vorausschicken.

Madiza Fall. 1810. Von den drei Arten wurden zwei durch Siphonella Macqu. 1835 absorbiert, so daf der Fallénsche Name fiir 1 . glubra zil gelten hat.

Parallelomma Becker ist kein Synonym zu Mosina R. D., da letztere entschieden mehr zu Cordylura Fall. gehört.

Nach Osten-Sacken stammt Tetrnocera von Dumeril., Mag. Encycl. v. IT., pag. 433 (1798). Ich kenne diese Arbeit nicht. In der Zool. analyt. 1806 wird Mrusca reticulata F. angegeben, die rattung aber Tetanocrins genant; desgleichen in den Consid. génér. sur la classc des Ins., 1823, pag. 230. 312. Die auf Tafel 49, F. 3 als Tet. reticulata F. abgebildete Fliege ist aber Coremacera marginata F.! Welches ist also die Type? Latreille (1805) zitiert auch reticulatı F. Wollte man nach Coquillett Latreille folgen, so miibte unsere Gattung Phertrina R. D. nun Tetunocer Dum. heifen. Welchen Namen wiirlen dann die bisberigen Tetranocrro-Arten erhalten? Tielleicht MIycetomyzr Fall. 1810, Type $M$. rlata F. Die sache bleibt unklar.

Plyysiphore Fall. ist präokkupiert. daher bleibt Chrysomyza Fall. Trirtia Meig. ist hiezu kein Sýnonym.

Nun dic Bemerkungen z.11m Katalog selbst. 


\section{Subfam. Cordylurinae.}

Wollte man den ältesten Namen wählen, so miifte man Scopermatinae gebrauchen. Der Name Scatomyzidac ist nicht zulässig.

1. Cordylura Fallén 1810. Coquillett behält die von Fallén ursprünglich gewählte Schreibweise Cordilura bei. Da der Name aber von ropóśì $=$ Keule abgeleitet ist, muf man wohl die von Fallén 1819 selbst gemachte Korrektur annehmen.

2. Megophthalmum. Becker, statt Megaphthalmum.

3. Scopeuma Meigen 1800, statt Scatophaga Meig. 1803.

4. Norellisoma nom. nov. füi Norellia auct. nec Rob. Desv. Der Name Norellia muß der einzig Robineau bekannten Art spinipes Meigen $=$ (pseudo-narcissi) bleiben und kann nicht auf die anderen Arten bezogen werden. Achantholena Rond. ist ein Synonym zu Norellice R. D.

5. Olieniella Hendel für Okenia Zett.

6. Trichopalmus Rond. 1856 statt Tricopalpus. Coquillett hat unnötigerweise im Journ. N. Y. ent. Soc. v. 6, pag. 163, den neuen Namen Chaetosa vorgeschlagen, da er den Rondanischen Namen durch Trichopalpus Philippi 1865 für präokkupiert hielt.

7. Wenn Delina tibialis Rob. Desv. wirklich eine ClidoyastraArt in unserem heutigen Sinne ist, so miifte der Macquartsche Name weichen.

8. Volusia Rob. Desv. ist ein Synonym zu unserer Gattung Tanypeza.

\section{Subfam. Coelopinae.}

9. Malacomyza Hal. Ann. Nat. Hist. v. 2, pag. 186 (1839) statt Phycodroma Stenh. 1855. Halidays spätere Emendierung in Malacomyia halte ich fuir umnötig und unstatthaft.

10. Hcteromyza Fall. für Ocdoparea Loew. Coquillett hat hierin Recht. Fallén stellt nur zwei Arten in seine Gattung. Für eine, oculata Fall., errichtete Rob. Desvoidy 1830 die Gattung Thelida, weshalb Heteromyza für die zweite Art, buccata Fallén, bleiben mup.

11. Ion Coelopa Meigen ist die Gattung Fucomyia Hal. zu trenmen. 


\section{Subfam. Cypselinae.}

12. Cypsele Meig. 1800 für Borlurus Meig. 1803. Weil Curtis 1833 Musen subsultans F. als Gattungstypus ron Borborns annalm, gibt Coquillett unserer (rattung' den Namen Copromyza

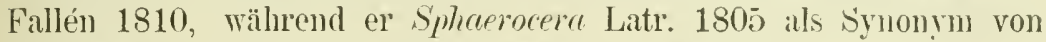
Borborus atuffatst. Da aber die Musca subsultuns von Latreille schon 1805 zum Typus seiner Gattung angenommen wurde, kann sie 1833 von Curtis nicht zur typisehen Art für Borlorus gemacht werden und so bleibt der Name ('ypssla (Bortorms.' für die anderen Arten.

13. Heteropter Macquart 1835 gehört als Synonym zu Limosimu nud nicht zu splearrocera. Typus ist Bortorens uretemgulus Zett. (= pusillus Meig. nec. Fallén).

14. Wemn Leptocera nigna Olivier (1813) wirklich eine Limosinc-Art ist, so hat Leptoefve die Priorität für Limosina (1835).

\section{Subfam. Dryomyzinae.}

15. Newroctena Rondani 1868 ist von Mryomyza Fall. \%u trennen.

16. Helcomyza ustulatr Curtis (1825) hat vor Actorce acstum Meigen (1826) die Priorität.

\section{Subfam. Clusiinae.}

17. Clusiodes Coquillett Proc. Ent. Soc. Wash.. v. 6, pag. 93 (1904) statt Heteroncurce Fall. 1828, präokkupiert durch Heteronenra Fall. 1810, ein Synonym zn Callomyia Meig. 1804.

\section{Subfam. Helomyzinae.}

18. Suillia Rob. Desv. (1830) fïr Helomyza auct. Der Name Helomyza Fallén 1810 hat den Arten zu verbleiben, die wir bisher als Leria-Arten (Rob. Desv. 1830) oder als Blepharoptera-Arten (Macqu. 1835̄) bezeichneten, da von Fallén 1810 nur die Musca serrata Limné genannt wird. Co qu i ll ett nimmt F a llé ns ursprïngliche Schreibweise Helermyzu an, was doch wegen ق̋.ros= Sumpf nicht angelit.

19. Helomyza Fall. 1810 fïr Blephoroptera Macruart 1835.

20. Heteromyiella nom. nov. für die Heteromyzu-Arten der Autoren, von denen Fallén keine einzige kannte.

21. Eurygnathomyia C\%erny 1904 für Heterom. opomyzina Zett. Ich fing ein $q$ dieser seit \%etterstedt unbekannt geblie- 
benen Fliege in Mai bei Grünbach am Schneeberg. C ze r'n y stellte sie mit Recht in die Nähe von Helcomyza Curtis.

22. Lentiphora Rob. Lesv. 1830. für Tephochlamys Loew 1859 und Actenoptera C\%erny 1904 für Frymmomyza Strobl, nec Fallén, die wleich Mosillus Latr.

\section{Subfam. Sciomyzinae.}

23. Stciomyan Fall. 1820 fiur Bischofia Ilendel, da Rob in ea u I) ('svoid! sehon $18: 30$ mit Melima (rimarien = dulira Fallén) die Scromyza-Arten unserel bishrrigen Auffassmng ausgeschieden hat.

Die rattung Ditaenir Hendel ist nur als Subgenus von Mrlimu R. I). aufrecht zu erhalten.

\section{Sublam. Ortalinae.}

24. (1) Otites Latreille 1805 fiir Ortrulis auct. Latreilles Typus ist seine degans, ein Synon!m zu Musca formoser l'anzer. Der Name Ortalis Fallén 1810 hat für die .Thelietir- oder AnacamptaArten zu gelten. Typus Musca urticae Limn. Fallén fiihrt 1810 noch Musce vilions L. auf, die aber schon 1817 von Kirby zur typischen Art der Clintimen-Gattung Sroptorn Kirb. gemacht wurde. Corpullett ist daher im L'nrecht. Wenn er Sroptera Kirby num Ortulis Fall. nennt, nur deshalb, weil Westwood 1840 Mrusca vibrans als Typus von Ortalis angab.

24. b) Homalocephala Zetterstedt 1838 (nec 1840) statt I'surroptere Wahlherg 1839. Kongl. Vet. Akad. Handl. for 1838, pag. 18, nach Coquillett.

\section{Gruppe Myrmecomyinate.}

25. Tia Cephatia Meig. 1726 durch Cephatein Panzer 1805 präokkupiert jst. tritt der Name Myrmecomyia Rob. Desv. hiefür ein. Die norlamerikanische Gattung Mymmecomyia Rob. Desv. sens. Loew neme ich Myrmecothea nom. nov.

\section{Gruppe Platystominae.}

26. I'latystoma KKlein, Molluse. 1753 kann. als vor der Edit. X. von Li nnés Syst. Nat. 1758 erschienen, den M eigenschen Namen nicht präokkupieren. weshalb es nicht angeht, die Gruppe Mcgaglossinae zu nennen, wie es in juingster Zeit geschah. 


\section{Gruppe Ulidiinae.}

26. Scoptera Kirby 1817 statt Myodina. Rob. 'Sesv. 1830.

27. Die Caltung Empyelorera Loew ist mit Timin Wierl. zu vereinigen.

28. Coniceps carbonarins Loew hat Arometopire rerlomaria zu heiben und ist zu den Orhthiphilinen zu stellen.

\section{Subfam. 'Tephritinae.}

Nach dem ältesten Namen bezeichnet, hielje sie Trypaneinue. ${ }^{1}$ ) 29. Ich schliefbe mich hier Coquilletts Vorgang teilweise an, den ich sonst für vollkommen korrekt halte.

Latreille erwähnt bei seiner Gattung Teploritis (1805) nur Muscu solstitialis Lim., weshalb unsere Trophora-Arten den Genusnamen Teplevitis zu tragen haben.

Iie von Meigen 1803 bei Trypeta $=$ Euribia 1800 aufgezählten Arten sind: 1 . armicue, rerasi, niticur und artemisiae. Von diesen schieden aus: 1810 urticur: als (Jrtulis Fallén, 1830 artemisiae (onopordi) als Forellia R. D. = Phorellia Rond. - die SprilogrephtaArten Loews miissen diesen Namen erhalten -, 1862 cerasi als Rihagoletis Loew, bleibt also automatisch für armirae der Name Euribia (Trypeta) Meigen, für jene (rattung, die die Autoren mit Tepluitis Latr. bisher bezeichneten.

Fiir unsere Tryphetr-Arten hat der älteste Gattungsname, das ist Teralla Rob. Desv., einzutreten, ein Name, der ja in diesem Sinne schon von Il acyllat und Walker gebrancht wurde.

Warum Coquillett unseren Tepleritis-Arten den Namen syathulina Rnd. und den Spilograpler-Arten den Namen Euribia (Trypeta) beilegt, sehe ich nicht ein.

30. Ich glaube auch wohl, dalo Nocetu Rob. I)esv. 1830 dieselbe (iattung wie C'urphlutriche Loew 1862 vorstellt.

31. Ein älterer Tame als Trollia Rob. Desv. ist nach Bezzi Tringenen Sichrank 1795 .

\section{Subfam. Sepsinate.}

32. Prendora Halid. für Saltella R. D). Saltelle It. D. ist für mich eine unbekamnte (iattumg.

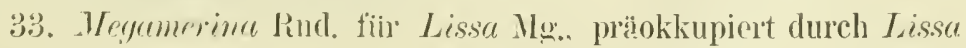
Leach., ('rust. 1815.

1) Crophora temis Hendel 1910, nec Becker 1907, andere ich in l. tenuior ab. 


\section{Subfam. Tylinae.}

34. Trepidaria Meig. $18 \not 10$ für Calobata Mg. 1803.

35. Tylos Meig. $18 / 10$ für Micropezu Mg. 1803. Der Satz „I a tête prolongée en cône" macht mir doch die synonymie mit Micr. corrigiolata F. sicher ó. (zú̀̇os, die Schwiele.)

\section{Subfam. Chloropinae.}

Über diese Gattungen liegt uns B e c k e r s neueste Monographie vor. 36. Cemarotu Meig. statt Oscinis Latr. 1805̃. Oscinis Latr. ist doch ein offenbares Synonym zu Chloroms Meig. 1803 und darf daher nicht fiir andere Gattungen verwendet werden. Dit miißten gar viele neue Gattungsnamen fallen, wenn man alle alten Synonyme wieder ins Leben riefe.

Man kann nicht sagen, die von Latreille auch genannte Musca lineatu F. kommt als Typus nicht in Betracht. II eigen hat die Art ja durch seine Gattung nicht später ausgeschieden, so daß curvinervis übrig blieb, sondern Chlorops ein Jahr früher aufgestellt. Oscinis Latr. ist keine indere Gattung als Chlorops Mg.

37. Dargegen ist Beckers Vorgang ganz korrekt, wenn er das Genus Oscinis auct. neu benennt: Oscinella Beck. Es existieren zwar, wie anch Coyuillett anführt, mehrere Namen von Lioy; ich glaube aber mit Recht zu handeln, wenn ich die Arbeiten dieses Autors imnoriere. Coquillet hat das Machwerk Lioys leider zu ernst genommen: ich mag ihm hierin nicht folgen!

38. Die Beschreibung von Titaniu Meig. 1800 stimmt wegen der angegebenen Berleckung der Fühlerborste nicht mit Chlorops IIg. 1803. Nle Arten haben nackte Arista! Chlorops Meig. ist daher beizubehalten.

39. Ich halte Rond an is Gattung Siphunculinu 1856 fiir genïgend charaliterisiert, um sie anzmehmen. Microncurm Recker ist hiezu ein Synonym.

\section{Subfam. Ephydrinae.}

40. Mosillus Latr. 1805 statt Gymnope Fall. 1820.

41. Psilope Fall. 1823 statt Ephygrobia Schin. 1862.

42. Discocerima Macqu. 1835 statt Clasiona Stenh. 1844.

43. Hydrina R. I). 1830 statt Hyerlina Halid. 1839.

44. Napaea R. 1) 1830 statt L'arydra Stenh. 1844.

\section{Subfam. Drosophilinae.}

45. Amiotu Loew, Nai 1862 stutt Pleortica Schin., Dez. 1862. Coun. 46. Astia Ilg. statt Asteia. 


\section{Subfam. Geomyzinae.}

47. Geomyza Fallén 1810 hat als angeführte Art nur M. combinata L. Daher hat Balioptera Lw. den Namen Geomyza zu führen.

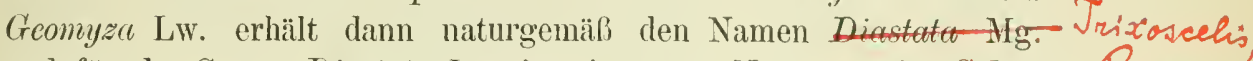
und für das Genus Diastate Lw. ist ein neuer Namen Calop- Rrnd. terella Coquillett 1910e her.

\section{Subfam. Chamaemyiinae.d}

48. Chamaemyia Meig. 1803 statt Ochthiphila Fall. 1823.

\section{Subfam. Milichiinae.}

49. Milichiella Gigl. Tos für Stenoporomyia Hendel; nach Becker. Die Synonymie mit Ophthalmomyia Willist. konstatierte ich selbst früher.

50. Cerodonta Rnd. 1861 für Ceratomyza Schin. 1862.

$$
\text { *) Woaktry: Wim. Ent. Eeitg. } 1911 \text { n. }
$$





\section{Vier neue mediterrane Otites-Arten.}

Fon Frierlich Hemlel.

Die vier mediteranen Otites-drten (Ortulis sens. Loew) nutho-

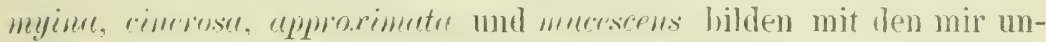
bekamnten Arten atrigms Loew und immuruluta liondani eine Gruppe, welche sich durch die ganz ungefteckten oder nur mit ganz zarten Nebelflecken versehenen Fliigel, die nie als .gezeichnet" benannt werlen kïnnen, charakterisiert.

Die ersten drei der oben grmannten Arten weichen ron dem Gattungstrpus insoferm ab, als ihr Thoraxricken nicht blof hinter der (uernaht behorstet ist, sonderu auch ror derselben Lorsozentralborsten zeigt. Iladureh nähern sie sich der (rattung Herumyiu Ji. I). (Crrmocuris Loew). Auljerden finde ich hier wie bei vielen anderen Ortalididen an allen Schienen P'räapikalbörstchen, klein. aber sehr deutlich ausgeprägt. Auler den Wittelschienen haben auch die vordersten einen ganzen Kranz. freilich viel zarterer Endsporne. Im Habitus gleichen diese Arten melur Anthomyiden als ortalididen.

I) Arten dieser Gruppe lissen sich wie folgt unterscheiden: Hinterleib glänzend schwarz, unbestäubt. Flïgel ohne jeden schatten und Nebel.

Otit. immaculata kiond.

- Hinterleib grau getfeckt oder gebändert.

1. Fühler weniwstens an ren zwei Wurzelgliedern rot, mindestens die Fiihlergruben glänzend.

- Fiihler ganz schwarz: Klypens (Kiel und Fühlergruben) matt bestäubt.

2. Beine ganz sehwarz: Hinterleih quer bandiert.

Die viel hinteren Schienen rothraun. Ciesiclitskiel ganz glänzend rotgelb. Hinterleih gefleckt.

Otit. anthomyina n. sp.

3. Beine ganz schwarz. Gesichtskiel glänzend pechschwarz, nur oben zwischen vlen Fühlern gelb.

Otit. atripes Loew.

- Alle Gelenke rot. (iesichtskiel rot, in der Mitte matt weif bestäubt.

Otit. mucescens $\mathrm{n}$. sp.

4. Kleine Querarler iber der Mitte der I)iskalzelle. Hinterleih vorherrschend grau.

Otit. cinerosa n. sp.

- Kleine Querader iiber dem letzten Inittel rler I iskalzelle. Hinterleih vorherrschend glänzend schwar\%. Otit. approximata n. sp. 


\section{Otites anthemyina n. sp.}

ơ aus Oristano, sardinien (leg. Krausse) im Wiener Hofmuselum.

Lüngsmitte der stirn (Strieme), ungefähr die Hälfte der Stirnbreite einnehmend, gelbrot, außen dunkelbraun gesäumt und nur dort etwas vom weißlichen Reif der Augenränder zart iberhaucht. I)ie breiten Stirnamgenränder und die damit zusammenhängenden Wangen dicht seidenartig weiß, der Hinterkopf bräunlich weißgrau bestäubt. Die Grundfarbe der ersten ist wie die der (zellen und Scheitelplatten. sowie die des Hinterkopfes schwarz, jene der Wangen rotgelb. Der ganze Klypeus ist vollkommen unbestäubt, glänzt stark und ist in den Fühlerrinnell schwarz, auf dem Längskiele rotgelb. Backengruben unter den Augen rotbraun, hinten durch die lotrechte Leiste der Backen schwar\% abgegrenzt.

Fühler gelbrot, drittes Glied schwarz. T'aster und Riissel rotbraum. Die ziemlich dichte und rauhe Grundbeharung der Stirn ist schwarz. Besonders langhaarig ist auch der untere Hinterkopf, resp. die Backen.

'Thorax und Hinterleib von gläinend schwarzer Grundfarbe, größtenteils von einer dichten bräunlichen oder graubräunlichen Bestäubung verdeckt. Thoraxriicken und Schildchen trotz der Bestäubung aber ziemlich auffallend glänzend, mit zwei hinten abgekiirzten Mittellängsstriemen zwischen den Dorsozentralborsten und je einer an der Quernaht unterbrochenen auferhalb derselben von der glänzend schwarzen Girundfarbe. Schildchen am Hinterrande und der Unterseite kaum bestäubt, glänzend. Die ganzen Pleuren. die Hiiften und der Metathorax dicht bräunlich bestäubt.

Thoraxriicken bis vorn hin beborstet. 5-6 Borsten hinter, 2 -3 vor der Quernalıt, lang. aber oft haarförmig diinn. Längs der Mesopleuralnalst zirka fiunf lange Borsten. Zwei Sternopleurale nebeneinander, die vordere schwächer.

Am zweiten bis fïnften Abdominaltergit sieht mim seitlich am Hinterrande je einen abgestumpft dreieckigen oder trapezförmigen, glänzend schwarzen Fleck der Grundfarbe, der den Vorderrand der Ringe nicht erreicht und mit dem Fleck der andern Seite in der Tergitmitte einen bestäubten graubraunen Längsfleck einschlieft, der mit jenen der anderen Tergite eine zusimmenhängende Medianstrieme des Abdomens bildet. Auferdem sind die auferhalb der glänzenden Lateralftecke liegenden dreieckigen Vorderecken der Tergite ebenfalls graubraun. Die Bc- 
borstung der Hinterränder der Tergite, der Seiten und des Bauches ist ziemliel lang und schwarz. I)as sechste Tergit und das erste Glied des Ovipositors sind braun bestäubt.

Schenkel glänzend schwarz, spärlich bereift; Knie. schienen und Fuiße dunkelrotbraun. 'Tarsen gegen die Spitze hin dunkler. Fliigel etwas bräunlichgrau tingiert. mit rotbraunen, gegen die Wurzel sogar rotgelben Adern. die alle verwaschen hreit rostgelb umsäumt sind, Wurzel der Kostalzelle schwach bräunlich getrübt. Submarginalzelle und ein schwacher Nebel in der Spitze der Marginalzelle gleichfarbig rostgelh. Kleine Querader am dunkelsten gefürbt. etwas jenseits der Diskoidalzellenmitte stehend. Erste Hinterrandzelle an der Mündung deutlich verengt. Letzter Abschnitt der Diskoidalis $1 \frac{1}{2}$ mal so lang wie der vorletzte. Schippchen weif. Schwinger hellgelb.

Körper und Flïgel 5-ti mn: lang:

\section{Otites cinerosa n. sp.}

$4 \sigma^{\circ} q$ aus Iascara. Algerien. in der Sammlung Dr. Villeneuves.

Der Otit. anthomyina aufserordentlich ähnlich und mit derselben leicht zu verwechseln.

Die bei Otit. anthomyina bräunliche Bestäubung ist aber hier hell aschgrau. oft bläulichgrau. die Fühler sind ganz schwarz, die Stirn ist in der YIitte nicht eben. sonder'n vor den Gzellen Hach muldig ausgehöhlt. Die weifgraue Bestäubung der Stirnseiten zieht sich viel dichter und weiter nach einwärts auf die rote stirnstrieme, dal diese viel weniger auffïllt und undeutlich abgegrenzt erscheint. Die Augen sind viel rundlicher als bei der vorigen Art. Der Längskiel des Klypeus und die Fiihlergruben sind dicht weißlich bereift, olne jeden Glanz. Die Backengruben sind dichter weilb bestäubt, nur etwas braun schillernd. Thorax und Schild sind matt, fast olme jeden Glanz.

Die Hinterleibszeichnnng ist die gleiche wie hei otit. anthomminar. jedoch sind die Grenzen viel verwaschener. die hier aschgraue Bestäubung ausgedehnter. die Mittelstrieme schmäler. Die schwarzen Flecken sind auch sehr zart graulich iberhaucht, nicht so stark glänzend als wie bei $O t$. anthommina. Das Abdomen des $q$ ist breiter als bei Otit. anthomyinu.

Beine schwar\% nur die Kniespitzen rot, deutlich graulich angestäubt. 
Am Fliigel ist die Trübung der Kostalzellenwurzel und der Nebel in ler Marginalzelle etwas intensiver. Auch iiber der Radialisgabel ein schwacher Schatten. Die schwarze kleine Querader ist undeutlich schınal grau umsäumt und steht ungefähr iiber dler Mitte der Diskalzelle. Die erste Hinterrandzelle ist an der Miindung noch stärker als bei Otit. anthomyina verengt und der letzte Abschnitt der Diskoidalis ist zirka zweimal so lang wie der vorletzte. Schiippchen und schwinger hellgelb.

Der Hinterleibriicken des $\sigma^{7}$, das ich für zugehörig halte, ist dicht einfach grau bestäubt und sieht durch feine Querwurzeln und Hohlpinktehen an den Haarwurzeln wie chagriniert ans.

Körper und Flïgel 5-6.5 mm lang.

\section{Otites approximata $n$. sp.}

1 Q ans II ascara, Algier, in der Sammlung Dr. Tillenenves.

Unterscheidet sich von Otit. cinerosa durch folgendes: Die kleine Querarler stelit iiber dem letzten Drittel der Diskalzelle und der letzte Abschnitt der Diskoirlalis ist dreimal so lang wie der vorletzte. Die glänzend schwarzen Seitenmakeln des Hinterleibriickens erreichen beilerseits der schmalen grauen Medianstriene den Vorderrand der einzelnen Tergite und lassen seitlich aufen am Vorderrande nur schmale graue Säume frei. Der Hinterleib ist also hier vorherrschend glänzend schwarz und nicht iberwiegend grau wie bei otit. cinerose.

Auch die Gesichtslängsleiste ist hier am Mundrande matt schwinz. Körper $4.5 \mathrm{~m}$, Flïgel $4 m m$ lang.

\section{Otites mucescens n. sp.}

2 ㅇ ans Nyons (Dep. Drôme in Siidtrankreich) aus der Sammlung Ir. Villeneuves.

Bestäubung des Körpers bräunlichgrau, in der Vitte zwischen dem Braun der otit. anthomyiur und dem reinen Grau der otit. cinerosic.

Stirn wie bei Otit. cincrosa gefärbt und geformt. Augen noch rundlicher, so dab hier der lotrechte Angendurchmesser nur so grolb wie die Backenhöhe dlarunter ist, wälırend derselbe bei den anderen Arten die Backenhöhe ïbertrifft. Backengruben deutlich rot. Klypeus rot, auch die Fiuhlergruben. Diese und der oberste und unterste Teil des Längskieles glänzend, unbestäubt. Nur die Kielrïckenmitte ist weili bereift. 
Erstes und zweites Fïhlerglied rotbraun. 'T'horax matt. so ziemlich glanzlos. Schilel iberall dicht bestïnht.

Hinterleibstüken dicht bestäubt. Ile solmalen Hinterranulinien der 'Tergite etwas rötlich. Am zweiten bis vierten Tergit sind am Hinterrande las Invittel bis die Hältte der Länge glänzend schwar\%. Was gregen den Vorderland allmählich durch dir liestäubung verschwindet. Das fünfte und seehste 'Terogit. sowie der (ovipositor' sind matt bestäubt. In gewisser Boleuchtung tritt tine den Hinterleib durchlatente, hellere Vledianlängslinie hervor.

Beine schwarz. deutlich grau bestäubt. Alle felenke schnal rot.

Thoraxiteken mu' hinter der Quermaht mit drej bis vier Iborsozentralborsten besetzt.

Flïgel grandich, an dex Wurzel etwas welblich getriibt. mit gelbroten Adern. Nirgemds kimm ich eine intensivere Färbung, eine Wolke oder dergleichen wahruelumen. Dow erste Hintermandzelle ist fast parallelrandig. die dunklere kleine Querader steht wie hai otit.

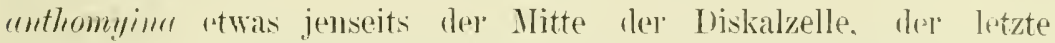
Abschnitt der Diskoidalis ist nicht wauz zweimal so lane wie der vorletzte. Inir Inalzelle ist hier grobler als hei den anderen Arten. bei denou dic Analis fast doppelt so lang wie die Zelle ist. Die Subkosta mündet genau gegentiber der kleinen querader. bej den anderen Irten jedoch etwas jenseits derselben.

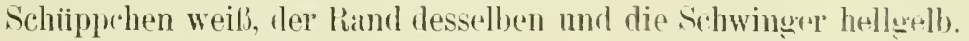
Kiirper 9 mm. Flijgel $8 \mathrm{~mm}$ lang.

\section{Nachtrag zu: Über die Nomenklatur der Acalyp- tratengattungen etc.}

(Wien. Eut. Zeitg. 1910, pay. 307.)

Ton Friedrich Hemlel in Wien.

Ich habe überschen, dall schon lioudin i im Isipterol. Ital. I'rorlrom. Vol. 1, pay. 154, 1856, also schon vor L 0 ew, für Diastata costatr Meig. den Gemsnanen Diustutı Meig. beibehielt, für Geomyza olsscurella Fall. aber den Genusnamen Trixoscelis neu aufstellte. Dadurch wird Culopterella Corp. ïhertliissig und Germuza sens. luoew hejbt num Trixoserlis lionul. 



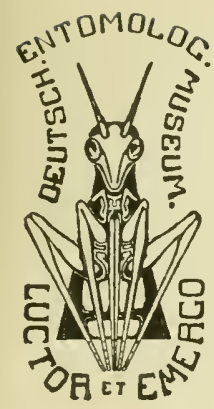

\section{Separatabdruck aus}

\section{Supplementa Eniomologica}

Herausgegeben auf Kosten der Jagor-Stiftung vom

Deutschen Entomologischen Museum

[Redaktion: S. Schenkling und H. Wagner]

H. Sauter's Formosa - Ausbeute

F. Hendel: Genus Dacus (Dipt.). Mit Tilfel I 



\title{
Genus Dacus, Fabricius (1805) (I)ipt.)
}

\author{
Von Friedrich Hendel, Wien.
}

Bei der Untersuchung der artlich schwer voneinander abgrenzbaren Dacus-Arten, deren Variabilität noch zahlreicher Untersuchungen bedarf, ist es ein großer Vorteil, wenn zahlreiche Stücke zur Vergleichung vorliegen. Dies war bei den meisten mir zur Determination überwiesenen Dacus-Spezies aus Formosa der Fall.

Hierbei fand ich ziemlich konstant und zur Unterschoidung brauchbar:

1. die Fleckung an den Wurzeln der Orbitalborsten - der braune Mittelfleck der Stirne stellt die Verdunkelung dos oberen Endes der Stirnblase dar;

2. die allgemeine Anlage der Körperzoichnung;

3. die Stirnbreite und Zahl der Frontorbitalborsten;

4. die Flügelzeichnung.

Unabänderlich scheint mir die Zahl der Schildchenborsten zu scin. Wichtige Unterschiede gibt teilweise auch die Flügeladerung. Ob die Verschiedenheit in der Flügelzeichnung bei Stücken verschiedener Provenienz, wie sie z. B. auch hier hei Dacus caudatus F. erwähnt wird, nur auf Artvariabilität beruht oder verschiedene Spezies bedingt, kann ich derzeit nicht entscheiden. Bei den größeren Serien der Formosaner-Arten fand ich keine bedeutenden Abweichungen in der Flügelzeichnung.

Wenig bekannt scheinen die sexuellen Unterschiede zu sein. Viele $\bar{\delta}$ - alle hier angeführten - haben am Hinterrande des dritten Abdominaltergites seitlich eine Reihe abstehender Wimperborsten. Alle mir bekannten $\delta$ zeigen an der Mündung der Analis eine Einkerbung des Flügelhinderrandes, so daß dort die dritte Hinterrandzelle einen vorspringenden Lappen bildet. Die beim $\delta$ verkürzte Analis trägt an ihrer Mündung einen grauen Fleck, den z. B. auch das $\delta$ von Dacus oleae Gmel. besitzt, den ich aber nirgends orwähnt finde. Die verkürzte Analis ist kein spezifisches Merkmal, wic Prof. de Meijere (1911) annimmt, sondern nur ein sexuelles.

Das Studium der Dacus-Arten wird durch die Arbeit Prof. Bezzis im Boll. Lab. Zool. Portici, Vol. 3, p. 273-313 (1909) sehr gefördert. Den bis dorthin beschriebenen Arten wären noch Dacus vespoides Doleschall (1859), Dacus Frauenfeldi Schiner, Novar. Dipt., p. 262, 95 (1868) und Dacus xanthodes Broun, New Zeal. Dep. Apric. Bull. 4, p. 3 (1905) ergänzend anzufügen. 
Im folgenden bringe ich eine Liste von als Dacus beschriebenen Arten, die in andere Gattungen gehören und meist Ortalididen sind.

Dacus acroleucus Wiedemann (1840) = Conradtina acroleuca Wied., Tephritid.

Dacus addens Walker (1860) = Conicipithea (n. g.) addens Walk., Platystomin.

Dacus basalis Walker (1849), vielleicht eine Scotinosoma-Art.

Dacus bicolor Walker $(1849)=$ Icteracantha (n. g.) chalybeiventris Wiedem., Platystom.

Dacus bicolor Wiedem. (1830), wahrscheinlich eine MelanolomaArt, Richard.

Dacus contrahens Walk. (1860) u. exigens Walk. (1860) sind zwei Arten der Platystominen-Gattung Pseudepicausta m., ähnlich chalybea Dolesch.

Dacus detrudens Walk. (1865) u. expertus Walk. (1862), wahrscheinlich ebendahin gehörig.

Dacus devius Walk. (1861), eine Antineura-Art, Platystom.

Ducus divergens Walk. (1860), eine Philocompus-Art, Platystom. Dacus furcifer Walk. (1862), eine Lagarosict-Art, Tephritid.

Dacus imitans Walk, (1860), eine Plagiostenopterina- (n.g.) Art. ähnlich aenea Wied.

Dacus inaptus Walk. (1860), eine Art der Gruppe Stenopterinina. Ducus inflexus Fabr. = Elassogaster ${ }^{1}$ )-Art.

Dacus latifascia Walk. (1859), wahrscheinlich eine Xiria-Art, Platystom.

Dacus lativentris Walk. (1859), eine mir unbekannte Platystomine.

Dacus lituratus Walk. (1861) = Cleitamia liturata Östen-Sacken. Dacus longivitta Walk. (1859), eine Plagiostenopterina-Art, Platystom.

Dacus macilentus Wied. (1830), eine Rivellia-Art, Platystom.

Jacus mutilloides Walk. (1859), eine Pseudepicausta-Art, Platystom. Ducus obtrudens Walk. (1859) = Pseudepicausta chalybea Dolesch. Dacus pompilioides Walk. (1859) = Pseudepicunsta-Art.

Dacus pubiseta Walk. (1861), eine Antineur(t-Art, Platystom.

Dacus sepsoides Walk. (1861) = Elussoyaster') (unimaculatus Kiertész).

Dacus signatipes Walk. (1861), eine Elassogaster-Art, Platystom. Dacus sordidus Walk. (1861), eine Art der Gruppe Stenopterinina.

1) Evicausta Loew = Myiodella Rondani. 
Ducus strigifer Walk. (1862), eine Antineur $\alpha$-Art, Platystom.

Darus succinatus Wiedem. (1830), eine Rivellia-Art, Platystom. Dacus varialis Walk. (1S65), oine Elassogaster-Art.

Calantra smierö̈des Walk. (1860) stellt eine Dacus-Art mit gestieltem Abdomen vor, ähnlich wie D. sepedonoüdes Walk., longicornis Guér., vespö̈des Doleseh. und conopsö̈des do Meij. Ich kann ïher die Gattungsberechtigung gegenwärtig kein sicheres Urteil abgeben.

\section{Dacus cilifer n. spee., (Taf. I, Fig. 1).}

22 ơ $q$ aus Formosa, Alikang, Koshun; Juni-November.

Schildehen nur mit dem apikalen Borstenpaar versehen, das basale fohlt. Ein Präscutellarpaar und zwej Paare untere Frontorbitalborston vorhanden. Ptoropleurale stark.

Typische Dacus-Art. Kopf, Fühler und Taster rotgelb. Stirno nur wachsglänzend, jederseits mit drej dunkelrotbraunon runden Flecken an den Wurzeln der drej Orbitalborsten und einem gleichfarbigen Mittellängsfleck von unregelmäßiger Gestalt, der vorne abgekürzt ist, hinten aber in einer Linie den Ocellenhöcker und mit Seitenausläufern häufig die vorderen zwei der Seitenflecke erreicht. Scheitelkante in einem Querbande glänzend schwarz (Ocellen- und Scheitelplatten). Lunula dunkelbraun. Gesicht beim $\delta$ mit zivei dunkelbraunen bis glänzend schwarzen Querbändern, das obere in der Gosichtsmitte, das untere unmittelbar über dem schmal gelben Mundrande. Beim $q$ sind beide Querbinden, mindestens aber oine von beiden in zwei Querflecke aufgelöst, die versehiedene Entfernung volleinander haben können.

Drittes Fühlerglied gogen die Spitze hin mehr oder weniger intensiv gebräunt. Arista nackt. Praelabrum nur in der Mitte golb, seitlich dunkelbraun. Hinterkopf mit Ausnahme eines schmalen gelben Saumos am hinteren Augenrande und hinter dor Scheitelkanto gläızend sehwarz.

Thorax und Hinterleib sehwarz, dicht und foin chagriniert und anliegend gelblichweiß pubesziert, daher wenig glänzend. Thoraxriicken mit zwei wenig deutlichen grauen Längsstriemen in der Mitte und einer gleichen Querstrieme iiher die Quernaht. Weißgelb sind: der Humeral-, der Notopleural- und der doppelte Hypopleuraleallus, eine schiefe Querbinde am Hinterrande der Mesopleuren, die mit der Spitze etwas in die Sternopleura eindringt, das Schildchen und eine gerade Linie in der Supraalargegend des Rüekens, von der Quernaht nach hinten bis zur innersten der drei Supraalarborsten. 
Hlinterrand des fünften Abdominaltergits beim đo schmal gelbrot, heim $q$ höchstens rotbraun. Am Hinterrande des dritten Tergits stehen beim $\delta$ jederseits schwarze, abstehende Wimperborsten in einer Reihe. Sternite schwarz. Bauchhaut rotbraun. Erstes Glied des Ovipositors schmal, fast streifenförmig, hinten wenig verjüngt, so lang wie das vierte und fünfte Tergit zusammen, rotbraun. Fünftes Tergit seitlich der Mitte nur etwas feiner chagriniert.

Hüften, Vorderschenkel, Hinterschienen und die Spitzen der vier hinteren Schenkel - die mittleren zu zwei Drittel, die hinteren zu ein Drittel - pechschwarz. Dor Rest der Beine hell rotgelb. Die Mittelschienen, seltener auch die vorderen können von der Basis her gebräunt sein.

Flügel glashell. Subkostalzelle, ein Randfleck an der Mündung dor Cubitalis, der längs der Kosta nur durch einen sehr schmalen und helleren Saum mit ersterer zusammenhängt und ein Längswisch am spitzen Zipfel der Analzelle dunkelbraun. Der sich beim $\delta$ daranschließende graue Fleck an der Mündung der Analis ist bald heller, bald dunkler und liegt zum größeren Teile im Schulterlappen. Erste Basalzelle mit nackter Flügelhaut. Schüppchen weißtich, Schwinger rotgelb.

Körper 5-6 mm, Flügel 4,5 bis fast $6 \mathrm{~mm}$ lang.

Anmerk. Diese Art scheint dom ebenfalls schwarz gefärbten Ducus terminifer Walker, Proc. Linn., Soc. Lond., Vol. 4, p. 152, 183 (1860) aus Makassar ähnlich zu sein. Walker erwähnt aber weder die gelbe Rückenlinie des Thorax, noch die gelbe Farbe von Schulter- und Hypopleuralbeulen, noch die Fleckung der Stirne.

2. Dacus caudatus, Fabricius (Wiedemann), var. nubilus n. v. (Taf. I, Fig. 2).

16 ơ aus Formosa, Tainan, Fuhosho; März, August.

Schildchen mit vier Borsten; ein schwächeres basales Paar ist vorhanden. Ein Paar Präscutellarborsten und drei Paare untere Frontorbitalborsten sind sichtbar; die vordersten zwei Paare stehen stark genähert beisammen. Ein Paar paralleler, wenn auch kleiner Postvertikalborsten entwickelt. Pteropleurale schwächer.

Kopf hellgelb, Fühler, Taster und Hinterkopfscheibe rostgelb. Stirne in der Mitte matt und dort mit einem runden, unscharf bogrenzten rotbraunen Fleck. Orbiten ungefleckt. Scheitelkante mit dunkelbraunem Querbändchen. Lunula dunkelbraun. Gesicht mit zwei glänzend schwarzen, ungefähr runden Flecken über dem Mlundrande, die beim $q$ etwas größer sind. Die Spitze des dritten 
Antennengliedes kann etwas verdunkelt sein. Arista nackt. Rand des Hinterkopfs hellgelb. Beiderseits des Cerebrales ein kleinor, brauner, nicht immer deutlichor Fleck. Cerebrale iiher dem Halse mit einem schwarzen V-Fleck.

Thorax rostfarbig. Hellgelb sind dieselhen Teile wie hei $D$. cilifer angegeben. Die Sternopleura ist aher am Oberrande in einem größeren Querfleck gelb gefärbt und der Thoraxrücken zeigt hinter der Quernaht drei gerade hellgelbe Längsstriemen. Die seitlichen liegen wio bei $D$. cilifer angegeben in der Supraalargegend, sind aher breiter; die mittlere erweitert sich nach hinten keilförmig und ist dort abgekürzt. Pechschwarz oder dunkelbraun sind zum größten Teil die zwei Zwischenräume zwischen diesen drei gelhen Striemen, ein größerer Fleck zwischen dem Humeral- und Notopleuralcallus, der sich nach abwärts auf die Pleuren streifig fortsetzt und die gelben Stellen derselben vorne einfabt; eine Längsmittellinie des Rückens vor der Naht, zwei rostfarbige, graulich bereifte Längsstriemen trennend, sowie der Hinterrücken mit Ausnahme der Mitte. Rücken, Schild und Hinterleib sind fein goldig pubesziort.

Hinterleib am Vorderrande des ersten bis dritten Tergites schwarzbraun gesäumt, desgleichen am Seitenrande der ersten zwoi Ringe. Die Tergite vier und fünf sind in den Seitendritteln des Vorderrandes gleichfalls, aber etwas breiter schwarzbraun eingefaßt, was sich am Seitenrande ein wenig erweitert. Eine gleichfarbige Medianlinie durchläuft die Tergite drei bis fünf. Bauchhaut gelb. Sternite dunkelbraun. $\sigma$ seitlich am Hinderrande des dritten Tergits wie bei D. cilifer borstig gewimpert. Das fünfte Tergit ist in den zwei lateralen Vertiefungen zwar matt, aber feiner chagriniert; dieselben reichen bis zum Hinterrande desselben. Erstes Glied des Ovipositors glänzend gelbrot, etwas länger als das fïnfte Tergit, schlank trapezförmig, an der Basis doppelt so breit wie am Ende.

Hüften und Beine hell rotgelb, Schienen gesättigter, melr rostliurbig. Mittelschienen an der Basis, Hinterschienen an beiden Enden schwarzbraun oder dunkelbraun gefärbt. Metatarsus auffällig heller als die anderen Fußglieder, weißlich belıaart.

Flïgel an der Wurzel glasig, gegen die Spitze hin gelblichbraun angelaufen. Subkostal-, Marginal- und obere Hälfte der Submarginalzelle sowie ein damit zusammenhängender großer Apikalfleck an der Mïndung der Cubitalis schwarzbraun. Analzellenzipfel mit einem braunen Längsschweif, der sich beim $\sigma$ an der Spitze deutlich erweitert, beim $q$ jedoch spitz ausgezogen ist. An der Posticalismündung liegt ein verwaschener brauner Fleck. Die 
Fliigelhaut ist in der ersten Basalzelle vor der Querader ausgedohnt behaart.

Schüppchen weißlich, Schwinger gelb.

Körper $6,5-8 \mathrm{~mm}$, Flügel 6 bis fast $8 \mathrm{~mm}$ lang.

Anmerkung 1. Nach Ausscheidung des $q$ aus der Wicdemaun'schen Beschreibung des Dacus caudatus, das eine andere Art vorstellt, bleiben als typische Stücke jene übrig, deren hintere Querader dunkel gesäumt ist und deren Schenkel vor der Spitze oinen dunkelbraunen Punkt haben. Ich sah im Wiener Hof-Museum 8 o $f$ aus Ostjava, Montes Tengger, von Fruhstorfer gesammelt. Nur die hintere Querader ist breit braun gesäumt, was sich an der Posticalismündung etwas erweitert. Der braune Kostalsaum reicht nur etwas unter die Radialis herab. Die braunen Querbinden an den Seiten des dritten bis fünften Tergites sind breit, oft so broit, daß nur ein schmaler gelber Hinterrandsaum übrig bleibt oder ganz sehwarz bis hinten. Die Schenkel zeigen meist auch vorne einen braunen Fleck, so daß oin dunkler Ring vor der Spitze entsteht.

Fünf Stiicke aus Ostindien, leg. Felder, ebenfalls im Wiener Museum, unterseheiden sich dadurch, daß die hintere Querader nicht gesäumt ist und nur an der Mündung der Posticalis ein dunkler Schatten liegt. Allo Schenkel haben posterodorsal vor der Spitze einen braunen Punktfleck.

Von zwei Stücken der Wiedemann'schen Sammlung aus Javi hat das eine eine schmal gesäumte Querader, das zweite nur den dunkleren Wisch an der Posticalismündung. Beide haben an den Schenkelspitzen braune Punkte.

Die Formosaner Stücke haben alle nur einen braunen Schatten an der Posticalismündung und mit Ausnahmo von drei Stücken, die eine Spur von braunen Flecken posterodorsal an den Schenkelspitzen zeigen, einfarbig gelbe Schenkel.

Die Fabricius'sche Beschreibung deckt sich mit der von Wiedomann nicht befriedigend. So erwähnt Fabricus auf dom Thoraxriicken nur zwei gelbe Längslinien und den dunklen Saum der hinteren Querader gar nicht.

Anmerkung 2. Dacus apicalis de Meijore von Java ist sehr ähnlich, hat aber nur zwei Schildchenborsten und an der Posticalismündung keinen braunen Fleck.

\section{Dacus dorsalis n. sp. (Taf. I, Fig. 3.)}

119 o $q$ aus Formosa, Koshun, September.

Schildchon nur mit zwei Borsten, den apikalen, versehen; außer- 
dem zwei untere Frontorbitalborsten, ein Paar Präscutellare. Pteropleurale sehwach.

Typische Dacus-Art. Kopf, Fühler und Taster rotgelb. Stirne wachsglänzend, in der Mitte matt und dort mit einem unscharf bogrenzten rotbraunen Fleck, an den Orbiten jederseits mit drei rotbraunen Punkten an den Wurzeln der Borsten ${ }^{1}$ ). Ocellenhöcker schwarz, Scheitelplatten daneben rot. Lunula dunkelbraun. Gesicht bei $\sigma$ und $f$ mit zwei rundlichen, glänzend pechschwarzen Flecken oberhalb des Mundrandes. Drittes Fiihlerglied am Oberrande und an der Spitze meist etwas gebräunt. Arista nackt. Hinterkoptseheibe rostfarben, am Rande hellgelb; beiderseits des Cerebrales mit einem verwischten dunkler braunen Flecken von geringer Ausdehnung, der anch ebensooft fehlt. Gegen den Hals zu laufen vior kurze rotbraune Linien zusammon.

Thorax rostfarbig. Zitronengelb sind genau dieselben Stellen, wie bei $D$. cilifer angegeben. Es fehlt also dem Rücken die golbe Mittelstrieme hinter der Queruaht. Der Rücken ist sonst größtenteils schwarz, mit aschgrauer Reife bedeckt. Die rostbraune Grundfarbe zeigt sich nur rund um den hellgelben Humeralcallus, in den Qnernahtästen, der Supraalargegend und einem Querstreifon vor dem Schilde, wo das Präscutellarpaar steht. Aus dem grauen Reife des Riickens treten droi dunkle Längslinien ziemlich doutlich hervor; die seitlichen sind an der Quernaht unterbrochen.

Auch auf den Plouren sind die hellgelben Stellen pechbraun eingetaßt, bei den dunkleren Stücken ausgedehnter, ja vorherrschend. Die dichtanliegende Pubeszenz ist auf dem Rücken und dem Schildo goldgelb, sonst weiß. Die rote Mittelstrieme des sonst schwarzen Hinterriickens ist nicht immer gut sichtbar.

Hinterleib vorherrschend rotgelb bis rostrot. Seitenl'lecken am ersten, ein schmaler Vorderrandsaum am zwoiten und ein breiter solcher am dritten Tergit, sowie eine von diesem bis zum Hinterleibsende führende Medianlinie sehwarzbraun. Die Querbinde des dritten Tergits ist in der Mitte und an den Seiten am sehmälsten und erweitert sich beiderseits dazwischen oft fleckenartig fast bis zum Hinterrande des Tergits. Seitlich am Vorderrande des vierten, seltener auch dos fünften 'liegt ein schiefer, dreieckiger', schwarzbrauner Fleck. $\sigma$ seitlich am Hinterrande des dritten Tergites wie bei $D$. cilifer gewimpert. Bauch rotgelb, Sternite braun. Erstes

1) Diese Punkte fehlten von den 119 Stücken nur drei unausgrefärbten ㅇ. 
Glied des Ovipositors trapezförmig, etwas kürzer als das fiinfte Torgit. Dioses ist in den zwei lateralen, ovalen Vertiofungen, die in der Mitte zwischen Vorder- und Hinterrand liegen, vollständig glatt und glänzend.

Hüften und Beine rotgelb. Vorderschienen an der Basis, die hintersten an beiden Enden mehr oder weniger ausgedehnt und intensiv gebräunt. Fußenden bräunlich. Ferse hellgelb behaart.

Flügel glashell. Subkostalzelle und ein sich daranschließender, überall gleich breiter Kostalsaum bis über die Mündung der Cubitalis hinaus, sowie ein Analzellonschweif dunkelbraun. Die Flügelhaut ist in der ersten Basalzelle von der Querader ausgedehnt behaart.

Schüppchen weißlich, Schwinger gelb.

Körper $6-8 \mathrm{~mm}$, Flügel $5-7 \mathrm{~mm}$ lang.

Anmerkung: Dacus ferrugineus Fabricius unterscheidet sich nach Wiedemann's Beschreibung durch rostgelbliche - also ungefleckte Stirne. Der Thoraxrücken ist roströtlichbraun und nicht ausgesprochen schwarz.

Froggatt erwähnt nun aber in seinen „Fruit Flies“, 1910, p. 13, die große Variabilität dieser Art in der Färbung von rotbraun bis schwarz. Leider sagt er uns nichts darüber, ob die Stirne gefleckt ist oder nicht. Sein Flügelbild Pl. V, Fig. 8, stimmt mit den Formosaner Stïckelı überein.

Sehr charakteristisch für unsere Art sind die zwei glänzenden Flocke des fünften Tergites. Es ist sehr wahrschoinlich, daß sie ein Teil dessen ist, was Froggatt u. a. für ferrugineus $\mathrm{F}$. beschrieben haben.

4. Dacus scutellatus n. sp. (Taf. I, Fig. 4.)

$1 \sigma$ aus Formosa, Koshun.

Schild mit vier Randborsten; drei untere Frontorbitalborsten, die vordersten zwei derselben eng beisammen. Ein Paar Präscutellare. Pteroplcurale stark. Die Stirne ist schmäler als gewöhnlich, merklich schmäler als ein Auge und gut doppelt so lang wie breit. Postvertikalborsten gut entwickelt.

Typische Dacus-Art. Kopf, Fiihler und Taster rotgelb. Stirne in der Mitte matt und mit einem rotbraunen, rundlichen Flecke. Am Augenrande an den Borstenwurzeln jederseits drei dunkelrotbraune Punkte; der vorderste ist etwas länger, weil zwei Borsten tragend. Scheitelkante mit dunkelbraunem Querbändchen. Lunula dunkelbraun. Gesicht mit zwei großen eiförmigen, glänzend schwarzen 
Flecken oherhalb des Mundrandes. Drittes Fühlerglied ctwas gesätligter gefärbt, mehr rötlichbraun. Arista nackt. Hinterkopfscheibe kaum dunkler als der Rand. Gegen den Hals zu laufen vier rotbraune Linien zusammen.

Thorax wie bei $D$. dorsalis gefärbt, namentlich ist auch der Rïcken im zentralen Teil schwarz, aschgrau bereift und mit drei dunklen Längslinien versehen. Der Humeralcallus ist aber oben nicht rostfarbig umrandet, sondern wird vom Schwarz begrenzt; das obere Ende der Quernahtäste ist hellgelb, nicht rostrot. Hinter der Quernaht außer den zwei seitlichen auch noch eine vorne und hinten zugespitzte mittlere schmale Längstrieme von hellgelber Farbe. Pleuren außer den hellgelben Flocken vorherrschend pechschwarz. Metanotum schwarz, nur mit einer schmalen, dunkelroten Längslinie. Schildchen an der Spitze, dort, wo die zwei apikalen Borsten stehen, mit einem größeren, eiförmigen, dunkelrotbraunen Fleck.

Hinterleib rotgelb. Erstes Tergit an den Seitenrändern schwarzbraun. Die Vorderrändor der Tergite zwei bis fünf habon unteroinander gleichbreite schwarzbraune Quersäume, von denen nur dor des fünften Tergits in der Mitte schmal unterbrochen ist. Eine schsarzbraune Medianlinie durchzieht die Tergite drei bis fünl. Fünfles Tergit seitlich gegen den Hinterrand zu glänzend. Bauchhaut rot, Sternite braun. Drittes Tergit $\left(\sigma^{\top}\right)$ seitlich bewimpert, wic bei $D$. cilifer.

Vorderhïften und Boine hellgelb. Die vier letzten Fußglieder bräunlich. Die vier vorderen Schienen an der Wurzel und die vier Hinterhüften braun. Hinterknie und die Hintersehienen mit Ausnahme der Mitte dunkelbraun.

Fiügel glashell; Subkestalzelle, ein sich daranschließender gleichbreiter Kostalsaum bis über die Cubitalismündung hinaus, der sich an dieser etwas fleckenartig erweitert, sowie ein Analzellenlängswisch dunkelbraun. Die hintere Querader ist von einem nach unten hin sich erweiternden, braunen Saum bedeckt. Flügelhaut der ersten Basalzelle vor der Querader ausgedehnt bohaart.

Schüppchen gelblich, Schwinger rotgell).

Körper $8 \mathrm{~mm}$, Flügel $7,5 \mathrm{~mm}$ lang.

\section{Dacus parvulus 11. sp.}

Fiinl ơ $f$ aus Formosa, lianshiroi, April.

Schild mit zwei Randhorsten. Zwei untere Frontorbitalborsten. Ein Paar Praescutellare und eine starke Pteropleurale vorhanden. Postvertikale fehlen. Kopf- und Thoraxborsten rot. Stirne von normaler Breite. 
Typische kleino Dacus-Art, von dor Färbung des Dacus scutellatus mit folgenden Unterschieden. Die schwarzen Gesichtsflecken sind lang-eiförmig und größer. Die Hintorkopfscheibe ist von dem hellgelben Rand scharf abgesetzt, dunkel rotbraun.

Das obere Ende der Quernahtäste ist hier schwarz. Das Schwarze herrseht überhaupt auf dem Thorax und Hinterleib vor. Auch dio Supraalargegend ist schr dunkel, die dortigen gelbon Seitenstriemen sehr schmal, linienartig. Eine Mittelstrieme fehlt. Schild einfarbig gelb.

Hinterleib pechschwarz. Das 1. Tergit ist am Hinterrande nur schmal linienartig rotgelb, das 2. aber dort breit, hellgelb gesäumt. Die Hinterleibsspitze ist in geringerer oder gröberer Ausdohnung gelbrot oder rotbraun gefärbt und zeigt eine nur undeutliche, dunklere Medianlinie. 5. Tergit seitlich nur feiner chagriniert, 3. Tergit beim $\delta$ hinten an der Seite bewimpert. Bauch rötlich gelb, Sternite hraun. Erstes Glied des Ovipositors kurz trapozförmig, rotbraun, merklich kürzer als das 5. Tergit.

Hüften dunkelbraun, Beino hellgelb. Schenkel vor der Spitzo mit einem schmalen schwarzbraunen Ring, dor nur vorne so breit ist wie die halbe Schenkellänge. Vorderschienen heller, Hintersehienen dunkelbraun, mittlere nur an der Basis gebräunt. Metatarsus weiBlich, Fußenden braun.

Flügel glashell. Sulkostalzelle dunkolbraun; ein sich daranschliebender, gleichbreiter Saum der Kosta zunächst in der Mitrginalzelle heller braun, dann an der Mündung der Cubitalis breiter und gosättigtor werdend. Analzellenzipfel mit braunem Längswisch. Flügelhaut der ersten Basalzelle distal behaart. Flügel sohr ähnlich Fig. 1. Das Cubitalisendo ist aber etwas wellig nach abwärts geschwungen und der Fleck dort etwas größer.

Schüppchen weißlich. Sehwinger gell.

Körper $5 \mathrm{~mm}$, Flügel $4,5 \mathrm{~mm}$ lang.

\section{Dacus spez. $\alpha$.}

1 i aus Formosa, Koshun, Septemher.

Sehild mit vier Randborsten. Zwei untere Frontorbitalborsten. 1 Paar Praescutellare. Postvertikale nicht sichtbar. Stirne merklich schmäler als ein Auge, gut zweimal so lang wie breit.

Kopf und Thorax wie bei Dacus $\&$ gefärbt und gezeichnet. Die Stirnpunkte sind aber weniger prononciert. Oberhalb des Mundrandes drei schwarzbraune kurze Längsstriche. 
Das obere Ende der Quernaht ist nicht gelb. Die drei hellgelben Längsstriemen hinter der Rückenquernaht sind breiter und nicht ganz linienartig schmal. Schild an der Spitze mit einem rotbraunen Fleck.

Hinterleib samt Ovipositor wie $D$. caudatus $F$. gezoichnet und geformt.

Schenkel hellgelb, posterodorsal vor der Spitze mit einem rotbraunen Fleck. Schienen braun, besonders die hintersten, in der Mitte ein wenig heller. Füße bräunlich, Ferse weißlichgelb.

Flügel wie bei $D$. cilifer, Fig. 1 . Die Marginalzelle ist aber nicht heller gefärbt und der Kostalsaum verbreitert sich ganz gleichmäßig und ohne innere Erweiterung an der Cubitalis. Er endet in der Mitte der Mündung der ersten Hinterrandzelle, erste Basalzelle distal etwas behaart.

Körpor $5 \mathrm{~mm}$, Flügel $4,5 \mathrm{~mm}$ lang.

\section{Dacus spez. $\beta$.}

1 q aus Formosa, Koshun, Septomber.

Schild nur mit einem Paar Borsten. Droi untere Frontorloitalborsten, Ein Paar Praescutellare. Postvertikale klein.

Typische Art. Kopf samt Anhängen rotgelb. Stirne weißschimmernd, mit braunen Punkten an den Borstenwurzeln, undeutlichem braunen Mittelfleck und schwarzbraunen Querbändchen an der Scheitelkante. Lunula braun. Hinterkopfscheibe mit einem durch das Cerebrale unterbrochenen braunen Kreisbogen. Gesicht mit einom die halbe Höhe einnehmenden glänzend schwarzen Bande oberhalb des Mundrandes. Drittes Fühlerglied gegen die Spitze hin etwas gebräunt. Arista nackt.

Thorax wie bei Dacus scutellatus gezeichnet und gefärbt. Schildchen aber ganz gelb.

Hinterleib rotgelb. Seiten des ersten Tergits, ein schmaler Vorderrandsaum des zweiten und die folgenden Tergite mit Ausnahme der Hinterleibsspitze schwarzbraun. Erstes Glied des Ovipositors so lang wie die letzten drei Tergite zusammen, sehr schlank trapezförmig, rot. Bauch rotbraun, Sternite schwärzlich.

Vorderschenkel mit Ausnahme der Wurzel, Mittelschenkel in der Endhälfte, Hinterschenkel im Enddrittel pechschwarz. Schienen dunkelbraun, in der Mitte holler. Füße bräunlich, Ferse weißlichgelb.

Flügel wie bei $D$. cilifer, Fig. 1. An der Mündung der Posticalis ein kleiner Schatten. Erste Basalzelle teilwoiso boharrt.

Körper $6,5 \mathrm{~mm}$, Flügel $6 \mathrm{~mm}$ lang. 
8. Dacus chrysotoxus, n. sp. (Taf. I, Fig. 5.)

1 ㅇ von den Key-Inseln, leg. Kühn. Sammlung B. Lichtwardt

Vier Schildchenborsten, drei untere Frontorbitalborsten. Postvertikale ziemlich deutlich. Ein Paar Praescutellare. Die Grundbehaarung von Kopf und Leib ist relativ lang und abstehend, goldgelb, Stirne breit, nicht viel länger als breit.

Kopf und Anhänge hell gelbrot. Stirne ungefleckt. Scheitelkante und Hinterkopfsscheibe rostfarbig. Gesicht mit zwei runden schwarzen Flecken oberhalb des Mundrandes.

Thorax und Schild wie bei $D$. caudatus $\mathrm{F}$. gefärbt.

Hinterleib rotgelb. Am Vorderrande des 1.-3. Tergites eine schwarze schmale Querbinde; die des 3. am breitesten und intensivsten. Nur der 4. und 5. Tergit haben eine schwarze Medianlinie. 4. Tergit seitlich im Vorderrando mit einer schwarzbraunen Querbinde. Ovipositor, erstes Glied, gelbrot, trapezförmig, etwas länger als das 5. Tergit, konisch, nicht von oben her kompress.

Hüften und Beine rotgelb.

Flügel mit einer gelblich rotbraunen Zeichnung nach Figur 5. Adern rot. Schüppchen gelblich. Schwinger rotgelb.

Körper $10 \mathrm{~mm}$, Flügel $9,5 \mathrm{~mm}$ lang.

Anmerkung: Dacus discipennis Walker scheint eine sohr ähnliche Art zu sein, namentlich in der Flügelzeichnung. Was aber Walkel von der Thorax- und Hinterleibsfärbung sagt, paßt nicht auf unsere Art. 


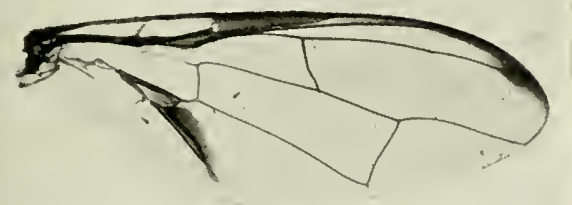

1.
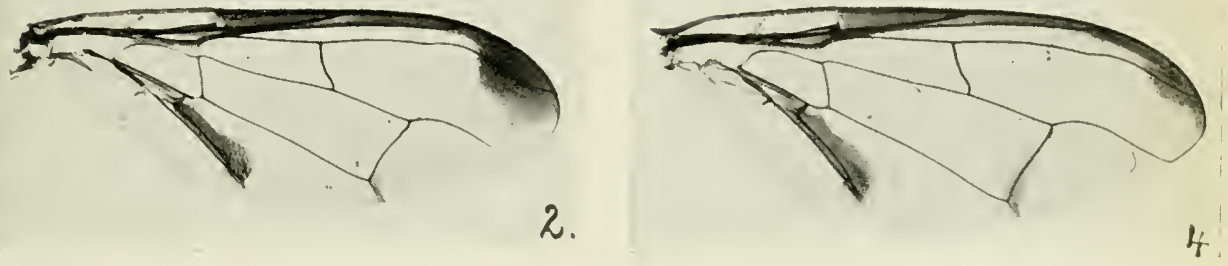

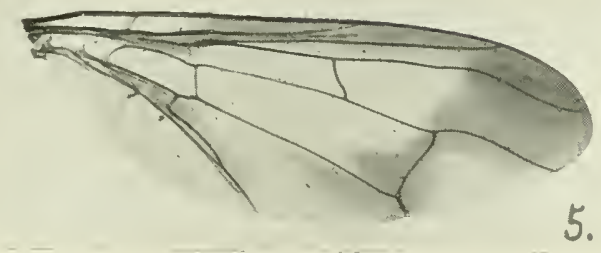

F. Hendel, Dacus.

1. D. cilifer nov spec. 2. D. caud. r. mubilus nor. 3. D. dorsalis nor. spec. 4. D. scutellatus nor. spec. 5. D. chrysotoxus nor spec.

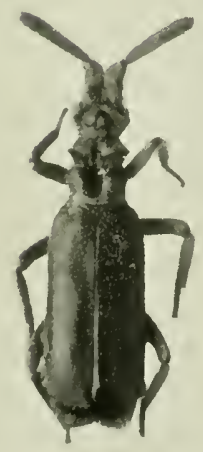

li.

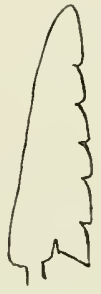

$7 a$.

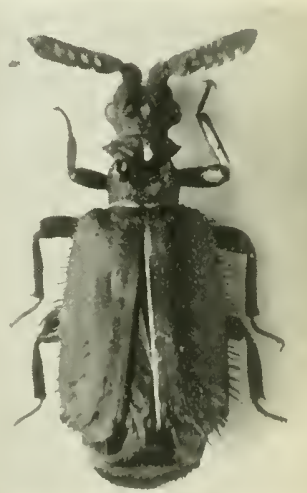

7.

F. Wasmann, Permssus.

i. I. Sauleri noy. spec.

7, 7 a. P. formosus nov. spec. 





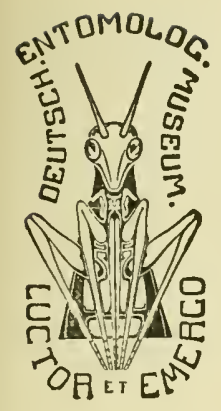

\section{Separatabdruck aus}

\section{Entomologische Mitteilungen}

Herausgegeben vom Verein zur Förderung des Deutschen Entomologischen Museums

[Redaktion: S. Schenkling und C.Schaufuss]

\section{F. Hendel,}

Nene Drosophiliden aus Südamerika und Neugninea (Dipt.). 



\title{
Neue Drosophiliden ans Südamerika und Neuguinea (Dipt.).
}

\author{
Von F. Hendel, Wien.
}

(Mit 2 Figuren im Text.)

Oxyleucophenga nov, gen. (Fig. 1).

Die nackte Stirne und das Gesicht gleich breit, mit parallelen Augenrändern, erheblich schmäler als ein Auge. Kopf im Profile last halbkreisförmig umrissen, da die Stirne nicht vorsteht, die Backen linear sind und das Vibrisseneck nur etwas sichtbar wird. Hinterkopf stark für den Thorax ausgehöhlt. Zwei kräftige, gleich starke, nach oben gebogene Frontorbitale, deren vordere etwas vor der Stirnmitte steht. In gleicher Höhe mit ihr, etwas einwärts geriickt, steht die ebenfalls gleich starke, nach vorne gelogene Borste. Ozellare und Vertikale normal. Postvertikale sehr klein. Lunula bedeckt. Gesichtskiel nur zwoi Drittel des Gesichtes lang, niedrig, aber scharf, wenig auffallend; er drängt die Fühler nicht auseinander, die an der Basis eng beisammen und noch etwas oberhalb der Angenmitte stehen. Fühler etwas kürzer als das Gesicht, nickend. Zweites Glied etwas kappig vortretend; drittes Glied oval. Arista oben mit sieben, unten mit fünf oder sechs langen, abstehenden Fiederstrahlen versehen. Vibrissen gut entwickelt. Prälabrum niedrig, etwas von vorne sichtbar. Taster fädlich. Rüssel. und Mundöffnung kleln.

Thorax wie bei den Drosophiliden im allgemeinen hoch gewölbt. Die Rüickenbehaarung ist sehr dicht und kurz, anliegend. Vor dem einzigen Dorsozentralborstenpaar steht noch ein kürzeres Borstenpaar. Schild fast halb so lang wie der Rücken, eiförmig, oben flach, nackt; am Rande mit vier Borsten, die apikalen gekreuzt. Auf dem Pleuren nur zwei Sternopleuralborsten nebeneinander. Hinterleib wie bei Leucoplenga, nach hinten verjüngt.

Die auffälligsten Merkmal bietet der Flügel, der an der Cubitalismündung, wo auch die sonst dicke Kosta schon endet, eine scharfe Spitze zeigt. Subkosta sehr kurz, zirka ein Viertel der Flügellänge, Radialis wellig, ziemlich weit vor der Fliigelspitze 
mündend. Cubitalis hinter der vor der Mitte der Diskalzelle stehenden kleinon Querader aufgebogen, dann aber ganz gerado, Discoidalis gelade, parallel mit der Cubitalis. Hintere Querader mi der Posticalis oinen spitzen Winkel einschliefend. Dio zweite Basalzelle ist nur unvollkommen mit der Diskalzelle verschmolzen. lileine Querader weit vor der Mitte der Diskalzello.

Vorderbeine schwach und etwas verkiirzt. Präapikalbörstchen uur an den Mittelschienen deutlich.

Wio bei Leucophenga ist auch hier die Stirne und dio ganzo Oborseite der Fliege mit silberweißem Schimmor iibergossen.

Gattungstypus 0 . undulata nov. spec.

1 đ aus Per'u, UrubambafluB, Umahuankilia, 11. November. Lresdner Museum.

Das ganze Tier ist von hellrotgelber Farbe, das Gesicht am hellsten gefärbt. Borsten und Haare schwarz.

Die Hinterränder der Abdominaltergite sind heller gelb. Wer Schildeindruck des basalen Doppelsegmentes und je ein kurzes Strichlein in der Mitte des Vorderrandes des dritten und vierten Tergites, sowie kloine Mittelpunkte an den Seitenrändern der Tergite 3 bis 6 sind schwarzbraun.

Flügel etwas bräınlich hyalin, mit braunen, nur an der Wurzel grelben Adern und dunkelbraunen Flecken nach der Figur.

Körper und Flügel $3 \mathrm{~mm}$ lang.

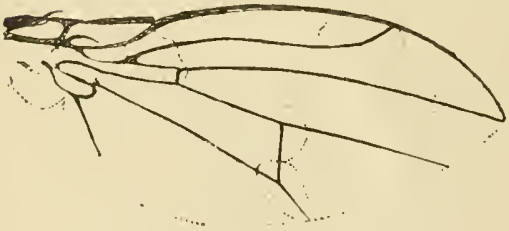

Fig. 1.

Drosophilura nov. gen. (Fig. 2).

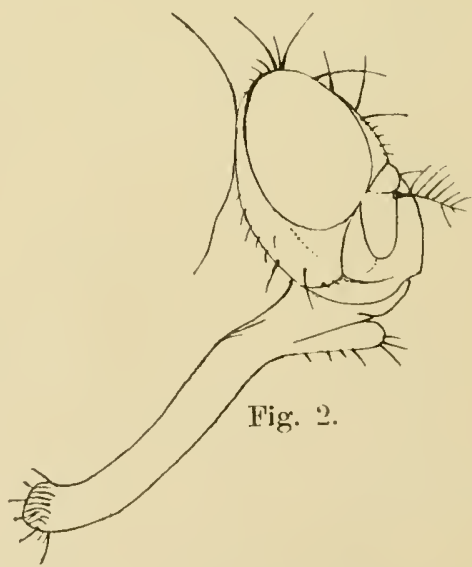

Stirne vorne so breit wie cin Auge, am Scheitel noch erheblich verbreitert. Von den Fühlerwurzeln nach abwärts sind dic Augenränder ziemlich parallel. Das Ozellendreick ist scharf abgesetzt, 
oben die Hälfte der Stirne breit und erreicht mit der Spitze den vorderen Stimrand. Die schmalen, mit dem Augenrande parallelen Scheitelplatten sind etwas kürzer. Die drei Frontorbitalbol'sten sind fast gleich lang und stark; die vordersto steht im orsten Stirndrittel und ist nach vorne gebogen; gleich dahinter steht die vordere der zwei nach oben gebogenen Borstell. Ozellare und Postvertikalo kräftig entwickelt. Vertikalborsten normal.

Gesichtskiel scharf und sehr hoch, im Profile in konvexem Bogen, der oberhalb des Mundrandes am stärksten gekriimmt ist und am weitesten volsteht, ganz auffallend nasenartig über die Fühler vortretend, so lange wie das Gesicht, oben die Fïhler an del Wurzel auseinander keilend. Die Seitenränder des Mundrandes stehen etwas flügelartig vor. Fühlorgluben tief cingefurcht, so lang wie das Gesicht, außen kantig.

Fühler den Furchen angedrückt, nngefähr dor Augonmitte gegeniiber inseriert. Zweites Glied nieht kappig, oben mit langer, abstehender Borste. Drittes Giied oval. Arista oben mit sechs, unten an der Spitze mit zwei langen Fiederstrahlen versehen. Vibrissen kräftig ausgebildet. Zwei Backenborsten. Das Prälabrum füllt den Mundrand von unten knopfig aus. Taster lang, dünn, am Ende erweitert, unten rauh beborstet. Rüssel schlank und lang, deutlich länger als der Kopf, mit kleinen kopfigen Labellen. Wangen sehmal, Backen zirka ein Drittel eines Auges hoch. Hinterkopf stark ausgehöhlt.

Thorax oben stark gewölbt. Sehild etwas über ein Irittel des Rückens lang, eiförmig, oben flach gewölbt und nackt, am Rando mit vier Borsten, die apikalen gekreuzt. Drei Humerale, zwei Notopleurale, eine Präsuturale, vier Supraalare, zwei Paare Dorsozentrale ganz hinten. Präseutellare fehlen. Grundbehaarung des Rïckens in dichten Längsreihen stehend, kurz. Pleuren nur mit zwei Sternopleuralen nebeneinander, deren vordere etwas schwächer ist.

Hinterleib beim $q$ brcit eiförmig, breiter als der Thorax. Das basale Doppelsegment ist ungefähr ein Drittel des Abdomens lang. Von den folgenden siebel sichtbaren Tergiten ist das letzte das kürzeste. Aus diesem steht ein kurzes, flach zylindrisches und am Ende borstlich behaartes Tastorgarn, das die Hinterleibsspitze bildet, vor", Unter ihm, ventral, setzt in einem breiten, nach unten gerichteten Kegel der Ovipositor an, der dann sich holnartig verjüngt und mit schlanker Spitze nach hinten richtet. Das Endo ist dreieckig zugespitzt und am Rande dornig gezähnelt. Der ganze Ovipositor ist ungefähr so lang wie der halbe Hinterleib and sein schlanker Endteil oben etwas rinnenartig hohl. 
Subliosta kurz, der kleinen Querader gegenüber mündend. Diese stcht übor dem ersten Viertel der Diskalzelle, die wieder mit der zweiten Basalzelle wegen Fehlens der Querader zusammenschmilzt. Radialis fast gerade, jenseits der Mitte des letzton Discoidalisabschnittes mündend, welcher nur wenig länger als der vorletzte ist. Die erste Hinterrandzelle ist an der Mündung deutlich verengt. Dio Kosta reicht bis zur Mündung der vierten Längsader.

Gattungstypus: D. caudata nov. spec.

1 \& aus Bolivia. Firma Staudinger und Bang-Haas.

Stirndreieck und Scheitelplatten glänzend, diese und die Orbiten braungelb. Die beiden Schenkel der Stirnstrieme samtig schwärzlich rotbraun. Gesicht, Backen, Riissel, Taster, Pleuren des Thorax, Motanotum, Hüften und Beino hell ockergelb, glänzend. Fühler vorherrschend, Taster an der Spitze sepiabraun. Thoraxrücken und Oberseite des Schildes sepiabraun. In der Linio der Dorsozentralen zwei durchlaufende gelbe Längslinien, die vorne oberhalb der Schultern nach außen und wieder nach rïckwärts umbiegen. Eine feine gelbe Medianlinie ist weniger deutlich ausgeprägt. Außordem sind noch die Lateral- und Supraalargegend des Rückens, sowie die Schildränder gelb.

Der dreieckige Eindruck an der Wurzel des Hinterleibes und kleine auch dreieckige Seitenfleckchen vorne am fünften und sechsten Tergit, dann der Bauch und der Ovipositor sind rotgelb. Haare und Borsten alle sehwarz.

Der Flügel ist ziemlich gleichmäßig bräunlich tingiert, nur gegen die Wurzel hin etwas heller. Adern braun. Sehwinger gelb.

Körper und Flügel $4 \mathrm{~mm}$ lang.

Periscelis nebulosa nov. spec.

Vier Stücke aus Buenos Aires, Argentinien, an Baumjauche. Wiener Hofmuseum.

Die Art ist in allen plastischen Merkmalen unserer $P$. annulatı Fallen so ähnlich, daß sie in keine andere Gattung gobracht werden kann. Ein Zottel an der Nadel berichtet „Durch die Augenmitte oin dünnes dunkelrotbraunes Querbändchen. Obere Facetten rotbraun, untere grün, etwas größer".

Stirne, Thorax und Hinterleib mit Ausnahme des gelben basalen Doppelsegmentes glänzend pechbraun, unbestäubt, Stirne oberhalb der Fühler mit Querfurche. Mundrand zuın Unterschiede von den anderen Arten mit zwoi vibrissenähnlichen Haaren. Arista oben mit fïnf, unten mit vier Kammstrahlen. 
Hiiften und Beine gelb. Schenkel außer der Wurzel und Schienen außer der Spitze, sowie die zwei letzten Fufglieder pechbraun.

Flügeladerung genau wie bei der Fallen'schen Art. In der Flügelmitte liegt zwischen den beiden Queradern eine braune Wolke, die sich schief nach oben in die Spitze dor Subkostalzelle hineinzieht. Auch die Flügelspitze ist an der zweiten und dritten Längsader gebräunt.

Schwingen hellgelb.

Körper $2,5 \mathrm{~mm}$, Flügel $2 \mathrm{~mm}$ lang.

Eostegana nov, gen.

Gloicht mit folgonden Unterschiedon der Gattung Stegana. Dio Augen sind nicht wagerecht eiförmig, sondern noch höher als lang. Die erste Hinterrandzelle ist an der Mündung nicht verengt, sonder'n hat fast die Tendenz sich zu erweitern.

Der gerade, über die Fühlerwurzelı vorgezogene Stirnrand, die posterodorsal reihig beborsteten Mittelschienen und die getrennte zweite Basalzelle, sind ebenfalls charakteristische Merkmale unserer Gattung.

Typus: Eost. Biroi nov. spec.

Mehrere Stücke aus Neu-Guinea, Sattelberg, Huongolf (Biro) und Moroka, 1300 m (Loria) im Ung. Wat. Mus. und im Mus. Civ. Genova.

Das ganze Tier ist pochbraun. Rot sind: der Scheitelrand und die Scheitelplatten, eine Stelle unter den Fïhlerwurzeln, stellenweise die hinteren Pleuren und das Metanotum. Der Hinterleib kann auch deutlich rötlichen Stich haben; die Hinterrandräume der Tergite sind stets heller rot gefärbt.

An den Beinen sind nur die Füße abstechend hell rotgelb. Über dem Mundrande liegt ein breites silbriges Querband. Oben meist acht, unten meist drei lange gelbliche Fiederstrahlen auf der Arista. Gesicht konkav, zurückweichend. Vibrissen stark.

Flügel tief schwarzbraun, nach hinten zu heller. Hyalin sind die zweite Basalzelle, dann dio Schulterlappen und die Wurzel und der Hinterrand der dritten Hinterrandzelle. An der Flügolspitze zwei milchwoib schimmernde schiefe Querbinden. Die erste läuft ganz durch und durchquert die Mitte der ersten Hintorrandzelle; sie liegt an der Kosta weiter wurzelwärts als hinten. Die zweite Binde besteht aus zwei an der Cubitalis getrennten Flecken an der Flügelspitze. Die obere Hälfte der ersten Binde ist gewölnnlich deutlich gelb tingiert. Schüppchen rostfarben. Schwinger schwarz. Kleine Querader jenseits der Mitte der Diskalzelle.

Körper $4,5 \mathrm{~mm}$, Flügel $4 \mathrm{~mm}$ lang. 


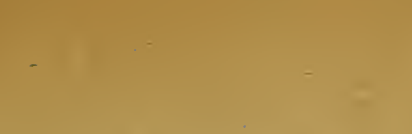



\title{
Neue amerikanische Dipteren.
}

\section{Beitrag.}

\section{Von Friedrich Hendel, Wien.}

\author{
Mit 5 Textfiguren.
}

Durch die freundliche Vermittlung des Herrn Prof. K. M. Heller erhielt ich aus dem Kgl, zoolog. und anthrop. Musemm in Dresden eine Reihe von Dipteren aus der Gruppe der acalyptraten Musciden zur Bearbeitung, die alle durch die Sammeltätigkeit der Herren W. Schnuse und Garlepp im Andengebiete Süd-Amerikas zusammengetragen wurden. Es werden wohl noch Jahre vergehen, bis das reiche Naterial, das W. Schnuse sammelte und das sich jetzt zum grofsen Nutzen der Wissenschaft in besten Händen befindet, vollständig aufgearbeitet sein nnd eine Übersicht gestatten wird.

Im Anschlusse daran beschreibe ich anch einige mir von anderer Seite zugekommene Amerikaner, zum weitans grölsten Teile neotropische Formen.

Die Verhältnisse bedingen eine Anfeinanderfolge der Arten in zwangloser Reihe. - Im besonderen mache ich in dieser Arbeit auf die seit Wied emann (1830) unbekannt gebliebene Gattung 'zygothrica und auf die Übersicht über alle bisher bekaunt gewordenen neotropischen Curtonotum-Arten aufmerksam.

$$
\text { Trixoscelis dimidiata n. sp. }
$$

4 or 우 ans Peru, Cuzco, 3700 m, 26. III. und Bolivia, Sorata, $2300 \mathrm{~m}, 20$. XII. Dresil. Mus.

Stirnstrieme matt rotgelb; Scheitelplatten, wie auch der Hinterkopf hell aschgrau. Stimaugenrand, Gesicht und Backen weifslich. Ocellenfleck dunkelbraun. Zwischen Fühler und Auge kein dunkler Fleck. Fühler orangerot; drittes Glied kurz oval. Arista schwarz, an der Wurzel etwas verdickt, wie nackt. Backen 1/: eines Auges hoch. Taster rotgelb. Augen nur wenig höher als lang.

Die Oberseite des Tieres ist hell aschgrau, die Unterseite scharf abgesetzt dunkel kaffeebraun. Die Grenze bildet an Thorax die Notopleuralnaht und am Hinterleib die geradlinige Fortsetzung nach hinten $\mathrm{zu}$, wodurch nicht nur der Bauch, sondern auch ein schmaler Seitenrand des Hinterleibsrückens braun ist. - - Auf dem Thoraxrücken laufen 3 braune Längslinien nach hinten, die mittlere zwischen den 2 Acrostichallü̈rchenreihen, die 2 seitlichen in der Reihe der Dorsozentralborsten. Diese 3 Striemen vereinigen sich vor dem Schilde in eine breite, die dann auch auf das letrtere 
übertritt. - In der Medianlinic jedes Abdominaltergites je ein langovaler kaffeebranner Fleck, die auch eine Längsstrieme bilden können.

Beborstung und Behaarung schwarz, wie beim Gattungs-Typus angeordnet.

Hüften und Schenkel kaffeebraun, Schienen und Füfse heller rotbraun.

Flügel hyalin, milchweifsschimmernd, mit gröfseren braunen Flecken am Vorderrande und oben an der hinteren Querader und braunen Querfleckchen in den Zellen beiderseits des letzten Cubitalisabschnittes und der Posticalis. Auch die Queradern sind braun gesänmt und in der Mitte der zweiten Hinterrandzelle liegt ein brauner Punkt. Die Marginalzelle ist bis auf $2-3$ helle Zwischen-

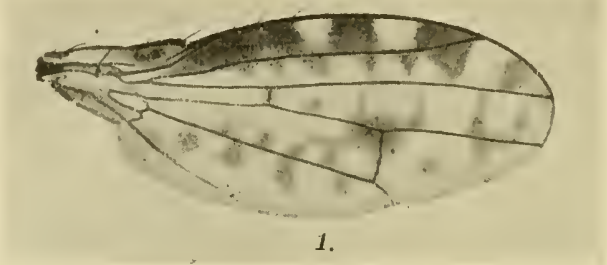

Fig. 1. Flügel.

räume ganz schwarzbraun. Costalzelle in der Spitze mit einem braunen Inselfieck. Radialis sanft wellig geschwungen. Kleine Querader auf der Mitte der Discalzelle. Schwinger und Schüppchen gelblichweils.

Körper $3,5 \mathrm{~mm}$, Flügel $3 \mathrm{~mm}$ lang.

A n merkung: Die zweite neotropische Art dieser Gattung ist Trix. chilensis Schiner, Novara-Dipt. p. 235 (1868) (Diastata), nach den Untersuchungen $\mathrm{C} z$ ernys zur Gattung Geomyza sens. Loew, das ist unsere Trixoscelis Rond, gehörig.

\section{('w) fonotum Macquart.}

Macquart, Dipt. exot. vol, 2/3. p. 193. tab. 25. f. 9.10 (1843).

Tabelle der neotropischen Arten.

2 Sternopleuralborsten, die vordere und obere schwächer. 1.

Nur 1 Sternopleuralborste; die vordere, obere fehlt . 6.

1. Thoraxrücken, Pleuren und Schild ohne dunklere Punktierung. C. simplex Schiner ').

Thoraxrücken und Schild stets dunkel punktiert . . 2.

1) Schiner, Novara-Dipt. p. 23i. 19 (1868). 
2. Flügel dunkelbraun, von zahlreichen weifsen Flecken durchbrochen . . . . . 1. C. trypetipenne n. sp.

Flügel nicht gitterartig weifs gefleckt. . . . . 3.

3. In der braunen Flägelspitze liegt an der Mündung der ersten Hinterrandzelle ein milchweifser Randfleck. Thoraxrïcken und Schild von dunkelbranner Grundfarbe. Hinterleib mit einer dunklen Längsstrieme . 2. C. apicale n. sp.

Flügel ohne weifsen Apicalfleck. Thorax und Schild von roter Grundfarbe. Hinterleib mit 3 dunklen Längsstriemen. 4.

4. Flügel hellgraulich hyalin. Hinterleib nit schmalen Striemen und Hinterrandsäumen. Die 2 rechteckigen hellen Flecke am Vorderrande der Tergite dicht gelbgrau bestäubt und dunkel punktiert . . . 3. C. murinum n. sp.

Flügel intensiv rauchbraun tingiert. Hinterleib mit breiten Striemen und Hinterrandsäumen. Die 2 rundlichen hellen Flecke am Vorderrande der Tergite schütter blangrau bereift und unpunktiert .

5.

5. Gesicht und Stirne gleichbreit. Die Abdominaltergite $3-5$ haben aufser in der Mitte noch 2 seitliche dunkle Längsstriemen, die den Vorderrand verbreitert erreichen. Wangen und Backen breiter. . . . . 5. C. gibbum Fabric.

Gesicht schmäler als die Stirne. Die Seitenstriemen der Abdominaltergite $3-5$ erreichen den Vorderrand der Ringe nicht. Wangen und Backen sehr schmal.

4. C. pantherinum Walker.

6. Thoraxrïcken und Schild ohne dunkle Punktierung an den Haarwurzeln und anch ungestriemt. . . . . . 7. Rücken und Schild dunkel punktiert und auf Rücken und Stirne mit dunklen Längsstriemen . . . . . . 9.

7. Grundfarbe des ganzen Tieres rostgelb. Stirne ungestriemt. 8 . Grundfarbe dunkel kastanienbraun. Stirne mit 2 braunen Längsstriemen . . . . 6. C. impunctatum n. sp.

8. Flügel fast ganz gleichmäfsig braun tingiert. Hinterleib am dritten bis fünften Tergit mit dunkelbrauner Medianstrieme. Schild oben dunkelbraun . . 7. C. fumipene $\mathrm{n}$. sp. Flügel gelblich, mit brawnen Flecken an den Mündungen der zweiten bis vierten Längsader nnd an der hinteren Querader. Hinterleib ohne Medianstrieme. Schild oben rostgelb.

8. C. vulpinum n. sp.

9. Notopleuralnaht mit brauner Längsstrieme. Flügel am ganzen Vorderrande scharf abgesetzt dunkelbraun gesäumt und mit ebenso scharfer, gleichbreiter Zickzackbinde an der hinteren Querader

9. C. bathmedum n. sp. 
Notopleuralnaht ohne braune Längsstrieme. Flügel am Vorderrande nur mit braunem Flecke an der Radialismündung. 10. C. taeniatum n. sp.

\section{Curtonotum trypetipenne n. sp.}

10 o $^{7}+$ aus Peru, Urubambaflufs, 15.-27. XI.; Pichis Pto. Permudes, 10.-15. XII.; Pinipini und Ucayali, Unini, Oktober. Dresd. Mus.

Das Gesicht ist nur um etwas schmäler als die Stime, diese mehr als doppelt so breit wie ein Auge. Die Scheitelplatten sind $3 / 4$ der Stirne lang; die nach vorne gebogene Orbitalborste steht noch vor der Stirmmitte. Wangen und Backen viel schmäler als das dritte Fühlerglied. Oberstes Mundrandhärchen verstärkt. Gesichtskiel nur in der oberen Gesichtshälfte kantig vorstehend, im Profile gerade und nicht über die Augenlinie vortretend. 2 Sternopleuralborsten; die obere schwächer. Oben 13, unten 8 lange Fiederstrahlen an der Arista.

Stirne rostfarben, mit 4 nicht sehr scharfen dunkelbraunen Längsstriemen, 2 innerhalb der Scheitelplatten, je eine direkt am Augenrande. Die Spitzen der Scheitelplatten, feine Linien am Augenrande und breite Säume an den Wangen, wie auch gröfstenteils das Gesicht silbrigschimmernd. Die Grundfarbe des letzteren ist in der Nitte unter den Fühlern dunkelbraun, an den Seiten und am Mundrande gelb. Fühler dunkel rotbraun, an der Wurzel und am Ende mehr oder weniger verdunkelt, schwarzbraun. Zweites Glied oben weifschimmernd. Taster schwarzbraun.

Thorax und Schild von dunkelbrauner Grundfarbe, nur an den Schultern und am Schildrande rötlich. Der Reif ist zart weifsgrau. Die Mesopleuren und namentlich der Rücken sind dicht und ziemlich grob und vielfach zusammenfliefsend dunkel sepiabraun punktiert, das Schild oben ganz von dieser Farbe, die auch den Gesamtton des ganzen Tieres bildet.

Hinterleib schwarzbraun, deutlich glänzend, seitlich mehr rotbraun und dort jederseits am Vorderrande mit einem gröfseren weifslich bereiften Fleck, der durch dunkle Wurzelpunkte an den Haaren durchbrochen wird. Die Hinterränder der einzelnen Tergite sind entschieden viel dunkler, fast scliwarz gefärbt. Die Randborsten der Tergite sind hinten etwas aufgerichtet.

Vorder- und Mittelschenkel rotbraun, die vorderen dunkler; Hinterschenkel, Schienen und Füfse rotgelb, erstere mit brauner Spitze, die Schienen vor der Mitte und an der Spitze mit bräunlichen Ringen, die Fülse am Ende gebräunt. Hüften an der Wurzel braun, sonst bräunlichgelb. Haare und Borsten überall schwarz.

Flügel schwarzbraun, vorn dunkler als hinten, mit je einer 
Reihe von weifsen, viereckigen Flecken zwischen den Längsadern. Costalzelle ungefleckt. Marginalzelle mit 4, Submarginalzelle mit $7-8$, erste Hinterrandzelle mit $2-3$ Flecken oberhalb der hinteren

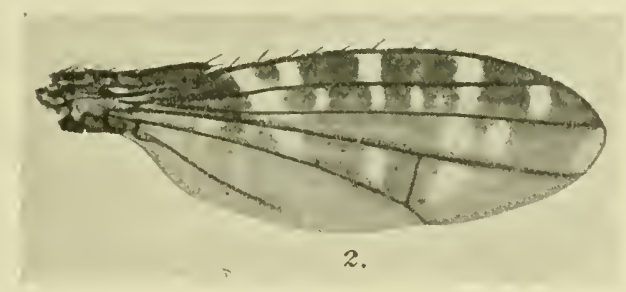

Fig. 2. Flügel.

Querader und einem an der Mündung, Discalzelle mit 4-5 Flecken, zweite Hinterrandzelle nur mit einem grofsen Fleck, dritte Hinterrandzelle mit $3-4$ Querflecken. Schwinger hellgelb.

Körper 5,5-7 mm, Flïgel 5-6,5 mm lang.

\section{Curtonotum apicale n. sp.}

8 万ㅇ aus Peru, Pachitea-Mündung, $150 \mathrm{~m}, 19 .-26$. XI. Dresd. Mus.

Die Stime ist nur 1 m geringes breiter als das Gesicht und etwas breiter als die doppelte Augenbreite. Sclieitelplatten und Stimbeborstung wie bei Curtonotum murinum. Die Wangen und Backen sind schmäler als das dritte Fühlerglied. Nur das oberste Haar am Mundrande ist etwas stärker. Gesichtskiel flach, unten nicht sichtbar. In Profile ist das Gesicht unter seiner Mitte scliwach konvex, tritt aber nur wenig über die Augenlinie vor. Augen mälsig hoch. - Eine starke Sternopleuralborste; oberhalb derselben und weiter vorn noch eine zweite, schwächere Borste. Oben 11-12, unten meist 6 lange Fiedelstrahlen an der Arista.

Der Kopf ist wie bei $C$. mumum gefärbt; die Scheitelplatten und der Hinterkopf sind aber von dunklerer Grundfarbe. Das Gesicht schimmert unter den Fühlern in der Mitte schwärzlich. Das dritte Fühlerglied ist nicht gebrïunt.

Thorax von dunkelbranner Grundfarbe, an den Schulteru rot. Die Bestäubung ist auf dem Rücken, den Schild und den Mesopleuren gelbgrau and überall von dichtstehenden, etwas gröfseren schwarzbraunen Wurzelpunkten an den Haaren durchbrochen. Nur selten treten undeutlich Spuren von 3 breiten dunkleren, scheinbar unter der Bestäubung liegenden Längsstriemen hervor. Die Bestäubung der unteren Pleuren, des Metanotums und des Hinterleibes ist aschgrau. Die Abdominaltergite $2-5$ zeigen am Hinter- 
rande je 2 , vorn bogig konvex begrenzte, dunkel sepiabraune Saumflecke, die am zweiten in der Mitte getrennt sind, an den Tergiten $3-5$ aber durch eine durchlaufende, gleichfarbige Medianstrieme verbunden werden. Randnacrochäten lang und abstehend.

Hüften und Beine bräunlich ockergelb. Vorderschenkel mit Ausnahme der Spitze, die Wurzel der mittleren Schenkel und die Spitzen der 4 hinteren dunkelbraun. Alle Schienen haben vor der Mitte und am Ende einen braunen Ring. Füfse am Ende gebräunt.

Flägel grau tingiert, gegen dunklen Grund blauschimmernd. Die Spitze der ersten Hinterrandzelle schimmert in Form eines schmalen, elliptischen Fleckes milchweifs. Dunkelbraun ist die Costalzelle und ein sich daranschliefsender schiefer Fleck, der auch die kleine Querader einschliefst, ein allmählich breiter werdender Zickzacksaum über die Posticalis, die hintere Querader und den letzten Discoidalisabschnitt, daranschliefsend der Saum ler Flügelspitze und der Costa. Letzterer ist am intensivsten und breitesten, reicht unten bis an die Längsfalte zwischen vier zweiten und dritten Längsader und ist wurzelwärts ein ziemliches Stiick vor der Subcosta plötzlich fast senkrecht abgeschnitten. Dort liegt an der Costa der hellste Teil des Flügels. Die beiden letzten Abschnitte der Discoidalis sind wenig an Länge verschieden. Schüppchen gelblichweifs, Schwinger gelb.

Körper 5-7 mm, Flügel 4,5-6 $\mathrm{mm}$ lang.

3. Curtonotum murinum n. sp.

7 or $q$ aus Peru, Chanchamayo, Mitte Jänner; Meshagua, Urubambafluis, 9.-29. IX. Dresd. Mus.

Stirn am Scheitel breiter als vorn und als das Gesicht; letzteres ist um $1 / 5$ schmäler als der Scheitel, der ungefähr doppelt so breit als ein Auge ist. Die Scheitelplatten sind lang und schmal und lassen nur das vordere Stirnviertel frei. Die nach vorn gebogene Frontorbitale steht auf oder noch etwas vor der Stirnmitte. Die Wangen und Backen sind schmal und etwas mehr als $1 / 2$ des dritten Fühlergliedes breit. Von den kurzen Härchen am Mundrande ist das oberste etwas stärker und deutet die Vibrisse an. Gesichtskiel ziemlich stumpf, den Mundrand unten nicht erreichend. Im Profil ist das Gesicht gerade und tritt kaum über die Augenlinie vor. Augen märsig hoch. Oberhalb der starken Sternopleuralborste und etwas weiter nach vorn gerückt steht eine zweite, viel schwächere Borste. - Oben 7-8, unten meist 4 lange Fiederstrahlen an der Arista.

Stirnstrieme matt goldgelb, ohne Medianstrieme, am Innenrande der Scheitelplatten rötlich gesäumt. Augenrand, Gesicht, Wangen und Backen, sowie die Spitzen der Scheitelplatten und 
sehr deutlich auch die Oberseite des zweiten Fühlergliedes silberweifs. Seheitel- und Ocellenplatten, sowie der ganze obere Hinterkopf lıell gelbgrau bestäubt, schimmernd. Fühler rostbraun, drittes Glied in der Endhalfte gebräunt. Taster schwar.

Thorax und Schild hell graugelblich, unten an den Pleuren und am Metanotum grau bestäubt. Rücken, Schild und Mesopleuren sind an den Haarwurzeln sehr fein brann punktiert. Rücken ohne längsstriemen.

Hinterleib mehr graulich bestäubt als der Thorax. Zweites Tergit mit 2 breiten sepiabramen Dreiecken, die dem Hinterrande anliegen und sich in der Nlitte mit den Basen berühren. Drittes bis fünftes Tergit mit sepiabraunen Hinterrandsäumen und je 3 durehlaufenden, senkrechten Längsstriemen - einem in der Mitte und je einem weiter seitwärts - , welche mit denen der benachbarten Tergite 3 parallele, zusammenhängrende braune Längsstreifen bilden. Die ventral ungebogenen Seitenränder haben keine bramne Zeichnung. Hinterrandmacrochäten der Tergite lang und a bs te hend.

Beine ockergelb, weifslich bereift. - Haare und Borsten des ganzen Tieres schwarz.

Flügel nur schwach graulich hyalin. Am Vorderrande in der Spitzenhälfte und an der Flügelspitze verwaschen braun gesäumt. Die Säume beider Queradern sind intensiver braun. Von den beiden letzten Abschnitten der Discoidalis ist der vorletzte nur wenig länger. Schwinger weifslich, Schüppehen rostgelb.

Körper 5-6 mm, Flügel 4,5-5 $\mathrm{mm}$ lang.

\section{Curtonotum pantherinum Walker.}

Walker, List. Dipt. Brit. Mus. Vol. 4. p. 1090 (Helomyza) (1849).

or + aus Süd-Amerika, Coll. Wi e d e m a $n n$ als H. yibba Fab. - Nach Walker aus Brasilien. Wien. Mus.

Die Stirn versehmälert sichetwas beim Übergang in das Gesicht und ist am Scheitel dentlich schmäler als die doppelte Augenbreite. Die Scheitelplatten reichen etwas vor die Stirnmitte vor; die nach vorn gebogene Orbitalborste steht ungefähr in der Längsmitte der Stirne. W a ng e n u nd Backen die Hälfte des dritten Fühlergliedes breit. Das oberste Haar am Mundrande ist wenig länger als die anderen. Längskiel in den oben $2 / 3$ des Gesichtes dentlich, im Profil gerade und nicht über die Augen vorstehend. 2 Sternopleuralborsten; die obere viel dïnner und kürzer. Oben 13-14, unten meist 7 lange Fiederstrahlen an der Arista.

Stirnstrieme rötlich braungelb; 2 dunkler braune Längsstriemen sind nicht immer deutlich erkenubar und nie scharf ausgeprägt 
oder durch eine gelbe Linie getrent. Die Spitzen der Scheitelplatten, schmale Stirnangenränder, die Backen und das Gesicht weifsschimmernd bereift. Der Gesichtskiel zeigt mit einigem Glanze die wachsgelbe Grundfarbe des ganzen Gesichts. Fühler rostgelb; drittes Glied gegen die Spitze hin mehr oder weniger gebräunt. Taster dunkelbraun.

Thoraxrïcken von rotbrauner Grundfarbe, oben dunkler, an den Seiten heller. Rücken vorn wie die Pleuren und das Metanotum weifslich bereift, sonst aber matt ockerbraun und dicht mit gröberen sepiabraunen Punkten an den Haarwurzeln besetzt, die nach hinten mehr oder weniger, auf dem Schildchen aber stark zusammenfliefsen, so dals letzteres fast ganz braun ist. Nur die Mesopleuren sind punktiert, wenn auch schütterer.

Hinterleib von sepiabrauner, glänzender Grundfarbe, die aber nur in Form einer Medianstrieme vom dritten Tergit an und in Hinterrandsäumen übrigbleibt. Der Rest vorn seitlich an den Tergiten, namentlich die umgeschlagenen Ränder sind aschgrau bestäubt. Beiderseits der Medianstrieme dringen die Hinterrandsäume dreieckig bis zur oder selbst über die Mitte der Tergite (wie am zweiten und dritten Ring) hinans vor, ohne dort sehr scharf ansgeprägt zu sein. Am ventral umgebogenen Seitenrande sind die Säume nur linienartig schmal.

Beine hell ockergelb. Schenkel- und Schienenspitzen mehr oder weniger deutlich braun. Die Füfse erscheinen nur durch die dichtere schwarze Behaarung dunkler zu sein.

Flügel rauchbraun tingiert. Die ganze Costakelle und die erste Basalzelle bis um die kleine Querader, dann ein breiter intensiver Costalsaum beiderseits der Radialis, wurzelwärts nicht scharf begrenzt, zwischen den beiden Querarlern beginnend, dann die Mündungsstïcke der clritten und vierten Längsader, sowie ein breiter Saum der hinteren Qnerader schwarzbrann. Übrigens sind alle Längsadern, am deutlichsten aber die Posticalis schmal braun gesäumt. Die beiden letzten Abschnitte der Discoidalis sind ungefähr gleichlang. Schwinger und Schüppchen gelb.

Körper $7 \mathrm{~mm}$ lang.

5. Curtonotum giblum Fabricius.

Fabricius, System. Antl. p. 297. 70 (IIusca) (1805). - Wiedemann, Auisereurop. Zweifl. Vol. 2. p. 586. 1 (Helomyza) (1830). - Rondani, Esami Ditt. Brasil, Torino p. 18 (Curtonotum) (1848). - Macquart, Dipt. exot. Vol. 2/3. p. 193. tab. "25. f. 6 u. 7 (Curtonotum) (1843). - Schiner, Novara-Dipt. p. 237. 18 (1868).

Dem C. pantherimum Walk. mit folgenden Unterschieden gleich. Stirn und Gesicht sind gleichbreit, parallelrandig und doppelt so breit wie ein Auge. Die nach vorn gebogene Orbitalborste steht 
etwas höher an der Stirn. Die Wangen und Backen sind breiter, nugefälır so breit wie das dritte Fühlerglied.

J)ie Taster sind rostbrau. Am dritten bis fünften Tergit sieht man aulser der Medianstrieme noch jederseits rine dell Vorderrand der Tergite sogar verbreitert erreichende Seitenstrieme, durch welche die grau bereiften, unpunktierten Seitenflecke der Tergite in உ völlig isolierte Teile gespalten werden. Der immere derselben liegt noch dorsal, der äufsere ventral am umgeschlagenen Seitenrande.

Im Flügel ist das Braun der Costal- und ersten Basalzelle nicht so auffallend intensiver als der äbrige Flügelgrund wie bei C. mentherinum Walk.

Die Grölse ist durchschnittlich bedeutender und beträgt $9-10 \mathrm{~mm}$.

A n merkung: Im Wiener Hofmuseum befinden sich Wiedema $n$ sche Stücke der Helomyza gibba aus seiner Sammlung und aus der v. Winthems. Die in letzterer sind jene in $\mathrm{W}$ i e de m a $n \mathrm{~ns}$ Werk elwähnten aus Brasilien; auf sie bezieht sich vorstehende Beschreibung. Die andern Stücke tragen nur den Zettel: Amer. merid. und stellen eine andere Art vor. Ich habe sie als C. pritherina Walker gedeutet und als solche beschrieben.

\section{Curtonotum impunctatum n. sp.}

2 or $q$ aus Peru, Pachitea-Mündnng, 4. XII. Dresıl. Mus.

Die Stirn verbreitert sich nach unten zu in das Gesicht übergehend um 1/5. Der Scheitel ist $11 / 2 m a l$ so breit wie ein Auge. Die Scheitelplatten reichen otwas über die halbe Stirue vor, die nach vorn gebogenen Orbitalborsten stehen in der Stimmitte. Die Wangen mul Backen sind viel schmäler als das dritte Fühlerglied. Am Mumrande ist nur das oberste Haar etwas stärker. Gesichtskiel flach, unten verwischt, im Profil nicht über die Augenlinie vorstehend, gerade abfallend. Nur 1 Sternopleuralborste. Oben 12-14, unten 6-7 lange Fiederstrahlen an der Arista.

Stirnstrieme rotgelb, in der Längsmitte mit 2 rotbraunen Striemen, die durch eine gelbe Linie getrennt bleiben. Scheitelplatten vorn gell bestäubt. Stirnaugenrand nur vorn schmal weils gesämmt. Gesicht weilslich, unbestäubt und glänzend am Kiel. Wangen und Backen mehr gelblichweifs bereift. Fühler rot; dittes Glied in den 2 Enddritteln braun. Taster sclnwarz. Rïcken und Schild oben matt kaffeebraun, u n p u n k t e r t, mit 2 etwas dunkleren, hinten verkürzten Längslinien. Pleuren und Metanotum weifslich aschgrau bereift.

Hinterleib mit breiten dunkel sepiabraunen Hinterrandsäumen, die an dritten und vierten Tergit sogar breiter als der halbe 
Ring sind und auch auf den umgeschlagenen Seitenrand übergehen. Über den dritten bis fünften Tergit läuft auch eine gleichfarbige Medianbinde. Der Rest des Hinterleibes, namentlich die am Vorderrande seitlich übrigbleibenden rechteckigen Randflecke sind weifslichgrau bereift. Randborsten zarter und nicht abstehend.

Beine ockergelb. Die Schenkel sind aufsen intensiver gefärbt, mehr bräunlich und die 2 hinteren haben braune Spitzen. Fufsspitzen verdunkelt. - Alle Haare und Borsten des Tieres sind schwarz.

Flügel gelbbraun tingiert. Der dunkelbraune Costalsaum beginnt plötzlich breit in der Endhälfte der Radialis und geht dann in den etwas lichteren und nur an den Adernenden gesättigteren breiten Spitzensaum des Flïgels über. Hintere Querader und ihr Winkel mit der Posticalis fleckenartig braun gesäumt. Der letzte Abschnitt der Discoidalis ist nur ${ }^{3} / 4$ des vorletzten lang. Schwinger gelb, Schüppchen weifslich.

Körper $7 \mathrm{~mm}$, Flügel etwas über $6 \mathrm{~mm}$ lang.

7. Curtonotum fumipenne n. sp.

5 or ㅇ aus Bolivia, Mapiri, Sarampioni $700 \mathrm{~m}, 18$. III., 4. VI. Dresil. Nus.

Stirn und Gesicht gleichbreit, parallelrandig, etwas mehr als $1 \frac{1}{2}$ mal so breit wie ein Auge. Die Scheitelplatten reichen bis zur halben Stirnlänge vor, die nach vorn gebogene Orbitalborste steht fast schon oberhalb der Stimmitte. Wangen und Backen kaum die Hälfte des dritten Fühlergliedes breit. Oberstes Mundrandhärchen nur etwas stärker. Gesichtskiel schmal und ziemlich kantig, im Profile gerade und nicht über die Augenlinie vortretend. Nur eine starke Sternopleurale; die zweite ist durch ein Härchen angedentet. Oben $11-12$, unten 5-6 lange Fiederstrahlen an der Arista.

Stirnstrieme einfarbig samtig rot, bis an die Augen heran. Nur der Angenrand der Wangen und das Gesicht sind schimmernd hellgelb. Fühler und Taster schwarzbraun, höchstens an der Wurzel des dritten Fühlergliedes dunkel rotbraun. Gesichtskiel unbestäubt. - Pleuren nnd Metanotum hell rotgelb, weifslich bereift; ebenso die Hüften nnd Beine, nur die Fülse, namentlich die hinteren sind am Ende geschwärzt, wohl mehr durch die kurze Beharung hervorgerufen. Räcken einfarbig mattrot, unpunktiert. Schild auf der Oberseite schwarzbraun, am Rande rot.

Hinterleib gesättigt rotgelb, glänzend und unbestäubt. Die Tergite haben, vom zweiten angefangen, schmale und nach hinten zu immer breiter werdende, streifenförmige schwarze Hinterrand- 
säume und eine gleichfarbige Medianstrieme, die aber am zweiten Ringe nur mehr oder weniger deutlich auftritt und auch schon am dritten verwischt sein kann. Die Randborsten der Ringe sind zurückgelegt. Behaarung und Borsten überall schwarz.

Der Flügel ist fast ganz gleichmärsig rauchbraun tingiert und nur im Endteil der Radialis allmählich etwas intensiver braun gefärbt. Bei dieser Art ist der einspringende Winkel zwischen Schulteriappen und Alula schon ganz verwischt, beide gehen flach ineinander über, ersterer ist sehr schmal, letztere fehlt ganz. Der letzte Abschnitt der Discoidalis ist kamm 2/3 des vorletzten lang. Schüppchen und Schwinger hellgelb.

Körper $5-6,5 \mathrm{~mm}$, Flügel 4,5 l,is über $5 \mathrm{~mm}$ lang.

\section{Curtonotum vulpiuum n. sp.}

2 o 0 aus Peru, Pichis, Pto. Bermudes, 13. XII. Dresd. Mus. Stirn deutlich schmäler als das Gesicht, $1 \frac{1}{3}$ mal so breit wie ein Auge. Die Scheitelplatten sind etwas länger als die halbe Stirn. Die nach vorn gebogenen Orbitalborsten stehen in der Längsmitte der Stirn. Wangen und Backen linear. Gesichtskiel flach, im Profile gerade und nicht über die Augenlinie vorstehend. Oberste Mundrandborste kaum etwas stärker. Oben 11-12, unten 6 lange Fiederstrahlen an der Alista. Nur eine Sternopleuralborste.

Stirnstrieme bis zum Augenrande matt gelbrot; dieser nur vorn und an den Wangen, wie auch das ganze Gesicht weifsschimmernd. Fühler rot, drittes Glied in der Endhälfte gebräunt; zweites oben ohne deutlichen weifsen Schimmer. Taster gelb. Der ganze übrige Körper und die Beine sind rostgelb; die Oberseite ist etwas dunkler gefärbt. Rücken und Schild matt, auch unpunktiert. Die Pleuren sind zart weifslich angehaucht. Am unbestäubten Hinterleib sieht man ganz schmale schwarzbraune Hinterrandsäume an den Tergiten und vom dritten an in der Nitte derselben kleine, mit der Spitze nach vorn gerichtete gleichfarbige Dreiecke, die beim or zu einer Medianstrieme zusammenfliefsen. Die Randborsten liegen dem Leibe an.

Flïgel graugelb tingiert, mit dunkelbraunen, eiförmigen Flecken an den Mündungen der zweiten bis vierten Längsaderu, die am Flügelrande zusammenlaufen und innen relativ scharf abgegrenzt sind. Ein gleichfarbiger Fleck bedeckt die hintere Querader nebst dem letzten Posticalisabschnitt. Der vorletzte Discoidalisabschnitt ist $1 \frac{1}{2} \mathrm{mal}$ so lang wie der letzte. Schüppchen und Schwinger gelb.

Körper $7 \mathrm{~mm}$, Flügel $6 \mathrm{~mm}$ lang. 


\section{Curtonotumbathmedum n. sp.}

8 or $q$ aus Peru, Meshagua, 27. IX., Pachitea-Mündung, 4. XI., Pichis, Pto. Bermudes, 18. XII., Ucayaliflufs, Oktober. Dresd. Mus.

Stirn sehr breit, fast dreimal so breit wie ein Auge, mit dem Gesicht fast parallelrandig, letzteres kaum merklich breiter. Scheitelplatten kurz, die nach vorn gebogene Orbitale steht im obersten Stirndrittel. Wangen so breit wie das dritte Fühlerglied, Backen etwas breiter. Vibrissen fehlend, am Mundrand eine Reihe ganz kurzer Härchen. In den oberen $2 / 3$ des Gesichts ein scharfer Lüngskiel; Profillinie deutlich ïher die Augen vortretend, gerade oder fast konvex, nach unten etwas zurückweichend. Prälabrum stark vortretend. Augen relativ sehr hoch. - Nur eine Sternopleuralborste. Oben meist 12, unten 6 lange Fiederstrahlen der Arista.

Stirnstrieme, Fühler und Taster matt orangegelb. Ungefähr in den Dritteln der Stirnbreite 2 gerade, rotbraune Längsstreifen, dic sich scharf abheben und bis zur Scheitelkante reichen. Stirnaugenränder, Wangen und der Oberrand des zweiten Fühlergliedes silberweifs, Gesicht und Backen mehr gelblichweifs schimmernd; unter den Augen ein rotbrauner Fleck auf den Backengruben. Scheitelplatten, Hinterkopf und der ganze übrige Leib goldig ockergelb, matt bereift und nur hinten auf den Pleuren und dem Metauotum glänzend. An den Haarwurze]n des Thoraxrückens isolierte braune Pünktchen. Rücken mit 6 kaffeebraunen Längssstriemen. Die 2 mittleren sind die breitesten, einander genähert, werden nach hinten zu breiter und fliefsen oben auf dem Schilde derart zusammen, dafs dasselbe mit Ausnahme eines gelben Basalpunktes ganz braun ist. Die nächste Seitenlinie ist an der Quernaht unterbrochen, die äufserste verläuft an der Notopleuralnaht zwischen Schulter und Flügelwurzel. - Pleuren ganz unpunktiert.

Zweites bis fünftes Abdominaltergit schmal schwarzbraun gesäumt. Die Säume der Tergite $3-5$ sind in der Mitte nach vorn hin zu breiteren Längsstriemen ausgezogen, die einen fortlaufenden Medianlängsstreifen des Hinterleibes bilden. Von den längeren Borsten an den Hinterrändern der Tergite stehen nur die des fünften Ringes ab.

Auch die Beine sind mit dem Leibe gleichgefärbt. Manchmal sind die 4 linteren Schienenspitzen gebräunt. - Die Haare und Borsten des ganzen Tieres sind schwarz.

Flügel am ganzen Vorderrande bis etwas unter die Radialis herab gleichmäfsig breit schwarzbraun; dieser Raudsaum tritt dann an der Cubitalismïndung fleckenartig wurzelwärts zuriick, 
und ist wieder zwischen der dritten und vierten Längsader ganz schmal. Eine auffällige scharfbegrenzte und gleichbreite sesselförmige Binde beginnt an der Cubitalis unterhalb der kleinen Querader und läuft dann ïber die hintere Querader und den

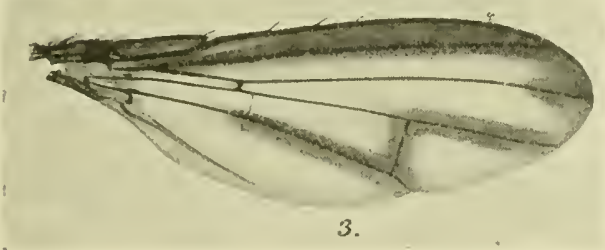

Fig. 3. Flügel.

letzten Discoidalisabschnitt. Unterhall, des Costalsaumes und an den Längsadern ist der Flügel rotgelb tingiert, sonst glashell. Die beiden letzten Abschnitte der Discoidalis verhalten sich wie 5: 4. Schïppchen und Schwinger rotgelb.

Körper und Flügel 6,5-9,5 $\mathrm{mm}$ lang.

10. Curtonotum taeniatum n. sp.

2 ㅇ aus Peru, Urubambaflufs, Umalınankilia, 19. IX. Drest. Mus.

Stirn und Gesicht parallelrandig, $2^{1} / 2_{2}$ mal so breit wie ein Ange. Die nach vorn gebogene Orbitalborste und die Spitze der Scheitelplatten erreichen ungefähr die Stirnmitte. Die Wangen und Backen sind ungefähr die IIälfte des dritten Fühlergliedes breit. Das oberste der sonst kurzen Härchen am Mundrande ist etwas länger und kräftiger, ohne eine Borste genannt werden zu können. In den oberen $2 / 3$ des Gesichts ist ein stumpfer Längskiel sichtbar; die Profillinie tritt kaum über die Augen vor und ist gerade. Augen mäfsig hoch. Nur eine Sternopleuralborste. In der Regel oben 12, unten 6 lange Fiederstrahlen der Arista.

Stirnstrieme, Fühler und Taster matt rotgelb. Vor dem Ocellendreieck eine weifsl,estäubte, aufsen braun eingefafste, gleichbreite Stirnmittellängsstrieme. Angenrand silberweifs. Gesicht, Wangen und Backen und der Oberrand des zweiten Fülılergliedes ebenfalls. - Scheitelplatten, Hinterkopf und der ganze Thorax matt goldockrig gefärbt und bestäubt, nur die unteren Pleuren sind mehr weifslich bereift. An den Haarwurzeln des Thoraxrückens und der Mesopleuren liegen kaffeebraune Pünktchen dicht nebeneinander. Schild oben ganz braun. Rücken mit 4 braunen Längsstriemen, die nach linten breiter werden. Die 
2 mittleren sind vorn dünn und stark abgekürzt, die 2 seitlichen erreichen vorn kaum die Quernaht.

Hinterleib mit dem Thoraxrücken gleichfarbig, aber ohne Haarwurzelpünktchen. Der vierte und fünfte Tergit haben schwarzbraune Hinterrandsäume und eine damit zusammenhängende Längsmittelstrieme, die Tergite 2 und 3 schmälere Hinterrandsäune, rie sich seitlich in je ein breites, nach vorn gerichtetes Dreieck mit unscharfen Grenzen verwischen, so dafs die Mitte dieser Tergite heller als die Seiten ist. Randborsten der Tergite deutlich, aber nicht abstehend.

Beine heller als der Thorax gefärbt. - Haare und Borsten des ganzen Tieres schwarz.

Flügel graubräunlich, an Vorderrande und an den Längsadern gelb]ichbraun getrübt. Am Vorderrande ein schmaler bratuner Saum, die Hiilfte der Costal- und Marginalzelle breit. Etwas jenseits der hinteren Querader sind die Mündungsstücke der zweiten und dritten Längsader schweifartig braun gesäumt, besonders breit die Radialis. Ein ähnlicher Saum liegt auch an der vierten Längsader, nur hängt er mit der Säumung der hinteren Querader und der schmalen der Posticalis zusammen. Alle diese Säume sind an den Grenzen verwaschen. Von den beiden letzten Abschnitten der vierten Längsader ist der vorletzte nur um geringes länger. Schwinger und Schüppchen rotgelb.

Körper und Flügel $9 \mathrm{~mm}$ lang.

$$
\text { Stegana maynifica n. sp. }
$$

1 if aus Peru, Neshagua, Urubambaflufs, 12. X. Dresil. Mus.

Stirne breiter als lang, vorn $1^{1 / 2}$, an Scheitel fast zweimal so breit wie ein Ange, ockergelb, wachsglänzend, um das Ocellendreieck herum braun, in der Mitte mit Quermulde, an glänzend schwarzen Vorderrand der Stirne erhöht und anch über die Fühlerwurzeln etwas hinansragend. - Stirnbeborstung wie bei Orthostegana angegeben. Augen eiförmig, wagrecht oval, unterer Rand gerade abgeschnitten; in seiner Verlängerung läuft über das Gesicht und den Hinterkopf eine schwarze Querlinie. Oberhalb derselben ist das Gesicht wie die Fühler rotgelb, unterhalb derselben wie die $1 / 3$ eines Auges hohen Backen silberweils schimmernd. Drittes Fühlerglied an der Spitze schwarz. Arista gelb, oben mit 11-12, unten mit 8 langen Fiederstrahlen. Rüssel und Taster rotgelb.

Thorax rostfarbig. Rücken mit 6 , Pleuren mit 2 pechschwarzen Längsstriemen. Die 2 mittleren Rückenstriemen sind breiter als die seitlichen und so breit wie auf den Pleuren. Sie werden nach hinten zu breiter und treten auf das Schildchen über, das nur in der Längsmitte gelb bleibt. 
Hinterleib und Schenkel pechschwarz; die mittleren an der Basis gell. Hüften, Schienen und Füfse rostgelb. Die 4 hinteren Schienen sind vor der Spitze breit pechbrann.

Flügel braungelb tingriert. Jenseits der Subcosta ist der Vorderrand zunächst bis zur Radialis, dann in der ersten Hinterrandzelle sogar bis etwas unter die Cubitalis schwarzbraun; in der Längsmitte dieser Zelle liegen in den Dritteln 2 ovale schwarzbraune Flecke. Beide Queradern und die ganze Discoidalis sind breit schwarzbraun gesäumt; unter der kleinen liegt anschlieísend daran ein gröfserer brauner Fleck. Aufserdem ist der Aufsenrand der zweiten Hinterrandzelle mit unregelmäfsiger Innengrenze breit braun, so dafs nur $2-3$ hellere Streifen oder Flecke übrigbleiben. Schwinger rostgelb.

Körper und Flïgel $6 \mathrm{~mm}$ lang.

\section{Orthostegrman, gen.}

In Willist on s Manual of N. Americ. Dipt., edit. 3, 1908. p. 300 fig. 1 und 2 sind Flügel und Kopf dieser neuen Gattung als Phortica Schin. ${ }^{1}$ ) abgebildet. Der Typus der letzteren Gattung weicht aber durch die breite Stirne, die breiter als lang ist, durch das noch gekielte Gesicht, das kurze dritte Fühlerglied, den ausgeschweiften hinteren Angenrand, den fehlenden Winkel des Gesichtsaugenrandes, das kräftig entwickelte Prïlabrum, den rundgewölhten Rücken und die Flügeladlerung ab. Die kleint Querader steht jenseits der Mitte der Discalzelle; die dritte und vierte Längsader sind nicht aufsergewöhnlich konvergent. Der Hinterleib ist macrochätenlos.

Die Gattung Steyana hat zwar auch eine an der Mündung ganz auffällig verengte erste Hinterrandzelle, aber die Verengung geschieht hauptsächlich durch die Krümmung der Cubitalis, während bei Orthosteyana die Discoidalis Griphoneura-artig aufgebogen ist. Stegana unterscheidet sich durch die quer abgebogenen Flügel, die kleine Querader steht auch noch jenseits der Discoidalzellenmitte, die Radialis ist stark wellig gebogen und die Angen sind eiförmig wagrecht oral. Der Thorax ist unproportional grofs.

Bei der nenen Gattung ist der Kopf fast halbkuglig, hinten stark ansgehöhlt und anch unten nicht vortretend. Die Stirn ist doppelt so lang wie in der Mitte breit, vorn die Hälfte eines Auges, oben am Scheitel so breit wie ein Ange. Neben den Fühlerwurzeln bilden die Augenränder einen stumpfen Winkel und

1) Trotzdem nach Coquillett Phortica Schin. im Dezember, amiota Loew im Mai 1862 aufoestellt wurde, ziehe ich doch jetzt den ersten Namen vor, da Schiner seine Gattung auch beschrieben hat. 
divergieren am Gesicht nach unten. Gesicht ohne Kiel. Mundrand nicht hinaufgezogen. Prälabrum klein und sehr niedrig. Wangen und Backen von linearer Breite. Fühler etwas kürzer als das Gesicht. Zweites Glied oben mit abstehender Borste; drittes Glied zweimal so lang wie breit, linear, vorn abgerundet. Arista sehr lang und abstehend gefiedert, oben mit 8, unten mit 6-7 Fiedern. - Kopfborsten bis auf die kleinen, stark gekreuzten Postvertikalen sehr kräftig. In der Stirmmitte eine nach vorn gebogene und gleich darüber, in gleichem Abstande vom Auge, eine nach oben gebogene und weiter oben noch 2 solche, zusammen also 3 Frontorbitalborsten. Ocellare und 2 Paare Vertikale, sowie eine einzige lange Vibrisse vorhanden.

Thoraxrücken im Profil gerade, gleichmälsig dicht behaart. 2 Humerale, 2 Notopleurale, 1 Präsuturale, 4 Supraalare, je 1 Paar Dorsozentrale und Präscntellare. Schild eiförmig, fast 1/2 des Rückens lang, oben flach, nackt, am Rande mit 4 Borsten, wovon die apicalen gekreuzt sind. - Mesopleuren unbehaart, nackt. 2 Sternopleurale; die hintere steht etwas tiefer. - Alle Schienen mit schwachen Präapicalborsten. Vorderschenkel posteroventral, Mittelschenkel noch dichter anteroventral mit Borsten besetzt. Mittelschienen dorsal mit einer Reihe liurzer Börstchen, an der Wurzel aber mit 2-3 langen und abstehenden Borsten versehen. - Hinterleib an den Hinter- und namentlich Seitenrändern der Tergite mit Borsten besetzt.

Mediastina nur als Falte sichtbar, rudimentär. Costa ohne Randdorn. Kleine Querader über dem ersten Drittel der Discalzelle stehend, der Subcostamündung gegenüber. Der Flïgel zeigt an den eng nebeneinanderliegenden Mündungen der dritten und vierten Lüngsader einen spitzen Randwinkel. Die Discoidalis biegt gegen die Mündung hin fast spitzenqueraderartig auf und ist dort etwas verdünnt. Beide Wurzelzellen deutlich abgegrenzt. Die Analis erreicht den Flügelrand nicht.

\section{O. acutangula n. sp.}

2 ans Bolivia, Mapiri, Sarampioni, 700 m, 24. I. Dresd. Mus.

Stirn matt rotbraun. Hinterkopf und Thoraxrïcken rostbraun, Gesicht, Pleuren und Schild allmälılich heller, mehr rostgelb gefärbt. Je weiter unten, desto heller. Hüften und Beine, Rüssel und Taster gelb. Fühler rotgelb. Borsten und Haare schwarz. Hinterleib pechschwarz und nur das hasale Doppelsegment mit Ausnahme seines Hinterrandes rotgelb.

Flügel rauchbraun tingiert. Hyalin sind die Wurzel bis zur kleinen Querader, die Hinterrandsäume der zweiten und dritten 
Hinterrandzelle und mit ersterem zusammenhängend ein rundlicher Fleck jenseits der linteren Querader. Schwinger rotgelb. Körper $4 \mathrm{~mm}$, Flïgel $3,5 \mathrm{~mm}$ lang.

\section{Zy!gothricr, Wiedemann.}

Wiedemann, Achias Dipt. Genus, Kiliae 1830. p. 16. 3. tah. 2. fig. 2. Osten-Sacken, Ann Mus. Nat. Genov. v. 16. p. 478 (1881).

Die Gattung wurde seit Wiedeman n nicht mehr aufgefunden.

Kopf an den Augen ähnlich wie bei der Platystominen-Gattung Asyntonu $0 .-\mathrm{S}$. verbreitert, viel breiter als der Thorax samt dem Srlhilde lang. Die Augen sind nach aufsen zu vorn und hinten mit einer Schneide versehen und laufen endlich in eine hornähnlich nach aufwïrts gebogene zweischneidige Spitze aus. Die Stirnaugenränder konvergieren stark nach vorn hin und bilden mit dem vorderen und hinteren Kopfrand einen Winkel von $45^{\circ}$.

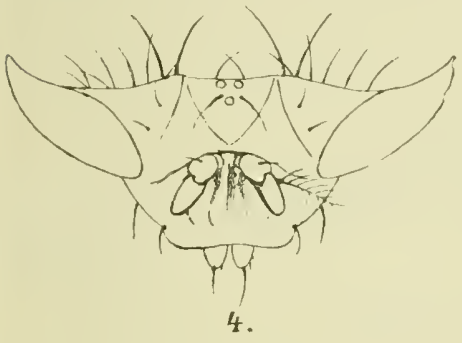

Fig. 4. Kopf.

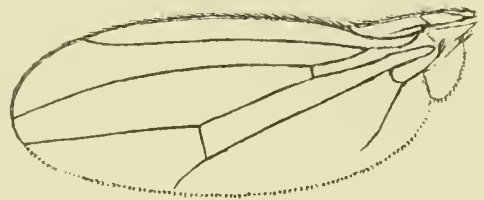

5.

Fig. 5. Flügel.

Die schwach erhabene Ocellenplatte ist grofs, dreieckig mit konvexen Seiten und erreicht mit der Spitze vorn den Stirnrand. Die matte Stirnstrieme wird dadurch in 2 ebenfalls dreieckige Teile? gespalten; ihre äufsere Grenze ist eine Linie vom vorderen Augenrande bis zur inneren Vertikalborste. Was aufserhalb dersellen liegt, isł wie die Ocellenplatte etwas erhaben und glänzend und enthält die Scheitelplatten.

Kopfbehorstung: Jederseits 2 Frontorbitalborsten hintereinander, die obere steht ungefähr in der Stirnmitte und ist nach hinten gebogen, die vordere ist nach vorn gebogen und ist noch weiter nach vorn gerückt. Ocellare kräftig. Postvertikale deutlich sichthar, gekreuzt. Innere und äufsere Vertikale stark entwickelt. Besonders lang sind die Postocularcilien entwickelt. Jerlerseits eine einzige deutliche Vibrisse und eine Backenborste.

Lumula ganz verdeckt. Die Stirnspaltenäste laufen schief nach seitwärts und niclıt längs der Facialien nach abwärts. Die Fühler sind an der Basis cinander genähert. Das erste Glied ist 
sehr kurz, das zweite kappenartig vergröfsert, kürzer, aber dicker als das dritte, oben mit abstehendem Börstchen. Das dritte ist oval, ungefähr $1 \frac{1}{2}$ mal so lang wie breit und würde unten den Mundrand nicht mehr erreichen. Die Arista ist basal, trägt oben 7, unten 4-5 Fiederstrahlen. Die Fiederbreite übertrifft die des dritten Fühlergliedes auffallend. Die namentlich an der Wurzel tiefen Fühlergruben werden durch einen scharfen, im Profile stark nasenartig konvex vorspringenden Längskiel des Gesiclıts voneinander getrennt.

Prälabrum von vorn kaum sichtbar. Taster von mäfsiger Breite, aber etwas verlängert, behaart und unten ror der Spitze mit je einer starken Borste. Rüssel mit langem geraden Mittelteil, der länger als der Kopf hoch ist und mit kurzen, nicht zurückgeschlagenen Endlabellen.

Thoraxrücken ungefähr quadratisch, stark gewölbt. Schild mehr als $1 / 3$ desselben lang, eiförmig, oben nackt, schwach gewölbt, am Rande mit 4 Borsten; die apicalen gekreuzt. Pleuren nackt; nur 1 Sternopleurale. Humerale 2, Notopleurale 2, Präsuturale 1 ; jederseits $2-3$ Dorsozentralbörstchen ganz hinten. $\Lambda$ crostichalhärchen dazwischen sechszeilig.

Hinterleib eiförmig, vor dem kleinen Hypopyg mit 6 sichtbaren Ringen. Am Hinterrande der Tergite kurze Börstchen.

Beine von proportionaler Länge und Stärke. Schienen ohne Präapicalbörstchen.

Der Flïgel ist nach der Figur geadert.

Die Gattung ist ohne Zweifel eine Drosophilide, wie das schon Oste $n-\mathrm{S}$ a ck e $n$ nach Untersuchung des im Wiener Museum befindlichen Stückes, das aber kürzere, stumpfere Augen besitzt, festgestellt hat.

\section{Zyyoth. dispar Wiedem.}

Wiedemann, Aufsereur. zweifl. Ins. vol. 2. p. 556. 3 (Achias) (1830) et Achias Gen. Dipt. p. 16 (18?0).

2 o7 aus Peru, Rosalina, Urubambaflufs, 29. VIII. legg. Schnuse. - Nach Wiedemann aus Brasilien. Dresd. Mus.

Stirn braun, auf Scheitel- und Ocellenplatten glänzend. Die Oberseite des Tieres ist schwach glänzend rötlich ockergelb. Fühler, Gesicht, Pleuren und Beine sind viel heller gelb grefärbt.

Am Hinterleibe sind die Tergite 2-4 dunkel sepiabraun. Am zweiten ist der Vorderrand in der Mitte, beim dritten und vierten je ein scharf abgesetztes Dreieck am Seitenrande gelb. Der fünfte und sechste Tergit tragen nur kleine braune Flecke in der Mitte. - Behaarung und Beborstung überall schwarz. 
Flügel schwach graulich, gegen die Spitze lin deutlicher bräunlich getrübt. Adern gelbbrann. Sehwinger gelb.

Körper und Flügel 2,5 mm lang; Kopf $2 \mathrm{~mm}$ breit.

$$
\text { Ortalis lonyicauda n. sp. }
$$

2 or 9 ans Wells, Nerada, 12. VII., Prof. A l d rich. Mleine S.

Diese Art steht der Ortalis limatulata Hend., Wien. Ent. Zeit. 1911 p. 22, sehr wahe und besitzt wie diese anfser dem Flïgelapicalflecke noch einen zweiten ror und unter der Merliastinamïndung, der sich jedoch auch noeh unter die Discoidalis hinab erstreckt. Aufserdem ist bei dieser Art noch die Costalzelle an der Wurzel bis über die Schulterquerader hinaus schwarzbraun. Der Apicalfleck liegt $n$ r am Mündungsstücke der Radialis und reicht an der Costa kaum unter die Mündung dieser Ader herab, während er bei Ort. limaculate als Costalsaum bis zur Cubitalis, ja selbst bis zur Discoidalis herabzieht.

Die linie und die Wurzel der Mittelschienen sind wie bei Ort. bimaculata rot gefärbt, die Füfse sind aler ganz schwarz.

Das erste Glied des Ovipositors ist bei Ort. bimaculata so lang wie breit, hinten breit abgestntzt, an der Wurzel herzförmig, also dort mit ausgebauchten Seitenkanten. Hier ist dieses Glied lang dreieckig, erheblich länger als breit, hinten spitziger', an den Seitenkanten gerade.

Die Körpergestalt ist robuster als bei der verglichenen.

Körper $8,5-9 \mathrm{~mm}$, Flügel $7 \mathrm{~mm}$ lang.

$$
\text { Euxesta sanguinea n. sp. }
$$

1 f aus Brigham, Utah, 4. VII., Prof. A $1 \mathrm{drich}$. Meine S.

Kopf und Anhänge ganz und gar schwarz, an den unbestäubten Stellen mit dunkelblauem Schimmer. Ein breiter Augenrandsaum der Stirn, ein schmälerer der Wangen, die Scheitelplatten, die quere Scheitelkante, der Angenrandsaum des Hinterkopfes, das ganze Gesicht von oben bis unten und das Prälabrum weifs bereift. Die Stirn ist fast $1 \frac{1}{2}$ mal so breit wie ein Ange, vorn kaum etwas breiter als oben. In der Mitte eine Querfurche und darüber ein ovaler, ringsum abgesetzter flacher Querhöeker, auf dessen oberen Abhang die Ocellen liegen. Drittes Fühlerglied 11, mal so lang wie breit, vorn abgerundet.

Rücken und Schild erzgrün, nirgends deutlich glänzend, sondern überall weifslich ïberreift und gedämpft im Glanze.

Hinterleib lebhaft blutrot, nur das fünfte und die hinfere Hälfte des vierten Tergits sind erzgrün; ebenso das erste Gilied 
des Ovipositors, das breit herzförmig und so lang wie breit ist; seine Seitenränder sind etwas aufgebogen.

Hüften und Beine erzfarbig. Füfse dunkel rotbraun.

Flügel milchweifs mit gelben Adern. Costal- und Subcostalzelle dunkelbrann. An der Flügelspitze ein innen rechtwinklig begrenzter brauner Fleck wie bei Acrosticta foveolata Loew ( $\mathrm{V} g$. Hendel, Gener. Ulid. Taf. 4, Fig. 62), nur etwas weiter nach innen gezogen, so dafs anch die Spitze der Marginalzelle hineinfällt. Der letzte Abschnitt der Cubitalis ist in der IItte deutlich hinabgebogen. Kleine Querader jenseits der Mitte der Discalzelle. Schüppchen und Schwinger weils.

Körper $5 \mathrm{~mm}$, Flügel $4 \mathrm{~mm}$ lang.

\section{Euxesta undulatan. sp.}

1 우 aus Paraguay, leg. Fi e brig im Ungar. Nat.-Museum. Stirn ein wenig schmäler als ein Auge, vorn rot, in der Mitte rotbraun; Ocellen- und Scheitelplatten, Hinterkopf und Gesicht stahlblau. Vor den Ocellen eine Mulde in der Stirnstrieme. Augenrand von Stirn und Wangen linienartig weifs gesäumt. Zwischen den Fühlerwurzeln 2 weifse, durch einen dunklen Längsstrich getrennte Keilfleckchen. Die Backen sind gut $1 / 3$ eines Auges hoch nnd zeigen 4 auffällige weifse Längslinien, je eine oben am Augenrande und ganz unten, dann 2 in der Mitte auf den rotbraunen Backengruben, die auch teilweise unterbrochen sind. Auch das Prälabrum ist am Unterrande weifs gesäumt.

Fühler rotbraun.

Thorax und Schild stahlblau, zart weifslich überreift. Hinterleih und das erste Glied des Ovipositors glänzend schwarzblau, fünfter Tergit grörstenteils rotgelb.

Vorderhüften, die äufsersten Kniespitzen und die 4 hinteren Fiifse mit Ausnahme der grebräunten Spitzen rotgelb; die 4 hinteren Schienen rotbraun. Die ganzen Vorderbeine tiefschwarz.

Flügel ganz glasig hyalin - auch die Costalzellen. Unmittelbar vor der Miindung der Radialis liegt ein r'under schwarzbrauner Punktfleck. - Sehwinger und Schüppchen rostgelblich. Körper $4 \mathrm{~mm}$, Flügel $3,5 \mathrm{~mm}$ lang. 


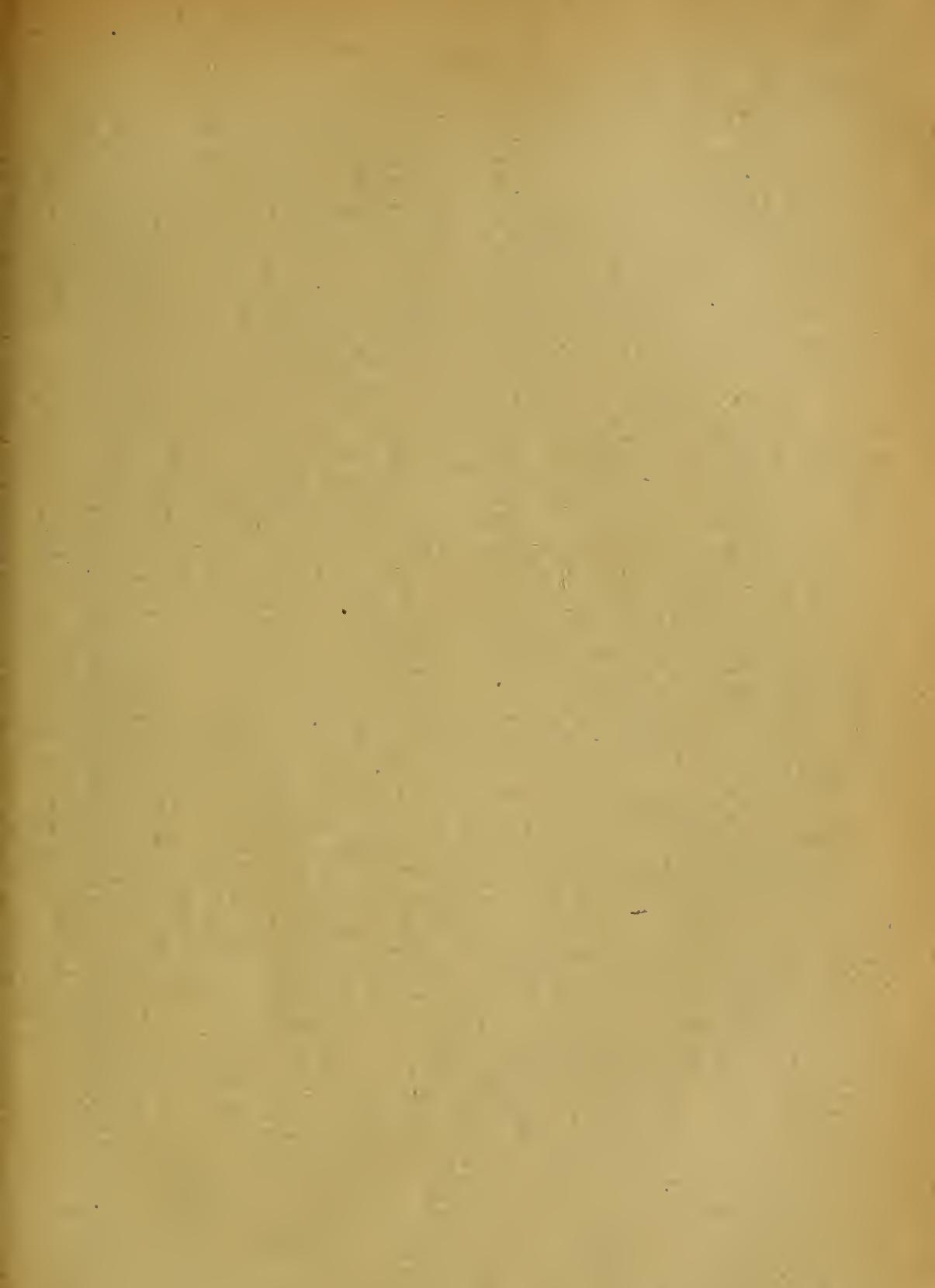

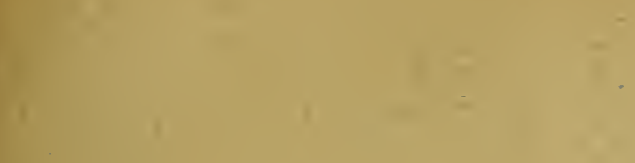

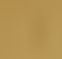





\section{Neue Beiträge \\ zur Kenntnis der Pyrgotinen.}

Von

Friedrich Hendel, Wien.

Mit einer Tafel und 5 Textfiguren.

\section{Abdruck aus dem \\ „Archiv für Naturgeschichte“.}

Herausgregeben

voll

Embrik strand

(Berlin).

79. Jahrgang 1913

Abteilung A

11. Heft.

\section{NICOLAISCHE}

VERLAG - B UCH H N DLUNG R. STRICKER Berlin. 

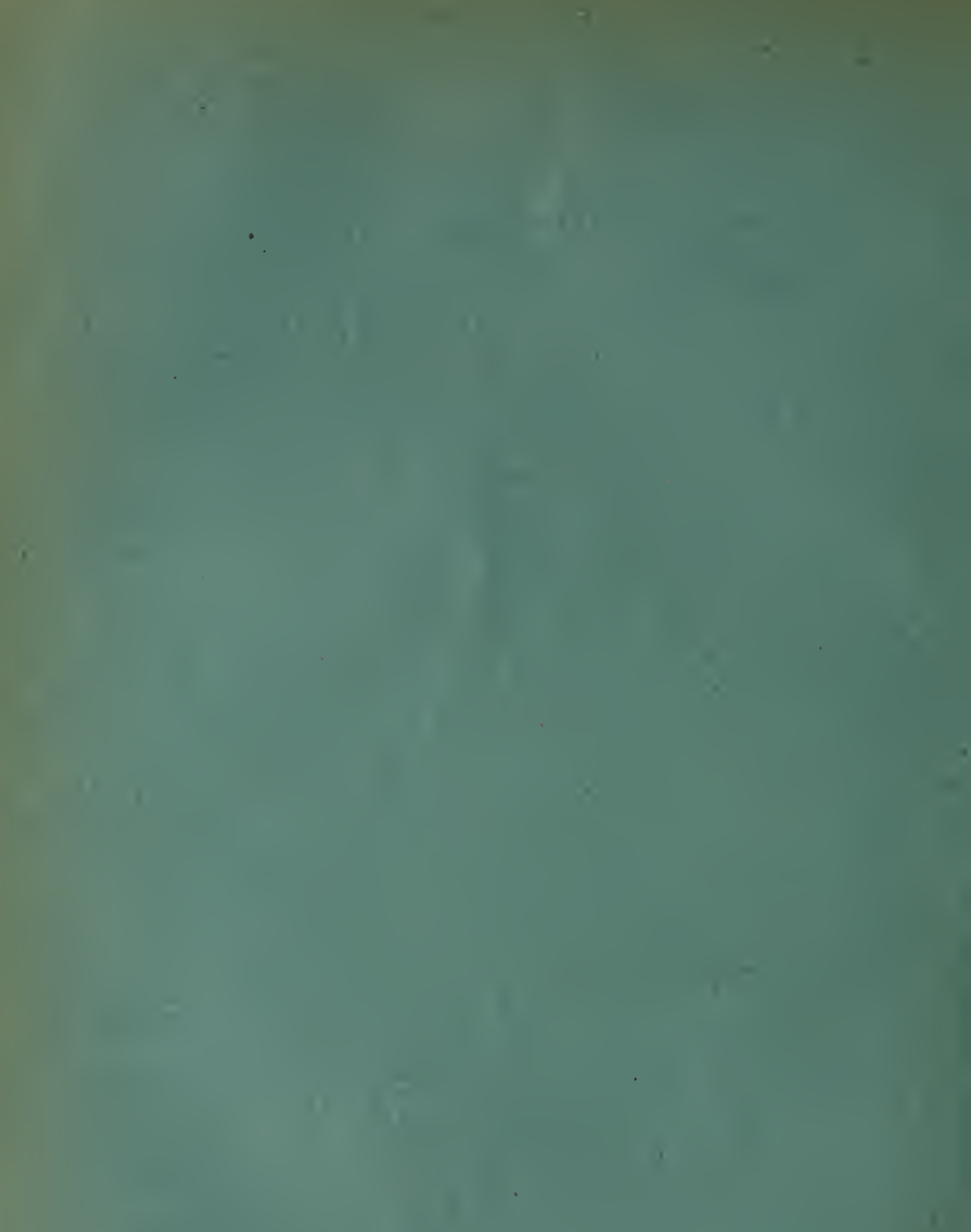

and

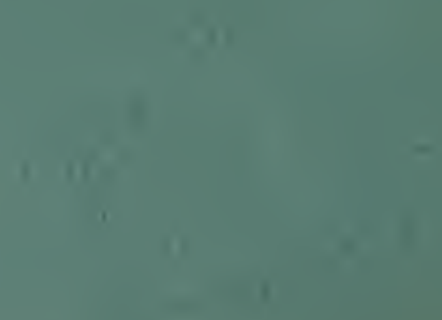

1 


\section{Neue Beiträge zur Kenntnis der Pyrgotinen.}

Von

Friedrich Hendel, Wien.

Hierzu eine Tafel und 5 Textfiguren.

Seit der Herausgabe der Pyrgotinae in den Genera Insectorum von Wytsman 1908 habe ich eine Reihe neuer Formen kennen gelernt, womit ich unsere Kenntnis von dieser inerkwürdigen Dipterengruppe nicht unerheblich erweitern kann. Das Interesse an diesen Sonderlingen der Gestalt wird durch die wichtige Entdeckung der Lebensweise der Fliegen durch S. A. Forbes noch besonders geweckt. Im 24. Report of the State Entomologist on the Noxious and Beneficial Insects of the State Illinois, 1908 p. 162 berichtet der Forscher, wie Pyrgota undata die weiche Abdominalhaut der amerikanischen Maikäfer (,Maybeetles“, Lachnosterna) unter den Flügeldecken anbohrt und die Eier einsenkt, so daß sich die ganze Metamorphose im Käfer-Abdomen abspielt.

Nun die Ergänzungen zu meiner Pyrgotinen-Arbeit.

Die Gattungen Bromophila Loew und Sphenoprosopa Loew scheiden aus und sind zu den Platystominen zu bringen. Ebenso gehört Dichromyia R. D. nicht in unseren Kreis hinein.

Eupyrgota luteola Coqu. lernte ich kennen und konnte so feststellen, daß meine Auffassung dieser Gattung nicht richtig war. Eupyrgota kann ich von Adapsilia nicht trennen. Für Eupyrgota Hendel 1908 tritt nun der Name Apyrgota ein. Ob Prosyrogaster Rond. zu Campylocera oder Adapsilia als Synonym gehört oder eine selbständige Gattung ist, kann ich bis jetzt nicht entscheiden.

Durch die Güte des Herrn G. H. Verrall hatte ich seinerzeit auch die hierhergehörige Teretrura flaveola Bigot kennen gelernt. Auch die Gattung Epicerella Macquart ist mir inzwischen bekannt geworden.

Nach meiner heutigen Auffassung der Gattungen können dieselben in folgender Weise von einander unterschieden werden.

\section{Tabelle der Gattungen der Pyrgotinen.}

3. Fühlerglied vorne abgerundet 1

- 3. Fühlerglied vorne oben mit scharfer Spitze oder Ecke 12

1. Kleine Querader vor der Flügelmitte. Hintere Querader auffallend schief, ihr Winkel mit der Posticalis daher sehr spitzig. Ovipositor dorsalwärts aufgebogen

- Kleine Querader auf oder hinter der Flügelmitte. Hintere Querader nicht auffallend schief. Ovipositor ventralwärts eingebogen oder zylindrisch gerade 
2. Schenkel unten bedornt. Analzelle in eine deutliche Spitze ausgezogen. Cubitalis unbcborstet Eumorphomyia Hend. (1907) typ. tripunctata Dolesch.

- Schenkel unbewehrt. Analzelle außen bauchig begrenzt. Cubitalader beborstet Geloeniyia Hend. (1908). typ. stylata Hend.

3. Radialis und Cubitalis nach aufwärts gebogen. Letztere mündet deutlich vor der Flügelspitze. Backen so breit wie der lotrechte Augendurchmesser

Diasteneura Hend. (1908). typ. laticeps Hend.

- Radialis und Cubitalis nach abwärts gebogen oder gerade; letztere mündet an der Flügelspitze. Backen weit schmäler als der lotrechte Augendurchmesser 4.

4. Cubitalis ganz oder doch wenigstens an der Wurzel beborstet 5 . - Cubitalis nackt

5. Ozellen vorhanden. Fühlergruben in eine Vertiefung vereinigt. Ovipositor gerade, zylindrisch

Teretrura Bigot (1885). typ. flaveola Bigot.

- Ozellen fehlen. Fühlergruben von einander getrennt. Ovipositor ventral eingebogen

6. Die Fühlergruben reichen bis zum Mundrande. Das basale Doppelsegment des Hinterleibes ist nur so lang wie die 2 folgenden Ringe zusammen. Ovipositor lang und schlank, länger als der Hinterleib

Hypotyphla Loew (1873).

typ. Loewi Hend.

- Die Fühlergruben enden weit über dem Mundrande. Das basale Doppelsegment des Hinterleibes ist länger als alle folgenden zusammen. Ovipositor kürzer, aber viel breiter und voluminöser

Pyrgota Wiedemann (1830).

typ. undata Wied.

7. Analzelle bauchig begrenzt, ohne Spitze. Vorderstirne mit 2 deutlichen vorderen Orbitalborsten. Backen hinten auffallend herabgesenkt, Gesicht stark zurückweichend. Fühler kurz

Toxopyrgota Hendel ${ }^{\mathbf{1}}$. typ. inclinata Hendel.

- Analzelle unten mit Spitze

8. Die Fühlergruben laufen in eine einzige Vertiefung zusammen 9.

- Die Fühlergruben bleiben von einander durch einen Längsrücken deutlich getrennt

9. Alula wohl entwickelt. Radialis kürzer als die Cubitalis.

Apyrgota Hend. (1908).

typ. scioida Hend.

- Alula rudimentär. Radialis länger als die Cubitalis.

Leptopyrgota n. g.

typ. amplipennis n. sp.

1) Res. scient. voyag. Alluaud et Jeannel en Afr. Or. 
10. Die Kosta reicht bis zur 3. Längsador. Stirn schmal, Scheitel ohne Querwulst, aber mit großem Ozellendreieck. Radialis ohne Aderanhang. Schild bchaart

Campylocera Macquart (1843). typ. ferruginea Macqu.

- Die Kosta reicht bis zur Mündung der 4. Längsader. Radialis meist mit Aderanhang

11. Flügel braun, weiß punktiert und gefleckt Tephritopyrgota n. g. typ. passerina n. sp.

- Flügel nicht weiß punktiert und gefleckt. Stirne breit. Scheitel mit Querwulst, ohne größere Ozellenplatte. Schild nackt oder fast nackt

Adapsilia Waga ${ }^{1}$ ) (1842). typ. coarctata Waga.

12. Ozellen vorhanden. Hinterleib gestielt

- Ozellen fehlen. Hinterleib breit ansitzend Acropyrgota n. g.

13. Flügel hyal $\mathrm{n}$ oder mit breiten braunen Querbinden

typ. flavescens n. sp.

Toxura Macqu. (1850).

typ. maculipennis Macqu.

- Flügel dunkelbraun, mit zahlreichen weißen Punkten.

Epicerella Macqu. (1850).

typ. guttipennis Macqu.

Teretrura Bigot.

Bull. Soc. Ent. France 1885 p. 165.

Kopf so breit wie der Thorax. Die Stirne ist oben so breit wie beide Augen zusammengenommen und tritt im Profile ungefähr die Hälfte des wagerechten Augendurchmessers vor die Augen vor. Der Stirnwinkel mit dem Untergesichte ist deutlich spitz. Die Augenränder der Stirne sind parallel, mit einer geringen Neigung, gegen das Untergesicht hin zu konvergieren. Wie bei allen Pyrgotinen bilden auch hier die Augenränder neben den Fühlerwurzeln keinen Winkel, sondern setzen sich fast gerade aufs Untergesicht fort, erst ganz unten nach hinten umbiegend. Die Scheitelplatten sind als ganz kurze, mit einer nach vorne und einwärts gebogenen Frontorbitalborste besetzte Platten oben neben dem Augeneck entwickelt, ohne merklich in die Stirne vorzudringen. Die Ozellenplatte ist etwas größer, ein gleichseitiges Dreieck, trägt eng nebeneinander 3 deutliche Ozellen, aber keine Ozellarborsten und liegt knapp vor der scharfen, emporstehenden Scheitelkante, kaum merklich vertieft. Stirnmittelstrieme mit kurzer, feiner Grundbehaarung bedeckt, eben; die von den Wangen aufsteigenden Orbiten sind mäßig konvex. Die Lunula scheint nicht bedeckt $\mathrm{zu}$ sein, wird aber beim typischen Exemplare teilweise durch die stark vorgequollene Stirn. blase verdeckt. Der Klypeus ist unter den Fühlern der Quere und Länge nach ausgehöhlt, die Fühlergruben sind nicht von einander

1) Inclusive Eupyrgota Coquill. 
getrennt, sondern fließen in cine zusammen. Unter der Mitte des Klypeus tritt von einer hufeisenförmigen Rinne umgeben kegelig das Epistom hervor, im Profile einen vorspringenden Winkel bildend. Dadurch reicht die Grube nicht bis zum hinaufgezogenen Mundrand hinab. Der Umriß der Klypeusspalte ist hufeisenförmig, am Mundrande etwas verengt. Facialien und Peristomalien stoßen neben dem letzteren in einem Bogen zusammen. Die Stirnspaltenäste laufen in geringer Entfernung außerhalb der Gesichtsleisten, fast parallel mit ihnen. Die Wangen und die Backen unter dem Auge sind nur schmal. Der Unterrand der letzteren ist stark geneigt, hinten durch den unteren Hinterkopf stark herabgesenkt. Backengruben kaum abgesetzt. Der Hinterkopf fällt an der Scheitelkante steil von der Stirne ab, tritt oben weniger, unten jedoch ziemlich stark hinter den Augen hervor; oben ist er schwach, unten stark konvex. Die Augen sind länglich oval, ungefähr senkrecht gestellt.

Fühler kürzer als das Untergesicht, nach dem deutlich vorstehenden ersten Gliede herabhängend, an den Wurzeln einander ziemlich genähert. Zweites Antennenglied ein Viertel kürzer als das dritte, stielförmig schmal, gegen das dritte Glied hin breiter, aber noch lange nicht so breit wie dieses, namentlich am Oberrande länger beborstet. Drittes Glied breit, rundlich oval, mit einer medialen nackten, an der Wurzel etwas dickeren Arista. Im Profile sitzen die Fühler weit oberhalb der Augenmitte.

Thorax von oben gesehen wenig länger als breit, abgerundet viereckig, oben ziemlich gewölbt. Grundbehaarung des Rückens kurz, wenig auffallend. Die Quernahtäste liegen etwas vor der Mitte und steigen fast senkrecht, aber mit einer Neigung nach vorne, was sonst bei anderen Pyrgotinen nicht vorkommt, auf. Schildchen ein Drittel des Rückens lang, oben gewölbt und nackt, am Rande mit 6 Borsten, wovon das Spitzenpaar gekreuzt ist. Postscutelium mittelgroß. Metanotum gewölbt, abschüssig, von normaler Höhe.

Beborstung: Humerale eine, Notopleurale zwei, Praesuturale eine, Supraalare drei. Ein Praescutellarpaar; außerhalb und vor demselben, aber hinter der Rückenquernaht jederseits drei, nach vorne an Größe abnehmende Dorsozentralborsten. Prothorax mit 2 langen abstehenden, divergierenden Borsten. Je eine starke Mesound Sternopleuralborste.

Beine sehr lang und schlank. Vorderhüften vorne nackt. Schenkel nicht verdickt, aber an der Spitze deutlich verjüngt. Mittelschenkel dorsal im Spitzenviertel mit einem Quereindruck. Hinterschenkel an der Wurzel etwas nach oben gebogen. Unterschenkel basal sehr dünn, dann allmählich stärker werdend. Mittlere innen ohne deutlichen Endsporn, hintere im Wurzeldrittel etwas nach einwärts gebogen. Füße lang und gegen die Spitze zu merklich stärker. Längere Haare und Borsten fehlen überall an den Beinen.

Der eigentlich streifenförmige Hinterleib ohne Legeröhre ist die Hälfte derselben oder zwei Drittel des Thorax lang und hat sechs sichtbare Segmente, von welchen das letzte Tergit nur als ein schmaler 
Saum erscheint. Das basale Doppelsegment ist etwas länger als zwei der darauf folgenden gleich langen drei Tergite zusammengenommen. Der lange und dicke Ovipositor hat eine fast zylindrische Gestalt, die nur in der Mitte etwas weiter und vor dem Ende ein wenig eingeschnürt ist. Dorsal ist diese Röhre jedoch der ganzen Länge nach rinnenförmig eingedrückt und an ihren Rändern nach innen gerollt.

Flügel lang und schmal. Kosta vorne gerade. Subkosta noch vor der Flügelmitte sehr spitzwinkelig mündend, der ganzen Länge nach fein behaart. In geringer Entfernung vor ihr mündet die vollständig getrennte und nur vor dem Aufbiegen zur Kosta mit ihr in einem Punkte verbundene Mediastina. Subkostalzelle daher sehr klein. Die Längsadern 2-4 sind im allgemeinen sanft nach unten gebogen, nur die Radialis an der Mündung nach aufwärts. Erste Hinterrandzelle an der Spitze nur wenig erweitert. Beide Queradern gerade, unten etwas nach außen gestellt, daher schief. Die kleine steht auf der Mitte des Flügels und wenig hinter jener der Discoidalzelle. Hintere Basal- und Analzelle von gleicher Länge, letztere aber viel breiter, außen durch eine im stumpfen Winkel nach innen gebrochene Querader abgeschlossen, unten also mit einem kräftigen, aber kurzen spitzen vorspringenden Zipfel versehen. Die Analader reicht bis zum Rande. Axillarfalte lang und deutlich ausgeprägt. Schulterlappen und Alula normal. Schüppchen kurz.

Teretrura flaveola Bigot loc. cit.

9. Chile. - Obne Ovipositor $8 \mathrm{~mm}$ lang. Type Bigot's.

Ganz glänzend hellgelb. 3. Flügelglied rotgelb. Stirnstrieme matt. Borsten und Haare gelbrot. Flügel hell gelblich, längs der Adern intensiver gelb tingiert.

\section{Tabelle der Adapsilia-Arten.}

Schild außer den Randborsten auch noch behaart 1. - Schild sonst unbehaart

1. Radialis mit Aderanhang; Flügel mit einer über die kleine Querader laufenden gebogenen Querbinde A. magnicornis n. sp.

- Radialis ohne Aderanhang; obige Querbinde nur als Wisch angedeutet

A. scutellata 11. sp.

2. Alle Haare und Borsten des Tieres rot

- Borsten und Haare schwarz

3. Vorderschenkel dorsal kurz behaart. Schild am Rande mit 4 Borsten

A. flavopilosa $n$. sp.

- Vorderschenkel posterodorsal lang und dicht rauh behaart. Schild am Rande mit 10 Borsten

A. vulpina $n$. sp.

4. Backen höher als ein halbes Auge. Die Fühlergruben enden ein zieinlich großes Stück oberhalb des Mundrandes

- Backen schmäler als ein halbes Auge. Die Fühlergruben enden in der Nähe des Mundrandes 
5. Flügel intensiv rauchbraun tingiert, in der Vorderhälfte durch breite Säume der Adern noch dunkler braun. Schenkel schwarz

A. fusea n. sp.

- Flügel nur bräunlich hyalin mit einem dunkleren Apikalfleck; Schenkel rotbraun

6. Der Kostalabschnitt zwischen der 2. und 3. Längsader ist doppelt so lang wie der zwischen der 3. und 4. Erste Basalzelle vor der kleinen Querader gebräunt A. Bralıma n. sp.

- Kostalabschnitt 2-3 ist nur etwas länger als der zwischen 3 und 4; Basalzelle vor der kleinen Querader nicht gebräunt

A. Iuteola Coquillett.

7. Schild zweiborstig. Lange und schlanke Art A. longina Hend. ${ }^{1}$ ) - Schild vierborstig. Gedrungene Arten

8.

8. Cerebrale am Oberrande mit 2 nierenförmigen schwarzen Flecken; Wangen glatt

- Cerebrale ohne schwarze Flecken, gelb; Wangen mit Hohl punkten 9.

A. armipes n. sp.

9. Thoraxrücken an den Flügelwurzeln breiter als lang. Schild am Rande mit 6 längeren Borsten

A. Iatipennis Walk.

- Thoraxrücken deutlich länger als breit. Schild am Rande mit 4 längeren Borsten

10.

10. 3. Fühlerglied zweimal so lang wie breit. Thoraxrücken rotbraun, schwarz behaart

- 3. Fühlerglied dreimal so lang wie breit. Thoraxrücken rostgelb, rot behaart

A. ypsilon n. sp.

A. cafira n. sp.

\section{A. fusca n. sp. (Fig. 1).}

2 우 aus Japan," Yokohama District (leg. H. Prior) im Brit. Mus. London.

Stirne sehr breit, vorne neben den Fühlern gut dreimal so breit wie ein Auge, am Scheitel etwas verschmälert. Von vorne gesehen divergieren die Augenränder allmählich nach unten und bilden im Gesichte keinen Winkel. Scheitelkante wulstig emporragend, in der Mitte mit nach vorne gerichteten Haaren und mit stark gegeneinander gebogenen, fast liegenden inneren Scheitelborsten besetzt. Andere Kopfborsten fehlen. Stirn oben konkav; Strieme nur mäßig lang behaart. Stirn und Wangen um den wagerechten Augendurchmesser vor die Augen vortretend; Gesichtsprofil fast gerade und lotrecht. Backen $3 / 4$ eines Auges hoch; Peristomalien zun Mundrand stark aufsteigend. Hinterkopf am Halse um den wagerechten Augendurchmesser vorstehend. Klypeus parallelrandig, schmäler als eine der Wangen; die Fühlergruben sind $2 / 3$ des Gesichtes lang, ebenso lang die Fühler. Das 3. Fühlerglied ist am Oberrande gemessen so lang wie das 2., 2 mal so lang wie an der Basis breit, gegen die abgerundete Spitze hin etwas verjüngt, oben gerade, unten konvex. Arista medial,

1) Res. soient. voyag. Alluaud et Jeannel en Afr. Or. 
nackt, sehr lang und dünn. Taster sehr lang und breit, in der Mitte ain breitesten, vorragend, dicht beborstet.

Thoraxrücken relativ kurz, aber dicht und geneigt schwarz behaart. Schild nackt am Rande jederseits circa 5 dünne und lange Borsten; 2-3 derselben stehen auch weiter oben.

Das basale Doppelsegment des Hinterleibes verschmälert sich nur wenig und ganz allmählich gegen die Wurzel hin und ist wenig länger als hinten breit, aber länger als die darauf folgenden, an Größe nach hinten abnehmenden 4 Tergite $3-6$ zusanmen. Ovipositor so lang wie das basale Doppelsegment, breit und dick, von oben gesehen dreieckig, etwas länger als an der Basis breit, am ventral umgebogenen Ende stumpf. Ovipositor und Hinterleib, namentlich ersterer, sind lang und dicht, vorne schwärzlich, hinten rot behaart.

Kopf, Fühler und Taster rutbraun. Stirnstrieme matt. Am oberen Augenerk jederseits ein nach innen auf die Stirn gerichtetes und dann dünn nach vorne biegendes schwarzbraunes Querstriemchen. Wangen glänzend. Fühlergruben glänzend schwarz. Unter den Augen ein dunkler brauner Fleck.

Thorax und Schild rotbraun. Auf dem Rücken sind eine breite, hinten abgekürzte Mittelstrieme, je eine breite; vorne abgekürzte, mit ersterer fast zusammenfließende Seitenstrieme und die Notopleuralnaht schwarzbraun. Die Pleuren sind mit Ausnahme eines ovalen Fleckes auf den Mesopleuren und des Metapleuracallus ganz schwarzbraun, desgleichen das Metanotum..

Hinterleib rotbraun. Das basale Doppelsegment mit Ausnahme des Hinterrandes, sowie Vorderrandsäume der übrigen Tergite schwarzbraun. ơ unbekannt.

Beine außergewöhnlich stark und kräftig. Alle Schenkel verdickt, am Ende dorsal oder posterodorsal lang und dicht beborstet, schwarz, nur ventral an der Spitze rot. Die Mittelschenkel tragen in der Spitzenhälfte an der Vorderseite eine rote Längsrinne. Schienen und Füße rot, leuchtend rot behaart.

Der Flügel ist intensiv rötlichbraun tingiert, was gegen die Wurzel hin in ein Gelbrot übergeht. Breit braun gesäumt sind die Enden der 2. und 3. Längsader jenseits der hinteren Querader, diese selbst, dann die Discoidalis von der Wurzel bis zur hinteren Querader, die kleine Querader und die Äste der Radialisgabel. Der letzte Abschnitt der Discoidalis und der Costa-Abschnitt der 1. Hinterrandzelle werden gegen ihre Mündung hin haardünn. Radialis mit Aderanhang.

Schüppchen und Schwinger rostfarbig.

Körper ohne Ovipositor und Flügel $15 \mathrm{~mm}$, Ovipositor oben ge?nessen $5 \mathrm{~mm}$ lang.

\section{A. Iuteola Coquillett. (Figur 2 und 3.)}

Eupyrgota luteola Coquillett, Proc. U. S. Nat. Mus. Vol. 21 p. 337 (1898). London.

2 of $f$ aus Japan, Yokohaina District (leg. H. Prior) im Brit. Mus. in 
Die Stirne und die Wangen stehen die Hälfte des wagerechten Augendurchmessers vor die Augen vor, erstere etwas mehr, desgleichen der Hinterkopf hinter dieselben. Die Backen sind dic Hälfte eincs Auges hoch. Der Klypeus ist so breit

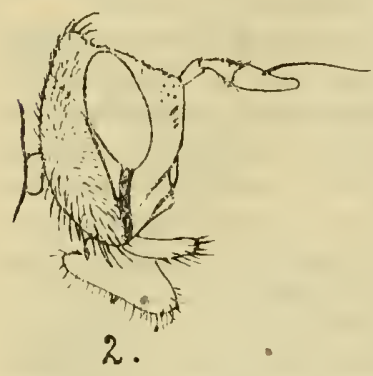
wie eine Wangenplatte des Gesichts. Die Fühlergruben und Fühler sind gut $2 / 3$ des Gesichts lang.

Das basale Doppelsegment des Hinterleibes ist beim $\sigma^{t}$ von der Wurzel bis zur Mitte stielartig verjüngt und erweitert sich dann plötzlich; es ist erbeblich länger als hinten breit und länger als die folgenden Ringe zusammen. Beim $\hat{o}$ ist das letzt sichtbare 5 . Tergit $1 \frac{1}{2}$ mal so lang wie das 4 . oder 3 . Beim o ist Hinterleib und Ovipositor wie bei $A$. fusca geformt und behaart, aber an der Wurzel doch stärker verjüngt, wenn auch nicht in gleichem Maße wie beim ô. Alle übrigen plastischen Merkmale wie bei $A$. fusca angegeben.

Kopf, Fühler und Taster hell rotbraun. Am Augeneck des Scheitels je ein kleiner dunkelbrauner Fleck. Strieme matt, Wangen glänzend. Fühlergruben glänzend dunkelbraun. Unter den Augen ein glänzend ${ }_{s}$ chwarzbraunes Dreieck.

Thorax, Schild und Hinterleib rostfarbig. Auf dem Thoraxrücken eine breite, gespaltene braune Längsmittelstrieme, die hinten stark abgekürzt ist. Daneben je eine ebensolche, aber vorne verkürzte Seitenstrieme, die sich hinten verjüngt und erst seitlich neben der Schildwurzel endet. Auch die Rinne vor den Scutellum und die Quernahtäste dunkelbraun. Auf den Pleuren ist die Brust, eine Querstrieme hinter dem Prothorakalstigna, ein großer Fleck auf den Pteropleuren und das Metanotum dunkelbraun. Thoraxrücken schwarz, Hinterleib rot behaart. Am Abdomen ist nur das basale Doppelsegment oben in der Mitte gebräunt.

Beine ganz rostrot, viel schwächer als bei $A$. fusca. Die lange und starke Beborstung im Endteile der Schenkel wie bei dicser Art, aber nur beim $\uparrow$. Dem weiblichen Stücke fehlen die Mittclschenkel.

Flügel an der Spitze und am Hinterrande rostbraun, vorne und an der Wurzel rostgelb. Breit dunkelbraun gesäumt sind nur die Enden der 2. und 3. Längsader jenseits der hinteren Querader; schwach gesäumt erscheint die kleine Querader. Der letzte Abschnitt der Discoidalis ist jenseits der hinteren Querader stärker hinaufgebogen als bei $A$. fusca. Radialis mit Aderanhang.

Schwinger und Schüppchen rostfarbig.

Körper ô 14,5.mm, q ohne Ovipositor $12 \mathrm{~mm}$, letzterer circa $3 \mathrm{~mm}$, Flügel $14 \mathrm{~mm}$ lang. 


\section{A. Brahma n. sp.}

1 t aus Süd-Indien, Nilgiris (leg. Hampson) im Brit. Museum London.

Stirne vorne fast 3 mal, am Scheitel zweimal so breit wie ein Auge. Scheitelkante wulstig vorstehend; Stirne nur vor dieser etwas konkav, sonst eben. Ohne Augenrandwinkel im Gesicht. Kopfborsten haarförmig und nicht länger als die zerstreute, mittellange Stirnbehaarung. Im Profile tritt die Stirne an den Fühlern fast um die Länge des wagerechten Augendurchmessers vor die Augen vor; die Wangen sind wenig schmäler und eine davon breiter als der Klypeus; dessen Prof:l gerade. Fühlergruben $2 / 3$ des Gesichtes lang. Backen gut die Hälfte eines Auges hoch. 3. Fühlerglied ungefähr so lang wie das zweite, jenseits der medialen, nackten und dünnen Arista etwas schmäler, aber gegen die stumpf abgerundete Spitze hin nicht verjüngt. Taster verbreitert.

Rücken kurz und spärlich behaart. Alle Borsten und Haare des Tieres sind gelbrot. Schildchen nackt, am Rande mit circa 8 haarartigen Börstchen. Das basale Doppelsegment des Hinterleibes ist fast doppelt so lang als hinten breit, vor der Mitte stielartig verjüngt und so lang wie die folgenden 3 Segmente, von denen das 5. am längsten ist, zusammen genommen. Die Schenkel sind ventral kurz, aber nicht dornenartig beborstet.

Stirnstrieme rotbraun, die Augenränder und eine breitere Querbinde am Scheitel wie der übrige Kopf gelbrot. Oben an der Stirn befindet sich jederseits am Augeneck ein kleiner dunkelbrauner Fleck. Die unterste Spitze der Fühlergruben und ein Fleck auf den Backen unterhalb der Augen glänzend schwarzbraun. Eine Querbinde oben am Cerebrale hinter der Scheitelkante und nach unten verwischte Grenzlängsstreifen außen an demselben dunkelbraun. Fühler und Taster gelbrot.

Thorax wie bei $A$. armipes gefärbt und gezeichnet. Außerdem sieht man aber auf dem Rücken eine breite dunkelbraune Medianlängsbinde vor der Naht und je eine schmale, schwarzbraune Seitenstrieme, die an der Quernaht breit unterbrochen ist. Hinterleib pechbraun, die Hinterränder der einzelnen Tergite rot. Beine gelbrot.

Flügel ähnlich wie bei $A$. ypsilon gezeichnet (Abbild. Fig. 4). Kostal-, Subkostal- und Marginalzelle, die äußerste Flügelwurzel und die Ränder der Analzelle gelb. Erste Basalzelle gelbbraun. Apikalfleck dunkelbraun. Erste Hinterrandzelle an der Mündung weit schmäler als bei ypsilon. Der letzte Discoidalabschnitt ist nur etwas länger als der vorletzte. Schwinger rot.

Körper $14 \mathrm{~mm}$, Flügel $13 \mathrm{~mm}$ lang.

\section{A. flavopilosa n. sp.}

1 우 aus Japan, Yokohama.District (leg. H. Prior) im Brit. Museum in London.

Dem $q$ der $A$. luteola bis auf folgende Unterschiede gleich. Die Stirn tritt an den Fühlerwurzeln spitzig und etwas stärker vor, das 
Gesicht weicht dann auch im Profile deutlich nach unten hin zurück. Die Fühler und deren Gruben sind länger, nur etwas kürzer als das Gesicht. Das dritte Fühlerglied ist selbst am Oberrande gemessen länger als das z.weite.

Das basale Doppelsegment ist stärker in der Mitte verengt und gleicht in dieser Beziehung mehr dem ot von luteola.

Die allgemeine Färbung ist viel heller, rostgelb. Die Längsstriemen des Rückens sind nur angedeutet und nur die Seitenstriemen hinten deutlicher erkennbar; sie setzen sich auch auf das Metanotum fort. Sonst ist der ganze Leib rostgelb.

Wesentlich ist, daß alle Haare und Borsten des Tieres hellgelb bis rot sind, auch an den Beinen. An diesen fehlen die langen Haare und Borsten an den Schenkeln ganz. Nur die kurzen Börstchen ventral an den Vorderschenkeln sind schwärzlich.

Im Flügel liegt die kleine Querader näher der hinteren; beider Abstand ist merklich kürzer als die hintere Querader, die mit der Posticalis einen spitzen Winkel bildet. Der Abstand der Cubitalismündung von der der Radialis ist $1 \frac{1}{2}$ mal so lang wie der von der Discoidalis.

Der Flügel ist ähnlich wie bei $A$. luteola tingiert; es sind aber alle Längs- und Queradern schmal bräunlich gelb eingefaßt. Die breiten braunen Endsäume der 2. und 3. Längsader fehlen. Der letzte Abschnitt der Discoidalis hat die Gestalt wie bei $A$. fusca, ist aber ebenso wie der Costalabschnitt der ersten Hinterrandzelle stärker als bei dieser. Die hintere Querader ist aber nicht gerade, sondern in der Mitte etwas in die Discalzelle hineingebogen. Radialis mit langem Aderanhang.

Schwinger und Schüppchen rostgelb.

Körper ohne Ovipositor $13 \mathrm{~mm}$, dieser circa $3 \mathrm{~mm}$, Flügel $15 \mathrm{~mm}$ lang.

\section{A. vulpina $n . s p$.}

1 o aus Sikkim (leg. F. A. Müller) im Brit. Mus. London.

Stirn vorne deutlich breiter als die doppelte Augenbreite, am Scheitel etwas verengt, dort wulstig erhaben und oben konkav. Augenränder allmählich auf das Gesicht herab divergierend, ohne Winkel. Stirnbehaarung kurz. Auf dem Scheitelwulst sieht man in der Mitte einige nach vorn gebogene, seitlich je 2 eng nebeneinanderstehende, cinwärts gebogene Borsten von geringer Länge und Stärke. Die Stirn steht an den Fühlerwurzeln etwas mehr als den wagerechten Augendurchmesser, die Wangen stehen fast so weit über die Augen vor. Im Profile weicht das Gesicht nach unten zurück und steigen die Peristomalien von unten zum Mundrande lang und steil auf. Die Backen sind ungefähr die Hälfte eines Auges hoch, die Wangen sind fast so breit wie die wagerechte Augenlänge und um eine gleiche Dimension steht der gepolsterte mntere Hinterkopf vor. Die Fühlergruben enden ein wenig oberhalb des Mundrandes. Das dritte Fühler- 
glied ist ungefähr so lang wie das zweite; der Oberrand ist nicht gerade, sondern noch vor der medialen Arista ausgebuchtet, sodaß er gegen die schmälere, aber abgerundete Spitze in einer Stufe abfällt; Unterrand konvex. Arista nackt, lang und dünn. Taster lang und breit.

Thoraxrücken lang und rauh behaart. Schildchen am Rande mit circa 10 langen, aufrechten, etwas nach vorne gebogenen Borsten besetzt, sonst ohne Haare.

Der Hinterleib ist bei der Type leider stark seitlich zusammengequetscht, so daß über die Form des basalen Doppelsegmentes und des Ovipositors nichts Sicheres gesagt werden kann. Es ist länger als die 4 folgenden Tergite zusammen genommen und so lang wie der Ovipositor, der einen mehr schmalen Eindruck macht und am Ende schwach ventral eingebogen ist. Behaarung wie am Thorax rauh.

Das ganze Tier, mit allen Haaren und Borsten, ist lebhaft gelbrot gefärbt, auch die Flügel sind feurig rotgelb tingiert. Das dritte Fühlerglied ist dunikler, mehr rotbraun. Die Peristomalien bis zum unteren Ende der Fühlergruben, sowie je ein Querstreifen der Backen unterhalb des Auges sind schwarzbraun.

Beine lang und kräftig, Schenkel gleichmäßig lang und dicht, dorsal oft borstenartig behaart.

Die gelbe Tingierung des Flügels ist am Vorderrande und gegen die Wurzel hin am lebhaftesten. Vordere Basalzelle mit einem braunen Längsschweif, der sich jenseits der Radialisgabel allmählich verliert. Kleine Querader dunkler umschattet. Eine kaum merkliche dunklere Wolke zieht vom langen Aderanhang der Radialis bis oben an die hintere Querader heran und verwischt sich gegen die Flügelspitze hin. Die Kosta reicht bis zur Mündung der Discoidalis. Schwinger rotgelb.

Körper mit Ovipositor $15 \mathrm{~mm}$, Flügel $14 \mathrm{~mm}$ lang.

\section{A. armipes n. sp.}

1 \& aus Sikkim, Kangra Valley (4500 Fuß), August (leg. Dudgeon) im Brit. Museum London.

Stirn vorne doppelt so breit, oben am Scheitel $1 \frac{1}{2}$ mal so breit wie ein Auge; ihre Augenränder geradlinig auf das Gesicht fortgesetzt. Die Scheitelkante ragt zwar nicht wulstig empor, jedoch ist die Stirn vor derselben konkav. Kopfborsten haarförmig kurz, Stirnbehaarung fast fehlend. Im Profile tritt die Stirne an den Fühlerwurzeln fast die Hälfte des wagerechten Augendurchmessers vor die Augen vor, die Wangen in der Mitte mehr als ein Drittel derselben. Klypeusprofil fast gerade. Klypeus und Fühlergruben gut $3 / 4$ des Gesichtes lang. Wangen so breit wie das 3. Füblerglied, Backen circa $1 / 4$ des Auges hoch. Fühler so lang wie der Klypeus; drittes Glied oben gemessen länger als das 2., 2 mal so lang wie breit, oben gerade, unten konvex, am Ende nicht verjüngt, stumpf abgerundet. Arista medial, dünn und nackt, so lang wie die Fühler. Taster lang und breit.

Rücken nur kurz schwarz behaart. Schild nackt, am Rande mit 6 Borsten, von denen das mittlere Paar schwächer und weiter 
oben inseriert ist. Das basale Doppelsegment des Abdomens ist wenig länger als hinten breit, in der Wurzelhälfte aber stark verjüngt, wie gestielt. 3.-6. Tergit sichtbar; die letzten zwei sehr schmal. Ovipositor so lang wie das basale Doppelsegment, $3 / 4$ mal so lang wic an der Wurzel breit, von oben gesehen fast dreieckig, schwach ventral cingebogen. Behaarung am ganzen Hinterleibe mittellang, ibberall am Leibe schwarz.

Der Kopf rotgelb. Stirne oben mit 2 schwarzbraunen bogigen Striemen, die miteinander eine mit der Spitze nach vorne gerichtete pfeilförmige Figur bilden. Die unteren Enden der Fühlergruben und ein Fleck auf den Backen unterhalb der Augen glänzend schwarzbraun. Zwei nierenförmige, in der Mittellinie vereinigte Flecke oben an Cerebrale, sowie je eine Strieme seitlich desselben am Hinterkopfe, die sich unten am Halse verbreitert, matt schwarzbraun. Fühler und Taster gelbrot.

Thorax, Schild und Hinterleib, Beine ebenfalls heller oder etwas dunkler rotgelb. Hellgelb sind die Schulterbeulen, die nittleren Pleuren und die Metapleuren. Schwarzbraun: ein Ring um den Hals herum, eine lotrechte Strieme quer über die Mesopleuren hinter dem Stigma, die oben längs der Notopleuralnaht nach hinten läuft, die Quernahtäste bräunt und die Rinne vor dem Schilde breit ausfüllt. Dunkelbraun sind auch die Ptero- und Hypopleuren, sowie je eine Seitenstrieme des Metanotums. Hinterleib teilweise rotbräunlich verdunkelt.

Alle Schenkel in der Spitzenhälfte ventral zwei. zeilig mit kurzen, dornähnlichen Borsten besetzt. Vorderschenkel posterodorsal lang und rauh behaart.

Flügel wie bei ypsilon (Abbild. Fig. 4). Schwinger gelb.

Körper über $11 \mathrm{~mm}$, Flügel $10 \mathrm{~mm}$ lang.

\section{A. Jatipennis Walker.}

Oxycephala latipennis Walker, List Dipt. Brit. Mus., Vol. 4 p. 1087 (1849).

$q$ aus Aequatorial - Afrika, Ruwenzori, Mubecki-River im Brit. Mus. London.

Stirn vorne $7 / 4 \mathrm{mal}$ so breit wie ein Auge, am Scheitel etwas verengt. Augenränder der Stirn und des Gesichtes in einer geraden Fortsetzung gelegen. Scheitelkante wulstig erhaben; alle Kopfborsten nur haarartig kurz und schwach. Oberstirn konkav, ohne Scheiteldreieck. Die Stirne tritt an den Fühlern $1 / 2$, die Wangen $1 / 3$ des wagerechten Augendurchmessers vor die Augen vor; letztere sind dicht mit Hohlpunkten versehen und so breit wie das 3. Fühlerglied. Die Backen sind etwas höher als $1 / 4$ eines Auges. Der Klypcus ist parallelrandig, fast zweimal so breit wie eine Wange; die Fühlergruben enden wenig oberhalb des Mundrandes, sind aber wie die Fühler fast so lang wie das Gesicht. Das 3. Fühlerglied ist oben gemessen so lang der kaum länger als das 2., lang eiförmig, am Ende stumpf abgerundet und etwas schmäler als an der Wurzel. Arista etwas vor der Mittc inseriert, nackt, lang und dünn. Taster lang und breit. 
Thoraxrücken merklich breiter als lang, mittellang abstehend schwarz behaart. Schild oben nackt, am Rande mit 8 Borsten besetzt. Hinterleib in der Mitte des basalen Doppelsegmentes, das länger als die noch sichtbaren Tergite 3-6 zusammen ist, stark verjüngt, also gestielt, kurz anliegend behaart. Tergit 3 und 4 gleich lang, 5 und 6 kurz. Ovipostior so lang wie die Tergite 3-6 zusammen genommen, von oben besehen dreieckig, $11 / 2 \mathrm{mal}$ so lang wie an der Basis breit, an der Spitze etwas ventral umgebogen.

Kopf bräunlich gelb, Vorderstirn und Wangen verdunkelt. Backen unter dem Auge mit braunem Fleck. Fühler und Taster rot. Cerebrale hellgelb, seine Grenznähte und 2 gegen den Hals zu konvergierende Längsstriche auf demselben schwarzbraun.

Thorax rostbraun, in gewisser. Beleuchtung zart weißlich bereift. Von der Rückenstriemung sind nur jederseits die 2 dunkelbraunen Seitenflecke vor und hinter der Naht deutlich sichtbar. Schild hellgelb. Hinterleib rostbraun; der Vorderrand der einzelnen Tergite ist dunkelbraun, der Hinterrand gelb.

Hüften und Beine rostrot, schlank und lang. Schenkel nicht verdickt, nur ventral mit einigen kürzeren, abstehenden Borstenhaaren besetzt.

Flügel wie bei ypsilon (Abbild. Fig. 4), die kleine Qnerader ist aber von der hinteren mindestens die Länge dieser entfernt. Schwinger gelb.

Körper mit Ovipositor $12 \mathrm{~mm}$, Flügel 11,5 mm entfernt.

Anmerkung: Mir liegt ein von Mr. Austen als latipennis Walker bestimmtes Stück vor. Walker sagt aber von seiner Art: clothed with very short yellow hairs, wäbrend das Exemplar schwarz behaart ist. Walker erwähnt auch nicht die Rückenstriemen -und das Aderrudiment der Radialis, wohl aber die punktierten Wangeñ. Da Mr. Austen die Type ja vergleichen konnte, schließe ich mich seiner Ansicht an.

\section{A. ypsilon n. sp. (Fig. 4.)}

1 ㅇ aus West-Afrika, Sierra Leone, März (leg. Arbuckle) im Brit. Mus. London.

Von der vorigen Art durch folgende Merkmale verschieden.

Die Stirne ist breiter, vorne doppelt so breit wie ein Ange. Fühlergruben arn Innenrande schwarz.

Thoraxrücken deutlich länger als breit, ungestriemt, aber nach hinten zu deutlicher und dichter gelblich bereift. Schild sogar dunkler als der Thorax, mit 4 Borsten besetzt.

Stirn rotgelb, Scheitelkante und Cerebrale noch heller. Auf der Mitte des letzteren ist ein schwarzes, dem Halse aufsitzendes $\mathrm{Y}$ sichtbar. Der übrige Hinterkopf ist rotbraun. Fühler und Taster gelbrot.

Hinterleib rostbraun.

Flügel nach Figur 4, gezeichnet. Die Kostal-, intensiver die Subkostal- und Marginalzelle rotgelb. An der Radialisgabel und 
oberhalb der kleinen Querader ein brauner Wisch. Apikalfleck des Flügels dunkelbraun. Posticalis an der Wurzel und Analzelle gelb gesäumt. Schwinger rostfarbig.

Körper über $15 \mathrm{~mm}$, Flügel $13 \mathrm{~mm}$ lang.

A. caffra n. sp.

1 o aus Port Natal, Südafrika in Brit. Mus. London.

Diese Art gleicht sehr der A. ypsilon und unterscheidet sich nur durch Folgendes.

Das 3. Fühlerglied ist schlanker, circa $3 \mathrm{mal}$ so lang wie breit, bei ypsilon nur doppelt so lang wie breit. Die punktierten Wangenplatten glänzen kaum und sind seitlich bereift.

Thorax und Schild rostgelb, aber viel heller gefärbt. dichter bereift und ersterer gelbrot behaart. Auch das Schildchen ist bereift und glänzt nicht. Cerebrale wie bei $A$. latipennis Walk. beschrieben.

Das basale Doppelsegment des Hinterleibes ist in der Mitte nur etwas eingeschnürt, der Hinterleib an der Wurzel daher nur viel weniger verjüngt. Der Ovipositor ist an der Basis sehr breit, wenig länger als breit, plump, von oben besehen nicht dreieckig, sondern an den Seiten hinter der dicken Wurzel eingebuchtet. Die Spitze ist ziemlich stark ventral eingebogen.

Beine sehr kräftig, Schenkel merklich verdickt; die vordersten posterodorsal reihenweise beborstet.

Flügel und Größe wie bei ypsilon (Abbild. Fig. 4).

\section{A. magnicornis n. sp.}

4 万우 aus Ceylon, Pundalnoya (leg. E. E. Green) im Brit. Mus.

Stirn parallelrandig, so breit oder etwas schmäler als ein Auge, 1 und $1 \frac{1}{2}$ mal so lang wie breit, oben nicht konkav, an der Scheitelkante nur etwas wulstig emporragend. Die Augenränder nähern sich im Untergesichte etwas einander und biegen dann unten ohne Winkel nach außen um. Stirnbehaarung lang und schwarz; ebenso die Beborstung kräftig: je eine Frontorbitale, äußere und sehr lange innere Scheitelborsten, ein Postvertikalpaar und ein Ozellarpaar. Im Profile treten die Stirn nur etwas, die linearen Wangen sehr wenig vor die Augen vor; Klypeus konkav. Backen $1 / 5$ des Auges hoch. Fühler ind deren Gruben so lang wie das Gesicht. 3. Fühlerglied so lang wie das 2., groß, abgerundet rechteckig geformt, wenig länger als breit. Arista fast wie nackt, lang und dünn. Taster sehr lang und breit.

Rücken und Schild mittellang, Hinterleib länger und rauher, schwarz behaart. Schild am Rande nur mit 4 kräftigen Borsten. Das basale Doppelsegment des Hinterleibes ist hinten merklich breiter als lang und verjüngt sich nur mäßig gegen die Wurzel.hin. Beim ô ist das 5 . Tergit verlängert, beim ㅇ sind die Tergite $3-5$, namentlich aber das 4. und 5. sehr kurz. Ovipositor groß, so lang wie der Hinterleib, stumpf konisch, schwach ventral eingebogen, von oben gesehen, 
hinter der brciten Wurzel eingezogen. Er erscheint von der Seite breiter als von oben. Beim o sind die Vorderschenkel lang $u$, dicht abstehend behaart, posterodorsal mit einer Reihe langer Borsten versehen. Alle Schenkel haben ventral an der Wurzel einige lange Borstenhaare. Beine und Brust des o nur behaart.

Kopf hell bräunlich gelb; Stirnstrieme matt und wie das stark glänzende Gesicht manehmal verdunkelt. Backengruben unter dem Auge mit braunem Fleck. Fühler und Taster hell rotbraun.

Thorax und Schild gelb. Rücken mit 4 breiten rotbraunen Längsstriemen; die mittleren sind hinten verkürzt, die seitlichen an der Quernaht unterbrochen. Schild oben rotbraun. Mesopleuren mit einem großen schwarzbraunen hufeisenförmigen Fleck, der nach hinten geöffnet ist. Auch die unteren Pleuren sind teilweise dunkelbraun gefleckt.

Hüften gelb. Sehenkel gelbrot, Schenkelspitzen, Sehienen und Füße rotbraun. Sehienen manchmal in der Mitte heller.

Hinterleib gelbrot, in der Mitte größtenteils rotbraun.

Flügel beim $\widehat{o}$ gräulich hyalin; Subkostalzelle, eine Querbinde darunter bis über die hleine Querader, unter der sie in der Discalzelle wurzelwärts umbiegt und versehwimmt, ein Fleck an der Radialisgabel, ein breiter Saum der hinteren Querader und ein Apikalfleck braun. Beim + ist diese Zeiehnung so verwachsen, daß sie kaum bemerkbar ist. Schwinger rostgelb.

Körper 6,5 mm, Flügel $5,5 \mathrm{~mm}$ lang.

\section{A. scutellata n. sp.}

1 o aus Indien, NW. Provinzen (leg. C. Horne) im Brit. Mus. London.

Stirn flach, in der Mitte so breit wie ein Auge, am Scheitel wenig, vorne deutlich schmäler. Von vorne gesehen divergieren die Gesichtsaugenränder in einem bogigen Winkel. Scheitel ohne Kante und Wulst, mit scharf abgesetztem, glänzendem Dreieck und ebenso deutlichen, schmalen, nach vorne hin konvergierenden Scheitelplatten, die an der Spitze eine Borstennarbe tragen. Ein paar große innere, kleinere äußere Vertikalborsten und aueh Postvertikalborsten vorhanden. Strieme zerstreut und kurz behaart. Die Stirn steht ungefähr ein Drittel des wagereehten Augendurebmessers vor die Augen vor; die Wangen sind schmäler als das 3 . Fühlerglied. Backen weniger als $1 / 5$ des Auges hoch. Gesichtsprofil gerade, etwas zurückweichend. Hinterkopf unter dem Halse un den wagerechten Augendurehmesser vorstehend. Klypeus parallelrandig; Fühlergruben bis zum Mundrande reichend. Das 3. Fühlerglied ist am Oberrande gemessen etwas länger als das zweite, dreimal so lang wie in der Mitte breit, oben gerade, gegen die stumpfe Spitze hin etwas verjüngt. Arista dünn, nackt, lang. Taster lang vorstehend, breit.

Thoraxrücken, Sehild und Hinterleib schwarz behaart. Am Hinterleibe sehimmern die Haare teilweise rot. Sehild 4-borstig. Das basale Doppelsegment des Hinterleibes versehmälert sich nur 
allmählich zur Wurzel hin und ist kürzer als hinten breit. Die Tergite 3-6 nehmen nach hinten zu an Größe ab. Der Ovipositor ist erheblich länger als der ganze Hinterleib, von oben gesehen hinter der breiten Basis plötzlich seitlich kompreß; von der Seite gesehen relativ hoch und fast gerade.

Kopf und seine Anhänge rotgelb. Scheiteldreieck, Scheitelplatten und der obere Hinterkopf mit Ausnahme eines gelben Mitteldreieckes braun. Unter den Augen ein dunkelbrauner Fleck auf den Backen. Drittes Fühlerglied gegen die Spitze hin gebräunt. - Thorax rotgelb. Ein breiter Schildehenrand, die Pleuren und die Brust hellgelb. Zentralrücken und Mitte des Schildes rot. Quer ïber die Mitte der Pleuren läuft eine breite dunkelbraune Binde, die sich oben auf dem Rücken verwaschen bis ïber die Supraalargegend hinzieht. Eine Rückenzeichnung ist nur ganz undeutlich erkemnbar. Hinterrücken und die angrenzenden Pleuren rot gefleckt. Hinterleib und Ovipositor rotbraun. Die Wurzel des ersteren und eine dorsale Mittellinie rotgelb.

Beine rotgelb. Schienen und Füße rotbraun. An den 4 hinteren Beinen sind auch die Schenkel an der Spitze von unten herauf heller gebräunt.

Flügel schwach bräunlichgrau hyalin. Die 2.-4. Längsader sind jenseits der hinteren Querader in abnehmender Breite braun gesäumt. Außerdem sind beide Queradern, ein zarter kurzer Wiseh oberhalb der kleinen, die Radialisgabel und die Costicaliswurzel etwas braun gesäumt. Radialis sehwach wellig, ohne Aderanhang. Letzter Cubitalisabschnitt fast gerade. Queraderndistanz kleiner als die hintere Querader. Der Winkel dieser mit der Posticalis ist spitz.

Schwinger und Sehüppchen gelb.

Körper mit Ovipositor $9 \mathrm{~mm}$, Flügel $6 \mathrm{~mm}$ lang.

\section{Tabelle der Campylocera-Arten.}

Die Endabschnitte der 2. und 3. Längsader und die hintere Querader sind auffällig intensiv und breit braun gesäumt 1 .

- Obige Aderteile ungesäumt oder nur sehr schmal und unscharf gesäumt

- Die Kosta von der 1. bis 3. Längsader und beide Queradern schmal braun gesäumt. Auffallend seblanke Art mit grossen Fühlern

C. gracilis n. $\mathrm{sp}$.

1. Thoraxrïeken und Hinterleib dunkelbraun bis schwarz. Pleuren und Schild gelb

- Thoraxrücken und Hinterleib rostfarben

4.

2. 2. Fühlerglied oben länger als das 3., dieses gegen die Spitze hin kaum verjüngt

C. piceiventris ${ }^{1}$ ) Hendel.

- 2. Fühlerglied oben kürzer als das 3., dieses an der Spitze stark verjüngt

1) Res. scient. voyage Alluaud et Jeannel en Afr.-Orient. 
3. Mesopleuren gelb, ungefleckt. Stirne vorne so breit wie ein Auge. C. nigriventris $\mathrm{n} . \mathrm{sp}$.

- Mesopleuren gelb, oben mit einem großen, glänzend schwarzen Fleck

C. pleuralis n. $\mathrm{sp}$.

4. 2. und 3. Fühlerglied gleich lang, dieses am Ende kaum verjüngt. Rücken mit 4 schwarzen Längsstriemen $C$. thoracalis n. sp. - 3. Fühlerglied viel länger als das 2. und am Ende stark verjüngt. Rücken ungestrient

C. myopa n. sp.

5. Pleuren ungefleckt

6.

- Mesopleuren mit einer schwarzen Mittelquerstrieme, die das mittlere Drittel einnimmt

C. maculifer n. sp.

6. Gesicht unter den Fühlern zweimal so breit wie ein Auge; Wangen fast zweimal so breit wie das 3. Fühlerglied C. latigenis n. sp.

- Gesicht unter den Fühlern erheblich schmäler als ein Auge, Wangen linear $\quad C$. angustigenis n. sp.

- Gesicht ungefähr so breit wie ein Auge; Wangen so breit wie das 3. Fühlerglied

7. Kleine Art, $6 \mathrm{~mm}$. Ovipositor plump C. ferruginea Mequ. - Grössere Art, $11 \mathrm{~mm}$. Ovipositor schlanker, konisch

C. oculata n. sp.

\section{Campylocera gracilis n. sp.}

1 q aus S.-Nigeria. 21. Aug. (Dr. Mayer). Ent. Res. Comm.

Stirn vorn so breit wie ein Auge, am Scheitel erheblich verengt. Innere Vertikale stark. Postvertikale und I Paar Orbitalborsten deutlich erkennbar. Strieme vorn lang behaart. Scheitel nicht wulstig. Die Stirn tritt $1 / 2$ des wagerechten Augendurchmessers vor die Augen vor, Stirnwinkel spitz, Gesicht geradlinig zurückweichend. Backen $1 / 5$ eines Auges hoch. Wangen in der Mitte viel schmäler als das 3. Fühlerglied. Klypeus nach unten etwas breiter werdend. Fühlergruben bis zum Mundrande. Fühler schr lang und groß. Das 2. u. 3. Glied zusammen so lang wie das Gesicht. Das 2. Glied ist zum größten Teile griffelartig dïnn, $2 / 3$ des 3 . lang. Dieses breit, abgerundet recbteckig, etwa dreimal so lang wie breit. Arista lang und dünn, medial. Taster stark verbreitert und weit vorstehend.

Thoraxrücken wenig länger als breit, wie das Schildchen zart und nicht lang behaart. Letzteres am Rande 4-borstig.

Hinterleib länger, aber viel schmäler als der Thorax, schlank, gegen die Basis allnählich verjüngt. Basales Doppelsegment gut $3 / 5$ des Abdomens lang, 3-5. Tergit allinählich kïrzer werdend. Ovipositor schlank zylindrisch-konisch, an der Basis etwas breiter, so lang wie der Hinterleib, in der Mitte ventral eingebogen.

Flügel graulich hyalin. Adern an der Wurzel gelb, sonst braun. Schmal braun gesäumt sind: die Kosta zwischen der 1. bis 3.Längsader und die beiden Queradern. Radialis ohne Anhang. Letzter Abschnitt der Cubitalis gleichnäßig sanft gebogen, in der 
Flügelspitze mündend; jener der Discoidalis jenseits der hinteren Querader nur sehr schwach gebogen. Hintere Qucrader etwas wellig und sehr schief gestellt; der Winkel mit der Porticalis beträgt $45^{\circ}$. Kleine Querader oberhalb des letzten Drittels der Discalzclle. Der Flügelrand zwischen der 3. bis 5. Längsader ist nicht konvex, sondern in der Mitte eingebuchtet. Das ganze Tier ist bell rotgelb, schwarz behaart und beborstet. Backen ohne dunklen Fleck. Spitze des 1. und 3. Fühlergliedes, sowie das ganze 2. gebräunt.

Flügel $9 \mathrm{~mm}$ lang, Körper ohne Legeröhre ungefähr gleichlang.

Campylocera nigriveutris n. sp. (Fig. 5).

$2 \delta$ ㅇ aus Westafrika, Ashanti, Obuasi, Juni (leg. Dr. Graham) im Brit. Mus. London.

Stirn vorn nur so breit wie ein Auge, am Scheitel deutlich verschmälert; ihre Augenränder sanft konkav. Von vorn gesehen biegen die Augenränder unterhalb der. Fühlerwurzeln divergierend nach außen um. Scheitel nicht wulstig emporragend, in der Höhe der Augen gelegen, abgerundet, mit einen scharf differenzierten, glänzenden, mit der Spitze nach vorn gerichteten Dreieck. An der Stelle der Ozellen stehen drei nach vorn gerichtete Borsten. Außerdem sind mit den Spitzen nach vorn gerichtet die 2 Postvertikale, divergierend und je eine obere Frontorbitale. Sehr lang sind die inneren, kürzer die äußeren Vertikalborsten. Stirnstrieme in der Mitte konkav, mittellang schwarz behaart. Die Stirn tritt an den Fühlern $1 / 3$ des wagerechten Augendurchmessers vor die Augen vor. Gesichtsprofil gerade, nach hinten zurückweichend. Backen $1 / 6$ (ㅇ) bis $1 / 4\left(0^{1}\right)$ eines Auges hoch; Peristomalien nach vorne aufsteigend. Hinterkopf an Halse um den halben wagerechten Augendurchmesser vortretend. Klypeus parallelrandig, gut doppelt so breit wie eine Wange, diese nur so breit wie das 3. Fühlerglied an der Arista, die Fühlergruben reichen bis zum Mundrande; ebenso lang sind die Fühler. Das dritte Fühlerglied ist am geraden Oberrande gemessen $4 / 3$ mal so lang wie das 2 . und gegen die runde Spitze hin stark verjüngt. Arista medial, nackt und dünn. Taster stark verbreitert, beborstet.

Thoraxrücken mittellang, geneigt, nach hinten zu länger schwarz behaart. Thorax und Schildborsten sehr lang. Schild auch behaart und am Rand mit vier Borsten versehen.

Der Hinterleib verschmälert sich deutlich, aber nur ganz allmählich gegen die Wurzel hin. Das basale Doppelsegment ist beim 우 etwas länger als die vier folgenden Tergite 3 bis 6 zusammen, beim $\hat{o}$ so lang wie das 5., letzt sichtbare oder so lang wie das 3. u. 4. Tergit zusammen. Der Ovipositor ist so lang wie der ganze Hinterleib, schlanker, aber ähnlich geformt wie bei fusca; von oben gesehen hat er die Form eines Dreiecks, das zweimal so hoch wie basal breit ist. Hinterleib und Ovipositor sind wie der Thoraxrücken behaart, die letzten Tergite vor diesem aber tragen längere Randborsten.

Kopf samt Anhängen rotgelb. Die matte Stirnstrieme satter gefärbt, mit zwei rotbraunen Längsstriemen, die oben parallel sind, 
unten aber divergieren. Beim zwciten Stücke sind dieselben in der Mitte zusammengeflossen. Das erwähnte glänzende Scheiteldreieck, sowie der obere Hinterkopf mit Ausnahme eines gelben Längsfleckes oberhalb des Halses dunkel rotbraun. Ein kleiner glänzend brauner Fleck unten an Auge. Gesichtskiel und untere Enden der Fühlergruben gebräunt. Beim ô sind die ganzen Backengruben und der untere Teil der Wangen glänzend schwarz.

Thorax und Schild rotgelb. Der Rücken zeigt die bei fusca erwähnten schwarzbraunen Längsstriemen hinten bis zum Sehildchen, die seitlichen vorn abgekürzt, ist aber dureh Zusammenfließen derselben fast ganz glänzend sehwarzbraun zu bezeichnen. Gleichgefärbt ist noch das Metanotum. Mesopleuren längs der ganzen Wulst und Sternopleuren oben schwarz und lang beborstet.

Hinterleib glänzend sehwarz. Ovipositor rot.

Hüften und Beine rotgelb, Schienen, namentlich dorsal dunkelbraun; Behaarung und Beborstung schwarz. Die Füße, besonders die vordersten sind dunkler rot gefärbt. Die Beborstung der Schenkel ist auch beim o ? an den Vorder- und Hinterschenkeln eine schwache.

Flügel graulich hyalin, mit dunkelbraunen Adersäumen nach der Figur 5. Radialis ohne Aderanhang. Schwinger rostfarben.

Körper mit Ovipositor $9 \mathrm{~mm}$, Flügel $8 \mathrm{~mm}$ lang.

\section{Campylocera pleuralis n. sp.}

1 ơ aus Afrika, Gold-Küste, Weshiang, R. Dainsu, 26. Nov. (Dr. Ha milton). Ent. Research Comm.

Sehr ähnlich der C. nigriventris Hend. Die Stirn ist am Scbeitel so breit wie ein Auge, vorn breiter und ganz und gar gelb, auch das glänzende Ozellendreieck. Die Backen sind mehr als $1 / 3$ eines Auges breit. - Das basale Hinterlejbssegment ist $1 / 2$ des Abdomens lang. Backen und Wangen gelb. Pleuren, Sehultern und Seheitel weißgelb. Metanotum und Hinterleib und ein großer Fleek auf dem Mesopleuron glänzend sehwarz. Thoraxrücken rotbraun, am Außenrande schwarz.

Am Flïgel sind die dunklen Säume an der Spitze viel breiter und noeh intensiver. Die Queradern sind ein wenig weiter von einander entfernt.

Körper und Flügel fast $7 \mathrm{~mm}$ lang.

\section{Campylocera thoracalis $n . \mathrm{sp}$.}

2 ơ우 aus Maao Negros, Philippinen, 14. Mai leg. C. S. Banks im Brit. Mus. London.

Stirn so breit wie ein Auge, am Scheitel kaum verschmälert; Augenränder sanft konkav. Beborstung und Kopfform ähnlich wie bei $C$. nigriventris, doch kann ich keine genaueren Angaben machen, da beide Stücke mehr oder weniger verdrückte Köpfe besitzen. Die Fühler sind fast so lang wie das Gesicht; das zweite und dritte Glied sind oben gemessen gleichlang. Das dritte Glied ist an der Spitze ab- 
gerundet und nur wenig verjüngt; es ist ungefähr $1 \frac{1}{2}$ mal so lang wie breit. Arista nedial, nackt und dünn. Backen 1/3 eines Auges hoch. Der flache Augenrandwinkel liegt unten in der Mitte des Gesichtes.

Schild behaart, an Rande mit vier Borsten. Der Hinterleib verjüngt sich allmählich gegen die Basis hin. Das basale Doppel-segment ist bei $\hat{o}$ und of so lang wie der halbe Hinterleib; das 5. Tergit des $\widehat{0}$ ungefähr $1 \frac{1}{2}$ mal so lang wie das dritte oder vierte. Der Ovipositor ist so lang wie der ganze Hinterleib, dick, ventral eingebogen; von oben gesehen an der Basis verbreitert, an der Spitze verjüngt, in der Mitte ziemlich gleichbreit. Er ist von oben her kompreß, ohne aber Seitenkanten zu bilden.

Kopf samt Anhängen rostbraun. Stirnstrieme matt rostrot. Scheitelteile wenig glänzend. Beborstung und Behaarung des ganzen Tieres schwarz, höchstens letztere teilweise mit rotem Schimmer der Spitzen. Thorax und Hinterleib glänzend rostfarbig. Lateralgegend des Thoraxrïckens und Schild heller gefärbt. Auf ersteren sieht man vier glänzend schwarze einander stark genäherte Längsstricmen; die zwei mittleren sind hinten stark abgekürzt, die seitlichen an der Quernaht unterbrochell. Sie bestehen aus einer Makel vor und einem bis nach hinten reichenden Keilstrich hinter der Wulst. Pleuren ungefleckt.

Hüften und Schenkel von der Farbe des Thorax. Schienen schwarzbram, Füße rot. Schenkel, besonders beim 우 lang beborstet.

Die Zeichnung des Flügels ist die gleiche wie bei $C$. nigriventris, die Aderung verschieden. Die Radialis ist beinahe ganz gerade. Die Discoidalis miindet etwas tiefer unterhalb der Fliigelspitze. Die Queradern sind weniger genähert, ihr Abstand von einander ist nur etwas geringer als die Länge der hinteren.

Körper und Flügel $7 \mathrm{~mm}$ lang.

\section{Campylocera myopa n. sp.}

1 q aus Süd-Afrika, Nyasaland (leg. Old). Ent. Res. Commit.

Stirn am Scheitel so breit wie ein Auge, vorn etwas breiter, so wie bei gracilis beborstet. Scheitel nicht wulstig. Die Stirn tritt $\mathbf{1} / \mathbf{2}$ des wagerechten Augendurchmessers vor, Stirnwinkel ein Rechter, Gesicht sehr sehwach konkav, zurückweichend. Backen $1 / 4$ eines Auges hoch. Wangen in der Mitte so breit wie das dritte Fühlerglied. Klypeus fast parallelrandig, Fühlergruben bis zum Mundrande. Fühler lang, so lang wie das Gesicht; das dritte Glied ist oben ganz deutlich länger als das zweite, gegen die Spitze hin lanzettlich verjüngt, aber dort abgerundet. Arista lang und dünn, etwas vor der Mitte.

Thoraxrücken kurz, fast breiter als lang, wie das Schildchen ziemlich dicht und relativ rauh behaart; letzteres vierborstig. Hinterleib etwas länger, aber wenig schmäler als der Thorax. Das basale Doppelsegnent ist ganz wenig länger als $1 / 2$ desselben; 3.-5. Tergit alhiählich kürzer werdend. Ovipositor allmählich konisch verjüngt; 
zweimal so lang wie an der Wurzel breit, gerade und nur am Ende etwas ventral abgebogen. - Beine kurz behaart und schwach beborstet.

Das ganze Tier ist einfarbig rotgelb, überall schwarz behaart und schwarz beborstet. Unter dem Auge ein kleiner brauner Fleck. Der Hinterleib ist verdunkelt, mehr rostbraun. - Flügel wie bei $C$. nigriventris, nur ist der Abstand beider Queradern länger und nur etwas kürzer als die hintere Querader.

Körper und Flügel $7,5 \mathrm{~mm}$ lang.

Campylocera oculata n. sp. (Fig. 6).

2 ‘ㅇ aus West-Afrika, Ashanti, Acra, 26./V1. (leg. Dr. Graham) und N. Nigeria, 4./IX. (leg Dr. Foy) im Brit. Museum London.

Der Kopf gleicht mit folgenden Unterschieden dem von nigriventris. Das glänzende Scheiteldreieck ist etwas kleiner und zahlreicher beborstet. Die oberen Frontorbitalborsten, je ein Stück, sind kleiner und nach außen gebogen. Die Stirne tritt an den Fühlern $1 / 2$ des wagerechten Augendurchmessers vor die Augen vor; das Gesichtsprofil ist nach unten hin sanft konkav und weicht nach hinten zurück. Backen niedrig, kaum $1 / 6$ des Auges hoch. Wangen so breit wie das dritte Fühlerglied an der Basis. Die Fühlergruben enden etwas oberhalb des Mundrandes - um Wangenbreite. Das dritte Fühlerglied ist am geraden Oberrande gemessen ungefähr so lang wie das

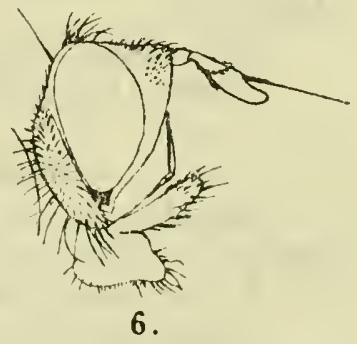
zweite und verjüngt sich mäßig gegen die abgerundete Spitze hin. Arista etwas vor der Mitte inseriert, lang und dünn.

Die schwarze Behaarung des Thoraxrückens, Schildchens und Hinterleibes ist weitaus länger, rauher und dichter als bei nigriventris und aufrecht. Der Ovipositor ist bei beiden Exemplaren nicht ganz gleich und ist es vielleicht möglich, daß zwei Arten vorliegen. Er ist weitaus länger als der Hinterleib, schlank konisch zugespitzt und von oben betrachtet nicht dreieckig, da seine Seiten nicht allmählich in die Spitze übergehen, sondern hinter der breiten Basis plötzlich stark eingezogen werden, so daß er sich plötzlich verjüngt. Im Profile ist er bei den $O$ Exemplaren etwas verschieden geformt, aber bei allen nur schwach ventral umgebogen. Beim $\widehat{\jmath}$ ist das basale Doppelsegment so lang w:e das dritte und vierte Tergit zusammen, je cines von diesen aber nur $2 / 3$ des fünften lang.

\section{Campylocera angustigenis n. sp.}

2 우 aus Süd-Afrika, Natal, Malvern, Mai (leg. Marshall) u. aus WestAfrika, Sierra-Leone, Sherbro, Jänner (leg. Dr. Hunter) im Brit. Museum London. 
Mit oculata leicht zu verwechseln, aber durch folgendes sicher verschieden. Das Gesicht ist unter den Fühlern deutlich schmäler als ein Auge und die Wangen nur linear. Die Stirn tritt nur wenig, nur $1 / 4$ des wagerechten Augendurchmessers vor die Augen vor. Auch die Backen sind noch weit nicdriger und nur einen geringen Bruchteil eines Auges hoch.

Alles übrige wie bei der genannten Art. Auch bei C. angustigenis können Schienen und Füße verdunkelt sein, manchmal auch der Ovipositor.

\section{Campylocera latigenis n: $\mathrm{sp}$.}

1 ơ aus N. Kamerun, Joh. Albrechtshöhe, leg. Conradt, in der Sammlung B. Liohtwardt.

Das Gesicht ist unter den Fühlern doppelt so breit wie ein Auge, die Wangen in der Mitte ungefähr doppelt so breit wie das dritte Fühlerglied; die Backen über ein Drittel eines Auges hoch. Die Stirn tritt an den Fühlern mehr als den halben Augendurchmesser vor die Augen vor.

Alles übrige wie bei $C$. oculata $\mathrm{m}$.

Körper $11 \mathrm{~mm}$, Flügel $10 \mathrm{~mm}$ lang.

\section{Campylocera ferruginea Macquart.}

Diptères exot., Vol. $2 / 3$ p. 220, T. 30 Fig. 1 (1843). - Bezzi, Bull. Soc. Ent. Ital. V. 39 p. 133 (1908).

1 q aus Koren, Ost-Afrika (Coll. Bezzi) - Senegal (Macquart).

Gleicht mit folgenden Unterschieden $\operatorname{der} C$. oculata. Die Frontorbitalborste ist deutlicher entwickelt, nach vorne und außen gebogen. Die Wangen sind deutlich schmäler als das dritte Fühlerglied.

Der Ovipositor ist länger ais der Hinterleib, aber viel plumper als bei oculata, hinter der breiten Wurzel zusammengezogen und dann bis zur stumpfen Spitze hin fast gleichbreit, nicht schlank kegelig geformt. Von der Seite betrachtet ist er stumpf konisch, ventral nicht e ngebogen.

Rückenstriemung deutlich sichtbar, rotbraun: zwei Mittellinien und zwei breitere, an der Quernaht unterbrochene Seitenstriemen. Der Kopf, der Leib und die Beine sind rotgelb.

Flügel graulich hyalin mit gelben Adern und der Nervatur von C. nigriventris (Fig. 5).

Körper mit Ovipositor $6 \mathrm{~mm}$, Flügel $5 \mathrm{~mm}$ lang.

Macquart sagt zwar von seiner Art „3. Fühlerglied doppelt so lang wie das zweite", während hier beide gleich lang sind, doch ist diese Angabe deshalb nicht so genau zu nelımen, weil das 3 . Fühlerglied an Unterrande gemessen weitaus länger als das 2. ist und Macquart nic ht sagt, wo er beide Fühlerglieder maß. Ich schließe mich daher Bezzis Determination an. 


\section{Campylocera maculifer n. sp.}

1 ơ aus Süd - Afrika, Natal, Estoourt, Sept.-Oot. (leg. Marshall) im Brit. Museum London.

Mit folgenden Unterschieden gilt im übrigen die Beschreibung von nigriventris. Stirn vorn viel breiter als ein Auge, $8 / 5 \mathrm{mal}$ so breit ,am Scheitel etwas verengt, im Prcfile etwas mehr als $1 / 3$ des wagerechten Augendurchmessers vortretend. Backen etwa $1 / 6$ eines Auges boch. Die Wangen haben in der Mitte die Breite des dritten Fühlergliedes. Klypeus fast doppelt so breit wie eine Wange. Die Fühlergruben enden etwas oberhalb des Mundrandes. Drittes Fühlerglied am Oberrande gemessen so lang wie das zweite, an der Spitze breit abgerundet, nicht verjüngt. Arista etwas vor der Mitte inseriert, nackt, lang und dünn.

Thoraxrücken und Oberseite des Schildes nur kurz und schütter schwarz behaart.

Kopf rotgelb, teilweise verdunkelt. Dunkelbraun sind: das Scheiteldreieck, die Ränder der Fïhlergruben und des Mundes, das Praelabrum und ein glänzender Fleck unterhalb der Augen auf den Backen. Rotbraun sind zwei Längsstreifen, die an den Seiten des Cerebrales bis auf den unteren Hinterkopf herablaufen und je ein Fleck seitlich am oberen Hinterkopf. Fühler und Taster gelbrot.

Thorax und Schild, wie der vorgequollene untere Hinterkopf heller gelb, der Rücken aber hell rotbraun, mit Ausnahme der ab. stechenden Schulterbeulen. Schild oben an der Wurzel mit einem dunkelbraunen Querfleck. Die Mesopleuren zeigen ein breites, scharf abgesetztes schwarzbraunes Querband in der Mitte. Gleichfarbig sind dic Seiten des Metanotums, das Postscutellum und die Hypopleuren, sowie der ganze Hinterleib.

Hüfte hellgelb, Schenkel pechschwarz, Knie breit gelbrot, Schienen rotbraun, deren Spitzen und die Füße rot. Dic Haarborsten an der Unterseite der Schenkel sind schwach und kurz. An den Hinterschenkeln oben vor der Spitze nur einige Borsten.

Flügel graulich glashell, jenseits der hinteren Querader bis zur Spitze gesättigter grau. Die in diesem Apikalfleck gelegenen Enden der Costa, der Radialis mit ihrem Aderrudiment und der Cubitalis sind ebenso wie beide Queradern schmal dunkler gesäumt. Im übrigen gleicht die Aderung der von $C$. nigriventris.

\section{Hypotyphla caudata n. sp. (Fig. 7).}

1 o aus West-Afrika, Ashanti, Obuasi (leg. Dr. Graham) im Brit. Museum London.

Stirn oben erheblich schmäler als ein Auge, vorn so breit wie eines. Die Augenränder divergieren dann noch weiter auf das Gesicht hinab, ohne einen Winkel zu bilden. Stirn oben etwas konkav, an Scheitelrande schwach erhaben, mit stumpfem, glänzendem Dreieck ohne Ozellen. Stirnbehaarung sehwach. Orbitalborsten sehr klein. 
Innere Scheitelborsten lang und stark, äußerc kleiner. Postvertikale lang, wenn auch dünn. Im Profil treten die Stirn etwa $1 / 3$ des Auges, die Wangen um die halbe Breite des dritten Fühlergliedes vor die Augen vor; Klypeus geradlinig. Packen etwas niedriger als $1 / 3$ eines Auges. Fühler und deren Gruben solang wie das Gesicht. Drittes Fühlerglied so lang wie das zweite, abgerundet rechteckig, zweimal so lang wie breit, jenseits der Arista sehr schwach konkav, am Ende breit abgerundet. Arista lang, dünn, nackt. Taster lang und breit.

Thoraxrücken und Schild zerstreut, aber länger schwarz behaart. Schildchen mit vier langen schwarzen Borsten. Hinterleib von fast zylindrischer Gestalt. Das basale Doppelsegment ist doppelt so lang wie hinten breit, die noch sichtbaren Tergite 3 bis 5 kurz und von gleicher Länge. Der Ovipositor ist doppelt so lang wie der ganze Hinterleib, sehr stark ventral eingebogen, hinter dem ersten Drittel plötzlicher, dann aber allmählich sich verjüngènd. Abdomen und Ovipositor wie der Thorax behaart.

Alle Schenkel sind ventral mit längeren und kürzeren Borstenhaaren gewimpert und an der Spitze zweizeilig mit 5-8 kurzen, dornartigen Borsten besetzt.

Das ganze Tier ist glänzend rotgelb gefärbt. Stirnstrieme matt. Hinterschienen und Füße etwas dunkler. Rückenstriemung angedeutet.

Wie bei $H$. Loewi Hend. ist auch hier die Cubitalis an der Wurzel beborstet. Flügel graulich hyalin mit braunen Adern. Abbildung Fig. 7. Braun sind die Subkostalzelle, die Spitze der Marginalzelle und schmale Säume der Kosta zwischen 2. und 3. Längsader, der Spitze der letzteren, der beiden Queradern, der Radialisgabel und sehr zarte der Posticalis. Die Kosta endet etwas unterhalb der Kubitalismündung. Radialis mit Aderanhang. Die Querader der Analzelle ist spitzwinklig in diese Zelle hineingedrückt.

Schwingerkopf bräunlich.

Körper etwa $11 \mathrm{~mm}$, Flügel $10 \mathrm{~mm}$ lang.

\section{Tabelle der Tephritopyrgota-Arten.}

Radialis mit Aderanhang. Stirn am Scheitel so breit wie ein Auge T. vesicatoria $)^{\mathbf{1}}$ Hend.

- Radialis ohne Anhang

1. Arista griffelartig kurz und dick. Stirn doppelt so breit wie ein Auge

- Arista lang und dünn

T. stylata ${ }^{1}$ ) Hend.

2. Sirn höchstens z.weinal so breit wic ein Auge. Schild mit vier starken Randbortsen

- Stirn mehr als dreimal so breit wie ein Auge. Schild hinten ohne Borsten

1) Res. scient. voyage Alluaud et Jeannel en Afr.-Orient. 
3. Fühlergruben die Hälfte des Gesichtes lang. Stirn eben Gruben $2 / 3$ des Gesichtes lang. Stirn konkav, im Profil spitzkegelig um Augenlänge vorspringend (Fig. 9).

T. tipuloides n. sp.

4. Basales Doppelsegment des Hinterleibes größer als $1 / 2$ desselben. Stirn gut dreimal so breit wie ein Auge. T. tephritoides n. sp. - Kürzer als der halbe Hinterleib. Stirn viermal so breit wie ein Auge

T. Muiri n. sp.

5. Schenkel und Hinterleib samt Ovipositor glänzend pechschwarz 6 . - nur teilweise und nie zugleich schwarz

6. Stirn um den wagerechten Augendurchmesser vortretend. Backen mehr als $1 / 2$ des Auges hoch. Größere Art. T. belzebuth n. sp.

- Stirn weniger als ein Auge vorstehend. Backen höchstens $1 / 3$ eines Auges hoch. Kleinere Art.

$T$. carbonarian. sp.

7. Schildchen oben außer den Randborsten nackt. Stirn spitzkegelig um Augendurchmesser vorspringend. Kleine, schlanke Art

- Schildchen behaart

T. tenuis n. sp.

8.

8. Rauh und lang behaarte Art. Im Flügel herrscht das Braun den kleinen hellen Punkten gegenüber vor. T. hirsuta n. sp.

- Spärlicher und kurz behaarte Art. Im Flügel herrschen die hellen Stellen weitaus vor T. passerina n. sp.

\section{Tephritopyrgota Muiri n. sp.}

1 ㅇ aus Süd-Afrika, Durban (leg. Muir) im Zool. Museum Cambridge.

Stirn viermal so breit wie ein Auge, sonst genau wie bei tephritoides m. beschrieben, der sie bis auf folgende Unterschiede gleicht. Die Stirn tritt um die Augenlänge vor; da aber die Profillinien der Stirn und des zurückweichenden Gesichtes gerade und nicht wie bei tipuloides konkave Linien sind, ist der Stirnwinkel viel weniger spitz. Backen fast $1 / 2$ eines Auges hoch, Wangen in der Mitte $1 / 3$ eines Auges lang. Arista wie nackt.

Das basale Doppelsegment des Hinterleibes ist weitaus kürzer als der halbe Leib, die folgenden vier Tergite sind fast von gleicher Länge. Der Ovipositor ist an der Wurzel schmäler, erscheint also schlanker als bei tephritoides.

Die Kopf- und Körperfärbung ist sonst genau dieselbe wie bei tipuloides beschrieben. Fühler und Taster jedoch dunkler rotbraun. Unter dem Auge auf den Backen eine dunkelbraune, lotrechte Strieme, die bei beiden vorhergehenden Arten fehlt. Thoraxrücken deutlich zart weißlich bereift. Schild in der Mitte und an den Seiten braun, hinten ohne Borsten (auch ohne Narben), oben dicht kurz geschoren behaart. - Beine wie bei tipuloides, aber etwas kürzer.

Flügel in der Zeichnung wie bei der genannten Art, nur fehlen der helle Fleck am Ende des Submarginalzelle und die Flecke in der Nähe des 
Flügelhinterrandes. Der letzte Discoidalisabschnitt ist nur etwas länger als der vorletzte, bei tipuloides aber doppelt so lang. Schwinger gelb.

Körper mit Ovipositor $12 \mathrm{~mm}$, Flügel $9 \mathrm{~mm}$ lang.

Tephritopyrgota tipuloides n. sp. (Fig. 8 u. 9).

1 q aus S.-Afrika, Transvaal (leg. Chomley) im Brit. Mus. London.

Stirn sehr breit, gut dreimal so breit wie ein Auge, am Scheite] kaum verengt. Die Augenränder der: Stirn und des Gesichtęs bilden zusammen gerade und parallele Linien. Scheitelkante erhaben. Stirn deutlich konkav. Beborstung nicht mehr genau erkennbar. Die Behaarung des ganzen Tieres, auch des

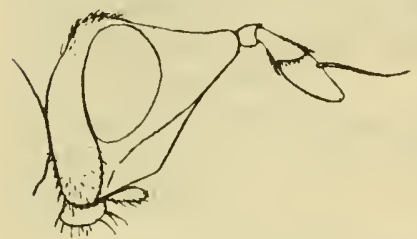

9. Schildes, ist kurz und schütter, schwarz. Die Stirn tritt im Profil um den wagerechten Augendurchmesser in Form eines sehr spitzen Kegels vor die Augen vor. Das Gesicht weicht dann nach unten in konkaver Linie stark zurück. Backen fast die Hälfte eines Auges hoch. Wangen und Klypeus wie bei T. tephritoides. Die Fühlergruben und Fühler sind aber $2 / 3$ des Gesichts lang. Drittes Fühlerglied länger als das zweite, hinter der Arista plötzlich zur Spitze hin verjüngt, am Ende abgerundet. Arista so lang wie die Fühler, zweigliedrig. Das Endglied an der Wurzel schwach spindelig verdickt, am langen dünnen Ende sehr kurz, aber dicht pubesziert. Taster kurz, verbreitert. Rüssel klein.

Hinterleib und Ovipositor wie bei T. tephritoides, nur sind die Tergite 3-5 fast gleich lang, das sechste etwas länger.

Kopf rostgelb. Stirn oben am Scheitel mit einem rundlicheri schwarzen Fleck und mit zwei dunkelbraunen Mittellängsstriemen, die sich nach vorn hin spitzig verjüngen und schwach konvergieren. Zwischen Fühlerwurzeln und Auge ein breiter brauner Schillerfleck.

Auf dem Hinterkopfe laufen vom Scheitelrande gegen den Hals zu konvergierend vier dunkelbraune Striemen, die oben breit und unten spitzig sind. Die zwei mittleren liegen auf dem Cerebrale und sind unten abgekürzt, die zwei äußeren begrenzen das Cerebrale außen. Auf dem Gesichte sieht man zwei parallele schwarze Linien von den Fühlern bis zum Mundrande. Fühler, Taster und Rüssel rot.

Thorax und Hinterleib rostgelb. Thoraxrücken mit drei breiten schwarzbraunen Längsstriemen, die nur schmal getrennt und hinten gegen das Schildchen verjüngt sind. Die zwei seitlichen sind vorn etwas abgekürzt, die mittlere tritt auch auf das Schildchen über. Wie bei T. tephritoides kann ich auch hier nicht genau sagen, ob das Schildchell am Rande Borsten getragen hat oder ob es umbeborstet ist. Ich vermute aber letzteres. Die Pleuren sind unter der Noto-; über der 
Sternopleuralnaht gebräunt, ebenso die Brust, der Prothorax und das Metanotum.

Die Beine sind auffällig lang und schlank, unbeborstet. Hinterschienen im Basaldrittel verdünnt und etwas abgebogen.

Flügel graulich hyalin mit bräunlich grauer Zeichnung in der Spitzenhälfte nach Figur 8 . Kosta bis zur Discoidalismündung. Radialis ohne Anhang.

Schwinger rostgelb.

Körper mit Ovipositor $10 \mathrm{~mm}$, Flügel $9 \mathrm{~mm}$ lang.

Tephritopyrgota tephritoides n. sp. (Fig. 10).

ㅇ aus Süd-Afrika, Deelfontain (leg. Col. Sloggett) im Brit. Mus. London.

Stirn sehr breit, mehr als dreimal so breit wie ein Auge, amScheitel etwas verengt. Die Augenränder der Stirn und des Gesichtes bilden zusammen gerade, nach unten hin schwach divergierende Linien. Scheitelkante erhaben, wenn auch nicht wulstig vortretend. Stirn ziemlich eben, mit einer vom Scheitel her nach vorn vordringenden Medianlinie, die etwas leistig erhöht erscheint. Die schwarze Beharung des ganzen Körpers von Stirn, Rücken, Schild und Hinterleib ist kurz und schütter. Die Stirn tritt an den Fühlern $4 / 5$ des wagerechten Augendurchmessers spitzig vor die Augen vor. Das Gesicht weicht dann nach unten geradlinig zurück. Backen $2 / 5$ eines Auges hoch. Wangen die Hälfte des wagerechten Augendurchmessers breit. Klypeus kaum so breit wie eine Wange, parallelrandig, Fühlergruben nur die Hälfte des Gesichtes lang; ebensolang die Fühler. Das kurzelliptische dritte Fühlerglied ist etwas länger als das zweite, am Oberrande gemessen. Arista zweigliedrig, medial, lang, dünn, äußerst kurz pubesziert. Taster und Rüssel kurz, erstere verbreitert.

Hinterleib gegen die Wurzel hin allmählich verschmälert; das basale Doppelsegment ist so lang wie die vier folgenden, an Größe nach hinten abnehmenden Ringe zusammen genommen. Der Ovipositor ist so lang wie der halbe Hinterleib, von oben gesehen dreieckig und am Ende mittelmäßig ventral eingebogen.

Kopf rostgelb; Stirnstrieme schwach glänzend. Scheitelfleck braun. Fühler und Taster rot, drittes Fühlerglied schwarz. Gesichtsleisten fein braun gerandet.

Thorax und Schild hellgelb. Pleuren an der Sternopleuralnaht und an der Brust braun gefleckt. Auf dem Rücken ist ein hinten abgekürzter Längsstreifen in der Mitte und seitlich davon je eine in zwei isolierte Flecken vor und hinter der Quernaht, wovon der vordere eiförmig ist, aufgelöste Strieme, sowie das Metanotum rotbraun.

Hinterleib und Beine rostfarbig. Letztere lang, schlank und unbeborstet.

Im Flügel reicht die Kosta deutlich bis zur Discoidalismündung. Radialis mit Aderrudiment. Die Grundfarbe des Flügels ist hellbraun und wird durch weißlich schimmernde und dunkler braune Flecke, wie die Abbildung 10 zeigt, unterbrochen. 
Schwinger rostfarben.

Körper mit Ovipositor $11 \mathrm{~mm}$, Flügel 10,5 mm lang.

\section{Tephritopyrgota passerina n. sp.}

4 ㅇ aus Süd-Afrika, Nyasaland, Mt. Mlanje, Dezember. Ent.Res.Comm.

Stirn $1 \frac{1}{2}$ mal so breit wie ein Auge, wie das Gesicht parallelrandig. Scheitel ohne Wulst. Stirn eben. Kopfborsten kräftig: innere Vertik., Postvertik., Ozellare und ein Paar Orbitale. Stirn und Thorax sonst ziemlich kurz und schütter behaart. Alle Borsten und Haare schwarz. Die Stirn tritt an den Fühlern deutlich weniger als der horizontale Augendurchmesser beträgt, vor die Augen vor. Das Gesicht weicht nach unten in gebrochener Linie zurück. Die Fühlergruben sind etwas länger als die Hälfte des Gesichtes. Klypeus ungefähr von Wangenbreite. Backen 1/2 des Auges hoch. Drittes Füblerglied eiförmig zugespitzt, oben so lang wie das zweite Glied. Arista lang und dünn, fast nackt. Taster und Rüssel relativ klein und kurz. Rücken abgerundet quadratisch. Schild $1 / 3$ desselben lang, etwas behaart und mit vier starken Randborsten. Thoraxbeborstung kräftig.

Basales Doppelsegment des Abdomens kürzer als die Hälfte desselben. 3.-6. Tergit allmählich kürzer werdend. Ovipositor etwas länger als $1 / 2$ des Abdomens, konisch, ventral eingebogen, von oben besehen dreieckig.

Kopf braungelb. Stirn matt dunkelbraun, ein Dreieck vor dem Scheitel, dieser und das Cerebrale gelb. Darauf drei schwarze Flecke an den Borstenwurzeln nebeneinander. Cerebrale außen braun gesäumt. Die vorn aufsteigenden Peristomalien schwarz. Fühler und Taster rotbraun.

Thorax braungelb, vorherrschend dunkelbraun gefleckt und bandiert. Auch das Schild mit solchem Mittelfleck. Rücken mit zwei genäherten durchlaufenden Median- und zwei breiteren und vorn verkürzten, unterbrochenen Seitenstriemen. Hinterleib rostfarben, teilweise verdunkelt, noch am stärksten vom ganzen Leibe behaart. Hüften und Beine braungelb. In verschiedenen Grade gebräunt sind die Schenkelspitzen, die Schienen und Füße.

Radialis weniger gebogen als in Fig. 10 bei tephritoides und ohne Aderrudiment. Die hellen Flecke sind größer und weniger zahlreich, die Subkosta mündet deutlich jenseits der kleinen Querader.

Körper und Flügel $8 \mathrm{~mm}$ lang.

\section{Tephritopyrgota belzebuth $\mathrm{n}$. sp.}

$1 \delta^{\tau}$ ans Süd-Afrika, Nyasaland, Mt. Mlanje. Dezember. Ent. Res. Comm.

Stirn doppelt so breit wie ein Auge, parallel. Die Stirne tritt uin den wagerechten Augendurchmesser vor. Fühlergruben $1 / 2$ des Gesichtes lang. Klypeus schmäler als eine Wange. Backen $2 / 3$ eines Auges hoch. Drittes Fühlerglied kürzer als das zweite, am Ende verjüngt, ciförmig. Arista dünn, nur so lang wie die Fühler, wic nackt. Schild unbehaart, vierborstig, dazwischen noch zwei kurze Härchen. 
- 5. Abdominaltergit fast so lang wie das 3. und 4. zusammen. Schenkel, besonders die vorderen verdickt. Beine sehr kräftig.

Dunkler als T. passerina gefärbt. Backengruben und Fühler dunkelrotbraun. Auch der Längskiel des Gesichtes schwarz. Hinterleib und die Schenkel mit Ausnahme der Spitze pechschwarz.

Alles übrige wie bei $T$. passerina angegeben.

Körper und Flügel $10 \mathrm{~mm}$ lang.

\section{Tephritopyrgota carbonaria n. sp.}

1 o aus Süd-Afrika, Nyasaland, Mt. Mlanje. Dezember. Ent. Res. Comm.

Auch diese Art ist der T. passerina sehr ähnlich und durch folgendes verschieden. Das Cerebralc ist mit Ausnahme eines helleren Längsfleckes ganz schwarzbraun. Das dritte Fühlerglied ist kürzer als das zweite, die Borste nur von Fühlerlänge. Die Färbung des ganzen Tieres ist dieselbe wie bei $T$. belzebuth, also im allgemeinen viel dunkler, vorherrschend pechbraun und schwarz. Hinterleib samt Ovipositor schwarz. Letzterer stumpfer als bei passerina. Schild außer den vier Borsten nicht behaart. Schwinger hellgelb. Schenkelringe rostgelb. Füße rotbraun. Die Endabschnitte der Adern 2-4 sind weniger gebogen als bei den zwei verglichenen Arten.

Körper und Flügel $6 \mathrm{~mm}$ lang.

\section{Tephritopyrgota hirsuta n. sp.}

\section{1 ㅇ ans Süd-Afrika, Bothaville, Dr. Branns. Meine S.}

Diese Art fällt nicht nur durch die Länge der Beborstung, sondern auch durch die Dichte und Rauhigkeit der Behaarung auf. So sind die Stirn, das zweite Fühlerglied, die Taster und die ganzen Beine besonders auffallend behaart und beborstet. - Stirn vorn etwas breiter, am Scheitel etwas schmäler als die doppelte Augenbreite; sie tritt $2 / 3$ des wagerechten Augendurchmessers vor. Gesicht zuerst fast lotrecht, unten dann schräg abfallend. Backen $1 / 2$ eines Auges hoch. Fühlergruben $3 / 5$ des Gesichtes lang, so breit wie die Wangen. Drittes Fühlerglied kurz eiförmig zugespitzt, kürzer als das zweite. Arista lang, dünn, wie nackt. - Thoraxrücken breiter als lang. 1+3 Supraalare, zwei Dorsocentrale. Schild außer den 4 Randborsten nur noch mit zwei Härchen.

Beine und Füße fast zottig behaart. Alle Schenkel unten reihig lang beborstet. - Das basale Doppelsegment des Abdomens ist kürzer als $1 / 2$ desselben; das 5 . Tergit kürzer als das dritte und vierte zusammen.

Körperfärbung wie bei $T$. passerina angegeben, nur sind die Schenkel gesättigter gefärbt. - Flügel braun, mit wenigen kleinen, isolierten und weit von einander entfernten hellen Punkten. Kosta, 1. und 2. Längsader sowie die Queradern dunkel gesäumt. Radialis ohne Anhang. Letzter Discoidalisabschnitt wenig gebogen, dünn und hell; die Kosta reicht aber deutlich bis zu seiner Mündung.

Körper und Flügel $8 \mathrm{~mm}$ lang. 


\section{Tephritopyrgota tenuis $\mathrm{n}$. sp.}

1 q aus Süd-Afrika, Bothaville, Dr. Brauns. Meine S.

Kleine und schlanke Art. - Stirn $11 / 2$ mal so breit wie ein Auge, wie das Gesicht parallelrandig, im Profil spitzkegelig, mehr als der wagerechte Augendurchmesser beträgt, vorspringend. Gesicht stark zurïckweichend. Fühlergruben kaum $1 / 2$ des Gesichtes lang, so breit wie die Wangen. Backen etwa $1 / 2$ eines Auges hoch. Drittes Fühlerglied so lang wie das zweite, länglich elliptisch, oben gerade, am Ende deutlich verjüngt. Arista so lang wie die Fühler, dünn, nackt.

Thoraxrücken breiter als lang. Schild $1 / 3$ des Rückens lang, nackt, vierborstig. - Hinterleib und alles übrige wie bei $T$. passerina beschrieben.

Flügel mit kleineren und zahlreicheren hellen Flecken, mehr wie bei tephritoides gezeichnet. Radialis ohne Anhang.

Körper $6,5 \mathrm{~mm}$, Flügel $5 \mathrm{~mm}$ lang.

\section{Apyrgota Marshalli n. sp.}

1 tิ aus Süd-Afrika, Nyasaland; Mt. Mlanje. 21. Nov. Eut. Res. Comm.

Stirn am Scheitel doppelt so breit wie ein Auge, vorn viel brciter, fast geradlinig divergierend auf das Gesicht herablaufend. Scheitelkante wulstig erhaben. Stirn ohne deutliche Borste, oben konkav und nur vorn behaart, im Profil fast um den doppelten horizontalen Augendurchmesser vor die Augen vorstehend. Wangen daher außerordentlich breit, erheblich breiter als der Klypeus, glatt. Stirnwinkel spitzig, Gesicht stark zurückweichend, gerade. Backen mehr als die Hälfte eines Auges hoch. Auge doppelt so hoch wie lang. Die zusammenfließenden Fühlergruben sind etwas kürzer als das Gesicht, ebenso die Fiihler. 2. und 3. Fühlerglied oben gleichlang, 3. dreimal so lang wie in der Mitte breit, gegen die abgerundete Spitze hin verjüngt. Arista lang und dünn, nackt. - Rüssel dick, Taster verbreitert.

Thoraxrücken abgerundet viereckig, etwas länger als breit, sehr spärlich und zart behaart. Zwei kurze Dorsozentrale hinten. Keine Praescutellare und keine Praesuturale. Schild nackt, etwa 1/4 des Rückens lang, mit 4 Borsten, die apikalen gekreuzt. Das basale Doppelsegment des Hinterleibes ist schlank, mehr als doppelt so lang wie binten breit und $1 / 2$ des Abdomens lang. Tergit 3 und 4 gleichlang, 5 länger.

Beine kräftig, sehr kurz und spärlich behaart. Alle Schenkel ventral an der Spitze kurz zweizeilig behaart.

Die ganze Fliege ist lebhaft rotgelb, der Hinterleib mehr rotbraun. Jederseits ein mattschwarzer runder Fleck auf der Stirn oben am Augenrande und ein solcher hinten in der Mitte der Scheitelkante. Stirnstrieme matt. Die unteren Ecken der Fühlergruben schmal glänzend schwarz. Unter dem Auge jederseits ein glänzend pechschwarzer lotrechter Streifen auf den Backen. - Borsten und Behaarung der Fliege schwarz. 
Kosta bis zur Discoidalis kräftig. Flügeladerung ähnlich wie meine Figur 4 von Adapsilia ypsilon darstellt.

Radialis mit starkem Anhang. Der Endabschnitt der Cubitalis ist aber gleichmäßig sanft gebogen und die kleine Querader steht ungefähr oberhalb der Mitte der Discalzelle. - Kostal-, Subkostalund Marginalzelle, sowie deren Adern gelb; sonst ist der Flügel deutlich rauchig getrübt. Dunkel gesäumt sind: die Enden der Längsadern 3-5, alle Queradern, auch die der Wurzelzellen, die Posticalis, die Radialisgabel und Wische in der Submarginal- und Discalzelle. Cubitalis nackt. Schüppchen und Schwinger rostgelb.

Körper und Flügel fast $15 \mathrm{~mm}$ lang.

\section{Apyrgota pictiventris n. $\mathrm{sp}$.}

\section{1 \& aus Ceylon (leg. Green) im Brit. Museum in London.}

Stirn vorn doppelt so breit wie ein Auge, am Scheitel merklich verengt, so lang wie in der Mitte breit, fast eben, am Scheitel mit kaum erhabener Kante, in deren Mitte zwei lange und starke nach vorn gebogene und divergierende Borsten außer den zwei langen inneren und den zwei kurzen äußeren Scheitelborsten stehen. Je eine deutliche, nach vorn gebogene Frontorbitalborste jederseits. Stirnbehaarung mittellang und schwarz, schütter. Ein schwaches Paar Postvertikalborsten. Die Stirnaugenränder biegen im Gesichte divergierend ohne Winkel nach außen. Im Profile tritt die Stirne an den Fühlerwurzeln fast die Hälfte des lotrechten Augendurchmessers vor die Augen vor. Die Wangen sind so breit wie das dritte Fühlerglied, die Backen etwas höher als $1 / 4$ des Auges. Fühler so lang wie das Gesicht. 2. und 3. Glied oben gleichlang; 3 . Glied $21 / 2$ mal so lang wie breit, an der Wurzel wenig breiter, oben gerade, unten konvex, an der Spitze breit abgerundet. Arista lang und dünn, nackt. Taster sehr lang, vorragend, verbreitert.

Thoraxrücken nur spärlich rauh schwarz behaart. Jederseits hinten drei bis vier nach vorn an Größe abnehmende Dorsozentralborsten. Schild nackt, nur mit zwei Borsten am Ende. Das basale Doppelsegment des Abdomens ist hinten schmäler als es lang ist und gegen die Wurzel hin nicht unerheblich verengt. Die noch sichtbaren Tergite 3 bis 6 nehmen nach hinten stark an Länge ab. Ovipositor $3 / 4$ des Hinterleibes lang; von oben gesehen dreieckig, $1 \frac{1}{2}$ mal so lang wie basal breit, etwas ventral eingebogen. Die Behaarung desselben ist rauh, der Hinterleib selbst ist grob beborstet. Alle Schenkel sind ventral zweizeilig gleichmäßig kräftig beborstet; die Länge dieser Borsten nimmt gegen die Spitze hin stark ab. Die Vorderschenkel sind auch posterodorsal reihig lang beborstet.

Der ganze Körper samt Anhängen ist hellgelbrot. Oben auf der matten Stirn liegen an den Augenecken zwei nach vorn und innen gerichtete dunkelbraune Bogenflecke. Das Cerebrale hat oben einen schwarzen, elliptischen Querfleck und schwarze Längslinien an den Grenzen. An den Enden der Fühlergruben und auf den Backen unter den Auge ein glänzend schwarzer Fleck. Fühler etwas dunkler rot, 
namentlieh die Spitze des zweiten Gliedes. - Thoraxrücken mit sehwarzbrauner Längsfleckung; zwei kurze Mittellinien ganz vorn, die sich nur als hellbrauner Schein nach hinten fortsetzen. Je ein größerer eiförmiger Fleck seitlich vor der Quernaht und ein Mäanderstreifen, der aus der Fortsetzung dieses Fleckes hinter der Naht, der Verbindung dieser beiden Striemen in der Schildchenrinne hinten und den kurzen Querstriemen in den Nahtästen nach außen gebildet wird, ebenfalls schwarzbraun. Die Meso- und Sternopleuren sind vorn, die Brust unten schwarz. Dieselbe Farbe haben das Metanotum, ein Fleck auf den Pteropleuren und die breiten Vorderränder der Abdominaltergite, die in der Mitte verschmälert sind und dort eine nach hinten gerichtete dreieckige Spitze zeigen. Von der rotgelben Grundfarbe sind dann also eigentlich nur die Hinterränder an den Tergiten, die in der Mitte fast unterbrochen sind, sowie die Wurzeln des 1. und 2. Segmentes und die Legeröhre.

Füße etwas dunkler, mehr rotbraun. - Flügel graulieh hyalin; die Spitze der Radialis, deren Anhang und Basisgabel braun gesäumt. Schwinger gelb.

Körper und Flügel $8 \mathrm{~mm}$ lang.

\section{Apyrgota unicolor $\mathrm{n}$. sp.}

1 t aus Ceylon (leg. Col. Yerburg) im Brit. Mus. London.

Sie gleicht in den plastischen Merkmalen bis auf folgende Unterschiede sonst ganz der vorigen Art. Die Stirn ist vorn etwas schmäler als die doppelte Augenbreite. Das dritte Fühlerglied ist schlanker und an der Spitze etwas verjüngt.

Der Ovipositor ist so lang wie der Hinterleib, größer und breiter, spärlich behaart. Wurzelwärts an seiner Mündung sieht man jederseits einige dicke schwarze Borsten, deren Spitzen hakenförmig umgebogen sind. Die zweizeiligen Borsten der Schenkel sind so kurz, dass sie fast dornenartig aussehen.

Der ganze Körper ist einfarbig glänzend gelbrot. Stirnstrieme streifenartig abgesetzt mattrot. Drittes Fühlerglied dunkler. Untere Enden der Fühlergruben mit kleinem schwärzliehen Flecke. Backen und Hinterkopf ungefleckt, desgleichen der Thoraxrïeken. - An den Beinen sind die Füße rotbraun.

Am Flügel ist das Ende der Radialis mit dem Aderanhang nicht braun gesäımt.

Körper samt Ovipositor und Flügel $8 \mathrm{~mm}$ lang.

Apyrgota pubiseta $\mathrm{n} . \mathrm{sp}$.

1 of von unbekannter Lokalität, sicher aber aus der indischen Region im Brit. Mus. London.

Stirn oben und vorn gleichbreit, $5 / 3$ eines Auges breit; Augenränder konkav, unter den Fühlern sich etwas nähernd und dann bogig nach außen laufend, einen abgerundeten Winkel bildend. Die Stirn ist der ganzen Länge und Breite nach konkav, am Scheitelrande aufgeworfen, 
fast nackt. Kopfborsten lang. aber dünn: Ein Paar nach außen divergierende Postvertikale, etwas längere, gegeneinander gebogene innere, dann äußere Vertikalborsten und je eine nach vorn und innen gebogene Frontorbitalborste. Im Profil steht die Stirn an den Fühlerwurzeln spitzwinklig etwa $1 / 3$ des wagerechten Augendurchmessers vor die Augen vor. Die Wangen sind in der Mitte kaum so breit wie das dritte Fühlerglied. Die Backen sind $1 / 3$ eines Auges hoch. Fühler sehr lang, so lang wie das Gesicht. Erstes Glied $1 / 2$ des zweiten, dieses $4 / 3$ des dritten lang; alles oben gemessen, denn am Unterrande ist das dritte Glied länger als das zweite. Drittes Glied etwa dreimal so lang wie breit, abgerundet rechteckig, an der Wurzel kaum breiter. Arista länger als das dritte Fühlerglied, dicht kurz und mehr anliegend behaart. Taster von normaler Länge, etwas verbreitert.

Thoraxrücken lang dicht und rauh behaart. Hinten nur ein Dorsozentralborstenpaar. Schild außer den vier langen Randborsten noch mit einigen längeren Haaren auf der Oberseite. Das basale Doppelsegment des Hinterleibes ist etwa $1^{3} /$ mal so lang wie die noch folgenden Tergite $3-6$ zusammen, die stark nach hinten an Größe abnehmen.

Es ist gegen die Wurzel hin stark verengt, so lang wie hinten breit und so lang, wie der, von oben besehen, dreieckige Ovipositor. Dieser ist $1^{1 / 2}$ mal so lang wie breit, dick und ventral nur schwach eingebogen.

Alle Schenkel ventral lang und dicht rauh behaart oder fast beborstet, an der Spitze kurz und zweizeilig geordnet. Die Hinterschenkel tragen dorsal in der Mitte ein Büschel längerer Borsten.

Hinterkopf, die Fühler, die Backengruben unter dem Auge, ein großes Scheiteldreieck, das mit der Spitze fast bis zur Stirnmitte vorreicht, die Stirnseiten, nach vorn breiter werdend ein Fleck vorn an der Stirn pechbraun. Die äußersten Stirnaugenränder und der Rest der Stirn, sowie das Gesicht gelbrot. Der Mundrand und die Fühlerrinnen glänzend schwarz. Die Mitte der gemeinsamen Grube ist aber gelb. Taster rot.

Thorax und Schild dunkel rotbraun. Rückenmitte pechbraun, Seiten und Schultern heller. Hinterleib pechbraun, an der Wurzel und der Spitze des Ovipositors heller, rotbraun. Beine rotbraun, Schenkel pechbraun. Alle Haare und Borsten des ganzen sind rot.

Ain Flügel sind alle Längs- und Queradern hell rotbraun gesäumt, an der Wurzel und am Vorderrande breiter, so daß dort die Säume zusammenfließen und der Flügel von der Kosta bis zur Discoidalis herab rotbraun gefärbt erscheint. Die zwei Wurzelzellen sind in der Mitte glashell. Der Zipfel der Analzelle wird aber von einem breiten Fleck eingeschlossen. Längskerne in der Submarginal- und ersten Hinterrandzelle, sowic deren Spitzen, namentlich die der letzteren hyalin, graulich. Radialis mit kurzem Aderanhang. Erste Hinterrandzelle an der Mündung weit offen. Kleine Querader von der hinteren 
weiter entfernt, aber jenseits der Mitte der Discalzelle. Cubitalis sehr wenig gebogen. Schwinger gelb.

Flügel $12 \mathrm{~mm}$, Körper etwa $13 \mathrm{~mm}$ lang.

\section{Leptopyrgota $n$. gen.}

Eine abweichende, sehr interessante Form, von der mir leider nur ein nicht gut erhaltenes + vorliegt.

Die Augenränder haben am Scheitel und am Gesicht gleichen Abstand von Augenbreite, während sie sich seitlich der Fülilerwurzeln deutlich ausbauchen. Die Stirn ist relativ kurz, konkav, die Scheitelkante ragt empor. Von Kopfborsten sehe ich nur eine schwache, nach innen geneigte Vertikale. Strieme wie nackt. Im Profil steht die Stirn spitzig, aber nur sehr wenig, die linearen Wangen gar nicht vor die Augen vor; Gesicht völlig gerade, etwas zurückweichend. Backen 1/4 eines Auges hoch. Beide Fühlergruben bilden eine gemeinsame, fast die ganze Gesichtsbreite einnehmende Kon. kavität ohne Längsleiste, von der Länge des ganzen Gesichtes. Fühler so lang wie das Gesicht. Erstes und zweites Glied dünn; erstes fast die Hälfte des zweiten lang, dieses oben gemessen merklich länger als das viel breitere dritte. Letzteres parallelrandig, zweimal so lang wie breit, vorn stumpf abgerundet. Arista?

Mundöffnung, Rüssel und Taster relativ klein. Letztere etwas verbreitert.

Thorax fast nackt, sehr kurz und zerstreut behaart und sehr spärlich und schwach beborstet. Von Borsten sehe ich nur eine Supraalare und eine Pteropleurale.

Hinterleib lang und schlank. Basales Doppelsegment stielartig dünn, mehr als doppelt so lang als die folgenden Tergite 3 bis 6 zusammengenommen. Diese nehmen nach hinten zu an Länge ab, an Breite zu. Ovipositor ungefähr so lang wie der ganze Hinterleib, leider verquetscht.

Beine borstenlos, sehr lang und dünn; besonders verlängert sind die zwei hinteren Paare, an denen Schenkel und Schienen an der Wurzel dünn, an Ende etwas keulig verdickt sind.

Am charakteristischsten ist der Flügel gestaltet. Alula rudimentär, Schulterlappen schmal. Die Radialis ist die längste Ader. Sie läuft zunächst knapp unterhalb der Kosta und parallel mit ihr, um sich dann jenseits der hinteren Querader plötzlich in einer flachen Welle herabzubiegen und der Cubitalis sich zu nähern. Nur die Subkosta beborstet. Die Kosta endet an der Discoidalismündung. Die Querader der Analzelle ist S-förmig gebogen und der untere Zipfel dieser Zelle ist sehr kurz und klein.

Typische Art:

Leptopyrgota amplipennis n. sp. (Fig. 11).

1 옹 aus Bolivien, Yungas de la Paz, $1000 \mathrm{~m}$, im Brit. Mus. London.

Kopf und Thorax samt Schild rotgelb, Hinterleib and Beine gelbrot. Stirn glänzend, in dem vertieften Teile, den oberen zwei 
Dritteln pechschwarz. Fühler rotbraun. Unter dem Auge auf den Backen ein brauner Fleck. Rüssel und Taster gelb.

Thoraxrücken zart ockrig bereift, mit folgender dunkelbrauner Zeichnung. Vor der Quernaht in der Mitte ganz vorn eine trapezförmige Längsbinde, die mit der ausgewischten Spitze nach hinten zeigt. Seitlich berühren sie zwei grosse eiförmige Fleske, in deren Verlängerung hinter der Naht zwei sich nach hinten verjüngende Längsstriemen verlaufen. Eine Querbinde vor dem Schilde in der Rinne. Auch die Schildchenseiten, das Metanotum, ein Fleck vor dem Prothorakalstigma, eine lotrechte Querlinie der Meso- und Sternopleuren und ein rundlicher Fleck auf den Pteropleuren sind dunkelbraun.

Hinterleib teilweise verdunkelt.

Flügel graulish hyalin, an der Wurzel und am Vorderrande gelb, Adern gelbrot; ebenso Schüppchen und Schwinger. Apikalfleck schwarzbraun.

Flügel $13 \mathrm{~mm}$, Körper samt Ovipositor ungefähr gleichlang:

\section{Acropyrgota n. gen.}

Diese Gattung steht Toxura Macquart am nächsten, hat wie diese allein ein spitziges drittes Fühlerglied, aber keine Ozellen. Der ganze Körper ist gedrungen, plump, der Hinterleib breit ansitzend, nicht gestielt, der Kopf fast kugelig rund, aufgeblasen.

Die meisten plastischen Merkmale der 'Type sind folgende. Stirn vorn dreimal so breit wie ein Auge, am Scheitel etwas verengt und vor demselben mit einer kleinen und seichten Mulde. Augenränder von vorn gesehen unten divergierend, ohne Winkel. Scheitel abgerundet, allmählich in den gleich von oben an konvexen, blasigen Hinterkopf übergehend. Die Stirn steht im Profil den wagerechten Augendurchmesser vor die Augen vor, keineswegs aber kegelig spitz, sondern mit dem ganzen Gesichte stumpf und massig, ebenfalls wie blasig vorgetrieben. Der Klypeus ist schmäler als eine der breiten Wangen, die etwa schmäler als die Augenlänge sind. Backen $2 / 3$ eines Auges hoch. Die Augen selbst sind elliptisch. Die Fühlergruben sind nur die Hälfte des Gesichtes lang, durch einen hohen Kiel getrennt, der im Profile oberhalb der Gesichtsmitte einen konvexen Vorsprung bildet. Klypeus darunter quergerunzelt, am schwach ausgeschnittenen Mundrande etwas aufgeworfen. Praelabrum von geringer Größe, wenig sichtbar. Fühler deutlich kürzer als das halbe Gesicht, zweites und drittes Glied von gleicher Länge; zweites Glied so lang wie am distalen Ende breit; drittes Glied dreieckig, wenig länger als basal breit, oben gerade, unten konvex, vorn scharf zugespitzt. Arista medial, nackt, lang, gegen die Wurzel hin etwas verdickt. Taster von normaler Länge, verbreitert. Stirn sehr kurz und sehr zerstreut und spärlich behaart. Borsten von mittlerer Stärke. Jederseits eine nach außen und hinten gebogene Frontorbitale. 'Ein Paar längere und gekreuzte 
innere und cin Paar k]cinere äußere Vertikalborsten. Postvertikale klein, nach vorn geneigt und divergierend.

Thoraxrücken ziemlieh lang und rauh behaart; nur ein Paar Dorsozentralborsten. Sehild oben spärlich behaart, am Rande mit sechs Borsten. Hinterleib ungefähr so lang wie der Thorax. Das basale Doppelsegment ist nur $1 / 3$ des Abdomens lang, hinten erheblich breiter als lang, basal etwas verengt. Das vierte Tergit ist etwas kürzer als das dritte oder fünfte.

Flügeladerung nach der Abbildung. Cubitalis nackt. Borstenreihen finden sich an den Vorderschenkeln postero-ventral und -dorsal, stärker an den Hinterschenkeln anteroventral. Beine von proportionaler Länge und Stärke.

Typische Art:

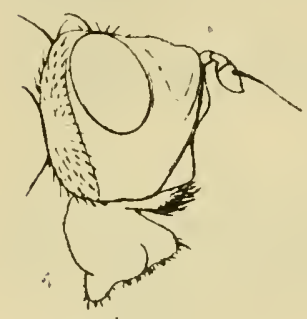

12.
Acropyrgota flavescens $\mathrm{n}$. sp.

(Fig. 12).

Das ganze Tier ist von ziemlich gleichmäßig hell rostgelber Farbe. Am hellsten ist die wachsglänzende Stirn und das Gesicht. Der übrige Körper ist glänzend und unbereift. Flügel hyalin mit gelben Adern. Arista und Sehwinger gelb. Behaarung und Beborstung ïberall schwarz. Schüppchen weißlich.

Körper $12 \mathrm{~mm}$, Flügel $9,5 \mathrm{~mm}$ lang.

Tabelle der Toxura- und Epicerella-Arten.

Flügel dunkelbraun mit zahlreichen weißen Punkten.

Epicerella Macqu. 1

- Fülgel hyalin oder mit breiten braunen Querbinden

Toxura Macqu. 2.

1. Große Art, $19 \mathrm{~mm}$, Schild mit 10-12 langen Randborsten.

Kleinere Art, 10-11 mm. Schild mit vier Randborsten

E. punetulata n. sp.

E. niliacea $\mathrm{n}$. sp.

2. Flügel ungefleckt, gleichmäßig hyalin

- Flügel mit breiten braunen Halbbinden

3. Backen breiter als ein Auge

- Backen etwas niedriger als $1 / 2$ Auge

4. Stirne $1 / 2$ eines Auges breit

- Stirn breiter als ein Auge

T. microps n. sp. T. longipalpis Hend.

T. angustifrons $\mathrm{n}$. sp. T. variegata Hend.

Epicerella miliacea n. sp. (Fig. 13).

7 çㅇํ aus Queensland, Townsville und Burpengary (leg. Dodd u. Bancroft) im Brit. Mus. London.

Stirn vorn $\mathbf{1}^{1} / \mathbf{2}$ mal, am Scheitel so breit wie ein Auge. Die Augenränder bilden unten im Gesicht einen abgerundeten u. sehr stumpfen 
Winkel. Die Scheitelkante ragt nicht wulstig empor, trägt in der Mitte ein kleines Dreieck und auf demselben zwei bis drei deutliche Ozellen. Stirn oben eben, nicht konkav. Jederseits eine kleinere, nach außen gebogene Frontorbital- und äußere Vertikalborste und eine lange und starke aufrechte innere Scheitelborste. Postvertikalpaar schwächer, aber sehr deutlich. Stirnbehaarung kurz und wenig auffallend. Im Profil steht die Stirn an den Fühlerwurzeln fast die Hälfte des wagerechten Augendurchmessers vor die Augen vor, die Wange etwas weniger. Das Klypeusprofil ist von den Fühlerwurzeln bis zum unteren Ende des Gesichtskieles, das buckelig vorspringt, konkav. Die untere Hälfte des Gesichtes fällt von hier bis zum Mundrand nach hinten ab. Backen $7 / 12$ eines Auges hoch. Peristomalien hoch und schief aufsteigend. Die Fühlergruben sind etwa die Hälfte des Gesichtes lang, parallel und zusammen wenig breiter als eine Wange. Fühler etwas kürzer als das halbe Gesicht; drittes Glied so lang wie das zweite, dreieckig zugespitzt, unten konvex. Arista medial, kaum so lang wie die Fühler, etwas spindelig verdickt, an der dünneren Endhälfte sehr kurz und dicht pubeszent. Taster von mittlerer Größe, etwas verbreitert. Augen $3 / 5$ so lang wie hoch; sonst doppelt so hoch wie lang oder noch höher. Taster der ơ kürzer und dünner als be'm

Thorax oben kurz behaart; Schild nackt, vierborstig, manchmal dazwischen jederseits eine schwächere Borste, dann sechsborstig. Hinterleib bein o wie bei millepunctata beschrieben. Ovipositor aber kürzer, nur etwas länger als vorn breit. Beim o* ist das letztsichtbare 5 . Tergit etwas länger als das 3 , oder 4 . allein.

Kopf heller und dunkler gefärbt. Bei zwei Stücken ockergelb mit leuchtenderer matter Stirn. Auf dieser zwei schmal getrennte, durchgehende Parallellängsstreifen, die oben schwarzbraun, unten rot sind. Die Wangen zwischen Fühler und Auge, sowie die Backengruben vorn und hinten mit dunkelbraunem Schillerfleck. Der obere Hinterkopf ist seitlich vom Cerebrale, dieses in der Mitte in zwei breiten Längsstreifen schwarzbraun. Fühler rotbraun, Fühlergruben dunkelbraun, Taster rot. Bei anderen Stücken sind die Stirnstriemen ganz schwarzbraun, die Kopffärbung wird allmählich dunkler, bis bei den dunkelsten Formen Stirn und dasGesicht ganz schwarz erscheinen. Auch die Fühler, weniger die Taster und der untere Hinterkopf nehmen an der Verdunkelung teil.

Thorax heller oder dunkler rötlich braun, oben schwach glänzend und mit vier dunkleren Längsstriemen, die schmal durch heller bereifte Linien getrennt werden. Die zwei mittleren fließen vor und auf dem Schilde in eine Fläche zusammen. Metanotum und Brust heller gefärbt. Behaarung des ganzen Körpers schwarz.

Hinterleib dunkel rotbraun bis pechbraun, bei einem $\widehat{\sigma}$ viel heller gefärbt.

Hüften und Beine hell rotbraun; Schenkel gegen die Spitze hin und Schienen von der Wurzel her verdunkelt. Beim o sind alle Schenkel ventral lang, kräftig und dicht beborstet; die Vorder- und Hinter- 
schenkel auch auf der Oberseite, letztere aber nur vor der Spitze. Die Beborstung der dunkleren Stücke ist kräftiger als die der helleren. Flügel nach Figur 13 auf dunklem, bramem Grunde heller punktiert Diese hellen Punkte sind aber nicht weiß, sondern nur hell gelblichbraun. Adern rotbraun. Radialis mit Anhang. Schwinger hellgelb.

Körper und Flügel $10-11 \mathrm{~mm}$ lang.

\section{Epicerella punctulata n. sp. (Fig. 14).}

1 우 aus W.-Australien (leg. G. Clifton) im Brit. Mus. London.

Stịrn vorn $1 \frac{1}{2}$ mal so breit wie ein Auge, am Scheitel etwas verengt. Augenränder im Gesicht keinen Winkel bildend, gerade. Scheitelkante wulstig vortretend, mit einem Postvertikalborstenpaar, einem äußeren und einem langen und starken inneren Scheitelborstenpaar versehen. Jederseits auch eine sehr deutliche, nach hinten und außen gebogene obere Frontorbitalborste vorhanden. Sonst ist die Stirnbehaarung kurz und mehr anliegend. Stirn schwach konkav, im Profil $3 / 5$ des wagerechten Augendurchmessers vor die Augen vortretend, aber mit einer umso auffälligeren Spitze, als sowohl die Stirn, als auch der Klypeus eine relativ stark konkave Linie bilden. Der Gesichtskiel bildet am unteren Ende der Fühlergruben im Profil einen über den Mundrand hinaus vortretenden Buckel, der im unteren Drittel des Gesichtes liegt. Die Fühlergruben nehmen also nur die zwei oberen Drittel ein, sind parallelrandig und breiter als eine Wange. Diese ist etwa $1 / 3$ des wagerechten, die Backe fast die Hälfte des lotrechten Augendurchmessers breit. Das dritte Fühlerglied ist kaum länger als das 2., oben nach dem geraden Wurzeldrittel, an dem die Arista steht, konkav, unten konvex, am Ende mit scharfer Spitze. Arista gegen die Wurzel hin spindelig verdickt, etwas länger als die Fühler, äußerst kurz pubesziert, Taster lang und breit.

Thoraxrücken lang, dicht und fein behaart, Schild nackt, jederseits am Rande mit 5 bis 6 langen und starken Borsten besetzt.

Das basale Doppelsegment des Hinterleibes ist hinten breiter als lang, verschmälert sich nur allmählich und wenig gegen die Wurzel hin und ist so lang wie die folgenden noch sichtbaren vier Segmente zusammen genommen. Behaarung kurz, nur seitlich am Hinterrande einige Borsten. Länger und viel dichter ist der Ovipositor behaart, der deutlich kürzer als der Hinterleib und von oben betrachtet hinter der Basis nicht zusammengeschnürt ist. Sein Ende ist sanft ventral umgebogen; er ist fast doppelt so lang wie an der Basis breit.

Kopf rotbraun. Scheitelwulst, ein nach unten offener hufeisenförmiger Fleck an Cerebrale, seitlich von diesem je ein größerer Fleck am hinteren Augenrande, die Fühlergruben und der Mundrand schwarzbraun. Stirn matt gelbrot, mit zwei parallelen durchgehenden rotbraunen Längsstreifen in der Mitte, mit denen sich oben vor der Orbitalborste jederseits eine gleichartige schiefe Seitenstrieme vereinigt, die unten fleckenartig auf den Wangen endet. Der schmale Augenrand und die Zwischenräume zwischen den Striemen schimmern goldgelb. Fühler 
dunkelbraun, das dritte Glied schwarzbraun. Taster rotbraun mit dunkler Spitze.

Körperbehaarung schwarz. Thorax rotbraun; Rücken mit zwei durch einen schmalen Zwischenraum getrennten durchgehenden, vor dem Schilde verbreiterten und auf diesem sich vereinigenden schwarzbraunen Längsstriemen. Schmälere Seitenstriemen nur hinter dem schilde deutlich.

Hinterleib und Ovipositor schwarzbraun. Beine lang und kräftig, dunkel rotbraun. Schenkel ventral, die vorderen und hinteren auch dorsal mittelstark beborstet. Hinterschienen an der Basis plötzlich verjüngt, gerade.

Flügel (Figur 14) rauchbraun ${ }^{1}$ ) mit zahlreichen helleren Punkten besetzt. Radialis mit kurzem Anhang, an der Mündung der Cubitalis genähert. Discoidalis vor der kleineren Querader stark bauchig eingedrückt. Flügelwurzel gelb. Schwinger rotgelb.

Körper mit Ovipositor $19 \mathrm{~mm}$, Flügel $17 \mathrm{~mm}$ lang.

Toxura microps n. sp. (Fig. 15).

$2 \sigma^{\pi}+$ alls Australien, Sydney und Moreton Bay (leg. Damel) im Brit. Mus. London.

Kopf und Thorax samt Schild feurig glänzend gelbrot, Hinterleib glänzend schwarz. Augen klein, lotrecht oval. Die Stirn ist fast doppelt so breit wie ein Auge und steht im Profil um Augenlänge vor die Augen vor. Die Strieme ist beinahe matt und zeigt in der Längsmitte vor dem schwarzen Ozellenhöcker einen braunen kurzen Wisch. Behaarung derselben kurz und spärlich; Beborstung: zwei Frontorbitale eng beisammen, ein rudimentäres Ozellarpaar, ein langes inneres und ein kurzes äußeres Vertikalpaar. Fühler deutlich kürzer als das halbe Gesicht, an der Basis rot, drittes Glied dunkel rotbraun, oben gerade, vorn mit scharfer Spitze, fast zweimal so lang wie das zweite. Arista zweigliedrig, nur so lang wie die Fühler, zweites Glied an der Wurzel verdickt, sonst kurz pubesziert. Fühlergruben die Hälfte des Gesichtes lang, durch einen scharfen, niedrigen Kiel getrennt. Gesichtsprofil fast gerade, unter den Gruben bis zum Mundrand nur wenig abschüssig. Taster von normaler Länge, verbreitert, gelb, am Ende breit rotbraun.

Brustseite und Metanotum des Thorax schwarz. Der Rücken und beim ㅇ auch die Oberseite des Abdomens sind auffällig lang und rauh schwarz behaart. Schild am Rande nur mit vier Borsten. Die übrige Beborstung wie bei den anderen Arten.

1) Aber heller als in der Figur zum Ausdruck kommt! 
Beim $0^{\wedge}$ ist das 5 . Tergit verlängert; beim q sieht man die Tergite 3-6 von fast gleicher Länge. Der Ovipositor ist stark ventral eingebogen, ungefähr so lang wic basal breit, wächst ganz allmählich aus dem Hinterleib heraus und verjüngt sich gleichmässig. Wic bei $T$. angustifrons ist auch hier die Spitze mit der Offnung seitlich nach links herausgedreht.

Hüften und Beine pechbraun, Knie und Füße rotbraun.

Flügel schwach graulich hyalin, Subkostalzelle und Wurzel gelblich, Adern meist gelb. Die Subkosta mündet der kleinen Querader gegenüber, diese steht über oder fast über dem letzten Drittel der Discalzelle. Der letzte Abschnitt der Cubitalis ist wenig gebogen und mündet etwas oberhalb der Flügelspitze. Schwinger gelbrot.

Körper und Flügel $5 \mathrm{~mm}$ lang.

\section{Toxura angustifrons $\mathrm{n}$. $\mathrm{sp}$.} London.

2 우 aus S. Queensland, Burpengary (leg. Dr. Bancroft) im Brit. Mraseum

Stirn und Cerebrale gelb; erstere matt, nach vorn hin dunkler, mehr rot, ganz vorn rotbraun. Stirnaugenränder schmal weißschimmernd. Gesicht, Taster, Rüssel und Hinterkopf rotgelb, am hellsten das Epistom. Backengruben etwas verdunkelt. Jederseits des Cerebrales ein brauner Fleck. Fühler schwarz; erstes Glied und die Gruben rotbraun. Die Fühler sind kürzer als die Hälfte des Gesichtes. Das dritte Glied ist so lang wie das zweite und etwas länger als breit, oben nicht konkav, unten konvex, vorn mit deutlicher Spitze. Arista im Wurzeldrittel, nackt, lang und dünn. Die Fühlergruben sind die Hälfte des Gesichtes lang, durch einen scharfen Längskiel von einander getrennt. Unterhalb derselben tritt das Gesicht im Profil konkav vor und fällt dann bis zum Mundrande nach hinten ab. Die Stirn ist nur die Hälfte eines Auges breit, parallelrandig, aber am Scheitel etwas breiter. Backen $1 / 3$ eines Auges hoch. Kopfborsten: Je eine Frontobitale, ein Paar sehr kleine Ozellare und zwei Paar Scheitelborsten. Taster ziemlich lang, verbreitert.

Thorax und Schild glänzend gelb. Rücken etwas ockerig bereift und mit zwei vollständigen inneren und zwei breiteren, an der Naht unterbrochenen äußeren Längsbinden von rotbrauner Farbe, die wenig von dem Gelb freilassen. Oberseite des Schildes gleichfalls rotbraun; desgleichen heller rot die Pleuren unten und vorn am Thorax, sowie das Metanotum. Thorakalbeborstung wie bei den anderen Arten.

Hüften und Schenkel gelbrot; letztere in der Spitzenhälfte verwaschen begrenzt rotbraun.

Hinterleib dunkelbraun, an der Wurzel und an den Hinterrändern der Tergite rot. Ovipositor glänzend schwarz, an der Spitze rotbraun, fast so lang wie der Hinterleib, von oben besehen allmählich sich verjüngend, also dreieckig, nicht ganz zweimal so lang wie basal breit, schwach ventral eingebogen, sehr zart und äußerst kurz behaart, 
während die Randborsten der Tergite ziemlich kräftig sind. Die Tergite 3 bis 5 sind ungefähr gleichlang, das 6 . viel kürzer.

Flügel wie bei Tox. variegata Hend., Gen. Pyrgot. Taf. 1, Fig. 22. Jedoch liegt in der Mitte des ersten braunen Querfleckes ein runder glasheller Fleck am 1. Cubitalabschnitt und sieht man in der ersten Hinterrandzelle zwei hellere Längsflecke unten an der Cubitalis und ein bis zwei solche noch an der Mündung der Zelle. Außerdem erscheint aber auch die zweite und dritte Hinterrandzelle sehr verwaschen heller und dunkler grob gefleckt. Schüppchen und Schwinger gelb.

Körper samt Ovipositor $10 \mathrm{~mm}$, Flügel $8,5 \mathrm{~mm}$ lang.

\section{Abbildungen.}

1. Adapsilia fusca n. sp. Flügel.

2. " luteola Coqu. Kopf.

3. $" \#$. Flügel.

4. $"$ ypsilon n. sp. Flügel.

5. Campylocera nigriventris n. sp.

Flügel.

6. $\quad$ oculata n. sp. Kopf.

7. Hypotyphla caudata n. sp. Flügel.

8. Tephritopyrgota tipuloides n. sp.

Flügel.
9. Tephritopyrgota tipuloides n. sp. Kopf.

10. Tephritopyrgota tephritoides n. sp. Flügel.

11. Leptopyrgota smplipennis n. sp. Flügel.

12. Acrometopa flavescens n. sp. Kopf.

13. Epicerella miliacea n. sp. Flügel.

14. $" \quad$ punctulata n. sp. Flügel.

15. Toxura microps n. sp. Kopf.

Die Abbilc̈ungen vou den Flügeln siehe Taf. I.

\section{Erster Versuch einer Einteilung der exotischen Aphodien in Subgenera and als Anhang einige Neubeschreibungen. $\left.{ }^{1}\right)$}

Von

Adolf Schmidt, Berlin.

I. Aphodien mit sehr langem Schildchen, welches ein Drittel bis ein Fünftel der Flügeldeckenlänge einnimmt.

1) Eine tabellarische Untersoheidung der Subgenera erfolgt in meiner Arbeit im ,Tierreich". 
1. Subgenus Megatelus Reitter.

Verh. Ver. Brünn XXX 1892 p. 172.

Kleine, schwarze Arten, mit gelblichen Flügeldecken; diese sind nur so lang als das Halsschild und haben eine schwarze Makel von verschiedener Ausdehnung.

\section{Arten:}

1. contractus Klug, Symb. Phys. V 1845 t. 42 f. 3 Nordostafrika, Syrien 2. scolytoides H. Lucas, Explor. Algier, Zool. II 1846 p. 259

3. Doriae Harold, Col. Hefte VIII 1871 p. 18

4. brahminus Harold, Col. Hefte XVI 1879 p. 227. Birma scolytiformis Reitter, Verh. Ver. Brünn XXX 1892 p. 179.

5. bostrichoides Harold, Ann. Soc. ent. Fr. (3) VIII 1860 p. 615

Algier

Abessinien

Syrien

Nordindien

6. dimidiatus Roth, Arch. Naturgesch. XVII 1 Tigré, Abessinien, 1851 p. 133 Senegal

2. Subgen. Colobopterus Mulsant.

Hist. nat. Col. Fr. Lamell. 1842 p. 165.

Große und mittelgroße Arten mit tieferliegendem Schildchen, Kopf nur mit Mitteltuberkel, Flügeldecken auf dem Rücken abgeflacht, an der Spitze mehr oder weniger deutlich abgestutzt.

\section{Arten:}

1. scrutator Herbst, Natursyst. Ins. II 1789 Mittel- u. Südeuropa p. 161. Azoren, Kaukasus

var. aequinoctialis Harold, Berliner ent. Zeitschr. V 1861 p. 98.

„submaculatus Mulsant, Hist. Nat. Col. Fr. Lamell 1842 p. 169.

" nigricollis Mulsant, Hist. Nat. Col. Fr. Lamell 1842 p. 169.

" brunnipes Mulsant, Hist. Nat. Col. Fr. Lamell. 1842 p. 169.

" latemarginatus Dalla Torre, Ber. Ver. Nat. Oberösterreichs X 1879 p. 106.

„ angustemarginatus Dalla Torre, Ber. Ver. Nat. Oberösterreichs X 1879 p. 106.

2. subterraneus Linné, Syst. Nat. ed. X 1
1758 p. 348.
Europa, Asien

var. coerulescens Harold, Berlin. ent. Zeitschr. V 1861 p. 103.

"f fuscipennis Mulsant, Hist. Nat. Col. Fr. Lamell. 1842 p. 171.

3. antiquus Faldermann, Mém. prés. Ac. Pétr. Sibirien.

II 1835 p. 367.

4. maculicollis Reiche, Voy. Ferr. et Galin. III Küstenländer Afrikas. 1847 p. 341.

5. indagator Mannerheim, Bull. Soc. Moscou Sibirien. XXII 11849 p. 233.

apicalis Harold, Berlin. ent. Zeitsehr. V Japan, China, Korea, 1861 p. 93 u. 96. Ostsibirien. 




\section{Krolls Buchdruckerei, Berlin S.}

Sebastianstrasse 76 .

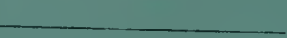




\section{Nenes iber afrikanische Chrysomyza-Arten.}

Von Friedrich Hendel, Wien.

\section{Chrysomyza sericea n. sp.}

1 o aus Abyssinia, Dire-Dana, November, leg. Kovács, im Ungar. Nat.-Museum.

Stirne nur wenig breiter als ein Auge, in der Nitte des Augenrandes mit weißem, halbkreisförmigem Fleckchen, an Vorderrande wie auch die Lunula glänzend pechschwarz, darüber mit einem großjen samtig matten, violettschwarzen Fleck, der sich nach oben verliert, nach vorne mit einer Spitze in der Mitte vordringt. Vor den Ozellen ist die Stirne violett-purpurn, seitlich davon griinblau, überall, wie auch auf dem Thoraxricken und den oberen Pleuren nur mit schönem und lebhattem seidenartig matten Schimmer, ohne Polierglanz wie auf den unteren Pleuren und dem Hinterleibe.

Hinterkopf samt C'erebrale metallisch schwarz, Gesicht am Nundrande erzfarbig, zum größten Teile dicht weililich bestäubt. Die Grenze ist aber nicht geradlinig, sondern dreilappig. Fühler rot, das 3. Glied rotbraun, schlanker, 2 mal so lang wie breit. Arista an der Wurzel rot. Taster schwarzbraun. Stirne oben glatt, ohne die Spur der gewöhnlichen 4 Längswiilste.

Thorax smaragdgriin, mit tiefblauem Schimmer und auf dem Rücken mit purpurnen Längsstriemen, deren Verlauf das große Nadelloch verbirgt. Schild schwärzlich, oben gewölbt. Hinterleib schwarzgriin.

Hüiten und Beine metallisch schwarz. Vorderfïbe ganz schwarz, die 4 linteren gelbrot.

Der Flügel ist wie bei Chrys. demumlute F. geadert, weicht aber dadurch von allen bekannten Arten ab, daf der Kiostalrand von der Müindung der 2. Längsader bis zur Flügelspitze deutlich braun gesäumt ist. Schwinger und Schüppchen gelblichweib. Körper $5 \mathrm{~mm}$, Flügel $4 \mathrm{~mm}$ lang.

\section{Chrysomyza demandata Fab.}

j $0^{\pi}$ o aus Aden hathen auch die Scheitelplatten rot.

\section{Chrysomyza smaragdina Loew.}

$2 \delta^{2}$ o aus $\Lambda$ byssinia, Val Djerrer, November, leg. Kovács im Ungar. Nat.-Nuseum.

Wiener Fntomologische Zeitung, XXXII. Jahrg., Heft VII, VIII u. IX (15. Juli 1913). 


\section{Chrysomyza obscura, n. sp.}

万o aus Mozambique. Samml. Mus. in Cambridge.

Dunklen Exemplaren der Chr. demandata F. ähnlich. Der Thoraxrücken ist aber ungefähr von der Quernaht nach rückwärts samt dem Schilde völlig matt-schwarz und zeigt von hinten besehen 5 noch dunklere Längsstriemen: die mittlere linienartig, die 2 seitlichen breiter und hinten \pm abgekürzt. Auch die Mitte der Mesopleuren ist matt. Schulterbeulen und Notopleuralnaht glänzen. Pleuren blauschwarz, Hinterleib und Kopf glänzend schwarzblau. Kopf an den Fühlern teilweise, an Wangen und Backen deutlich rotbraun. Der Gesichtsrücken ist im Profile nicht winklig gebrochen und oben unter den Fiihlern auch nicht zusammenhängend mit den Fiihlergruben weiß bestäubt, sondern dort nur mit einem kleinen, diinnen, mit der Spitze nach oben gerichteten $\mathrm{V}$ versehen.

Huiften, Schenkel und die ganzen Torderbeine, mit Ausnahme des weißen Metatarsus derselben, schware. Die 4 hinteren Schienen rotbraun, mit schwärzlichen Spitzen. Hinterfuiße gelb, Enden geschwärzt.

Letzter Abschnitt der Cubitalis ganz gerade. Alles tibrige wie bei Chr. demandata F. Körper $5 \mathrm{~mm}$, Flügel $4 \mathrm{~mm}$ lang.

\section{Chrysomyza aenea Fab.}

Ich sah Stücke dieser Art aus Sïd-Afrika, Durban, aus der Samml. Mus. Cambridge. Bisher war diese Art mit Sicherheit noch nicht vom afrikanischen Kontinente bekannt. 


\section{Sonderabdrack aus der „Zeitschrift für wissenschaftliche Insektenbiologìe',}

friiher: "Allgemeine Zeitschrift für Entomologie".

(Bd. IX, [1. Folge Bd. XVIII], 1913, Heft 11, p. 345.)

Selbstverlag des Herausgebers H. Stiche1, Berlin-Schöneberg.

Angituloüdes n. gen. (Dipt.).

Diese Gattung steht Angitula Walker sehr nahe und soll im Vergleiche mit dieser beschrieben werden.

Der Hinterkopf ist noch stärker geschwollen, das Epistom aber niedriger und weit weniger vortretend als bei Angitula, bei der es schildartig die. Mundöffnung ïberragt. Das dritte Fiihlerglied ist elliptisch, zweimal so lang wie breit, oben und unten konvex; die Arista fehlt leider. Bei Angitula ist das dritte Fïhlerglied dreimal so lang wie breit, schlanker, oben und unten fast gerade. Wie bei dieser Gattung ist der Prothorax vorne oben in eine halsartige Rinne ausgezogen, die aber in 4 gegen den Kopf hin gerichtete, gerade Zahnspitzen endet und nicht wie bei Angitula ganzrandig abschliesst.
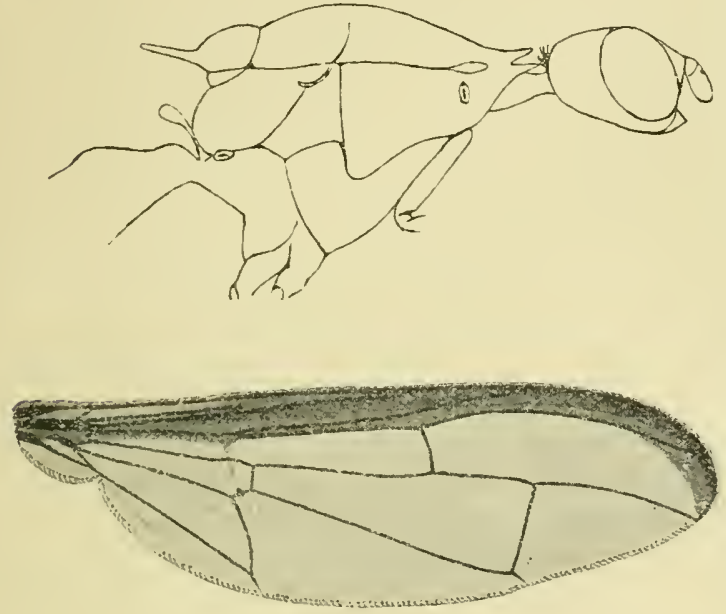
Das konvexe Schildchen trägt hinten ebenfalls 2 gerade, divergierende Spitzen fast von Schildchenlänge. Ebenfalls mit Angitula gemeinschaftlich ist der selur charakteristische Verlauf der Sternopleuralnaht; die Mesopleura dringt von oben spitzwinkelig in die Sternopleura ein.

Auch der Bau des Hinterleibes ist derselbe. Das basale Doppelsegment ist gestielt, trägt dorsal unmittelbar hinter der Wurzel zwei stumpfe Zähnchen, hat in der Mitte eine Abschniirung und ist vor derselben wulstig aufgetrieben. Die darauf folgenden Tergite 3 bis 6 nehmen nach hinten zu an Länge ab; Terg. 6. ist nurkurz und ist schon ventral eingebogen. Das erste Glied des Ovipositors ist schlank trapezförmig, so lang wie das 4. Tergit, von oben her flach zusammengedriickt.

In der Fliggeladerung besteht zwischen den beiden Gattungen ein wesentlicher Unterschied. Bei Angitula liegen Mediastina, Subcosta und die Radialis vor der Gabelung so eng nebeneinander, dass sie kaum unterschieden werden können, während bei Angitulö̈les die Radialis weiter entfernt ist und auch die beiden anderen Adern deutlich erkannt werden können. Hier ist die Radialis kurz, bei Angitula lang. Bei letzterer ist die kleine Querader kurz und stelit vor der Mitte der Discalzelle und die Analzellenspitze ist nur so lang, dass die Analis fast doppelt so lang wie die Analquerader ist. Bei Angitulöides dagegen ist die kleine Querader lang und steht jenseits der Mitte der Discalzelle und die Spitze der Analzelle ist so lang, dass sie beinahe den Fligelhinterrand erreicht. Alles ijbrige wie bei Angitula Walker.

Typische Art: A. Ansteni n. sp. 1 \& von den Salomons-Inseln (leg. Woodford) im Brit. Museum London.

Kopf samt Anhängen, Hüften und Beine rotgelb. Füsse am Ende gebräınt, desgleichen die hinteren Kniespitzen. Der ïbrige Körper schwärzlich stahlblau, zum Teil violett schimmernd, glatt und glänzend, nackt. Bauchhaut rotbraun.

Flïgel bräunlich hyalin mit schwarzbraunem Vorderrandsaume, der in der Kostalzelle heller ist. Schïppchen rudimentär. Schwingerkopf dunkelbraun.

Körper $9 \mathrm{~mm}$, Fliigel $8 \mathrm{~mm}$ lang.

Ich widme diese interessante Form Herrn E. E. Austen in Anerkennung der wertvollen Unterstiitzung meiner Arbeiten, die er mir durch Heraussuchen von Studien-Material aus den reichen Schätzen des British Museum zuteil werden liess. 




\section{Analytische Übersicht iiber die Anastrepha- Arten (Dipt.). \\ Von Friedrich Hendel, Wien.}

Unter Beniitzung der von Prof. Bezzi bekannt gemachten 'T'abelle iibergebe ich hier eine durch elf neue Arten erweiterte Synopsis der Öffentlichkeit. - Die Fliegen haben durch den an Orangen, Kern- und Steinobst. Psidium-Arten und anderen Früchten angerichteten Schaden höchstes ökonomisches Interesse.

Subgenus: Pseudodacus n. slog. Nur eine Frontorbitalborste. Fühler mindestens so lang wie das Gesicht. Die Flügelzeichnung ist braun und besteht nur aus einem zusammenhängenden Kostalsaume von der Wurzel bis zur Flügelspitze und aus je einer isolierten Strieme an der Analis und längs der hinteren Querader (Typus: daciformis Bezzi) .

- Subgen. Anastrepha Schiner s. str. '/wei obere Frontorbitalborsten. Fühler kürzer als dis Gesicht. Die Flügelzeichnung ist gelb und braun scheckig, der Kostalsaum meist unterbrochen und immer sind auljerdem noch $\mathrm{S}$ - oder $\mathrm{V}$-förmige schiefe Querbinden („Bäche“) vorhanden . . . . . . . 2

1. Der Kostalsaum wird unten durch die Radialis scharf al)gegrenzt. Ebenso ist der dunkle Saum der hinteren Querader streifenartig abgesetzt, von gleicher Breite. Hinterleib mit gelben Quersäumen an den Hinterränder'n der Tergite. ()vipositor' etwas länger als der Hinterleib. - Brasilie n, Argent in i en, P'araguay.

A. daciformis Bezzi.

- Der Kostalsaum reicht unten bis an die Kubitalis herab. An der hinteren Querader liegt ein verwaschener, unregelmäßiger bräunlicher Wolkenfleck. Hinterleib schwarzbraun mit gelber Medianbinde. Ovipositor zweimal so lang wie der Hinterleib. - Paraguay.

A. macrura n. sp.

2. Hintere Basalzelle glashell

- Hintere Basalzelle in das Gelbbraun der Flügelwurzel mit eingeschlossen . . . . . . . . . . . 29

3. An die Säumung der hinteren Querader schließjt sich oben eine schiefe, durch die zweite Hinterrandzelle herablaufende Querbinde an, wodurch eine deutlich V-förmige, wenn auch oben oft offene Keichnung entsteht . . . . . . . . 4

- Obige V-förmige /eichnung unvollstïndig durch Fehlen des distalen Schenkels oder mindestens undeutlich 
4. Eine von der zweiten Basalzelle schief nach aufwärts ziehende, ununterbrochene glashelle Bogenbinde miindet gleich hinter der Subkosta oder etwas darunter und ist in der Mitte nicht unterbroclsen . . . . . . . . . . . . . . . 5 Obige glashelle Bogrenbinde ist in der Mitte nehr oder weniger breit unterbrochen und daher in Fleche anfgelöst. . . . 9

5. Die in 4 beschriebene glashelle Bogenbinde erreicht oben die Kosta nicht ganz und verschmälert sich nach oben zu. Ovipositor länger als der Körper. - Brasilien. Tenezuela.

\section{A. integra Juew.}

- Obige glashelle Bogenbinde mündet breit in die Kosta ein . 6

6. Auf dem Thoraxriicken vor dem Schilde und auf jedem der Tergite drei bis fünf je zwei schwarze Flecke. - Paraguay.

A. punctata n. sp.

- Rücken und Hinterleib olne schwarze P'unkttlecke... . †

7. Die $Y$-förmige, in 3 beschriebene braune Binde ist in der ersten Hinterrandzelle geschlossen

- Diese Binde ist oben offen und in zwei getrennte Äste gespalten. - Brasilien.

A. soluta Bezzi.

8. Unmittelbar jenseits der kleinen Querader ist die Submarginalzelle durch eine wellige Biegung der Radialis und einen Aufbug der Kubitalis merklich verengt. Die $Y$-förmige Binde kann oben (neist $q$ ) mit dem Kostalsaume an der Kubitalis \pm verbunden sein. - Mexiko, Brasilien, Iraraguay.

\section{A. parallela Wiedem.}

Submarginalzelle jenseits der kleinen Querader nicht verengt. Kuba, Brasilien, Tenezuela. I'eru, Paraguay.

A. obliqua Macqu. (= munda Schiner).

9. I)ie Binde üher die hintere Querader ist am Hinterrand des Flügels mit jener ïber die kleine Querader laufenden verbunden. Analwisch isoliert. Thorax und Metanotum schwarz gestriemt.
- Peru.
A. lambda n. sp.

- Die Binde iiber die hintere (puerader hinten frei. Dagegen ist der Analwisch mit der Querbinde iiber die kleine Querader verbunden . . . . . . . . . . . 10

10. Die in 3 beschriehene $V$-förmign IBinde hängt oberhalb der Kubitalis mit dem Spitzenrandsamme des Flügels zusammen 11

- Dic V-förmige Binde bleibt am Scheitel durch einen parallelen lyalinen Zwischenraum vom Spitzenrandsaume getrennt . . 15

11. I)as byaline Kostaldreieck jenseits der Subkosta reicht unteu mit der Spitze nur bis an rie Radialis . . . . . . . 14

Wiener Fntomolngische Zeitung, XXXIII. Jehrg., Heft I 11. II (1. Jänner 1914). 
- Der hyaline, trapezörmige Fleck jenseits der Subkostanüudung beriihrt unten die Kubitalis . . . . . . . . . . . 12

12. Fühler so lang wie das (iesicht; drittes Gitied mehr als viermal so lang wie das zweite. Hinterleib hellbraun, schwar\% behaart. Taster gelb, schwal"z behorstet. - J a m a ika, Fl o r i da.

A. Acidusa Walker.

-_ Fïhler kiirzer. Hinterleib und 'Taster hell behaart. . . . 13

13. Subkostaniindung und die Spitze des in 10 erwähnten trapezförmigen hyalinen Fleckes yor der kleinen Querader. - Peru.

A. distans n. sp.

- Subkostamiindung und spitze des hyalinen Kostaltleckes der kleinen Querater gegeniber gełegen. - Bolivia.

A. conjuncta n. sp.

14. Schildspitze und zwei Flacke am .Yetanotum schwarz. - II exiko.

A. tripunctata V. d. Wulp.

- Schild und Metanotum gelb. Las Randmal und der darunterliegende T'eil des Flügets bis zur ('ubitalis schwanzbraun. I'er'u.

A. cryptostrepha n. sp.

15. Kopf-, Thorax- und Beinborsten auch rotgelb . . . . 20

- Borsten dunkelbraun bis schwarz. . . . . . . . 16

16. '/weite und dritte Längsader' mit ähnlicher' Biegung jenseits der' kleinen (Queraler wie in 8 beschrieben. Die Ovipositorlänge verhält sich zur Abdominallänge wie 1: 1-4 (teste Loew). Brasilien.

A. consobrina Loew.

Zweite und dritte Längsader ohne obgenannte Biegungen . 17

17. Taster schwarz. - Peru, Bolivia.

A. nigripalpis n. sp.

- Taster gelb, schwarz oder well behart

18. Taster schwarz behaart. - Brisilien.

A. Ethalea Walker.

- 'Taster gelb behairt

19. Ovipositor länger" als der halbe Hinterleib. Füinftes 'Tergit des o' kiirzer als das dritte und vierte zusimmen genommen. Mexiko, Kuba, Costa-Rica, l'ortoriko, Nicaragua, Neu-Granada, Columbien, Bolivia, Peru, Brasilien, l'araguay, Argentinien.

A. fraterculus Wiedemann. ()vipositor kiirzer als der halbe Ilinterleib. - Brasilien.

A. pseudoparallela Loew.

- Füinftes Tergit des o’ länger als das dritte und vierte zusammen. Ovipositor länger als der ïbrige Hinterleib. - Mexiko.

A. Iudens Loew.

20. 'Toraxrïcken vor them schilde und jedes der T'ergite drei bis fünf mit zwei schwarzbraunen Punktflecken. - Paraguay. 
- Thorax und Hinterleib mupunktiert. - Brasilien.

A. xanthochaeta n. sp.

21. Hie apikale Fligellängsbinde begleitet das Eule der Kubitalis und wird von der Kosta dureh einen lyalinen Saun getrennt. - Nen-Granada.

A. grandis Macqu.

- Die apikale Flïgelbinde begleitet die líostat

22. Die Binde ïber die hintere Querader längt mit dem Kostalsaume des Flïgels nicht zusammen . . . . . . . . 24

- Ist oben mit lem hostalsaume verbunden . . . . . . . 23

23. Die Fliigelquerbinde iiber die hintere Querader ist vorn mit einer schief nach abwärts iiber die kleine Querader zur Postikaliswurzel verlaufenden verbunden. -- Brasilien.

A. hamata Loew.

- In der Wurzelhälfte des Flügels keine schiefe Querbinde.siid-Texas.

A. pallens Coquillett.

24. Ein ununterbrochenes lyalines Bogenband beginnt jenseits der Subkostamiindung und endet in der zweiten Basalzelle. Bolivien.

A. leptozona n. sp.

- Obiges hyalines Band nie ohne Unterbrechung, sondern in Flecke aufgelïst

25. 'Taster pechbraun. - J a m a ika.

A. Ocresia Walker.

- T'aster gelb .

26. Her äußere schenkel der $\mathrm{V}$-förmigen Binde, das ist die schiefe Querbinde durch len letzten Ibschnitt der 1)iskoidalis, fehlt ganz. Thorax und Hinterleib vorherrschend schwarzbraun. Ersterer mit drei gelben Längsstriemen auf' dem Riicken und solchen an der Noto- und Sternopleuralnaht; letzterer mit gelben Hinterrandsäumen am ersten und zweiten 'Tergit und einel' solchen Medianstrieme am dritten bis fünften. - Mrasilien, I'eru.

A. serpentina Wiedemann.

- Der änliere Schenkel der V-förmigen Binde ist wenigstens in del zweiten Hinterrandzelle etwas sichthar.

27. Thoraxrïcken mit zwei schwarzen oder schwarzbraunen Lüngsstriemen. Hinterleib ohne schwarze Querbinden . . . . 28

- 'l'horaxriicken ungestrient. Hinterleih gelb mit drei schwarzen Querbinden. - Hatit?

A. tricincta Loew.

28. Jenseits der' Subkostamiunlung ein hyaliner Fleck. Der gelbe Spitzenrandsaum des Fliigels ist schmal, von ler Breite der Marginalzelle. - Bolivia, Peru.

A. striata Schiner. Der ganze Flïgelvorderrand von der Wmyel bis zur Spitze ist bis herab zur Kullitalis gell). - Bolivia. A. Schineri n. sp.

Wiener Entomologisebe Zeitung, XXXIII. Jahrg., Heft I แ. IJ (1. Jänner 1914). 
29. Der Y-förmige Fleck an der hinteren Querader ist in seinen heiden Schenkeln entwickelt . . . . . . . . 31

- Der äußere Schenkel des Gabelfleckes fehlt . . . . . 30

30. Jenseits der Subkostamündung ein glasheller Fleck. Die braune Binde über die hintere Querader ist isoliert. - Brasilien.

A. bivittata Macqu.

- Der hyaline Fleck nelsen der Subkostamïndung fehlt. Die braune Binde iber die hintere Querader ist teilweise mit dem Braun der Wrurzelhälfte des Fliigels verbunden. - Surin am.

A. atrigona $\mathrm{n} . \mathrm{sp}$.

31. Hinterleib rostgelb und gelh behaart. - Mexiko, Kuba, Brasilien. Venezuela.

A. suspensa Loew.

- Hinterleih braun und schwarz behaart. - Jamaika, Florida.

A. Acidusa Walker. 


Neue amerikanische Dipteren.

2. Beitrag ${ }^{1}$ ).

Von Friedriclı Hendel, Wien.

Mit 16 Textfiguren.

Neodryomyzr nov. gen. (Dryomyz.)

Typus: N. lentiphora n. sp.

Aus der Subfamilie der Dryomyzinae.

Stirne breiter als lang, parallelrandig, doppelt so breit wie ein Auge, sehr flach gewölbt. Scheitelplatten wenig deutlich abgesetzt, dem Auge anliegend, kürzer als die halbe Stirne. Ocellendreieck kaum kürzer. Kopf so breit wie der Thorax, im Profile erheblich höher als lang; der Stirnwinkel ist ein rechter, vorne nicht über die Augen vortretend.

Kopfborsten alle stark und lang: je eine nach oben gehogene obere Frontorbitale, ein Paar weit vorgebogener Ocellarbor'sten zwischen den Punktaugen inseriert. $\ddot{u}$ usere divergierende und

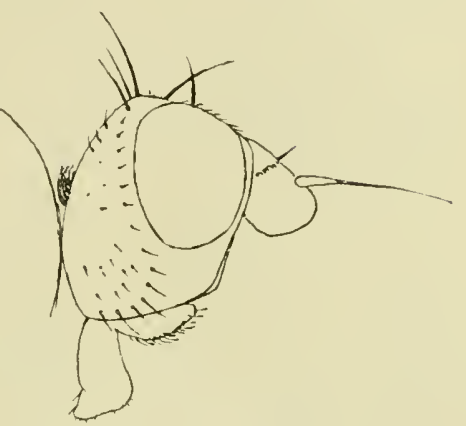

Fig. 1. Kopf. innere konvergierende Vertikale. Postvertikalpaar kräftig, stark divergierend, etwas hinter der Linie der Scheitelborsten stehend. Strieme nur vorne kurz und rauh behaart. Unterer Hinterkopf am Ranrle mit einigen Börstchen. Vibrissen fehlen. Scheitelkante

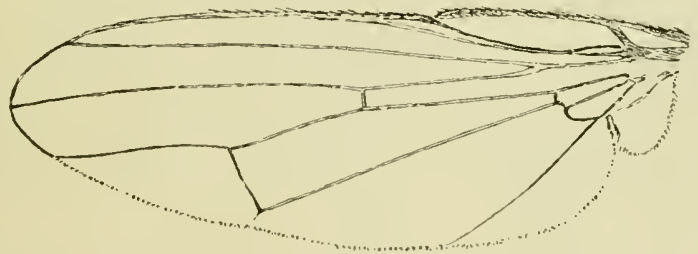

Fig. 2. Flügel.

ahgerundet, unmittelbar vor ihr die Ocellen in einem kleinen Dreieck. Oberer Hinterkopf sanft gewölbt, unterer stärker, unten auch gepolstert. Gesichtsprofil gerarle, am Mundrande nicht winklig, sondern stark abgerundet.

1) 1. Beitrag: Deutsch. Entom. Zeitschr. 1913, 1. 617-636.

Deutsche Entomol. Zeitsehrift 1914. Heft 11. 
Fühlergruben deutlich ausgehöhlt, parallel. Der zwischen ihnen liegende Gesichtsteil schmal, wenig erhöht, ziemlich flach, aulsen kantig. Die Stirnspalte geht flachbogig über die Fühler hinweg, ihre Äste laufen mit geringer Divergenz nach abwärts. Zwischen ihnen und dem Auge Wangen von mittlerer Breite. Lunula sichtbar, aber niedrig.

Fühler etwas geneigt, an den Wurzeln voneinander entfernt, in den Dritteln der Stirubreite und oberhalb der Augenmitte stehend. Erstes Glied kaum sichtbar, zweites kurz, oben mit stark aufgerichteter Borste, drittes grofs, fast kreisrund, oben etwas abgeflacht und vor der Mitte mit einer nackten, zweigliedrigen Borste, deren Wurzelglied dicker ist.

Prälabrum nur von vorne sichtbar, sclrmal und niedrig. Taster streifenförmig, etwas verbreitert, an der Spitze länger behaart. Rüssel von mittlerer Gröfse, mit zurückgeschlagenen Labellen.

Thoraxrücken länger als breit. Quernahtäste gut entwickelt, vor den Seitenmitten, wie bei Dryomyza Dorsozentrale $2+3$, 1 Paar Präscntellare; 1 Humerale, einige Posthumerale, 1 Präsuturale, 2 Notopleurale; 4 Supraalare. - 1 Prothoracale, 2 anfgebogene Sternopleurale. Pleuren oberhalb der Sternopleuralnaht nackt, darunter zottig behaart. Rückenhärchen undeutlich geordnet, zwischen den Dorsozentralen ca. 8 Reihen. Schildchen eiförmig, oben gewölbt, am Rande rauhhaarig and mit 3 Paaren von Borsten, deren apicale gekreuzt sind.

Hinterleib eiförmig, so breit, aber etwas kïrzer als der Thorax. Das basale Doppelsegment ist beim or fast so lang wie der halbe Hinterleib, beim $q$ kürzer. Daranf folgen beim $\sigma^{7}$ noch 3 sichtbare Tergite von fast gleicher Länge, beim o t deren 4. Der Oripositor erimnert an die Bohrfliegen, ist dreigliedrig und hat ein flachgedrücktes konisches Basalglied. Der Hinterleib des $\sigma^{7}$ ist abstehend, fast wollig behaart, der des $q$ nur kurz und zeigt an den Tergithinterrändern längere Borstenhaare. Tergite am Rande ventral umgeschlagen. Sternite nur $1 / 3$ des Bauches breit. Hypopyg kuglig.

Schenkel, besonders die vorderen und hinteren verdickt und beim $\sigma^{7}$ zottig, vornehmlich die vorderen. Diese auch posterodorsal und -ventral mit einer Reihe von Borsten. Hinterschenkel ventral jenseits der Mitte mit starker Borste und anterodorsal mit 1 bis 2 Börstchen. Mittelschienen am Ende mit einem gekrümmten Endsporn. Präapicalbörstchen der Schienen fehlen ganz.

Costa unmittelbar vor der Mediastinamündung unterbrochen. Subcosta nackt. Die Analis erreicht nur als Falte den Hinterrand 
des Flügels. Die Analzelle ist banchig begrenzt, ihre Querader an der Analis stark zur Basis zurückgezogen. Die übrige Nervatur zeigt die Figur.

$$
\text { Neodryomyza lentiplera n. sp. }
$$

4 ơ, $4 q$ aus Chile, P'unta Arenas, 7. Februar. Dresd. Mus. Kopf und Thorax samt Schild rostgelb. Stirnstrieme rot, matt. Drittes Fühlerglied am Oberrande etwas gebräunt. Gesicht. und Backengruben und noch intensiver ein Fleck oberhalb rles Halses auf dem Cerebrale weilsschimmernd. Pleuren mehr gerötet als der Rücken; dieser durch Reif im Glanze geschwächt. Borsten und Haare des ganzen Tieres schwarz.

Hinterleib dunkel rotbraun, gegen die Hinterränder der Tergite zu und am Bauche dunkelbraun.

Beine hell rotbraun. An den Vorder- und Hinterbeinen sind die Schenkel und teilweise auch die Schienen verdunkelt.

Flïgel schwach gelbgrau hyalin mit rotgelben Adern. Schwinger und Schïppchen rostgell).

Körper 6-6,5 $\mathrm{mm}$, Flügel $6,5-7 \mathrm{~mm}$ lang.

\section{Tricomopsis 11. g. (Laurem).}

Typus: T. longicornis $\mathrm{n}$. sp.

Diese Lanxaniinengattung wirl durch die 3 spitzkegligen Gesichtshöcker leicht kenntlich gemacht. Figur 3.

Stirne doppelt so breit wie ein Ange, parallelrandig, breiter als lang, eben. Augenränder neben den Fühlerwurzeln ausgebuchtet. Ocellen in der Nähe der scharfen Scheitelkante, nicht weit voneinander entfernt. Oberer Hinterkopf stark ausgehöhlt, konkav, unterer konvex.

Der mittlere Gesichtskegel steht unterhall, und zwischen den weit voneinander entfernten Fühlerwurzeln, die 2 anderen darunter, oberhall, des Mundrandes. Prälahrum schmal, aber deutlich sichtbar vorstehend. Taster dünn, an der Spitze beborstet. Rüssel an der Type verletzt.

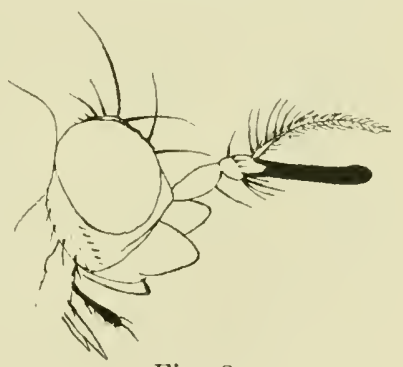

Fig. 3.

Fühler lang vorgestreckt. Erstes Glied viel länger als das zweite, anfgerichtet, unten mit abstehender Borste; zweites normal, drittes lang linear, gerarle, allein schon länger als das Gesicht. Arista weifs, zart und mehr anliegend, weifs gefierlert nnd auf der Oberseite ron der Wurzel her lang schwarz und abstehend gekämmt. 
Thoraxrücken abgerundet viereckig, flacl gewölht, länger als breit, vorne abschüssig. Schild ca. 1/4 des Rückens lang, eiförmig, oben nackt.

Hinterleib wie bei Lauxanir.

Beborstung lang und stark, Behaarung des Riickens rauh, in der Mitte in 6 Längsreiłen geordnet. Die obere Orbitalborste steht in der Stirnmitte und ist nach aufwärts gebogen, die untere steht weiter vorne und etwas weiter innen und ist nach vorne und einwärts gebogen. Ocellare stark, nach vorue gebogen. Scheitelborsten und Postvertikale normal gerichtet, wohl entwickelt. - 1 Humerale, 2 Notoplenrale, 3 Supraalare, 2 Paar Dorsozentrale, 4 Schillborsten, die apicalen divergent. - Je eine starke Borste anf dem Meso- und Stermopleuron.

Beine proportional. Vorderschenkel posterodorsal und-ventral beborstet. Vorder- und Mittelschienen mit kräftigen Präapicalbörstchen.

Merliastina und Subcosta eng beisammen, im ersten Flügelviertel und vor der lileinen Querader mündend. I)iese jenseits der Mitte der Discalzelle, über dem zweiten Drittel dieser Zelle stehend. Letzter Abschnitt der Discoidalis so lang wie die Discalzelle. Erste Hinterrandzelle parallelrandig. Rarlialis sanft gebogen, his zur Mïndung mit rer Cubitalis parallel.

\section{T. longicornis n. sp.}

1 or aus Paraguay, S. Bernhardino (leg. F i e br i gr). Wiener Hof-Museum.

Das Stiick hat durch Schimmel gelitten, weshalb die Farbenangaben keine bestimmten sein können.

Stirne, Thorax, Schilt und Hinterleib ron schwarzbrauner Grundfarbe. Letzterer glänzend, die ersteren matt, wie dunkelgrau bereift. Stirnvorderand, Fülıler, Gesicht, Pıälabrum und Backen gelb. Drittes Fühlerglied mit Ausnahme der Wurzcl scluwarz. Die 2 unteren Gesichtskegel sind am Aufsemrande braun. Taster schwarz. Borsten und Haare schwarz.

Hüften und Beine gelb. Dunkelbraun sind: die Spitzen der Vorderschenkel, weniger intensiv die der 4 hinteren, dann die Vorderschienen und die Vorderferse, sowie die Wurzeln der 4 hinteren Schjenen. Vorderfuls sonst weifs.

Flügel dunkelbraun. Weifs sind die Wurzel, die Subcostalzelle und ein Randfleck darunter, ein Dreieck in der Mitte des Flügelvorderrandes, das mit seiner Spitze die Cubitalis unten nicht mehr erreicht, je ein Fleck neben der Posticalismïndung, ein Fleck an der Mündung der Analisfalte, Sätume an den beiden Queraderu, sowie endlich ausgebuchtete Randsäume an der Flïgel- 
spitze zwischen der zweiten und dritten, dritten und vierten und noch unterhalb der vierten Längsader. Schwinger hellgelb.

Körper olıne Fühler $3^{1 / 3} \mathrm{~mm}$, Flügel $2,5 \mathrm{~mm}$ lang.

\section{Celypholrenxermier n. (Lauxan).}

Typus: C. scutellata n. sp.

Die Gattung unterscheidet sich von allen Lanxaniinen durcli die Celyphus-ähnliche Schildbildung. Das charakteristische Kopfprofil zeigt die Figur 4.

Stirne breiter als lang, eben, parallelrandig, doppelt so breit wie ein Auge. Augenränder in Gesichte ohne Winkel, kanm mehr genähert als an der Stirne. Stirne ganz glänzend glatt, mit schwach abgesetzter Medianfurche, aher ohne differenzierte Scheitelplatten. Ocellen eng beisammen, wenig erhöht, an der konvexen Scheitelkante liegend. Hinterkopf durchaus konvex. Stirne im Profile in spitzem Winkel stark vorspringend, Untergesicht zurïckweichend, kurz, breiter als lang, mit schwach welliger Profillinie; Mundrand gerade. Rüssel grofs, dick, Taster auffallend verbreitert, spatelförmig.

Fühler vorgestreckt, lang, der Augenmitte gegenüber, an den Wurzeln entfernt voncinander inseriert. Erstes

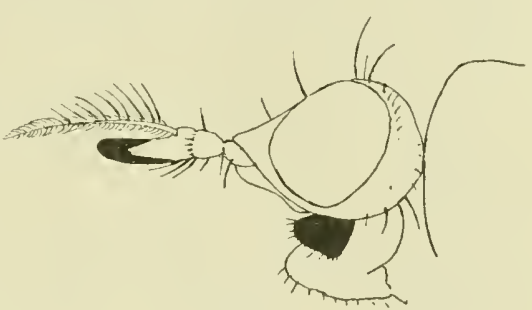

Fig. 4. Glied dentlich sichtbar, unten nit abstehender Borste; zweites Glied so lang wie das erste, normal geborstet; drittes lang, linear, oben an der Borstenbasis ausgerandet. Arista weifs, zart und mehr anliegend weifs gefierlert und auf cler Oberseite mit ca. 9 langen schwarzen Strahlen gekämmt.

Rücken und Schild im Profile fast geradlinig, hauptsächlich der Quere nach gewölbt. Rücken vorne höckerartig abschüssig, viereckig abgerundet, wenig länger als breit. Das Schild ist länger als der halbe Rürken, abgerundet viereckig, flach gewölbt scharfrandig und überragt dachartig die Hinterlejbswurzel.

Hinterleib $\left(\sigma^{\top}\right)$ breit eiförmig, ungefähr so lang wie dor Thorax. 1)rittes Tergit so lang wie das vierte und fünfte zusammen.

Beborstung: Scheitel- und Postvertikalborsten normal. Ocellare fehlen. Oberes Orbitalpaar etwas oberhalh, unteres etwas vor der Stirnmitte. Ersteres stärker und nach rückwärts, letzteres schwächer und einwärts gebogen und nach einwärts gerückt. 1 Humerale, 2 Notopleurale, 3 Supraalare, 2 Dorsozentrale und 1 Paar Präscutellare. Härchenreihen am Rücken im ganzen 8. - 
1 Meso- und 1 Sternopleurale. - 4 Scutellare, 2 an den Seiten und 2 an den abgerundeten Hinterecken desselben. - Hinterleib abstehend borstiich rauh behaart, auch in der Nitte der Tergite.

Beine proportional. Alle Schienen mit Präapicalbörstchen. Vorderschenkel posterodorsal und -ventral mit Borstenreihe gegen die Spitze hin.

Mediastina und Subcosta eng beisammen, vor der im ersten Flügeldrittel (vor der Discalzellenmitte) stehenden kleinen Querader mündend. Dritte und vierte Längsader sanft gegeneinander gebogen, konvergierend. Letzter AJschnitt der vierten so lang wie die ganze Discalzelle. Radialis fast gerade.

$$
\text { C. scutellata n. sp. }
$$

1 or $^{7}$ aus Pern, Pichis, Pto. Bermudas, Dezember. Dresdner Mus.

Kopf, Fühler, Thorax und Beine gelbrot, glänzend. Stime zart violett schimmernd. Fühler am Unterrande und an der Spitze, Taster ganz schwarz. Der Rücken schimmernd vorne auch schon metallisch blan und violett, wird aber in der hinteren Hälfte wie das ganze Schildchen dunkel stahlblau, purpurn schillernd. Hinterleib stahlblau mit grünem Schimmer. Borsten und Haare schwarz.

Flügel intensiv gelb tingiert, an der Wurzel schwarzbrann. Adern gelbbraun. Das Braun der Flügelwurzel erreicht hinten die Flügelfalte der Analis, vorne nur die Mitte der Costalzelle.

Körper ohne Fühler $3,5 \mathrm{~mm}$, Flügel kaum $3 \mathrm{~mm}$ lang.

Peltopsilopre n. g. (Ephydlr.).

Typus: P. aspistes n. sp.

Aus der Gruppe der Notiplilinae und durch den Celypluss-artigen IIabitus ganz besonders auffallend.

Kopf so breit wie der kurze Thoraxrïcken, stark von vorne her zusammengedrückt, im Profile viel höher als breit, von vorne aber erheblich breiter als hoch. Er ist hinten für den Thorax sehr stark ausgehöhlt, konkav, so dafs die Scheitelkante und der obere Rand der Augen sehr scharf sind. Stime und Gesicht gehen ohne Winkel in einer einzigen Wölbung ineinander über. Erstere ist durch 2 Längsfurchen dreiteilig, letzteres gleichmäfsig gewölbt. Siehe Figur 6. Die Stimangenränder laufen nach vorne zusammen und nähern sich an meisten in der stark verengten Mitte des Gesichtes. Oberhalb dieser Stelle sind sie etwas ausgebuchtet, auf der Stirne gerade. - Die Fühler stehen hoch oberhalb der Augenmitte. Das zweite Glied zeigt innen ein deutliches, nach vorne gebogenes Dörnchen und oben ein auf- 
gerichtetes Haar. Das dritte ist länglich rund, ca. $1 \frac{1}{2} \mathrm{mal}$ so lang wie breit, am Ende alstehend behaart. Arista oben lang und abstehend gekämmt, mit 7 Strahlen. - Prälabrum etwas vorstehend. Mundöffnung nicht grols. Taster und Rüissel an der Type nicht gut sichtbar.

Beborstung des Tieres sehr spärlich und schwach. Am Kopfe sieht man aufser einer leider abgeknickten Burste am

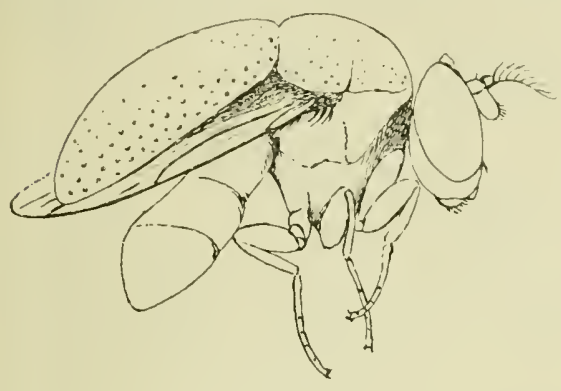

Fig. 5.

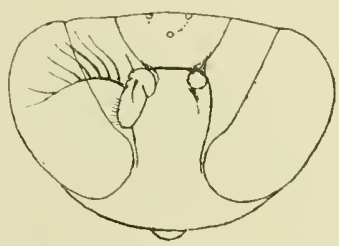

Fig. 6.

Scheitelrande und einem konvergenten Borstenpaare unter der Gesichtsmitte am Augenrande keine Borsten. Am Thorax kann ich nur 2 Mesopleuralborsten unterscheiden.

Thoraxrücken viel breiter als lang, abgerunclet rechteckig, mit dem Schilde in gleicher Wölbung verlaufend. Quernahtäste senkrecht, vor der

Mitte aufsteigend.

Schild Celyphus - artig entwickelt, im Umrisse $\mathrm{kr}$ e is r u nd, breiter als Rücken und Kopf, kaum kür'zer als der Hinterleib und flacher gewölbt als eine Halbkugel. Sein Hinter-

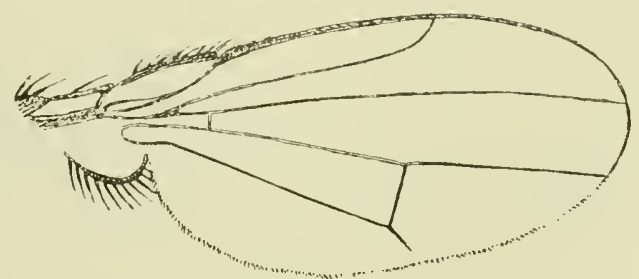

Fig. 7. rand erreicht den nach hinten gerichteten Flügel an der hinteren Querader. Hinterleib rundlich im Umrisse, von oben her flach, scheinluar dreiringlig. Aufser dem basalen Doppelsegment ist nur noch das dritte und das etwas längere vierte Tergit $\left(\sigma^{7}\right)$ sichtbar. - In Profile ist der Thorax viel höher als lang.

Beine relativ schwach, ohne besondere Beborstung. Flïgel nach der Figur 7 geadert, so lang wie das ganze Tier. Costa basal beborstet, bis zur Mündung der vierten Längsader reichend. Alula am verdicktem Rande ebenfalls borstlich gewimpert. 


\section{P. aspistes n. sp.}

$1 \sigma^{\top}$ aus Columbia, Aracataca, Februar. Ungar. Nat.-Mus.

Stirne und Gesicht glänzend glatt poliert, metallisch dunkelgrün. Ebenso der Hinterleib, purpurn schimmernd. - Fühler, Schienen, Knie und Füfse ockergelb. Schenkel schwarz. Thorax und Schild metallisch blauschwarz, Rücken schwächer, Schild dichter mit Hohlpunkten versehen, chagriniert, aber doch glänzend.

Flïgel, namentlich am Vorderrande bräunlichgelb tingiert, an der Wurzel gebräunt.

Körper und Flügel $2 \mathrm{~mm}$ lang.

\section{Psrevopterellı n. g. (Myrmecomyünae).}

Typus: macrocephala n. sp.

Im Habitus und im Flügelgeäder der Gattung Homaloceplaclu Zett. (= Psaeroptera Wahlb.) sehr ähnlich. Der Kopf ist im allgemeinen rundlich, etwas aufgehlasen, im Vergleiche mit dem Thorax relativ grofs, breiter als derselbe; im Profile verhält sich die Höhe zur

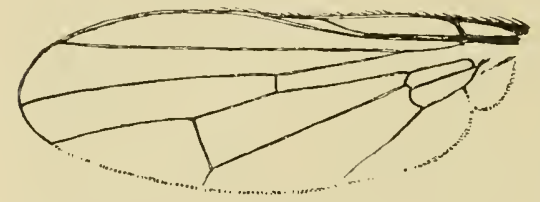

Fig. 8.

Länge wie $11: 9$, von volne die Höhe zur Breite wie $6: 5$, während bei Homalocephala der Kopf länger und viel breiter als hoch ist. Die Augen sind etwas länger als hoch und liegen schief. Die ebene Stirne ist oben wenig

breiter als ein Auge und erweitert sich etwas nach vorne hin, wo sie an den Fühlerwurzeln nur schwach in stumpfem Winkel über die Augen vorsteht. Gesichtsprofil ganz gerade, auch am Mundrande; etwas zurückweichend. Fühlergruben tief eingedrückt, parallel, $3 / 4$ des Gesichts lang, durch einen steil gewölbten, etwas vorstehenden Längsrücken getrennt. Hinterkopf gewölbt. Backen fast die Hälfte eines Auges hoch, unten konvex.

Lunula halbkreisförmig, frei. Fühler nur geneigt, etwas länger als clas halbe Gesicht, noch unterhalb der Augen und an den Wurzeln voneinander entfernt inseriert. Drittes Glied etwas mehr als doppelt so lang wie das zweite, länglich eif ö $\mathrm{rm}$ i g, oben hinter der nackten, wurzelwärts deutlich verdickten Arista eine Strecke gerade.

Kopfborsten von mittlerer Länge, aber dünn. 2 obere Frontorbitale im obersten Stirndrittel, 1 Ocellarpaar, nach vorne divergierend, 1 Paar sehr dentliche, parallele Postvertikale und 2 Paar Scheitelborsten. Die Ocellen liegen eng beisammen in der Höhe des hinteren Augenrandes. Scheitelplatten unscheinbar. 
$\mathrm{R}$ ï s s e l s e lı $\mathrm{r}$ l e i n, Taster relativ kurz, etwas verbreitert. Prälabrum nicht vorsteliend.

Thorax schwach. Rücken kaum länger als breit, viereckig. Quernahtäste etwas vor der Seitemmitte. Schild kurz, ca. 1/4 des Rückens lang, breit eiförmig, oben gewölbt und nackt; vierborstig. Rücken in Längsreihen behaart. In der Linie der Dorsozentralborsten eine durchlaufende Reihe längerer Borstenhaare. 1 Humerale, 2 Notopleurale, 3 Supraalare Ke ine Prothorakale. Mesound Sternopleuren behaart, letztere hinten mit 1 längeren Haare.

Hinterleib $q$ länger als der Thorax, länglich eiförmig, mit 6 sichtbaren Segmenten. Erstes Glied des Ovipositor's trapezförmig, flachgedrückt.

Beine von proportionaler Stärke, ohne besondere Beborstung.

Flügel nach Figur 8. Das Ende der Subcosta ist zart behart oder wie nackt. Erste Hinterrandzelle parallelrandig. Analzelle aulsen stumpf, bauchig begrenzt.

Anmerkung: Ich liabe in den Genera Insectorum, Pterocallinae p. 47 gesagt, dafs Iliatus Cresson sehr wahrscheinlich ein Synonym von Psaeroptera Wahlberg sei.

Da ich unterdessen besser erhaltene Stücke von letzterer Gattung gesehen habe, möchte ich dies nicht mehr behaupten. Die Cressonsche Beschreibung weicht in einigen Punkten ab.

Hiatus hat eine Prothorakalborste, die Homalocephala und Psaeropterella fehlt.

$$
\text { Ps. macrocephala n. sp. }
$$

3 ㅇ aus Claremont (leg. Baker), Verein. Staat. v. NordAmerika, von Prof. Ald rich.

Stirne, Fühler, Gesicht, Backen, Hüften und Beine rotbraun. Stirnstrieme matt. Drittes Fühlerglied in der Spitzenhälfte, Ocellenfleck und Hinterkopf dunkelbraun. Taster schwarz. Gesicht, Stimorbiten und Backen umbestäubt, glänzend.

Thorax, Schild und Hinterleib metallisch grünschwarz, alle oben durch graulichen zarten Reif im Glanze gemildert. Borsten und Behaarung schwarz.

Vorderschenkel mit Ausnahme der Spitze grünschwarz. Bei einem Stücke sind auch die Hinterschenkel, noch undentlicher die hinteren Schienen in ler Mitte gebräunt. Fufsspitzen braun.

Flügel gleichmälsig bräunlichgrau getrübt, an der Cubitalis mit sehr verwaschenem dunkleren Mündungsflecke. Adern dunkelbraun, an den Wurzelzellen gelblich.

Schïppchen weifs, Schwinger dunkel rotbraun.

Körper und Flïgel $4 \mathrm{~mm}$ lang. 


$$
\text { Ps. punctifrons n. sp. }
$$

1 o aus Vernon, Britiscl Columbia, 5. Mai leg. Miss R i c a r do im Brit. Mus. London.

Der vorigen Art bis auf folgendes gleich. Die Stirne ist hier glänzend und deutlich mit Hohlpünktchen versehen, auch dunkler rotbramn. Das dritte Fïhlerglied ist oben fast etwas konkav, vorne aber auch rund. Die Arista ist in der Basalhälfte spindlig verdickt, nicht allmählich.

Die Grundfarbe des Leibes ist rein schwarz. Schenkel mit Ausnahme der Spitze, Schienen aufser beiden Enden und die Fufsspitzen schwarz, der Rest rotbraun.

Flügel hyalin, nur vorne an der Wurzel etwas gebräunt, bis zur Mitte der Costalzelle. An der Mündung der Cubitalis liegt ein scharf sich abhebender dreieckiger brauner Randfleck, der an der Costa die Discoidalis berührt.

Sonst wie Ps. macrocephala.

Grölse nur $3 \mathrm{~mm}$.

Megraloprepemyial') excellens n. sp.

2 f aus Bolivia, Yungas von Coroïco, 1000 m, 18. November. Dresd. Mus.

Stinstrieme rotbraun. Ocellen- und Scheitelplatten wie der obere Hinterkopf dunkelbraun. Fühler, Prälabrum und Taster

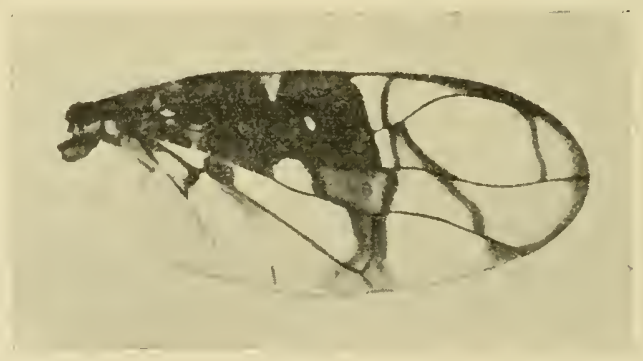

Fig. 9.

rotgelb bis lederbraun. Gesicht und Backen wachsgelb, ersteres mit Glanz.

Thorax, Schild und Hinterleib glänzend pechbraun; Pleuren ins Rötliche neigend. Rücken nur zart bereift. Hinterleib oben durch feine vertiefte Pünktchen sehr schwach chagriniert. Eirstes

1) nom. nov. für Megalaemyia Hendel praeoec. durch die gleichnamige Dipterengattung Bigots.

Siehe schon Gener. Pteroc. Taf. 1. Fig. 1 Megaloprepemyia Elsae Hend. 
Glied des Ovipositors gleichfärbig, herzförmig, so lang wie breit. Alle Borsten und Haare schwarz.

Hïften und Beine gelbbraun. Alle Schenke] in der Mitte, die Vorderschienen, die Hinterschienen mit Ausnahme der Spitze und die Enden der Füfse braun.

Flügel mach der Figur 9. Subcosta dicht und fein, kurz geschoren behaart.

\section{Neomyemis 11. g. \\ Typus: N. appendiculata Hendel.}

Die neotropischen Myemis appendiculata Hend., zebra Hend. und nigra Hend. weichen von rler typischen paläarktischen Form, wie auch von Xanthacrona v. d. Wulp durch nackte Subcosta, eine Stirmmittelleiste und gekriummte Hinterschienen, von Myemis aufserdem noch durch viel kürzeren Analzellenzipfel ab. Ich halte diese Arten für generisch verschieden von Myemis octopunctata Coqueb.

\section{Chondrometopum leve n. sp.}

1 q aus Bolivia, Mapiri, S. Carlos $800 \mathrm{~m}$; Dresd. Mus.

Diese Art verändert einigermafsen die von Ch. aruatum Hent. entnommenen Gattungsmerkmale, indem ihre Stirne glatt und ungekörnt und oben nur so breit wie ein Ange ist; vorne neben den Fühlern ist sie noch etwas enger. Die Unterscheidungscharaktere der Gattung liegen im Flügelgeäcler.

Thre Legeröhre ist mit dem Hinterleibe gleichfärbig. Hüften und Beine hell rotbrann, Schenkel in rler Mitte breit verdunkelt.

Die hintere Querader steht etwas weniger schief. Die über sie lanfende Querbinde ist ganz gerade, die erste Hinterrandzelle ist an der Mündung weniger verengt; der abgebogene Endteil der Radialis ist hier viel kürzer. Die Queradern der 2 Wurzelzellen sind bramn gesäumt. Alles Übrige wie beim Gattungs-Typus.

Körper und Flügel kaum $3 \mathrm{~mm}$ lang.

$$
\text { Pterocalla ophthalmoptera n. sp. }
$$

2 o aus Peru, Pichis, Pto. Jessup, Jänner und Ucayaliflufs, Unini, 22. Oktober. Dresd. Mus.

Stirne am Scheitel etwas schmäler als ein Auge, vorne nur $3 / 5$ eines solchen breit, vorne matt hell rotbrann, oben derart lunkelbraun, dafs die Borsten auf dunkleren Flecken zu stehen scheinen.

1 Keilfleck vor den Ocellen, je 2 Flecke am Augenrande, vor und hinter den Orbitalborsten und die Lunula samt schmalen Augenrandsäumen vorne oberhalb der Fühler weifslich bereift. Gesicht und Backen rotbraun, weifs schillernd. 
Fühler und Taster rotbraun, am Rande etwas gebräunt. Körper kaffeebraun. Die Zentralregion des Rückens zum gröfsten Teile, die Basis des Schildchens und hreite Hinterrandsäume der Tergite hell oliven- oder beim anderen Stücke am Rücken gelbgrau bereift. Rücken mit Lüngsreihen dicht stehender feiner dunkelbrauner Punkte an den Haarwurzeln, die stellenweise fleckig zusammenfliefsen. Ebenso sind die Hinterleibstergite fein punktiert. Plenren oberhalb der Sternopleuralnalıt mit 2 punktierten granen längsbinden. Schild im übrigen ganz kaffeebraun, ziemlich glänzend. Erstes Glied des Ovipositors so lang wie breit, herzförmig, glänzend und unbestäulot braun.

Hüften und Beine gelbbraun, Schenkel mit Ausnahme beider

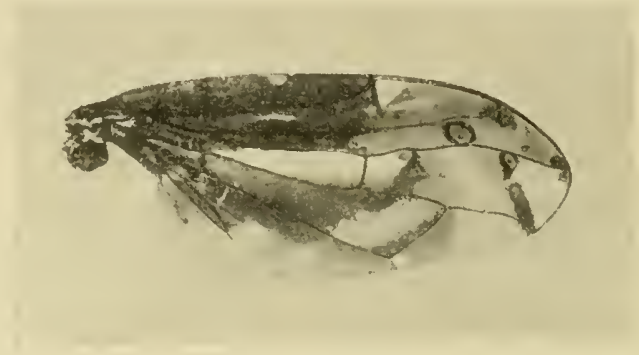

Fig. 10 .

Enden dunkler gefärbt. Hinterschienen mit 2 undentlichen dunkleren Ringen. Füfse gelblich.

Flügel nach der Figur 10 gearlert und gezeichnet. Die dunklern Schatten sind sepiabraun, die helleren ockergelb. Beiderseits des letzten Cubitalisabschnittes 3 leuchtend schneeweifse, bram geringelte Augenflerke; der basale derselben hat einen innen offenen braunen Ring. Schwinger rotgelb. Schüppchen braun, dunkler gerandet.

Körper 4-5 mm, Flïgel 4,5-5,5 $\mathrm{mm}$ lang.

$$
\text { Pterocalla pentophthalma n. sp. }
$$

1 o ans Bolivia, Yungas von Coroïco $1000 \mathrm{~m}$, 18. Februar.

Der Pt. plumitarsis Hend. $q$ bis auf folgende Unterschiede. gleich. Der Gesichtsangenrandwinkel ist ein rechter, bei plumitursis deutlich stumpf. Die Färbung des Stückes ist eine hellere, die Zeichnung tritt daher nicht so kontrastreich hervor. Die 2 langovalen, nach vorne konvergierenden braunen Flecke der Vorderstirne fohlen. - Das Gesichtsquerband ist nur angedeutet.

Die Zeichmung des Rückens mit grofsen braunen Flecken ist 
die gleiche, nur sind die Flecke ein wenig kleiner. Das Schild hat auf der Oberseite einen grofsen, in der Mitte zusammenlıängenden, bis zur Basis reichenden braunen Doppelfleck, nicht 2 kleinere runde Mittelflecke, die mit dem Seitenrande zusammenhängen.

Hinterleib hell olivengran, matt, am Vorderrande der Tergite 2-5 mit 4 grofsen, rechteckigen, durch kleinere Zwischenräume getrennten dunkelbraunen Flecken in gleichen Abständen. Der Hinterrand der Tergite, melır als $1 / 3$ derselben breit, bleibt grau und ist in der Mitte spärlich braun punktiert.

Erstes Glied des Ovipositor's auch grau und braun punktiert, breiter als lang.

Hüften und Schenkel, diese mit Ausnahme der Spitze, dunkel-

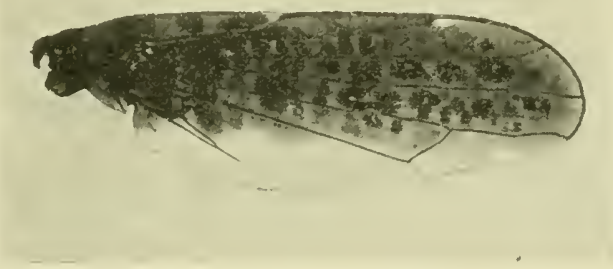

Fig. 11.

braun. Sonst sind die Beine hell ockergelb. Vor de rf ü fse erheblich kïrzer als die Schienen, bei plumitursis dagegen länger als die Schienen.

Flïgel nach der Figur 11 geadert und gezeichnet; braungrau, mit schwarzbraunen Flecken. 2 Augenflecke in der Submarginal-, 3 in der ersten Hinterrandzelle. Der spitze Zipfel der Analzelle ist kürzer als der Rest der Analis bis zum Flügelrande. Ilintere Querader weniger gess hwungen.

Schwinger hellgelb. Schïppchen brann, schwarz gcrandet. Körper $6 \mathrm{~mm}$, Flügel $7^{3} / 4 \mathrm{~mm}$ lang.

$$
\text { Pterocalla proxima n. sp. }
$$

$3 q$ aus Pern, Meshagua, Urubambaflufs, 13. November.

Hierher gehören auch die Stïcke, die ich in der Deutsch. lint. Zeitschr. 1909, Beiheft p. 31 als var. von Pt. orellutu F. mit breiterer Stirne beschrieben habe.

bie 3 sehr nahe stehenden Arten lass'n sich folgendermafsen unterscheiden :

Grofse Art, Flügel $8 \mathrm{~mm}$. Stirne relativ schmal, steil ab- 
fallend, nicht rortretend. Fühler unterhalb der Augenmitte sitzend. Kopf viel höher als lang. Thoraxrücken oft mit braunen Längslinien. Beide Queradern höclıstens die Länge der hinteren voneinander entfernt, diese sehr schief. Kleine Qnerader der Mündung der Subcosta gegenüber. Dritte Hinterrandzelle gröfstenteils braun, unterhalb der Posticalis mit kräftigen braunen Querstrichen. Flügelfläche lebhaft perlmutterartig irisierend. Pt. acellata Fabr.

Mittlere Art, Flügel $6,5 \mathrm{~mm}$. Stirne breiter, weniger alofallend, vorne mit deutlichem Winkel vortretend. Fühler der Augenmitte gegenülser. Kopf nur wenig höher als lang. Rücken mit Punktquerreihen. Boide Queradern die doppelte Länge der hinteren voneinander entfernt, diese sehr schief. Kleine Querader weit vor der Mündung der Subcosta. In der dritten Hinterrandzelle ist mur ein deutlich braun gestrichelter Saum jenseits der Posticalis braun. Flügelfäche wenig merklich irisierend.

Pt. proxima n. sp.

Kleine Art. Flügel $5 \mathrm{~mm}$ lang. Beide Queradem sind etwas mehr als die Länge der hinteren voneinander entfernt; diese ist viel weniger schief gestellt als bei den 2 vorigen Arten. Kleine Quevader der Subcostamündung gegenüber. In der dritten Hinterrandzelle ist nur ein nicht oder kaum punktierter Saum unterhalb der Posticalis braun. Sonst wie vorige Art.

Pt. punctatu Hend.

Es stehen also die beiden letzteren Arten näher als die ersten 2. Sie hahen hellere Flügel, kleinere, mehr punktartige braune Querstriche in den Zellen und einen anderen Kopfban. Pt. punctata hat auch zum Unterschiede von den beiden anderen Spezies eine bis auf das aufgebogene Ende gerade Radialis.

$$
\text { Paragorgopsis discrepans n. sp. }
$$

$1 \sigma^{7}$ aus Bolivia, Yungas von Coroico, $1600 \mathrm{~m}$, 19. Oktober. 1)resd. Mus.

Diese Art weicht durch die nicht gegitterte Flügelzeichnung von den Paragoryopsis-Arten etwas ab und könnte bei oberflächlicher Betraclitung für eine Apterocerina-Art gehalten werden. Ihre parallele Stirne ist aber doppelt so breit wie ein Auge; von oberen Fronturlbitalborsten ist nur eine vorhanden; vor dieser sinrl einige schwächere Härchen sichtbar, deren stärkste noch uberhalb der Stirnmitte steht. Die Ocellaren sind kurz. J)er Kopf ist merklich breiter als der Thorax. Am Flügel ist das Nündungsende der Radialis anfgebogen und die Cubitalis ist nubeborstet.

Kopf und Anhänge ockergelb. Stirne schwach glänzend, schwarz behaart. Clypeus leller gelb. Scheitelplatten und 
Hinterkopf glänzend. Backen ca. 1/2 eines Auges breit. Gesichtsprofil schwach konkav. Fühlerhorste sehr kurz behaart.

Thorax kaffeebraun; Prothorax und die Umgebung der Hüften

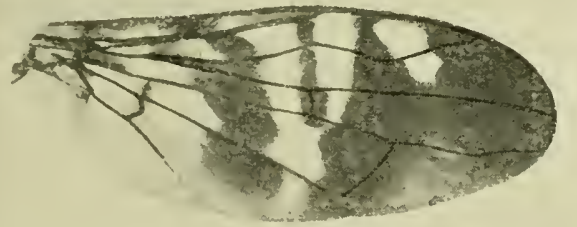

Fig. 12.

rotgelb hindurchscheinend. Alles bedeckt ein zarter ockeriger Reif. Hinterleib glänzend pechbraun, an der Wurzel breit rötlich. Beine bräunlichgelb. Schenkel und Schienen mit Ausnahme der beirlen Enden, Tarsen gegen die Spitze hin braun.

Flügel hyalin, an der zweiten und dritten Längsader gelb tingiert, nach Figur 12, gezeichnet. Die Zeichnung ist von sepiabranuer Farbe.

Körper $5 \mathrm{~mm}$, Flügel gut $6 \mathrm{~mm}$ lang.

$$
\text { Parayoryopsis argyrata n. sp. }
$$

1 o7 ans Peru, Pichis, Pto. Jessup, Jänner. Dresd. Nus.

Kopf dentlich breiter als der Thorax. Stirne vorne zirka so hreit wie ein Auge, oben breiter, breiter als lang. Die Augen-

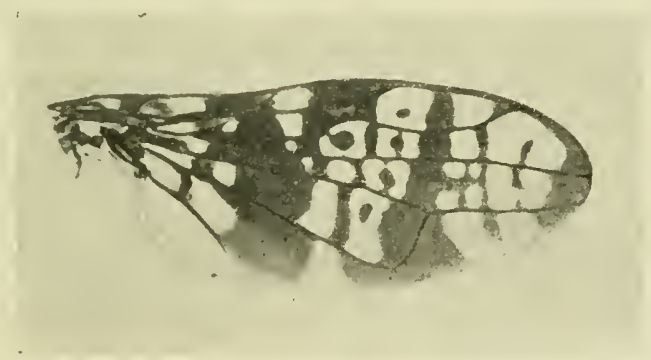

Fig. 13.

ränder biegen in der Höhe der Fühlerwurzeln wagrecht nach aufsen um. Strieme der Stirne matt rotgelb. Scheitelplatten und Ilinterkopf glänzend warhsgelb. Gesicht und Backengruhen 
von weifser Grundfarbe, silherweifs schimmernd; ebenso die Taster. Fühler abgebrochen.

Schild und Metanotum samt Umgebung pechlıraun, der übrige Thorax hell rotbraun und dicht ockergelb bestäubt. Rücken mit dunklen Punkten, die nicht genau in Längsreihen geordnet sind. Hinterleib glänzend pechbraun, an der Wurzel rot.

Hüften und Beine rotgelh. Schienen mit 2 verwaschenen braunen Ringen.

Flïgel nach der Figur 13.

Körper und Flügel $5 \mathrm{~mm}$ lang.

\section{Ophthalmoptera undulata n. sp.}

1 o aus Bolivia, Yungas von Coroico, $1700 \mathrm{~m}, 28$. Oktoler ; leg. S c h nus e. Dresd. Mus.

Gleicht mit einigen Unterschieden rer O. lonyipemis Hendel, Deutsch. Ent. Zeitschr. 1909, Beiheft p. 69. 70, und Gen. Insect., Subfam. Pterocallinae Taf. 4, Fig. 78-80.

Anf der Stirne sind die Augenränder schmal weils eingefarst, die Scheitelplatten und die Lumula deutlich weifs bestäubt. Thoraxrïcken und Schild gesättigter als die Plenren und die Beine gefärbt, mehr rostbraun.

Die anffälligsten Unterschiede bietet der Flïgel. Die Radialis ist gegenüber der hinteren Querader stark und weiter spitzenwärts nochmals, aber schwächer wellig gebogen. Die erste Hinterrantzelle gleicht fast jener der $O$. elegans Hendel, siehe Gen. Insect., Sulbam. Ulidinae, Taf. 3, Fig. 93, und ist an der Mündung erweitert; der Endabschnitt der Discoidalis ist aber an der Mündnng dentlich nach unten gebogen. Hintere Querader gerade nnd etwas weniger schief als bei $O$. longipemis liegend. Von den 5 Angenflecken dieser Art fehlt hier jener an der Radialis. Der gegenüberliegende an der Cubitalis ist nicht wie bei $O$. longipemis mit dem hyalinen Hinterrande der zweiten Hinterrandzelle verbunden, da dieser nicht einmal die Discoidalis berührt. Dagegen zeigt unsere Art einen unvollkommen abgesonderten fünften weifsen Punkt gleich jenseits der kleinen Querader in der ersten Hinterrandzelle. Die Grundfarbe um die 4 Angenflecke der Flügelspitze ist hellbraun, nicht gelb. Die breite branne Querbinde ïber die hintere Qnerader zum Flügelhinterrande ist anfsen beiderseits scharf begrenzt und parallelrandig.

Körper $5 \mathrm{~mm}$, Flïgel $6 \mathrm{~mm}$ lang.

Prorophtherlucoptere" (11. g.) picen n. sp.

2 q ans Bolivia, Yungas von Coroico, $1000 \mathrm{~m}, 16$. November; lerg. Schnuse. Dresd. Mus. 
Der O. bipunctata Hendel, loc. cit. p. 70. 71 et Gen. Insect., Subfam. Pterocall. Taf. 4, Fig. 81, ähnlich. Stirne dichter behaart. Gesicht und Prälabrum ganz gelb, ohme silbrige Querbinde. Die Augen sind kamm länger als hoch, wodurch diese Art von den anderen Gattungsgenossen abweicht.

Thorax, Schild und die Endhälfte des Hinterleibes glänzend pechschwarz, ohne jede Bestäubung. Auch die silbrige Längsstrieme oben an den Pleuren fehlt. Hinterleib an der Wurzelhälfte rot bis rotbraun, bei einem Stücke mehr verdunkelt. Erstes Glied der Legeröhre herzförmig, länger als breit. Hüften und Beine rotgelb.

Flügelzeichnung anch in der Wurzelhälfte gelb. Braun sincl nur die vordere Basalzelle, Säume an den Wurzelqueradern, der hinteren Querader, an der Flïgelspitze und an den weifsen Flecken der Wurzelhälfte des Flügels, sowie ein rundlicher Schattenfleck vor der Mündung der Analis. An der Mündung der Mediastina und unter der Mitte der Subcostalzelle in der Marginalzelle je ein braun gerandeter weifser Augenfleck. Gleich jenseits der Subcostamündung liegt ein gleichfalls braun gerandeter weifser rechteckiger Einschnitt, der unten die Cubitalis berührt und an der Costa etwas erweitert ist. Beim anderen Stücke ist er durch die Radialis in 2 Flecke geteilt. Die 2 Angenflecke der $O$. biprnctata Hend. an der Spitze der Submarginalzelle sind zu einem länglichen Flecke verschmolzen, der nicht braun gesäumt ist. Der braune Saum der hinteren Querader ist so breit, wie diese Ader lang ist.

Körper $3 \mathrm{~mm}$, Flügel 3,5 $\mathrm{mm}$ lang.

Anmerkung: Diese Gattung gründe ich auf Ophthalmoptera bipunctata Hend. Sie unterscheidet sich namentlich durch die Stellung. der hinteren Querader, die mit der Posticalis einen spitzen Winkel bildet, und durch rie kürzeren und breiteren Flügel.

$$
\text { Pterocerina anastrepha n. sp. }
$$

1 or aus Peru, Meshagua, Urubambaflufs, 30. Septemb. Drest. Mus.

Kopf und Anhänge rotgelb, Fühler gesättigter gefärbt. Die Stirne zeigt mit Ausnahme des Vorderrandes in gewisser Richlung einen dunkelbraunen Schimmer und sieht wie angebrannt aus. Arista sehr lang gefiedert.

Körper und Beine wie der Kopf rotgell gefärbt, auf den Pleuren und am Rücken ockerig bestäubt und auf letzterem mit undeutlich brauner Zeichnung, die aus 2 längslinien und einer an der Quernaht unterbrochenen breiten Strieme besteht, versehen.

Hinterleib auf dem dritten und vierten Tergit mit einem 
breiten braunen Hinterrandsaume, der sich in der Mitte nach vorne erweitert, und einem schmalen Saume am fünften Tergite gezeichnet.

Fülse gegen das Ende hin gebräunt.

Der Flügel ist durch seine Aderung charakterisiert.

Der letzte Abschnitt der Cubitalis ist von der kleinen Querader an allmählich und sanft aufwärts gebogen und mündet deutlich oberhalb der Flügelspitze. Die kleine Querader steht nur wenig jenseits der Mitte der Discalzelle. Radialis normal wie bei Pterocerina. Die Flügelzeichnung ähnelt dem in Figur 56 auf Taf. 3 der Gen. Pterocall. abgebildeten. Er ist schwach rauchig getrübt, zeigt einen schwächeren Schatten an der Radialisgabel, einen intensiven braunen Fleck, der die Spitze der Subcostalzelle und den ersten Wellenberg der darunterliegenden Radialis einschliefst, aber nicht tiefer reicht. Die Flügelspitze ist braun, nach unten hin allmählich heller. Vor der Spitze der Submarginalzelle liegt ein rundlicher hellerer Fleck. Jener in der ersten Hinterrandzelle ist kaum angedentet.

Schüppchen weils, Schwinger gelb.

Körper 5,5 mm, Flïgel $5 \mathrm{~mm}$ lang.

$$
\text { Pterocerina ruficauda n. sp. }
$$

1 q aus Mexico, Jalapa, leg. Crawford, Samml. Prof. B e z z i.

Durch die unterhalb der Posticalis zusammenfliefsenden basalen Flügelquerbinden der Pt. furcata Hend. nahestehend.

Kopf gelb. Stirne seidenartig, am Augenrande breit weifsschimmernd. Gesicht weirslich bereift. Fühler und Taster rotgelb. Ocellenfleck allein braun. Hinterkopf oben seitlich braun, ockerig bestäubt.

Thorax und Schild dunkel rotbraun, Pleuren nach unten hin allmählich pechbraun. Bestäubung dicht, ockerfarbig. Hinterleib sepiabraun, glänzend, am Vorderrande der Tergite bläulichgrau schimmernd. Erstes Glied des Ovipositors gelbrot, breit trapezförmig.

Beine rotgelb. Schenkel mit Ausnahme der Spitze, dann die Vorderschienen und die Spitzen der hintersten Schienen dunkelbraun.

Der Flügel gleicht mit folgenden Unterschieden dem von Pteroc. furcata Hend., Gen. Pteroc. Taf. 3, Fig. 47. Die beiden basalen Querbinden sind von der Costa bis zur Posticalis durch einen fast gleich breiten hyalinen Streifen getrennt, der gemeinsame Stiel ist viel breiter und berührt die Analis. Die erste Querbinde ist breit streifenförmig, die zweite von der kleinen Querader 
abwärts linienförmig. Die dritte, über die hintere Querader laufende Querbinde verbreitert sich am Hinterrande des Flügels und berührt dort fast die zweite. Die durch die Mitte der zweiten Hinterrandzelle lanfende Halbbinde ist bei dieser Art oberhalb der Discoidalis mit der dritten Flügelquerbinde verbunden. Die Spitzenrandbinde geht noch unter die vierte Längsader herab. Alle braunen Querbinden zeigen am Flügelvorderrande breite braungelbe Kerne eingeschlossen. Die Queradern der Wurzelzellen sind braun gesäumt.

Schüppchen weifs, Schwinger gelb.

liörper ohne Ovipositor $3,5 \mathrm{~mm}$, Flügel über $4 \mathrm{~mm}$ lang.

$$
\text { Pterocerina basalis n. sp. }
$$

1 $q$ aus Peru, Madre de Dios. Dresd. Mus.

Auch durch die Flügelzeichnung der Pt. furcata Hend. sehr ähnlich, aber durch das schwarze Gesicht verschieden. Stirne und Fühler rot. Augenrand schmal weifsgelb schimmernd. Hinterkopf, Clypeus, Prälabrum und Taster braunschwarz. Clypeus in der oberen Hälfte weifs bereift, unten glänzend. Backengruben rotbraun.

Der ïbrige Körper und die Beine schwarzbraun. Thoraxrücken dicht ockerig bestïubt, das Schild nur zart.

Am Hinterleibe ist das basale Doppelsegment und der Vorderrand des dritten hellgelb. Ovipositor breit trapezförmig.

An den mittleren Beinen sind die Füfse bräunlich. Die Hinterbeine fehlen.

Am Flügel sind auch die 2 Querbinden über die Queradern am Hinterrande schmal verbunden. Die Halbbinde der zweiten Hinterrandzelle fehlt. Die Spitzenrandbinde ist breiter, geht unter die vierte Längsader herab; ihre innere Grenze ist fast senkrecht auf den Adern.

Schüppchen weifs, Schwinger gelb.

Körper mit Ovipositor $5,5 \mathrm{~mm}$, Flügel fast $5 \mathrm{~mm}$ lang.

$$
\text { Pterocerina Townsendi n. sp. }
$$

$1 \sigma^{7}$ aus Yahuarmayo, Peru, 3. Februar. Coll. Townsend.

Fühler, Gesicht, Backengruben, Prälabrum und Tasterspitzen samtartig leuchtend orangerot. Stirne matt braungelb. Ein Fleck oberhalh der Lunula, die Scheitel- und Ocellenplatten und je ein dreieckiger Fleck beiderseits des Cerebrale pechbraun. Augenrand schmal weifsgelb schimmernd. Rest des Kopfes rotgelb. Arista abstehend gefiedert. Mundrand winklig vorstehend.

Thorax pechbraun, auf dem Rücken und in einem Streifen 
vor der Mesopleuralnaht dicht ockerbräunlich bestänbt. Schild schwach bereift. Pleuren vorne und unten stark glänzend.

Hinterleib am dritten und vierten Tergit samtschwarz, an der Basis, an den Vorderecken des dritten Tergites und an der Spitze des fünften gelbrot.

Hüften und Beine gelb. Vorderschenkel an der Spitze schwach gebräunt.

Der Flügel ist hyalin, zwischen der Subcosta und Costa oben, der Discoidalis unten und der Radialisgabel innen lebhaft orangegelb tingiert. Costalzellenspitze schwach gebrïunt. Ein Spitzenrandsaum, der jenseits der Subcosta schmal beginnt, sich dann verbreitert und an der Cubitalis das äufserste Drittel deren letzten Abschnittes einnimmt, ist dunkelbraun. Er endet an der Längsfalte der ersten Hinterrandzelle und steht an der Spitze derselben mit einem gleichfarbigen Zickzacksaume in Verbindung, der den Endteil der Discoidalis, die hintere Querader und einen kurzen Teil der Posticalis bedeckt. In der Submarginalzelle liegt in der Verlängerung der hinteren Querader ein grofser, abgerundet viereckiger weifser Fleck.

Schüppchen weifslich, Schwinger gelb.

Körper $6 \mathrm{~mm}$, Flügel $6,5 \mathrm{~mm}$ lang.

\section{Apteroceriun nov. subgen.}

Typus: $A$. argentea n. sp.

Dieses Subgenus unterscheidet sich von Pterocerina nur durch die nicht gefiederte, blofs kurz behaarte bis nackte Arista. Cubitalis beborstet.

$$
\text { Apterocerina aryentea n. sp. }
$$

2 우 aus Bolivia-Mapiri, Sarampioni, $700 \mathrm{~m}$, und S. Antonio, $1000 \mathrm{~m}$, Februar. Dresd. Mus.

Stirnstrieme oben dunkel wachsgelb, vorne, dann die Lunula und die obere Hälfte des Gesichts, sowie die Wurzelhälfte der Fühler lebliaft gelbrot. Die ganze Stirne ist zart weils über reift, an den Seiten und an Scheitel dichter. Drittes Fühlerglied in der Endhälfte allmählich rotbratn. Unterhalb des Augenrandes sind das Gesicht und die Backengruben scharf abgesetzt leblaft silberweifs. Cerebrale und unterer Hinterkopf bräunlich gelb, oberer Hinterkopf seitlich schwärzlich. Taster hell rotbraun.

Thorax und Schild kaffeebraun, dicht gelbgrau bestäubt. Metanotum und Pleuren unter der Sternopleuralnaht glänzend pechbraun. 
Hinterleib rotgelb. Drittes und viertes Tergit mit Ausnahme des Vorderrandes und das erste Glied des Ovipositors pechbraun. Letzteres breit trapezförmig. Fünftes Tergit weils bereift.

Hüften und Beine schwarzbraun. Die 4 hinteren Schenkelringe und Fufswurzeln bräunlichgelb.

Fln̈gel mit folgenden Unterschieden dem von Pterocerina fureata Hend., Gener. Pterocall. Taf. 3, Fig. 47, gleich. Der gemeinsame Stiel der Gabelbinde erreicht den Flügelhinterrand nicht. Die Halbbinde in der Mitte der zweiten Hinterrandzelle fehlt. Die Spitze der Marginalzelle ist ganz braun. Die zweite und dritte Querbinde sind an der Subcostamündung breit getrennt.

Schwinger und Schüppchen gelblichweifs.

Körper ohne Ovipositor und Flïgel $4 \mathrm{~mm}$ lang.

$$
\text { Apterocerina recta n. sp. }
$$

2 우 aus Bolivia, Jungas von Coroico, 1800 m, 20. November Dresd. Mus.

Durch die Flügelzeichnung der Pt. colorata Hend. 웅 Gener. Pterocall. Taf. 3 Fig. 48 nahestehend, aber wegen der wie nackten Arista zum Subgenus Apterocerina gehörig.

Kopf rotbraun, lederfarbig; oberer Hinterkopf dunkelbraun, graulich bestäubt. Stirnstrieme in gewisser Richtung weifsschimmernd; Scheitelplatten dunkelbraun, etwas glänzend, vorne durch samtartige Farbe der Strieme eingefafst. Augenrand weifs. Gesicht und Backengruben weifslich bereift. Untere der 2 Frontorbitalborsten in der Stirnmitte. Ocellare relativ kurz. Fühler und Taster lebhafter rotbraun.

Thorax, Schild und Hinterleib von glänzend pechbrauner Grundfarbe. Pleuren aschgrau, Schild und Rücken des Thorax gelbgrau bereift, letzterer mit deutlichen Wurzelpunkten der Grundfarbe an den Haaren und Borsten und einer undentlichen dunklen Längsstriemung.

Erstes Glied des Ovipositors schlank und fast so lang wie der Hinterleib.

Hüften, Knie und die 4 hinteren Füfse mit Ausnahme der Spitze rötlich. Vorderfüfse an der Basis rotbraun. Rest der Beine pechbraun.

Die Flügelzeichnung unterscheidet sich von obengenannter Art (q) durch die geringere Breite der Querbinden, so ist namentlich die über die hintere Querader lanfende vorne stark verschmälert. Beide Queradern der Wurzelzellen sind braun gesäumt. Die Endabschnitte der dritten und vierten Längsader sind gerade 
und konvergieren. Unterhalb der Subcostamündung liegt an der Welle der Radialis ein brauner Punktfleck.

Schüppchen etwas gebräunt, Schwinger hellgelb.

Körper mit Ovipositor $6 \mathrm{~mm}$, Flügel $5 \mathrm{~mm}$.

Acimoirles nor. gen. (Perocall.).

Typus: Ac. insecta n. sp.

Mit Ausnahme der folgenden Unterschiede gilt für dieses Gemus die Beschreibung von Pterocerina Hend., Genera Pterocall. p. 24. 8 (1909).

Das Gesicht hat keine Querfurche, ist im Profile geradlinig und tritt am Mundrande nicht vor. Die Backen sind niedriger als 1/3 der Augenhöhe. - Die Arista ist nur kurz behaart.

Die Mittelschenkel sind hinten nicht länger gewimpert. Die erste Hinterrandzelle ist an der Mündung nicht verengt, sondern

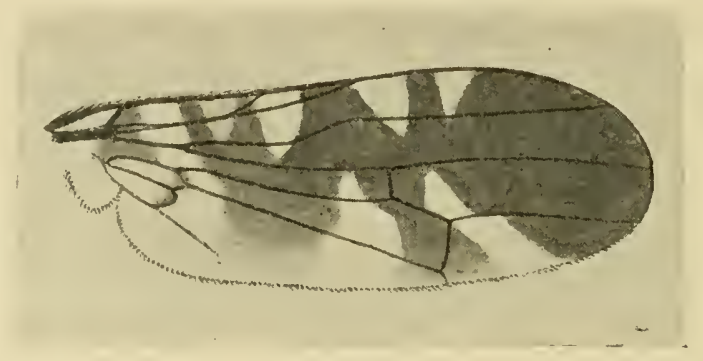

Fig. 14 .

ganz parallelrandig. Queraderu gerade, einander genähert, auf der Posticalis senkrecht stehend; ihre Entfernung voneinander beträgt ca. $1 / 5$ der Discalzellenlänge.

Die Analzelle ist aufsen ganz bauchig begrenzt. Die Cubitalis ist unbeborstet.

$$
\text { A ciuroides insecta n. sp. }
$$

1 o aus Paraguay, Hohenau, 250 m, 21. Oktober. Dresd. Mus.

Kopf liellrötlich ockergelb, auf der Stirue und dem Clypeus etwas gebräunt. Stirmstrieme wachsglänzend, am Augenrande schmal gelloschimmernd gesäumt. Gesicht scliwach weifslich bereift. Fühler und Taster rotgelb.

Thorax rötlich kaffeebraun, Schild rotbraun; Hinterleib pechbraun. Der Glanz wird überall durch eine helle, gelblichgraue Bestäubung stark beeinträchtigt. Behaarung kurz, wie die Borsten schwarz.

Hüften und Beine rötlich ockergelb. Schenkel in der Mitte breit braun, ebenso die Schienen mit Ausnahme der beiden Enden. 
Flügel nach Figur 14 gezeichnet, älnnlich der Tephritinengattung Aciura. Die Zeichnung ist braun, die hyalinen Stellen schimmern gegen dumklen Grund betrachtet milchweifs. Die hellere Stelle in der Spitze der Costalzelle und die darunterliegende sind gelb.

Schwinger hellbraun.

Körper 4,5 mm, Flügel $5 \mathrm{~mm}$ lang.

Micropterocerus n. g. (Pterocall.).

Typus: M. longifacies n. sp.

Schon durch die Gröfse abweichend. - Oberer Hinterkopf nicht hohl, sondern linter der abgerundeten Scheitelkante flach gewölbt, unten stark gewölbt, unterhall, der Mitte inseriert. Gesicht lang, so lang wie die Stirne, im Profile ganz ger a de, ohne Querfurche, nach unten zurückweichend. Wangen ${ }^{1 / t}$ des

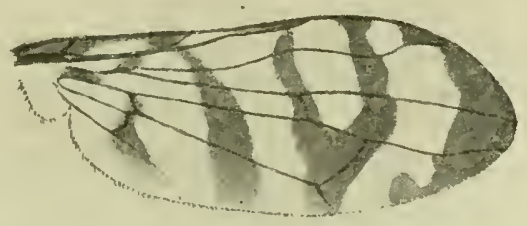

Fig. 15.

Gesichtes breit. Fühlergruben deutlich vertieft, parallel zuteinander.

Stirne nach vorne verbreitert, dort doppelt so breit wie ein Auge. Fühler ca. 1/2 des Gesichtes lang. Backen breit, hinten herabgesenkt und dort $1 / 2$ der rundlich ovalen Augen hoch. Arista mit Ausnahme der dickeren Wurzel kurz pubesciert. Vor der einzigen Orbitalborste auf den Scheitelplatten stelit jederseits eine Reihe nach vorne hin an Länge abnehmender Haare, die nach aufsen gebogen sind. Die oberste derselben gleicht einer schwacheu Orbitale. Die übrige, ziemlich dichte Behaarung der Vorderstirne ist nach vorne gerichtet.

Cubitalis an der Wurzel beborstet. Subcosta am Ende der Costa stark genähert, Randmal dort sehr schmal. Kleine Querader schief, weniger von der hinteren entfernt als die Länge dieser Ader beträgt.

Alles übrige wie bei Pterocerina Hend. 


\section{M. longifacies n. sp.}

1 ㅇ aus Bolivia-Mapiri, Lorenzopata, 11. Mai. Dresd. Mus.

Das ganze Tier ist lebhaft rotgelb. Stirne, Fühler, Gesicht und Backen matt, sonst glänzend; auch Ocellen- und Scheitelplatten glänzen. Unter dem Auge ein loter Querfleck hinten an den Backengruben. Thoraxrücken und Schild gesättigter gefärbt.

Zweites bis fünftes Hinterleibstergit mit nach hinten zu immer breiter werdenden glänzend schwarzen Hinterrandsämmen. Erstes Glied des Ovipositor's glänzend schwarz, herzförnig, breit abgestutzt, fast so lang wie der halbe Hinterleil).

Spitzen der Vorder- und Hinterschienen, sowie alle Fufsenden dunkelbraun. Flügel an der Wurzel gelb. Querbinden sepiabraun.

Schüppchen braun gerandet, Schwinger gelb.

Körper samt Legeröhre und Flügel 8,5 $\mathrm{mm}$ lang.

\section{Antimenromyir n. g. (Richardiunae).}

Typus: A. clavata n. sp.

Stirne am Scheitel so breit wie ein Auge, vorne die Hälfte so breit, eben. Die schmalen Scheitelplatten reichen bis zur

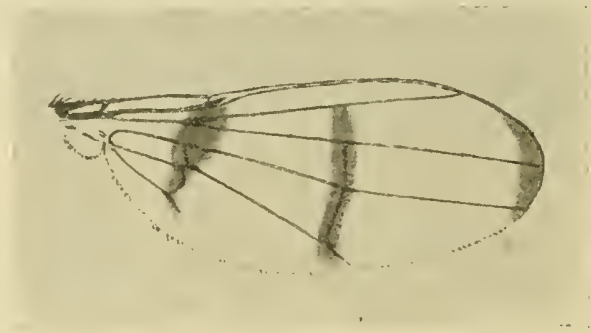

Fig. 1j.

Stirnmitte vor, das Ocellendreieck ein wenig weiter. Vordere Ocelle in der Stirnmitte, die genäherten 2 oberen liegen der abgerundeten Scheitelkante etwas näher als der vorderen. Die starken Ocellaren und das Orbitalborstenpaar steht in der Iängsmitte der Stirne. Sonst sind nur noch 2 Paare Scheitelborsten vorhanden. Augen schief oval liegend. Über deren Umrifs tritt die Stirne und der flache obere Hinterkopf gar nicht, der konvexe untere Hinterkopf nur mäfsig vor. Gesicht in der Mitte winklig gebrochen, am Mundrande etwas stärker als an den Fühlerwurzen vortretend, Unterrand des Kopfes gerade, wagrecht. Wangen linear, Backen sehr schmal. Prälabrum stark vorstehend.

Fühler länger als das Gesicht, so lang wie dieses samt dem 
Prälabrum, nickend; die 2 Wurzelglieder kurz, drittes streifenförmig, an der Spitze rund, ca. viermal so lang wie breit. Arista basal, locker und abstehend gefiedert, Fiederbreite gut jener des dritten Fühlergliedes gleichkommend. Taster etwas verbreitert; Lunula schmal.

Thoraxrücken vorne verjüngt, am Vorderrande nur so breit wie die Stime in der Nitte, aber auch zwischen den Flïgelwurzeln schmäler als der Kopf. Schild oben abgeflacht, vierborstig. 1 Humer., 2 Notopl, 3 Supraal. kräftig. 1 Meso- und 1 Sternopleuralborste, 1 I'räscutellare und 2 Paare Dorsozentrale selır schwach und dünn.

Hinterleib wenig länger als der Thorax, keulenförmig, gestielt. Den Petiolus bildet das erste Segment; das zweite (die andere Hälfte des basalen Dopprelsegmentes) erweitert sich dann allmählich bis zur vollen Breite des Ilinterleibes. Von den noch sichtbaren Tergiten $3-5$ ist der mittlere etwas kürzer. Auf den Seitenmitten des zweiten Tergites länger abstehende Haare in der Querreihe.

Schenkel nicht verdickt. Nittelbeine fehlen der Type. Vorderschenkel in der Endhälfte, Hinterschenkel mit Ausnalmme des Basaldrittels ventral zweireihig bedornt.

Flügeladerung nach Fig. 16. Radialis gerade, ebenso die einzelnen Abschnitte der anderen Längsadern. D i e beiden Queradern stehen übereinander und bilden eine fast gerade Linie. Analis kurz. Gattungstypus

\section{Ant. clavata n. sp.}

$1 \sigma^{7}$ aus Trinidad, Port of Spain, 5. Febr. (G. A. K. II a r $\mathrm{sh}$ a 1 1). Brit. Mus. London.

Kopf und Anhänge hell rothraun; Stirne ziemlich glänzend, vorne etwas gebräunt, Ocelleupunkte schwarzbraun. Hinterkopf teilweise fleckig braun. Gesichtsaugenränder weifs.

Schultern und Prothorax hellgelb. Pleuren und Metanotum glänzend schwarz. Der Riücken und das Schildchen wachsglänzend. Ersterer zwischen den Schultern, zusammenhängend damit eine breite Medianstrieme des ganzen Rïckens und das Schildchen pechbraun. Jederseits neben der Medianstrieme noch eine schwärzliche Linie. Hinterleib pechbraun, oben zart punktiert. Behaaruug und Beborstung dunkel rotbraun.

Hïften gelhhraun, vordere dunkler. Schenkel und Schienen pechschwarz. Vorderschenkel in der Endhälfte, Hinterschenkel im Basis- und Endviertel gelb oder rotgelb. Füfse weifsgelb, Endglied dunkler gefärbt. 
Flügel hyalin mit sepiabrauner Bandierung nach der Figur. Ader'u nur in der dunklen Zeichnung dunkel-, sonst hellbraun.

Schwinger weifs, Schüppchen hellgelb.

Körper $5 \mathrm{~mm}$, Flügel über $4 \mathrm{~mm}$ lang.

$$
\text { Poecilomyia annulatan. sp. }
$$

$1 q$ aus Trinidad, Port of Spain, 5. Febr. (G. A. K. M a r shall). Brit. Mus. London.

Unterscheidet sich von der typischen Form durch dunkel rotbranne, oben offene und ziemlich breite Ringe vor den Schenkelspitzen.

liörper ohne Flügel und Ovipositor $7 \mathrm{~mm}$, Flügel $6 \mathrm{~mm}$ lang.

Richardia podagrica Fah. of $q$, Richardia proxima Schiner, Euxesta stigmatias Lw. und Euxesta annonae F. Alle aus Trinidad, S. Fernando (anfangs Mai). Brit. Mus. London. 




\section{Die Gattungen der Bohrfliegen.}

(Analytische Übersicht aller bisher bekannten Gattungen der Tephritinae).

Von Friedrich Hendel, Wien.

Sonderabdruck aus der „Wiener Entomologischen Zeitung“, XXXIII. Jahlrgang, 1914. 



\section{Die Gattungen der Bohrfliegen.}

(Analytische Übersicht aller bisher bekannten Gattungen der Tephritinae.)

Von Friedrich Hendel, Wien.

Anmerkung: I = Paläarktisches, II = äthiopisches, III = indo-australisches, $\mathrm{IV}=$ nearktisches, $\mathrm{V}=$ neotropisches Gebiet.

Beborstung unvollständig. Es fehlen am Kópfe die Ocellarborsten und Postverticalen - die Occipitalbürstchen sind fast verkiimmert -, am Thorax die Humerale, die Präsuturale, die Dorsozentralen (1) und die Sternopleuralen. - Fühler verlängert.

D a cina s. lat. . . . . . . . 1

- Beborstung vollständig. Nur ausnahmsweise fehlt eine oder die andere der folgenden Borsten, nie alle zugleich: Ozellare, Postverticale, Präsuturale, Dor'sozentrale oder Stemopleurale. (2) Occipitalbörstchen mehr oder weniger stark entwickelt. Fïhler gewöhnlich kur\%.

Tephritina s. str.

1. Schenkel ventral mehr weniger gedornt. Thoraxyuernaht durchlaufend. Hinterleib lang, zylindrisch.

Adramina

- Schenkel ventral nicht gedornt. Thoraxquernaht in der Mitte unterbrochen. Hinterleib eiförmig oder keulenförmig . . . 3

2. Fühler anßergewöhnlich verlängert, zweimal so lang wie das Gesicht und vorgestreckt. Ovipositor flach gedrückt.

Meracanthomyia Hendel (1910) III.

typ. maculipennis Macqu.

- Fühler nicht besonders verlängert, so lang wie das Gesicht, herahlı̈̈ngend. Ovipositor konisch.

Adrama Walker (1859) III.

typ. selecta Walk.

3. Hinterleib keulenförmig, an der Basis gestielt

- Hinterleil) eiförmig umrissen, nicht gestielt.

Dacina s. str.

- Hinterleib lang gestreckt, schlank, $\subsetneq$ mit sechs sichtbaren Segmenten vor dem Ovipositor. Auf dem Kopfe sind nur vier aufrechte Borsten vorhanden, zwei Orbitale in der Stirnmitte und zwei Scheitelborsten. Arista langgefiedert.

Neosophira Hend. (1914) III.

typ. distortı Walk. 
4.*) I)iscoidalis an deg Mindung atwas anfyelogen, die erste llintryrandzelle dort etwas varengt. Rarlialis wellig geschwungen, mit Aderanhängen verselın. O mit ïher körperlangem, gebogenem, zylindrischem (Ovipositor. Toxotrypana Gerst. (1860) V.

typ. curvicauda Gerst.

- Discoidalis an Encle nicht aufgebogen, erste Hinterrandzelle nicht verengt. Ratdialis normal. (Ovipositor von anderer Gestalt.

Calantra Walker (1860) III.

typ. smicroides Walk.

5. Präscutellarborsten felılen, Scapulare rudimentär . . . . 6

- Beide Borstenarten vorhanden . . . . . . . . . 7

6. Ovipositor flach. Hinterleib kurz und gerundet, mit deutlicher Segmentation.

Dacus Fab. (1805) I.

typ. oleae Gmel.

- Ovipositor zylindrisch. Hinterleil) länglich, mit verwischter Segmentation.

Leptoxyda Macqu. (1835) II.

typ. longisty'a Wiedem.

7. Fiügel ohne Querbinden.

Chaetodacus Bezzi (1913) III.

typ. ferrugineus Fab.

- Flïgel mit Querbinden.

Bactrocera Gnér. Menv. (1838) JII.

typ. umbrosa Fab.

8. Fliigel nicht ..gegittert", sondern bandiert oder braungefleckt oder glashell (3); sind sie braun mit größeren weißen Fleeken und Randeinschnitten, so daß ein Zweifel entstïnde, dann sind zugleich sechs Schildborsten rorhanden oder das Dor'sozentralborstenpaar stelit ganz hinten und mindestens linter der vordersten Supraalarborste und zugleich ist die Cubitalis beborstet . . . . . . . . . . . . . .

-. Flïgel „gegittert" oder wenigstens mit gegitterten Querbinden. Das Dorsozentralborstenpaar steht stets vor der ersten Supraalaren, der Quernalit des Riickens nahe. Cubitalis beborstet oder nackt . . . . . . . . . . . . 118

9. Das Dorsozentralborstenpaar steht ganz hinten, etwas vor dem Präscutellarpaar, mindestens aber noch hinter der geraden Ver-

*) Sind die Augen lang gestielt, so käme Pelmatops Ender1. 1912. (typ. ichncumoncus Westw.) O. Indien in Betracht, die ich für eine Tephritine halte.

Diplochorda O. S. (1881) ist keine Dacine, wie ich in den Genera Pyrgotinae angab, sondern bildet nach meiner jetzigen Anschauung mit Phytalmia, - Ingitula, Angituloides u. a. eine eigene Subfamilie Phytalmiinae Bigot, die zwischen Tephritinae und Tylinae (Micropezinae) zu stehen kommt.

Cardiacer Maequ. (1847) (typ. dispar Mequ., Tasmanien) halte ich für eine Pyrgotine. 
bindungslinie der vordersten Supraalarborste oder es fehit auch ganz .

- Das Dorsozentralborstenpar seht in oder vor der geraden Verbindungslinie der vorderen Supraalarborsten . . . . 72

10. Schenkel ventral gedornt ${ }^{*}$ ) . . . . . . . . . . 11

— Schenkel olne Bedornung. . . . . . . . . . . . . . 13

11. Fühler länger als das Gesicht. Hinterleib fast streifenförmig schlank. Kleine Querader jenseits der Mitte der Discalzelle. Alle Schenkel stark bedornt

- Fïhler kiirzer als das Gesicht. Kleine Querader vor der Mitte der Discalzelle. Hinterleib eiförmig, oben stark gewölbt. Präscutellare fehlen. Nur die vier hinteren Schenkel zart berlor'nt.

Callistomyia Bezzi (1913) III. typ. pavonina Bezzi.

12. Flïgel mit vier schmalen braunen Querbinden.

Conradtina Enderl. (1911) II. typ. longicornis Enderl.

Flügel an der Spitze breit braun, mit ein bis zwei weißen Apicalflecken, an der Wurzel mit ein bis zwei braunen Querbinden.

Celidodacus n. g. II.

typ. apicalis n. sp. S. Nigeria.

13. Ceratitis-ähnliche Fliegen. Der Flïgel ist in der Nähe der Basis erheblich verbreitert, die Mediastina entfernt sich in ihrem ganzen Verlaufe in einem konvexen Bogen von der Subkosta, die kleine Querader steht nie jenseits der Mitte der Discalzelle, die hintere Querader bildet mit der Posticalis nie einen stumpfen, meist aber einen spitzen Winkel, die Analzelle ist aufen durch eine "wurmfirmig" gekriimmte Querader abgeschlossen; stets $\| n \mathrm{r}$ vier Scutellare. - Flügel an der Wurzel meist durch punktund strichartige Zellkerne hell und dunkel getleckt, jenseits derselben mit folgenten vier, mehr oder weniger vollstündigen schiefen Querbinden, die strablig rom Vorlerrande des Flügels aus zum Hinterrande laufen: erste Binde durch die Wrurzelhälfte der Discalzelle übel die kleine Querader zur Analismiindung, zweite Binde iiber die lintere Querader zur' Posticalismiindung, dritte Binde schief dureh den letzten Abschnitt der I)iscoidalis (kann auch rudimentïr sein orler fehlen), vierte Binde lüngs der Kosta zur Flïgelspitze . . . . . . . 14

*) Atopognathus Pigot (1881) III (typ. platypalpus Big., Ternate) hat flügelartige Anhänge an den Backen ( $\left.\sigma^{\prime}\right)$. Wahrscheinlich Ihythatmyide.

Wiener Entomologische \%eitung, XXXIII. Jahrg., Ileft III $น$. IV (30. April 1914) 
- Fliegen, auf die der Komplex obiger Merkmale nicht zugleich paßt. Ist die Fliigelbandierung ähnlich, so bildet die hintere Querader mit der Posticalis einen stumpfen Winkel, oder die erste Binde geht $\mathrm{nicht}$ ïber die kleine, die zweite nicht iiber die hintere Querader . . . . 16

14. Drittes Fühlerglied verlängert, oben gerade und vorne mit scharfer Ecke . . . . . . . . . . . . . . 15

- Drittes Fühlerglied vorne abgerundet, ohne Ecke und Spitze. Ceratitis Mc. Leay (1829) sens. lat. I, II, III, V. typ. capitata Wied.

15. Die durchlaufende Querbinde iiber die lintere Querader senkrecht und der ganzen Länge nach von der vorhergehenden getrennt, auch an der Kosta. Kleine Querader auf der Mitte der Discalzelle.

Acroceratitis Hend. (1913) III. typ. plumosa Hend.

- Die Querbinde ïber die hintere Querader schief und vorne mit dem zusammenhängenden Kostalsaume verbunden. Kleine Querader vor der Mitte der Discalzelle.

Chelyophora Rond.*) (1875) III. typ. borneana Rond.

16. Arista lang gefiedert . . . . . . . . . . . 17

- Arista nicht gefiedert, höchstens behaart . . . . . . . 46

17. Sechs Schildchenborsten . . . . . . . . . . 18

- Vier Schildchenborsten . . . . . . . . . . . 29

18. Radialis wellig geschwungen . . . . . . . . . . 19

- Radialis nicht wellig geschwungen. (Dorsozentralborsten vorhanden) . . . . . . . . . . . . . 23

19. Queradern einander stark genähert, weniger als die Länge der kleinen voneinander entfernt. Erste Hinterrandzelle an der Miindung durch plötzliches Zusammenbiegen der zwei Läıgsadern stark verengt. Radialis beiderseits mit Aderanhängen versehen, welche Brïcken mit der ersten und dritten Längsader herstellen.

Polyara Walker (1859) III. typ. insolita Walk.

- Fliigeladerung anders gestaltet

20. Endabschnitt der Discoidalis wellig aufgebogen, erste Hinterrandzelle daher an der Miindung verengt. Fliigel mit Quer-

*) syn. Stictaspis Bezzi (1913). 
binden. Basalzellen sehr lang und schmal. Nur eine untere Orbitalborste.

Colobostroter Enderlein (1911) III. typ. pulchralis Enderl.

- Erste Hinterrandzelle an der Miindung nicht verengt. Flïgel dunkelbraun mit größeren weißen Flecken am Rande und einigen wenigen in der Vitte . . . . . . . . . . . 21

21. Gesicht stark konvex, am Mundrande zuriickweichend. Fühler kiirzer als das halbe Gesicht. Vordere obere Orbitalborste in vordersten Stirnviertel stehend, sehr stark. Vier Supraalare. Sechs gleichstarke Scutellare. Stirne nach oben hin verengt. Posticalis nackt. Radialis schwach geschwungen.

Themaroïdes n. g. III.

typ. quadrifera Walk.

- Gesicht konkav, mit vortretendem Mundrande. Fuihler etwas kiirzer als das Gesicht. Vordere der oberen Orbitalborsten weiter hinten stehend. Drei Supraalare. Die mittleren Schildborsten schwach. Stirne parallelrandig oder vorne verengt . . . 22

22. Sternopleuralborste vorhanden. Winkel der hinteren Querader mit der Posticalis spitz. Dritte und vierte Längsader nach außen mehr weniger deutlich divergierend.

Themara Walker (1S57) II, III. typ. maenlipennis Westw.

- Sternopleurale fehlend. Winkel der hinteren Querader mit der Posticalis stumpf. Dritte und vierte Längsader parallel. Flügel vorne rotgelb, hinten braun mit zwei hyalinen Buchten.

Themarictera n. g. II.

trp. rufipennis n. sp. S. Nigeria.

23. Erste, dritte und fünfte Längsader beborstet . . . . . . 24

- Posticalis nicht beborstet . . . . . . . . . . . 25

24. Fühler länger als das halbe Gesicht. Untere Orbitalborsten nach vorne und einwärts gebogen. Mittel- und Hinterschienen ohne besondere Borsten. Drei Supraalare. Mittelschienen am Ende ähnlich wie bei folgender Gattung, aber schwächer gedornt, nur mit zwei stärkeren Endspornen.

Trypanocentra $\mathrm{n}$. g. IIl.

typ. nigripennis n. sp.

- Fübler und Gesicht wie bei Themaroides angegeben. Untere Orbitale nach aufwärts gebogen, sehr stark. Mittelschienen mit einem Kranze von Enddornen, darunter drei starke und posterior mit drei Borsten. Hinterschienen antero-ventral mit zwei bis drei Borsten, dorsal mit der gewöhnlichen Borstenreihe. Mittel- 
schenkel vorne stark beborstet. Hinterschenkel ventral mit zwei starken Borsten.

Themarohystrix n. g. III. typ. crinaceus n. sp.

25. Fliigel braun, mit weißen Einschnitten am Rande.

- Flügel hyalin und ockergelb, mit braunen und gelben Längsstriemen und Wischen

26. Kileine Querader auf der Nitte der Discalzelle. Präsuturale fehlt.

Sophiroïdes n. g. III,

typ. fammosa n. sp. Ceylon.

- Kleine Querader jenseits der Mitte der 1)iscalzelle.

Sophira Walker (1857) III.

typ. venusta Walk.

27. Augen schmal und hoch.

Diarrhegma Bezzi (1913) III. typ. modestum Fabr.

- Augen rundlich

28. Arista gekämmt, nur auf der Oberseite mit Fiederstrahlen. 1. Hinterrandzelle an der Miindung durch eine Aufbiegung der Cubitalis erheblich erweitert. Winkel der hinteren Querader mit der Posticalis stumpf. Thorax im Verhältnis zum Kopfe sehr massig.

Rioxa Walker (1857) III.

typ. lanceolata Walk.

- Arista beiderseits gefiedert. Letzter Abschnitt der Cubitalis nach abwärts gebogen. Winkel der hinteren Querader mit der Posticalis meist spitz.

Rioxoptilona n. g. III, typ. vaga Wiedem.

29. Kileine Querader viel länger als ihr Abstand von der hinteren. Ihr gegeniber ist die Radialis in kurzer Welle stark gebogen und mit der Miindungsstelle der Subkosta verbunden. Tor ihr ist die Discoidalis in die Discalzelle eingebaucht. Erste Hinterrandzelle an der Mündung plötzlich stark zusammengezogen.

Henicoptera Maequart (1847) III, flara Macqu.

- Flügelgeädler nicht derartig kompliziert

30. Die Flïgelzeichnung besteht aus einem groben braunen QuerHeck, der beide Queradern umschliebt und den Hinterrand erreicht, aus einer kurzen braunen Querbinde an der ITurzel des Flïgels, vom Randmale bis zu den Queradern der Wurzelzellen und aus einem bis zwei schiefen apikalen oder subapikalen Spitzenrandstriemen.

Lagarosia V. d. Wulp. (1891) III. typ. lacteatir V. d. Wulp.

- Flügel anders gezeiclinet 
31. Flïgel mit Querbändern, wenigstens mit einem solchen in der Mitte, das auch hinten mit dem Braun des Flügels mehr weniger verbunden sein kann . . . . . . . . . . . . 34

- Fliigel braun mit hyalinen Randeinschnitten und Flecken in der Mitte. . . . . . . . . . . . . . . . 32

- Flïgel hyalin mit gelben oder braunen Längsstriemen, -Flecken oder - Wischen

32. Ocellarborsten kräftig vorhanden. Drei untere Orbitale. Präsuturale und Dor'sozentrale vorhanden. Drittes Fiihlerglied oben an Ende spitz.

Phaeospila Bezzi (1913) III. typ. varipes Bezzi.

- Ocellarborsten fehlen

33. Zwei bis drei untere Orbitale. Dorsozentrale vorhanden. Hinterschenkel ventral meist mit zirka vier Borstenharen. Cubitalis ganz beborstet.

Ptiloniola n. g. II. typ. Preussi n. sp. Kamerun.

- Eine untere Orbitale. I'räsuturale und Dorsozentrale fehlen.

Ptilona v. d. Wulp (1880) III. typ. Urericornis v. d. Welp.

34. Ocellare fehlen 35

- Ocellare vorhanden, wenn auch kleiner 38

35. Humerale fehlen. Dorsozentrale und Sternopleurale vorlanden. Fliigel mit Ceratitis-artiger Zeichnung.

Anoplomus Bezzi (1913) III.

typ. Hexuosus Bezzi.

- IIumerale vorhanden. Flïgelzeichnung nicht Ceratitis-artig • 36 36. Arista nur aul der Oberseite gefiedert. Fiihler unterhalb der Augenmitte inseriert.

x) Keine unteren Orbitalborsten.

Chaetellipsis Bezzi (1913) III. typ. paradoxa Bezzi o’.

ß) Untere Orbitalborsten vorhanden.

Poecillis Bezzi (1913) III. typ. judicanda Bezzi ㅇ.

- Arista beiderseits gefiedert. Fühler gegenïber oder oberhalb ler Augenmitte inseriert . . . . . . . . . . . . . 37

37. Strernopleurale fehlt. Nur cine untere Orbitalborste. lorsozentrale vorhauden. Uvipositor Hach. Radialis wellig.

Colobostrella n. g.. III.

typ. ruficauda n. sp. Celebes.

Wiener Entomologisele Zeitung, XXXIII. Jalırg., II eft III u. IV (30. April 1914). 
- Zwei bis drei untere Orbitale. Sternopleurale vorhanden. Jorsozentrale fehlen mindestens dem $Q$. Ovipositor konisch. Radialis nicht wellig.

Euphranta (4) Loew (1862) I, III. typ. connexa Fabr.

38. Fiihler so lang wie das (iesicht. Drittes Glied lang linear. Hinterleib mit schwarzen Flecken. Iie mit dem Spitzenrandsaume zusammenhängende, fast senkrechte Flïgelquerbinde läuft uiber die hintere Querader. Molynocoelia Gigl..Tos. (1893) V. typ. lutea Gigl.-Tos.

- Fiihler kiirzer als das Gesicht

39. Beide Queradern gerade. Hinterleib gelb mit schwarzen Querbinden oder wenigstens basal gelb. Flügel hyalin mit braunen Querbinden oder wenigstens basal gelb. Fligel hyalin mit braunen Querbinden .. . . . . . . . . . 40

- Beide Queradern wurzelwärts hinein gebaucht. Hinterleib glänzend schwarz. Flïgel dunkelbraun mit einer weißen Längsstrieme, die schief hinauf durch die Discalzelle in die erste Hinterrandzelle zieht und hier stumpfwinklig nach unten umbiegt. Hintere Querader mit der Posticalis einen stumpfen Winkel bildend . 41 40. Ende des dritten Fühlergliedes rund . . . . . . . 40x)

- Irittes Fühlerglied mit scharfer Ecke.

Acrotaeniostola n. g. III. tpp. sexvittata n. sp. Formosa.

$40 \propto$. Ocellare rudimentär.

Gastrozona Bezzi (1913) III. typ. fasciventris Macqu.

- Ocellare stark entwickelt. Taeniostola Bezzi (1913) III. typ. viltigera Bezzi.

41. Ocellare fehlen. Acht untere Orbitalborsten; die vorderste der zwei oberen im obersten Viertel der Stirne.

Carpophthorella n. g. III.

typ. magnifica n. sp. Formosa.

- Ocellare vorhanden. Irei untere Orbitale; die vorderste obere steht in der Stirnmitte. Carpophthoromyia Austen (1910) II (5). typ. vittata Fabr.

42. Kleine Querader auf oder vor der Mitte der Discalzelle stehend. Cubitalisende abwärts gebogen

- Kleine Querader jenseits der Mitte der Discalzelle stehend . 45

43. Nur cine untere Orbitalborste. Radialis gerade.

Dimeringophrys Enderl. (1911) II. typ. ortalina End.

- Zwei bis drei untere Orbitalborsten. Radialis wellig, an der Basis und vor der Mïndung der Cubitalis näher als in der 
Mitte. Flïgel mit drei gegen die Spitze hin divergierenden gelben Längsstriemen . . . . . . . . . . . . . . .44 44

44 Ocellare fehlen. Kleine Querader ungefähr auf der Mitte der Discalzelle steliend.

Xanthorrachis Bezzi (1913) III. typ. Annandalei Bezzi.

- Ocellare vorhanden. Kleine Querader über dem ersten Fünttel der Discalzelle stehend. Kopf balancierend, unterhalb der Nitte inseriert, höher als lang. Xanthorrachista n. g. II. typ. cephalia n, sp. O.-Afrika.

45. Erste Hinterrandzelle parallelrandig.

Euphranta (4) Loew (186:) I, III. typ. connexa Fabr.

- Erste Hinterrandzelle an der Mündung durch Aufbiegen der Cubitalis erheblich elweitert. Icteroptera v. d. Wulp. (1898) III. typ. limbipennis v. d. Wulp.

- Erste Hinterrandzelle durch Zusammenbiegen der dritten und vierten Längsader auffällig verengt. Radialis gerade. Fliigel lang und schlank, braun, nur am Hinterrande hyalin. Ocellare, Dorsozentrale und Präsuturale fehlen.

\section{Felderimyia n. g. III.}

typ. fuscipennis n. sp. O.-Indien.

46. Schild mit sechs oder mehr Randborsten . . . . . . . 47

- Schild mit zwei bis vier Randborsten . . . . . . . . . .53

47. Fühler eineinhalbmal so lang wie das Gesicht. Arista im ganzen verdickt. Kleine Querader im Wurzelviertel der Discalzelle steliend.

Ceratodacus n. g. V.

ıyp. longicornis n. sp. Peru.

- Fühler kürzer als das Gesicht, höchstens so lang wie dieses . 48

48. Schildchen zirka die Hälfte des Thoraxrïckens lang, flach, oben dicht und fast rauh behaart und am Rande mit zehn starken Borsten besetzt. Fliigel ganz braun, nur an der Spitze und am Hinterrande heller gefärbt. Ocellare fehlen.

\section{Xarnuta Walker (1857) III. \\ typ. le ucotela Walk.}

- Schild kürzer, oben nackt oder fast nackt, an Rande mit sechs Borsten. Ocellare nicht vorhanden

49. Radialis deutlich wellig geschwungen. I'osticalis nackt. Flügel dunkelbraun, mit größeren weißen Randeinschnitten und kleineren weißen Flecken in der Nitte. Themara Walker (1857) II, III.

typ. maculipcnnis Westw.

- Radialis nicht wellig 50

Wiener Eutomolugische Zeitung, XXXIII. Jahrg., Heft III U. IV (30. April 1914). 
50. Stirn mindestens so breit wie der halbe Kopf. Beide Queradern einander genähert. P'osticalis nackt. Die Flügelzeichnung besteht aus wenigen unregelmäßigen braunen Flecken.

\section{Xenochaeta Snow (1894) IV.}

typ. dichromata Snow.

- Stirn viel schmäler als die Kopflälfte. Die kleine Querader steht $\mathrm{um}$ dis Nitte der Discalzelle herum. Flügrelzeichnung nicht gefleckt . . . . . . . . . . . . . . . . . 51

51. Spitze der Analzelle kiirzer als der Rest der Analis. Die vordere der zwei oberen Orbitalbor'sten oberhalb der Stirnmitte. - Fliigel nicht auffällig verbreitert, in der Spitzenhälfte glashell, mit einer breiten braunen Querbinde iiber die hintere (unerader, die aber auch breit mit dem Braun der Flïgelwurzel zusammenhängen kann. Mit ihr ist vorne mindestens ein Spitzenrandsaum oder auch noch eine schiefe Subapikalbinde verbunden.

Hexachaeta Loew (1873) V.

typ. eximia Wiedem.

- Flïgel breit und ahgerundet, an der Spitze nicht bandiert, sondern dunkelbraun mit größeren weißen Flecken am Rande und kleinen in der Mitte . . . . . . . . . . . . 52

52. Hinterschenkel ventral beborstet. Analzellenzipfel kürzer als der Rest der Analis.

Hexacinia n. g. III. typ. stellata Macqu.

- Hinterschenkel ventral ohne Borsten. Analzellenzipfel länger als der Rest der Analis. Die vorlere der zwei oberen Orbitalen steht auf der Stirnmitte. Blepharoneura Loew (1873) V. typ. poecilosomu Schiner.

อ3. Analzelle bauchig begrenzt. Posticalis nackt. Radialis stark wellig gebogen. Discoidalis vor der kleinen Querader bauchig hinabgebogen.

Neoacanthoneura n. g. V. typ. magnipennis n. sp. Peru.

- Analzelle unten in eine Spitze ausgezogen . . . . . . .54

54. Posticalis beborstet. Kosta gewimpert. Radialis wellig geschwungen. Kopf beim ơ verbreitert, weniger heim $q$.

Acanthoneura Macquart (1843) III.

typ. fuscipennis Macqu.

- Posticalis nicht heborstet. Kosta nicht gewimpert. . . . 55

55. Kopf aufgetrieben, besonders der Hinterkopf hinter den Augen vortretend. Stim vorne zweimal so breit wie ein Auge, der länge nach vertieft, die beim on mit griffelartigen Borsten besetzten stirnorbiten leistenartig erhöht.

Straussia Rob. Desv. (18:30) IV.

typ. longipennis Wiedem. 
- Hinterkopf oben an Scheitel nicht geschwollen, nicht hinter den Augen vortretend . . . . . . . . . . . . 56

56. Stirn neben den Fühlern er hebli ch schmäler als ein Auge . 57

- Stirn dort kaum schmäler bis zweimal so breit wie ein Auge . 59

57. Stirn parallelrandig, mehrfach länger als breit . . . . 58

- Stirn gegen den Scheitel hin breiter werdend. Stirn des $\sigma^{\top}$ mit ähnlicher Bildung wie bei Straussia angegeben.

Vidalia Rob.-Desv. (18:30) III.

typ. impressifrons R. D.

58. Kleine Querader in der Mitte der Discalzelle. Fliigelvorderrand gelb, zwei sehiefe Binden der Spitze und ein Saum der hinteren Querader braun.

Poecilothea n. g. III.

typ. angustifions n. sp. Formosa.

- Queradern einunder stark genähert. Flïgelzeichnung schwarzbraun. х) Rostfarbige Art mit gepolstertem Hinterkopf.

Acidiella n. g. III.

typ. longipennis n. sp. Formosa.

ß) Hinterkopf auch unten flach, nicht gepolstert. Schwarze Arten.

Pseudospheniscus Hend. (1913) III.

typ. angulatus Hend.

- Kleine Queraler etwas jenseits der Mitte der Discalzelle. Gelbe Arten.*) Flügel hyalin mit gelben Querbinden.

Acidoxantha n. g. III.

typ. punctiventris n. sp. Formosa.

59. Hinterleib lang und sehr schlank, nach hinten zu etwas keulig verdickt. Fliigel fast hyalin. Untergesicht stark eingedrückt, ohne Mediankiel, an den Seiten durch scharfe Randleisten begrenzt, vorne wallartig in die Höhe gebogen.

Coelopacidia Enderl. (1911) Ir.

typ. madagascariensis End.

- Fliegen von anderem Typus

60. Backen mindestens die Hälfte eines Auges hoch. Unterer Hinterkopf stark vortretend, gepolstert

- Backen niedriger. Unterer Hinterkopf nicht besonders gepolstert 62 61.**) Drittes Fiihlerglied vorne abgerundet. Hinterschienen anterodorsal ohne Borstenreihe. Keine Sternopleurale. Radialis gerarle. Augen lotrecht oval. Ovipositor konisch. Platyparella n. g. I.

typ. discoülea Fabr.

*) Flügel braun, mit einigen weißen Flecken and Randeinschnitten and einem schwalbenschwanzartigen Zipfel am Hinterrande. Machaomyia n. g. III, typ. callate n. sp. Formosi.

**) IIieher gehört wahrscheinlich auch die mir unbekannte, nicht einreihbare Gattung Macrotrypeta Portschinsky (1892) I, typ. ortulidina Portsch. 
- Drittes Fühlerglied vorne oben mit Spitze. Hinterschienen anterodorsal mit Borstenreihe. Sternopleurale vorhanden. Radialis geschwungen. Augen queroval. Ovipositor flach, mit Seitenkanten.

Platyparea Loew (1862) I. typ. poecilopterc Schrank.

62. Discoidalis an der Mündung mehr weniger aufgebogen, dieselbe verengend. Dorsozentralborsten ganz hinten stehend. Ovipositor lang und drehrund.

Anastrepha (6) Schiner (1868) V. typ. serpentina Wiedem.

- Discoidalis nicht aufgebogen. Ovipositor mit Seitenkanten. 63

63. Subkosta vor der Mïndung plötzlich rechtwinklig aufgebeugt und verdickt. Hintere Querader so sehr schief gestellt, daß die I)iscalzelle oben nicht länger als die zweite Basalzelle ist.

Phagocarpus Rondani (1871) I, III. (Anomoed Walk.) typ. permundus Harris.

- Subkosta spitzwinklig mündend. Hintere Querader nicht auffällig schief gestellt. Discalzelle länger . . . . . . . . 64t

64. Entfernung beider Queradern von einander viel kleiner als die Länge der linteren Querader beträgt. Cubitalis der ganzen Lïnge nach beborstet. Stirn parallel, so breit wie ein Auge, $1 \frac{1}{2}$ mal so lang wie breit. Neanomoea I. g. III.

typ. approximata n. sp. Formosa.

- Queradern weiter von einander entfernt

65. Ocellarborsten fehlen. Nur eine obere Frontorbitalborste . 66

-- Ocellare vorhanden. Zwei obere Orbitale. . . . . . . . 68

66. Matt bestäubte Arten. Kopf des $\delta^{\lambda}$ olne besondere Beborstung . . . . . . . . . . . . . . 67

- Glänzende Arten. Kopf des $\sigma^{\top}$ mit ähnlicher Beborstung wie bei Straussia beschrieben. Stemonocera Rond. (1870) I.

typ. cornuta Scop. (1772).

67. Drittes Fiihlerglied dreimal so lang wie breit. Köorper schlank, verlängert.

Staurella Bezzi (1913) II, III. typ. crux Fabr.

- Drittes Fiihlerglied 1\%⿺ mal so lang wie breit. Körper gedrungen.

Rhacochlaena Loew (1862) I, II. typ. toxoneura Loew.

68. Drittes Fiihlerglied linear, viermal so lang wie breit. Augen fast doppelt so hoch wie lang. Ḱleine Querader stark schief gestellt.

Cryptodacus n. g. V.

typ. obliquus n. sp. Bolivia. 
- Drittes Fühlerglied oval. Augen mehr rundlich. Ḱleine Querader senkrecht

69. Drittes Fühlerglied vorne oben mit scharfer Ecke.

Zonosema Loew (1862) I, III.

typ. Meigeni Loew.

- Drittes Fïhlerglied vorne abgerundet

70. Kleine Querader deutlich vor der Discalzellenmitte stehend. Peristomalien, namentlich beim $\sigma^{\pi}$, beborstet.

Chaetostoma Rond. (1856) I.

typ. curvinervis Rond.

- Kleine Querader nicht vor der Mitte der Discalzelle stehend. Peristomalien ohne stärkere Borsten . . . . . . . 71

71. Fliigel mit „Bächen“, d. l. Querbinden, die abwechseld bald vorne, bald hinten zusammenhängen. An der Spitze stets mit einer schiefen Querbinde durch die Discoidalis.

Acidia Rob. Desv. (1830) I, IIT?

typ. cognata Wiedem.

- Flügel mit in isolierte Flecke aufgelösten Querbinden.

Phorellia Rob. Desv. (1830) (Spilographa Loew) I, III, IV, V. typ. artemisiae Fabr.

72. Schild mit sechs Borsten 73

- Mit zwei Borsten 75

- Mit vier Borsten

73. Arista lang gefiedert.

Themara Walker (1857) II, III. typ. maculipennis Westw.

- Arista höchstens pubeszent

74.*) Wurzelzellen lang und schmal, zirka viermal so lang wie breit und beide gleichlang.

Phorelliosoma n. g. III. typ. hexachaeta n. sp. Formosa.

- Wurzelzellen kurz, Analzelle kïrzer als die zweite Basulzelle. (Siehe auch bei Nr. 50.) Xenochaeta Snow. (1894) IV.

typ. dichromata Snow.

75. Kleine Querader erheblich von der Mitte der Discalzelle stelend. Diese kïrzer als der letzte Abschnitt der vierten längsader.

Rhithrum n. g. V.

typ. rimulatum n. sp. Peru.

- Kleine Querader jenseits der Mitte der Discalzelle

*) Von diesen zwei Gattungen mag sich durch unbeborstete Cubitalis und spitzenlose Analzelle die mir unbekannte Gattung Rhyncheterus Rond. (1865) I, typ. damascenus Rond. unterscheiden. 
76. Queradern fast ïbereinanderstehend, senkrecht auf den Längsadern. Sie werden von einer gremeinsamen durchlaufenden Querbinde bedeckt, die mit zwei Längsbinden zusammenhängt, welche teils längs des Fliigelvorderrandes, teils längs der Posticalis bis zur "Wurzel hinzielsen. An rler Fligelspitze noch eine Querbinde und ein Apikalfleck.

Phaeogramma Grimshaw (1901) III. typ. rittipennis Grimsh.

- Queradern nicht so stark genähert

77. Riüssel stark verlängert und gekniet. Fliigel braun gefleckt, Mundrand hinaufgezogen. Hetschkomyia n. g. V.

typ. maculipennis n. sp. Peru.

- Riissel nicht verlängert und gekniet 78

78. Fliigel auffallend breit und an der Spitze rund, vorne konvex, dunkelbraun, in der W'urzelhälfte vorne and hinten mit weilien Randeinschnitten, in der Mitte mit weißen l'unkten und an oder vol" der Spitze mit weißer "Sichelrandbinde".

Pseudeutreta n. g. V. typ. adspersa Wiedem.

- Flïgel schlanker', nicht von rundlichem Umrisse, stets ohne weile "Sichelrandbinde" der Spitze . . . . . . . . . 79

79. Glänzend schwarze, unbestäubte Arten . . . . . . 81

- Thorax und Schild matt bestäubt . . . . . . . . . . 80

80. Flügel mit vollkommenen Querbinden.

Pseudoedaspis n. g. V. typ. biseta n. sp. Argentinien.

- Fliigel mit braunen Flecken. Celidosphenella n. g. V. typ. maculata n. sp. Chile.

81. Postocularcilien scliwarz oder dunkel.

Aciura Rob. Desv. (1830) I, II, III. typ. earyli Rossi.

- Postocularcilien gelb

82. Radialis und Discoilalis gerade.

Tephrella Bezzi (1913) III. typ. decipiens Bezzi.

- Radialis anfgebogen. Discoidalis jenseits der stark schiefen linteren Querader aufgebaucht. Xanthaciura n. g. IV, v. typ. chrysura Thoms.

83. Hintere Querader stark schicf gestellt, mit der Posticalis einen spitzen Winkel bildend, so daf die Discalzelle oben gemessen kiirzer als der letzte Abschnitt der Discoidalis ist. Erste Hinter- 
randzelle unter der Fliigelspitze mindend und dort erweitert. Eine weibe sichelquerbinde an der Flügelspitze orler vor derselben. Sonst bestelit die Fliigelzeichnung aus weilien Einschnitten am Rande und rinigen Punkten in dex Mitte.

Polymorphomyia Snow (1894) V.

typ. basilica Snow.

- Hintere Querader nie so schief gestellt, dals dic I)iscalzelle kürzer als der letzte $\Lambda$ bschnitt der vierten Lüngsader ist . 84

84. Cubitalis von der Basis her oben in größerer Ausdehnung deutlich beborstet. . . . . . . . . . . . 85

- Cubitalis oben nackt oder fast nackt (7) . . . . . . . 98

85. Schild stark gewölbt, glänzend, wie poliert . . . . . . 86

— Schild n icht geschwollen . . . . . . . . . . 87

86. Schild ohne Nedianvertiefung. Flïgel mit vier bis fünf schiefen dunkelbraunen Querbinden und genäherten Querarler'n.

Cecidochares Bezzi (1910) V.

typ. rufesecns Bezzi.

- Schild mit Medianfurche, zweihöckerig. Die Flïgelquerbinden sind gelb und teilweise braun gerandet.

Peronyma Loew (1873) V.

typ. sarcinata Loew.

87. Kopf länger als hoch, Augen wagrecht oval. Fiihler doppelt so lang wie das kurze Gesicht, herabhängend. Schr lange und schlanke Art. Vorderbeine verkiirzt. Mittelschenkel verlängert und rerdickt. Mesoplemra hinter den Vorderhiiften mit eincr behorsteten Kante.

Phantasmiella n. g. III.

typ. cylindrica n. sp. Formosa.

- Von anderer Gestalt

88. Arten, deren Riicken der Länge nach und deren IIinterleib der Quere nach schwarz gebändert sind. Ocellare stark. Arista lang gefiedert.

Taeniostola Bezzi (1913) III.

typ. nttigera Bezzi.

- Nicht derart schwarz gestriemte Arten. Arista nicht lang gefiedert . . . . . . . . . . . . . 83

89. Am Thorax ganz matt bestäubte Arten . . . . . . . .90

— Glänzende oder wenig bestäubte Arten . . . . . . . . . .91

90. 'Zwei Paare Dorsozentralbor'sten, cin I'aar vor der Nalit, ein I'aar gleich dahinter. Subkostalzelle spitzwinkelig. Flügel mit dunklem Spitzenrandsaum und zwei schiefen subapikalen Querbinden.

Polionota v. d. Wulp. (1899) V.

typ. meida Gigl. Tos.

Wiener Entomologische Keitung, XXXI[l. Jahrg., Heft III u, IV (30. April 1914). 
- Nur ein Paar Dorsozentralborsten hinter der Naht. Subkosta vor der Miindung plötzlich rechtwinklig aufgebogen, die Zelle daher sehr kurz, nicht länger als breit. Kosta im Wurzelabschnitt bis zur Mediastina beborstet. Augen doppelt so hoch wie lang.

Stenopa Loew (1873) IV.

typ. rulnerata Lw.

91. Flïgel mit meist fünf sehr schiefen, gelben, braun gesïumten Querbinden und einander gen̈̈herten schiefen und fast parallelen Queradern.

Tomoplagia Coquillett (1910) (Plagiostoma Loew) IV, I. typ. obliqua Say.

-. Fliigel mit scliwarzbrauner, anderer Zeichnung. Queradern ungefähr senkrecht stehend . . . . . . . . . . . .92

92. Arista kur'z gefiedert, Fiederbreite gleich dem des dritten Fühlergliedes. Dieses ist viermal so lang wie breit und hat oben an der Spitze eine scharfe Ecke. Kleine Querader etwas vor der Mitte der Discalzelle. Flïgel mit sechs schmalen, braunen Querbinden.

Acrotaeniostola n. g. III.

typ. sexvittata n. sp. Formosa.

- Arista nicht gefiedert. Kleine Querader jenseits der Mitte der Discalzelle. Drittes Fühlerglied viel kiirzer und vorne abgerundet

93. Ocellare fehlen. Subkosta an der Mündung plötzlich senkrecht aufbiegend, Randmal daher nur so lang wie breit. Winkel der hinteren Querader mit der Posticalis auffallend stumpf. Zipfel der Analzelle nur wenig kïrzer als der Rest der Analis.

Parastenopa n. g. V.

typ. carinata n. sp. Bolivia.

- Ocellare vorhanden. Subkostalzelle spitzwinklig auslaufend, schlank . . . . . . . . . . . . . . . 94

94. Gesicht nur die Hältte der Stirn lang, F'ïhler unterhalb der Augenmitte inseriert. Augen am Hinterrande ausgesclıweift. Letzter Abschnitt der Discoidalis nur die Hälfte der Discalzelle lang. Der Winkel der I'osticalis mit der hinteren (Querader ist spitz und berihrt mit seinem Scheitel den Hinterrand des Flügels.

Calosphenisca n. g. III.

typ. rolucris n. sp. Formosa.

- Gesicht länger. Augenrand hinten nicht ausgeschweift. Letzter Ausläufer der Posticalis deutlich sichtbar . . . . . . . 95

95. Hinterkopf flach. Stirn zwei bis zweieinlalbual so lang wie breit, schmal.

Pseudospheniscus Hend. (8) (1913) III. typ. angulatus Hend. 
- Hinterkopf gepolstert. Stirn kürzer, ungefähr so breit wie ein Auge . . . . . . . . . . . . . . 96

96. Fliigel lang und schlank, dreimal so lang wie breit, dunkelbraun und nur am Uinterrande breit hyalin, ohne Querbindenrudimente daselbst. Längsadern ger:ade, dritte und vierte parallel.

Ocneros 0. Costa (18+4) I, II, III. typ. dimidiata O. Costa.

- Flïgel mit braunen, manchmal miteinander verbundenen Querbinden

97. Discoidalis vor der kleinen Querader gerade. Die Querbinde iiber die kleine (querader ist in der Discalzelle mit dem Bram der Flïgehwurzel verbunden. - Queradern einander genähert. Letzter Abschnitt der Discoidalis ungefähr so ling wie die Discalzelle.

Philophylla Rond. (1870) I, II, IV. typ. heraclei Linné.

- Discoidalis vor der kleinen Querader Rivellicartig in die Discalzelle hineingebaucht. Die über die kleine Querader laufende Querbinde ist von dem Braun der Fliggelwurzel vollkommen getrennt. Die schiefe Querbinde unter dem Spitzenrandsaum fehlt.

Epochra Loew (1873) IV.

typ. canadensis Loew.

98. Analzelle außen durch eine gerade oder konvexe Querader begrenzt, so dafo unten keine winklig vorstehende Spitze entstelit

- Analzelle auben durch eine konkave Querader abgeschlossen, unten in eine Spitze allsgezogen . . . . . . . . . 107

99. Riissel nornıl, nicht verlängert . . . . . . . . 100

- Rïssel verlängert und knieartig geknickt. Kleine (Querader auf oder vor der Mitte der Iniscalzelle . . . . . . . . 104

100. Kleine Querader vor der Mitte der Discalzelle . . . . 101

— Ḱleine Querader jenseits der Mitte der Discalzelle . . . 102

101. Kwei l'arare Iorsozentrale. Backen niedrig, Kopf nicht autgeblasen. Erste Hinterrandzelle an der Mindung nicht verengt.

Trigonochorium Becker (1913) I.

typ. oculatum Beck.

- Ein Paar Iorsozentrale. Backen so hoch wie ein Auge. Kopf aufgeblasen. Erste Hinterrandzelle an der Miindung stark verengt.

Nearomyia Becker (1913) I.

typ. flaroraria Beck.

Wiener Entomologische Zeitung, XXXIII. Jahrg., Heft III u IV (30. April 1914). 
102. Letzter Abschnitt der vierten Längsader gerade. Fliigel glashell, meist mit drei bis vier braunen Querbinden.

Tephritis Latreille*) (1805) I, II, V. typ. solstitialis Linn.

- Letzter Absclmitt der Discoidalis jenseits der hinteren Qucrader auffällig aufgebogen . . . . . . . . . . 103

103. Augen rundlich. Hinterkopf Hach. Flügelzeichnung Aciura-artig.

Tetraciura n. gen. V.

typ. quadrisetosa n. sp. Bolivia.

- Augen erheblich höher als lang. Hinterkopf konvex. Flïgel dunkelbraun mit zwei hyalinen Buchten am Hinterrande beiderseits der Posticalis.

Hypenidium (9) Loew (1862) I.

typ. graecum Loew.

104. Erste Hinterrandzelle nicht verengt . 105

- Erste Hinterrandzelle an der Nündung erheblich verengt, oberhalb der Flügelspitze miundend. Augen rund. Fliigel mit mehreren fleckenartigen Halbbinden.

Myiopites Brebisson (1827) I.

typ. Blotii Breb.

10引. Schild mit sechs Borsten, die zwei mittleren kleiner.

Rhyncheterus Rondani (1865) I.

typ. damrscenus Rond.

- Schild mit vier Borsten .

106

106. Gesicht schnauzenartig vorgezogen, mit nasenartigem Mittellängskiel. Flügel mit vier ganzen Querbinden.

Gonioglossum Rondani (1856) I.

typ. Wiedemanni Meig.

- Gesicht ohne obige Bildung.

Asimoneura Czerny (1909) I. typ. Stroblii Czern.

107. Arista kurz; aber dicht gefiedert. I'räscutellare fehlen. Thorax und Hinterleib schlank.

Staurella Bezzi (1913) III.

typ. crux Fabr.

- Arista nur kurz pubesziert. Präscutellare vorhanden. Thorax und Hinterleib nicht schmal und verlingert . . . . . 108

108. Kleine Querader in der Nähe der Discalzellenmitte stehend. Drittes Fiihlerglied vorne oben meist mit einer Spitze . . 109

- Kleine Querader der hinteren genähert. Drittes Fühlerglied vorne abgerundet oder oben höchstens mit einer Ecke. . 111

109. Gelbe Arten mit schwarzen Flecken auf dem Rüicken und dem Schilde und gelben Flïgelquerbinden.

Carpomyia (10) A. Costa (1854) I, III. typ. vesuriana A. Cost.

*) Urophora Rob. Desv. 1830. 
- Glänzend schwarze Arten; höchstens das Schild gelb: Flïgel mit schwarzbraunen Querbinden . . . . . . . . . 110

110. Stirn so breit wie ein Auge, länger als breit.

Rhagoletis Loew. (1862) I, IV, V. typ. cerasi Linn.

- Stirn breiter als lang, doppelt so breit wie ein Auge. Thorax mit gelben Stoppelhaaren bedeckt.

Neorhagoletis n. g. V.

typ. latifrons n. sp. Bolivia.

111. Erste Hinterrandzelle an der Mïndung durch Herabbiegen der Cubitalis dentlich verengt. Flügel hyalin, mit zwei gelben Längsstriemen, an der Kosta und Posticalis.

Craspedoxantha Bezzi (1913) III.

typ. octopunctata Bezzi.

- Erste Hinterrandzelle nicht verengt. Fliigel anders gezeichnet. 112

112. Fliigelzeichnung Aciura-intig. Fliigel kurz und breit. Thoraxbehaarung und Occipitalborsten gelb.

Platensina (11) Enderl. (1911) III.

typ. sumbana Enderl.

- Flïgel mit Querbinden .

113. Schildchen stärker gewölbt, wie aufgeblasen, stark glänzend poliert

- Schildchen oben abgetlacht, nicht aufgeblasen und nach hinten zu mehr zugespitzt, wenig glänzend. Stirn schmäler, nehen den Fühlern verengt .

113. a) Stirn sehr breit, deutlich breiter als lang. Lunula auffallend grol, hoch ausgeschnitten. Körper, namentlich das Schildehen, gelb, nit schwarzen Flecken. Dritte und vierte Flïgelquerbinde hinten gegabelt.

Oedaspis Loew (1862) I.

typ. multifasciata Loew.

- Stirn höchstens so lang wie breit. Lunula mäßig ausgeschnitten. Fliegen von glänzend schwarzer Grundfarbe.

Procecidochares n. g. IV, V.

typ. atra Loew.

114. Fühler an der Wurzel einander genähert; Fiihler des ठ normal . .

- Fülıler an der Basis weiter voneinander entfernt. Zweites Füillerglied $\delta^{\pi}$ innen mit einem langen, nach vorn gerichteten Fortsatz, der oben dornartig beborstet ist.

Ceriocera Rond. (1856) I.

typ. ceratocera Hend. 
115. Occipitalbörstchen gelb . . . . . . . . . . 116

- Occipitalbörstchen schwarz. Von glänzend schwarzer Grundfarbe. Flïgel schwarzbraun mit hyalinen Ausschnitten am Vorderund Hinterrande. Queradern einander stark genähert.

Spheniscomyia Bezzi (1913) (Spheniscus Beck.) I, II, III. typ. quadrincisa Wiedem.

116. Flügelzeichnung wie bei Sphıniscomyia. Drittes Fühlerglied fast dreimal so lang wie breit. Der ganze Körper von metallisch schwarzer Grundfarbe, der Hinterleib glänzend und ganz unbestäubt.

Metasphenisca n. g. I.

typ. gracilipes Loew.

- Flügel glashell oder mit Querbinden, die auch nur als Fleckenrudimente vorhanden seiı können. Körper nie glänzend schwarz . . . . . . . . . . . . . . . 117

117. Discalzelle erheblich länger als der letzte Abschnitt der Discoidlalis. Flügel nicht milchig getriibt.

Terellia Rob. Desv. (1830) (Trypeta Loew) I, II, IV. typ. serratulae Linn.

- Discalzelle so lang wie der letzte Abschnitt der Discoidalis. Weißgrau bestäubte Arten mit milchigen Flügeln.

Neoaspilota Ost.-Sack. (1878) IV. typ. alba Loew.

118. Vorderrand des Flügels, entsprechend der Mediastina, eingeschlitzt, so daß ein beborsteter Zipfel vorragt . . . . 119

— Flïgelvorderrand ohne abstehenden Zipfel . . . . . . . 121

119. Analzelle unten ohne Spitze. Erste Hinterrandzelle an der Mïndung auffaillig erweitert. Beborstung normal . . . 120

- Analzelle unten spitzig. Erste Hinterrandzelle heinahe parallelrandig. Beborstung bald haarfein, bald stark verdickt.

Rhabdochaeta de Meij. (1904) III. typ. pulchella de Meij.

120. Stirn und Mundrand stark vorspringend. Vier Schildchenborsten. Die Cubitalis mündet an der Flügelspitze.

Schistopterum Becker (1903) II. typ. Möbiusi Beck.

- Stirn nicht vorspringend, Mundrand ein wenig vorgezogen. Sechs Schildehenborsten. Die Cubitalis mündet vor der Flïgelspitze.

Rhochmopterum Speiser (1910) II. typ. ncuropteripenne Speis.

121. Gesicht und Wiangen, meist auch die Stirn mit schwarzen Flecken und Punkten. Cubitalis beborstet. Arista wie nackt . 122 
- Stirn und Gesicht ohne schwarze Punkte, höchstens zwischen Fïhler und Auge ein dunkler Fleck . . . . . . . . . 127

122. Kleine Querader vor der Mitte der Discalzelle stehend. Fuilhler fast bis zum Mundrande verlängert. Stirn konisch, vorstehend, Gesicht zuriickweichend. Hinterschenkel unten „brevissime spinulosa".

Ischyropterum Bigot (1883) V.

typ. nigricandatum Big.

- Kleine Querader jenseits der Mitte der Discalzelle. Kopf anders geformt . . . . . . . . . . . . . . . 123

123. Flügel lang und schmal parallelogrammförmig, aufen stumpf abgerundet. Hintere Querader selir schief, mit der Posticalis einen stumpfen Winkel bildend. Alle Schenkel ventral mit gelben Borsten besetzt.

Rhachiptera (12) Bigot (1859) V.

typ. limbata Big.

- Fliigel von normalem, mehr eiförmigem Umrisse, kiirzer und breiter . . . . . . . . . . . . . 124

12t. Die Scheitelplatten und die darauf stehenden zwei oberen Orbitalborsten dringen nach vorn zwischen den die unteren Orbitalen trigenden, dem Augenrande anliegenden Wangenplatten vor. 125

- Bleiben dem Augenrande genähert und dringen nicht nach vorn innerhalb der unteren Orbitalen vor . . . . . 126

125. Untere Frontorbitale stärker als die oberen, aufrecht stehend und nach hinten gebogen. Flügel am Rande strahlig gezeichnet, innen mit Augenflecken. Paracantha Coquillett (1899) IV, V.

typ. culta Wiedem.

- I'ntere Orbitale küizer als die oberen, nach vor'n und einwärts gebogen. Flïgel fein gegittert.

Dictyotrypeta n. g. V.

typ. syssema n. sp. Peru.

126. Stirn zirka doppelt so breit wie ein Auge, parallel, gewölbt, mit breitem und stark glänzendem Ocellendreieck, Scheitelplatten und Lunula, die beulig konvex vortreten und glänzend schwarze Flecke zeigen.

Strobelia Rondani (1868) V.

typ. baccharidis Rond.

- Stirn schmäler, seicht konkav oder Hach, matt und ohne schwarze Flecke, vorn etwas verengt. Flügel sehr breit, vorn und linten stark konvexrandig.

\section{Eutreta Loew (1873) V.}

typ. sparsa Wiedem.

127. Flïgel mit folgenden dunklen und melır oder weniger deutlich hell gegitterten Striemen: einer gemeinsamen Querstrieme über

Wiener Entomologische Zeitung, XXXIII, Jahrg., Ileft III u. IV (30. April 1914). 
beide Queradern und einem Spitzenrandsaume. Riissel knieartig einschlaghar, mit verlängerten Labellen.

Sphenella*) Rob.-Desvoidy (1830) I, III. typ. marginata Fall.

- Flïgel ohne obige, heller punktierte Querstrieme . . . . 128

128. Schildchen blasig gewölbt, glänzend (schwarz), wie polielt. Körper „stoppelhaarig“ . . . . . . . . . . . . . . . 129

-- Schildchen nicht blasig und auch nicht glatt poliert . . . 130

129. Zwei Paar Dorsozentalborsten, nur zwei Schildborsten, drei untere und zwei obere Frontorbitale.

Ditricha Rondani (1856) (Carphotricha Loew) I. typ. guttularis Meig.**)

- Ein Paar Dorsozentralborsten. Vier Schildborsten. Ein bis drei I'ar untere und vier Paar obere Orbitalborsten, letztere auf einwälts geriickten Scheitelplatten.

Hoplogaster Rondani (1856) (Carphotricha Loew) I. typ. pupillata Fall.

130. Flïgel im Verhältnisse zur Länge selır breit, braun, dicht und fein lieller punktiert, an der Spitze breit gerundet, dort gelh nit hyalinen Einschnitten oder Randflecken.

Acrotaenia Loew (13) (1873) IV, V. typ. latipennis Wiedem.

- Fliigel von normalem Umrisse oder sehr lang und schmal. 131 131. Analzelle außen durch eine gerade Querader abgeschlossen, unten daher ohne Spitze. Fliigel sehr lang und schmal, parallelrandig, mit stumpfer Spitze. Stirn neben den Fïllern viel schmäler als ein Auge.

Elaphromyia (14) Bigot (1859) II, III. typ. ululu Loew.

- Analzelle unten mit einer Spitze. Flïgel nicht von schmaler streifenförmiger Gestalt . . . . . . . . . . . 132

132. Stirn viel breiter als die Hälfte des Kopfes, drei- bis viermal so breit wie ein Auge

- Stirn schmäler, höchstens doppelt so breit wie ein Auge . 134

133. Drittes Fïhlerglied verlängert, vorn mit scharfer Ecke. Gesicht zurtickweichend.

Acidogona Loew (1873) IV. typ. mclanure Loew.

- Fïhler kurz, kaum ein halb des Gesichtes lang, drittes Glied vorn abgerundet. (Fïhler an der Basis etwas entfernt ron einaniler.)

Eurosta Loew. (1873) IV. typ. solidayinis Fitch.

*) Sind die Flügel milchig und an der Spitze mit ein bis zwei ausgezackten, wenig dunklen Querbinden versehen, so liegen Neoaspilota-Arten vor.

**) Ich glaube, daß Carphotricha Andiveuxi Tavares (1901) dieselbe Art ist. 
134. Flügel dunkelbraun, im Innern mit mehr weniger zahlreichen größeren und kleineren gelben Tropfen, die dort auch vorherrschen und das Braun zu einem zerrissenen Gitter gestalten können. Der Spitzen- und Hinterrand des Fliigels bleibt aber braun und enthält nur weiße Punkte. Zwischen Fiihler und Auge häufig ein schwarzer Punkt.

Icterica Loew. (1873) IV, V.

typ seriata Loew.

-- Fliigel gelb, mit hyaliner Zeichnung, bestehend aus Einschnitten vom Rande des Fliigels her und aus einigen größeren Flecken in der Nitte.

Baryplegma*) v. d. Wulp (1899) V.

typ. gilva vo d. W.

- Fliigel mit braunem bis schwärzlichem Gitterwerk auf hyalinem, resp. weißem Grunde oder ungekehrt . . . . . . . 135

135. Stirn konvex ïber die Augen emporgewölbt. ơ Vorderschenkel verdickt. Hinterleib in der Endhälfte plötzlich fast zylindrisch verjiingt. $Q$ Ovipositor konisch. Rïssel von normaler Länge, nicht gekniet.

Camaromyia n. g. I, V.

typ. bullans Wiedem.

- Stirn Hach bis konkav. Hinterleib des $\sigma^{\pi}$ am Ende nicht plötzlich zusammengezogen. Ovipositor Hach . . . . . 136

136. Flügelgitter an der Spitze durch radiär zum Rande lin ausstrahlende braune Bändchen mehr weniger sternförmig gestaltet. Sind die Strahlenbändchen nicht entwickelt, die Spitze und der Hinterrand des Flïgels also hyalin, so bleibt nur der verschieden lange dunkle Kerntleck in wechselnder Intensität in der Vorderhälfte des Flïgels, meist subapikal gelegen, übrig 142 Flïgelgitter nicht sternfürmig gestaltet. Der Spitzen- und Hinterrand des Fligels bleiben nie hyalin, vom braunen Gitter unbedeckt. . . . . . . . . . . . 137

137. Riiissel stark verlängert, die Labellen knieartig zuriickgeschlagen und von Kopflänge.

138

- liiissel normal lang, Labellen kurz, und weun etwas verlängert und zuriickgeschlagen, so doch kürzer als der Kopf . . . 141

138. Angen wagrecht oval liegrend. Die Stime tritt an den Fühlern weit über die Augen vol, der Kopf ist doppelt so lang wie hoch, die Stiru dreimal so lang wie das kurze, schnauzenartige Gesicht.

Protensina n. g. V.

typ. Tongiceps n. sp. Peru.

- Augen lotrecht- oder schief oval. Stirn nur wenig iiber die Augen vorstehend, Kopf' und Stirn viel kürzer .

*) nec Baryphlegma.

Wiener Entomologische Zeituug, XXXIIr. Jahrg., Heft III u. IV (30. April 1914). 
139. Hinterleib ganz poliert, glänzend schwarz, beim ơ zylindrischkonisch. Genitalien grob, mit drei Paaren ventral lang vorstehender Lamellen.

Lamproxyna n. g. V.

typ. vitidula n. sp. Peru.

— Hinterleib nie unbestäubt glänzend schwarz, beim ơ nie zylindrisch . . . . . . . . . . . . . . . . . . . 140

140. Backen und Wangen sehr schmal; zwei bis drei untere Frontorbitale. Kopfrand unten gerade und lang, Mundrand stark vortretend. Stirn durchsehnittlich länger als breit, schmal. Fliigel schlank, lyyalin bis gegittert. Die Larven in Bliitenböden von Compositen.

Ensina (15) Rob.-Desv. (1830) I, II, III, IV, V. typ. sonchi Linné.

- Backen und Wangen relativ breit; nur eine untere Orbitale. Kopfrand unten konvex und kürzer, Mundrand nur wenig vorstehend. Stirn so breit wie lang oder fast breiter. Fliigel eiförmig, breiter. Die Larven erzeugen Stengelgallen an Compositen.

Oxyna (16) Rob.-Desv. (1830) I. typ. flavescens Rob.-Desv.

141. Cubitalis auf der Oberseite deutlich beborstet.

Xyphosia (17) Rob.-Desv. (1830) (Oxyphora s. Loew) I. typ. Hlava Geoffr.

- Cubitalis oben nackt oder nur undeutlich beborstet.

Euribia Meigen (1800) (Tephritis s. Loew) I, II, III, IV, V. typ. arnicae Linn.

142. Endlappen des Ruissels ctwas verlängert und zuriickgeschlagen. Das Braun des Fliigels wird von vielen kleinen weißen Punkten durchbrochen. Die braunen Strahlen am Rande und an der Spitze des Flügels sind kurz und breit, gleichartig und werden dureh ziemlich gleich große runde Tropfen separiert, die nicht tief eindringen.

Campiglossa Rondani (1870) I, III. typ. irrorata Fallén.

- Die braunen Randstrablen sind lang und schmal, die sie trennenden hyalinen Einschnitte keilförmig und tief, nicht runde Flecke 143

143. Fliigel mit Ausnahme der äubersten Wurzel dunkelbraun, in der Nitte nur mit wenigen hyalinen Tropfen, die kein Gitter bilden, am Rande und an der Spitze strahlig. Fluigel von eifürmiger, vielfach breiterer Gestalt. Zwei bis vier Scutellare. Cubitalis oben nackt oder beborstet.

Euaresta Loew (1873) I, IV, V. typ. festica Loew. 
— Flïgel mit einem dunklen Kernfleck in der Oberhälfte, meist nur vor der Spitze gelegen und gewölnnlich dunkle strahlenbändchen zur Fliigelspitze und zum Rande aussendend. Wnrzelwärts davon ist der ganze Fliigel aber glashell oder seltener mit einem mehr weniger zerrissenen hell braunen orler gelben Citterwerk, das von dem dunklen Kernfleck absticht, versehen. Ausnahmsweise ist auch der Strahlenkern fast ganz verschwunden. Flïgel von schlanker, mehr streifenförmiger Gestalt. Zwei bis vier Scutellare. Cubitalis nackt oder nur unten beborstet.

Trypanea (18) Sehrank (1796) (L'vellie s. Loew) I, II, III, IV, V. typ. stellata Fuessly.

A nmerkungen.

1. Das Dorsozentralborstenpar steht stets mehr oder weniger weit vor dem Präscutellarpaar, so daß dann dieses leicht irrtiimlich für ein erstes, jenes für ein zweites Paar gehalten werden kömmen.

2. Die Sternopleuralborste fehlt auch so manchen Tephritinen, wie z. B. Acillia cognata, Platyparella discoidea, den meisten Arten von Anastreplia, Colobostrella, Henicoptera, Themarictera, Neosopleiva usw.

Eine echte I'rothorakalborste, unmittelbar oberhalb der Vordcrhiiften fehlt allen Teplnitinen sens. lat. durchwegs.

3. Ist der Flïgel glashell oder fast glashell, so ist es angezeigt, beide Alternativen zu verfolgen, denn manche Trymanea-Arten haben fast ungezeichnete Flügel. Ist der Riiissel stark verlängert und gekniet, so kommt eine Ensinct-Art in Betracht.

4. Den Vorderschenkeln fehlt normal die posteroventrale Borstenreihe. Die hieher gehörende Ptitona Bischofi Kertész besitzt sie jedoch.

5. Ich rechne zu Carpophthoromyia Iusten s. str. nur noch tritea und scutellata Walker. Die anderen Arten gehören zu Ceratitis sens. lat.

6. Als Subgenus: Pseudodacus n. subg. typ. daciformis Bezzi habe ich Arten mit nur einer oberen Orbitalborste und abweichender Flügelzeichnung abgetrennt.

7. Bei manchen Rhagoletis-Arten ist die Cubitalis oben mit einzelnen Borsten bedeckt. Bei Platensima Enderl. stehen im Wurzeldrittel einige Borsten.

8. Für diejenigen Arten hier nochmals anfgefïhrt, deren D). Z.Borste ungefähn in der Höhe der Supralalaren stelit. 
9. Zu Hypenidium gehören die verkannten Arten Hemilea Nocaki Strobl (= Acitla pulchella Tavares 1901) und Hemilea Robororoyi Becker.

10. Myiopardalis Bezzi (1910), typ. purdalina Bigot unterscheidet sich von Carpomyia durch den Besitz starker Ocellarborsten und durch ganz kurzen Aderanhang an der Radialis. Carpomyiu vesuriana besitzt nach meinen Untersuchungen an vielen Stiicken nur Rudimente von Ocellaren, dagegen Carpomyia Schineri deutlich entwickelte Ocellenborsten, aber keinen Aderanhang an der Radialis. Der Unterschied beider Gattungen wird dadurch unscharf gemacht.

11. Tephlrostola Bezzi (1913), typ. acrostucta Wiedem. ist hiezu ein Synonym.

12. Percnoptera Phil. (1873), typ. angustipennis Phil. ist hiezu ein Synonym.

13. Subgen. nov. Pseudacrotaenia (typ. vespillo Schiner): Flïgelspitze nicht mit gelben Querbinden, sondern mit gelben, nach allen Seiten radiär auslaufenden Strahlen.

14. Paralleloptera Bezzi (1913), typ. pterocallaeformis Bezzi ist hiezu ein Synonym. - Ich halte El. melas Bigot für gleich mit ulula Loew.

15. Ensina ist hier nicht auf den Typus sonchi beschränkt (Loew 1862), sondern im Sinne Loew's, Monogr. N. Amer. Dipt. v. 3 p. 292 (1873) erweitert.

16. Hieher gehören noch $O$. parietina L., proboscidea L. und O. lutulenta Loew.

17. Xyphosia Rob.-Desv, hat fiir Oxyphoin Loew, nec. Rob.-Desv. einzutreten, wie Rondani meiner Ansicht nach richtig sagt, wenn man ïberhaupt diese Gattung aufrecht erhält.

Die mir untergekommenen amerikanischen Arten konnte ich auf Grund der Cubitalisheborstung nicht in die zwei Genera Xyphosia und Euribia verteilen, die Paläarkten aber wohl.

Ist Oxyphora cardui Rob.-Desv. = Westermami Meig., dann wäre vielleicht Icterica Loew und Oxyphora identisch. Acinia Rob.-Desv. fällt mit Xyphosia zusammen.

18. Will man Acanthiophilus Becker aufrecht erhalten, so gehört dazu auch Trypanca eluta Meig.-Euribia (Tephritis) lanta Loew, die gleich Tephritis veliformis Becker ist, hat meiner Ansicht nach eine von cluta Mleigen sehr verschiedene Flügelzeichnung. 




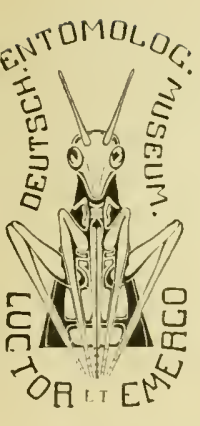

No. 3.

27. Januar 1914.

\section{Separatabdruck aus}

\section{Supplementa Entomologica}

Ilerausgegeben auf Kosten der Jagor-Stiftung rom

Deutschen Entomologischen Museum

[Redaktion: S. Schenkling]

H. Sauter's Formosa-Ausbeute.

F. Hendel, Acalyptrate Musciden (Dipt.) III 


\section{H. Sauter's Formosa- Ausbeute.}

Acalyptrate Musciden (Dipt.) $L I I *)$.

Von Friedrich Hendel (Wien).

Mit 7 Textfiguren.)

Celyphinae.

Genus Celyphus Dalman (1818) (Typus: C. obtectus Dalm.).

Die uns derzeit vorliegenden Beschreibungen der Celyphus-Arten sind so wenig charakteristisch und meist so nichtssagend, daß man ohne typische Stücke keine Klarheit über die Zugehörigkeit zu einer bestimmten Spezies gewinnen kann. Da ich in der glücklichen Lage war, die Wiedemannschen Exemplare zu untersuchen, können meine Angaben eine Ergänzung der Beschreibungen bringen.

Der obere Hinterkopf ist flach (eben) und fällt hinter der abgerundeten, nicht erhabenen Scheitelkante, schief nach unten zu ab. Der vordere Stirnrand ist nicht über die Lunula emporgewölbt, steht

*) Siehe Entom. Mitteil. v. 2, p. 33-43 (1913); dann Suppl. Entomol. v. 1, p. 13-24 und v. 2, p. $77-112$. 
auch nicht über die Augen vor. Das Gesicht fällt gerade und lotrecht ab, fast etwas nach hinten geneigt, hat in der Mitte eine seichte gebogene Querrinne und steht am Mundrande gar nicht vor; dieser ist flach konvex. Der untere Hinterkopf tritt um den horizontalen Augendurchmesser hinter den Augen vor, Backen also stark gepolstert. Prälabrum sehr niedrig, wenig von vorne, noch weniger von der Seite sichtbar. Taster von proportionaler Länge, schmal, an der Spitze mit einigen abstehenden Haaren. Rüssel dick.

Von Borsten sieht man am Kopfe nur die divergierenden äußeren und die konvergierenden inneren Scheitelborsten, sowio ein Paar nach innen hin einander genäherter und nach innen geneigter Borstenhaare auf der Vorderstirne; am Thorax nur die zwei Supraalarborsten.

Das basale Fühlerglied ist schlank, griffelartig und so lang wie das dritte Glied.

Das Schildchen ist halbkugelig gewölbt und aufgeblasen; es überragt hinten den Hinterleib und ist doppelt so breit wie der Thorax an den Schultern.

Im Flügel sind die beiden Wurzelzellen relativ lang, ein Drittel der Discalzelle lang. Die Radialismündung ist nur sanft aufgebogen.

Alula auffallend groß, durch tiefen Einschnitt getrennt. Schüppchen und Schwinger normal.

Vorder- und Hinterschieno mit Präapikalborste (Haar), Mittelschienen mit einem längeren Sporn. Vorderschenkel posterodorsal beborstet.

Celyphus obtectus Dalman (1818).

Zahlreiche of + aus Kosempo, Mai. Noch nicht aus Formosa bekannt.

Die Fliegen sind alle ganz und gar rötlich wachsgelb, nur mit Spuren metallischen Schimmers auf Stirn und Rücken versehen, bilden also eine konstante gelbe Varietät, unterscheiden sich aber sonst in nichts von der metallisch blauen Grundform.

ln der Mitte des glattpolierten Thoraxrückens zeigt sich häufig eine Bräunung in wochselnder Form und Teilung, die von den darunterliegenden vertrockneten Muskelteilen herrührt (C. Dohrni Bigot, 1880 ?).

Das Gesicht ist jederseits vor den braunen Flecken zwischen Auge und Unterrand des Kopfes abstehend zart behaart. Tasterspitzen etwas gehräunt.

Der Flügel ist hyalin, im Spitzendrittel zitronengelb. Die boiden letzten Abschnitte der Dicoidalis sind ungefähr gleich lang. Schüppchen und Schwinger gelb. 
Die gelbe Arista ist bis zu Dreifünftel ihrer Länge lanzettlich verbreitert, deutlich schmäler als das dritte Fühlerglied. In der Figur de Meijere's, Tijdschr. v. Entomol., v. 54, Tafel 20, fig. 36 (1911), ist das Basalglied etwas zu kurz geraten.

Der Thoraxrücken ist vorne kugelig gewölbt, viel breiter als lang, vorne breiter als der Kopf. Quernahtäste in den Seitenmitten. Schildchen oben narbig, doch in der Tiefe der Skulptur etwas wechselnd, da es auch Stiicke giht, deren Schildmitte ganz glatt erscheint, mit Randfurche.

Ohne Fühler durchschnittlich $5 \mathrm{~mm}$ lang; Schilddurchmesser $4 \mathrm{~mm}$.

\section{Celyphus punctifer nov. spec.}

Ein Stiick aus Hoozan.

Der gelben Varietät von $C$. obtectus, wie vorne beschrieben, senst in allem gleich. Die Arista ist aber nur im Enddrittel haar. fein. Die Füße sind nicht ganz gelb, sondern an den Vorderfüßen ist nur das Basalglied gelb, der Rest schwarzbraun. Auch die Enden der vier hinteren Füße sind gebräunt. Der Hinterleib ist ganz glänzend schwarz. Die Sternopleuren tragen vorne am Oberrande einen großen runden schwarzen Fleck. Das Schildchen ist fast glatt und zeigt in ganz gleichmäßigen Abständen verteilt braune Punkte eingestochøn, wodurch die Art sehr leicht kenntlich wird.

Genus Spaniocelyphus nov. gen. (Typus: Sp. scutatus Wiedem.).

Die Scheitelkante ist sehr scharf und in der Mitte erhöht, der obere Hinterkopf stark ausgehöhlt. Der vordere Stirnrand steht vor und ist über die Lunula emporgewölbt. Der Mundrand tritt erhoblich nach vorne vor, das Gesicht ist also konkav im Profile. Der untere Hinterkopf ist nicht gepolstert und steht nur etwas hinter den Augen hervor. Prälabrum hoch, von vorne und seitlich als vorstehend sichtbar.

Das basale Fühlerglied ist auffallend kürzer als das dritte und dicker als bei Celyphus.

Das Schildchen ist von eiförmigem Umrisse, länger als breit, seichter gewölbt, nur etwas breiter als der Thorax und kürzer als der Hinterleib.

Im Flügel sind die beiden Wurzelzellen (die zweite Basal- und die Analzelle) nur ein Viertel der Discalzelle lang. Die Radialismündung ist steil aufgebogen.

Alles übrige wie bei Celyph ıus. 
Spaniocelyphus scutatus Wiedemann (1830).

13 of $q$ aus Pilam und Chipun, Juli. Noch nicht aus Formosa bekannt. Stimmt mit der Interpretation de Meijere's, Tijdschr. r. Entomol., 1911, p. 385, Java.

liopf rot, Stirne violett schimmernd, die seitlichen Mundrandbeulen und das Prälabrum violettschwarz. Fühler rotbraun, namentlich das dritte Glied verdunkelt. Arista und Taster, diese mit Ausnahme der Wurzel dunkelbraun. Die Arista ist so breit wie das dritte Fühlerglied und nur im Enddrittel dünn. Ihre Behaarung schimmert gelb.

Der Thorax ist vorne so breit wie der Kopf, nicht auffallend verbreitert und nicht kugelig, sondern zylindrisch gewölbt. Quernahtäste vor den Seitenmitten. Die Längsmitte desselben und das ganze Schildchen sind narbig; letzteres mit Randfurche! Rücken und Schild lebhaft metallisch, meist stahlblau, etwas violett, nur ein Stück grün.

Pleuren und Hinterleib mehr schwarz und letzterer nur seitlich und am Ende lebhafter metallisch glänzend.

Vorderhüften, Schenkelspitzen, Schienen und Füße rot. Schenkel metallisch braun bis schwarz. Schienen mit drei dunklen Ringen.

Flïgel am Vorderrande und auch an der Spitze gelb gefärbt. Der letzte Discoidalisabschnitt länger als der vorletzte. Schüppchen bräunlich, Schwingerkopf schwarz. Stigma nicht gelsräunt, hellgelb.

Körper ohne Fühler $3,5 \mathrm{~mm}$ lang.

Anmerkung. Die Karsch'sche Auffassung des scutatus Wiedemann ist eine irrige. Arista und Schildskulptur weichen ab. Im übrigen sind die Arten dieses Autors wenig mehr als Katalognamen. Es hat infolgedessen auch Röder den hyalinus Karsch nochmals als Karschii, freilich, nicht viel ausführlicher beschrieben.

Anmerkung. Die Celyphinae stehen in jeder Hinsicht den Lauxuniinae sehr nahe und unterscheiden sich eigentlich nur durch die abnorme Schildbildung. Die Fühlerform von Celyphus finden wir bei Cerataulina Hend., die lanzettförmige, subapikale Arista bei Kertésziclla Hend., das Anfangsstadium des vergrößerten Schildchens bei einer neuen siidamerikanischen Lauxaniinen-Gattung mit einem Camptoprosopellet-Kopfe.

Im übrigen gibt es auch eine Konvergenzform bei den Notiphilinen, eine ebenfalls neue neotropische Gattung mit celyphusartigem Schilde.

Spaniocelyphus stigmaticus nov. spec.

4 I + aus Tappani, Kankau, September, Suisharyo, Oktober. 
Das erste Fühlerglied ist noch kürzer und dicker als bei $s c u$ tatus Wied., die Borste wie bei dieser Art, doch gelb oder wenigstens hellbraun. Das Schildchen ist etwas stärker gewölbt und nicht so stark verlängert. Während es bei scutatus anderthalbmal so lang wie breit ist, ist es hier nur zirka vierdrittelmal so lang wie breit. Es zeigt beinahe keine Skulptur, namentlich oben. Die Randfurche fehlt. Der Thoraxrücken ist ganz glatt poliert.

Die Gesamtfärbung des Rumpfes ist ein glänzendes Schwarz mit olivengrünem Schimmer.

Flügel mit dunkelbraunem Stigma. Alles übrige wie bei sculatus Wiedem.

\section{Diopsinae.}

Teleopsis Bigotii nov. spec. syn. Teleopsis belzebuth Hendel, Entom. Mitteil., II, p. 37, 25 (1913).

Ich habe mir durch die Güte des Herrn liollegen Collin in Newmarket Kenntnis von den Bigotschen Typen verschaffen können und kann nun die mir brieflich gemachte Mitteilung Prof. Bezzi's bestätigen, daß eine Identität mit der Formosaner Art nicht besteht.

Bei T. belzebuth Big. sind die Augenstiele länger und dünner, von der Wurzel bis zu den Fühlern doppelt so lang wie das Gesicht zwischen den Stielen; die Borstenwarzen sitzen vor der Stielmitte auf. - Die helle Flügelspitze ist nicht so stark abgesetzt hyalin, sondern nur heller bräunlich. Die äußere Grenze des großen dunkelbraunen Fleckes vor der helleren Spitze schneidet oben die Radialis ein ziemliches Stück vor der Mündung. Die innere Grenze derselben ist überall auch in der ersten Hinterrandzelle isoliert und hängt dort nicht mit der braunen Mittelquerbinde des Flügels zusammen. Die Wurzelquerbinde ist nur hinten an den Queradern der Wurzelzellen und an der Analis sichtbar, fehlt aber nach vorne hin. Die Mittelquerbinde des Flügels ist an der kleinen Querader nur schmal und zieht sich auch nur schmal nach aufwärts. Sie berührt die liosta nur jenseits der Vorlängerung der Querader. - Der Mundrand ist beiderseits des Prälabrums in eine ziemlich auffallende scharfe Spitze ausgezogen.

Das Exemplar der T. fulviventris Bigot gleicht in den angegebenen Merkmalen der T. belzebuth mit folgenden Unterschieden. Die Borstenwarzen sitzen jenseits der Augenstielmitten. Die helle Flügelspitze hebt sich kontrastreicher vom braunen Subapikalflecke ab, dessen äußere Grenze oben die Radialismündung berührt. Die Mittelquerbinde des Flügels wird oberhalb der kleinen Querader wieder 
breiter und berührt jenseits der Verlängerung der Querader in größerer Breite die Kosta. Ob die Wurzelquerbinde bis zur Kosta hinaufreicht, kann ich wegen Verschimmelung des typischen Exemplars nicht erkennen.

Die Formosaner-Art ist also nach diesen Vergleichen für neu zu halten.

Die Augenstiele sind von der Wurzel bis zu den Fühlern ungefähr so lang wie das Gesicht oben breit. Die Borstenwarzen mit der Frontorbitalborste sitzen zwischen Wurzel des Stieles und Augenrand. - Der Mundrand ist seitlich des Prälabrums abgerundet und in keine Spitze ausgezogen.

Die helle Flügelspitze ist kontrastreich abgesetzt. Die äußere Gronze des braunen Querfleckes davor berührt oben die Radialismündung. Die Mittelquerbinde geht in gleichmäßiger, erheblicher Breite durch den ganzen Flügel hindurch und ist in der ersten Hinterrandzelle mit der nur wenig breiteren, aber intensiveren subapikalen verbunden. - Die basale dunkle Querbinde erreicht auch oben den Flügelrand.

Rot sind die Hüften, Beine, Fühler und Schwinger. Von glänzend pechbrauner Grundfarbe sind der Kopf, der Thorax samt Schildchen, mehr schwarz der Hinterleib. Thoraxrücken, Schild und obere Pleuren durch bräunliche Bereifung fast matt. Hinterleibspetiolus in der Mitte mit schmalem weißlichen Reifring. Ebenso ist am dritten Tergit ein in der Mitte unterbrochener Vorderrand- und ein Seitensaum silberweiß bereift.

An den Beinen sind die Schienen, namentlich die vorder'sten und hintersten, dann ein oben offener schmaler präapikaler Ring an allen Schenkeln, sowie mehr weniger deutliche Längslinien vorne und hinten an den Hinterschenkeln dunkelbraun. Die Schilddomspitzen und häufig auch die Thoraxdorne sind rot.

In del Färbung zeigt sich eine ziemliche Variabilität darin. daß zunächst der Kopf, dann der Hinterleib von der Basis her und ausnahmsweise auch der Thorax in verschiedener Ausdehnung statt pechbraun rotbraun gefärbt sein kann.

Körper 5-6 mm, Flügel $3,5-4,5 \mathrm{~mm}$ lang.

\section{Sphyracephala cothurnala Bigot (1874).}

Aus Celebes und den Philippinen bekannt.

4 to aus Kosempo, Mai. Man vergleiche die Bemerkungen. Osten-Sacken's in der Berl. Ent. Zcitschr., 1882, p. 234. 


\section{Milichince.}

\section{Genus Desmometopa Loew.}

Die Desmometopa-Arten mit deutlichen Chitinleisten der Stirne sind nur schwer und nur bei genauer Vergleichung miteinander sicher zu bestimmen. Ich will hier meine Beobachtungen an den drei bisher bekannten Arten geben.

- Schwingerknopf wirklich hellgelb, weiflich überhaucht, Stiel dunkel. Scheitel, Rücken und Schild dicht aschgrau bereift, Schild ganz matt, Rücken mit kaum merklichem Glanze, nur in gewisser Richtung sichtbar. Flügel rein milchig getrübt, mit hellgelben, durchscheinenden Adern.

- Schwingerkopf größtenteils dunkelbraun oder rotbraun, oben gesättigter als an der Verbindungstelle mit dem schwarzen Stiele. Scheitel, Rücken und Schild durch eine zarte dunkelolivenbraune Bereifung im Glanze wenig alteriert, von glänzend pechschwarzer Grundfarbe. Flügel wenig milchig, etwas rauchig getrübt. Adern entschieden dunkler, bräunlich gefärbt

D. sordida Fall.

1. Füße gegen hellen Hintergrund gehalten durchscheinend gelbrot gefärbt (die zwei Endglieder verdunkelt). Backen rot. Taster nur an der Wurzel rot. Fühler schwarz . . D. tarsalis Loew.

- Füße gegen hellen Grund gehalten dunkel, nicht durchscheinend, braun bis schwarz. Gegen dunklen Hintergrund betrachtet, täuscht oft die rote kurze Pubeszenz. Backen schwarz, wenn auch am Unterrande grau überstäubt. Taster hellrotgelb, mit schwarzer Spitze. Fühler an der Wurzel oft rot D. $M$-nigrum Zett.

Desmometopa tristicula nov. spec.

$\delta f$ aus Anping, Mai.

Die neue Art gleicht der weitverbreiteten und nicht seltenen D. sordicla Fall. ganz außerordentlich und ist nur durch relative Unterschiedo kenntlich zu machen.

Die bräunliche Bereifung des Rïckens und Schildes ist noch schütterer, so daß der Glanz dieser Teile aufällt. Der Kopf ist bei sordida Fall. viel höher, fast zweimal so hoch wie lang, hier ist er mehr ahgerundet, deutlich niodriger, hinten weniger hohl, die Backen sind noch schmäler, linear, wie bei sordida schwarz, wie auch die Taster' der Mundrand ist weniger vorgezogen, dio Kopfborsten sind zarter und küirzer. Die Füße sind bei sordida und tristicula wie bei M.-nigrum gefärbt. Bei unausgefärbten Stïcken ist die Farbe freilich nicht dunkel und ist darauf Rücksicht zu nehmen.

Körper 2-2,5 mm lang, boi $D$. sordida Fall. 2,5 bis fast $3 \mathrm{~mm}$. 
Prodesmometopa Wulpi Hendel, Wien. Ent. Zeitschr., 1907, p. 242. Syn. Agromyza minutissima V. d. Wulp. (1897) präncc.

Durch die Liebenswürdigkeit Dr. Kertész' konnte ich die typischen Stücke dieser Art untersuchen und trotz der schlechten Erhaltung derselben noch folgendes erkennen. Besondere Chitinleisten der Stirne für die Kreuzborsten fehlen, die Stirne ist ganz schwarz. Rücken und Schild sind wie bei $D$. sorlida vorherrschend glänzend pechschwarz, noch weniger als bei dieser Art bestäubt. Füße mit Ausnahme der Spitze und Schwingerkopf rotgelb. Taster schwarz. Flügel etwas milchig, Adern bräunlich. Der letzte Discoidalisabschnitt ist doppelt so lang wie die Discalzelle; siehe Fig. 1.

Die kleine Querader ist der hinteren genähert, steht erheblich jenseits der Mitte der Discalzelle. Die vierte Längsader ist vor dieser Querader etwas eingebaucht, nicht gerade.

Etwas über $1 \mathrm{~mm}$ lang.

Für die Arten ohne besondere Chitinleisten der Stirne und mit verkürzter Discalzelle, die nur die Hälfte des letzten Discoidalisabstandes lang ist, stelle ich die Gattung Prodesmometopa nov. gen. auf, Typus $P$. latipes Meign.

\section{Phyllomyza epitacta nov. spec.}

3 Stiick aus Chipun und Paroo, Juli, August.

Die Gattung Phyllomyza steht Desmometopa so nahe, dab $q$ der ersteren häufig in letztere Gattung gestellt wurden.

Als Unterscheidungsmerkmale habe ich stets verläblich gefunden: Alle drei oberen Orbitalborsten sind nach auswärts gebogen, bei Desmometopa nur die zwei vorderen, während die oberste der drei viel kleiner und nach einwärts und aufwärts gerichtet ist. Die Augen sind bei Phyllomyza deutlich hehaart.

Zum weiteren Vergleich siehe auch meine Bemerkungen in der W'ien. Ent. Ztg., 1903, p. 251. Die Divergenz der Schildborsten als wesentliches Mcrkmal ron Phyllomyza habe ich nicht konstant gefunden. Ebenso nicht die Zahl der Supraalaren. Dagegen fehlt das bei Desmometopa vorhandene Präscutellarpar bei Phyllomyza. Eine Sternopleurale ist bei beiden Gattungen vorhanden.

Von Ph. seruricornis Fall., der sie sonst ganz gleicht, unterscheidet sich unsere Art dadurch, dab die Taster mit Ausnahme der Spitze ganz gelb sind und daß nur zwei Dorsozentrale hinten am Rücken vorkommen. Ph.securicornis Fall. hat schwarze Taster und vier Dorsozentralborsten.

Das dritte Fühlerglied ist unten teilweise rotbraun. Sonst ist das ganze Tier von schwarzer Grundfarbe, mäßig glänzend. 
Stirnstrieme einfarbig samtschwarz; Kreuzbörstchen nicht auf farbig abgesonderten Chitinleisten. Rücken etwas graulich bereift. Die Spitzen der kurzen schwarzen frundbehaarung des Rückens und Hinterleibes schimmern in gewisser Beleuchtung rot. Sonst sind alle Borsten und Haare schwarz.

Vorderhüften teilweise, dann dio Schenkelspitzen, die Schienen und die Füße bleich gelb. Schentel und die Mitte der hintersten Schienen schwarz.

Flügel milchig gotrübt, mit hellgelben Adern. Schüppchen und Schwingerkopf gelb.

Nicht ganz $2 \mathrm{~mm}$ lang.

\section{Canaceinae.}

Genus Canace Hal. sens. lat.

In den heurigen Ferien fing ich Canace salonitana Strobl bei Abbazia und sah jetzt, daß die bisher bekannt gewordenen Arten generisch nicht vereint bleiben können. Die gleiche Ansicht äußerte mir gegenüber auch mein verehrter Freund Dr. Kortész.

So bilden die früher von mir aus Formosa beschriebenen Arten C. orientalis und C. magna mit C. ranula Loew, sowio auch $C$. biseta Hendel für sich je eine neue Gattung.

1. Canace Halid. s. str. (1839) (typ. C. nasica Halid.). Gesicht am Mundrande gerade abgeschnitten, nicht viereckig ausgebuchtet, so hoch wie breit, Prälabrum niedrig. Backen, Ozellendreieck und Pleuren beborstet, Rücken bis vorne hin beborstet, Schild vierborstig. Beborstung stark, wie die rauhe schüttere Behaarung schwarz. Vierte Längsader jenseits der hinteren Querader nicht aufgebogen, gerade.

2. Chaetocanace n. g. (typ. C. biseta Hend.). Gesicht am Mundrande viereckig ausgeschnitten, die Bucht vom Prälabrum orfüllt. Gesicht etwas breiter als hoch. Backen und Plouren nackt, unbeborstet, Schild nur mit zwei Borsten. Sonst wie vorige Gattung.

3. Xanthocanace nov. gen. (typ. ranula Loew). Gesicht zwoimal so breit wie hoch, Mundrand stark viereckig ausgeschnitten, vom sehr großen Prälabrum erfüllt. Borsten kurz und zart, wie die dichte, kurze und feine Behaarung des ganzen Tieres, namentlich auch des Ocellendreieckes hellgelb. Rücken nur hinten mit Borsten. Vierte Längsader jenseits der hinteren Querader mehr oder weniger stark aufgebogen. 


\section{Ephydrinae.}

Psilephydra nov. gen. (Fig. 2 u. 3, Typus: P. cyanoprosopa nov.spec.).

Die Gattung zeichnet sich durch die auffallend spärliche Beborstung und Behaarung von allen Gattungen der engeren Sippe Eplinglrinae aus.

3.
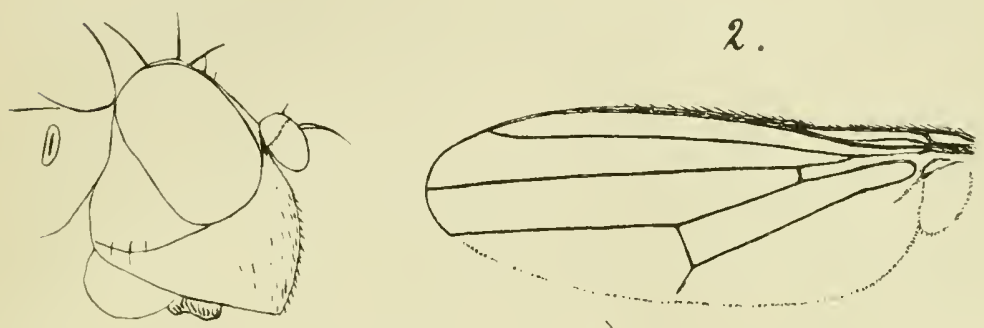

1.
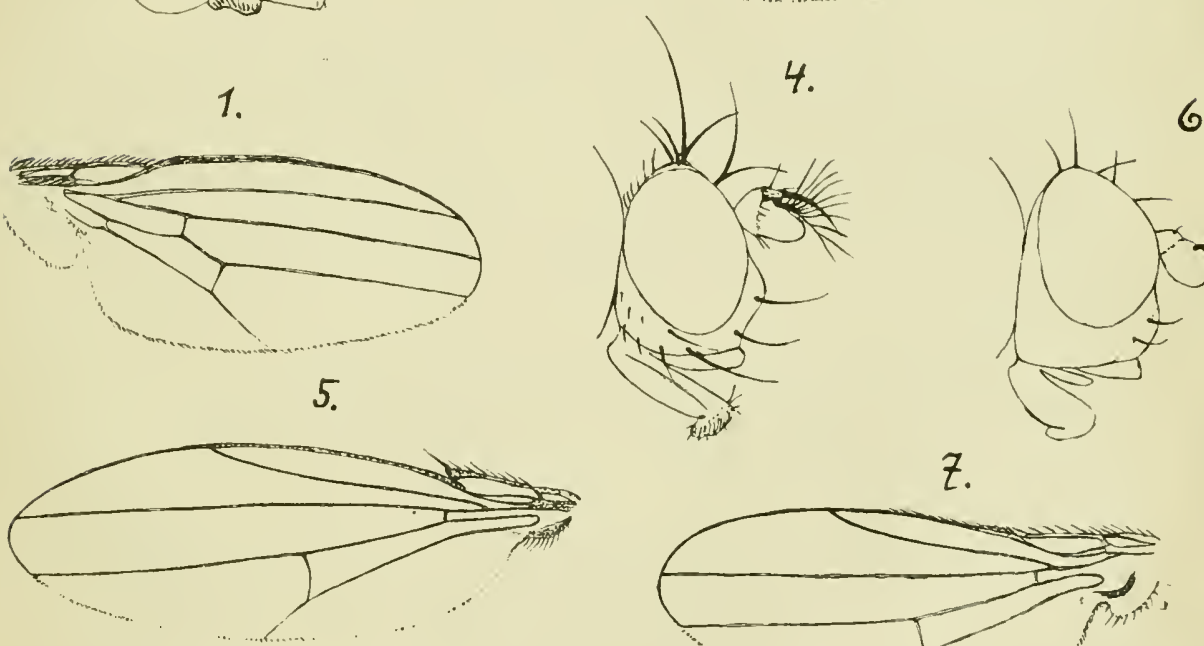

Z.

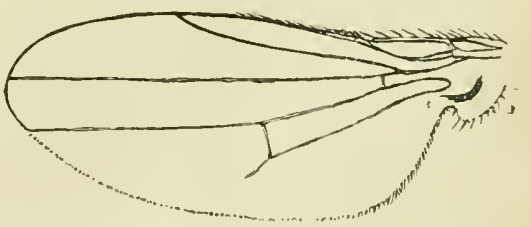

Untergesicht einfach kugelig oder gleichmäßig schildförmig gewöll,t, stark vorstehend, unbeborstet und nur kurz und fein pubesziert, unten gerade abgeschnitten, das Prälabrum ganz verdeckend, mit sehr großer Mundöffnung. Stirno flach, nıır oben am Augenrande, an den Scheitelplatten etwas wulstig erhaben, doch sind weder Ozellendreieck noch jene abgesetzt. Die Stirne ist vorne neben den Fühlern mehr als doppelt, oben mehr als dreimal so breit wie ein Auge, in der Mitte dreimal so breit wie lang; sie ist nackt und zeigt nur folgende Borsten: die stärksten sind die divergierenden äußeren und die konvergierenden inneren Sehoitelborsten; dann noch ein Paar etwas schwächerer, nach vorne divergierender Ozellarhorsten, 
zwischen den eng beisammenliegenden, oben an der abgerundeten Scheitelkante befindlichen Ozellen inseriert, und endlich zwei kleine, nach außen gebogene obere Orbitalborsten, deren vorderes so klcin ist, daß es schwer erkennbar bleibt.

Fühler kurz und klein, der Augenmitte gegenüber, an den Wurzeln entfernt voneinander inseriert. Das zweite und dritte Glied bilden zusammen ein kurzes Oval. Das dritte ist kaum länger als breit, das zweite trägt oben ein kurzes, abstehendes feines Härchen. Arista kurz, so lang wie das zweite und dritte Glied der Fühler zusammen, gebogen, nackt, spindelig.

Wangen linear, Backen die Hälfte eines Auges hoch. Augen schiefliegend, am Hinterrande etwas ausgeschweift. Hinterkopf oben flach ausgehöhlt, unten stark vorgequollen.

Rüssel dick, mit halbkugeligen chitinösen Kinne und kurzen Labellen.

Rücken etwas länger als breit, nackt. Nur eine Notoplourale und ein Supraalare sowie drei Dorsozentrale hinter der Naht, nach vorne hin an Stärke abnehmend. Pleuren nackt, nur eine Mesopleurale.

Schild eiförmig, ein Drittel des Rückens lang, oben gewölbt pubesziert, am Rande mit vier Borsten, die basalen kurz, die apikalen parallel.

Hinterleib so lang und so breit wie der Thorax, oval. \$: Zweites bis viertes Tergit gleich lang, erstes und fünftes kürzer.

Beine von normaler Länge und Stärke, fast wie nackt. Die Vorderschenkel sind etwas dicker als die hinteren vier. Klauen gekrümmt, Pulvillen vorhanden.

Flügel nach der Figur 2 geadert. Costa bis zur vierten Längsader reichend, vor der Mündung der Subcosta wohl unterbrochen, aber nicht eingeschnitten. Alula wohlentwickelt. Die Mediastina verschmilzt erst knapp vor der Mündung der Subcosta mit dieser.

\section{Psilephydra cyanoprosopa nor. spec.}

12 to 9 aus Hoozan.

Von stahlblauer Grundfarbe, am Rücken und auf der Stirne weniger, am Hinterleibe lebhafter glänzend, weil bei ersteren der Glanz durch zarten, matt rotbräunlichen Schimmer gemildert wird, was beim Hinterleib in geringerem Maße der Fall ist.

Pleuren und Metanotum graulich überreift, noch dichter der Hinterkopf. Am lebhaftosten ist die Färbung des Gesichtes; dasselbe ist zwar matt, zeigt aber prachtvollen tiirkisblauen Schimmer. In gewisser Richtung schimmert es auch weiß, in anderer erscheint es 
ganz dunkel. Seine kurze Pubeszenz ist schwarz. Alle Borsten schwal'z.

Fühler schwarz. Beine erzfarben, Füle rotbraun, am Ende schwärzlich.

Flügel graulich hyalin, Adem schwarzbraun. Schwinger gelb. Körper über $3 \mathrm{~mm}$, Flïgel $3 \mathrm{~mm}$ lang.

\section{Notiphilinae.}

Notiphila similis de Meijere.

Tijdschr. v. Entomol., v. 51 (1908), p. 162, 1. Aus Java beschrieben. Zahlreiche Stücke aus Tainan, Mai.

Eine Mittellinie der Stirne und die Augenränder sind hellgrau, die Strieme mit dem Thoraxrücken und Schilde gleichförmig. Diese sind hell olivengrau und mehr oder weniger stark bräunlich uiborreift. An den Borstonwurzeln koino deutlichon braunen Punkte. Stirne wenig breiter als lang, neben den Fühlern ungefähr so broit wie cin Auge. Gesicht hollgrau. In soiner oberen Hälfte ist der Mittelkiel ziemlich scharf ausgeprägt. Taster weißgelb: Arista mit 11 bis 12 liammstrahlen. Drittes Fühlerglied am Ende oft etwas gebräunt. Nesopleuren mit kleinem braunon Mittelfleck.

Am Hinterleibe sind die mittleren der vier braunen Flecke der einzelnen Tergite meist schmäler als die äuBeren, doch auch gleichbreit. Selten sind sie paarwoise am Vorderrande verbunden.

Flïgel hyalin, hintere Querader nicht gesäumt. Der vorletzte Alschnitt der Discoidalis nur um geringes länger als der letzte. Wangen und Backen schmal, Gesicht nur mit zwei starken Borsten. Das nach vorne gebogene Orbitalbörstchen vor der starken Borste ist winzig klein oder fehlt ganz.

Körper $3-4 \mathrm{~mm}$, Fliigel 2,5-3 $\mathrm{mm}$ lang.

Notiphila phaea nov. spec.

Tainan, Mai.

Unterschoidet sich von der $N$. similis durch folgendes: Stirne und Oberseite des Thorax noch deutlicher bräunlich bereift, mit deutlichen bramon Wurzelpunkten an allen Borsten. Gesicht lederbraun. Mesopleuren stärker braun gefleckt.

Flïgol rauchbräunlich getrübt, hintere Querader fein grau gesäumt. Der vorletzte Abschnitt der Discoidalis ist ganz erheblich länger als dor letzte.

Das lünfte Tergit ist fast ganz glänzend bratull.

Kïrper $3, \overline{5} \mathrm{~mm}$, liliigol is $\mathrm{mm}$ lisıg. 
Notiphila latigenis nov. spec.

Anping, Mai.

Auch diese Art gleicht der $N$. similis in allem sehr. Da ihr aber der braune Hauch der Oberseite fehlt, ist sie im Gegensatze zu voriger Art mehr hell olivengrau. Der Gesichtskiel ist ganz flach. Die Backen sind breit, in der Augenachse ein Drittel des Auges, hinten, wo sie herabgesenkt sind, die Hälfte eines solchen hoch. Arista mit nur acht Fiederstrahlen. An den Borstenwurzeln dunkle Punkte. Mesopleuren ungefleckt oder fast ohne braunes Fleckchen. Stirne erheblich breiter als lang, neben den Fühlern viel breiter als ein Auge.

Der letzte Discoidalisabschnitt ist etwas kürzer als bei similis Meij. Körper 3,5-4,5 mm, Flügel $3-3,5 \mathrm{~mm}$ lang.

\section{Notiphila maculifrons nov. spec.}

1 o aus Tainan, Maj.

Eine sehr charakteristische, leicht kenntliche Art.

Stirne breiter als lang; unter den Fühlerwurzeln biegen die Augenränder gegeneinander und verengen das Gesicht, das viel schmäler als ein Auge ist. Stirne mit hellem Augenrande und solcher Mittellinie, oben am Scheitel jederseits zwischen Ocellen und Augenrand ein großer runder samtschwarzer Fleck. Strieme, Rücken und Schild hellolivengrau, etwas bräunlich bereift. Zwischen Fühlerwurzel und Auge noch ein kleines schwarzes Dreieck. Gesicht goldockerig bereift; Längskiel scharf, im Profilo konvex; die Seiten ohne Borsten, aber dort bis über die Mitte hinauf mit einer Reihe von fünf bis sechs kurzen feinen Haaren besetzt. Taster hellgelb, Fühler gelbrot. Arista mit 11-12 Kammstrahlen. Wangen und Backen sehr schmal. Augen relativ hoch.

Unterer Hinterkopf, Pleuren, Metanotum, Hüften und am Hinterleib eine schmale Medianstrieme am 3. bis 5. Tergit, sowie die Hinterränder an den Seiten des 2. bis 5. Tergites weißlich grünlichgrau. Abdomen sonst sepiabraun. Thoraxrücken mit fünf braunen Längsstriemen. Dio mittleren drei linionartig, die folgende nach außen erst hinter der Quernaht beginnend und breiter, die äußersto am breitesten, oberhalb der Notopleuraldepression, ganz durchlaufend. Schild braun, eine Mittellinie und breitere Seitenränder hellgrau.

Schenkel mit Ausnahme der Spitze schwarzbraun; ebenso die Vorderschienen, ausgenommen die Wurzel. Hinterschienen unterhalb der Mitte breit braun. Vorderfüße gebräunt. Sonst sind die Beine gelb. 
Flügel grau, am Vordorrande jenseits des Dornes breit, an allen Adern normal dunkelbraun gesäumt. Adern schwarz. Schwingerkopf weißgelb.

Körper $3.5 \mathrm{~mm}$, Fliigel $3 \mathrm{~mm}$ lang.

Notiphilacantha nov. gen.

(Typus: $N$.dorsopunctata Wied.)

Von Notiphila durch den gekämmten ersten Costalabschnitt und durch die deutliche, wenn auch kurzo Beborstung der ganzen Costa jenseits des Randdornes kenntlich.

Die Paläarkten zeigen keine so ausgesprochene Gesichtsbeborstung wie die hier genannten vier Arten.

In diese Gattung gehört auch noch Notiphila ciliata v. d. Wulp, Dipt. Sum. Exped., p. 55, 1 (1881).

Notiphilacantha dorsopunctata Wiedemann. Außereurop. Zweifl., v. 2, p. 591, 5 (1830); Anal. Ent., p. 58, 134 (182t); v. d. Wulp, Tijdschr. v. Entom., v. 34, p. 215; de Neijere, ibidem v. 51, p. 163,3 .

of aus Tainan, Mai. Bekannt aus Ostindien und Java.

Gleicht in der Färbung ganz der $N$. similis de Veij., namentlich in der Fleckung des Hinterleibes, nur liegen an allen Borstenwurzeln dunkelbraune Punkte. Der Flügel ist vorne und an den Längsadern etwas zart gelbbraun tingiert.

Das nach vorne gebogene Stirnbörstchen ist deutlich vorhanden. Stirne breiter als lang, neben den Fühlern breiter als ein Auge.

Gesicht jederseits mit 3-4 Borsten, die unterste schwächer.

Sein Riicken in der oberen Hälfto des Gesichtes gut ausgeprägt.

Backen in der Verlängerung del Achse nicht ganz ein Viertel eines Auges hoch, hinten höher. Arista mit 10-12 Kammstrahlen.

Körper und Fliigel $4-5 \mathrm{~mm}$ lang.

\section{Tabelle der orientalischen Paralimna-Arten.}

Flïgelqueradern deutlich braun gesäumt . P. picta Kertész.

- Ohne dunkle Säume . . . . . . . . . . . 1.

1. Jo ein großer samtschwarzer Fleck zwischen Fühler und Auge und einer zwischen den Fühlerwurzeln; erstere silberig eingefaßt.

$P$. liviticornis de Meij.

- Vordorstirne ohne diese drei Samtflecke, höchstens mit einem dunklen Fleck zwischen Fïhler und Auge . . . . . . 2.

2. Thorax mit dunklen Punkten an IIaaron und Borsten . . 3 .

- Thorax unpunkticrt . . . . . . . . . . . . . 9. 
3. Jederseits zwei gleich starke, nach vorne gebogene Frontorbitalborsten

- Jederseits nur eine starke, nach vorne gebogene Orbitalborste, die obere fehlt oder ist nur schwach vorhanden . . . . 5.

4. Gesicht jederseits mit, vier bis sechs Borsten. Zweites Fühlerglied ohne weißen Punkt . . . . . . P. major do Meij.

- Gesicht jederseits nur mit zwei sehr langen, gleich starken Borsten . . . . . . . . . P. biseta nov. spec.

5. Zweites Fühlerglied oben mit einem silberweißen, schimmernden Fleck . . . . . . . . . . . . . . 6 .

- Dieser weiße Punkt fehlt . . . P. insignis de Meij.

6. Brustseiten weiBgrau, unpunktiert und ungefleckt.

P. punctata de Meij.

- Mesopleuren braun punktiert und gefleckt . . . . . . 7.

7. Thoraxrücken von matt gelbgrauem Aussehen; die feine braune Punktierung herrscht nicht vor; auch der Hinterleib ist vorherrschend matt gelbgrau. Die Tergito $3-5$ zeigen nur am Vorderrande eine in der Mitte unterbrochene, in zwei Flecke zerlegte braune Binde . . . . . . . . . 8 .

- Thoraxrücken durch die dichte und dunkle Punktierung von vorherrschend dunkelbraunem Aussehen. Hinterleibstergite sepiabraun, etwas glänzend, am Hinterrande mit scharf ab. gesetzten, in der Mitte unterbrochenen gelbgrauen Säumen. $P$. sinensis Schiner.

8. $6,5 \mathrm{~mm}$ lang . . . . . . . P. cinerella nov. spec. $4 \mathrm{~mm}$ lang . . . . . . . . P. minor nov. spec.

9. Untergesicht und Brustseiten weißgrau. Tarsen gelb.

P. javana V. d. Wulp.

Gesicht und Brustseiten gelbgrau. Tarsen schwarz.

$P$. lineata de Meij.

\section{Paralimna hirticornis de Meijere i. litt.}

12 of aus Kankau, September.

Die Stirne ist dreimal so breit wie ein Auge, die Backen die Hälfte eines Auges hoch. Die Augen sind nur etwas höher als lang. Die Profillinie des Gesichtes ist nur schwach konvex gestaltet, fast gerade. Die Stirne steht über die Augen kaum vor; die Wangen sind linear. Seitlich am Gesichte, auf den Facialien nur ein stärkeres, kurzes Haar und darunter noch zwei bis drei zarte Härchen. Von den zwci nach vorne gebogenen Frontorbitalen steht die vordere vor der Stirnmitte, die hintere ist haarartig fein und unscheinlrar. 
Grundfarbe schwarz. Eine Längsstrieme der Stime, die das mittlere Drittel einnimmt, scharf abgesetzt, glänzend schwarz. An den Borstenwurzoln schwarze Punkte auf hellgrauem Grunde. Die übrige Stirne ist matt schwarzbraun. Vorne zwischen Fühler und Auge je ein großer samtschwarzer Fleck, der oben und unten weiß eingefaßt ist. Gleichfalls santschwarz ist ein Fleck zwischen den Fühlerwurzeln. Die Scheitelkante glänzt, der übrige Hinterkopf ist grau. Gesicht, Backen, Prälabrum, die Lateralgegend des Thoraxrückens und die Pleuren sind einfärbig weiblich aschgrau bostäubt. Fühler schwarz; zweites Glied oben mit silberweißem Punkte. Arista mit zehn Kammstrahlen. Der Thoraxrïcken ist vorne matt, nach hinten zu aber allmählich glänzend schwarzbraun. Aus gelben Punkten werden vier helle Längslinien gebildet, zwei in der Mitte, je eine in der Richtung der Dor'sozentralborsten. Schildchon in der Wurzelhälfte aschgrau, etwas dunkel punktiert, an der Spitze matt sepiabraun.

Hinterleib hell gelblichgrau. Dio Tergite $2-5$ haben scharf aljgesetzte sepiabraune Vorderrandsäume, die seitlich die Hälfte der Ringe breit sind, gegen die Mitte hin aber schmäler werden. Die Tergite $3-6$ durchläuft eine gleichfarbige Medianlinie.

Hüften und Beine schwarz, graulich bestäubt. Füße rotblaun. Die Schienen schimmern dorsal silberwoib.

Flügel glashell mit lichteren Adern. Schwingen hellgelb.

Bei dieser Art allein ist der letzte Abschnitt der Discoidalis nicht kürzer als der vorletzte, sondern gleichlang.

Körper 2,5-3,5 mm lang.

\section{Paralimna biseta nov. spec.}

Zahlreiche Stücke aus Tainan, November.

Die Stirne ist nur ganz wenig breiter als der doppelte Augendurchmesser. Die Backen sind $1 / 3$ eines Auges hoch. Die Augen sind senkrecht oval, erheblich höher als lang. Die Profillinie dos Gosichtes ist ganz gerade und senkrecht. Seitlich am Gesichte, auf den Facialien, stehen jederseits nur zwei, aber kräftige, gleich starke Borsten, die nach vorne und oinwärts gebegen sind. Die beiden nach vorne gebogenen Frontorbitalbersten sind gleich stark und die vordere derselben steht schon etwas vor der Stirnmitte. Stirne an den Fühlern nicht über die Augen vorstehend. Wangen sehr sehmal, liniar.

Grundfarbe dos Tieros schwarz, Bestäubung überall dicht, hell aschgrau. Von brauner Farbe sind zarte Schatten im Gesichte, je 
ein Fleck auf den Mesopleuren und dorsal auf dem Dreieck vor der Quernaht, Punkte an den Borstenwurzeln, eine gespaltene und hinten abgekürzte Mittellängslinie und undeutliche, an der Quernaht unterbrechene, oft nur fleckenartige Seitenbinden. Stirne dunkelgrau, am Scheitel dunkelbraun. Der vordere Augenrandsaum und zwei nach vorne konvergierende Linien vor den Ozellen woibgrau. Fühler schwarz, graulich bereift. Zweites Glied oben ohne weißen Punkt. Arista mit 7-8 Kammstrahlen. Hinterloib mit in der Mitte sehr schmalen, an den Seiten etwas verbreiterten, mattbraunen Vorderrandsäumen.

Hüften und Beine schwarz, aschgrau bestäubt. Die äußersten Knie und die Wurzeln der Füße, besonders der vier hinteren, rotbraun. Die oberste der zwei dorsalen Mittelschienenborsten steht beträchtlich unterhalb des Gelenkes.

Flügel ganz hyalin. Adern an der Wurzel bräunlichgelb. Ebenso Schüppchen und Schwinger.

Körper $3,5 \mathrm{~mm}$, Flügel $2^{3} / 4 \mathrm{~mm}$ lang.

Anmerkung: Prof. de Meijere hat die Art mit javana v. d. Wulp verglichen und schreibt mir: "Ihre Art unterscheidet sich dur'ch mehr gelbliches Gesicht mit bräunlichen Stellen, auch am Mosopleuron und auf dem Notopleuraldreieck finden sich braune Flecken. Bei $P$. javana sind alle diese Teile einfarbig bläulichweißgrau; dagegen hat $P$. javana breitere braune Vorderrandbindon am Hinterleibe."

Paralimna sinensis Schiner. Novara Dipt., p. 241, 27 (Notiphila).

Zahlreiche Stücke aus Kankau, September. Aus Hongkong beschrieben.

Die Stirne ist dreimal so breit wie ein Auge u. $11 / 2$ mal so breit wie lang. Die Backen sind gut $: / 2$ eines Auges hoch. Die Augen sind nur 5/ti der Höhe lang. Die Profillinie des Gesichtes ist eine ziemlich stark vorgewölbte, konvexe Linie, dio unter der Mitte einen schwachen Absatz zeigt. Seitlich am Gesichte, auf den Facialien jedorseits eine Reihe von zirka fünf $\mathrm{nach}$ unten und cinwärts gobogenen Borstenluärchen, von denen das oberste stärker ist. Die hintero der zwei nach vorne gebogenen Frontorbitalen ist schwächer als die vordere, in der Stirnmitte stehende. Dic Stirne steht an den Fühlern otwas über die Augen vor. Die Wangen sind ein wenig schmäler als das dritte Fühlerglied.

Grundfarbe der Fliege schwarz. Kopf überall rötlich, ockerbraun, am Hinterkopfe aschgrau bestäubt. Zwisehen Fühlerwurzel und Auge 
oin schwarzel Flock. An allen Borstenwurzeln der Stirue großo schwarze Punkte. Die zwei ockergelben Linien an den Ocellarborsten sind außen durch schwarzbraune Säume begrenzt und laufen am Vorderrande der Stirne glänzend schwarzbraun aus. Auch die vorderen Stirnaugenränder sind ockergelb. - Der Thoraxrücken und die Mesopleuren sind graugelb bestäubt und an den Haarwurzeln dicht schwarzbraun punktiert. Auberdom stehon an den Borstenwurzeln größere braune Punkte. Dieso braunen Punkte fließen zwischen den Dorsozentralborsten $z u$ drei einander stark genälerten Längsstriemen zusammen. Seitlich daran sieht man hinter der Quernaht je eine ähnliche Strieme. Das Schild ist auf der Oberseite mit Aus. nahme einer hellen Mittellinie dicht braun punktiert und glänzt an der Spitze und am Seitenrando deutlich. Mesopleuren ganz braunfleckig. Die übrigen Pleuren und das Mesonotum sind einfärbig hell olivengrau, unpunktiert.

Fühler dunkelbraun, die zwei Wurzelglieder schwarz. Zwei oben mit silberweifem Punkte. Alista gewöhnlich mit vierzehn Kammstrahlen.

Hinterleib sepiabraun, deutlich glänzend, am dritten bis fünften Tergit mit holl olivengrauen, in der Mitte unterbrochenen Hinterlandsäumen, die $1 / 3$ lis $2 / 5$ der Tergite breit sind. Zweiter Tergit olivengrau mit, braunem, in der Mitte unterbrochenem Vorderrandsaum.

Hiiften und Beine schwarz, schwach grall bereift. Füße mit Ausnahme der Spitze rot. Die oberste der zwei dor'salen Mittelschienenborston steht unmittelbar unter dem Gelenke.

Flügel gleichmäßig rauchbraun tingiert, mit an der Wurzel roten Adern. Meist sind auch alle Adern etwas bräunlich gosäumt. Sehwinger hellgelb.

Körper $6 \mathrm{~mm}$, Flügel $5 \mathrm{~mm}$ lang.

Anmerkung: Stoht der $P$. insignis do Meij. sohr nahe. Diese hat aber keinen silberigen Punkt oben auf dem zweiten Fühlerglied. $P$. punctata de Meij. hat keine Streifung am Ruicken und die Backen sind bedeutend schmäler.

Paralimna cinerella nov. spec.

Zahlreiche Stücke aus 'Tainan, Mai.

Stime dreimal so breit wie ein Auge und $1 \frac{1}{2}$ mal so breit wie lang.

Backen $2 / 3$ eines Auges hoch. Die Augen sind fast ebenso lang wie hoch. Die hintere der zwei nacl vorne gebogenen Frontorbitalborsten ist sehr schwach und kurz. Lie Stirne steht an den Fiihleru 
ein ziemliches Stück über die Augen vor. Die Wangen sind so breit wie das dritte Fühlerglied. Die übrigen plastischen Merkmale wio bei $P$. sinensis angegeben.

Grundfarbe schwarz. Die Bestäubung ist überall sehr dicht, matt und von hell gelblich olivengrauer Farbe. An allen Borsten. wurzeln der Stirne und des Leibes stehen schwarze Punkte. Stirne wie bei $P$. sinensis gezeichnet, aber von anderem Kolorit, heller und dunkler olivengrau. Zwischen Fïhlerwurzel und Auge nur ein brauner Schillerfleck. - Der Thoraxrücken, die Mesopleuren und das Sehildchen sind mit scharf abgesetzten dunkelbraunen Pünktchen an den Haarwurzeln besetzt, die nicht zusammenfließen, aber doch dicht beieinander stehen. Zwischen den Dorsozentralborsten sieht man drei Längslinien von dunklerer Grundfarbo, auf die auch die Pünktchen verteilt und geordnet erscheinen. Jederseits oine ebensolche kurze Längsstrieme hinter der Naht. Wie bei $P$. sinensis stehen auch hier in der Lateralgegend des Tboraxrïekens und in der Mitte der Mesopleuren nocin braune Flecke und ist der Oberrand der letzteren auch braun gesäumt. Während abel $P$. sinensis einen kaffeebraunen Eindruck macht, ist hier das Aussehen hell olivongrau. Der Rest der Pleuren ist unpunktiert.

Hinterleib am Vorderrande der Tergite mit je zwei sepiabraunen, in der Mitte breit getrennten Flecken, die hinten kreisbogig begrenzt sind und nach hinten zu an Größe abnehmen.

Fühler schwarz, drittes Glied hell seidenartig schimmernd; zweites Glied oben mit silberwoifem Punkte. Arista mit 13 bis 14 Kammstrahlen.

Bei manchen Stücken zeigen das Gesicht, der Thorax und das Schildchen zarte, lederfarbige Flecke und sind die Flecke des Hinterleibes hinten weniger scharf begrenzt. Auch kann die Farbe der Punktiorung zwisehen sepia- und rotbraun weehseln.

Flügel hyalin, etwas gelbgrau tingiert. Schwingerkopf weißlichgelb.

Hüften und Beine schwarz, wie der Körper bereift. Knie und Füße rotbraun. Die oberste der dorsalen Mittelschienenborsten steht glcich am Gelenk.

Körper $6-6,5 \mathrm{~mm}$, Flügel $5 \mathrm{~mm}$ lang.

Paralimna minor nov. spec.

Zahlreiche Stücke aus Tainan, Mai.

Diese Form gleicht in allen Merkmalen und in der Färbung bis anf folgende geringe Untersehiede ganz der vorigen. Vor allem ist 
sie beständig kleiner und wird nur $4 \mathrm{~mm}$ lang. Dic Backen sind etwas nicdriger und wenig mohr als die Hälfte eines Auges hoch. Die dunklen Hinterleibsbinden sind schmäler und stets verwaschen, nie scharf ausgeprägt. Der Flügel ist heller.

Clasiopella nov. gen. (Fig. 4 u. 5) (Typus: C. uncinata nov. spec.). Steht einerseits der Gattung Discocerina Macqu. (Clasiopa Stonh.), anderscits Psilopa Fall. am nächsten.

Die Stirne ist doppelt so breit als lang und verschmälert sich nach vorne nur wenig. Unter den Fühlern aber biegen die Augenränder einwärts gegeneinander, wodurch das Gesicht auf die Hälfte der Stirne verengt wird. In der Stirnmitte stehen eng nebeneinander die zwei Orbitalborsten, die nach vorne gebogene außen, die nach oben gebogene innen. Alle übrigen Kopfborsten stehen an der scharfen Scheitelkante, an der auch die obersten zwei der Punktaugen liegen. Zwischen diesen sind die divergierenden Postvertikalen inseriert, nach hinten geneigt, knapp außerhalb der zwei Ocellenwurzeln die großen, nach vorne gebogenen, ungefähr parallelen Ocellarborsten. Die zwei Paare Vertikalborsten normal. Gesicht jederseits mit zwej starken Borsten, deren oberes Paar gekreuzt ist. Von den Backenborsten ist die unterste besonders lang. Oberer Hinterkopf stark ausgehöhlt. Gesicht in der Mitte mit einem nasenartig vorstehenden Höcker, unter den Fühlern konkav. Mundöffnung nicht groß. Prälabrum vorstehend, allseits sichtbar. Mittlerer Rïsselteil, an dem die kurzen Labellen stehen, verlängert, so lang wie der Kopf, relativ schlank. Taster nicht untersuchbar. Backen mäBig breit.

Fühler hoch oberhalb der Augenmitte inseriert. Der nach vorne gebogene Dorn des zweiten Gliedes sehr stark und so lang wie die Fïhler selbst. Arista sehr lang gefiedert (9 Kammstrahlen).

Eine Humerale, zwei Notopleurale, eine Präsuturalborste. In halber Schildlänge stehen vor dem Schilde vier Borsten in einer Reihe, die äußeren davon länger. Schild dreieckig zugespitzt, $1 / 3$ des Rückens lang, oben flach, nackt, am Rande mit vier langen Borsten, die apikalen divergierend. Mesopleuren mit einigen Börstehen, unten mit einer langen Borste. Zwei Stornopleurale nebeneinander.

Hinterleib länglich oval, länger als der Thorax, mit fünf sichtbaren Tergiten, der fïnfte am längsten und hinten behorstet. Begattungsorgane des $\delta$ kompliziert, vorstehend.

Vorderschenkel postero-, die vier hinteren Schenkel antero-ventral beborstet, die hintersten am schwächsten.

Flügel nach der Figur geadert. Kosta bis zur vierten Längrs- 
ader. Erster Kostalabschnitt beborstet. Alula flach, mit hornigem, gewimpertem Rande.

\section{Clasiopella uncinata nov. spec.}

$30^{7}$ 을 aus Anping, Mai.

Glänzend schwarz, Stirne blauschwarz. Lunula und Gesicht weiß bestäubt. Fühler mattschwarz. Oberseite des Körpers kaum merklich mit bräunlichem Reife iiberhaucht. Hüften und Beine rotgelb.

Haare und Beborstung des ganzen Tieres schwarz. Hinter der Schulter ein silberweißer Strich. Flügel grau, vorne rauchbraun getriibt. Schwinger und Kopf weib.

Kaum 2 mm lang, Flügel etwas kürzer.

Trimerogastra nov, gen. (Fig. 6 und 7) (Typus: T. cincta nov. spec.).

Der Gattung Trimerina Macquart am nächsten stehend. Wie bei dieser besteht hier der Hinterleib scheinbar aus drei Segmenten, indem hinter dem basalen Doppelsegment nur noch das dritte und vierte Tergit sichtbar bleiben. Auch die beiden Frontorbitalborsten sind weit voneinander getrennt und stehen ungefähr in den Stirndritteln, die vordere ist nach vorne, die obere nach außen gebogen. Die Ocellen stehen an der Scheitelkanto; neben den vorderen Ocellen stehen die nach vorne geneigten Ocellarborsten. Postvertikale klein. Vertikale normal. Stirne breiter als lang; ihre Augenränder gehen konvergierend ohne Winkel auf das Gesicht über, das danı nur $1 / 2$ des Scheitels breit ist. Der innerhalb des Hufeisens der Stirnspalte gelegene Gesichtsteil tritt eigenartig wulstig hervor. Gesicht unter den Fühlern vertieft, in der unteren Hälfte, oberhalb des ausgeschnittenen Mundrandes, buckelig vorstehend. Prälabrum vorstehend, Mundöffnung klein. Seitlich am unteren Gesichte, an den aufsteigenden Peristomalien jederseits zwei konvergierende Borsten; eine dritte weiter unter. Ocellenplatte breit trapezförmig, Stirnspaltenäste daneben nur sehr schmal.

Fühler kurz, rundlich, drittes Glied nicht länger als breit, zweites ohne besondere nach vorne gebogene Borste, nur mit einem nach oben und außen gerichteten Börstchen. Arista oben mit vier Kiammstrahlen. Rüssel normal.

Rücken fast kugelig, sehr hoch gewölbt. Schild halbrund, $1 / 4$ des Rückens lang, gewölbt, mit sechs Randborsten; die apikalen am längsten, die mittleren kurz. Rückenbeborstung kurz. Vor dem Schilde vier Borsten in einer Reihe. Die Härchen scharf 
in sechs Längsreihen geordnet. Eine Meso- und eine Sternopleuralborste.

Hinterleib flach, kurz oval, so lang wie der Thorax und so breit wie dieser, ohne Anhänge und Borsten. Das ganze Tier bietet ein kahles Aussehen.

Vorderschenkel posteroventral, Mittelschenkel anteroventral schwach beborstet.

Flügel nach Figur 7 geadert, ohne Randdorn. Kosta bis zur vierten Längsader. Die Posticalis erreicht den Fliigelhinterrand nicht.

Trimerogastra cincta nov. spee.

Zwölf Stücke aus Anping, Juni.

Von glänzend pechschwarzer, etwas ins Olivengriine neigender Farbe. Fühler teilweise rotbraun. Füße rot. Borsten und Haare schwarz. Flügel hyalin mit dunklen Adern. Schwingerkopf dunkelbraun. Hinterleib am dritten und vierten Tergit mit weißgrauen, an den Seiten breiteren Vorderrandbinden.

$1 \frac{1}{2} \mathrm{~mm}$ lang.

Tetramerogastra nov. gen. (Typus: fumipennis nov. spec.).

Mit folgenden Unterschieden der Trimerogastra gleich, Hinterleib mit sichtbaren Tergiten $3-5$ hinter dem basalen Doppelsegment. Ocellenplatte dreieckig, Stirnspaltenäste daneben breiter.

Rücken weniger" gewölbt als das Schildchen, rauher nnd länger behaart. Härchen dichtstehend, in zahlreiche Längsreihen geordnet. Vor dem Schilde auf dem Rïcken nur die zwei äuBoren Borsten vorhanden. Nur zwei apikale Schildborsten.

Flügel genau wie Figur 7, nur ist die Radialis länger und mündet näher gegen die Fliigelspitze hin.

Tetram. fumipennis nov. spec.

Zwei Stücke, Anping, Mai.

Matt olivenbraune Art. Augenränder, Gesicht und Backen heller gelbgrau bereift. Höcker und Ocellarplatte etwas glänzend. Fiihler rotbraun. Rücken mit vier grauen Längsstriomen, die äußeren an der Naht unterbrochen. Hinterleib graulich ïberhaucht, an den Vorderrändern der Tergite weifgraue Querbänder, die seitlich breiter als in der Mitte sind.

Flïgel graulich getrübt. S'chwingerkopf dunkelbraun.

Fast $2 \mathrm{~mm}$ lang. 


\section{Drosophilinae.}

Thaumastophila nov. gen.

Eine ganz eigenartige Gattung, die durch den Habitus und die glasklaren Flügel entfernt an Platypeziden erinnert, Cyrtonotum aber am nächston stoht.

Kopf flachgedrückt halbkugelig, hinten ausgehöhlt, doppelt so hoch wie lang. Im Profile sieht man nur das Auge; die Backen sind linear, der Mundrand steht kaum vor und ist vibrissenles. Ein zartes, kurzes Härchen deutet die rudimentäre Vibrisse an. Die Stirne ist beim $\delta$ vor den 0zellen fast linienartig schmal zusammengezogen, was bei acalyptraten Musciden ein Ausnahmefall ist. Sie erweitert sich dann etwas gegen die Fühler hin zu bis auf die Hälfte einer Augenbreite. Die gleiche Breite behält das parallelrandige Gesicht. Beim $\&$ sind Stirne und Gesicht völlig parallelrandig und so breit wie ein Auge. Das Gesicht zeigt einen von oben bis unten durchlaufenden streifenförmigen und wenig erhabenen Längsrücken, der im Profile fast gerade ist und nur oberhalb des Mundrandes eine kleine Konvexität bildet. Wangen linear. - Stirne nur mit einer starken, nach oben gebogenen Frontorbitalborste im obersten Drittel. Ozellare stark, Postvertikale klein. Vertikale normal. Praelabrum schmal und niedrig, aber auch von der Seite sichtbar vorstehend. Taster fadenförmig, am Ende etwas verdickt. Rüssel proportional.

Thorax von fast kugeligem Aussehen, so stark ist der Rücken emporgewölbt.

Eine Humerale nach rückwärts, eine zweite nach abwärts gebogen; zwei Notopleurale, drei Supraalare, ein Präsuturale, zwei Paare Dorsozentrale ganz hinten, das vordere Paar schwächer, ein Paar Präscutellare. Vier Scutellare, das apikale Paar divergent; zwei starke Borsten am Rande der beharten Mesopleuren; eine Sternopleurale rückiärts und nach unten gerückt.

Schild ein Drittel des Rückens lang, eiförmig, oben behaart.

Hinterleib länger als der Thorax, schlank, von konischer Form.

Flügel wie bei Cyrtonotum geadert. Die Mediastina bleibt vollständig getrennt und mündet an der gleichen Stello mit der Subkosta, im ersten Fünftel der Flügellänge. Noch weiter basalwärts ist die kleine Querader gerückt, während die hintere Querader dem Flügelrande so nahe steht, daß der letzte Discoidalisabschnitt ganz erheblich kürzer als der vorletzte ist. Die Längsadern sind beinahe gerade und divergieren allmählich gegen die Spitze hin. Die Ent- 
fernung der Mündungen $2-3$ ist kleiner als die zwischen 3 und 4. Alula fehlt. Der Einschnitt vor ihr ist flachbuchtig. Kosta ohno Bedornung.

\section{Th. hyalipennis nov. spec.}

Drei Stücke, ơ $q$ aus Pilam und Chipun (Formosa). Juli, Sauter. Stirne beim $q$ dunkelrotbraun mit fïnf bronzegelb bestäubten Längslinien. Beim $\delta$ ist diese Zeichnung eng zusammengepreßt. Gesicht, Prälabrum, Taster, Rüssel und Hinterkopf schwarz; ersteres silberig schimmernd. Fühler schwarzbraun; drittes Glied an der Wurzel rot. Arista, alle Borsten und Haare des Tieres schwarz.

Thorax und Hinterleib von sehwarzer Grundfarbe. Pleuren unten aschgrau, oben mehr bräunlich, Rücken und Sehild dicht ockerig braun bestäult. In der Längsmitte des Rückens drei dunkelbraxne Längslinien eng beisammen, die auch auf die Wurzel des Schildes übertreten. Die mittlere Linie ist die dünnste und vorne abgekürzt. Da aber die droi Stücke durch Feuehtigkeit gelitten haben, ist dieseZeichnung, auch dio des Hinterleibes, nur mehr wenig deutlich zu erkonnen.

Hinterleib dicht bräunlichgrau bereift, vom zweiten Ringe an mit umgekehrt $T$-förmigen schwarzbraunen Flecken versehen, dio nur auf der Oberseite gelagert sind.

Hüften und Beine ockergelb, weißlich bereift. Hinterschenkel vor dur Spitze mit dunkelbraunem Ringe.

Flügel vollkommen glasig und durchsichtig, mit braunen Adern. Schwinger gelb.

Körper $3,5-4,5 \mathrm{~mm}$, Flügel $2,5-3,5 \mathrm{~mm}$ lang.

\section{Drosomyiella nov. gen.}

Die Typo dieser Gattung ist dio Drosophila ablreviatu de Meij., die mir in einem Stücke aus Tappani, Formosa (Sautor) vorliegi. Die Gattung ist der Oxyleucophenga ähnlich, hat auch zwei nach oben gebogene, aber auffallend starke Frontorbitale, deren oberste lïnger und stärker als die Vertikalborsten ist. Postvertikale sehr klein. Die nach vorne gehogene Borste steht vor und einwärts der unteren aufgehogenen Orbitalborste. Gesicht parallelrandig, schmäler als dio Stirne an Seheitel und als ein Auge. Gesichtskiel schwach entwiekelt.

Hinterleib eiförmig, nieht konisch zugespitzt.

Die Spitze des Flügels an der Cubitalismiindung ist weniger scharf als hei Oxyleucoplenga, aber sehr dentlich. Die Radialis ist nur sanlt gebogen. Dic Discoidalis brieht vor dem Flïgelrande ab und verläuft. Siehe die Abbildung von Meijere, Tijdsehr. v: Entom. 1911, Taf. 21, Fig. 41. 
Leib ohne Silbersehimmer. Sonst wie bei der verglichenen Gattung. Paraleucophenga nov. gon.

Mit folgenden Unterschieden der frühor beschriehenen Oxyleucophenga gleich. Die nach vorne gebogene Frontorbitalborste steht vor und elwas cinwärts von der in der Stirnmitte inserierten unteren der zwei nach oben gelogenen Borsten. Die Arista ist nur aul der Oberseite lang gefiedert, unten an der Spitze nur mit ganz kurzen Härchen versehen, die nach außen gerichtet und nicht leicht zu sehen sind. Taster verbreitert. Gesicht mit sohr flachem, niedrigem Riicken.

Schild außer den Borsten seitlich etwas behart. - Drei Sternopleuralborstên, zwei starke untercinander riickwärts, eine schwächere Borste vorne.

Flügcl ohne scharfe Spitze, wenı auch etwas zugespitzt. Radialis lang, sanft, einfach gebogen, mit der Cubitalis parallel.

Körper mit Silberschimmer beim $\delta$.

Präapikalbörstehen der Schienon deutlich entwickelt.

Gattungstypus: Paraleuc. triseta nov. spec.

Irei Stücke aus Kankau (Koshun), Formosa, Mai und Septemlier. Sauter.

Kopf und Anhänge hell ockergelb. Schcitolplatten, Gesicht und Prälabrum weiß schimmernd. Hinterkopf oben in der Mitte dunkelbraun. Stirne mit einer braunen Medianlinie. Drittes Fïhlerglied am Oberrande etwas gebräunt. Arista oben mit meist elf langen Strahlen. Die Fiederchen an der Unterseite der Spitze sind sehr zart und kurz. Taster schwarz.

Pleuren, Hüften und Bcine hell ockergelb, erstere weißlich bereift. Die Lateralgegend des Rückens und der Schildrand sind hellgelb. Die Mitte beider rostbraun, dureh Bestäubung etwas im Glanze gemildert. Alle Haare und Borsten schwarz. Hinterleib rostgelb. Eine Mittellängshinie, die zwoi Außenrandlinien und schmale Hinterrandsäume der Tergite sind beim $q$ schwarzbraun. Beim anderen $q$ sind diese braunen T'eile so breit und ausgedehnt, dab sie vorherrschen. Bei dem mänılichen Stiicke ist der Hinterleib an dem Seitenrande und an der Spitze schwarzbraun.

Flïgel rauchig getrïbt, am Vorderrande jenseits der Subkosta noch intensiver. Hintere Querader dunkler gesäumt. Adern dunkelbraun. Vor der Subkostamiundung cin Randdorn. Schwinger hellgelb.

Körper $4,5 \mathrm{~mm}$, Flügel $4 \mathrm{~mm}$ lang. 


\section{Orthostegana curvinervis nov spec.}

Ein Stück aus Kosempo, Formosa. Mai. Sauter.

Kopf und Anhänge gelb. Stirne glänzend. Drittes Fühlerglied größtenteils dunkelbraun. Taster am verbreiterten Ende tiefschwarz. Arista oben mit sieben, unten mit vier Kammstrahlen. Thorax und Schild oben glänzend gelbbraun. Pleuren hellgelb Durch dic Mitte der Mesopleuren zieht von vorne bis zur Sehwingerwurzol ein breites dunkelbraunes Längsband. Auch der Oberrand der Sternoplenren ist dunkelbraun. Hinterleib dunkel rotbraun, seitlich rostfarben. Hinterränder der Tergite schwärzlich.

Beine gelb. Die Spitzen der Vorderschenkel und die vier hinteren Schenkel mit Ausnahme der Spitzen und Wurzeln dunkelbraun.

Flïgel an der Wurzel und am ganzen Hinterrande weniger, nach vorne hin immer intensiver rauchbrann getrübt. Der obere Randsaum der Spitze zwischen der zweiten bis vierten Längsader ist ausgehellt. I ie Cubitalis ist wellig geschwungen. Die erste Hinterrandzelle ist nur ganz schmal offen. Der letzte Abschuitt dor Discoidalis Ist doppelt so lang wie der vorletzte. Die kleine Querader steht etwas vor der Mitte der Discalzelle. Schwinger gelb.

liörper und Flügol etwas über $2 \mathrm{~mm}$ lang.

\section{Orthostegana convergens de Meijere.}

Drosophila ead., Meij., Tijdschr. v. Entumol. V., 53., p. 400., 11 (1910). Aus Java beschrieben, vier Stiicke aus liosempo, Formosa. Mai. Sa u ter.

Die Querader vor der Discalzelle ist deutlich vorhanden. Die orste Hinterrandzolle ist weniger stark verengt als bei den genuinen Formen. Radialis lang und fast gerade. Kleine Querader weit vor der Mitte der Discalzelle.

Wahrscheinlich gehören in diese Gattung auch noch andere der de Moijore'sehen Stegana-Arten.

\section{Orthostegana nigripennis nov. spec.}

Zwei Stïcke aus Sokutsu; Formosa. Juni. Sautor.

Kopf und Anhänge rotgelb. Stine etwas glänzend. Die Umgebung der ()zcllen, der Yorderrand der Stirne und der Mundrand sind dunkelbraun. Drittes Fühlerglied am Oberrande etwas gebräunt. Arista sehr lang gefiedert. Oben elf bis zwïl, unten sechs bis sieben liammstrablen.

Thorax rotgelb, an den Pleuren mit ciner schwarzbramnen Längsstriome rom Prothoraxstigma zum Sehwinger. Unmittelbar üher der Notopleuralnaht ebonfalls eine solche Längsstrieme, die vorne iibel 
die Schulterboulen hinaufgeht. In der Längsmitto dos Rückens zwei vorne schmal zusammenhängende, nach hinten sich stark vorloreiternde schwarzbraune Längsstriemen bis zum Schilde, die median nur durch einc gelbe Linie getrennt werden und deren jede in der Linio der Dol'sozentralborste hinter der Quernaht durch eine gelbe Längslinie gespalten wird. Schildchen oben dunkelbraun, am Rande gelb.

Hinterleib vorherrschend schwarzbraun, seitlich am Vorderrande der Tergite mehr weniger ausgedehnt rosthraun. Hypopyg rostgelb.

Hüften und Beine gelb. Schenkel an der Spitze etwas gebräunt.

Flügel an der Wurzel und am Hinterrande gelbbraun tingiort, nach vorne und gegen die Spitze hin allmählich dunkler braun und am Vorderrande endlich schwarzbraun. Runde gelbe Punkte liegen zwei in der ersten Hinterrandzelle, einer oberhalb der hinteren Querader, einer woiter spitzenwärts. Ein anderer solcher Fleck liegt oben in der Discalzelle, ungefähr in der Mitto zwischen den zwei Queradern; jenseits der hinteren Querader ein ähnlicher an der Discoidalis. Unterhalb der Posticalis und oberhalb der kleinen Querader in der Radialisgabel liegt je ein gröberer gelblicher Wisch. Radialis lang, fast gerade. Erste Hinterrandzelle an der Miindung verengt, aber nicht so stark wie bei Stegana. Die letzten Abschnitte der dritten und vierten Längsader sind sanft gegeneinander gebogen. Kleine Querader im ersten Drittel der Discalzelle. Letztor Abschnitt der Discoidalis deutlich länger als der vorletzte. Schwinger rostgelb.

Körper und Flïgel $5,5 \mathrm{~mm}$ lang.

\section{Amiota orientalis nov, spec.}

Eine Reihe von Stücken aus liankau (Kioshun), Formosa. Juni. Sauter.

Gleicht unserer heimischen Am.variegata Fall ganz auBerordentlich. Der Stirne fohlt aber der große schwarze Fleck in der Mitte. Es sind nur der Ozellenpunkt und kleino Flecke am oberen Augeneck der Stirne schwärzlich. Die Mittelstirne ist gelbrot gefärbt.

Die Grundfarbe des Thorax ist nicht schwarz, sondern rostgelb; die Fleckung ist rotbraun.

Der Hinterleib ist hellgelb. Die Tergite sind vom zweiten an mit Ausnahme einer weißen Randlinie am Hinterande mit breiten schwarzbraunen Querbinden ver'sehen, von denen nur die des zweiten in der Mitte unterbrochen ist. Am zweiten und dritten, seltener am vierten Tergite sieht man auch eine dunkelbrauno Medianlinie. Die Vorderränder der Tergite schimmern bei gut erhaltenen Siücken silberweib. 

schwal'z.

Hüften und Beine hellgelb. Die Schenkel sind bei A. varieguta

Der letzte Abschnitt der Discoidalis ist nicht gerade, sonst erbeblich noch zur Cubitalis hin gebogen.

Alles iibrige wie bei der Fallen'schen Art, auch die Größ乃e. 




















25.

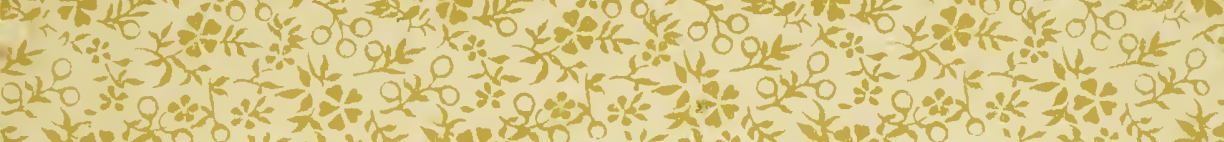

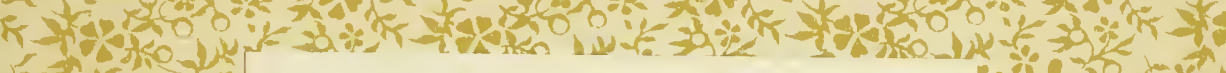
Fis.

L

TSE 531

H49l

Dent

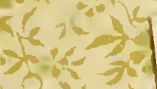

Cᄂ 21

531

H491

Ent.
Hendel, Friedrich.

Papers on Diptera.

Hendel, Friedrich.

Papers on Diptera.

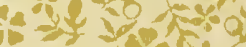

प्राए

$30,92=0,0$

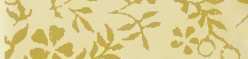
60150 a. to - sterk

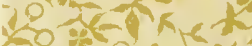

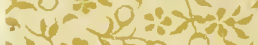

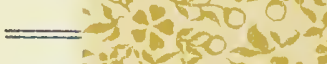
git 20 -

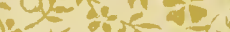
- 16 d-at yoc $5>-3 x+2 x$ r.tolo ont $5 x-\frac{20}{02}$ $k=1,2<0$

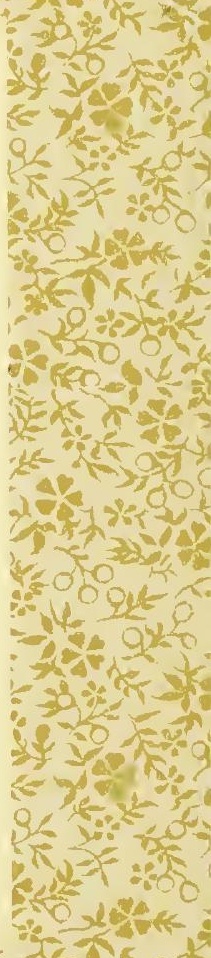

OI

531

H491

Ent.
ISSUED TO

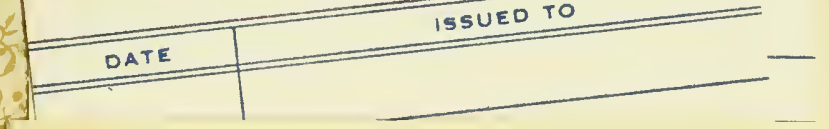

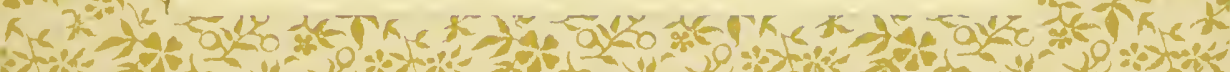

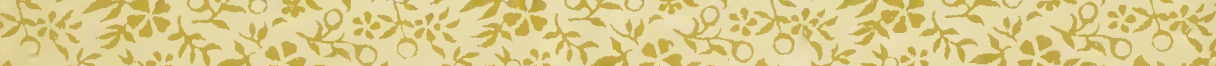

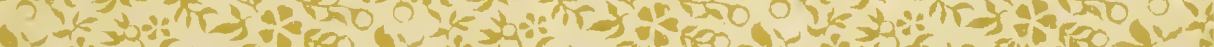

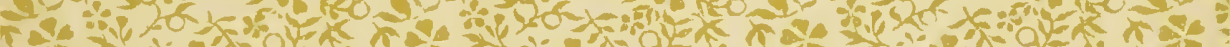
For

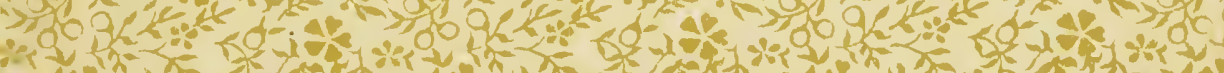

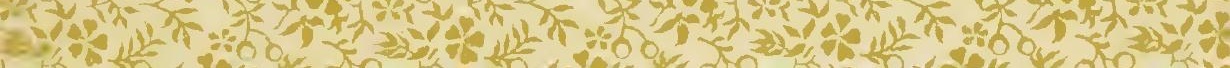


SMITHSONIAN INSTITUTION LIBRARIES 